\title{
Field Demonstration of Horizontal Infill Drilling Using Cost-effective Integrated Reservoir Modeling - Mississippian Carbonates, Central Kansas
}

\author{
Final Report \\ Report Period Start: July 17, 2001 \\ Report Period End: December 31, 2004 \\ Principal Author: Saibal Bhattacharya \\ Date of Issue of Report: Aug 31, 2005 \\ DOE Award No.: DE-FC26-01BC15276 \\ Kansas Geological Survey \\ Open File Report 2005-
}

This report summarizes results from KGS Open File Reports: 2001-69, 2002-67, 2002-69, 2003-76, 2003-79, and 2004-65

\begin{abstract}
Disclaimer
This report was prepared as an account of work sponsored by an agency of the United States Government. Neither the United States Government nor any agency thereof, nor any of their employees, makes any warranty, express or implied, or assumes any legal liability or responsibility for the accuracy, completeness, or usefulness of any information, apparatus, product, or process disclosed, or represents that its use would not infringe privately owned rights. Reference herein to any specific commercial product, process, or service by trade name, trademark, manufacturer, or otherwise does not necessarily constitute or imply its endorsement, recommendation, or favoring by the United States Government or any agency thereof. The views and opinions of authors expressed herein do not necessarily state or reflect those of the United States Government or any agency thereof.
\end{abstract}




\title{
FOREWORD
}

Contributors to this report include: Saibal Bhattacharya, Marty Dubois, Alan Byrnes, Susan Nissen, Tim Carr, and Evan Franseen from the Kansas Geological Survey, Mark Shreve and Steve Anderson (Mull Drilling Co. Inc.), Paul Gerlach (Charter Development Corp.), and Bob Knoll (Maurer Engineering Inc.).

\begin{abstract}
Mississippian carbonate reservoirs have produced in excess of 1 billion barrels of oil in Kansas accounting for over $16 \%$ of the state's production. With declining production from other age reservoirs, the contribution of Mississippian reservoirs to Kansas's oil production has risen to $43 \%$ as of 2004 . However, solution-enhanced features such as vertical shale intervals extending from the karst erosional surface at the top introduce complexities/compartmentalizations in Mississippian carbonate reservoirs. Coupled with this, strong water drives charge many of these reservoirs resulting in limited drainage from vertical wells due to high water cuts after an initial period of low water production. Moreover, most of these fields are operated by small independent operators without access to the knowledge bank of modern research in field characterization and exploitation/development practices. Thus, despite increasing importance of Mississippian fields to Kansas's production, these fields are beset with low recovery factors and high abandonment rates leaving significant resources in the ground. Worldwide, horizontal infill wells have been successful in draining compartmentalized reservoirs with limited pressure depletion. The intent of this project was to demonstrate the application of horizontal wells to successfully exploit the remaining potential in mature Mississippian fields of the mid-continent. However, it is of critical importance that for horizontal wells to be economically successful, they must be selectively targeted.
\end{abstract}

This project demonstrated the application of initial and secondary screening methods, based on publicly available data, to quickly shortlist fields in a target area for detailed studies to evaluate their potential to infill horizontal well applications. Advanced 
decline curve analyses were used to estimate missing well-level production data and to verify if the well produced under unchanging bottom-hole conditions - two commonly occurring data constraints afflicting mature Mississippian fields. A publicly accessible databank of representative petrophysical properties and relationships was developed to overcome the paucity of such data that is critical to modeling the storage and flow in these reservoirs. Studies in 3 Mississippian fields demonstrated that traditional reservoir models built by integrating log, core, DST, and production data from existing wells on 40-acre spacings are unable to delineate karst-induced compartments, thus making 3Dseismic data critical to characterize these fields. Special attribute analyses on 3D data were shown to delineate reservoir compartments and predict those with pay porosities. Further testing of these techniques is required to validate their applicability in other Mississippian reservoirs. This study shows that detailed reservoir characterization and simulation on geomodels developed by integrating wireline log, core, petrophysical, production and pressure, and 3D-seismic data enables better evaluation of a candidate field for horizontal infill applications. In addition to reservoir compartmentalization, two factors were found to control the economic viability of a horizontal infill well in a mature Mississippian field: a) adequate reservoir pressure support, and b) an average well spacing greater than 40 -acres. 


\section{TABLE OF CONTENTS}

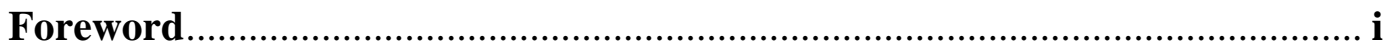

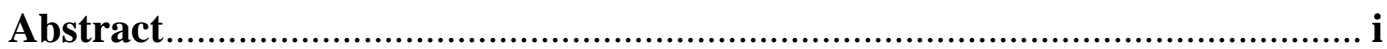

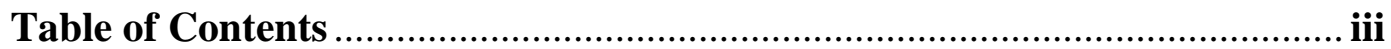

List of Figures....................................................................................... vi

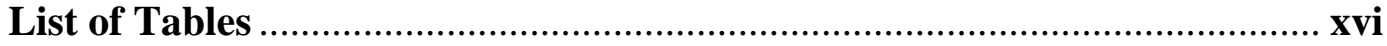

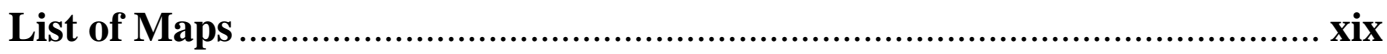

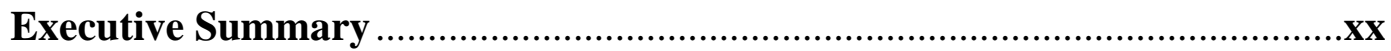

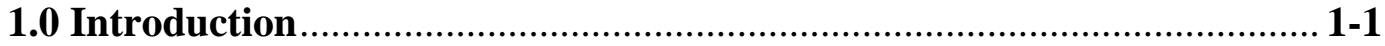

1.1 Constraints Affecting Production from Mississippian

Carbonate Reservoirs of Kansas .............................................................. 1-3

1.2 Productivity Potential of Mississippian Reservoirs .................................. 1-5

1.3 Effective and Quick Screening of Target Area to Select Candidates for Detailed Evaluation ....................................................... 1-6

2.0 Initial Screening Studies - 14 Fields ............................................... 2-1

2.1 Target Study Area ................................................................................. 2-1

2.2 Parameters for Initial Screening of Fields in Target Area ............................ 2-1

2.2.1 Reservoir Thickness and Aerial Extent.................................................. 2-2

2.2.2 Reservoir Porosity........................................................................... 2-2

2.2.3 Estimated Remaining Oil in Place ..................................................... 2-2

2.2.4 Reservoir Pressure .............................................................................. 2-3

2.3 Ranking of Target Fields in the Study Area ............................................. 2-4

3.0 Secondary Screening Studies - 6 Fields ..................................................... 3-1

3.1 Analytic Estimation of Performance of Horizontal Wells in Short-Listed

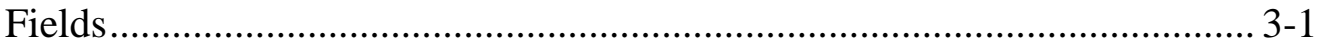

3.2 Inventory of Data Available for Short-Listed Fields .................................. 3-4

3.2.1 Riverside Field, Ness County, Kansas .................................................... 3-4

3.2.2 Ness City North Field, Ness County, Kansas ........................................... 3-4

3.2.3 Lippoldt Field, Hodgeman County, Kansas.............................................. 3-5

3.2.4 McDonald Field Ness County, Kansas .................................................... 3-5

3.2.5 Judica Field, Ness County, Kansas ...................................................... 3-6

3.2.6 Arnold Southwest Field, Ness County, Kansas ........................................ 3-7

3.3 Fralick West Field, Kiowa County, Kansas - A Special Consideration........ 3-7

3.4 Summary of Operational Notes on Previously Drilled Horizontal Wells

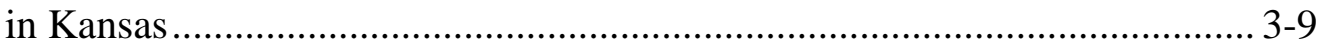

3.5 Selection of Candidate Fields for Detailed Studies ................................. 3-11

4.0 Integrated Reservoir Petrophysics ................................................. 4-1

4.1 Rock Catalog...................................................................................... 4-1

4.2 Geologic Setting, Depositional Environments, and Lithofacies................... 4-3

4.3 Lithofacies-Porosity-Permeability Relations ........................................... 4-7 
4.4 Capillary Pressure Properties ....................................................................... 4-13

4.5 Relative Permeability Properties................................................................. 4-17

4.6 Electrical Properties ............................................................................... 4-19

5.0 Sensitivity Studies on Select Candidate Fields ……................................. 5-1

5.1 Reservoir Input Parameters ....................................................................... 5-1

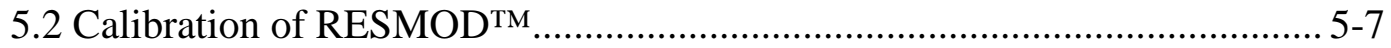

5.3 Sensitivity Studies on Judica Field ..................................................... 5-10

6.0 General Geology of Mississippian Oil Fields - Central Kansas ............... 6-1

6.1 Geologic Setting.........................................................................................

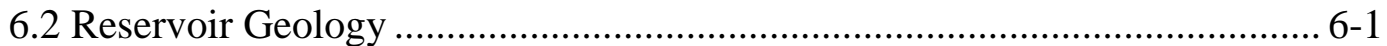

6.3 Static Model Building Procedure............................................................. 6-3

6.4 Ness City North Field Geology....................................................................... 6-4

7.0 3-D Reservoir Modeling and Simulation - 3 Candidate Fields ................. 7-1

7.1 Reservoir Characterization and Simulation of McDonald Field, Kansas ...... 7-1

7.1.1 Introduction......................................................................................... 7-1

7.1.2 Geologic Model ................................................................................... 7-1

7.1.3 Production Data Analysis ....................................................................... 7-2

7.1.4 Decline Curve Analysis ........................................................................ 7-3

7.1.5 Petrophysical Log Analysis - Super-Pickett plots ....................................... 7-4

7.1.6 DST Analysis ........................................................................................ 7-4

7.1.7 PVT and Relative Permeability/Capillary Pressure Inputs .......................... 7-4

7.1.8 Simulation Study - History Matching .......................................................... 7-6

7.1.9 Performance Evaluation of Different Horizontal Infill Trajectories............ 7-7

7.2 Reservoir Characterization and Simulation of Ness City North Field,

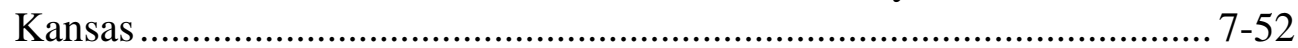

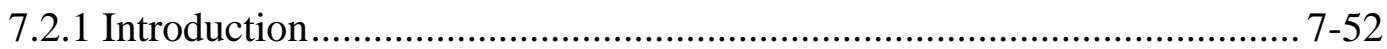

7.2.2 Geologic Model ............................................................................ 7-52

7.2.3 Production Data Analysis ................................................................... 7-53

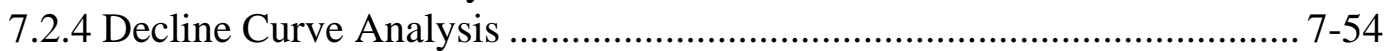

7.2.5 Petrophysical Log Analysis ......................................................... 7-55

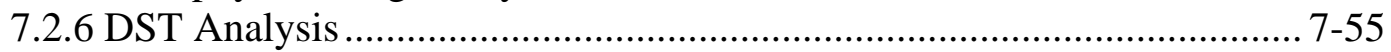

7.2.7 PVT and Relative Permeability/Capillary Pressure Inputs ......................... 7-56

7.2.8 Simulation Study - History Matching ................................................... 7-57

7.2.9 Performance Evaluation of Different Horizontal Infill Trajectories.......... 7-58

7.3 Reservoir Characterization and Simulation of Judica Field, Kansas.......... 7-104

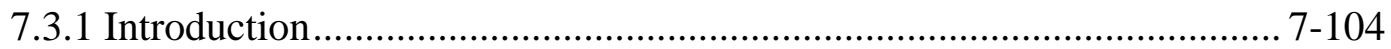

7.3.2 Geologic Model ......................................................................... 7-104

7.3.3 Production Data Analysis ................................................................ 7-105

7.3.4 Decline Curve Analysis ................................................................. 7-106

7.3.5 DST Analysis ............................................................................... 7-107

7.3.6 PVT and Relative Permeability/Capillary Pressure Inputs ...................... 7-107

7.3.7 Simulation Study - History Matching …………………………............ 7-108

7.3.8 Performance Evaluation of Different Horizontal Infill Trajectories....... 7-110 
8.0 Recommended Coring Practices in a Horizontal Well .............................. 8-1

8.1 Coring Plan .......................................................................................... 8-2

8.2 Analytical Test Procedures after Core Retrieval ........................................... 8-2

8.2.1 Basic Rock Properties .............................................................................. 8-2

8.2.2 Stimulation Test Procedures - Drilling Fluid Cleanup ................................. 8-4

8.2.3 Stimulation Test Procedures - Rock/Acid Compatibility............................. 8-5

9.0 Pilot Well at Judica Field, Kansas........................................................... 9-1

9.1 Evidence of Additional Reservoir Heterogeneity ……................................... 9-1

9.2 3 D-Seismic Survey over Judica Study Area.................................................... 9-2

\subsection{Characterization \& Simulation of Judica Field - Post 3D-Seismic}

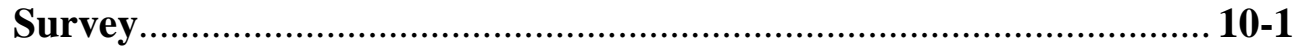

10.1 Analyses of 3D-Seismic Survey Data..................................................... 10-1

10.2 Reservoir Simulation Using Revised Judica Geomodel .............................. 10-2

10.3 Performance Prediction of Targeted Horizontal Infill Wells....................... 10-3

10.4 Future Plans to Identify Drilling Prospects Adjacent to Judica Field......... 10-4

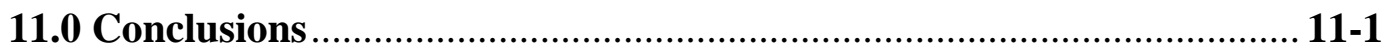

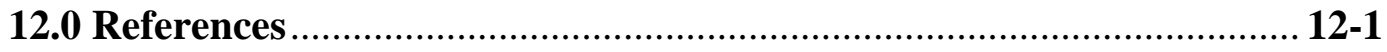




\section{FIGURES}

Figure 1.1: Contribution to Kansas oil production from different age

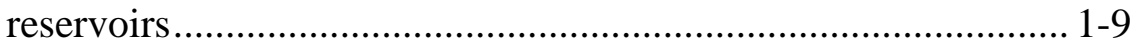

Figure 1.2: $\quad$ Structure on Mississippian and general locations of fields ....... 1-10

Figure 1.3: Mini-permeameter readings and core description including oil strains at quarter-foot intervals on a Mississppian core from Kansas ......................................................................... 1-11

Figure 1.4: Typical production profile from a Mississippian well, Ritchie Exploration Moore B1, Schaben Field, Kansas ............ 1-12

Figure 1.5: Recovery factor at the Welch-Bornholdt-Wherry Field, Rice County, Kansas, as of 1998.................................................... 1-13

Figure 1.6: $\quad$ Structure map and first derivative of Simpson sand structure in Hollow-Nickel Field, Harvey County, Kansas ...................... 1-14

Figure 2.1: $\quad$ Reservoir pressure depletion in Fralick West Field, Kiowa County, Kansas ...................................................................... 2-8

Figure 4.1 Example Rock Catalog Page constructed from on-line database of Mississippian data.

Figure 4.2 Mississippian subcrop map in Kansas showing the location of Mississippian fields

Figure 4.3 Southwest-Northeast cross-section illustrating the relationship of the Mississippian stratigraphic units with the Central Kansas Uplift.......................................................... 4-22

Figure 4.4 Location map of study area showing Mississippian fields selected for lithologic analyses ....

Figure 4.5: Interpreted regional ramp setting for deposition of Mississippian reservoir rocks.

Figure 4.6: Interpreted main-inner shelf environments for Mississippian Osagian-Meramecian deposition based on Schaben Field cores

Figure 4.7: $\quad$ Listing of important lithofacies present in all Mississippian reservoirs and symbols used in permeability-porosity figures .. 4-26

Figure 4.8: Thin-section photomicrographs of important lithofacies in the Schaben Field $4-27$

Figure 4.9: Permeability-porosity relationship for Mississippian rocks in Bindley Field showing major lithofacies in both core and thin-section photomicrgraphs.............................................. 4-28

Figure 4.10: Comparison of permeability-porosity data for various Mississippian fields.

Figure 4.11: Generalized permeability-porosity trends for different lithofacies of Mississippian reservoir rocks.

Figure 4.12: Crossplot of principal pore throat diameter versus permeability for undifferentiated sandstones and carbonates and differentiated Lansing-Kansas City and Mississippian moldic carbonates. 
Figure 4.13: Permeability versus porosity crossplot for Schaben Field Mississippian reservoir rocks showing relationship between lithofaceis and $\mathrm{k}-\phi$ trend 4-32

Figure 4.14: Permeability versus porosity crossplot for Bindley Field Mississippian reservoir rocks showing relationship between lithofacies and $\mathrm{k}-\phi$ trend

Figure 4.15: Permeability versus porosity crossplot for Ness City Field Mississippian reservoir rocks showing relationship between lithofacies and $\mathrm{k}-\phi$ trend

Figure 4.16: Crossplot of in situ Klinkenberg permeability versus routine air permeability for Mississippian reservoir rocks....

Figure 4.17: Crossplot of water saturation at 45 feet above free water level, determined by air-brine capillary pressure, versus permeability for various lithofacies in the Schaben Field ......... 4-36

Figure 4.18: Water saturations at $50 \mathrm{ft}$ above free water level for various lithofacies in Ness City Field versus porosity and permeability

Figure 4.19: Selected capillary pressure curves for various lithofacies ......... 4-38

Figure 4.20: Generalized capillary pressure curves for Mississippian rocks with different permeabilities

Figure 4.21: Change in capillary pressure curves for an $18 \%$ porosity rock from different lithofacies

Figure 4.22: Imbibition oil-water relative permeability measured on core sample (4450 feet) from the Beardmore Clifton \#1 well, Lippoldt Field, Hodgeman County, KS

Figure 4.23: Generalized oil-water imbibition relative permeability curves for Mississippian reservoir rocks

Figure 4.24: Mississippian capillary pressure/relative permeability Excel spreadsheet calculator....

Figure 4.25: Crossplot of in situ formation resistivity factor and in situ porosity for samples of various lithofacies from Schaben Field

Figure 5.1: $\quad$ History match of cumulative production for Ummel 1 (Ness City North Field) and RESMOD ${ }^{\mathrm{TM}}$ predicted initial production rates. $5-13$

Figure 5.2: $\quad$ History match of cumulative production for Ummel 2 (Ness City North Field) and RESMOD ${ }^{\mathrm{TM}}$ predicted initial production rates

Figure 5.3: $\quad$ History match of cumulative production for Thornburg $M$ (Judica Field) and RESMOD ${ }^{\mathrm{TM}}$ predicted initial production initial production rates ...................................................... 5-15

Figure 5.4: $\quad$ History match of cumulative production for Well Thornburg L (Judica Field) and RESMOD ${ }^{\mathrm{TM}}$ predicted initial production rates $5-16$

Figure 6.1: Generalized stratigraphic section for Kansas showing the three modeled fields producing from the Spergen-Warsaw ........ 6-6 
Figure 6.2: $\quad$ Map showing modeled areas located in the Spergen-Warsaw subcrop belt.

Figure 6.3: Mississippian sub-sea structure map of Ness County,

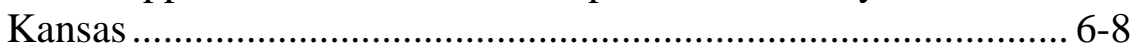

Figure 6.4: Judica area layering in the Spergen-Warsaw reservoir............... 6-9

Figure 6.5: $\quad$ Electric log calculations for Thornburg Q1 Spergen-Warsaw layers .......................................................................... 6-10

Figure 6.6: McDonald area index map showing locations of wells in the cross section .................................................................. 6-11

Figure 6.7: Example structural cross section in McDonald Field ................ 6-12

Figure 6.8: Judica area, index map showing locations of wells in the cross section .......................................................................... 6-13

Figure 6.9: $\quad$ Example structural cross section through Judica ...................... 6-14

Figure 7.1.1: Location and boundary of McDonald Field, Ness County,

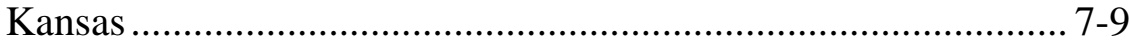

Figure 7.1.2: Distribution of wells with wireline logs and those with incomplete production histories in McDonald Field ................ 7-10

Figure 7.1.3: Subsea structure map on top of pay in McDonald Field .......... 7-11

Figure 7.1.4: Isopach of Layer 1 (L1) in McDonald Field............................. 7-12

Figure 7.1.5: Isopach of Layer 2 (L2) in McDonald Field............................. 7-13

Figure 7.1.6: $\quad$ Isopach of Layer 3 (L3) in McDonald Field.............................. 7-14

Figure 7.1.7: Porosity distribution in L1 in McDonald Field......................... 7-15

Figure 7.1.8: Porosity distribution in L2 in McDonald Field......................... 7-16

Figure 7.1.9: Porosity distribution in L3 in McDonald Field........................ 7-17

Figure 7.1.10: Distribution of initial water saturation in L1 in McDonald Field ................................................................................ 7-18

Figure 7.1.11: Distribution of initial water saturation in L2 in McDonald Field ......................................................................... 7-19

Figure 7.1.12: Distribution of initial water saturation in L3 in McDonald

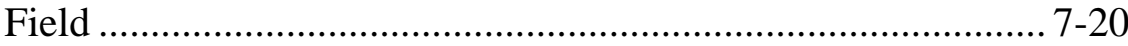

Figure 7.1.13: Well-level cumulative oil production from McDonald

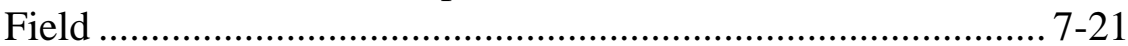

Figure 7.1.14: Decline curve analysis for Borger \#1 and Borger \#2 wells in McDonald Field ................................................................. 7-22

Figure 7.1.15: Decline curve analysis for McDonald \#3 and McDonald \#4 wells in McDonald Field..................................................... 7-23

Figure 7.1.16: Super-Pickett analysis of wireline log data from Borger \#3 well............................................................................ 7-24

Figure 7.1.17: Super-Pickett analysis of wireline log data from Borger \#4

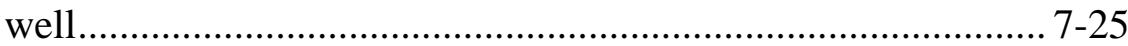

Figure 7.1.18: Super-Pickett analysis of wireline log data from Borger \#5

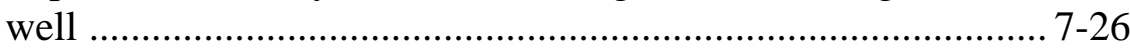

Figure 7.1.19: Super-Pickett analysis of wireline log data from McDonald \#5

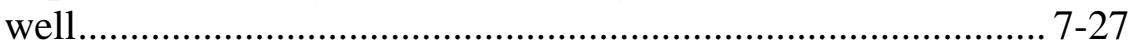

Figure 7.1.20: Super-Pickett analysis of wireline log data from Borger \#6 well $7-28$ 
Figure 7.1.21: Super-Pickett analysis of wireline log data from Voyager

\#8-3 Miner well...................................................................... 7-29

Figure 7.1.22: Plot of reservoir pressure from available DSTs in McDonald Field ..................................................................... 7-30

Figure 7.1.23: Comparison of DST- and core plug-derived permeability in McDonald Field ................................................................. 7-31

Figure 7.1.24: Production history match at Borger \#3 well in McDonald Field ............................................................................. 7-32

Figure 7.1.25: Production history match at Borger \#4 well in McDonald

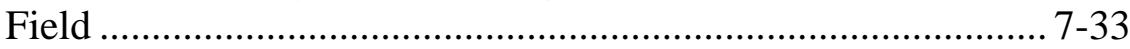

Figure 7.1.26: Production history match at Borger \#2 well in McDonald

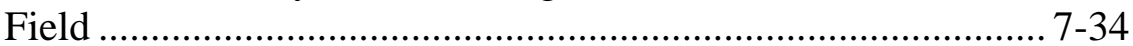

Figure 7.1.27: Production history match at Borger \#5 well in McDonald Field ............................................................................ 7-35

Figure 7.1.28: Production history match at Borger \#6 well in McDonald

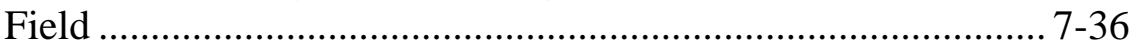

Figure 7.1.29: Simulator calculated fluid production matched against historic records at Borger \#1 well in McDonald Field ............. 7-37

Figure 7.1.30: Production history match at McDonald \#3 well in McDonald Field .................................................................. 7-38

Figure 7.1.31: Production history match at McDonald \#4 well in McDonald Field .................................................................... 7-39

Figure 7.1.32: Simulator calculated reservoir pressure distribution as of January 2003 in McDonald Field........................................... 7-40

Figure 7.1.33: Map of remaining potential in McDonald Field as of January 2003 ........................................................................ 7-41

Figure 7.1.34: Map of remaining potential in L2 (layer 2) in McDonald Field as of January 2003 .................................................... 7-42

Figure 7.1.35: Map of remaining potential in L1 (layer 1) in McDonald Field as of January 2003 7-43

Figure 7.1.36: Trajectories of two possible horizontal infill applications in McDonald Field .................................................................. 7-44

Figure 7.1.37: Effects of drainage on residual reserves (as of January 2008) due to production from Hwell 1 ................................... 7-45

Figure 7.1.38: Simulator calculated expected production from Hwell 1 .......... 7-46 Figure 7.1.39: Effects of drainage on residual reserves (as of January 2008) due to production from Hwell 2 $7-47$

Figure 7.1.40: Simulator calculated expected production from Hwell

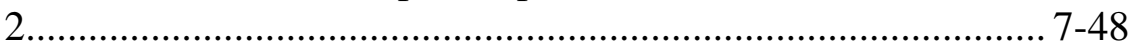

Figure 7.2.1: Location and boundary of the Ness City North Field, Ness County, Kansas ...................................................................... 7-60

Figure 7.2.2: Subsea structure on top of pay, Layer 1 (L1), in Ness City North Field .............................................................................. 7-61

Figure 7.2.3: $\quad$ Isopach of Layer 1 (L1) in Ness City North Field ..................... 7-62

Figure 7.2.4: Distribution of porosity and initial water saturation in Layer 1 (L1) in Ness City North Field.................................... 7-63 
Figure 7.2.5: Isopach of Layer 2 (L2) in Ness City North Field .................... 7-64

Figure 7.2.6: Distribution of porosity and initial water saturation in Layer 2 (L2) in Ness City North Field...................................... 7-65

Figure 7.2.7: $\quad$ Isopach of Layer 3 (L3) in Ness City North Field ..................... 7-66

Figure 7.2.8: Distribution of porosity and initial water saturation in Layer 3 (L3) in Ness City North Field.................................. 7-67

Figure 7.2.9: $\quad$ Isopach of Layer 4 (L4) in Ness City North Field ..................... 7-68

Figure 7.2.10: Distribution of initial water saturation in Layer 4 (L4) in Ness City North Field .......................................................... 7-69

Figure 7.2.11: Example cross section from Ness City North Field.................. 7-70

Figure 7.2.12: Trends of water-oil-ratio (WOR) with cumulative production in Ness City North Field....................................... 7-71

Figure 7.2.13: Decline curve analysis at Pfennenstiel \#1 well in Ness City North Field ....................................................................... 7-72

Figure 7.2.14: Decline curve analysis at Pfennenstiel \#1-24 well in Ness City North Field ............................................................. 7-73

Figure 7.2.15: Decline curve analysis at Ummel \#1 well in Ness City North Field .......................................................................... 7-74

Figure 7.2.16: Decline curve analysis at Ummel \#2 well in Ness City North Field ....................................................................... 7-75

Figure 7.2.17: Decline curve analysis at Ummel \#3 well in Ness City North Field .......................................................................... 7-76

Figure 7.2.18: Decline curve analysis at Pember \#5 well in Ness City North Field ........................................................................ 7-77

Figure 7.2.19: Decline curve analysis at Pfennenstiel \#2 (Sun) well in Ness City North Field ........................................................... 7-78

Figure 7.2.20: Super-Pickett analysis of wireline data from Ummel \#4 well in Ness City North Field .......................................... 7-79

Figure 7.2.21: Super-Pickett analysis of wireline data from Pfannenstiel \#1-24 well in Ness City North Field.......................................... 7-80

Figure 7.2.22: A Rhomma-Umaa plot using wireline log data from Pfannenstiel \#1-24 well in Ness City North Field .................... 7-81

Figure 7.2.23: Plot of reservoir pressure from available DSTs in Ness City North Field ................................................................ 7-82

Figure 7.2.24: Production history match at Ummel \#1 well in Ness City North Field .......................................................................... 7-83

Figure 7.2.25: Production history match at Ummel \#2 well in Ness City North Field ...................................................................... 7-84

Figure 7.2.26: Production history match at Ummel \#3 well in Ness City North Field ........................................................................ 7-85

Figure 7.2.27: Production history match at Pfannenstiel \#1 well in Ness City North Field ......................................................... 7-86

Figure 7.2.28: Production history match at Pfannenstiel \#2 well in Ness City North Field ....................................................... 7-87

Figure 7.2.29: Production history match at Pember \#5A well in Ness City North Field ...................................................................... 7-88 
Figure 7.2.30: Simulator calculated fluid production at Pfannenstiel \#2A-24

well matched with historically record production volumes ...... 7-89

Figure 7.2.31: Simulator calculated fluid production at the infill horizontal well (Ummel \#4H) drilled in Ness City North Field ............... 7-90

Figure 7.2.32: Remaining reserve, oil-feet, in Layer 3 (L3) as of January 2003 in Ness City North Field

Figure 7.2.33: Simulator calculated drainage, oil-feet, by a targeted horizontal infill, EWInfill, in Ness City North Field 7-92

Figure 7.2.34: Simulator calculated production from a targeted horizontal infill, EWInfill, in Ness City North Field ................. 7-93

Figure 7.2.35: Simulator calculated drainage, oil-feet, by a targeted horizontal infill, Dia, in Ness City North Field........... 7-94

Figure 7.2.36: Simulator calculated production from a targeted horizontal infill, Dia, in Ness City North Field 7-95

Figure 7.3.1: Location and boundary of Judica Field, Ness County, Kansas 7-112

Figure 7.3.2: $\quad$ Subsea structure on top of pay Layer 1 (L1) in Judica Field .................................................................................. 7-113

Figure 7.3.3: Isopach of Layer 1 (L1) in Judica Field................................. 7-114

Figure 7.3.4: Porosity distribution in Layer 1 (L1) in Judica Field............... 7-115

Figure 7.3.5: Initial water saturation distribution in Layer 1 (L1) in Judica Field ......................................................................... 7-116

Figure 7.3.6: Isopach of Layer 2 (L2) in Judica Field................................ 7-117

Figure 7.3.7: Porosity distribution in Layer 2 (L2) in Judica Field............... 7-118

Figure 7.3.8: Initial water saturation distribution in Layer 2 (L2) in Judica Field ....................................................................... 7-119

Figure 7.3.9: $\quad$ Isopach of Layer 3 (L3) in Judica Field................................. 7-120

Figure 7.3.10: Porosity distribution in Layer 3 (L3) in Judica Field............... 7-121

Figure 7.3.11: Initial water saturation distribution in Layer 3 (L3) in Judica Field ................................................................... 7-122

Figure 7.3.12: Isopach of Layer 4 (L4) in Judica Field.................................. 7-123

Figure 7.3.13: Porosity distribution in Layer 4 (L4) in Judica Field............... 7-124

Figure 7.3.14: Initial water saturation distribution in Layer 4 (L4) in Judica Field ........................................................................ 7-125

Figure 7.3.15: Isopach of Layer 5 (L5) in Judica Field .................................. 7-126

Figure 7.3.16: Porosity distribution in Layer 5 (L5) in Judica Field .............. 7-127

Figure 7.3.17: Initial water saturation distribution in Layer 5 (L5) in Judica Field ................................................................. 7-128

Figure 7.3.18: Plot of water-oil-ratio (WOR) versus time at Thornburg Q and Thornburg M wells in Judica Field ................................ 7-129

Figure 7.3.19: Decline curve analysis at Thornburg 1 well in Judica Field .... 7-130 Figure 7.3.20: Decline curve analysis at Thornburg L1 well in Judica Field .. 7-131 Figure 7.3.21: Decline curve analysis at Thornburg 1 well in Judica Field .... 7-132 Figure 7.3.22: Decline curve analysis at Thornburg 1 well in Judica Field .... 7-133 Figure 7.3.23: Plot of reservoir pressure from available DST and shut-in tests in Judica Field $7-134$ 
Figure 7.3.24: Map showing the area simulated in Judica Field along with well locations and a summary of data constraints ................... 7-135

Figure 7.3.25: Production history match at Thornburg M1 (Slawson), TM1s, well in Judica Field...................................................... 7-136

Figure 7.3.26: Production history match at Thornburg L1, TL1, well in Judica Field ..................................................................... 7-137

Figure 7.3.27: Production history match at Thornburg A1, TA1, well in Judica Field ...................................................................... 7-138

Figure 7.3.28: Production history match at Thornburg 1, T1, well in Judica Field ...................................................................... 7-139

Figure 7.3.29: Production history match at Thornburg B1, TB1, well in Judica Field .......................................................................... 7-140

Figure 7.3.30: Production history match at Thornburg M1, TM1, well in Judica Field.

Figure 7.3.31: Production history match at Thornburg M2, TM2, well in Judica Field.

Figure 7.3.32: Initial production history match at Thornburg Q1, TQ1, well in Judica Field $7-143$

Figure 7.3.33: Final production history match at Thornburg Q1, TQ1, well in Judica Field

Figure 7.3.34: Simulator calculated reservoir pressure distribution in Judica Field as of January 2003

Figure 7.3.35: Drainage over 10 years by a targeted horizontal infill well, HWell, in Judica Field ...................................................... 7-146

Figure 7.3.36: Simulator calculated production potential of targeted horizontal infill, HWell, in Judica Field

Figure 7.3.37: Interference effects at Thornburg M1 (Slawson) due to drainage from horizontal infill Hwell in Judica Field.

Figure 7.3.38: Drainage over 10 years by a targeted horizontal infill well, MULL 1, in Judica Field 7-149

Figure 7.3.39: Simulator calculated production potential of targeted horizontal infill, MULL 1, in Judica Field along with estimated production loss at Thornburg M1 (Slawson)........... 7-150

Figure 7.3.40: Drainage over 10 years by a targeted horizontal infill well, MULL 2, in Judica Field.

Figure 7.3.41: Simulator calculated production potential of targeted horizontal infill, MULL 2, in Judica Field along with estimated production loss at Thornburg M1 (Slawson).......... 7-152

Figure 7.3.42: Drainage over 10 years by a targeted horizontal infill well, MULL 3, in Judica Field $7-153$

Figure 7.3.43: Simulator calculated production potential of targeted horizontal infill, MULL 3, in Judica Field along with estimated production loss at Thornburg M1 (Slawson)........... 7-154

Figure 7.3.44: Drainage over 10 years by a targeted horizontal infill well, MULL 4, in Judica Field $7-155$ 
Figure 7.3.45: Simulator calculated production potential of targeted horizontal infill, MULL 4, in Judica Field along with estimated production loss at Thornburg M1 (Slawson)........... 7-156

Figure 7.3.46: Drainage over 10 years by a targeted horizontal infill well, MULL 5, in Judica Field.

Figure 7.3.47: Simulator calculated production potential of targeted horizontal infill, MULL 5, completed in Layer 5 in Judica Field along with estimated production loss at Thornburg M1 (Slawson) and Thornburg A1 wells

Figure 7.3.48: Simulator calculated production potential of targeted horizontal infill, MULL 5, completed in Layer 3 in Judica Field.

Figure 7.3.49: Simulator calculated production potential of targeted horizontal infill, MULL 5, completed in Layer 1 in Judica Field

Figure 7.3.50: Drainage over 10 years by a hypothetical vertical infill well, VWell L5 E, completed in Layer 5 in Judica Field $7-161$

Figure 7.3.51: Simulator calculated production potential of a hypothetical vertical infill, VWell L5 E, completed in Layer 5 in Judica Field.

Figure 7.3.52: Drainage over 10 years by a hypothetical vertical infill well, VWell E, completed in Layers 1, 3, and 5 in Judica Field....

Figure 7.3.53: Simulator calculated production potential of a hypothetical vertical infill, VWell E, completed in Layers 1, 3, and 5 in Judica Field

Figure 7.3.54: Drainage over 10 years by a hypothetical vertical infill well, VWell W, completed in Layers 1, 3, and 5 in Judica Field

Figure 7.3.55: Simulator calculated production potential of a hypothetical vertical infill, VWell W, completed in Layers 1, 3, and 5 in Judica Field.

Figure 9.1: $\quad$ Map showing the area simulated in Judica Field along with location of the pilot well and Thornburg F1 .............................. 9-3

Figure 9.2: $\quad$ Remaining reserves, oil-feet, map as of January 2003 along with the approximate location of the pilot well in Judica Field....

Figure 10.1: A) Structure map of Judica Field on Mississippian pay before 3D seismic survey, B) Revised structure map on Mississippian pay after incorporating 3D seismic analyses 10-5

Figure 10.2: $\quad$ Mississippian structure map derived from 3D seismic survey including and around the Judica study area ..... 10-6

Figure 10.3: A) A crossplot of porosity-height (well data) of the Judica zone versus amplitude of the Base Warsaw LS horizon, B) Amplitude map of Base Warsaw LS over and around Judica Field. 
Figure 10.4: Model of variation in amplitude of Base Warsaw LS horizon with increasing porosity of Judica zone.

Figure 10.5: A) Map of Base Warsaw LS Amplitude over and around Judica Field study area, B) Post 3D Mississippian structure map over and around Judica Field study area......................... 10-9

Figure 10.6: $\quad$ 3D reservoir volume based on the revised geo-model ............ 10-10

Figure 10.7: A) Boundary of the Judica study area, B) Water-oil-ratio (WOR) versus cumulative oil production from Thornburg Q1, C) Water-oil-ratio (WOR) versus time for Thornburg Q1 $10-11$

Figure 10.8: A) Boundary of the Judica study area, B) Production history-match for Thornburg M1 (Slawson) well, C) History match obtained from pre-3D model, D) History match of estimated water production based on WOR vs. time and WOR vs. cumulative production $10-12$

Figure 10.9: A) Boundary of the Judica study area, B \& D) Production history match for Thornburg L1 well, C) History match using pre-3D model.

Figure10.10: A) Boundary of the Judica study area, B \& D) Production history match for Thornburg L1 well, C) History match using pre-3D model

Figure 10.11: A) Boundary of the Judica study area, B \& D) Production history match for Thornburg Q1 well, C) History match using pre-3D model $10-15$

Figure 10.12: A) Boundary of the Judica study area, B) Simulator calculated decline on average reservoir pressure with time..... 10-16

Figure 10.13: A) Boundary of Judica study area post-3D, B \& C) Remaining reserves as of January 2005 using pre-3D and post-3D models $10-17$

Figure 10.14: A) Boundary of the post-3D Judica study area, B) Location of infill horizontal trajectory, C) Simulator estimated production potential of the infill horizontal well, D) Estimated drainage by infill horizontal well after 5 years of production $10-18$

Figure 10.15: A) Boundary of post-3D Judica study area, B) Simulator calculated production output from the horizontal infill well completed in layers 3 and 5

Figure 10.16: Effects of strengthening analytical aquifer on average reservoir pressure decline $10-20$

Figure 10.17: History matches of well-level oil production using a stronger analytical aquifer. $10-21$

Figure 10.18: Drainage and production potential of an infill horizontal well using a stronger analytical aquifer $10-22$ 
Figure 10.19: A) Location of a horizontal infill well extending into the neighboring lease, B) Drainage, oil-feet, after 5 years production from the horizontal infill, C) Simulator estimated production potential from the horizontal infill well................. 10-23 


\section{TABLES}

Table 2.1: Average petrophysical properties as obtained from type well(s) in 14 fields selected for initial screening ........................ 2-9

Table 2.2: $\quad$ Volumetric estimates based on analyses of type well(s) from 14 short listed fields for initial screening.............. 2-10

Table 2.3: $\quad$ Fields ranked as per estimated pressure depletion for initial screening.

Table 2.4: $\quad$ Fields ranked as per average well spacing for initial screening $2-12$

Table 2.5: $\quad$ Fields ranked as per estimated minimum and maximum pay thickness for initial screening... $2-13$

Table 2.6: $\quad$ Fields ranked as per recovery factors. 2-14

Table 2.7:

Table 2.8: Relative ranking of fields on the basis of their estimated average well spacing, minimum gross pay in undrilled areas, remaining oil in place per acre-foot, and recovery factors of vertical wells

Table 3.1a: Average petrophysical (and other input) data to

Table 3.1b: Average petrophysical (and other input) data to RESMOD ${ }^{\mathrm{TM}}$ for Ness City North Field, Ness County, Kansas.

Table 3.1c: Average petrophysical (and other input) data to RESMOD $^{\mathrm{TM}}$ for Arnold Southwest Field, Ness County,

Kansas

Table 3.1d: Average petrophysical (and other input data) to RESMOD $^{\text {TM }}$ for Judica Field, Ness County, Kansas................. 3-16

Table 3.1e: Average petrophysical (and other input data) to RESMOD $^{\text {TM }}$ for Riverside Field, Ness County, Kansas

Table 3.1f: $\quad$ Average petrophysical (and other input data) to RESMOD $^{\mathrm{TM}}$ for Lippoldt Field, Hodgeman County, Kansas

Table 3.1g: Average petrophysical (and other input data) to RESMOD $^{\mathrm{TM}}$ for Fralick West Field, Kiowa County, Kansas

Table 3.2: $\quad$ RESMOD ${ }^{\mathrm{TM}}$ predicted estimates of initial production (IP) rates and cumulative production (after 5 years) from infill and vertical wells.

Table 4.1: $\quad$ Summary of KGS Mississippian cores in the study area region .............................................................................. 4-45

Table 4.2: $\quad$ Data-fields in the on-line database........................................... 4-46

Table 4.3: Water/oil relative permeability data summary.......................... 4-47

Table 5.1: $\quad$ Recommended DMSF values per REMOD ${ }^{\mathrm{TM}}$ user manual for different reservoir-drive mechanisms. 
Table 5.2: $\quad$ Petrophysical properties used to obtain history match at Ummel 1 well in Ness City North Field .................................. 5-18

Table 5.3: $\quad$ RESMOD ${ }^{\mathrm{TM}}$ predicted production volumes compared with historic records at Ummel 1, Ness City North Field.......... 5-19

Table 5.4: $\quad$ Petrophysical properties used to obtain history match at Ummel 2 well in Ness City North Field ................................... 5-20

Table 5.5: $\quad$ RESMOD ${ }^{\mathrm{TM}}$ predicted production volumes compared with historic records at Ummel 2, Ness City North Field.......... 5-21

Table 5.6: Estimated average petrophysical parameters in the drainage area around the location of the horizontal well drilled in Ness City North Field ......................................................... 5-22

Table 5.7: $\quad$ RESMOD ${ }^{\mathrm{TM}}$ predicted production performance from a horizontal well drilled in Ness City North Field........................ 5-23

Table 5.8: Average petrophysical properties in the drainage area of Thornburg M (Well M) in Judica Field .................................. 5-24

Figure 5.9: Average petrophysical properties in the drainage area of Thornburg L (Well L) in Judica Field...................................... 5-25

Table 5.10: $\quad$ RESMOD ${ }^{\mathrm{TM}}$ predicted production performance from Thornburg M in Judica Field ................................................. 5-26

Table 5.11: $\quad$ RESMOD ${ }^{\mathrm{TM}}$ predicted production performance from Thornburg L in Judica Field ..................................................... 5-27

Table 5.12a: Part A - Results of sensitivity studies, on petrophysical and other inputs, on predicted productivity of an infill horizontal well in Judica Field............................................... 5-28

Table 5.12b: Part B - Results of sensitivity studies, on petrophysical and other inputs, on predicted productivity of an infill horizontal well in Judica Field. 5-29

Table 5.13: Summary of sensitivity of estimated cumulative production, from a horizontal infill well, on various input parameters ....................................................................... 5-30

Table 7.1.1: $\quad$ Input PVT properties for McDonald Field simulation study ..... 7-49

Table 7.1.2: $\quad$ Relative permeability - capillary pressure calculator for McDonald Field .................................................................. 7-50

Table 7.1.3: Well completion summary in McDonald Field ......................... 7-51

Table 7.2.1: Well-level cumulative production from Ness City North Field ........................................................................... 7-96

Table 7.2.2: $\quad$ PVT inputs to reservoir simulation study of Ness City North Field ..................................................................... 7-97

Table 7.2.3: Relative permeability-capillary pressure calculator for reservoir rock in Ness City North Field.................................... 7-98

Table 7.2.4: Relative permeability-capillary pressure calculator for non-reservoir rock in Ness City North Field............................ 7-99

Table 7.2.5: $\quad$ Estimated bottom hole pressures (BHPs) prevalent at wells in Ness City North Field............................................. 7-100

Table 7.2.6: Well completion summary in Ness City North Field............... 7-101 
Table 7.2.7: Production loss at nearby wells due to drainage from EWInfill well in Ness City North Field .................................... 7-102

Table 7.2.8: Production loss at nearby wells due to drainage from Dia well in Ness City North Field............................................... 7-103

Table 7.3.1: $\quad$ PVT inputs to reservoir simulation study of Judica Field........ 7-167

Table 7.3.2: Water PVT properties input for reservoir simulation of Judica Field.... $7-168$

Table 7.3.3: Relative permeability - capillary pressure table for reservoir rock in Judica Field.................................................. 7-169

Table 7.3.4: Relative permeability - capillary pressure table for non-reservoir rock in Judica Field ........................................... 7-170

Table 9.1: $\quad$ Summary of events at Judica Pilot well ........................................ 9-5

Table 10.1: $\quad$ Approximate drilling expenses from MDCI............................. 10-24 


\section{$\underline{\text { MAPS }}$}

Map 2.1: $\quad$ Location of fields selected for initial screening for potential for exploitation by horizontal infill wells ............................... 2-17

Map 10.1: $\quad$ Map showing location and extent of additional 3D data planned to be collected by MDCI in 2005 ............................ 10-25 


\section{EXECUTIVE SUMMARY}

Karst-induced solution-enhanced features such as vertical shale intervals result in reservoir compartmentalization in many Mississippian fields of Kansas. Such heterogeneities, in addition to thin pay zones, high water cut, low recovery factors, and lack of integrated reservoir characterization studies add to the challenges of exploiting significant remaining reserves in these fields, most of which are operated by independent operators with limited access to resources and technology. Many of these reservoirs produce under strong water drives. Thus, application of targeted infill horizontal wells is expected to drain remaining reserves trapped in one or more compartments that would otherwise be uneconomic to produce by vertical wells with limited drainage.

This project demonstrated the application of the following preferred management practices (PMPs) to rejuvenate production from mature Mississippian reservoirs of Kansas:

1) Quick and effective techniques to screen Mississippian fields using publicly available data to identify candidate leases/areas for detailed modeling to evaluate their potential for exploitation by horizontal infill drilling.

2) Application of cost-effective tools for integrated reservoir characterization and geomodel construction.

3) Creating a publicly accessible Mississippian rock catalog to obtain field-specific and/or analog petrophysical data necessary for reservoir simulation.

4) PC-based reservoir simulation to validate a geomodel through matching production/pressure histories, mapping residual reserves, and determining productivity potential of targeted horizontal infill wells.

5) Characterization of reservoir heterogeneity affecting fluid flow in Mississippian reservoirs using 3D-seismic attribute analyses to delineate reservoir compartments and predict the presence of pay-porosity in such compartments.

In addition to the above, this report summarizes publicly available information regarding operator experiences related to horizontal well drilling in Kansas, and also outlines the preferred coring strategy to be followed to drill, retrieve, and test core obtained from the pilot well of a horizontal lateral.

Mississippi (Spergen-Warsaw) reservoirs of central Kansas are layered by constituent lithofacies such as dolomitized carbonate mudstones, wackestones, and packstones. These lithofacies can be traced by electric log character from well to well and mapped on a local scale and were traceable within the boundaries of each of the 3 fields characterized in detail in this study. However, vertical shale intervals, formed as a result of karst processes, were found to compartmentalize these reservoirs. Such compartmentalization reduces drainage volumes making vertical wells less effective. Properly designed horizontal infill wells may link a series of compartments, each with pressure support and pay-porosity, like a string of pearls, thereby, recovering the remaining reserves economically. However, drilling experiences in Kansas suggest that 
these vertical shale intervals are unstable in open-hole lateral completions, and have on occasion collapsed to kill a producing horizontal well.

Based on inputs from the industry partner Mull Drilling Co. Inc. (MDCI), the target area was screened to select 14 fields on basis of cumulative primary production and pressure support as evident from publicly available DST data. These 14 fields were then put through a quick screening process which ranked them on the basis of reservoir thickness and extent, average porosity, average reservoir pressure depletion, estimated remaining reserves per acre-ft, and average well spacing. With limited resources available for screening of a target area, many of these inputs came from the analyses of one or more type wells in each field. Given the ownership structure prevalent in the Midcontinent, a company's ability to build an operational agreement with co-owners and/or interest holders appears to play a critical role in the selection of an appropriate target for horizontal infill operations. Single phase analytical (1-D) models were calibrated on representative vertical wells in a field and then used to estimate the production potential of horizontal wells based on average properties within the given drainage area. These models are quick to run and also help rank prospective candidate fields.

Detailed characterization and simulation studies were performed on 3 fields, and MDCI selected Judica Field, Ness County, Kansas, to locate a pilot well to drill a horizontal lateral. Log and core cuttings from the pilot well revealed a host of complexities that were not part of the Judica field reservoir geomodel. Diverging results from shut-in tests at 2 nearby wells also indicated that the field was more complex and heterogeneous (compartmentalized) than anticipated. This was followed by the shooting a 3D-seismic survey over the field in order to better characterize the underlying compartments. Attribute analyses carried out on the 3D data revealed the boundaries of different compartments in the study area. A methodology was also developed to discriminate between dry and productive wells in and around the study area. Based on the results from the 3D survey, the field geomodel was revised and re-simulated. Lack of evidence of pressure support and reduced drainage area due to compartmentalization resulted in low recovery volumes from various prospective infill trajectories starting from the pilot well. Based on the estimated recoveries from the revised simulation, associated risks, and other available targets within MDCI's portfolio, MDCI decided against drilling a lateral out of the pilot well in Judica study area.

Strong pressure support and average well spacing in excess of 40-acres appear to be critical requirements for an economically successful horizontal well in Mississippian reservoirs studied in this project. Karst-induced heterogeneities make Mississippian (Spergen-Warsaw) reservoirs complex, and reservoir models built by integrating log, core, DST, and production data from existing wells on 40-acre spacings may be insufficient to delineate reservoir compartments in these mature fields. Thus, detailed reservoir characterization based on geomodels developed by integrating wireline log, core, petrophysical, production and pressure, and 3D-seismic data enables effective evaluation of a candidate field for horizontal infill applications in Mississippian carbonate reservoirs of central Kansas. 


\section{Introduction}

Of the 6 billion barrels of oil produced in Kansas, Mississippian carbonate reservoirs account for nearly 1 billion (16.6\% as of 2000). With declining production in other age reservoirs the contribution of Mississippian reservoirs to the state's oil production has increased to 33\% over the past 10 years (Figure 1.1), and totaled about 21 million barrels (43\% of the state's annual production) in 1994. The majority of Mississippian production in Kansas occurs at or near the top of the Mississippian section just below the pre-Pennsylvanian unconformity. Figure 1.2 shows the structure on the Mississippian and the location of the fields producing from this interval. Small independent operators, with limited technical and financial resources, operate most of these fields. Reservoir heterogeneity, high water cuts, and low recovery efficiencies place operations in many fields at or near economic limits. Low average recovery factors, 13 to $15 \%$, result in high well abandonment rates, and leave significant residual reserves (estimated to be 5.5 billion barrels) in the ground. In this regard, improvement of field management practices that result in an additional recovery of as little as $10 \%$ of residual reserves translates to a boost in the domestic production by about 550 million barrels.

For Kansas producers, access to new technology is important for sustaining production and increasing profitability. Problems of low recovery efficiency in shallow shelf carbonate reservoirs and limited operator resources are present throughout the midcontinent region of the United States. To address these problems a US DOE-sponsored project, funded under the DOE PUMP (Preferred Upstream Management Practices) program, was initiated in August, 2001. The overall project objective is to demonstrate preferred management practices (PMPs) that address producibility problems in Mississippian shallow shelf carbonates resulting from inadequate reservoir characterization, limited drainage by vertical wells, high water cuts due to strong aquifer drives, lack of geologic and production data, and low recovery factors.

Previous studies (Carr et al., 1996; Franseen et al., 1998) have shown that Mississippian carbonate reservoirs of the mid-continent fall within the "Type C" 
reservoir classification of Fritz (1991) and are, therefore, suitable candidates for horizontal drilling applications. This project applies modern and cost-effective tools, techniques, and methodologies to evaluate and exploit residual reserves in mature Mississippian fields. The objective is to demonstrate the use of cost-effective technologies to characterize, model, and simulate reservoirs and to apply horizontal infill drilling to extend the economic life of these mature shallow-shelf carbonate fields, and in the process recover significant incremental reserves. This project highlights the practical implementation of integrated multi-disciplinary reservoir description to map remaining reserves in these mature and complex reservoirs. It also intended to demonstrate the applicability of targeted horizontal infill wells to exploit the residual potential.

This project involved the demonstration of the following PMPs:

1) Quick and effective techniques to screen Mississippian fields using publicly available data to identify candidate leases/areas for detailed modeling to evaluate their potential for exploitation by horizontal infill drilling

2) Application of cost-effective tools for integrated reservoir characterization and geomodel construction

3) Creating a Mississippian rock catalog to access field specific or analog petrophysical data necessary for reservoir simulation

4) PC-based cost-effective reservoir simulation to validate geomodel through matching production/pressure histories, mapping residual reserves, and determining productivity potential of targeted horizontal infill wells

5) Characterization of reservoir heterogeneity affecting fluid flow in Mississippian reservoirs of the mid-continent by using such tools as 3D-seismic attribute analyses to delineate reservoir compartments and fracture modeling based on analyses of horizontal core and fracture image log data

6) Bottom-up planning of drilling and completion of horizontal wells

7) Production optimization through post-drill monitoring 
This project is a partnership between the Kansas Geological Survey (University of Kansas - KU), the Tertiary Oil Recovery Project (KU), Mull Drilling Company Inc. (MDCI), Maurer Engineering Inc., and the US DOE. It is anticipated that the demonstration of the above PMPs to select, characterize, and locate a candidate lease to design, drill, and complete an effective infill horizontal well will help to develop a learning curve and, thereby, build confidence among independent operators of the midcontinent to employ targeted infill horizontal wells to recover remaining reserves from their mature fields.

\subsection{Constraints Affecting Production from Mississippian Carbonate Reservoirs of Kansas}

Mississippian carbonate reservoirs are major contributors to oil production of Kansas. These heavily dolomitized shallow-shelf carbonates are truncated by the prePennsylvanian unconformity. The subcropping Mississippian rock units tend to get progressively older near the Central Kansas uplift and are absent on the uplift. The top of the Mississippian is an erosional karst surface (Franseen et al., 1998, Carr et al., 1996 and Merriam, 1963). The combination of a karsted erosional surface, the influences of original depositional facies, and subsequent diagenesis have had a significant control on development and preservation of reservoir quality. The reservoirs consist of numerous vertically and laterally segregated compartments. Sedimentologic, stratigraphic, and paragenetic studies indicate that the most favorable areas for successful production may be where echinoderm-rich and spicultic-rich facies containing abundant evaporites intersect fractures associated with the post-Mississippian uncomformity and form topographic highs (Franseen et al., 1998).

Production from Mississippian reservoirs is constrained by:

1) Horizontal and vertical heterogeneity resulting from variation in depositional facies and from diagenetic overprinting

2) Proximity of a strong bottom water drive

3) Indications of the presence of a fracture network 
4) Limited drainage by vertical wells before onset of high water-cut

5) Limited technological and financial resources of independent producers operating these fields

Significant lateral changes in lithology at the interwell scale, from shale-rich low permeability to clean high permeability, are evident from gamma log run in a recently drilled 500 foot horizontal well in the Ness City North field, Ness County, Kansas. Most Mississippian fields are developed on 40-acre spacing in Kansas with expected drainage radii of approximately 750 feet. Lateral heterogeneities compartmentalize the reservoir into isolated pods. The presence of multiple isolated pods within the drainage area of a vertical well severely limits its drainage potential.

Figure 1.3 (Franseen et al., 1998) depicts a plot of mini-permeameter values (at intervals of quarter foot), simplified depiction of facies, fracturing, brecciation and other features as related to these values, and locations of oil staining, and reveals the extent of vertical stratification in the reservoir. Cased Mississippian wells often have higher cumulative production than wells completed open-hole after drilling the top few feet of the Mississippian. This may be indicative of flow barriers to vertical migration within the Mississippian, and that vertical heterogeneity significantly reduces the net pay interval in vertical wells that had open-hole completions.

Mississippian reservoirs in Kansas are generally underlain by active aquifers. These aquifers help to maintain reservoir pressure but also result in significant water production. Production data from different Mississippian fields reveal that most productive wells (such as Moore B1 from Schaben field, Ness County, Kansas, and shown in Figure 1.4) exhibit an initial period (varying between 6 to 24 months) of limited water production followed by a rapid drop in the oil cut, and then decades of a near constant but very high water-cut. Sub-surface cross sections and detailed core studies (Bhattacharya et al., 1999, and Carr et al., 1996) indicate possibility of oil migration across multiple correlated reservoir zones within the Mississippian. The characteristic well production profile and the nature of oil migration indicate the possibility of an active 
fracture system in these reservoirs. However, no detailed fracture characterization study has been reported on Mississippian carbonates in Kansas.

\subsection{Productivity Potential of Mississippian Reservoirs}

The volume and the scale of residual hydrocarbons left behind in mature Mississippian carbonate reservoirs is well illustrated by the Welch-Bornholdt-Wherry fields, Rice County, Kansas (Bhattacharya et al., 2003). These fields were discovered in 1964 and produce from a stratigraphic Mississippian trap. Cumulative production through 1997 was approximately 60 MMBO. Figure 1.5 reveals areas with significant volumes of residual oil (approximately $7 \mathrm{MMBO}$ per quarter section). Ineffective drainage by vertical wells in highly compartmentalized reservoirs leaves behind significant unswept reserves. Another example of residual potential in Mississippian reservoir is the Aldrich field, Ness County, Kansas (Bhattacharya et al., 2003). This field was discovered in 1929, and by 1973 had produced 1.04 MMBO from 15 producing wells. By 1973, the field production had declined to less than $400 \mathrm{BO} /$ month, and 8 vertical infill wells were drilled as a part of the infill-drilling program. By mid-1997, an additional 553 MBO of oil had been recovered from the field by the infill wells. Aldrich field is a typical example of a mature Mississippian field having significant recoverable reserves left behind due to inadequate drainage by vertical wells in a heterogeneous reservoir. Thus, production enhancement from such mature fields will not only boost the local economy, but will also result in the recovery of invaluable national resource which, otherwise, will remain unproduced.

Targeted horizontal infill wells are known to access and produce left behind reserves that would be uneconomic to recover by traditional vertical wells. However, one of the principal causes of failure for horizontal wells has been poor evaluation and target selection (Coffin, 1993, and Joshi, et al., 1996). Typically, a horizontal well costs about 1.4 to 3 times (Joshi, 1991) that of a vertical well. The industry's rule of thumb (Lacy, 1992) suggests that for a horizontal well to be an economic success, it should recover volumes that are between two to three times that of a vertical well. This makes the 
identification of reservoirs that are viable candidates for horizontal drilling to be of crucial importance, especially for an independent producer with limited resources. As of 2000, only 11 horizontal wells have been drilled in the Mississippian formations in Kansas. Limited available data show that the majority of these wells have been economically unsuccessful. The inability to identify appropriate horizontal well applications coupled with the higher drilling costs have been two of the major reasons why the horizontal drilling potential of Mississippian carbonates has not been fully utilized in Kansas.

\subsection{Effective and Quick Screening of Target Area to Select Candidates for Detailed Evaluation}

Accurate screening of prospective horizontal infill drilling candidates is critical to successful implementation. Often the independent operator's area of interest is widespread and a quick screening work-flow is required for practical application. A PMP for this region is the utilization of the numerous quick screening tests using publicly accessible databases to identify and rank prospective sites.

One of the principal causes behind the economic failure of a majority of horizontal wells drilled in Mississippian carbonate reservoirs of Kansas has been incorrect target selection often due to application of operator experience in similar reservoirs in another part of the continent but without comprehensive screening of the local target reservoirs. Issues regarding lease ownership, so prevalent in the midcontinent, often limit operators from applying screening techniques to evaluate the whole region or field to identify drilling locations with maximum potential. Inexpensive screening techniques that are locally applicable and help quickly define prospective horizontal infill targets in a field or producing region will appeal to independent producers enough to gain implementation.

Mature production areas often collectively have a rich bank of data that includes petrophysical log and core data, production and pressure test results and histories. The 
availability of regional data somewhat balances the often questionable quality and limited quantity of well-level production data available in many fields, and serves as an invaluable resource to develop reservoir models to evaluate remaining potential. The intent of this project is to demonstrate application of cost-effective techniques to select prospects for horizontal infill drilling. Potential areas were selected by applying one or a combination of methods (Bhattacharya et al., 2003) including: a) initial quick screening to short list fields in the target area using field production and pressure data and type well log analyses, followed by b) detailed geomodeling by integrating field production and pressure test analysis, field wide log analyses, geologic mapping, core petrophysical analyses, and finally c) validating the underlying geomodel through reservoir simulation in order to map residual reserves and evaluate productivity potential of targeted horizontal infill wells.

Bhattacharya et al, (2003) reviewed several simple and effective techniques for screening horizontal well candidates in mature Mississippian carbonates areas. Production data (lease- or well-level) is commonly available in most mature fields. It becomes apparent from these production histories that often a rapid decline of the oil cut occurs after an initial period of water-free production, and this is indicative of the significance of vertical permeability in fractured Mississippian reservoirs. In most cases, the high water-cut persists, at almost a constant level, for the major part of the well's producing life. Plotting production information at the well level quickly identifies areas with poor vertical sweep due to water conning. An additional screening tool is to overlay a map of cumulative production (at the well level) on a map of initial production rates (IPs). Areas where the cumulative production volumes are disproportionate to the corresponding IPs may indicate unswept reserves. Comparing cumulative production, at field- and well-level, before and after infill drilling in analogous reservoirs with similar well spacing is an effective way to identify fields that are candidates for horizontal infill drilling by virtue of excessive well spacing.

An important application of a horizontal infill well is the recovery of attic oil. First derivative structure maps can effectively delineate the axis of the attic (Figure 1.6) 
such as in the Hollow-Nickel field, Harvey County, Kansas. Additionally, horizontal wells effectively drain reserves trapped in thin pay zones in the Mississippian. Overlay of the cumulative production map on the oil-feet (product of pay, initial oil saturation, and porosity) map highlights areas with significant pay thickness but low cumulative production. Inability of vertical wells to effectively drain compartmentalized reservoirs may be the cause for this mismatch between pay thickness and cumulative production. These areas can be considered as potential candidates for horizontal infill wells. 


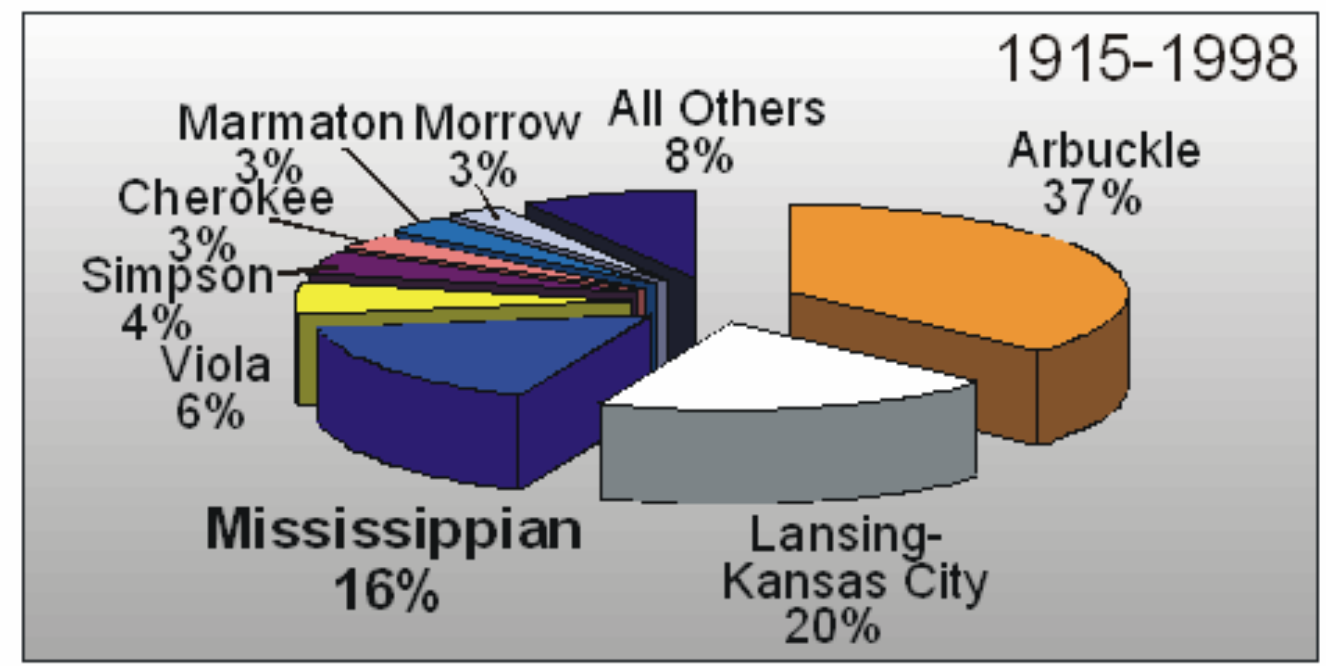

Figure 1.1: Contribution by reservoirs of different ages to the Kansas oil production. 


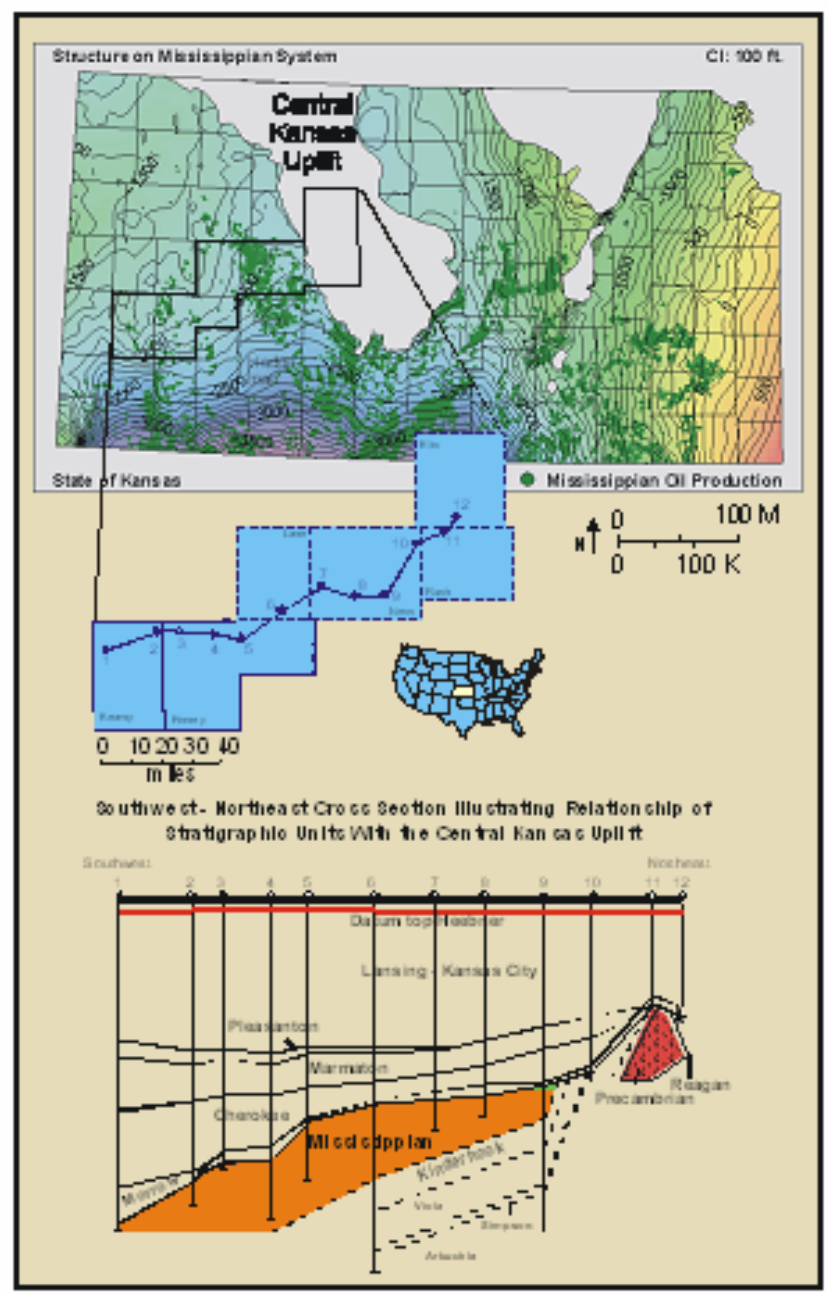

Figure 1.2: Structure on Mississippian and general locations of fields producing from this interval. 

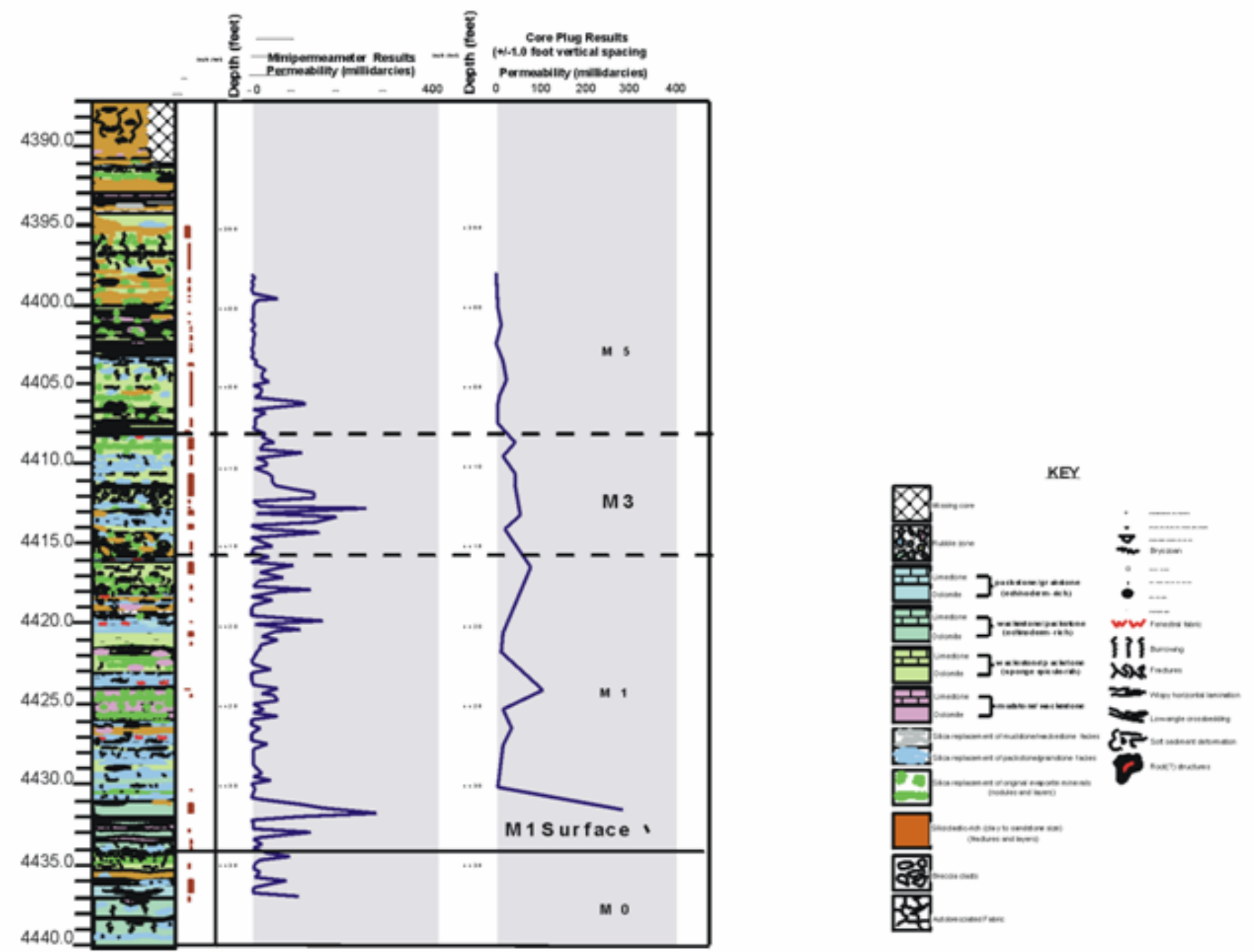

Figure 1.3: Mini-permeameter readings and core description including oil strains at quarter-foot intervals on a Mississppian core from Kansas. (Franseen et al., 1998) 


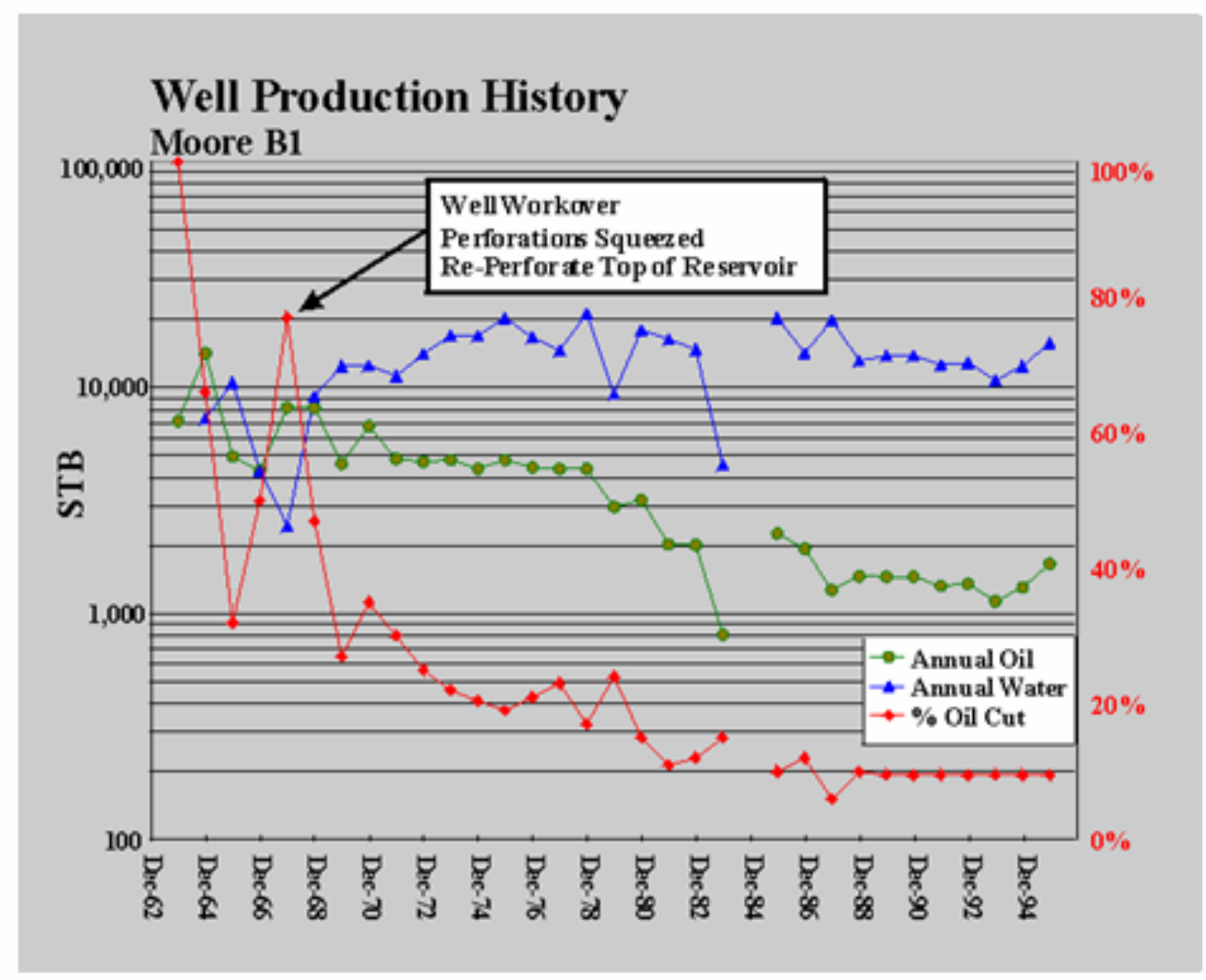

Figure 1.4: Typical production profile from a Mississippian well, Ritchie Exploration Moore B1, Schaben field, Kansas. 


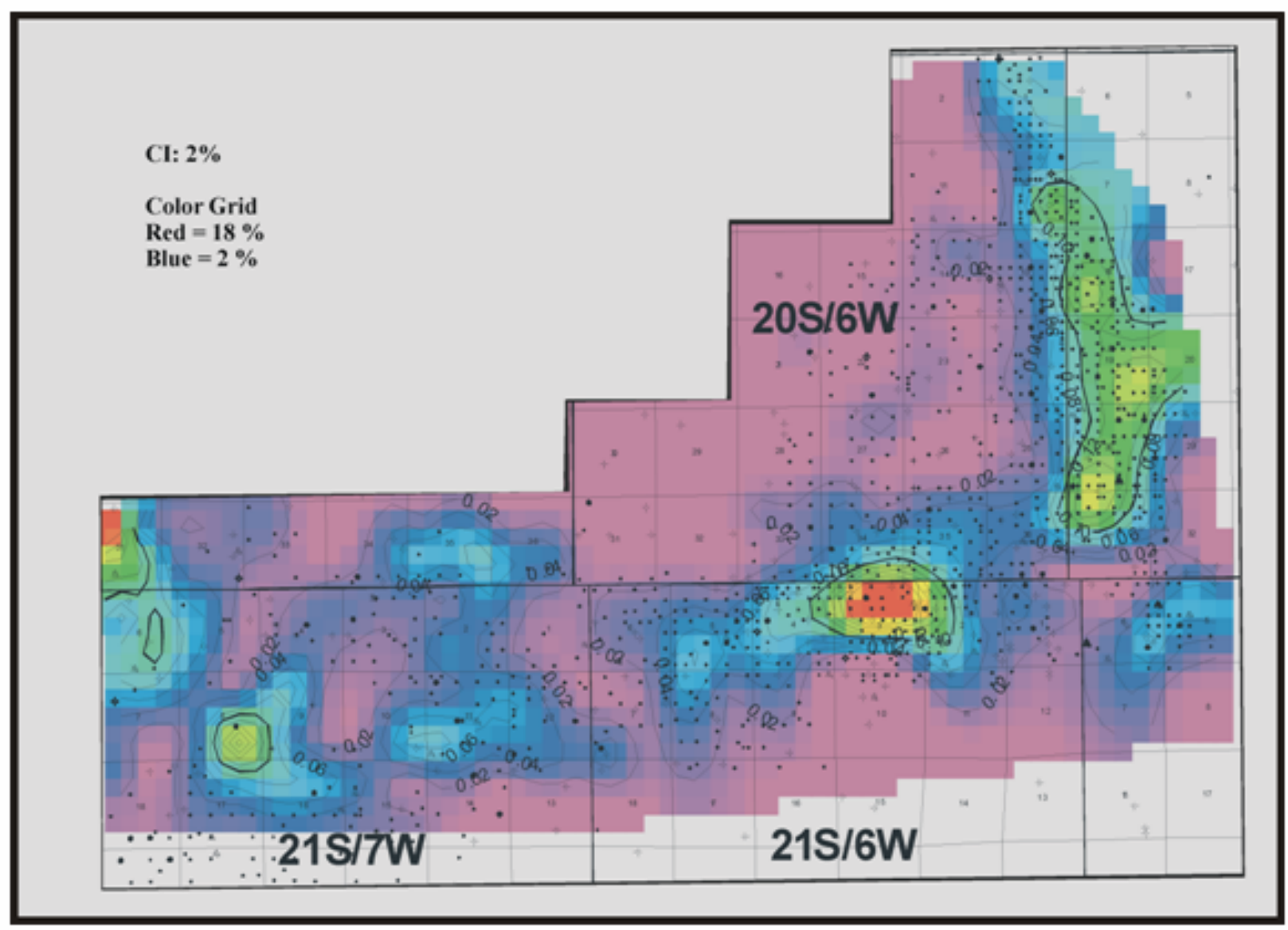

Figure 1.5: Recovery factor (fraction) at the Welch-Bornholdt-Wherry field, Rice County, Kansas, as of 1998. 


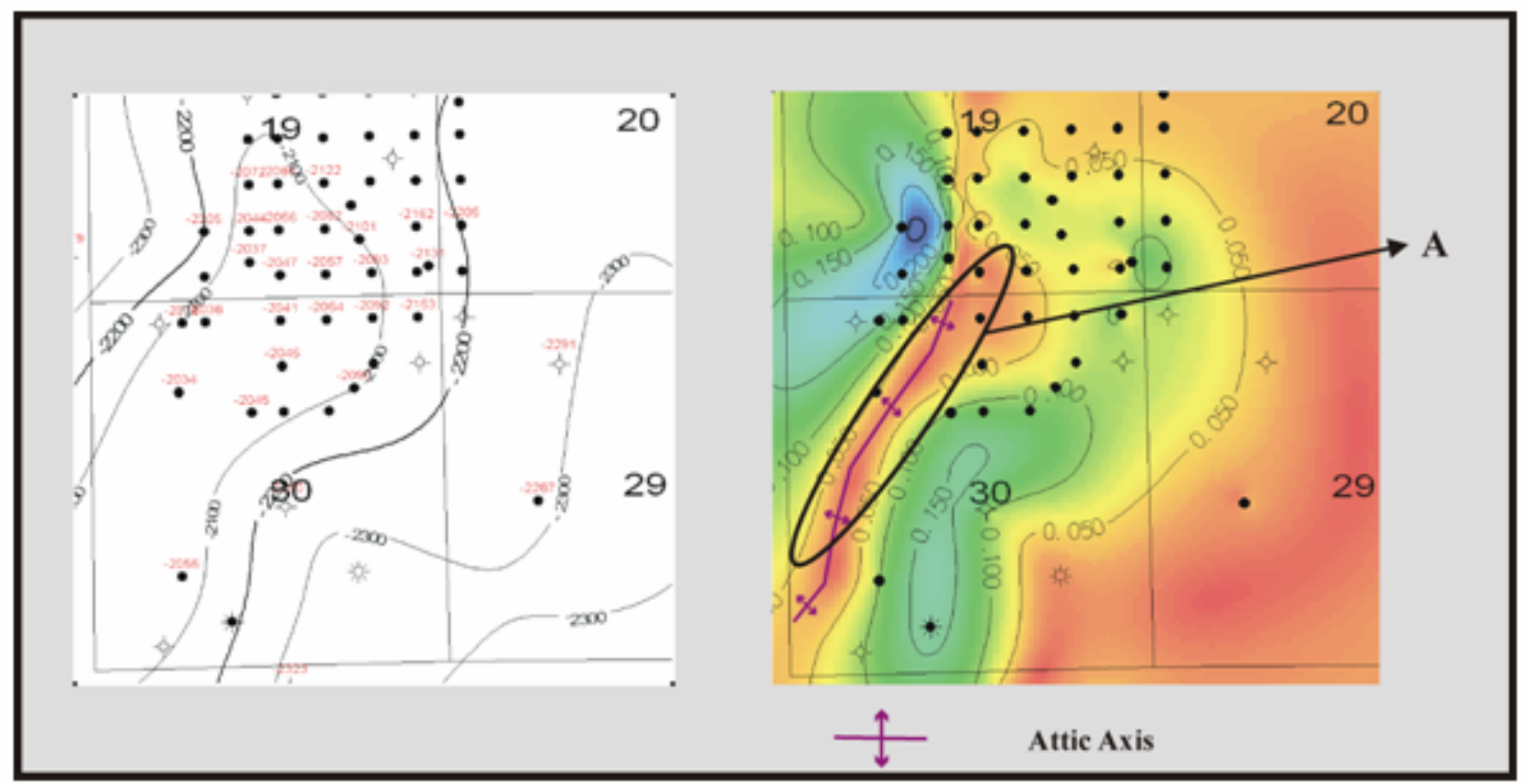

Figure 1.6: Structure map and first derivative of the structure of Simpson sand to identify possible attic axis in Hollow-Nickel field, Harvey County, Kansas (Bhattacharya et al., 2003). 


\section{Initial Screening Studies - 14 Fields}

\subsection{Target Study Area}

A "target region" for the project was selected in consultation with the industry partner Mull Drilling Company Inc. (MDCI). MDCI owns and/or has interests in several fields producing from Mississippian carbonate reservoirs in this region, and was therefore interested in identifying candidate fields/leases that have significant potential for exploitation through horizontal infill drilling. The initial study area was located in westcentral Kansas, in the area ranging from Township 16S to 27S and 20W to 26W (Map 2.1). Major Mississippian fields in this region (highlighted in color) are of different sizes (with wells per field ranging from 5 to 90) and of different vintages. A majority of these fields are in the mature stages of primary production. In the initial analysis, with input from MDCI, 14 fields from the area shown in Map 2.1 were selected for screening based on cumulative primary production and reservoir pressure support evident from publicly available DST records.

\subsection{Parameters for Initial Screening of Fields in Target Area}

Table 2.1 lists the 14 fields selected for the screening analysis to identify their residual potential. Identification of residual potential requires at minimum the determination of:

- $\quad$ reservoir thickness and areal extent

- porosity

- remaining oil in place

- reservoir pressure

Reservoir thickness and areal extent were delineated using wireline logs, drill stem test (DST), and initial production (IP) data. Porosity was obtained from wireline 
logs. Remaining oil in place was determined from calculations of original oil in place (based on reservoir size, porosity, and estimates of original oil saturation based on logs and/or capillary pressure relations) and reported production. Reservoir pressures were obtained from analysis of final shut-in pressure (FSIP) data through time. The following text briefly reviews each of these analyses.

\subsubsection{Reservoir Thickness and Aerial Extent}

Available DST and IP production rates were analyzed to delineate the boundary outside of which only dry wells exist for each field. Available wireline log data were analyzed to determine the presence or absence of the pay zone in some of the wells at the boundary of each field. A type well(s) was selected for each field to obtain average

values for petrophysical properties including pay height. Available fluid recovery data from DSTs were analyzed at the well level in each field to approximate an oil-water contact (OWC). For a first-pass evaluation, the height above the OWC to the top of the Mississippian interval was defined as net pay in each well, and net pay distribution maps were constructed for each field. Gross pay isopach and structure maps were generated for each selected field. The maps show that Mississippian fields in this region can exhibit gross pay thickness of 30-40 ft above the OWC, which in limited regions may extend up to $60-80 \mathrm{ft}$.

\subsubsection{Reservoir Porosity}

Reservoir porosity was obtained from wireline logs. For each field, either a single type-log or a pair of type-logs was selected. Most fields have recent wells drilled where "modern" compensated density-neutron porosity logs were recorded and thus available.

\subsubsection{Estimated Remaining Oil in Place}

Mississippian reservoirs generally display a decline in the oil rate with time accompanied by increasing and then near constant high water-cut. Newly drilled wells in 
mature fields, however, frequently produce at moderate oil rates with low water-cuts for an initial period indicating inefficient drainage by vertical wells. These high oil and low water production rates may also indicate reservoir compartmentalization. Gamma-ray logs of a recent horizontal well in a Mississippian reservoir revealed the presence of vertical shale barriers believed to result from infill of vertical fractures widened by karst processes. These vertical barriers would limit drainage of vertical wells making them ineffective in draining compartmentalized reservoirs resulting in significant remaining reserves in compartmentalized pockets. These significant remaining reserves provide good opportunities for infill horizontal drilling.

For initial screening purposes, the remaining oil in place was calculated by determining the difference between estimated original oil in place and reported cumulative oil production. Initial reserves in place were calculated using volumetric calculations based on log-derived average petrophysical parameters from type-well(s), located in each field, such as porosity, pay, and the initial water saturation. Gross pay, porosity, and saturation were used to calculate the OOIP (original oil in place volumes) on a lease level. Publicly available production data are reported at the lease level in the mature fields of the mid-continent, and they were used to calculate the distribution of cumulative production at a lease level. Remaining oil in place (ROIP) volumes and recovery efficiencies calculated on lease levels were then determined. Estimated (constant) residual oil saturation was used to obtain the recoverable reserve volume per lease in each of the fields. Field-wide recovery efficiencies were mapped from the estimates of initial reserves and the cumulative lease production.

\subsubsection{Reservoir Pressure}

To determine present reservoir pressure, readily available production data, including final shut-in pressures (FSIPs), final flowing pressures (FFPs), and initial production (IP) rates of oil and gas, were entered in a database. These data, collected at the well level during the time of their drilling, were then mapped for each field. In most fields, some level of drilling activity has continued over the productive life of the field. 
Plots of FSIPs through time provided an approximate measure of the decline in average reservoir pressure in each field.

\subsection{Ranking of Target Fields in the Study Area}

Both accurate screening of prospective horizontal infill drilling candidates and accurate ranking of prospect quality is critical to successful implementation. A PMP for this region is the utilization of the numerous screening tests that can be applied to identify and rank prospective sites. These tools utilize public databases available on the Internet and/or from publicly accessible data libraries. The process of selecting the best fields for implementation of the demonstration horizontal infill drilling program requires that the fields/leases be ranked on their suitability and potential for economic return.

Ranking of fields was based on the following criteria:

a) Estimated potential of recoverable reserves

b) Reservoir properties - permeability, pay thickness, drive mechanism

c) Current reservoir pressure, approximate rate of pressure decline

d) Availability of data - accuracy and resolution

e) - production data (lease/well level)

- wireline logs

- cores and petrophysical data

- reservoir fluid composition data

- DST, flowing, shut-in, fluid column, and other pressure test data

- analog Mississippian reservoir data

f) Anticipated drilling problems encountered in the target area

g) Ownership and operational rights

h) Uncertainties associated with the evaluation process

Final shut-in pressures, recorded by DST in discovery, developmental, and infill wells, were plotted over time for each field. In all cases, drilling activity, in and around 
the field, has continued over the life of the field. This helped to quickly determine the pressure support available in each field. Based on the reservoir pressure histories, 14 fields were selected from the area of interest shown in Map 2.1. MDCI recommended adding one more field, namely Fralick West, Kiowa County, Kansas, to this list. Previous studies and available pressure data indicate that this field has suffered from pressure depletion. However, MDCI's interest in this field was due to high production volumes recorded in vertical wells, large well spacing, and significant ownership rights.

For each field, a type well was selected. In some cases, 2 type wells were selected to represent 2 major regions of the field. Petrophysical logs from the type well were analyzed to estimate the pay height, porosity, and initial water saturation. Table 2.1 lists the results from this log analysis. An average drainage area was calculated for each field by dividing the area of the field by the number of wells that produced or are producing. Volumetric calculations were also used to estimate recovery factors (R.F.), and minimum and maximum volumes of remaining-oil-in-place (ROIP) per acre-ft, and are listed in Table 2.2.

The gross pay thickness was mapped in each field. Based on this map, the minimum and maximum pay thicknesses in the inter-well areas were estimated. Also, the best-fit line through the final shut-in pressure data versus time was used to approximate the original reservoir pressure and the current pressure. The ratio of the difference between the original and current pressure over the life of the field was taken as the proxy for aquifer support available to the field. These data are tabulated in Table 2.3.

Additional screening criteria used include ranking the fields on the basis of minimum pay (gross) thickness in the undrilled areas, average well spacing, R.F., and ROIP per gross acre-ft. The intent of the above ranking was to identify fields with high gross pay in undrilled areas, where the ROIP/acre-ft and average well spacing was high, and the average R.F. for vertical wells was low. Tables 2.3 to 2.5 list the fields as per their average pressure decline per year, average well spacing, and the minimum gross pay in the undrilled infill areas. Table 2.6 lists the fields in accordance to the average R.F. 
from vertical wells. It is expected that infill horizontal wells would be more effective (as compared to vertical infills) in fields where reservoir heterogeneity limited the drainage of vertical wells. The above rankings are based on the analysis carried out on data from only one or (at most) two type-wells per field. Hence, it important to note that it is more meaningful to compare the relative values of different screening criteria rather than emphasizing their absolute values.

Table 2.7 shows the relative rankings of the fields after taking into account their average well spacing, minimum gross pay in undrilled areas, ROIP/acre-ft, and R.F. of vertical wells. Fralick West is the top ranked field with a score of 6 . However, as will be discussed later, previous studies on this field and available pressure data (Figure 2.1) indicate that central parts of the reservoir have produced under a solution gas drive while the periphery has produced under a weak water drive. For the last 37 years, the field has produced without any pressure support, and this has resulted in significant pressure depletion. It is because of this severe pressure depletion that Fralick West failed to receive a rank (Table 2.8) in the final analysis. The Mississippian reservoirs in the study area produce from 3 major rock units (Map 2.1), namely Osage, Warsaw, and Spergen. The strong bottom water aquifer, that charges many of the Mississippian reservoirs in this area communicates with the Osage (the oldest) rocks. Most reservoirs producing out of Warsaw and Spergen rocks, which overlie the Osage, therefore have relatively weaker aquifer support. Fralick West produces from the Warsaw and this may be one of the reasons for its weak edge water drive.

Table 2.8 includes the ratings that MDCI provided as a proxy measure of the degree of difficulty that it anticipates in striking a working partnership with the other major operators/owners of each of these fields. A value of 1 signifies little difficulty on part of MDCI to implement a horizontal infill well in the field while a score of 4 signifies that it will be very difficult for MDCI to come to a consensus with the current operator(s) and/or owner(s). This is a common problem in the midcontinent, as independent operators like MDCI often do not own the whole field but only select leases and/or hold operating interests in the field/leases. Thus, the initial problem of locating prospective 
fields/leases and mapping pockets of residual reserves is further compounded by the fact that only a select few of these screened locations will be viable candidates because of various real life operational difficulties encountered by the interested independent operator(s).

The 6 fields selected, in consultation with MDCI, for the second round of screening studies, were:
a) Lippoldt
b) Riverside
c) Arnold SW
d) McDonald
e) Ness City North
f) Judica

MDCI wanted to include Fralick West in the second round of evaluation studies in order to compare the estimated recoveries from infill locations in other fields with that from Fralick West. 


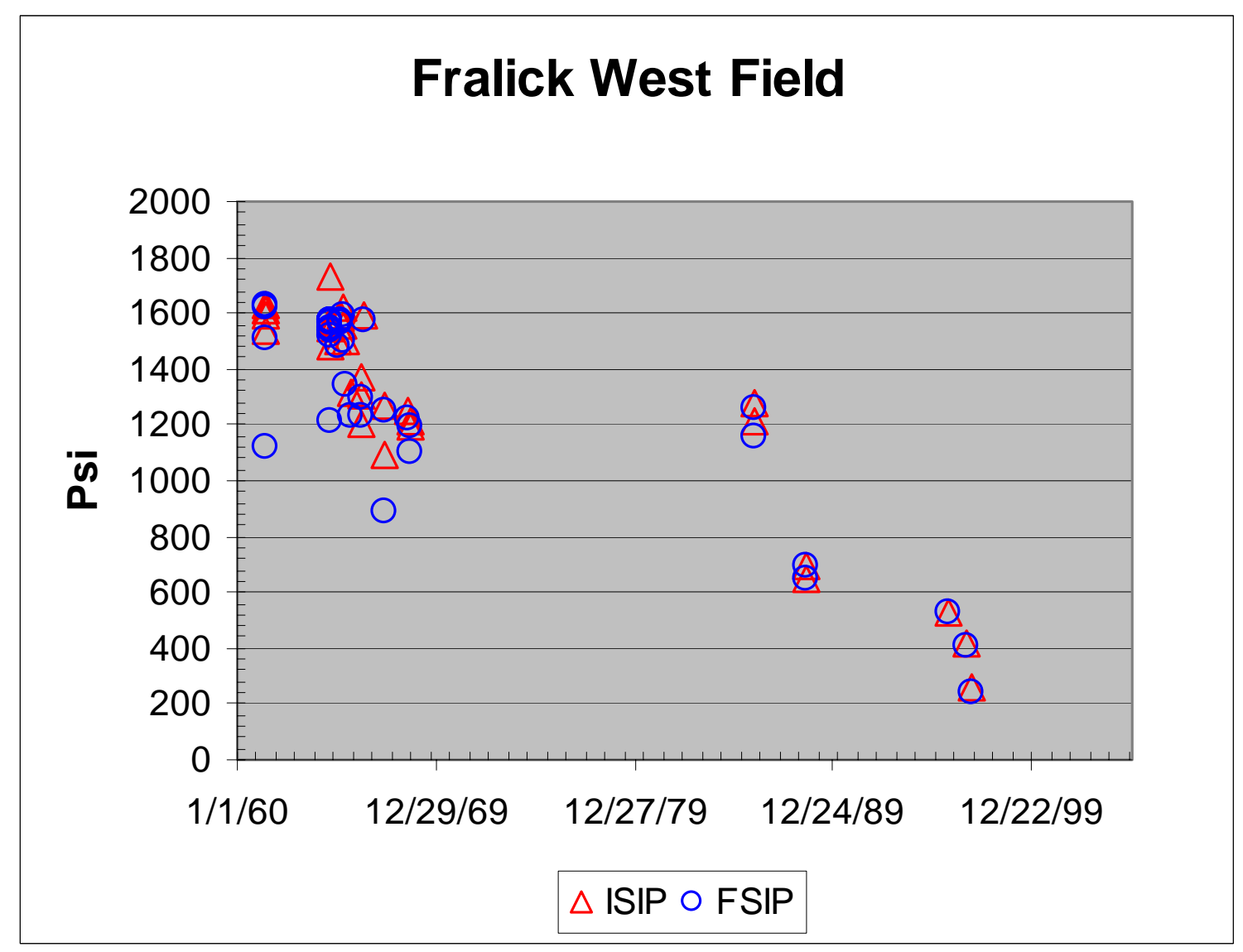

Figure 2.1: Reservoir pressure depletion in Fralick West field, Kiowa County, Kansas. 


\begin{tabular}{|c|c|c|c|c|c|c|c|c|c|c|c|c|c|c|}
\hline No. & Field Name & Sec & Miss Top & Miss Base & Low Por & High Por & Net Pay & Low Sw & High Sw & Reservoir & Phi min & Phi max & Sw min & Sw max \\
\hline & & & & & & & & & & & & & & \\
\hline \multirow[t]{3}{*}{1} & Aldrich N & 7 & -1894 & -1915 & 12 & 12 & 4 & 35 & 60 & Dolomite & 12.0 & 12.0 & 35.0 & 60.0 \\
\hline & Aldrich S & 13 & -1910 & -1923 & 18 & 18 & 5 & 25 & 58 & Dolomite & & & & \\
\hline & Aldrich S & 23 & -1907 & -1960 & 15 & 18 & 53 & 36 & 52 & Dolomite & & & & \\
\hline & & & & & & & & & & & & & & \\
\hline \multirow{3}{*}{2} & & & & & & & & & & & & & & \\
\hline & Arnold SW & 31 & -1923 & -1950 & 16 & 16 & 8 & 41 & 50 & Dolomite & 12.5 & 17.0 & 40.5 & 52.0 \\
\hline & & 29 & -1897 & -1949 & 9 & 18 & 26 & 40 & 54 & Dolomite & & & & \\
\hline \multirow{2}{*}{3} & & & & & & & & & & & & & & \\
\hline & Fralick W & 28 & -2544 & -2569 & 20 & 23 & 10 & 37 & 37 & 7 Dolomite & 20.0 & 23.0 & 37.0 & 37.0 \\
\hline \multirow[t]{2}{*}{4} & Stairett & 13 & -2089 & -2117 & 8 & 12 & 17 & 31 & 47 & Dolomite & 8.0 & 12.0 & 31.0 & 47.0 \\
\hline & & & & & & & & & & & & & & \\
\hline \multirow[t]{2}{*}{5} & Riverside & 13 & -2091 & -2121 & 13 & 18 & 30 & 38 & 48 & Dolomite & 13.0 & 18.0 & 38.0 & 48.0 \\
\hline & & & & & & & & & & & & & & \\
\hline \multirow[t]{2}{*}{6} & Judica & 3 & -1914 & -1933 & 24 & 28 & 19 & 28 & 50 & & 24.0 & 28.0 & 28.0 & 50.0 \\
\hline & & & & & & & & & & & & & & \\
\hline \multirow[t]{2}{*}{7} & Stutz E & 8 & -1944 & -1961 & 18 & 18 & 17 & 35 & 60 & Dolomite & 18.0 & 18.0 & 35.0 & 60.0 \\
\hline & & & & & & & & & & & & & & \\
\hline \multirow[t]{2}{*}{8} & Laird & 36 & -1994 & -2030 & 10 & 16 & 8 & 19 & 47 & Dolomite & 12.5 & 15.5 & 27.5 & 47.0 \\
\hline & & 36 & -1999 & -2039 & 15 & 15 & 10 & 36 & 47 & Dolomite & & & & \\
\hline & & & & & & & & & & & & & & \\
\hline \multirow[t]{2}{*}{9} & Lippoldt & 14 & -2218 & -2240 & 14 & 16 & 22 & 17 & 37 & Dolomite & 14.0 & 17.0 & 25.5 & 51.0 \\
\hline & & 13 & -2218 & -2252 & 14 & 18 & 34 & 34 & 65 & Dolomite & & & & \\
\hline & & & & & & & & & & & & & & \\
\hline 10 & Arnold & 23 & -1961 & -1976 & 16 & 16 & 8 & 41 & 50 & Dolomite & 16.0 & 16.0 & 41.0 & 50.0 \\
\hline & & & & & & & & & & & & & & \\
\hline \multirow[t]{2}{*}{11} & Arnold N & 10 & -1946 & -1975 & 10 & 20 & 12 & 35 & 40 & Dolomite & 10.0 & 20.0 & 35.0 & 40.0 \\
\hline & & & & & & & & & & & & & & \\
\hline \multirow[t]{2}{*}{12} & Steffen W & 25 & -2142 & -2166 & 18 & 18 & 24 & 51 & 62 & - Chery-dol & 18.0 & 18.0 & 51.0 & 62.0 \\
\hline & McDonald & 5 & -2021 & -2050 & 18 & 18 & 29 & 36 & 66 & & 180 & 180 & 360 & 660 \\
\hline 13 & 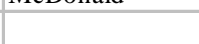 & & $202 x_{1}$ & 2000 & & 10 & 23 & 50 & 00 & & 10.0 & 10.0 & 0.0 & 00.0 \\
\hline \multirow[t]{2}{*}{14} & Ness City North & 23 & -2001 & -2001 & 10 & 14 & 16 & 45 & 60 & Dolomite & 12.0 & 17.5 & 32.5 & 55.5 \\
\hline & & 24 & -1998 & -2022 & 14 & 21 & 10 & 20 & 51 & & & & & \\
\hline
\end{tabular}

Table 2.1: Average petrophysical properties obtained from type well(s) in 14 fields selected for initial screening. 


\begin{tabular}{|c|c|c|c|c|c|c|c|c|c|c|c|c|c|c|c|}
\hline Field Name & Acre & Ac-ft & well \# & $\begin{array}{l}\text { Avg } \\
\text { Spacing, ac }\end{array}$ & PV (bbls) & Boi & $\begin{array}{l}\text { STB, } \min \\
\text { OOIP }\end{array}$ & $\begin{array}{l}\text { STB, max } \\
\text { OOIP }\end{array}$ & $\begin{array}{l}\text { Cum } \\
\text { Prod }\end{array}$ & $\begin{array}{l}\text { Min } \\
\text { R.F. }\end{array}$ & $\begin{array}{l}\text { Max } \\
\text { R.F. }\end{array}$ & $\begin{array}{l}\text { Min } \\
\text { ROIP/ac-ft }\end{array}$ & $\begin{array}{l}\text { Max } \\
\text { ROIP/ac-ft }\end{array}$ & $\begin{array}{l}\text { Avg } \\
\text { R.F. }\end{array}$ & $\begin{array}{l}\text { Avg } \\
\text { ROIP/ac-ft }\end{array}$ \\
\hline Aldrich N & 1337 & 29,053 & 44 & 30.4 & $225,528,986$ & 1.05 & $10,309,897$ & $16,753,582$ & $4,394,950$ & 0.26 & 0.43 & 204 & 425 & 0.34 & 314 \\
\hline Fralick W & 1619 & 59,733 & 23 & 70.4 & $463,687,844$ & 1.05 & $55,642,541$ & $63,988,922$ & $5,322,647$ & 0.08 & 0.10 & 842 & 982 & 0.09 & 912 \\
\hline Stairett & 1591 & 61,694 & 39 & 40.8 & $478,910,449$ & 1.05 & $19,338,860$ & $37,765,510$ & $3,595,005$ & 0.10 & 0.19 & 255 & 554 & 0.14 & 405 \\
\hline Riverside & 854 & 32,846 & 19 & 44.9 & $254,972,811$ & 1.05 & $16,415,392$ & $27,099,967$ & $1,833,454$ & 0.07 & 0.11 & 444 & 769 & 0.09 & 607 \\
\hline Judica & 216 & 3638 & 7 & 30.8 & $28,240,610$ & 1.05 & $3,227,498$ & $5,422,197$ & $1,621,847$ & 0.30 & 0.50 & 441 & 1045 & 0.40 & 743 \\
\hline Stutz E & 1160 & 29,255 & 23 & 50.4 & $227,097,047$ & 1.05 & $15,572,369$ & $25,305,099$ & $1,231,799$ & 0.05 & 0.08 & 490 & 823 & 0.06 & 657 \\
\hline Laird & 607 & 14,495 & 11 & 55.2 & $112,519,969$ & 1.05 & $7,099,474$ & $12,042,316$ & $1,222,114$ & 0.10 & 0.17 & 405 & 746 & 0.14 & 576 \\
\hline Lippoldt & 766 & 32,906 & 14 & 54.7 & $255,438,572$ & 1.05 & $16,688,653$ & $30,810,757$ & $1,217,343$ & 0.04 & 0.07 & 470 & 899 & 0.06 & 685 \\
\hline Arnold N & 369 & 7675 & 10 & 36.9 & $59,578,528$ & 1.05 & $3,404,487$ & $7,376,389$ & 902,785 & 0.12 & 0.27 & 326 & 843 & 0.19 & 585 \\
\hline Steffen W & 451 & 11,856 & 12 & 37.6 & $92,034,271$ & 1.05 & $5,995,375$ & $7,730,879$ & 814,064 & 0.11 & 0.14 & 437 & 583 & 0.12 & 510 \\
\hline McDonald & 245 & 7006 & 12 & 20.4 & $54,385,299$ & 1.05 & $3,169,886$ & $5,966,844$ & 585,355 & 0.10 & 0.18 & 369 & 768 & 0.14 & 569 \\
\hline Ness City N & 290 & 6600 & 8 & 36.3 & $51,233,653$ & 1.05 & $2,605,597$ & $5,763,786$ & 445,616 & 0.08 & 0.17 & 327 & 806 & 0.12 & 567 \\
\hline
\end{tabular}

Table 2.2: Volumetric estimates based on type well(s) from 14 short-listed fields for initial screening. 


\begin{tabular}{|r|l|r|r|r|r|}
\hline & & & & Avg \\
\hline No. & Field Name & Pr Initial & Yrs prod & Latest pr & psilyr decline \\
\hline \hline & & & & & \\
\hline $\mathbf{1}$ & Stutz E & 1100 & 25 & 1100 & 0.0 \\
\hline $\mathbf{2}$ & Aldrich N & 1000 & 45 & 1000 & 0.0 \\
\hline $\mathbf{3}$ & Lippoldt & 1300 & 35 & 1250 & 1.4 \\
\hline $\mathbf{4}$ & Laird & 1100 & 32 & 1000 & 3.1 \\
\hline $\mathbf{5}$ & Arnold N & 1000 & 30 & 900 & 3.3 \\
\hline $\mathbf{6}$ & Arnold SW & 1000 & 45 & 800 & 4.4 \\
\hline $\mathbf{7}$ & Ness City North & 1100 & 40 & 900 & 5.0 \\
\hline $\mathbf{8}$ & Arnold & 1100 & 40 & 900 & 5.0 \\
\hline $\mathbf{9}$ & McDonald & 1200 & 35 & 1000 & 5.7 \\
\hline $\mathbf{1 0}$ & Riverside & 1300 & 30 & 1100 & 6.7 \\
\hline $\mathbf{1 1}$ & Stairett & 1100 & 40 & 800 & 7.5 \\
\hline $\mathbf{1 2}$ & Judica & 1100 & 25 & 900 & 8.0 \\
\hline $\mathbf{1 3}$ & Steffen W & 1100 & 35 & 800 & 8.6 \\
\hline $\mathbf{1 4}$ & Fralick W & 1400 & 37 & 400 & 27.0 \\
\hline
\end{tabular}

Table 2.3: Fields ranked as per estimated pressure depletion. 


\begin{tabular}{|c|l|r|r|r|}
\hline & & & \multicolumn{2}{l|}{ Avg } \\
\hline No. & Field Name & Acre & well \# & Spacing, ac \\
\hline \hline & & & & \\
\hline $\mathbf{1}$ & Fralick W & 1619 & 23 & 70.4 \\
\hline $\mathbf{2}$ & Laird & 607 & 11 & 55.2 \\
\hline $\mathbf{3}$ & Lippoldt & 766 & 14 & 54.7 \\
\hline $\mathbf{4}$ & Stutz E & 1160 & 23 & 50.4 \\
\hline $\mathbf{5}$ & Riverside & 854 & 19 & 44.9 \\
\hline $\mathbf{6}$ & Stairett & 1591 & 39 & 40.8 \\
\hline $\mathbf{7}$ & Steffen W & 451 & 12 & 37.6 \\
\hline $\mathbf{8}$ & Arnold N & 369 & 10 & 36.9 \\
\hline $\mathbf{9}$ & Ness City North & 290 & 8 & 36.3 \\
\hline $\mathbf{1 0}$ & Arnold SW & 3030 & 88 & 34.4 \\
\hline $\mathbf{1 1}$ & Arnold & 259 & 8 & 32.4 \\
\hline $\mathbf{1 2}$ & Judica & 216 & 7 & 30.8 \\
\hline $\mathbf{1 3}$ & Aldrich N & 1337 & 44 & 30.4 \\
\hline $\mathbf{1 4}$ & McDonald & 245 & 12 & 20.4 \\
\hline
\end{tabular}

Table 2.4: Fields ranked as per average well spacing. 


\begin{tabular}{|c|l|r|r|}
\hline & & & \\
\hline No. & Field Name & Pay min & Pay max \\
\hline \hline & & & \\
\hline $\mathbf{1}$ & McDonald & 28 & 49 \\
\hline $\mathbf{2}$ & Lippoldt & 25 & 55 \\
\hline $\mathbf{3}$ & Stutz E & 23 & 53 \\
\hline $\mathbf{4}$ & Arnold SW & 20 & 60 \\
\hline $\mathbf{4}$ & Fralick W & 20 & 45 \\
\hline $\mathbf{4}$ & Stairett & 20 & 50 \\
\hline $\mathbf{4}$ & Riverside & 20 & 50 \\
\hline $\mathbf{4}$ & Laird & 20 & 40 \\
\hline $\mathbf{4}$ & Arnold N & 20 & 35 \\
\hline $\mathbf{4}$ & Steffen W & 20 & 47 \\
\hline $\mathbf{5}$ & Ness City North & 17 & 32 \\
\hline $\mathbf{6}$ & Aldrich N & 15 & 50 \\
\hline $\mathbf{6}$ & Arnold & 15 & 25 \\
\hline $\mathbf{7}$ & Judica & 8 & 32 \\
\hline
\end{tabular}

Table 2.5: Fields ranked as per estimated minimum and maximum pay thickness. 


\begin{tabular}{|c|l|r|}
\hline & & Avg R.F. \\
\hline \hline No. & Field Name & \\
\hline $\mathbf{1}$ & Lippoldt & 0.06 \\
\hline $\mathbf{2}$ & Stutz E & 0.06 \\
\hline $\mathbf{3}$ & Fralick W & 0.09 \\
\hline $\mathbf{4}$ & Riverside & 0.09 \\
\hline $\mathbf{5}$ & Arnold SW & 0.11 \\
\hline $\mathbf{6}$ & Steffen W & 0.12 \\
\hline $\mathbf{7}$ & Ness City North & 0.12 \\
\hline $\mathbf{8}$ & Laird & 0.14 \\
\hline $\mathbf{9}$ & Stairett & 0.14 \\
\hline $\mathbf{1 0}$ & McDonald & 0.14 \\
\hline $\mathbf{1 1}$ & Arnold N & 0.19 \\
\hline $\mathbf{1 2}$ & Aldrich N & 0.34 \\
\hline $\mathbf{1 3}$ & Judica & 0.40 \\
\hline $\mathbf{1 4}$ & Arnold & 0.42 \\
\hline
\end{tabular}

Table 2.6: Fields ranked as per recovery factors. 


\begin{tabular}{|c|c|c|c|c|c|}
\hline \multirow[b]{2}{*}{ Field Name } & \multicolumn{4}{|c|}{ 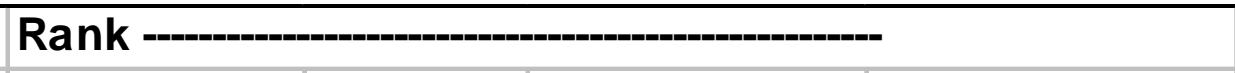 } & \multirow[b]{2}{*}{ Total } \\
\hline & Avg & Avg & Avg & Min Pay & \\
\hline & ROIP/ac-ft & R.F. & Well spacing & ft above OWC & Score \\
\hline Fralick W & 1 & 2 & $\overline{1}$ & $\overline{2}$ & $\overline{6}$ \\
\hline Lippoldt & 3 & 1 & 2 & 1 & 7 \\
\hline Stutz E & 3 & 1 & 2 & 1 & 7 \\
\hline Riverside & 3 & 2 & 3 & 2 & 10 \\
\hline Laird & 4 & 4 & 2 & 2 & 12 \\
\hline Arnold SW & 4 & 3 & 4 & 2 & 13 \\
\hline McDonald & 4 & 4 & 5 & 1 & 14 \\
\hline Stairett & 5 & 4 & 3 & 2 & 14 \\
\hline Steffen W & 4 & 4 & 4 & 2 & 14 \\
\hline Arnold N & 4 & 5 & 4 & 2 & 15 \\
\hline Ness City North & 4 & 4 & 4 & 3 & 15 \\
\hline Judica & 2 & 7 & 4 & 4 & 17 \\
\hline Aldrich N & 6 & 6 & 4 & 3 & 19 \\
\hline Arnold & 6 & 8 & 4 & 3 & 21 \\
\hline
\end{tabular}

Table 2.7: Relative ranking of fields on the basis of their estimated average well spacing, minimum gross pay in undrilled areas, remaining oil in place per acre-foot, and recovery factors of vertical wells. 


\begin{tabular}{|l|c|c|c|c|c|}
\hline Field & Score & Rank & $\begin{array}{c}\text { Mull's operational } \\
\text { difficulty }\end{array}$ & $\begin{array}{c}\text { Final } \\
\text { Score }\end{array}$ & $\begin{array}{c}\text { Final } \\
\text { Rank }\end{array}$ \\
\hline \hline Fralick W & & & 1 & 7 & \\
\hline Lippoldt & 6 & & 2.5 & 9.5 & 1 \\
\hline Stutz E & 7 & 1 & 4 & 11 & 2 \\
\hline Riverside & 7 & 1 & 3 & 13 & 3 \\
\hline Arnold SW & 10 & 2 & 2 & 15 & 4 \\
\hline McDonald & 13 & 4 & 1 & 15 & 4 \\
\hline Laird & 14 & 5 & 4 & 16 & 5 \\
\hline Ness City North & 12 & 3 & 1 & 16 & 5 \\
\hline Stairett & 15 & 5 & 3 & 17 & 6 \\
\hline Steffen W & 14 & 5 & 3 & 17 & 6 \\
\hline Arnold N & 14 & 5 & 3 & 18 & 7 \\
\hline Judica & 15 & 5 & 1 & 18 & 7 \\
\hline Aldrich N & 17 & 6 & 4 & 23 & 8 \\
\hline Arnold & 19 & 7 & 3 & 24 & 9 \\
\hline & 21 & 8 & & & \\
\hline
\end{tabular}

Table 2.8: Final rankings including field operator ratings that proxy degree of difficulty in creating operational agreements with cooperators and/or co-owners. 


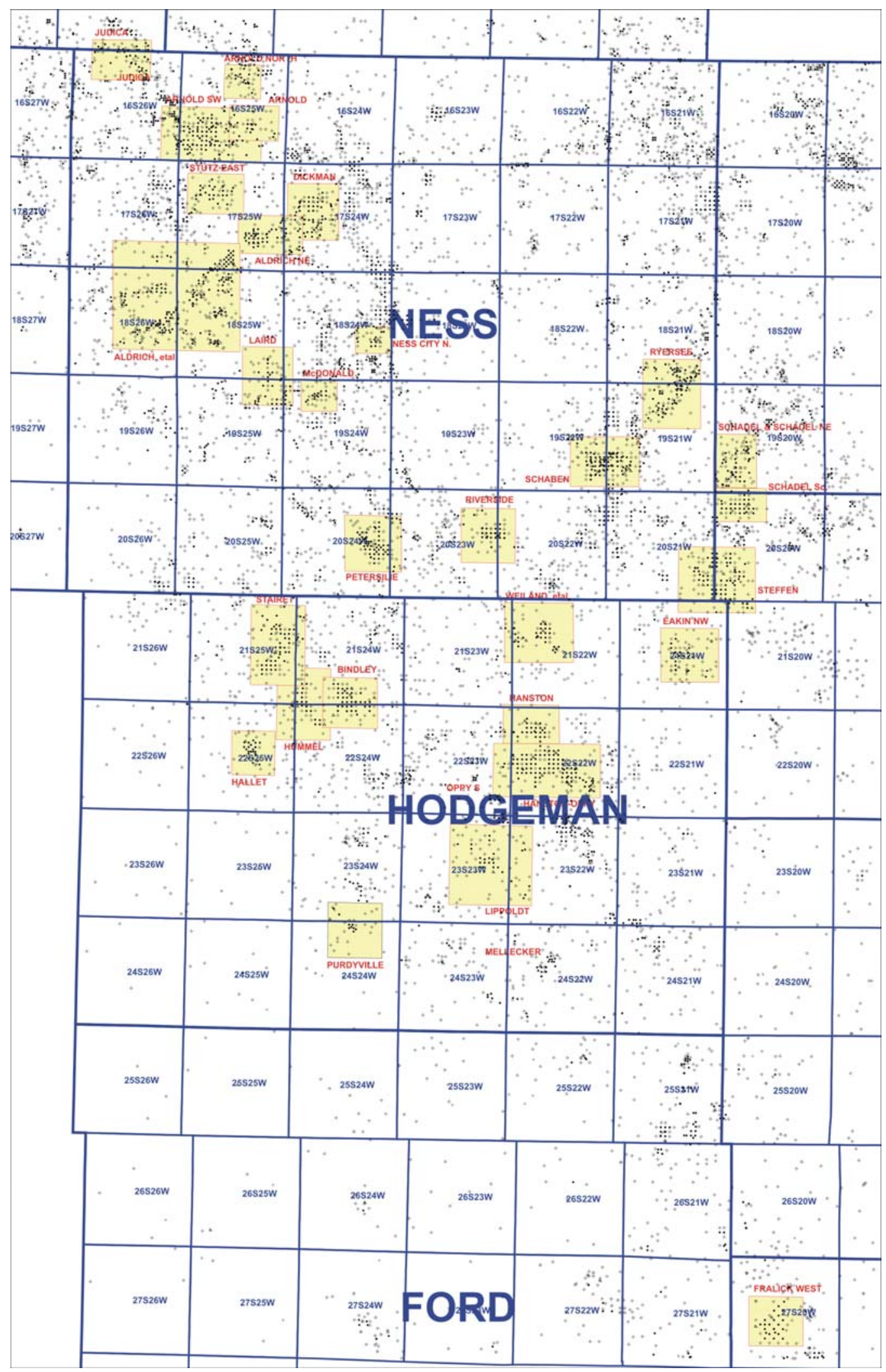

Map 2.1: Location of fields selected for initial screening for potential for exploitation by horizontal infill wells. 


\section{Secondary Screening Studies - 6 Fields}

\subsection{Analytic Estimation of Performance of Horizontal Infill Wells in Short-Listed}

Fields

The intent of this study was to approximate the productive potential (in terms of IPs and cumulative volumes) based on petrophysical properties estimated from type well(s) in each field, i.e., estimate the production from both vertical and horizontal infill wells in each of the fields provided the petrophysical properties of the drainage areas (of the infill wells) were similar to that obtained from type-well analyses. Such an exercise would enable one to relatively rank each of the short-listed fields. The tool used for this analytical exercise was RESMOD ${ }^{\mathrm{TM}}$ - a single phase closed tank model developed by Maurer Engineering Inc.

Assumptions inherent in the RESMOD ${ }^{\mathrm{TM}}$ model include:

a) Darcy's radial equation is used to model flow into the well.

b) Only single phase (oil) fluid flow is modeled.

c) The drainage area of the modeled well is assumed to be homogenous, and has a noflow boundary.

d) The modeled well is located at the center of the drainage area.

e) A conservative skin factor (Hall's skin factor) is applied to wells in the model.

f) The model ignores flush production. This makes the estimated production volumes conservative. However, such an assumption has little effect on the cumulative production volumes estimated.

The above assumptions point to the limitations of using RESMOD ${ }^{\mathrm{TM}}$. However during the initial screening phases, limited data is available for each field and it is insufficient to build an integrated geomodel suitable for input to a conventional 3D reservoir simulator. Also during initial evaluations, an operator may have multiple fields 
under consideration, and so only limited time and resources can be allotted to each field. Thus, these initial screening steps are based on reasonable assumptions and use ranges of expected values to provide effective and quick results.

Tables 3.1a to 3.1g list the basic petrophysical data that were used to model production performance of infill (horizontal and vertical) wells in each of the 6 fields. At this initial screening stage, because information that normally comes from a detailed geomodel was lacking, the formation thickness assigned to each field was the gross pay of the productive zone in type well(s). Also, only limited information was available about distributions of horizontal and vertical permeability and oil saturations in prospective inter-well regions. Based on the available data from routine analyses carried out on Mississippian cores, an assumption was made that 10 md of permeability could be considered as a conservative estimate for many Mississippian pay sections in the midcontinent. Most of these fields have been under primary production for more than 30 years, and thus remaining oil saturations in the inter-well regions can only be estimated by mapping current saturation distributions predicted by a full-field reservoir simulation study. Based on experience from previous simulation studies on Mississippian fields, it was assumed that for infill wells to be economically successful, they have to be located in pockets where the oil saturations were at least $45 \%$. A positive skin of 1 was applied to both horizontal and vertical wells modeled.

In RESMOD ${ }^{\mathrm{TM}}$, the reservoir drive mechanism in each field is described with the help of drive mechanism scaling factor (DMSF). Strong water drives, bottom and/or edge, correspond to highest recovery efficiencies, and are represented in this model as DMSF $=1$. Solution-gas-driven reservoirs are the least efficient and the model assigns a DMSF $=0$ to them. The DMSF factor was assigned in a relative sense based on the rate of decline of reservoir pressure observed in each of the fields. The flowing bottom-hole pressures (BHPs) were kept a few hundred psi below the initial reservoir pressures. In each field, both the horizontal and vertical wells have been produced under the same draw down. Along with this data set, some uniform cost parameters were used including $\$ 400,000$ to drill and complete a horizontal well and \$125/day in fixed well-operating 
costs. The discount rate was assumed as $17.5 \%$, and the net sale price for produced oil was assumed to be $\$ 19 /$ barrel (prevailing rates in 2002). The horizontal well in each field was assumed to have a productive length of $600 \mathrm{ft}$ as per MDCI suggestion.

Table 3.2 compares the estimated IPs and cumulative production (after 5 years) for an infill vertical and an infill horizontal well in each field. The results tabulated have been calculated using the base case values for each of the input parameters (Tables 3.1a to 3.1g). The relevance of this exercise lies not in the absolute values of the listed numbers but rather in interpreting the results (IPs and cumulative production volumes) in a relative manner. Also, RESMOD ${ }^{\mathrm{TM}}$ models single-phase flow, and it, therefore, does not include the effects of relative permeability existing between oil and water. All but one of the short-listed fields have produced both oil and water. Fralick West field has produced oil, gas, and water, and thus relative permeability effects assume importance in modeling flow in these fields. Exercises using RESMOD ${ }^{\mathrm{TM}}$ enables one to get a feel for the expected range of oil production volumes based on the input of a set (fixed) range of rock and fluid properties. This model does not predict water production volumes, and thus any economic evaluation minus the water pumping and disposal costs is only approximate.

RESMOD $^{\mathrm{TM}}$ is a quick screening tool, and a more detailed calibration process (described in Section 5) enhances its application making it field-specific. During the calibration process, the production history and petrophysical properties of a vertical well in a field are input in order to obtain a history match. The history matching process is iterative, wherein different petrophysical values are varied within the maximum and minimum ranges. This helps to obtain a better quantitative feel for the different fieldspecific parameters such as average drainage radius, draw down, DMSF, and skin. Then, the petrophysical properties for the prospective infill horizontal well location, in the same field, are adjusted in a similar manner as that required to history match the vertical well in order to estimate its productive potential. 


\subsection{Inventory of Data Available for Short-Listed Fields}

\subsubsection{Riverside Field, Ness County, Kansas}

Logs - available for 16 wells out of 29 .

Cores - None are available.

Production data - Individual well production data is available for 7 wells. Six leases have more than one producing well and thus the lease production can be allocated to the constituent wells only if barrel test information is available with the current (past) operator.

This field has 2 horizontal wells already drilled in it, and neither of them has turned out to be a good performer. MDCI has a bias against this field because neither vertical nor horizontal wells have been economically successful in this field. Vertical wells have produced water too early shortening the economic life of wells. Another horizontal well in this field may be similarly affected by early water breakthrough, thus, limiting production to the first 100 feet (from the heel) of the horizontal leg. Also, the shaly-conglomerate section, atop the Mississippian reservoir, presents an operational problem. Both the horizontal wells encountered this shaly-conglomerate problem during the drilling of the curve. (Most Mississippian fields, in the study area, have a conglomerate over the dolomite. However, the thickness of the conglomerate layer varies.) Production histories from both horizontal and vertical wells in this field appear to indicate that early water breakthrough occurs due to a fracture network in the reservoir and strong underlying aquifer.

\subsubsection{Ness City North Field, Ness County, Kansas}

Logs - logs are available in 8 wells out of 9 in the field. Most wells have RAG (resistivity and gamma) logs.

Cores - available from 2 wells (one inside and one outside the field).

Production data - Oil production data is available at the well level. However, barrel tests data (showing volumes of oil and water produced) are available for only 3 wells. 
One horizontal well has been drilled in this field. The well was producing at rates close to what a previous simulation study had predicted but it suddenly collapsed (and stopped producing fluids) after 60 days due to mechanical reasons. Production in this field appears to be related to the structure. The dolomite reservoir is charged by a strong aquifer at the bottom.

\subsubsection{Lippoldt Field, Hodgeman County, Kansas}

Logs - available for all the wells.

Cores - Available from 2 wells (3 boxes).

Production data - Lease level production data is available. Most leases have multiple producing wells and so allocation of lease production to constituent wells is possible if barrel test data is available with current and/or past operators.

It is perceived that the reservoir rock has interbedded shale and this may help mitigate the early water breakthrough problem.

\subsubsection{McDonald Field, Ness County, Kansas}

Logs - available for most wells. Wells have good penetration and some of the infill wells have modern suite of logs.

Cores - Available from 1 well (3 boxes).

Production data - Bulk of field production comes from 2 leases. However, this field is owned by MDCI and history of barrel test data is available.

Overall, this field has a relatively small pool size. However, the well spacing increases in the eastern side of the field. Also, MDCI has 3D-seismic data shot and analyzed over sections 4 and 5 (including the eastern part of the field). MDCI may consider deepening a non-producing well in section 5 to obtain a core if this field is selected for field demonstration study. 


\subsubsection{Judica Field, Ness County, Kansas}

Logs - Most wells have good logs showing penetration into the Mississippian.

Cores - None

Production data - All leases, but one, have only 1 constituent well. Thus, oil production data is available for all wells. However, limited water production records or barrel test data is available.

This field produces from a stratigraphic trap. It is thought that the depositional environment affects reservoir permeability, and this increases the uncertainties related to mapping the permeability distribution in the field. Dry wells are found in the middle of the field. The dolomite reservoir has significant lateral heterogeneity and this adds to complexity associated to modeling the reservoir. Wells in this field have produced limited volumes of water. The flowing shut-in pressures (FSIPs) recorded in the DSTs show little variation. This field is sparsely drilled, with productive and dry wells interspersed. This makes the field heterogeneous both laterally and vertically. It was noted that a 3D survey would help clarify the uncertainties related to characterization of this field. A long infill horizontal well can be drilled in this field. Such a horizontal well in a thin reservoir, such as this, will have significant advantages over a vertical infill well.

\subsubsection{Arnold Southwest Field, Ness County, Kansas}

Logs - Most wells have RAG logs. Few wells have resistivity and sonic logs. Few wells have good penetration and therefore it is difficult to characterize the reservoir. Cores - Available from 1 well.

Production data - Most leases have more than 1 producing well, and thus barrel test data is required to allocate lease production among constituent wells. Barrel test data may be available for wells located in only one of the sections.

This is the biggest field among those short-listed, and extends over 9 sections. This field has a producing horizontal well that appears to be well placed. This well was 
drilled 30-40' beneath the Mississippian top. This well has been a low fluid well having a cumulative production of 27,000 bbls and currently producing 17 bopd \& 17 bwpd. It is possible that the major portion of the lateral is too low and, therefore, is not located in the reservoir rock. The chances of high water production are low in this field given the fact that vertical wells have not produced significant quantities of water. There are many lease holders in this field, and MDCI has no lease holdings here.

\subsection{Fralick West Field, Kiowa County, Kansas - A Special Consideration}

Logs - Most wells have good logs.

Cores - Available from 1 well.

Production data - Oil production data available for most wells. Wells in this field have produced oil, water, and gas. No well-level gas production data could be traced.

Wells have good penetration in the south. Individual vertical wells have been good producers. The reservoir truncates in the direction of north-northeast. The initial reservoir pressure was estimated to be close to $1600 \mathrm{psi}$, and the available data of initial shut-in pressures (ISIPs) and final shut-in pressures (FSIPs) from DSTs indicate that severe pressure depletion has occurred in the reservoir (Figure 2.1). Current reservoir pressure is estimated to be close to 200 psi.

Reports are available detailing some of the past reservoir evaluation studies that have been conducted on this field. Relevant sections from some of these reports are quoted below.

\section{Alfred James Report}

"The field produces under a combination drive of gas cap expansion and edge water drive. Formation pressures have been observed to drop rather rapidly in the early years." 


\section{Walton \& Preston Report (1986)}

"Water-cut maps indicate that there is some water influx occurring in the reservoir. Major increases in water production have occurred primarily in the edge wells - specifically in the southern and northeastern wells. There is little increase, if any, in the center wells where the major oil production takes place. Other evidence, which would disprove a strong active water drive, is that over the past 20+ years of production, the pressure has dropped over 1200 psi. It also appears as though the center part of the reservoir, in effect, is sealed from a limited water drive acting aquifer because all water influx has taken place at the edge wells and that the center wells have not shown a substantial increase in water production.”

\section{Parker Report (1995)}

"The primary drive mechanism for the field is a combination of solution gas, gas cap expansion, and edge water drive encroaching from the south-southwest. Original aquifer energy was perceived as minimal due to the considerable decrease in reservoir pressure with corresponding fluid withdrawals. Original reservoir pressure, as measured by DST at the Falcon-Seaboard Brensing \#1, approximated 1625 psi. The average pressure depletion across the field was 40\% from inception (Apr 1961) to Apr 1968. Reservoir heterogeneities, including permeability barriers, both horizontal and vertical, prohibit pressure support in many areas of the field. However, several wells including Zeigler \#A1, \#3, Bissitt \#1, and Einsel \#B1 experienced less depletion primarily due to the Spergen dolomite in direct contact with either the gas cap, the underlying aquifer, or vertically fractured to one or both.”

All the above previous studies indicate that pressure depletion has occurred in this reservoir. Also, this field has recorded significant cumulative gas production over the course of its life. Thus, low reservoir pressures coupled with free gas in the reservoir are expected to adversely affect oil recovery from an infill horizontal well due to relative permeability effects. 
Permeability values prevalent in Fralick $\mathrm{W}$ are higher than what commonly occurs in other Mississippian reservoirs of Kansas, and this makes it a unique Mississippian field. It is believed that the reservoir rock is located close to a valley, and this resulted in significant leaching of the dolomite, which in turn has enhanced permeability. As such, this field is not representative of Mississippian reservoirs of the Midcontinent. Project demonstration in this field will, therefore, have limited applications elsewhere.

\subsection{Summary of Operational Notes on Previously Drilled Horizontal Wells in Kansas}

MDCI carried out a review of all publicly available information regarding operator experiences related to drilling horizontal wells in Kansas before 2003, and summarized their findings as shown below.

a) One of the major problems noted in the reports on previously drilled horizontal wells in Kansas is that pipe stuck-ups occurred 14 times in the first 2 wells because the drillers did not mud-up early.

b) A few of the wells had a curve radius of $660 \mathrm{ft}$ and used slotted liners. However, such a "tight" radius prevented running and placing lateral horizontal sub pumps.

c) Most of the wells failed to stay consistently at the top of the best reservoir rock. Production testing indicated predominance of oil producing from the heels in most cases. Well steering in accordance to the Mississippian structure appears to be absent.

d) External packers, for zone isolation, did not work in most wells.

e) An ideal candidate for a horizontal well in the Mississippian carbonates should meet as many of the following criteria as possible: 
i) It should be a field that produces from the Osage reservoir, and has vertical wells that have produced significant volumes of fluid. Most Osage reservoirs have strong water drives and often early breakthrough of water results in limited drainage by vertical wells and in significant fluid production.

ii) Incorporation of 3D data into reservoir model or application of some method that enables excellent well control would help steer the well in a manner such that it stayed at the top of the reservoir preferably within the top 10 feet.

iii) The horizontal leg should be started within proven reservoir and then extended into unproven regions if needed.

iv) A large curve radius should be used if there are plans to place downhole horizontal separator.

v) Salt water disposal costs ranged over $\$ 11,000 /$ month in several wells. Thus, horizontal wells that produce significant volumes of water often become economic failures though remaining technical successes because of the varying oil prices prevalent in Kansas (as of 2002).

Some of the mechanical concerns that were mentioned in the records include:

a) An appropriate mud strategy needs to be designed such that formation damage was minimized and lost circulation was controlled.

b) The well has to be planned and designed from the bottom to the top such that the selected curve radius would not come in the way in case intervention is required to solve future anticipated problems.

c) The economics and benefits of using a liner in the horizontal leg of the well against an openhole completion needs to be thoroughly evaluated. MDCI prefers 
to initiate production from a lateral section that is kept open hole. It expects that the bottom-up design and large diameter of the vertical section will ensure tool reentry to rectify problems if and when they occurred.

The operator of the Antrim-Cossman \#1HZ well believes that fractures present in the Mississippian chert reservoir resulted in high water production at the well. MDCI has significant operational experience in the study area, and in certain fields (such as the Riverside) it appears that the fracture porosity in the reservoir rock is the major contributor to Mississippian production. However, the high attendant vertical permeability results in early breakthrough and high water production in vertical wells. It has been noted by the operators in this area that fractures in Osage rocks have at times extended into the dolomite (Warsaw) on top. Also, it is believed that the Osage was exposed over a longer period of time than the overlying dolomite (Warsaw), and this perhaps resulted in higher vertical permeabilities in Osage as compared to the Warsaw.

\subsection{Selection of Candidate Fields for Detailed Studies}

Table 2.9 ranks the 14 fields from the target area from which 6 fields (listed in Table 11) were selected upon consultations with MDCI based on respective scores on technical criteria and MDCI's operational difficulties for each field (discussed under Initial Screening Studies Section). A quick estimate of the productive potential of an infill horizontal well was carried out in each of these 6 short-listed fields and Table 3.2 summarizes these results.

It became apparent from discussions with MDCI that one of the critical factors that controlled the final selection of 3 candidate fields for detailed studies depended on how easily the partner company could enter into a working agreement with other companies that held either interests or ownership in each of the fields or its constituent leases. It is not uncommon for multiple companies to hold interests and ownership rights in many of the short-listed fields that rank high as per technical screening criteria. But the final selection was strongly influenced by the ability and ease with which a partner 
company, such as MDCI, can enter into a contract with other related owners/interest holders. Finally, 3 fields, namely Judica, McDonald, and Ness City North, all located in Ness County, Kansas, were selected for detailed characterization and simulation studies. 


\begin{tabular}{|c|c|c|c|}
\hline \multicolumn{4}{|l|}{ Field - McDonald } \\
\hline & Base & Min & Max \\
\hline \multicolumn{4}{|l|}{ Rock Properties } \\
\hline Drainage Radius, ft & 660 & 330 & 990 \\
\hline Formation Thickness, ft & 38.5 & 28 & 49 \\
\hline Horizontal K, md & 10 & 1 & 100 \\
\hline Vertical K, md & 1 & 0.1 & 10 \\
\hline Porosity, \% & 18 & 17 & 19 \\
\hline External Drainage Pr, psi & 800 & 700 & 900 \\
\hline \multicolumn{4}{|l|}{ Fluid Properties } \\
\hline Oil Viscosity, cp & 2 & 1.8 & 2.1 \\
\hline Initial oil saturation, \% & 45 & 40 & 55 \\
\hline Formation volume factor, RB/STB & 1.05 & 1.03 & 1.07 \\
\hline Drive Mechanism Scaling factor (DMSF) & 0.6 & 0.5 & 0.8 \\
\hline \multicolumn{4}{|c|}{ (DMSF $=1$ for active water drive, DMSF = 0 for solution gas drive) } \\
\hline \multicolumn{4}{|l|}{ Vertical well data } \\
\hline Skin factor & 1 & -1 & 3 \\
\hline BHP, psi & 300 & 200 & 400 \\
\hline Residual oil saturation, \% & 30 & 25 & 35 \\
\hline Well bore radius, inch & 3.5 & & \\
\hline Well cost, $1000 \$$ & 200 & & \\
\hline Fixed Operational cost/day, $\$$ & 100 & & \\
\hline \multicolumn{4}{|l|}{ Horizontal well data } \\
\hline Skin factor & 1 & -1 & 3 \\
\hline BHP, psi & 300 & 200 & 400 \\
\hline Residual oil saturation, \% & 30 & 25 & 35 \\
\hline Well bore radius, inch & 3.5 & & \\
\hline Horizontal well length, $\mathrm{ft}$ & 600 & & \\
\hline Well cost, $1000 \$$ & 400 & & \\
\hline Fixed Operational costs, \$/day & 125 & & \\
\hline
\end{tabular}

Table 3.1a: Average petrophysical and other input data to RESMODTM for McDonald Field, Ness County, Kansas. 


\begin{tabular}{|c|c|c|c|}
\hline \multirow{2}{*}{ Field - Ness City N } & & & \multirow[b]{2}{*}{ Max } \\
\hline & Base & Min & \\
\hline \multicolumn{4}{|l|}{ Rock Properties } \\
\hline Drainage Radius, $\mathrm{ft}$ & 629 & 314 & 943 \\
\hline Formation Thickness, $\mathrm{ft}$ & 24.5 & 17 & 32 \\
\hline Horizontal K, md & 10 & 1 & 100 \\
\hline Vertical K, md & 1 & 0.1 & 10 \\
\hline Porosity, \% & 14.8 & 12 & 17.5 \\
\hline External Drainage Pr, psi & 700 & 600 & 800 \\
\hline \multicolumn{4}{|l|}{ Fluid Properties } \\
\hline Oil Viscosity, cp & 2 & 1.8 & 2.1 \\
\hline Initial oil saturation, \% & 45 & 40 & 55 \\
\hline Formation volume factor, RB/STB & 1.05 & 1.03 & 1.07 \\
\hline Drive Mechanism Scaling factor (DMSF) & 0.6 & 0.5 & 0.8 \\
\hline \multicolumn{4}{|c|}{$(D M S F=1$ for active water drive, DMSF $=0$ for solution gas drive) } \\
\hline \multicolumn{4}{|l|}{ Vertical well data } \\
\hline Skin factor & 1 & -1 & 3 \\
\hline BHP, psi & 300 & 200 & 400 \\
\hline Residual oil saturation, \% & 30 & 25 & 35 \\
\hline Well bore radius, inch & 3.5 & & \\
\hline Well cost, $1000 \$$ & 200 & & \\
\hline Fixed Operational cost/day, $\$$ & 100 & & \\
\hline \multicolumn{4}{|l|}{ Horizontal well data } \\
\hline Skin factor & 1 & -1 & 3 \\
\hline BHP, psi & 300 & 200 & 400 \\
\hline Residual oil saturation, \% & 30 & 25 & 35 \\
\hline Well bore radius, inch & 3.5 & & \\
\hline Horizontal well length, $\mathrm{ft}$ & 600 & & \\
\hline Well cost, $1000 \$$ & 400 & & \\
\hline Fixed Operational costs, \$/day & 125 & & \\
\hline
\end{tabular}

Table 3.1b: Average petrophysical and other input data to RESMOD ${ }^{\mathrm{TM}}$ for Ness City North Field, Ness County, Kansas 


\begin{tabular}{|c|c|c|c|}
\hline \multicolumn{4}{|l|}{ Field - Arnold SW } \\
\hline & Base & Min & $\operatorname{Max}$ \\
\hline \multicolumn{4}{|l|}{ Rock Properties } \\
\hline Drainage Radius, $\mathrm{ft}$ & 612 & 306 & 918 \\
\hline Formation Thickness, $\mathrm{ft}$ & 37.5 & 20 & 55 \\
\hline Horizontal K, md & 10 & 1 & 100 \\
\hline Vertical K, md & 1 & 0.1 & 10 \\
\hline Porosity, \% & 14.8 & 13 & 17 \\
\hline External Drainage Pr, psi & 600 & 500 & 700 \\
\hline \multicolumn{4}{|l|}{ Fluid Properties } \\
\hline Oil Viscosity, cp & 2 & 1.8 & 2.1 \\
\hline Initial oil saturation, \% & 45 & 40 & 55 \\
\hline Formation volume factor, RB/STB & 1.05 & 1.03 & 1.07 \\
\hline Drive Mechanism Scaling factor (DMSF) & 0.6 & 0.5 & 0.8 \\
\hline \multicolumn{4}{|c|}{ (DMSF = 1 for active water drive, $D M S F=0$ for solution gas drive) } \\
\hline \multicolumn{4}{|l|}{ Vertical well data } \\
\hline Skin factor & 1 & -1 & 3 \\
\hline BHP, psi & 300 & 200 & 400 \\
\hline Residual oil saturation, \% & 30 & 25 & 35 \\
\hline Well bore radius, inch & 3.5 & & \\
\hline Well cost, $1000 \$$ & 200 & & \\
\hline Fixed Operational cost/day, \$ & 100 & & \\
\hline \multicolumn{4}{|l|}{ Horizontal well data } \\
\hline Skin factor & 1 & -1 & 3 \\
\hline BHP, psi & 300 & 200 & 400 \\
\hline Residual oil saturation, \% & 30 & 25 & 35 \\
\hline Well bore radius, inch & 3.5 & & \\
\hline Horizontal well length, ft & 600 & & \\
\hline Well cost, $1000 \$$ & 400 & & \\
\hline Fixed Operational costs, \$/day & 125 & & \\
\hline
\end{tabular}

Table 3.1c: Average petrophysical and other input data to RESMOD ${ }^{\mathrm{TM}}$ for Arnold Southwest Field, Ness County, Kansas 


\begin{tabular}{|c|c|c|c|}
\hline \multirow[t]{2}{*}{ Field - Judica } & \multirow[b]{2}{*}{ Base } & \multirow[b]{2}{*}{ Min } & \multirow[b]{2}{*}{ Max } \\
\hline & & & \\
\hline \multicolumn{4}{|l|}{ Rock Properties } \\
\hline Drainage Radius, ft & 579 & 290 & 869 \\
\hline Formation Thickness, $\mathrm{ft}$ & 20 & 8 & 32 \\
\hline Horizontal K, md & 10 & 1 & 100 \\
\hline Vertical K, md & 1 & 0.1 & 10 \\
\hline Porosity, \% & 20 & 18 & 22 \\
\hline External Drainage Pr, psi & 700 & 600 & 800 \\
\hline \multicolumn{4}{|l|}{ Fluid Properties } \\
\hline Oil Viscosity, $\mathrm{cp}$ & 2 & 1.8 & 2.1 \\
\hline Initial oil saturation, \% & 45 & 40 & 55 \\
\hline Formation volume factor, RB/STB & 1.05 & 1.03 & 1.07 \\
\hline Drive Mechanism Scaling factor (DMSF) & 0.55 & 0.5 & 0.7 \\
\hline \multicolumn{4}{|c|}{$(D M S F=1$ for active water drive, DMSF $=0$ for solution gas drive) } \\
\hline \multicolumn{4}{|l|}{ Vertical well data } \\
\hline Skin factor & 1 & -1 & 3 \\
\hline $\mathrm{BHP}, \mathrm{psi}$ & 300 & 200 & 400 \\
\hline Residual oil saturation, \% & 30 & 25 & 35 \\
\hline Well bore radius, inch & 3.5 & & \\
\hline Well cost, $1000 \$$ & 200 & & \\
\hline Fixed Operational cost/day, \$ & 100 & & \\
\hline \multicolumn{4}{|l|}{ Horizontal well data } \\
\hline Skin factor & 1 & -1 & 3 \\
\hline BHP, psi & 300 & 200 & 400 \\
\hline Residual oil saturation, \% & 30 & 25 & 35 \\
\hline Well bore radius, inch & 3.5 & & \\
\hline Horizontal well length, $\mathrm{ft}$ & 600 & & \\
\hline Well cost, $1000 \$$ & 400 & & \\
\hline Fixed Operational costs, \$/day & 125 & & \\
\hline
\end{tabular}

Table 3.1d: Average petrophysical and other input data to RESMOD ${ }^{\mathrm{TM}}$ for Judica Field, Ness County, Kansas 


\begin{tabular}{|l|r|r|r|}
\hline Field - Riverside & & & \\
\hline & Base & Min & Max \\
\hline \hline Rock Properties & & & \\
\hline Drainage Radius, ft & 699 & 350 & 1049 \\
\hline Formation Thickness, ft & 35 & 20 & 50 \\
\hline Horizontal K, md & 10 & 1 & 100 \\
\hline Vertical K, md & 1 & 0.1 & 10 \\
\hline Porosity, \% & 15.5 & 13 & 18 \\
\hline External Drainage Pr, psi & 900 & 800 & 1000 \\
\hline & & & \\
\hline Fluid Properties & & & \\
\hline Oil Viscosity, cp & 2 & 1.8 & 2.1 \\
\hline Initial oil saturation, \% & 45 & 40 & 55 \\
\hline Formation volume factor, RB/STB & 1.05 & 1.03 & 1.07 \\
\hline & & & \\
\hline Drive Mechanism Scaling factor (DMSF) & 0.6 & 0.5 & 0.75 \\
\hline DMSF = 1 for active water drive, DMSF = for solution gas drive) & \\
\hline & & & \\
\hline Vertical well data & & & \\
\hline Skin factor & 1 & -1 & 3 \\
\hline BHP, psi & 300 & 200 & 400 \\
\hline Residual oil saturation, \% & 30 & 25 & 35 \\
\hline Well bore radius, inch & 3.5 & & \\
\hline Well cost, 1000 \$ & 600 & & \\
\hline Fixed Operational cost/day, \$ & 400 & & \\
\hline & 125 & & \\
\hline Horizontal well data & & & \\
\hline Skin factor & & & \\
\hline BHP, psi & & & \\
\hline Residual oil saturation, \% & & & \\
\hline Well bore radius, inch & & & \\
\hline Horizontal well length, ft & & & \\
\hline Well cost, 1000 \$ & & & \\
\hline Fixed Operational costs, \$/day & & & \\
\hline & & & \\
\hline
\end{tabular}

Table 3.1e: Average petrophysical and other input data to RESMOD ${ }^{\mathrm{TM}}$ for Riverside Field, Ness County, Kansas 


\begin{tabular}{|c|c|c|c|}
\hline \multicolumn{4}{|l|}{ Field - Lippoldt } \\
\hline & Base & Min & Max \\
\hline \multicolumn{4}{|l|}{ Rock Properties } \\
\hline Drainage Radius, ft & 772 & 385 & 1157 \\
\hline Formation Thickness, ft & 40 & 25 & 55 \\
\hline Horizontal K, md & 10 & 1 & 100 \\
\hline Vertical K, md & 1 & 0.1 & 10 \\
\hline Porosity, \% & 15.5 & 14 & 17 \\
\hline External Drainage Pr, psi & 1050 & 950 & 1150 \\
\hline \multicolumn{4}{|l|}{ Fluid Properties } \\
\hline Oil Viscosity, $c p$ & 2 & 1.8 & 2.1 \\
\hline Initial oil saturation, \% & 45 & 40 & 55 \\
\hline Formation volume factor, RB/STB & 1.05 & 1.03 & 1.07 \\
\hline Drive Mechanism Scaling factor (DMSF) & 0.7 & 0.6 & 0.9 \\
\hline \multicolumn{4}{|c|}{ (DMSF = 1 for active water drive, DMSF = 0 for solution gas drive) } \\
\hline \multicolumn{4}{|l|}{ Vertical well data } \\
\hline Skin factor & 1 & -1 & 3 \\
\hline BHP, psi & 450 & 350 & 550 \\
\hline Residual oil saturation, \% & 30 & 25 & 35 \\
\hline Well bore radius, inch & 3.5 & & \\
\hline Well cost, $1000 \$$ & 200 & & \\
\hline Fixed Operational cost/day, \$ & 100 & & \\
\hline \multicolumn{4}{|l|}{ Horizontal well data } \\
\hline Skin factor & 1 & -1 & 3 \\
\hline BHP, psi & 450 & 350 & 550 \\
\hline Residual oil saturation, \% & 30 & 25 & 35 \\
\hline Well bore radius, inch & 3.5 & & \\
\hline Horizontal well length, $\mathrm{ft}$ & 600 & & \\
\hline Well cost, $1000 \$$ & 400 & & \\
\hline Fixed Operational costs, \$/day & 125 & & \\
\hline
\end{tabular}

Table 3.1f: Average petrophysical and other input data to RESMOD ${ }^{\mathrm{TM}}$ for Lippoldt Field, Hodgeman County, Kansas 


\begin{tabular}{|c|c|c|c|}
\hline \multicolumn{4}{|l|}{ Field - Fralick W } \\
\hline & Base & Min & Max \\
\hline \multicolumn{4}{|l|}{ Rock Properties } \\
\hline Drainage Radius, ft & 876 & 437 & 1313.4 \\
\hline Formation Thickness, $\mathrm{ft}$ & 32.5 & 20 & 45 \\
\hline Horizontal K, md & 10 & 1 & 100 \\
\hline Vertical K, md & 1 & 0.1 & 10 \\
\hline Porosity, \% & 21.5 & 20 & 23 \\
\hline External Drainage Pr, psi & 200 & 100 & 300 \\
\hline \multicolumn{4}{|l|}{ Fluid Properties } \\
\hline Oil Viscosity, $c p$ & 2 & 1.8 & 2.1 \\
\hline Initial oil saturation, \% & 45 & 40 & 55 \\
\hline Formation volume factor, RB/STB & 1.05 & 1.03 & 1.07 \\
\hline Drive Mechanism Scaling factor (DMSF) & 0.2 & 0.1 & 0.5 \\
\hline \multicolumn{4}{|c|}{ (DMSF = 1 for active water drive, DMSF = 0 for solution gas drive) } \\
\hline \multicolumn{4}{|l|}{ Vertical well data } \\
\hline Skin factor & 1 & -1 & 3 \\
\hline BHP, psi & 75 & 15 & 90 \\
\hline Residual oil saturation, \% & 30 & 25 & 35 \\
\hline Well bore radius, inch & 3.5 & & \\
\hline Well cost, $1000 \$$ & 200 & & \\
\hline Fixed Operational cost/day, $\$$ & 100 & & \\
\hline \multicolumn{4}{|l|}{ Horizontal well data } \\
\hline Skin factor & 1 & -1 & 3 \\
\hline BHP, psi & 75 & 15 & 90 \\
\hline Residual oil saturation, \% & 30 & 25 & 35 \\
\hline Well bore radius, inch & 3.5 & & \\
\hline Horizontal well length, ft & 600 & & \\
\hline Well cost, $1000 \$$ & 400 & & \\
\hline Fixed Operational costs, \$/day & 125 & & \\
\hline
\end{tabular}

Table 3.1g: Average petrophysical and other input data to RESMOD ${ }^{\mathrm{TM}}$ for Fralick West Field, Kiowa County, Kansas 


\begin{tabular}{|c|c|c|c|c|c|c|}
\hline Field & $\begin{array}{l}\text { Vertical } \\
\text { IP rate } \\
\text { BBI/d } \\
\end{array}$ & $\begin{array}{l}\text { Horizontal } \\
\text { IP rate } \\
\text { BBI/d } \\
\end{array}$ & $\begin{array}{l}\text { Vertical } \\
\text { Rate after } 5 \text { yrs } \\
\text { BBI/d }\end{array}$ & $\begin{array}{l}\text { Horizontal } \\
\text { Rate after } 5 \text { yrs } \\
\text { BBl/d } \\
\end{array}$ & $\begin{array}{l}\text { Vertical } \\
\text { Cum Recovery } \\
\text { After } 5 \text { yrs, Mbbl } \\
\end{array}$ & $\begin{array}{l}\text { Horizontal } \\
\text { Cum Recovery } \\
\text { After } 5 \text { yrs, Mbbl }\end{array}$ \\
\hline Lippoldt & 90 & 268 & 56.5 & 72 & 131 & 273 \\
\hline Riverside & 80.7 & 268 & 34.8 & 20.4 & 99.8 & 176 \\
\hline Ness City N & 38 & 149 & 19 & 12 & 50 & 100 \\
\hline Arnold SW & 43.9 & 147 & 25 & 27.2 & 61 & 130 \\
\hline Judica & 31.4 & 134 & 16 & 10 & 42 & 88 \\
\hline McDonald & 74.5 & 241 & 38.7 & 34.9 & 100 & 195 \\
\hline Fralick W & 15 & 49 & 13.8 & 36 & 26.5 & 77 \\
\hline
\end{tabular}

Table 3.2: RESMOD ${ }^{\mathrm{TM}}$ predicted estimates of initial production (IP) rates and cumulative production (after 5 years) from infill and vertical wells. 


\section{Integrated Reservoir Petrophysics}

A PMP for Mississippian reservoirs is the construction of reservoir geomodels, based on integrated geologic, petrophysical, and engineering characterization of a site, prior to numerical simulation or drilling of the site. To accurately predict the production potential of a reservoir it is necessary to know the storage and flow properties of the rocks that comprise that reservoir. Because of the paucity of publicly available petrophysical data for Mississippian reservoirs, and the frequent lack of such data for many leases, a databank of representative petrophysical properties and petrophysical relationships was developed. From these data and relationships, characterization can be performed using petrophysical information from analog rocks, available from rock catalogs, and using cost-effective analysis tools such as the wireline log software PfEFFER. The on-line database is a principal product of the Integrated Reservoir Characterization task but additional analysis needed by operators includes a general summary of lithologic and petrophysical relations. The following sections discuss: 4.1) Rock Catalog, 4.2) Geologic Setting and Depositional Environments, 4.3) LithofaciesPorosity-Permeability Relations, 4.4) Capillary Pressure Properties, 4.5) Relative Permeability Properties, and 4.6) Electrical Properties.

\subsection{Rock Catalog}

As the first step in compiling Mississippian properties, basic reservoir rock properties (principally lithology, porosity, permeability, and grain density) have been compiled from publicly available sources and/or measured on representative rocks from available cores. Initial work focused on identification of publicly available cores, compilation of existing core petrophysical data, digitization of the available data, and integration of the data into the rock catalog database accessible through the public domain web application GEMINI (http://www.kgs.ku.edu/Gemini/index.html), which is focused on analysis and modeling of petroleum reservoirs/plays. GEMINI creates projects from on-line data either from the Kansas Geological Survey (including digital logs, core analysis and photos, DST, and production data) or from user-initiated uploads. 
Table 4.1 lists the Mississippian cores from within the study area, located on the west flank of the Central Kansas Uplift (16S-27S, 20W-26W), that were not chert facies (i.e., not Mississippian "Chat") and were available for sampling and analysis. Routine petrophysical properties were either obtained from data records or were measured on core plugs obtained from cores. Data from 1097 core samples, including 357 full-diameter analyses, 484 plug analyses, and 256 lithologic analyses, were collected. Wells highlighted in yellow in Table 4.1 were plugged and routine petrophysical properties measured by the Kansas Geological Survey. These basic data were digitized and entered into the database accessible on-line through GEMINI.

Essential rock properties, fluid type, and fluid volumes are fundamental to conducting quantitative reservoir characterization and geo-engineering modeling. The digital rock catalog presents a range of rock petrophysical data representing a range of lithologies, organized on the premise that individual "type" core samples exhibit petrophysical properties that are representative of a class of rocks of similar lithology. The relational nature of this rock catalog of wide ranging, diverse petrophysical parameters provides the basis to calibrate wireline logs. Once parameters, their values, and correlations (and derived parameters) are defined, the results can be integrated and utilized in other modules of GEMINI, e.g., display of parameters along with well logs.

The rock catalog information is presented in relational context and not limited to categorical data. GEMINI's rock catalog is project specific and relational, in that type sample properties are shown within the context of other samples of similar type or within context of all samples for a study. In other words, a sample can be compared to others to determine correlations and permit use of data models, e.g., permeability vs. porosity. The petrophysical data are related to wells by depth, location, field, and formation. The comparisons can be either categorical or relational. The relational context is specified by the user. Core data can be displayed on its own or integrated with rock photos and shown alongside corresponding well log data. The rock catalog module can also be accessed separate from a GEMINI project. The user accesses the digital core catalog via Oracle 
tables that are called by GEMINI software to accomplish the interactive analysis. The digital rock catalog is composed of petrophysical data including:

- Lithologic Properties

- Geologic Properties

- Porosity

- Permeability

- Capillary Pressure Properties

- Electrical Properties

- Mechanical Properties

Table 4.2 lists data fields within the petrophysical database for which data may be available for any given sample. Figure 4.1 shows an example Rock Catalog sheet constructed from on-line data using the GEMINI Rock Catalog interface. The example shown is for a Bindley Field sample. Similar pages can be constructed within a userdefined relational context for any of the Mississippian routine data. A present limitation of the database is that user-friendly interfaces do not exist for advanced rock properties such as capillary pressure and relative permeability because these utilize tables for a given sample. While these data are publicly available they are not accessible with the same facility as the routine data. These interfaces were beyond the scope of this project. However, public interfaces are being developed at the Kansas Geological Survey to provide easy access and query to data related to advance petrophysical analyses.

\subsection{Geologic Setting, Depositional Environments, and Lithofacies}

Mississippian shallow shelf carbonates exhibit a range of lithofacies, as the result of differences in depositional environments and subsequent karst and diagenetic events. The fields in the study area are located on the upper shelf of the Hugoton Embayment of the Anadarko Basin, on the southwest flank of the Central Kansas Uplift (CKU) beneath the sub-Pennsylvanian unconformity (Figure 4.2). The CKU is the southeastward extension of the Transcontinental Arch (see Goebel, 1968; Lane and DeKeyser, 1980). Several authors indicate that the CKU started to become a structurally positive element 
before and during early Mississippian deposition but that the structural movements were minor compared with later tectonic events (e.g. Goebel, 1966; Thomas, 1982; Rogers et al., 1995). Montgomery et al. (1998) and Watney et al. (2001) suggest that features associated with these early Mississippian events may have influenced depositional patterns.

Mississippian rocks are successively younger in a southwestward direction away from the CKU where all Mississippian rocks are absent (Figure 4.3). This pattern is due mainly to Late Mississippian - Early Pennsylvanian structural uplift related to the Ouachita orogenic event. This resulted in an extensive period of subaerial exposure and erosion of Mississippian strata forming a regionally significant unconformity that separates Mississippian from overlying Pennsylvanian rocks. The ramp strata in the study area were differentially eroded at the post-Mississippian unconformity resulting in paleotopographic highs (buried hogbacks).

The area of principal focus for Mississippian reservoirs in this project lies on the west flank of the CKU (16S-27S, 20W-26W) in Ness and Hodgeman Counties (Fig. 4.4). Example fields for which lithologic analysis is discussed in this section include Schaben, Ness City North, and Bindley fields. The Schaben Field area produces oil from lower Meramecian Warsaw and Osagian Keokuk cherty dolomites and limestones. The Ness City and Bindley fields produce from the Maramecian Warsaw. Strata in these fields represent shelf carbonates deposited on a gentle south-southwest sloping ramp. The transition from shelf carbonates to basin facies in Osage strata occurred some 15-20 km to the south of the Schaben Field area as mapped by Selks (1968). Post-depositional regional uplift, subaerial exposure, and differential erosion of the ramp strata at the prePennsylvanian unconformity resulted in paleotopographic highs (buried hills). These structural highs have been the targets of exploration and production efforts. The majority of Mississippian production in Kansas occurs at or near the top of the Mississippian section just below the sub-Pennsylvanian unconformity. Field locations can also be correlated in some areas with basement lineaments. 
Recent studies place this project's study area during Osagean-Meramecian time in a subtropical-tropical location, at about 20 degrees South. A number of biotic and nonbiotic associations indicate co-existence of warm and colder water. Presence of evaporites indicates arid conditions. However, the dominance of a heterozoan association (light-independent organisms such as echinoderms, siliceous sponge spicules, bryozoans) and the lack of a photozoan association (few light dependent organisms/skeletons, rare ooids, and peloids) points to nutrient-rich cool water conditions. Based on the subtropical-tropical setting and regional paleogeography, ramp characteristics during Osagean-Meramecian deposition are interpreted to result from upwelling of nutrient-rich colder waters from the Ouachita basin up onto the shelf (Figure 4.5). This larger setting produced the general setting of main-inner shelf environments shown in Figure 4.6, and resulted in the deposition of the principal lithofacies present in the Mississippian reservoirs shown in Figure 4.7. Each of these lithofacies exhibit unique petrophysical trends as discussed in Section 4.3.

Events important to development of lithofacies and their reservoir properties in the Schaben Field include:

- Burrow mottling created networks for diagenetic fluids rich in silica resulting in variable porous and tight areas

- Early dolomitization and dissolution of grains created moldic, intercrystalline, and vuggy porosity

- Early silica replacement and cementation tends to result in relatively tight and impermeable layers in echinoderm-rich facies

- Some silicified areas contain abundant microcrystalline porosity (tripolitic chert)

- Silica replacement and cementation in mudstones and sponge-rich facies is variable with more moldic and vuggy porosity being present, especially where evaporites were dissolved or replaced

- Silica replacement partially or totally replaces matrix and grains, or replaces the dolomite matrix and leaves spicules as molds 
- Several generations of fracturing, brecciation, cementation, and sediment fills create complex fabrics that variably enhanced or destroyed reservoir characteristics

- Early differential compaction resulted in brittle fracturing of silicified areas and soft-sediment deformation of surrounding matrix imparting a fracture and breccia fabric

- An internal subaerial exposure event resulted in coarse calcite replacement and cementation of strata in lower portions of cores (MO strata) that is important in occluding porosity in much of the echinoderm-rich facies

- Post-Mississippian subaerial exposure, burial compaction, and structural upliftment resulted in brittle fracturing and brecciation of all facies and previous diagenetic events

Figures 4.8 and 4.9 show thin-section properties for several important lithofacies in the Schaben and Bindley fields. Although there are many similarities between reservoir and non-reservoir facies in the Mississippian, differences exist in response to diagenetic modification of facies and variations in bioclastic constituent abundances. Comparison of the three fields being discussed indicates:

\section{Schaben Field}

Reservoir quality facies is sponge spicule-rich facies (packstones/wackestones)

- Abundant spicule molds

- Intercrystalline porosity in dolomite matrix

- Variable silica replacement; silica-replaced evaporites, commonly associated with this facies, usually contain vugs

Echinoderm-rich facies (packstones/wackestones), normally the best reservoir facies, are not effective reservoir facies in Schaben field because:

- Silica replacement and cementation is more pervasive in echinoderm-rich facies and occludes much porosity 
- Early calcite cementation and replacement associated with an internal subaerial exposure event occluded much porosity in echinoderm-rich facies

- Echinoderm-rich facies with good reservoir quality occur only as thin layers, which are interbedded with, and isolated by, surrounding facies that are cemented or replaced by silica and calcite

\section{Bindley \& Ness City North Fields}

Best reservoir facies is echinoderm-rich facies (packstones/wackestones with or without bryozoans) because of

- Abundant moldic porosity

- Intercrystalline porosity in dolomite matrix

- Relatively little replacement or cementation by silica and calcite compared to similar facies in Schaben

Sponge-spicule-rich facies (packstones/wackestones), similar to reservoir facies in Schaben, are not reservoir facies in Bindley and Ness City because:

- Calcite cement, of unknown age, fills or partially fills many sponge-spicule molds

- In general, silica replacement and cementation are minor compared to Schaben field, but appear to be more commonly associated with spongespicule facies, thereby contributing to porosity occlusion.

\subsection{Lithofacies-Porosity-Permeability Relations}

In all fields, porosity and permeability increase with transition through the following lithofacies: mudstone-wackestone-packstone-grainstone. A relationship between porosity, permeability, and grain size is consistent with previous work by Lucia (1995) but would not necessarily be predicted in these rocks since the porosity is not intergranular, as studied by Lucia (1995), but is moldic. 
Comparison indicates that Mississippian reservoirs tend to exhibit similar ranges in porosity and permeability for similar lithofacies within a variance that may provide sufficient accuracy for screening and analog purposes. Major conclusions concerning relationships between lithology, porosity, and permeability include:

1) A repeating association of original depositional facies and early diagenesis for these rocks produced lithofacies ranging from mudstones to grainstones with abundant moldic porosity.

2) The nature of the molds varied through time reflecting the change in primary carbonate grain constituents which for the Mississippian primarily involved carbonate/siliceous sponge-spicule, echinoderm, and brachipod molds.

Primary factors controlling reservoir properties include:

- Depositional facies - grainstones/boundstones exhibit best properties, properties improve from mudstone to grainstone/boundstones.

- Permeability and porosity decrease significantly and continuously with decreasing grain/mold size from packstone to mudstone.

o An exception is the echinoderm grainstone facies, which is commonly replaced or cemented by calcite or silica, and exhibits very low porosity and permeability.

- Permeability and porosity were enhanced by 1 ) the creation of moldic porosity from dissolution of echinoderm, bryozoan, and sponge spicule grains, and 2) dolomitization resulting in intercrystalline porosity.

- For the systems investigated, depositional facies are the dominant control even with: 1) extensive and various, early and late diagenesis; 2) biotic constituent differences; 3) warm-cool water environments; 3) karst overprinting; 4) burial overprinting.

- Reservoir properties for each system, including porosity and permeability, are strongly correlated with original depositional facies despite significant fabric transformation, and in some cases even complete reversal of solid and pore space, with reservoir quality increasing from mudstone through grainstone. 
- The final moldic rocks exhibit petrophysical-lithofacies trends that parallel those of original primary porosity carbonates.

- Understanding facies locations is important for both stratigraphic and structural plays.

Secondary factors that favor reservoir properties include:

- Stratigraphy - e.g., shallowing upward high-frequency cycles

- Diagenesis - e.g., dissolution of carbonate grains to form molds, extensive dissolution to establish direct mold-mold connections

- Paleotopography - e.g., local relief that accentuates diagenetic processes

- Structure/Burial - e.g., fracturing, crushing to establish direct mold connectivity

The permeability-porosity trends for all lithofacies are approximately bounded within 2 orders of magnitude by trendlines (Figure 4.10) defined by:

$$
\begin{aligned}
& \log \mathrm{k}_{\text {in situ }}=0.25 \phi_{\text {in situ }}-2.5 \\
& \log \mathrm{k}_{\text {in situ }}=0.25 \phi_{\text {in situ }}-4.5
\end{aligned}
$$

- Between these bounding trends, each lithofacies exhibits unique sub-parallel trends with permeability decreasing with decreasing grain/mold size for any given porosity.

- Standard error of prediction of permeability for a specific lithofacies is generally less than a factor of 3.

The relationship between permeability and porosity for each lithofacies can be represented by a log-linear function or a power-law function. The power-law function (Figure 4.11) is best represented by an equation of the following form:

$$
\mathrm{k}=\mathrm{A} \phi^{3.45}
$$

where $\mathrm{k}$ = in situ Klinkenberg permeability (md), $\mathrm{f}$ = porosity (\%), and the coefficient $\mathrm{A}$ varies with lithofacies:

Lithofacies

Packstone

Pack-Wackestone

Wackestone

\section{Coefficient A}

0.00525

0.00150

0.00043 


$\begin{array}{ll}\text { Wacke-Mudstone } & 0.00012 \\ \text { Mudstone } & 0.00004 \\ \text { Shaly Mudstone } & 0.00001\end{array}$

For a given facies, increasing mold content and porosity $(\phi)$ result in a permeability (k) increase that is subparallel and at a lower slope to the general $\mathrm{k}-\phi$ trend. This is consistent with matrix properties being the dominant control on flow. Shifts in permeability-porosity trends of similar lithofacies between the different fields are explained by differences in diagenetic processes. Correlation of permeability and pore throat size in moldic-porosity rocks (Figure 4-12) is similar to that of intergranularporosity rocks. This can be interpreted to indicate that, despite some rocks having very high moldic porosity, permeability is primarily controlled by matrix properties. However, the strong association of increasing permeability with increasing grain size and packing (i.e. mudstone to grainstone) indicates that matrix pores must also be increasing in size. Enhanced mold connectivity resulting from extensive dissolution, crushing, or fracturing can create high permeability parallel flow systems. Lithofacies progression from mudstone through grainstone results in a greater change in permeability than increasing porosity. Although permeability in moldic porosity-dominated rocks is strongly controlled by matrix properties, and is correlated with porosity, permeability is also controlled by other rock textural parameters including:

- Connectivity Index - a 1 to 4 index for the degree of connection between molds

- Packing Index - an index from 1 to 4 for the packing density of molds

- $\quad$ Size - an estimate of the average mold diameter in phi units

- Archie Matrix Porosity Index - Archie's 2nd parameter for matrix porosity

Dominant control of matrix properties in rocks with high moldic porosity is consistent with a pore-scale series-flow model of low permeability matrix and high permeability moldic pore bodies. The strong correlation of permeability with connectivity may result from the establishment of increasing pore-scale parallel flow, effectively "short-circuiting” the series-flow dominated system. 
Examination of the permeability-porosity crossplot for the Schaben Field indicates that lithofacies and early diagenesis are the major controls despite complex diagenetic overprinting by sub-Pennsylvanian subaerial exposure and burial processes (Figure 4.13). Permeability and porosity decrease significantly and continuously with decreasing grain/mold size from packstone to mudstone and from echinoderm-rich to spicule-rich facies with the exception of the echinoderm grainstone facies, which is calcite cemented and exhibits very low porosity and permeability. Between the bounding trends each lithofacies exhibits a generally unique range of porosity and permeability which together define a continuous trend with permeability decreasing with decreasing grain/mold size for any given porosity. Individual lithofacies exhibits a unique subparallel trend to the general trend. Statistically the general trend for Schaben Field reservoir rocks is dominated by the large number of spicule-rich samples, and is strongly influenced by mudstone and cemented echinoderm grainstone properties:

$\log \mathrm{k}_{\text {in situ }}(\mathrm{md})=0.24 \phi_{\text {in situ }}(\%)-3.78$

Subtrends for clusters of facies or individual facies may also be defined and are significantly more accurate with standard error of prediction of permeability decreasing with increasing selectivity of lithofacies characteristics. Standard error for a specific lithofacies is generally less than a factor of 3 . Linear regression trends for spicule- and echinoderm-rich facies are:

\section{Schaben Field:}

$$
\begin{aligned}
& \log \mathrm{k}_{\text {in situ }}(\mathrm{md})=0.19 \phi_{\text {in situ }}(\%)-2.88 \text { [Spicule-rich] } \\
& \log \mathrm{k}_{\text {in sit }} \mathrm{u}(\mathrm{md})=0.12 \phi_{\text {in situ }}(\%)-1.04 \text { [Echinoderm-rich] }
\end{aligned}
$$

Permeability (k)-porosity $(\phi)$ trends from Bindley and Ness City fields (Figures 4.14 and 4.15) are similar to those of the Schaben for similar lithofacies. One significant difference is that calcite cementation of spicule-rich pack-wackestones significantly occludes porosity and reduces permeability. Both fields exhibit a similar $\mathrm{k}$ and $\phi$ decrease with decreasing grain/mold size from packstone to mudstone and from 
echinoderm-rich to spicule-rich facies. Permeability-porosity trends are bounded within two orders of magnitude by the same trendlines defined for all Mississippian fields. Between the bounding trends each lithofacies exhibits a generally unique range of porosity and permeability. The bounding trends can be considered to define the range of porosity for a given lithofacies trend.

Trends for echinoderm-rich (red lines) and spicule-rich facies (blue lines) are significantly different:

\section{Bindley Field:}

$$
\begin{aligned}
& \log \mathrm{k}_{\text {in situ }}(\mathrm{md})=0.157 \phi_{\text {in situ }}(\%)-1.87 \quad \text { [Echinoderm] } \\
& \log \mathrm{k}_{\text {in situ }}(\mathrm{md})=0.230 \phi_{\text {in situ }}(\%)-4.04 \quad \text { [Spicule] }
\end{aligned}
$$

\section{Ness City Field:}

$$
\begin{aligned}
& \log \mathrm{k}_{\text {in situ }}(\mathrm{md})=0.147 \phi_{\text {in situ }}(\%)-1.50 \quad \text { [Echinoderm] } \\
& \log \mathrm{k}_{\text {in situ }}(\mathrm{md})=0.170 \phi_{\text {in situ }}(\%)-2.76 \quad \text { [Spicule] }
\end{aligned}
$$

Standard error of prediction of permeability ranges from a factor of 2 to 4.8 .

For all fields the lowest $\mathrm{k}-\phi$ slope and highest predictive accuracy is obtained for a single lithofacies. With successive addition of more lithofacies into a statistical analysis the resulting trend-line slope approaches that of the bounding trends. The intercept varies as a function of the nature of the population grain/mold size.

The Klinkenberg gas permeability, which is equivalent to single-phase inert liquid or high pressure gas absolute permeability, increases with decreasing pore size. The influence of Klinkenberg gas slippage, which results from greater gas movement due to molecule to molecule interactions at lower pressure, is characterized as:

$$
\mathrm{k}_{\text {gas }}=\mathrm{k}_{\text {liquid }}(1+4 \mathrm{cL} / \mathrm{r})=\mathrm{k}_{\text {liquid }}(1+\mathrm{b} / \mathrm{P})
$$


where $\mathrm{k}_{\mathrm{gas}}=$ gas permeability at pore pressure, $\mathrm{k}_{\text {liquid }}$ is liquid permeability, $\mathrm{c}=$ proportionality constant $(\simeq 1), L=$ mean free path of gas molecule at pore pressure, $r=$ pore radius, $\mathrm{b}=$ proportionality constant $(=\mathrm{f}(\mathrm{c}, \mathrm{L}, \mathrm{r}))$, and $\mathrm{P}=$ pore pressure $(\mathrm{atm})$. Since $\mathrm{b}$ is a function of pore radius distribution it can vary between rock samples. However, general values for $\mathrm{b}$ can be estimated from the relation presented by Heid et al. (1950):

$$
\mathrm{b}=0.777 \mathrm{k}_{\text {liquid }}{ }^{-0.39}
$$

In situ Klinkenberg gas permeabilities (ki), which are equivalent to single-phase liquid or high-pressure gas absolute permeabilities under reservoir conditions, were correlated with routine air permeabilities (ka) measured at approximately 400 psi (2760 $\mathrm{kPa}$ ) net confining stress (Figure 4.16). Based on laboratory data the relationship between ki and ka in these rocks can be expressed:

$$
\begin{array}{ll}
\operatorname{logki}=1.016 \text { logka }-0.16 & \text { for ka }>1 \mathrm{md} \\
\operatorname{logki}=1.337 \text { logka }-0.14 & \text { for ka }<1 \mathrm{md}
\end{array}
$$

The trend is due both to the increase in effect of confining stress on pore-throat size with decreasing permeability and to the increase in gas slippage (i.e., Klinkenberg effect) with decreasing pore-throat size and decreasing permeability.

\subsection{Capillary Pressure Properties}

Capillary pressure properties of Mississippian carbonates differ between lithofacies. Structural closure in many Mississippian Kansas fields is less than 60 feet limiting oil column heights. It is also important to note that these values represent the maximum oil column height and that much of the volume of a field may lie below these heights. At these oil column heights, understanding the exact capillary pressure relationship becomes important.

Single-point "irreducible" water saturation was generally determined using a porous-plate capillary pressure cell to produce approximately 18.5 or 23.3 pounds per 
square inch absolute (psia) air-brine capillary pressure for the majority of the samples shown to simulate oil column heights of 45-55 feet. Laboratory capillary pressure data were converted to reservoir oil-brine capillary pressure data using the standard equation (Purcell, 1949; Berg, 1975):

$$
P c_{\text {res }}=P c_{\text {lab }}\left(\sigma \cos \theta_{\text {res }} / \sigma \cos \theta_{\text {lab }}\right)
$$

where $P c_{\text {res }}$ is the gas-brine capillary pressure (psia) at reservoir conditions, $P c_{\text {lab }}$ is the laboratory-measured capillary pressure (psia), $\sigma$ is the interfacial tension (dyne/cm), $\theta_{\text {res }}$ the the contact angle (degrees) at reservoir conditions, and $\theta_{\text {lab }}$ is the contact angle at laboratory conditions. For air-brine capillary pressure measurements, an air-brine interfacial tension of $72 \mathrm{dyne/cm}$ was assumed and a contact angle of 0 degrees was assumed. To determine the water saturation in any given rock type as a function of height above the free-water level, or the saturation at the top of a given gas-filled structure, it is necessary to convert the capillary pressure data to height above free-water level. This conversion was performed using the standard relation (Hubbert, 1953; Berg, 1975):

$$
\mathrm{H}=P c_{\text {res }} /\left(\mathrm{C}\left(\rho_{\text {brine }}-\rho_{\text {gas }}\right)\right)
$$

where $\mathrm{H}$ is the height (ft) above free-water level, $P c_{\text {res }}$ is the capillary pressure (psia) at reservoir conditions, $\rho_{\text {brine }}$ and $\rho_{\text {gas }}$ are the density of brine and gas at reservoir conditions and $\mathrm{C}$ is a constant $(0.433(\mathrm{psia} / \mathrm{ft}) /(\mathrm{g} / \mathrm{cc}))$ for converting density to pressure gradient.

From the air-mercury capillary pressure data, pore-throat diameter was calculated using the modified Washburn (1921) relation:

$$
d=4 \mathrm{C} \sigma \cos \theta / P c
$$

where $P c=$ capillary pressure $(\mathrm{psia}), \mathrm{C}=0.145((\mathrm{psia} \cdot \mathrm{cm} \cdot \mu \mathrm{m}) / \mathrm{dyne}), \theta=$ contact angle (140 degrees), $\sigma=$ interfacial tension (484 dyne/cm), and $d=$ pore-throat diameter $(\mu \mathrm{m}$, 
microns). This relationship assumes that the nonwetting phase (i.e., gas) enters the pores through circular pore throats.

Variables in the above equations that change with reservoir pressure, temperature, gas chemistry, and brine chemistry include $\sigma, \rho_{\text {brine, }}$ and $\rho_{\text {gas }}$. To convert laboratory properties to reservoir properties for use in the equations above, values for the Mississippian were defined as: 1) reservoir pressures between 1,000 to 1,500 psia, 2) temperatures from 90 to $110{ }^{\circ} \mathrm{F}, 3$ ) oil density between 0.75 to $0.85 \mathrm{~g} / \mathrm{cc}$, and 4) brine density ranging between 1.0-1.1 grams/cubic centimeter (g/cc). For the above mentioned temperature range, oil-water interfacial tension (IFT) ranges between 20 to 25 dyne/cm (approximately), and was assigned a value of $21 \mathrm{dyne} / \mathrm{cm}$. In this discussion the water saturation obtained at 18 to 21 psi air-brine capillary pressure has been defined to be "irreducible" water saturation or $S_{w i}$, although the definition of "irreducible" condition is not unambiguously defined.

Air-mercury intrusion analysis was performed by step-wise increase in injection pressure and recording of volumes injected to injection pressures up to 10,000 psi. These complete curves provided a basis for calculating the principal pore throat size, showing the general range of capillary pressure curves, and obtaining curve shape functions.

Air-brine capillary pressure measurements indicate that water-saturations (Sw) at 45 to 50 feet above the free water level (elevation where capillary pressure is zero) increase with decreasing porosity and permeability. Because of the close correlation between lithofacies and $\mathrm{k}-\phi$, Sw also increases with decreasing grain/mold size from packstone to mudstone. $\mathrm{Sw}_{45}$ in Schaben can be predicted within $\pm 14 \%$ (saturation \%) using the formula below (Figure 4.17) :

$$
\mathrm{Sw}_{45}(\%)=-20 * \log \mathrm{k}_{\text {insitu }}+61
$$

Within the echinoderm-rich facies in Ness Field, $\mathrm{Sw}_{50}$ is correlated with $\phi$ and $\mathrm{k}$ (Figure 4.18): 


$$
\begin{array}{ll}
\text { Sw50(\%) }=-3.21 \phi_{\text {insitu }}+87.6 & \text { All (SE=19) } \\
\text { Sw50(\%) }=-2.95 \phi_{\text {insitu }}+74.5 & \text { Echinoderm (SE=9.3) } \\
\text { Sw50(\%) }=-5.76 \phi_{\text {insitu }}+156.4 & \text { Spicule (SE=6.7) } \\
\text { Sw50(\%) }=-17.5 \log 10 \mathrm{k}_{\text {insitu }}+42.1 & \text { Echinoderm (SE=8.7) } \\
\text { Sw50(\%) }=-25.5 \log 10 \mathrm{k}_{\text {insitu }}+63.8 & \text { Spicule (SE=6.6) }
\end{array}
$$

Examination of the Sw- $\phi$ and Sw-k crossplots reveals how subtle changes in lithology can affect saturations. Increase in mud and spicule content elevates $\mathrm{Sw}$ in the echinoderm pack-wackestones, increase in dense chert content decreases porosity without changing Sw.

Changes in Sw between 50 and 150 feet in oil column height are small for spicule-rich facies indicating they are at "irreducible" Sw at 50 feet. While echinodermrich facies have low saturations, additional capillary pressure continues to decrease Sw.

To provide predictive tools for saturation as a function of height above free water level it is necessary to measure the complete capillary pressure curve. Capillary pressure data were obtained from previous analysis on 8 cores from the Schaben Field and airmercury capillary pressure analysis was performed on 17 samples, representing a range in lithology, porosity, and permeability from other Mississippian fields. Figure 4.19 shows a representative range of the measured capillary pressures.

To provide capillary pressure curves for the reservoir simulation it was necessary to develop generalized curves that represented the specific permeabilities that might be assigned to a grid cell. Equations to construct generalized capillary pressure curves were constructed based on the relationships evident from the entry pressures and curve shapes in the air-mercury capillary pressure curves, and from the saturations evident in the airbrine capillary pressure analysis. The relationships between increasing entry pressure, “irreducible" wetting phase saturation, and the capillary curve curvature (reflecting increasing pore throat size heterogeneity) with decreasing permeability were utilized to 
develop equations that would predict the capillary pressure curve using permeability as the independent variable.

Entry pressure, or the first pressure at which wetting phase desaturation begins, is similar to R35, exhibits a strong correlation with permeability and can be predicted using:

$$
\text { Pcow }_{\text {entry }}=2.3903 \mathrm{ki}-0.4039
$$

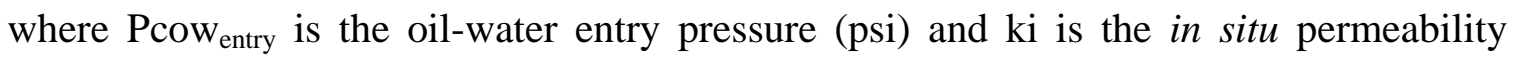
(md). This equation was obtained from the Mississippian samples shown in Figure 4.12. The capillary pressure curve shape factor was modeled using:

$$
\text { Pcow }_{\text {shape }}=-0.0218 \ln (\mathrm{ki})-1.069
$$

where Pcow shape represents the fractal slope of the capillary pressure curve and $\ln (\mathrm{ki})$ is the natural logarithm of the in situ Klinkenberg permeability (md). This shape factor represented the average for all lithofacies and the least error in predicted saturation for both the air-water and air-mercury capillary pressure data. Synthetic curves for a range of permeabilities are shown in Figure 4.20. The first standard deviation error using these equations is $\pm 12 \%$ (saturation percent). Figure 4.21 illustrates the saturation difference present in rocks of different lithology but with similar porosity (18\%). This illustrates how important lithologic information is for accurate prediction of petrophysical properties.

\subsection{Relative Permeability Properties}

No public imbibition relative permeability data could be located for the Mississippian. To pin down relative permeability end-points measurement were performed on selected samples to obtain data for 1) effective Klinkenberg gas permeability at critical water saturation (krg, Swc), 2) relative permeability to water at

residual oil saturation (krw, Sorw), and 3) residual oil saturation to waterflood (Sorw). 
Capillary pressure measurements discussed above provided data for initial water saturation. A single sample from the Beardmore Clifton \#1 well, Lippoldt Field, from $4450 \mathrm{ft}$ depth, was selected to perform a complete imbibition oil-water relative permeability curve to obtain curve shapes for modeling. Measured data for this sample are presented in Table 4.3 and in Figure 4.22. Since relative permeability end point saturations change with permeability (e.g., "irreducible” water saturation changes with permeability), the relative permeability curves also change with absolute permeability. Using the end point data measured and the curve shapes provide by the Clifton \#1 sample, relative permeability curves for any given permeability were modeled using Corey-type equations where Swi was obtained from Pc-k relations and assigned average absolute permeability values (Figure 4.23).

Corey (1954) derived his empirical equation based on Burdine’s (1953) work, and by assigning a value of 2 to the $\mathrm{m}$ and $\mathrm{n}$ exponents consistent with work by Carman (1937) on isotropic, homogeneous porous media and with experimental data obtained on high permeability sandpacks and consolidated sandstones. Corey (1954) found that for a large number of rock types, generally with $\mathrm{k}>10 \mathrm{md}$, $\mathrm{m}$ and $\mathrm{n}$ were approximately 2 , although, it was recognized that $\mathrm{m}$ and $\mathrm{n}$ can change with pore structure. Brooks and Corey (1966) more thoroughly investigated the influence of pore size distribution on relative permeability. None of these studies involved carbonate rocks or moldic carbonates whose unique pore structures necessitate the use of values other than 2 for the two exponents $m$ and $n$.

Exponent $\mathrm{m}$ and $\mathrm{n}$ values were initially obtained from measured data and were modified during simulation to reproduce lease production data.

$$
\begin{aligned}
& \text { kro }=a_{1}(1-S w D)^{m} \\
& \text { krw }=a_{2} S w D^{n} \\
& S w D=(S w-S w i) /(1-S w i-S o r w)
\end{aligned}
$$


For moldic-porosity Mississippian rocks residual oil saturation to waterflood also changes with permeability and/or Swi following the general trend: Sorw $=(1-($ Swi +0.5$))$. For reservoir simulation, initial pseudo-Swi values were assigned to each layer using Pc$\mathrm{k}$ relations discussed.

\section{Simulator Worksheet Tool}

To facilitate simulator modification and history matching an Excel worksheet was constructed that contained all relevant equations linked to permeability (and/or porosity). To provide capillary pressure and relative permeability curves for any given permeability for use in reservoir simulation the equations presented in Sections 4.4 and 4.5 were incorporated in an Excel workbook. This workbook requires only input of lithofacies and permeability, and the complete table of relative permeability and capillary pressures (at varying saturations) are calculated using equations presented in the above text. An example worksheet for a $10 \mathrm{md}$ sample is shown in Figure 4.24. With this worksheet, if the simulator required an adjustment of the permeability, the corresponding capillary pressure and relative permeability properties could be re-calculated for input, thus, keeping all petrophysical properties “coupled.”

\subsection{Electrical Properties}

Traditional wireline log calculation uses cementation (m) and saturation exponent (n) values of 2.0 in the Archie equation to calculate saturations. Formation resistivity factors $(\mathrm{Ro} / \mathrm{Rw})$ measured at $\mathrm{Rw}=0.045 \mathrm{ohm}-\mathrm{m}$ (Figure 4.25) indicate that the Archie cementation exponent (assuming an Archie intercept of 1.0) averages $m=1.97 \pm 0.09$ for

all facies. Echinoderm-rich facies can exhibit cementation exponents between 2.0 and 2.1 . 


\section{GEMINI}

\section{Rock Catalog}

Mississippian Bindley Field Packstone

Find all Rock Core Analysis Data in the Kansas Geologica . Lithology is Packstone

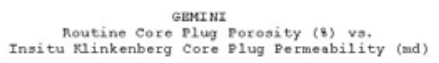

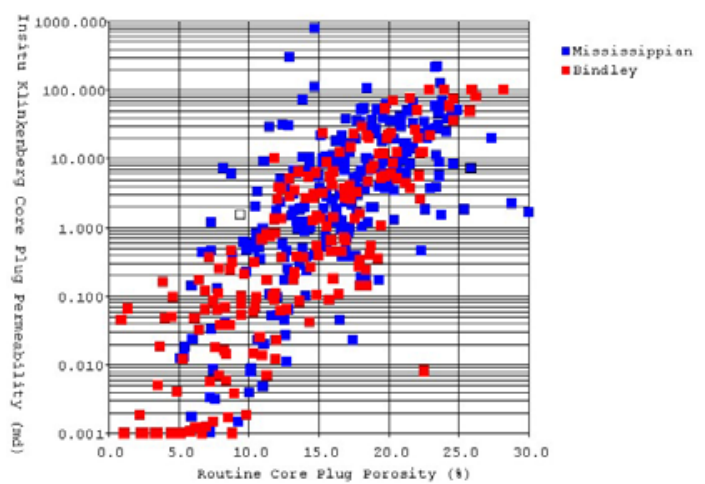

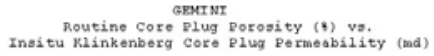
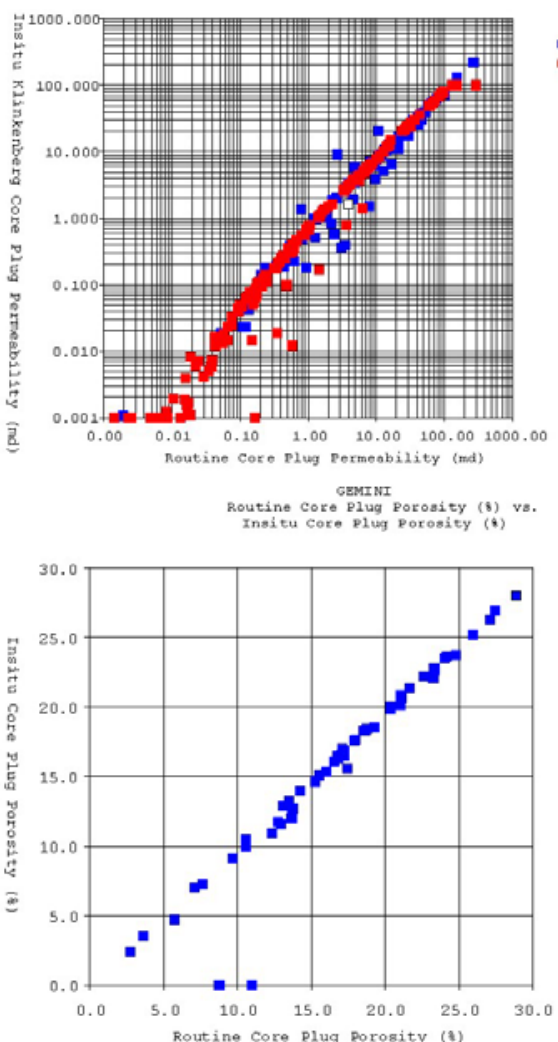

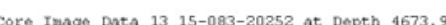

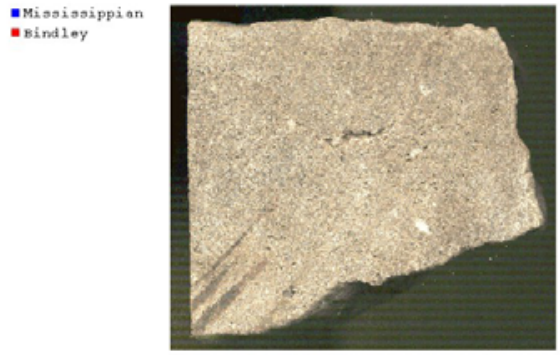

Mell Information
APT-Number: $15-083-2025$

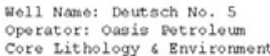

No Data
stratigraphic Unit

Top
porosity (8) - Coro plug

$\begin{array}{ll}\text { Routine } & =16.2 \\ \text { Insitu } & =\text { No DATA }\end{array}$

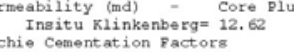

Ingitu No DATA
Arehie saturation Factors
Insitu

Decription: No Data

Core Image Data 13 15-083-20252 at Depth 4673.9

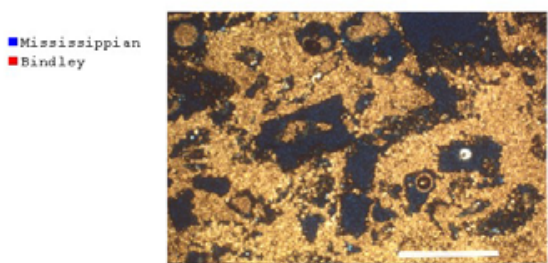

Wo11 Information
API-Number: 15-083-20252

Well Nene: Deutsch No. 5
Operator: Oagis petrole um

Operator: Oasis Retrole um
Core Lithology \& Bnvi ronmert

Lithology:
Bchinode nin pack-wackertono

Depositional gnvironment:

stratigraphic Unit:
Missigsippian

Depth (ft)

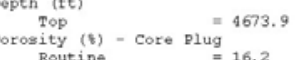

$\begin{aligned} \text { Routine } & =16.2 \\ \text { Insitu } & =\text { No DATA }\end{aligned}$

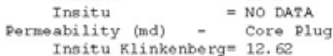

Archio cement ation iong 12 .

$=$ NO DATA
Arehio gaturation Pactora

Insitu

Figure 4.1: Example Rock Catalog page constructed from on-line database of Mississippian data. 


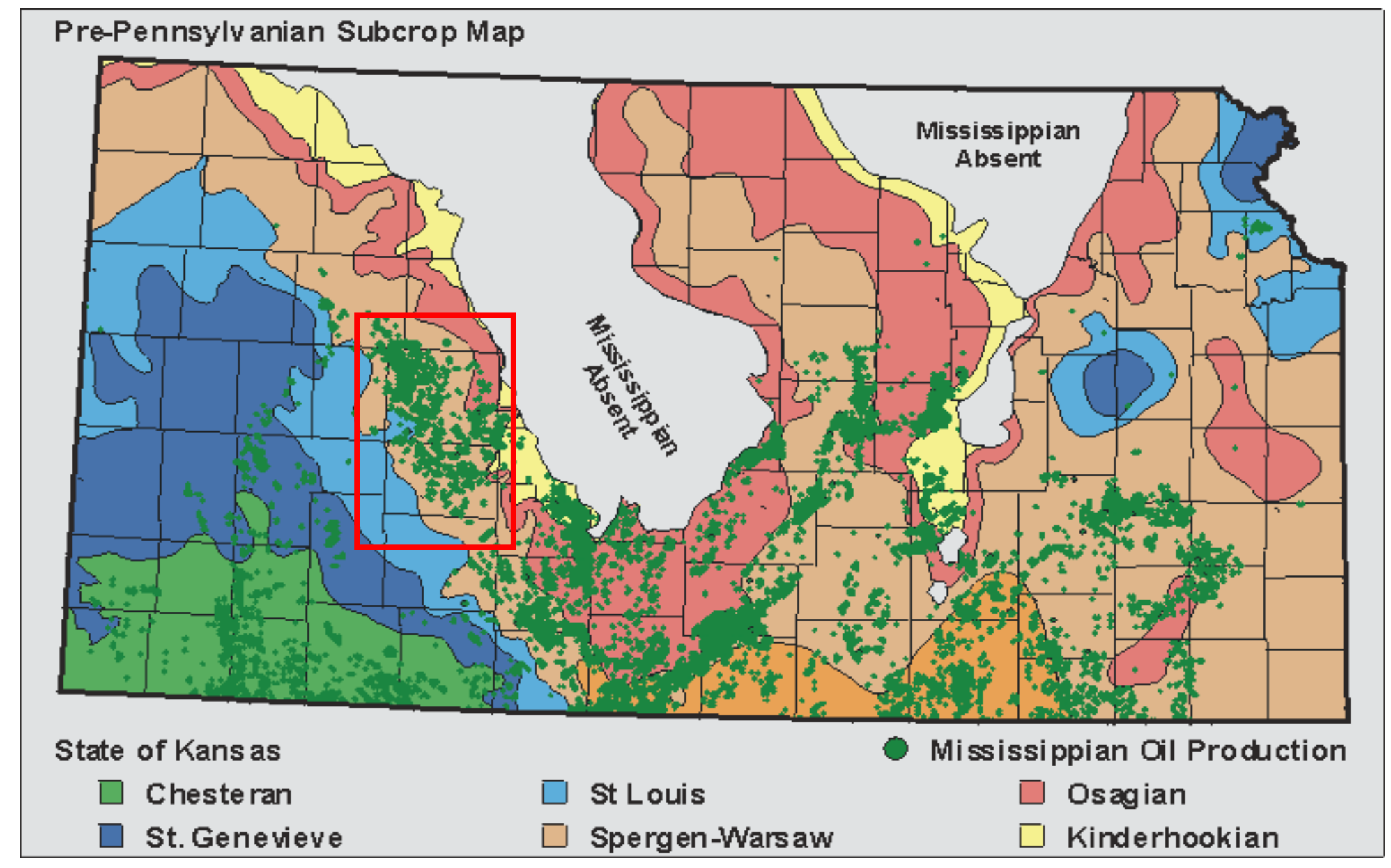

Figure 4.2: Mississippian subcrop map in Kansas showing the location of Mississippian fields (green dots). The Mississippian fields of principal focus in this project lay on the west flank of the Central Kansas Uplift (16S-27S, 20W-26W) in Ness and Hodgeman counties (within red rectangle). 

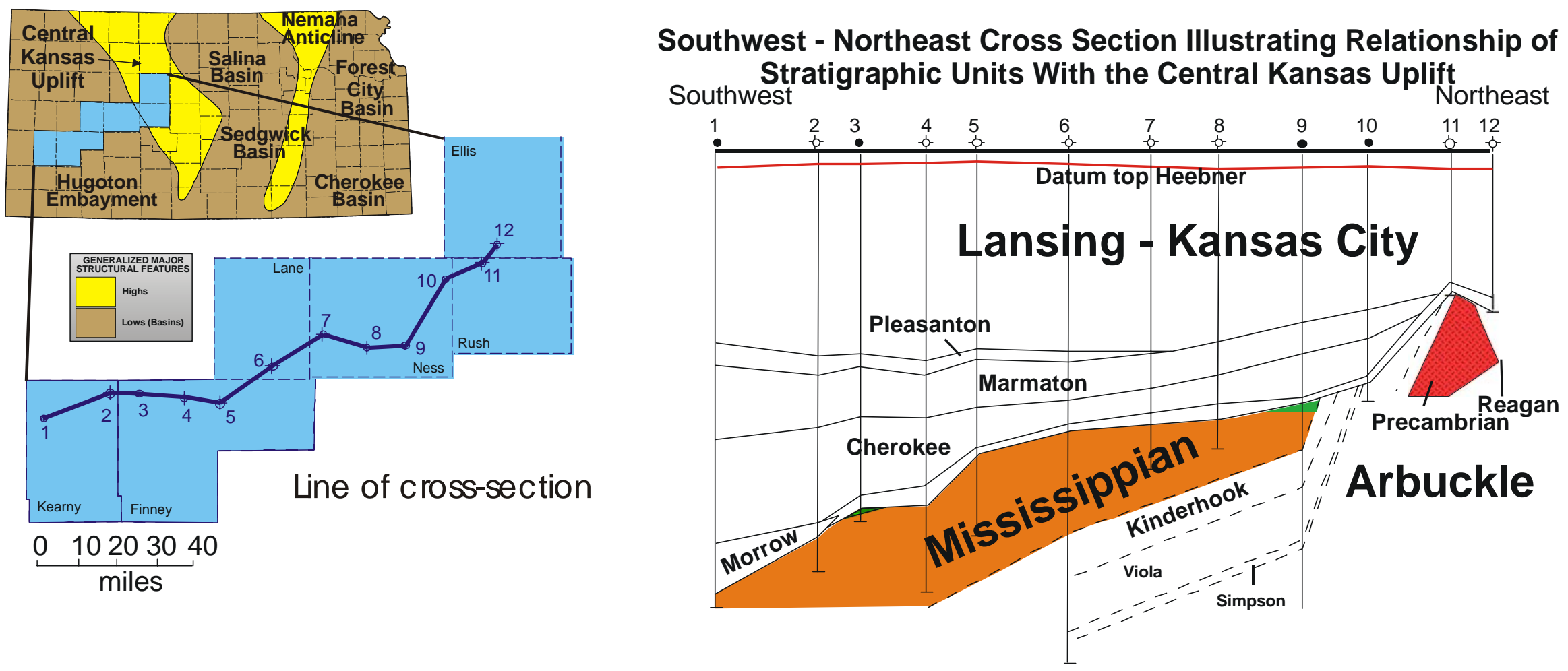

Figure 4.3: Southwest-Northeast cross-section illustrating the relationship of the Mississippian stratigraphic units with the Central Kansas Uplift. The Mississippian units are unconformably overlain by Pennsylvanian strata. Post-depositional regional uplift, subaerial exposure, and differential erosion of the ramp strata at the post-Mississippian unconformity resulted in paleotopographic highs (buried hills). Modified from Carr et al. (1996). 

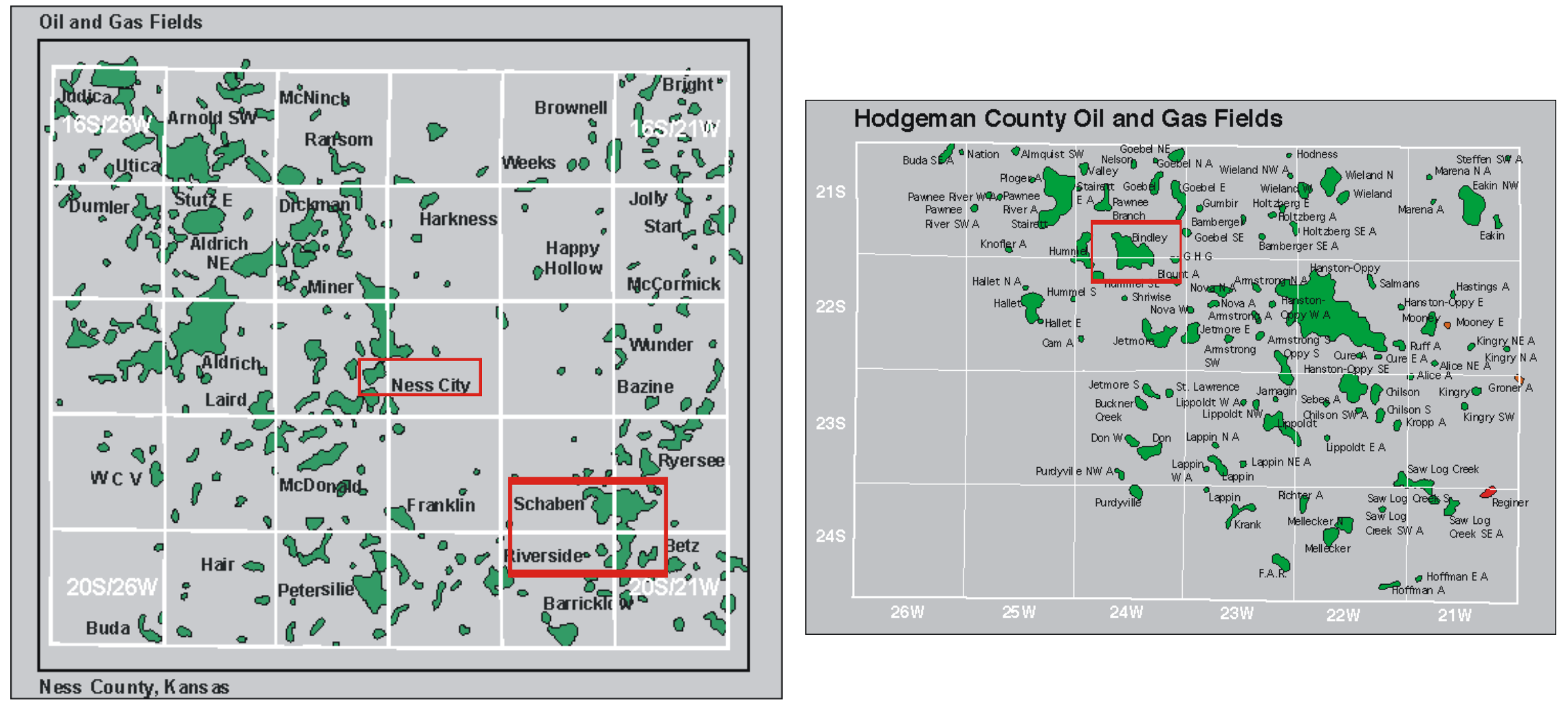

Figure 4.4: Location map of study area showing Mississippian fields selected for lithologic analysis. 


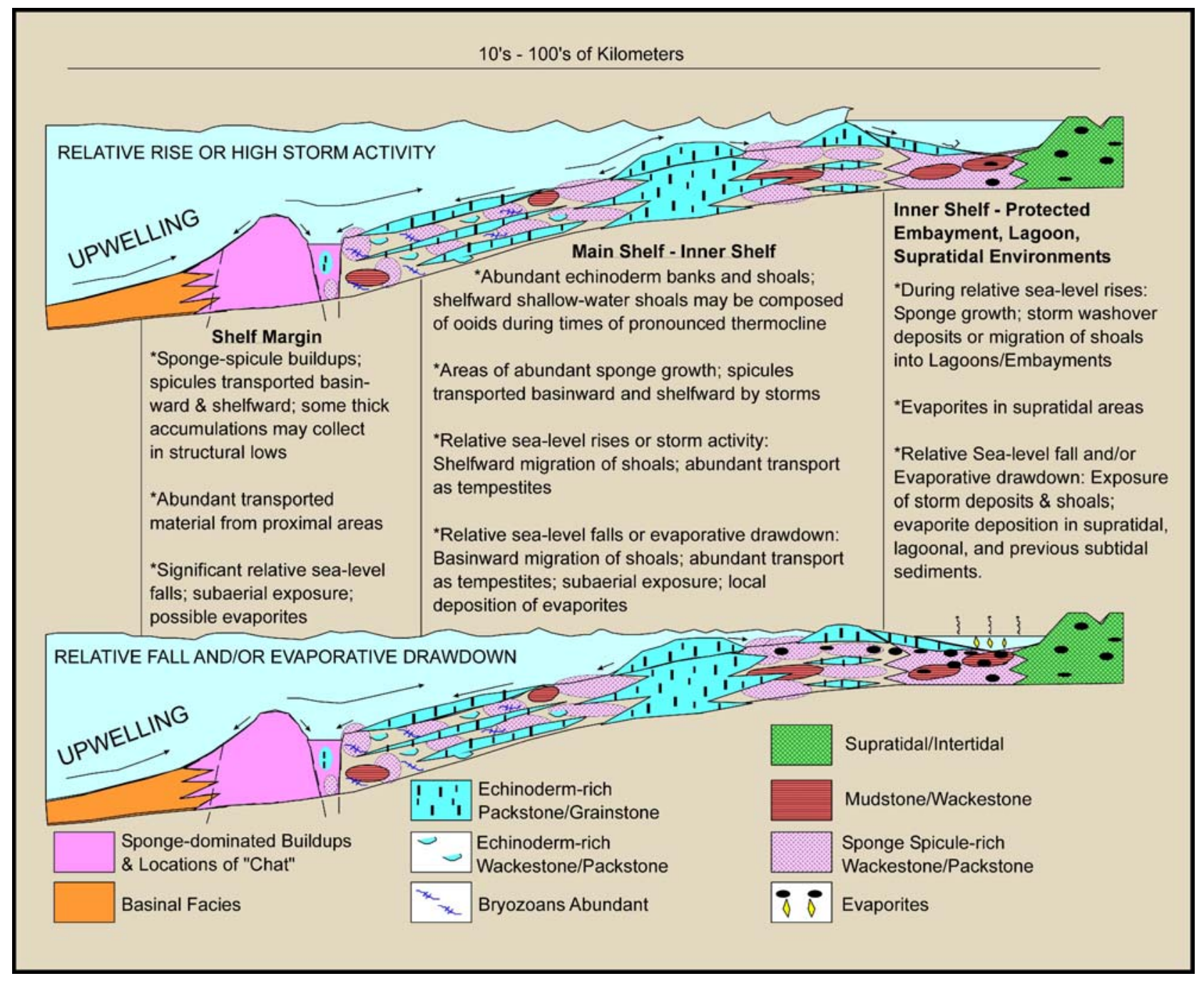

Figure 4.5: Interpreted regional ramp setting for deposition of Mississippian reservoir rocks. (Byrnes, 2003) 


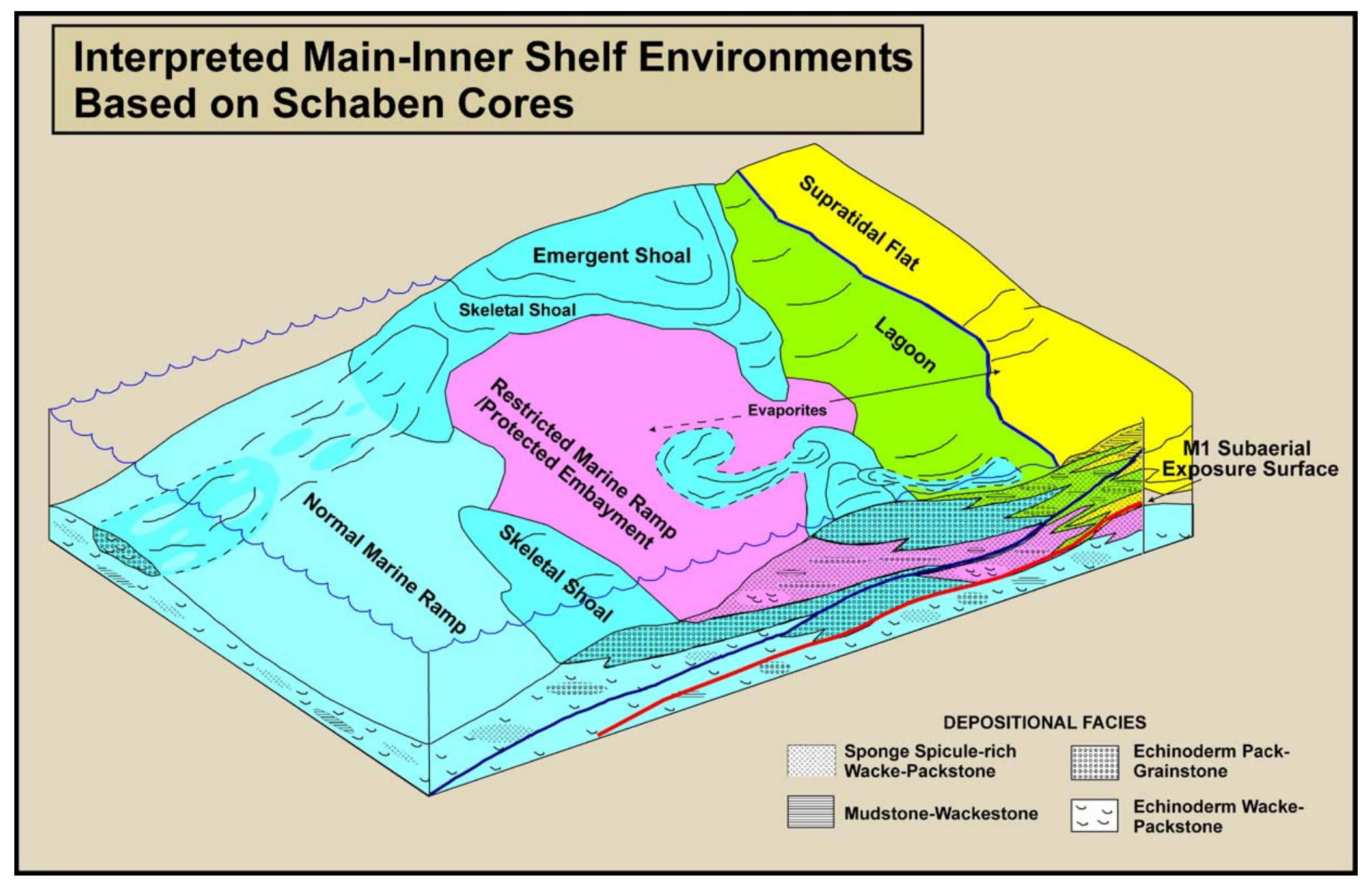

Figure 4.6: Interpreted main-inner shelf environments for Mississippian Osagian-Meramecian deposition based on Schaben field cores. (Byrnes, 2003) 


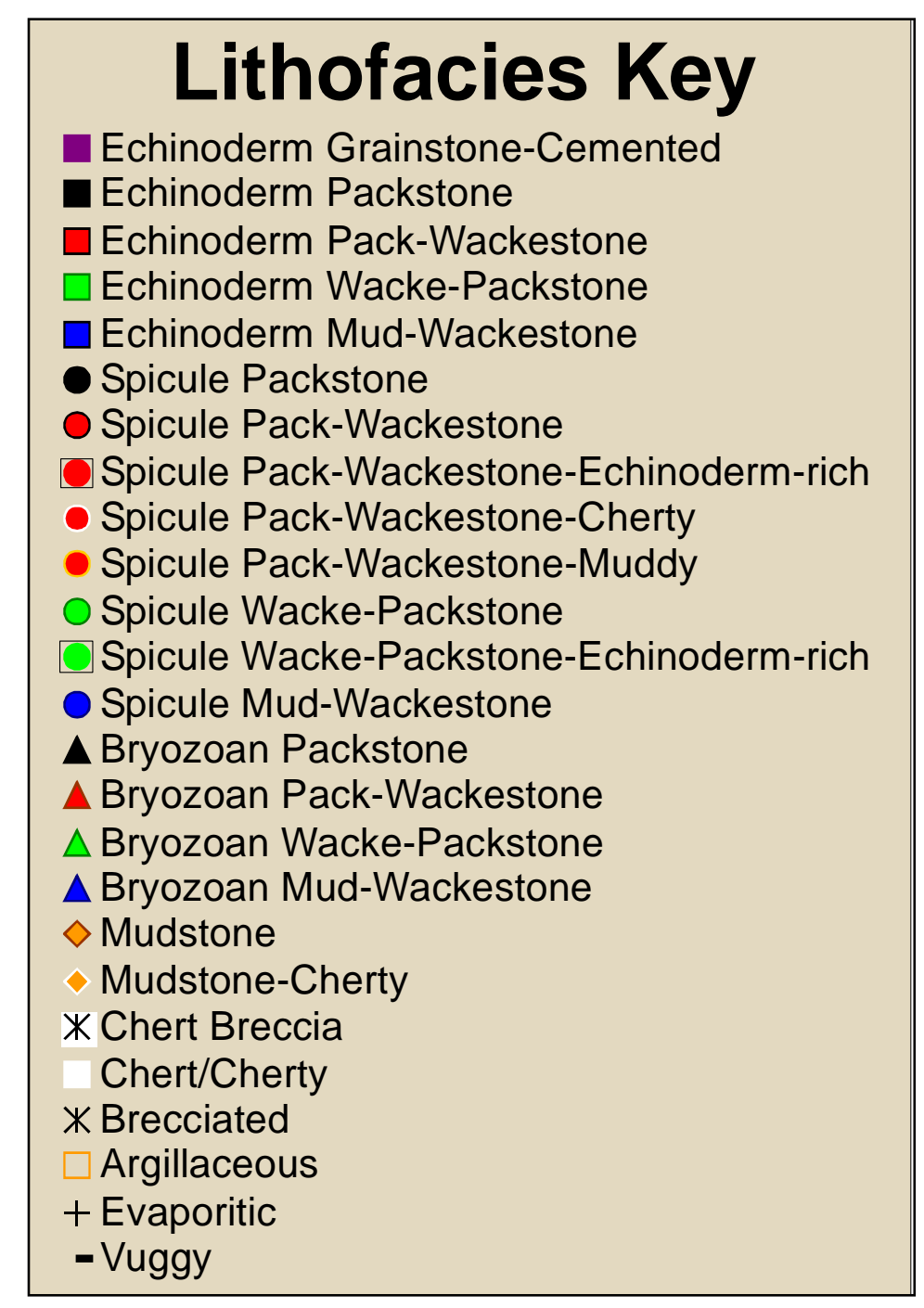

Figure 4.7: Listing of important lithofacies present in all Mississippian reservoirs and symbols used in permeability-porosity figures. 


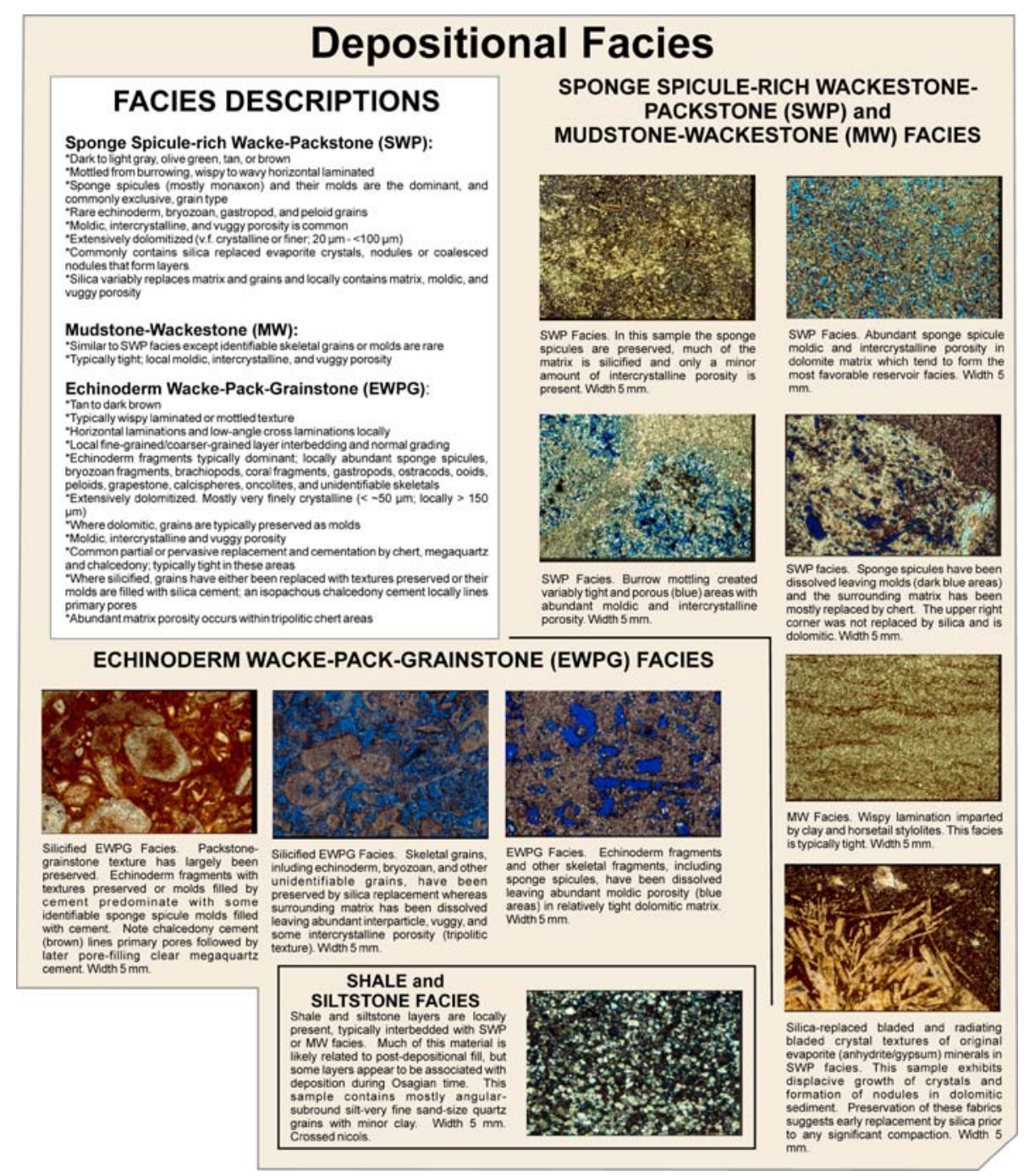

Figure 4.8: Thin-section photomicrographs of important lithofacies in the Schaben Field. (Byrnes, 2003) 


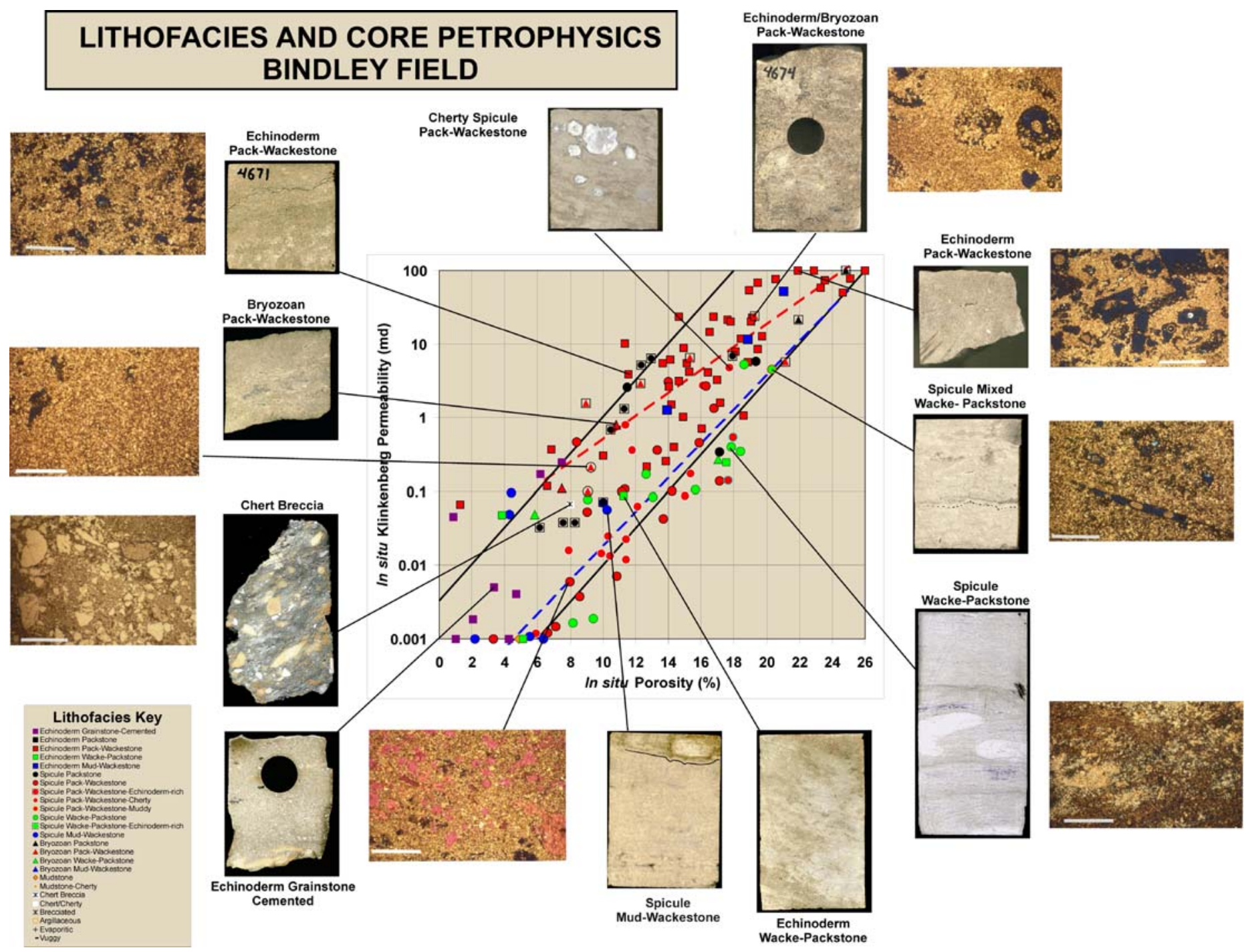

Figure 4.9: Permeability-porosity relationship for Mississippian rocks in Bindley Field showing major lithofacies in both core and thin-section photomicrgraphs. 

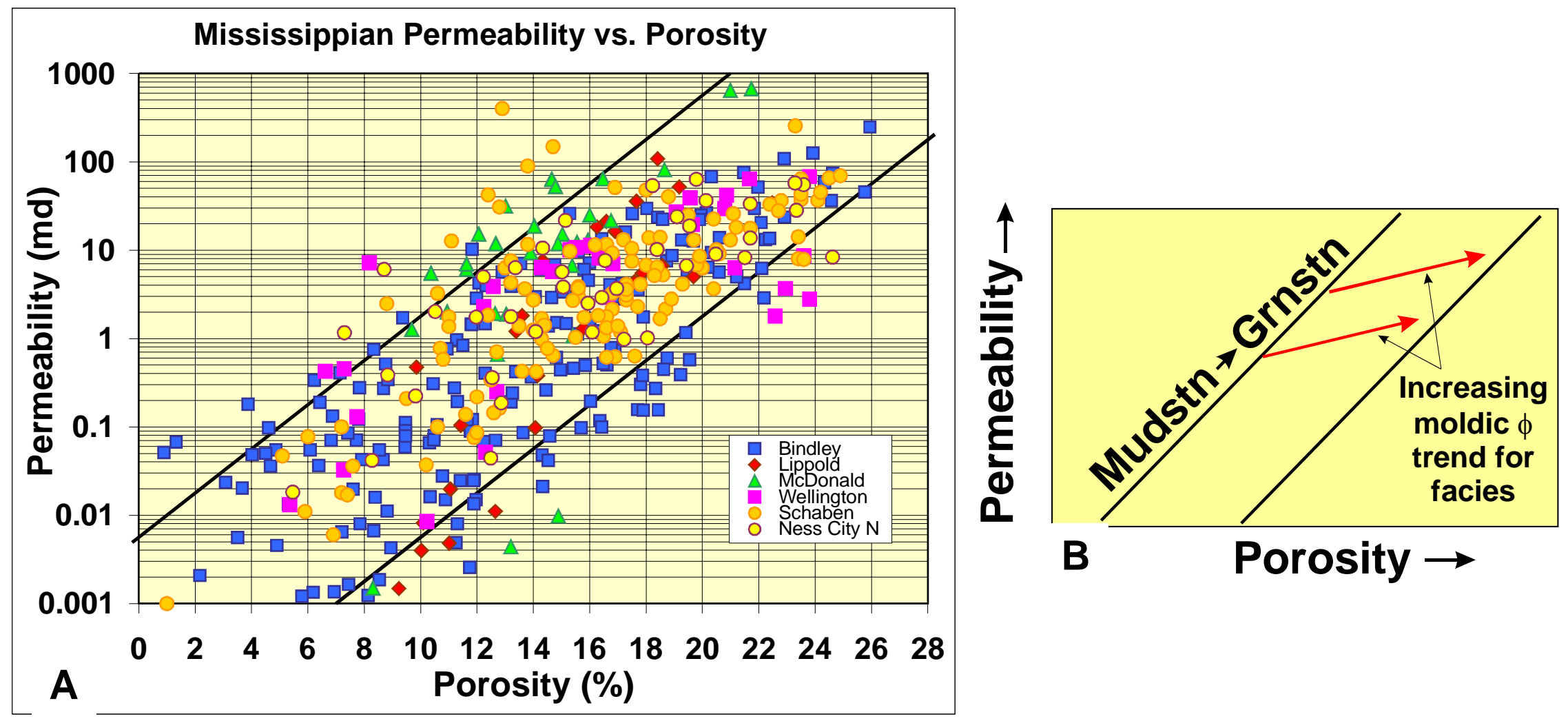

Figure 4.10: Comparison of permeability-porosity data for various Mississippian fields showing bounding trend lines (A) and generalized trend (B) showing increase in permeability with facies change from mudstone to grainstone. Within any given lithofacies, increases in porosity and increases in moldic porosity (red arrows) exert minor influence on increases in permeability. 


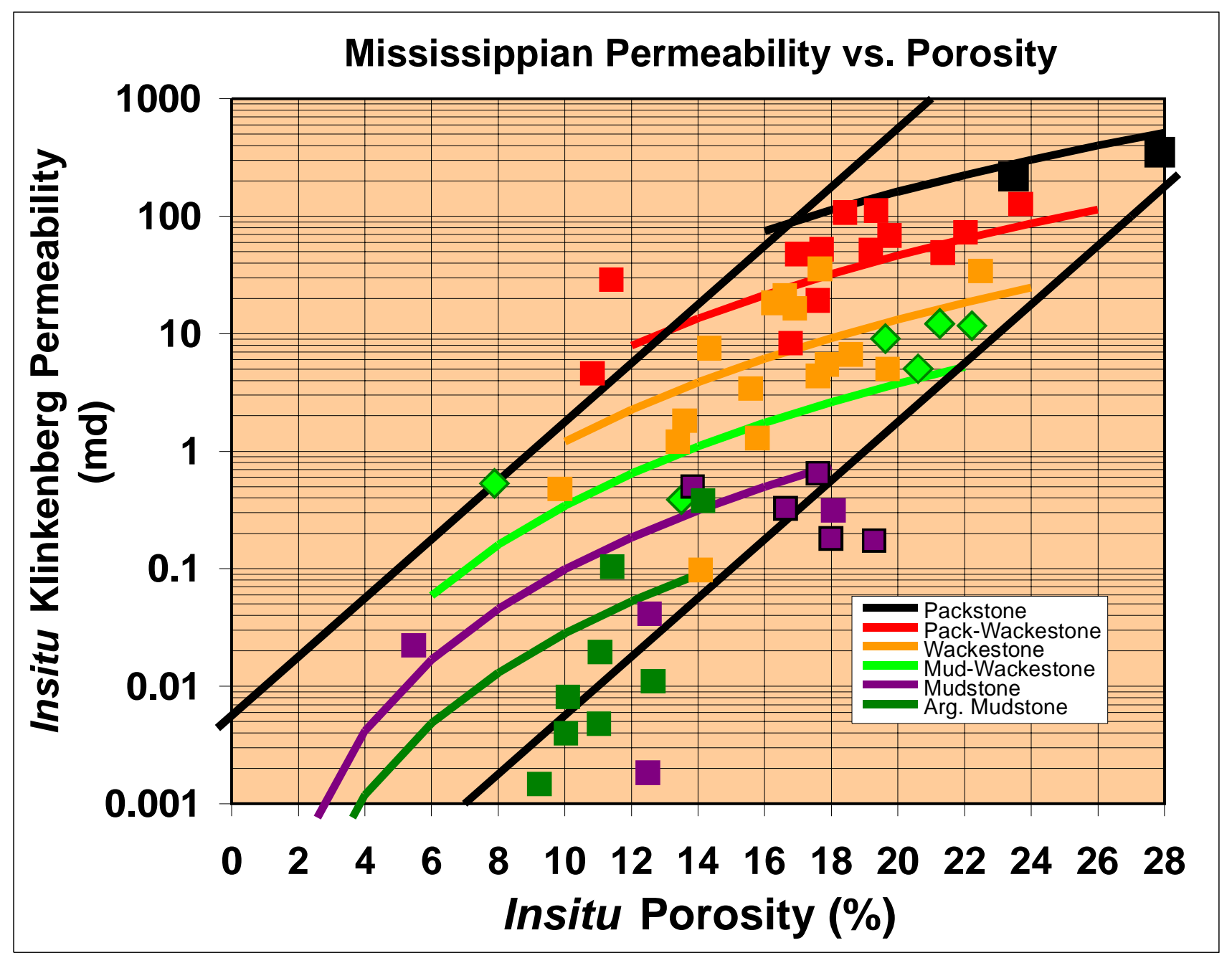

Figure 4.11: Generalized permeability-porosity trends for different lithofacies of Mississippian reservoir rocks. Trend line for each facies represents power-law function and is not log-linear relationship. Trend lines represent equations presented in text. 


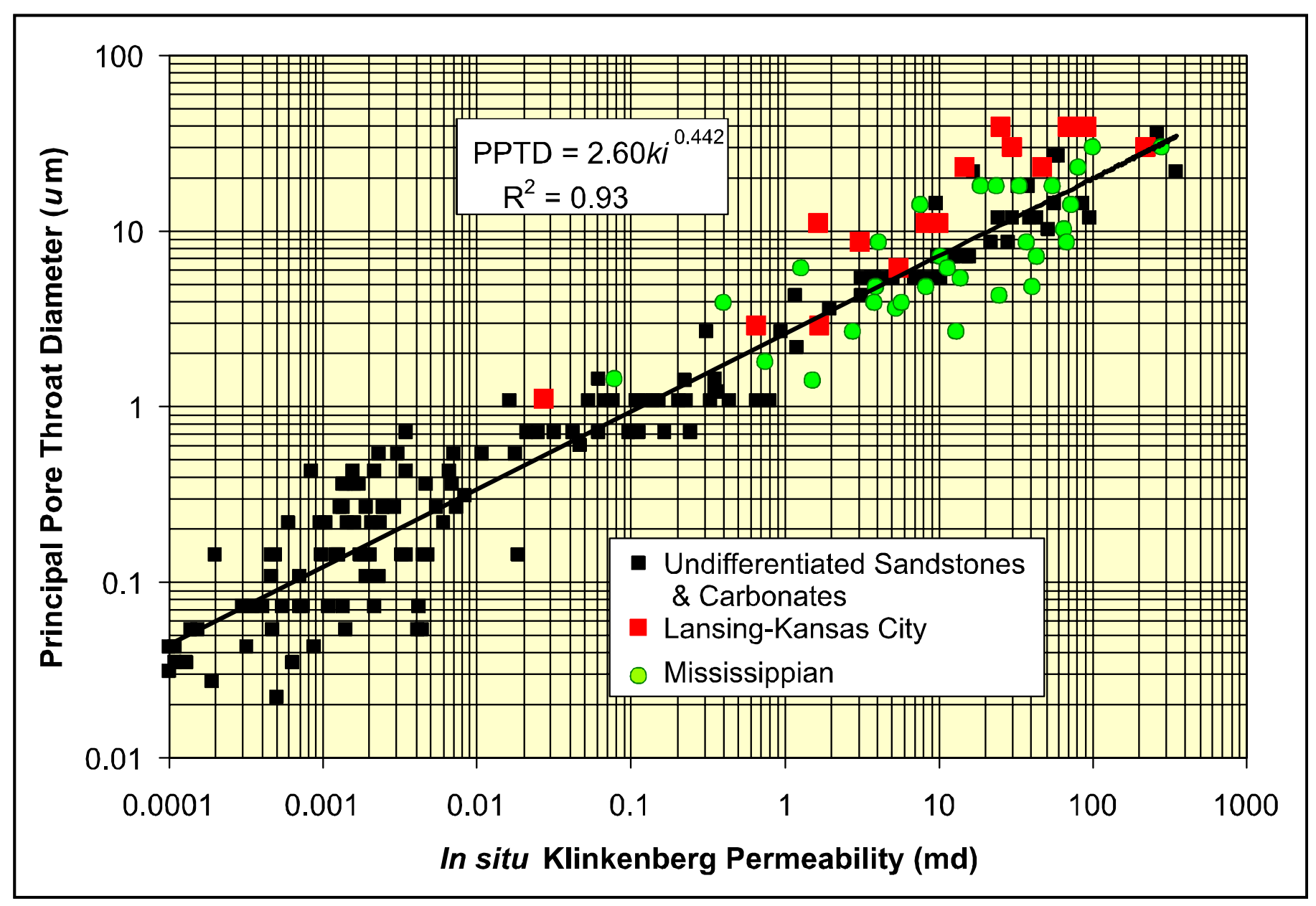

Figure 4.12: Crossplot of principal pore throat diameter versus permeability for undifferentiated sandstones and carbonates and differentiated Lansing-Kansas City and Mississippian moldic carbonates. The similarity of correlation shows the controlling influence of matrix pore throat size in the moldic carbonates. (Byrnes, 2003) 


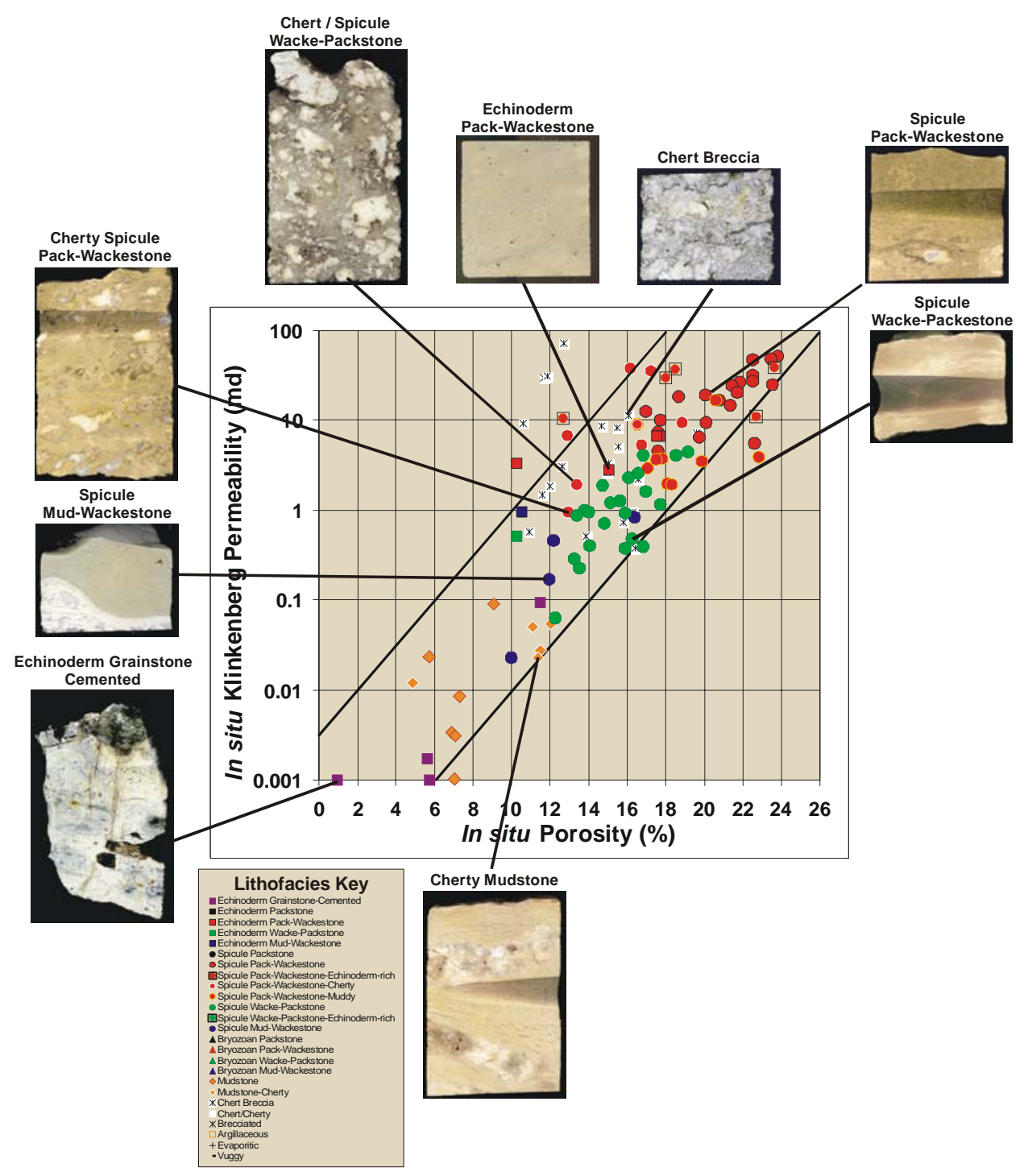

Figure 4.13: Permeability versus porosity crossplot for Schaben Field Mississippian reservoir rocks showing relationship between lithofaceis and $\mathrm{k}-\phi$ trend. 


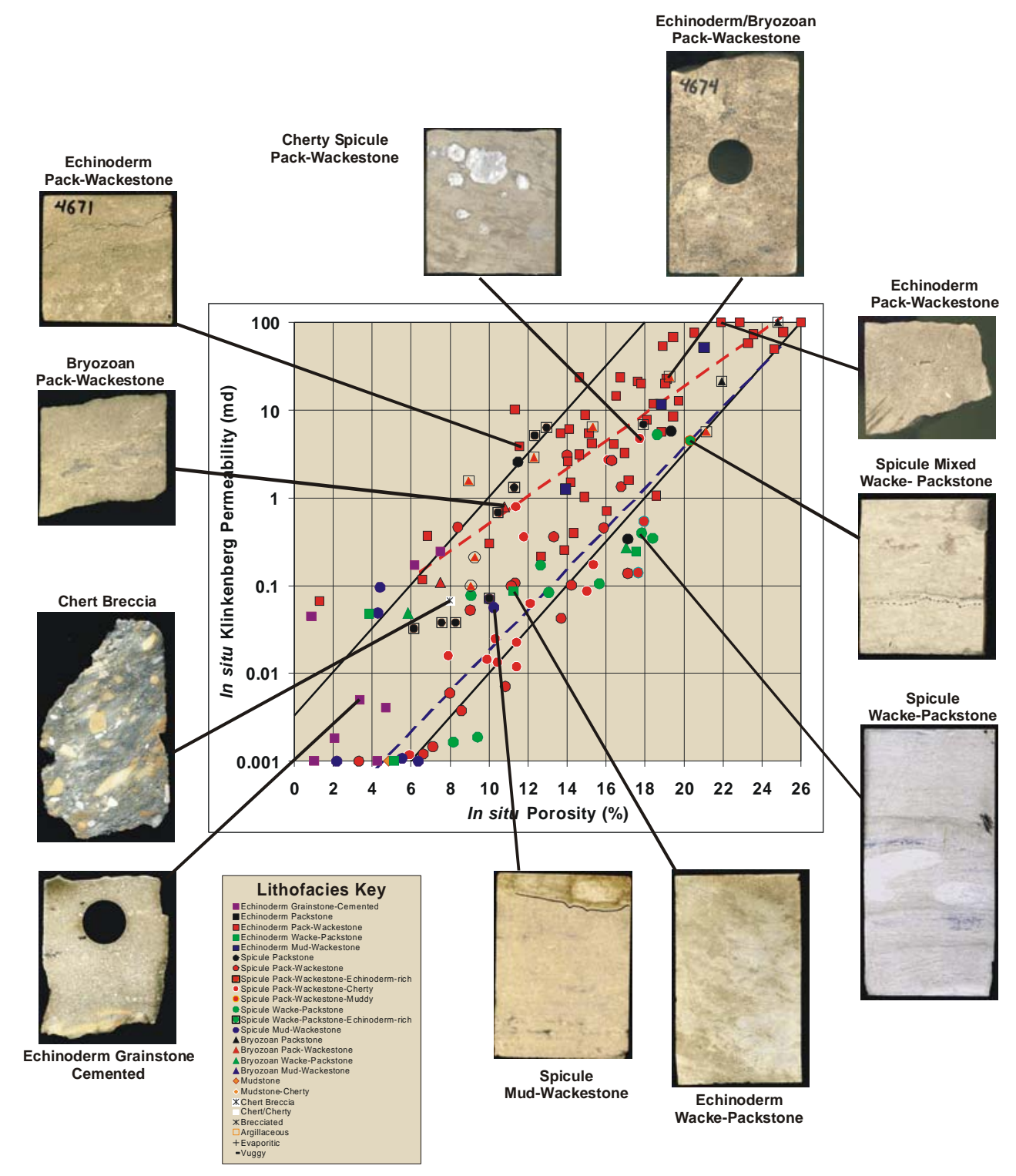

Figure 4.14: Permeability versus porosity crossplot for Bindley Field Mississippian reservoir rocks showing relationship between lithofacies and $\mathrm{k}-\phi$ trend. 


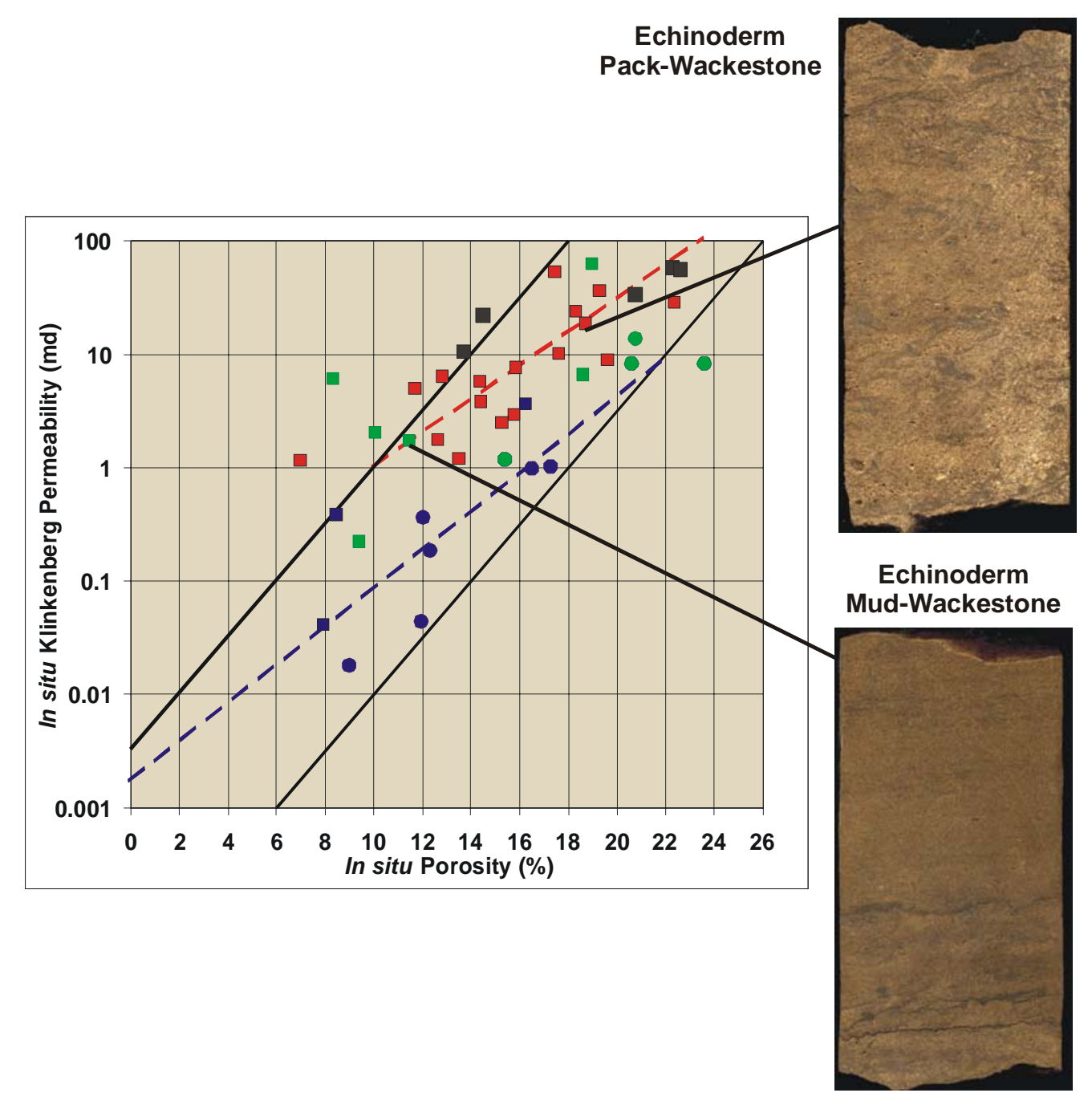

Figure 4.15: Permeability versus porosity crossplot for Ness City Field Mississippian reservoir rocks showing relationship between lithofacies and $k-\phi$ trend. 


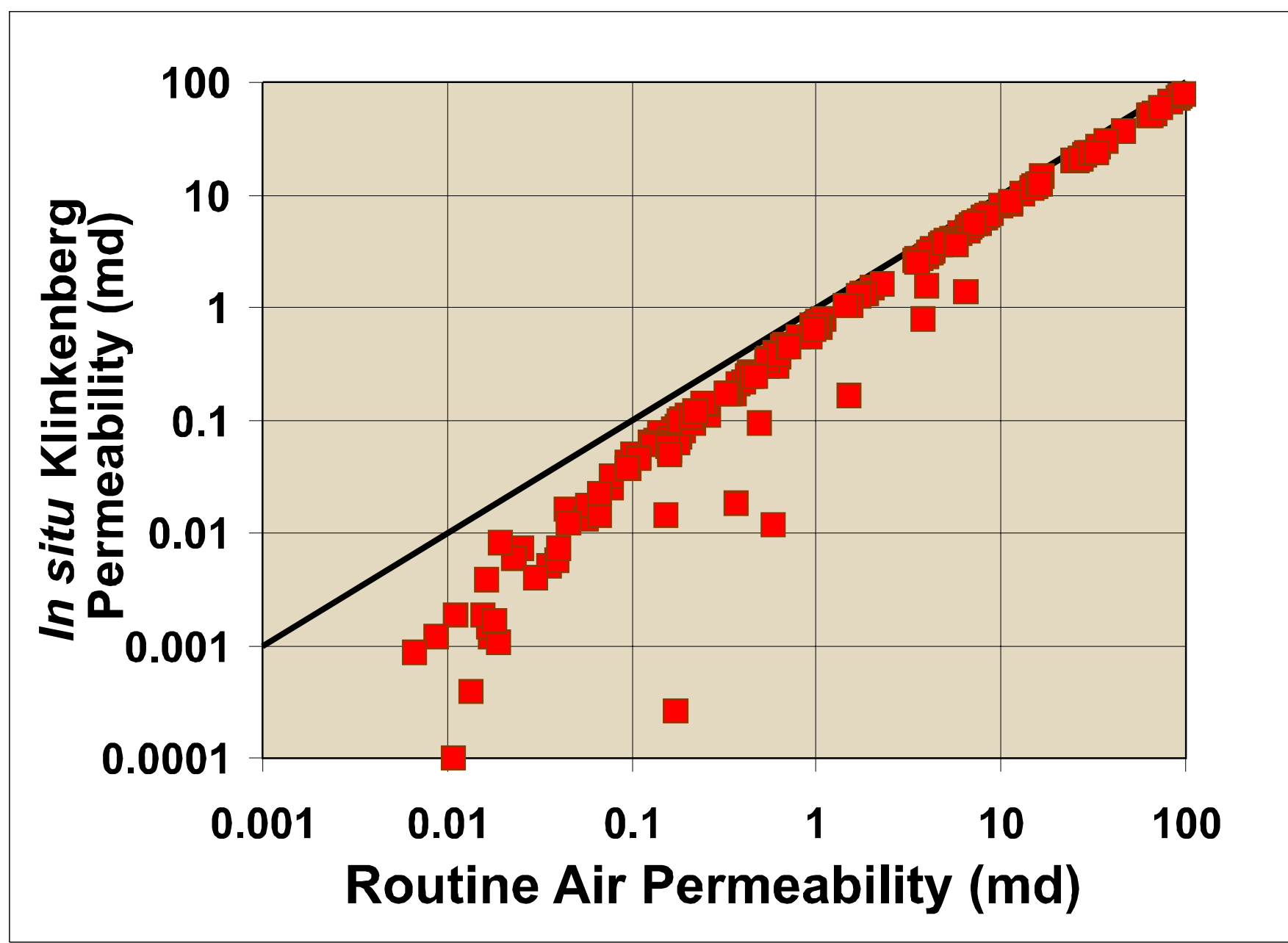

Figure 4.16: Crossplot of in situ Klinkenberg permeability versus routine air permeability for Mississippian reservoir rocks. 


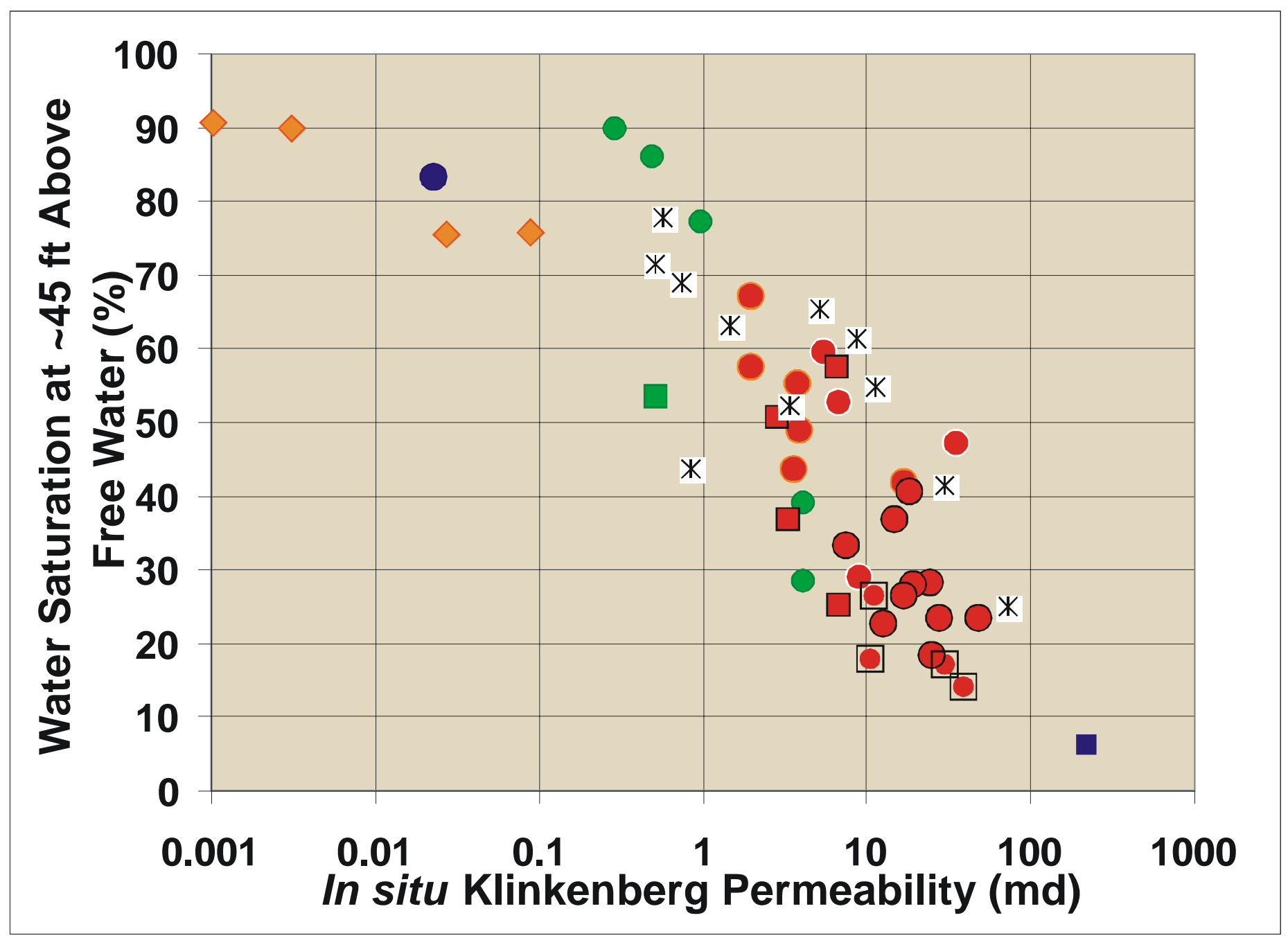

Figure 4.17: Crossplot of water saturation at 45 feet above free water level, determined by air-brine capillary pressure, versus permeability for various lithofacies in the Schaben Field. Lithofacies symbol key is presented in Figure 4.7. 

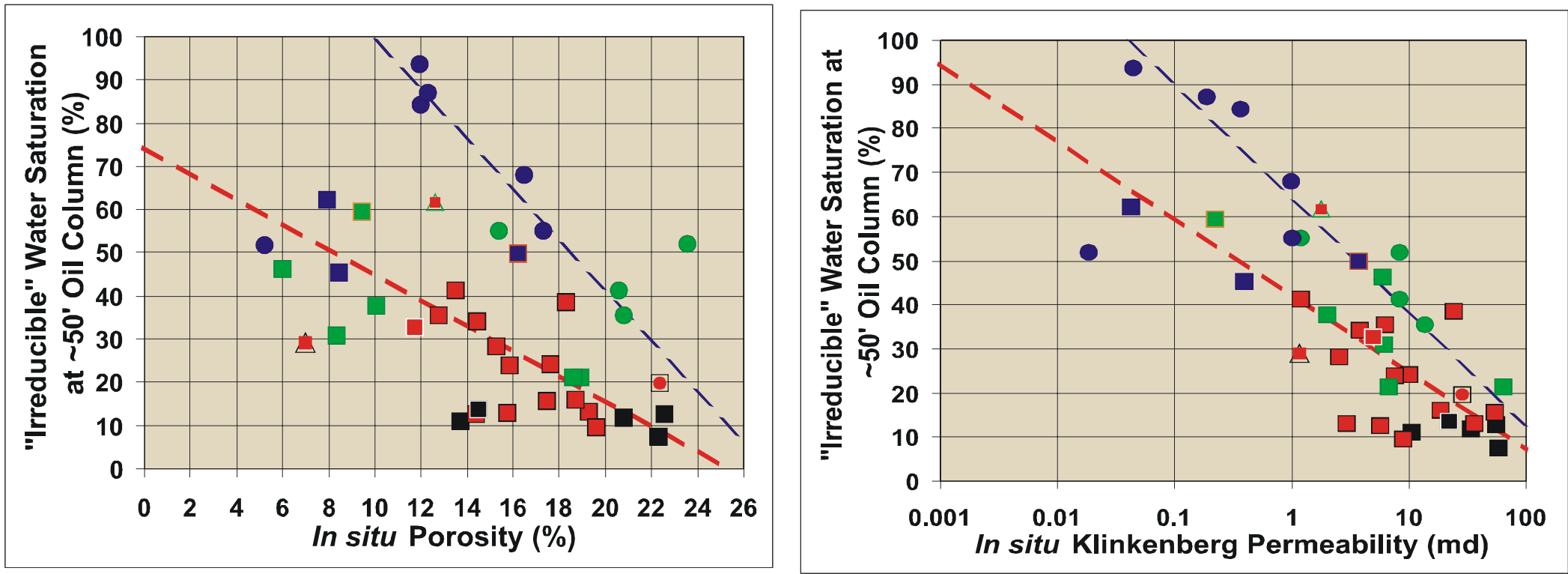

Figure 4.18: Water saturations at $50 \mathrm{ft}$ above free water level for various lithofacies in Ness City Field versus porosity and permeability. Lithofacies symbol key is presented in Fig. 4.7. Equations for lines are presented in text. 


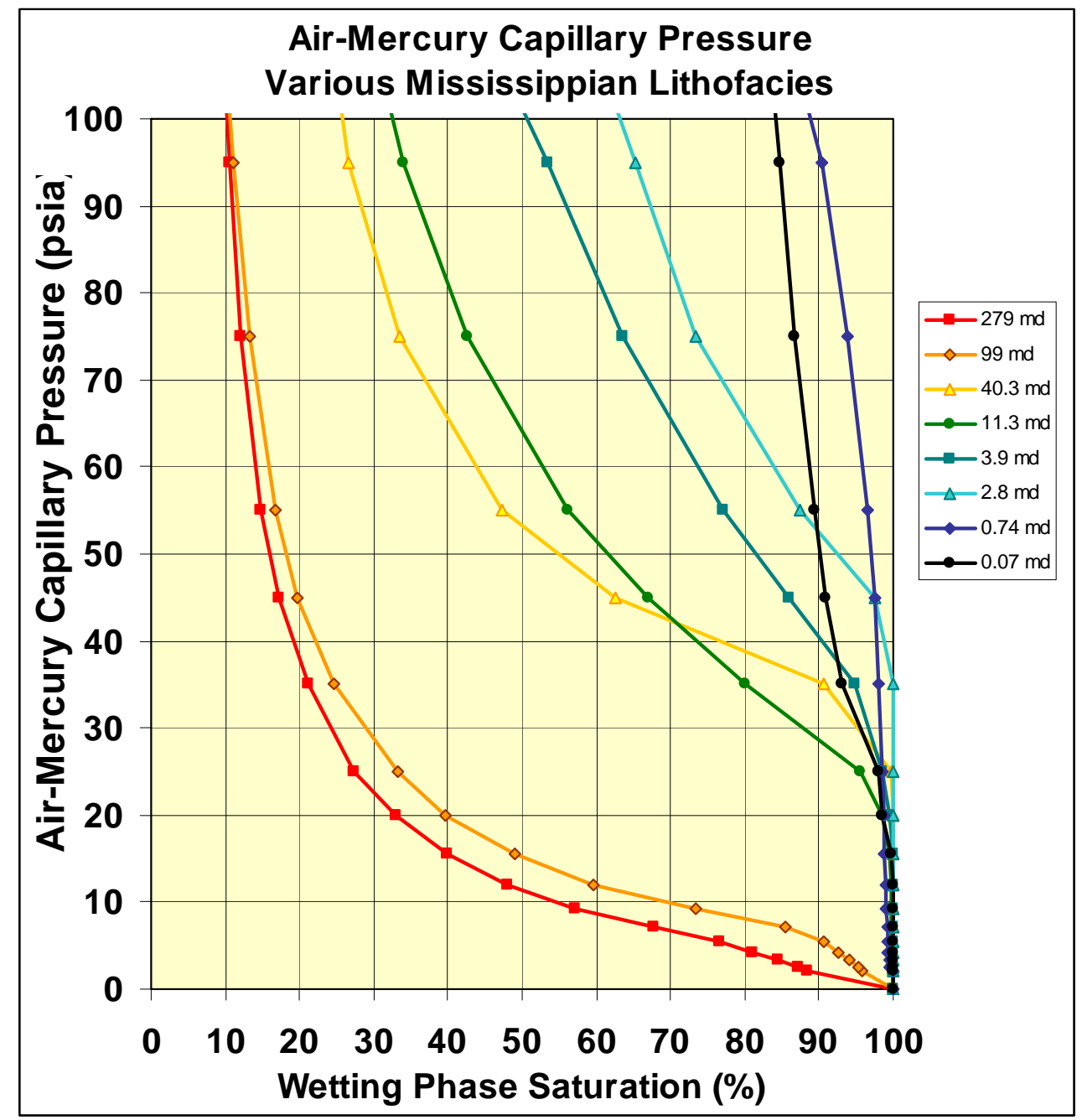

Figure 4.19: Selected capillary pressure curves for various lithofacies showing commonly observed shift to higher capillary pressures and water saturations with decreasing permeability. 


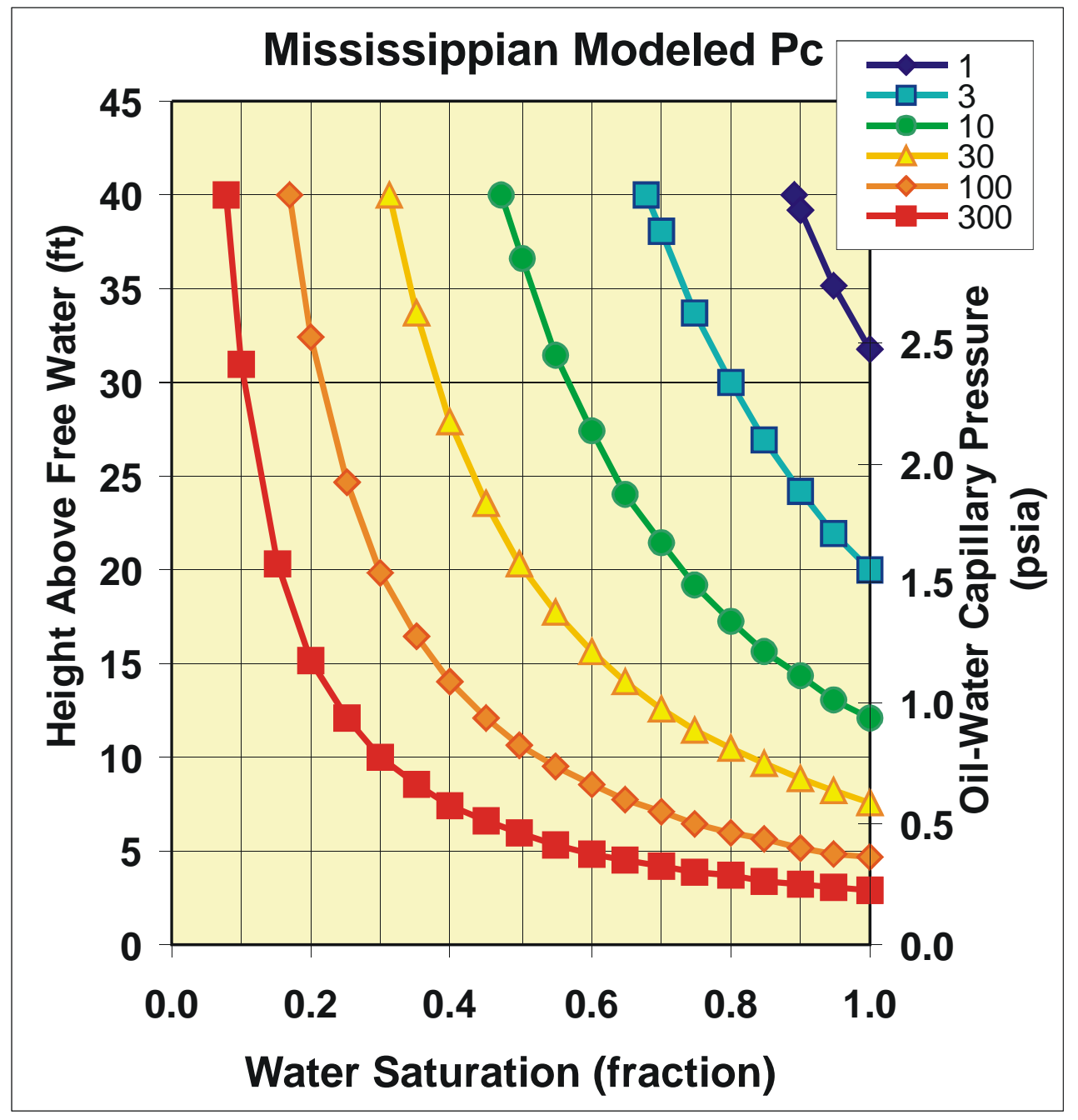

Figure 4.20: Generalized capillary pressure curves for Mississippian rocks of various permeabilities. 


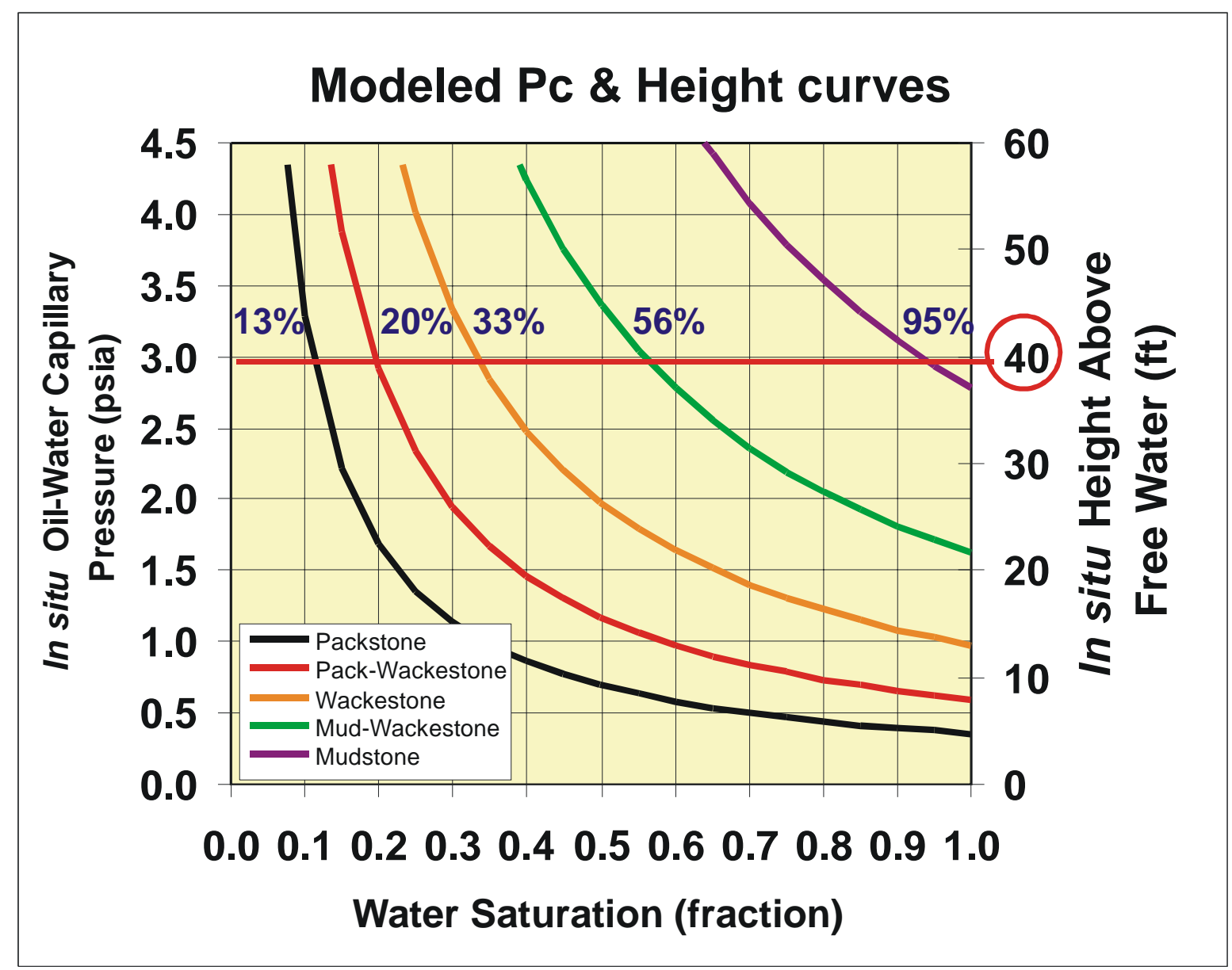

Figure 4.21: Example of how capillary pressure curves change for an 18\% porosity rock from different lithofacies. Shifts in the curves reflect change in permeability and pore throat sizes with lithofacies. The significant difference between water saturations, at typical hydrocarbon column heights, read from these curves illustrates the importance of having lithologic information to predict petrophysical properties. 


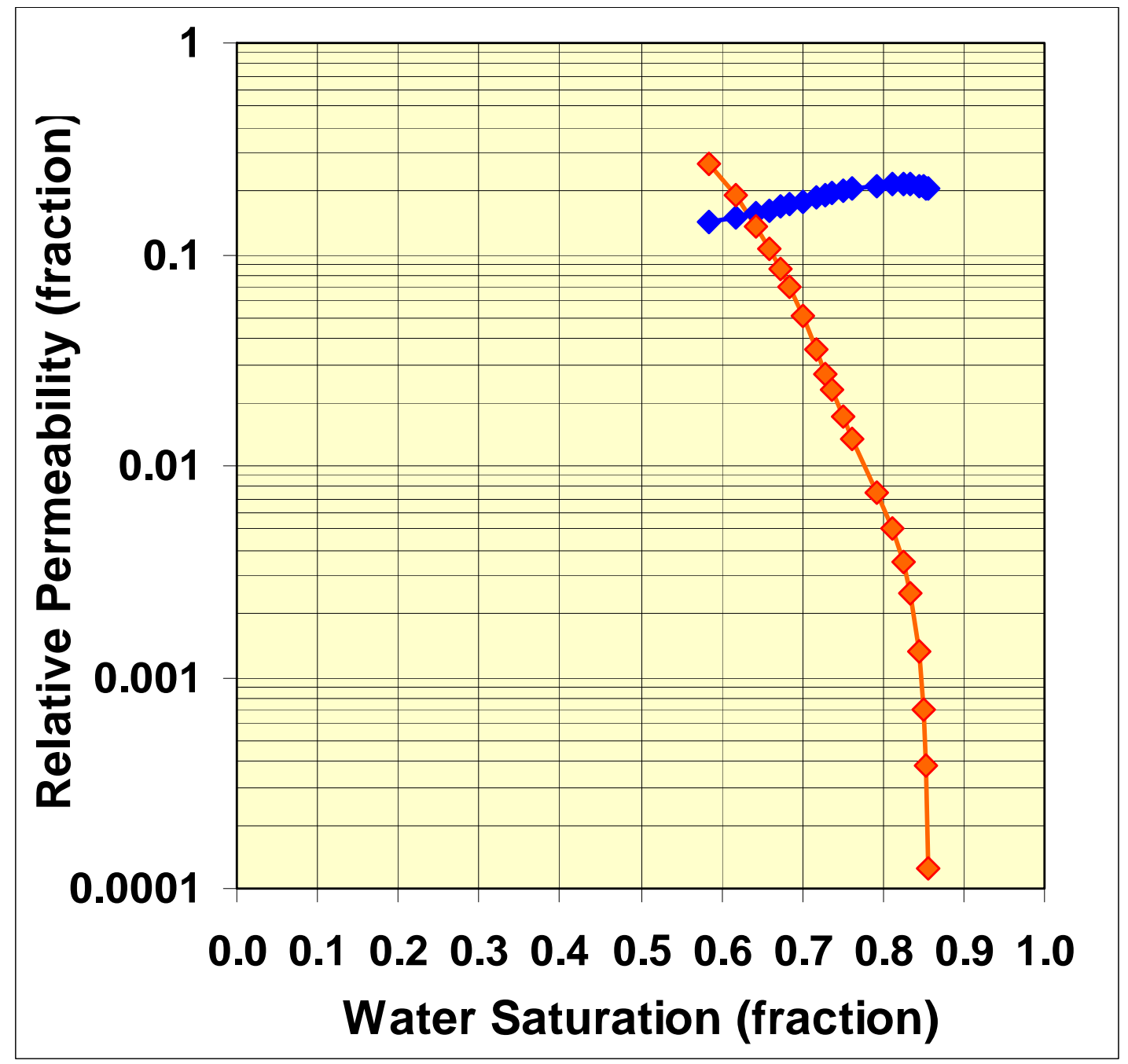

Figure 4.22: Imbibition oil-water relative permeability measured on core sample (from 4450 feet) at the Beardmore Clifton \#1 well, Lippoldt Field, Section 1, T23S R23W, Hodgeman County, KS. Data are presented in Table 4.3. 


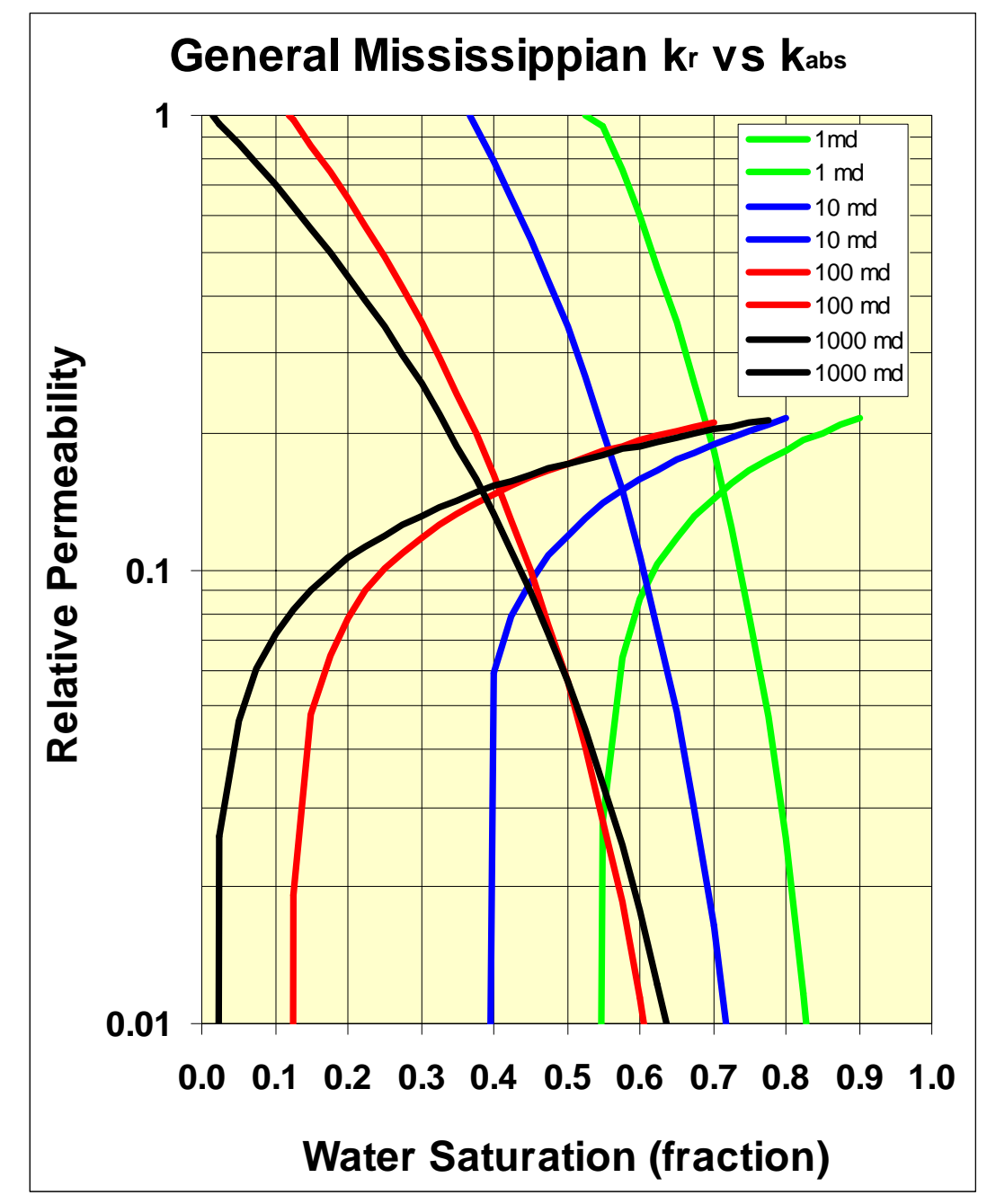

Figure 4.23: Generalized oil-water imbibition relative permeability curves for Mississippian reservoir rocks constructed utilizing Swi values from air-brine capillary pressure measurements, curve shapes from measured relative permeability, and Sorw measured on multiple cores. 


\section{Calculator for Capillary Pressure and Relative Permeability}

\begin{tabular}{|c|c|c|c|c|c|c|}
\hline$K(m d)=$ & 10.00 & Phi(\%)= & 15.42 & & & \\
\hline Krwmax= & 0.22 & Kromax $=$ & & Pcentry= & 0.943 & \\
\hline Krw -m= & 0.5 & Swi $=$ & 0.223 & Pcs $=$ & -1.019 & \\
\hline Kro - n= & 3.1 & Sorw $=$ & 0.277 & PcSwiH(ft)= & 60.0 & \\
\hline water grad & 0.438 & W sp grav= & 1.0111 & input value & & \\
\hline oil grad & 0.365 & Oil sp grav= & 0.8439 & calc value & & \\
\hline Krgmax= & & Kromax = & & & & \\
\hline $\mathrm{Krg}-\mathrm{m}=$ & & Sgc for kro= & & Sgc for krg= & & \\
\hline Kro $-n=$ & & Sorg for kro= & & Sorg for $\mathrm{krg}=$ & & \\
\hline IFTgo/IFTow= & & Sorg for kro= & & & & \\
\hline & & & & & Height above & \\
\hline SW & KRW & KROW & PCOW & & free water (ft) & SwD \\
\hline 0.2232 & 0.000000 & 1.000000 & 4.344 & & 60.00 & 0.00000 \\
\hline 0.2500 & 0.050929 & 0.843035 & 3.870 & & 53.46 & 0.05359 \\
\hline 0.3000 & 0.086219 & 0.596348 & 3.214 & & 44.40 & 0.15359 \\
\hline 0.3500 & 0.110787 & 0.403859 & 2.747 & & 37.94 & 0.25359 \\
\hline 0.4000 & 0.130820 & 0.258568 & 2.398 & & 33.12 & 0.35359 \\
\hline 0.4500 & 0.148168 & 0.153570 & 2.127 & & 29.38 & 0.45359 \\
\hline 0.5000 & 0.163688 & 0.082068 & 1.910 & & 26.39 & 0.55359 \\
\hline 0.5500 & 0.177859 & 0.037388 & 1.734 & & 23.94 & 0.65359 \\
\hline 0.6000 & 0.190981 & 0.013006 & 1.587 & & 21.91 & 0.75359 \\
\hline 0.6500 & 0.203258 & 0.002590 & 1.462 & & 20.20 & 0.85359 \\
\hline 0.7000 & 0.214834 & 0.000074 & 1.356 & & 18.73 & 0.95359 \\
\hline 0.7500 & 0.220000 & 0.000000 & 1.264 & & 17.46 & 1.00000 \\
\hline 0.8000 & 0.220000 & 0.000000 & 1.184 & & 16.35 & 1.00000 \\
\hline 0.8500 & 0.220000 & 0.000000 & 1.113 & & 15.37 & 1.00000 \\
\hline 0.9000 & 0.220000 & 0.000000 & 1.050 & & 14.50 & 1.00000 \\
\hline 0.9500 & 0.220000 & 0.000000 & 0.993 & & 13.72 & 1.00000 \\
\hline 1.0000 & 0.220000 & 0.000000 & 0.943 & & 13.02 & 1.00000 \\
\hline 1.0000 & 0.220000 & 0.000000 & 0.943 & & 13.02 & 1.00000 \\
\hline 1.0000 & 0.220000 & 0.000000 & 0.943 & & 13.02 & 1.00000 \\
\hline 1.0000 & 0.220000 & 0.000000 & 0.943 & & 13.02 & 1.00000 \\
\hline 1.0000 & 0.220000 & 0.000000 & 0.943 & & 13.02 & 1.00000 \\
\hline
\end{tabular}

Figure 4.24: Example Mississippian capillary pressure/relative permeability Excel spreadsheet calculator used to calculate synthetic capillary pressure and relative permeability curves for any given permeability with input of lithofacies code and porosity. This tool was used to provide input to reservoir simulations. 


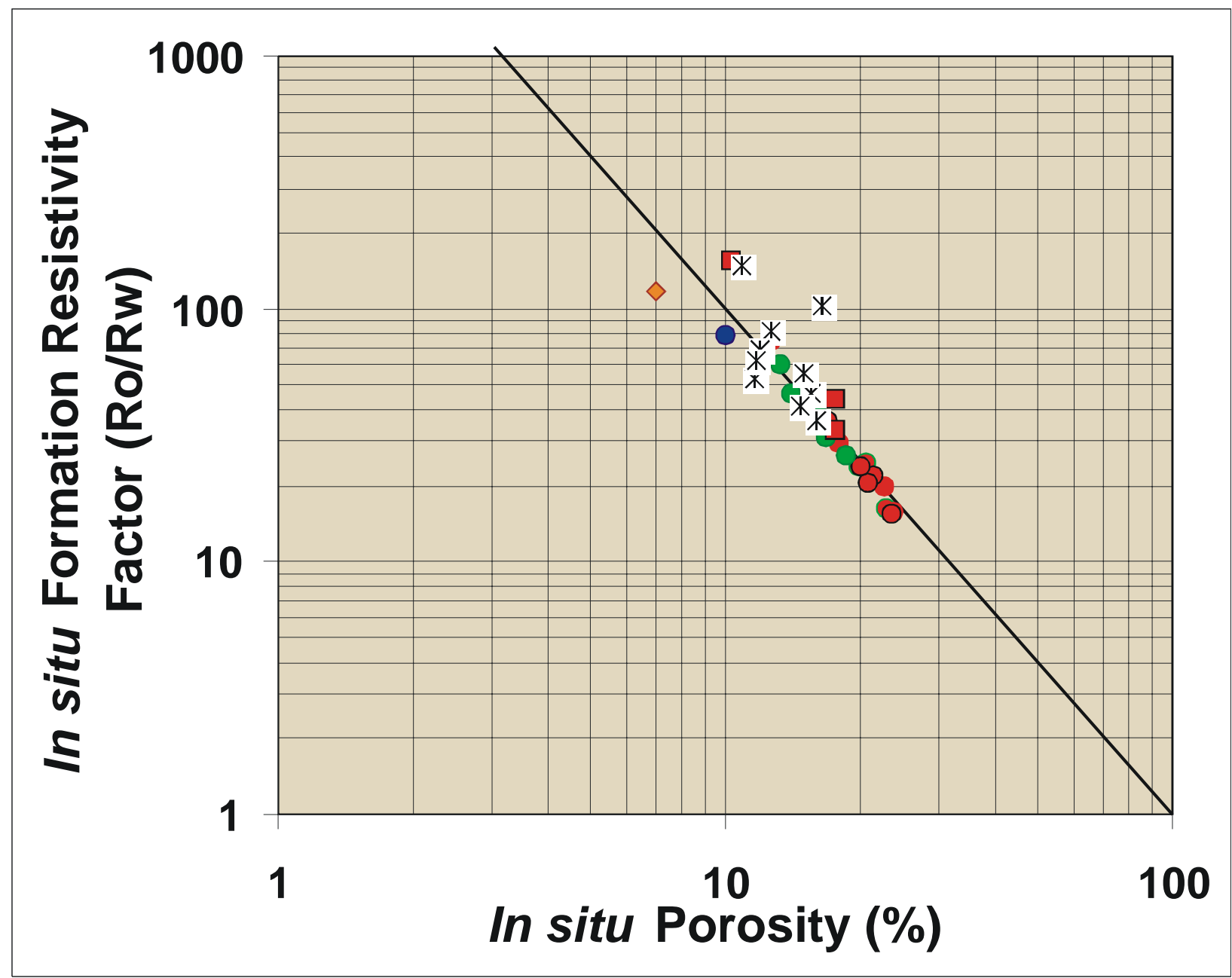

Figure 4.25: Crossplot of in situ formation resistivity factor and in situ porosity for samples of various lithofacies from Schaben Field. Line shows trend for Archie cementation exponent $m=2.0$. Data exhibit average $m=1.97 \pm 0.09$ for all facies. 
Table 4.1

Summary of KGS Mississippian Cores in the Study Area Region

\begin{tabular}{|c|c|c|c|c|c|c|c|c|}
\hline OPERATOR_NAME & LEASE_NAME & Well\# Twn & Rng & $\sec 1$ & SPOT & COUNTY & TOPT: & BTM \\
\hline EXETER & BOYD & \begin{tabular}{l|l|l}
$6-23$ & $16 \mathrm{~S}$ & 2 \\
\end{tabular} & $26 \mathrm{~W}$ & 23 & SE-SE-NW & & & \\
\hline WALTERS DRLG. & TILLEY & $17 \mathrm{~s} 2$ & $24 \mathrm{~W}$ & 8 & SE-SW- & Ness & \begin{tabular}{|c|c|c|}
$\mid 4446$ & 2
\end{tabular} & 446 \\
\hline WALTERS DRLG. & KLITZKE & $1|17 \mathrm{~s}|_{2}^{2}$ & $24 \mathrm{~W}$ & 12 & C-SE-SE & Ness & 4483 & 4496 \\
\hline WALTERS DRLG. & LYNCH & $1|17 \mathrm{~S}| 2$ & $24 \mathrm{~W}$ & 13 & C-NE-NE & Ness & $4475 \mid 2$ & 4495 \\
\hline ANADARKO & WEGELE A & $1|18 \mathrm{~s}| 2$ & $22 \mathrm{w}$ & 21 & C-SE- & Ness & $|4298|$ & 4316 \\
\hline MOBIL & ELSASSER HRS & $118 \mathrm{~s} 2$ & $22 \mathrm{w}$ & 29 & C-SE-SW & Ness & 4321 & 4351 \\
\hline ANADARKO & ENDICOTT A & $118 \mathrm{~s} 2$ & $23 \mathrm{w}$ & 13 & SW-SE-SE & Ness & 4310 & 4324 \\
\hline SUN & UMMEL & $1|18 \mathrm{~s}| 2$ & $24 \mathrm{~W}$ & 23 & C-SE-NE & Ness & 4290 & 4298 \\
\hline SUN & PFANNENSTIEL & $18 \mathrm{~s} 2$ & $24 \mathrm{~W}$ & $24 \mid$ & SE-SW- & Ness & 4265 & 428 \\
\hline SUN & PFANNENSTIEL & $2|18 \mathrm{~s}| 2$ & $24 \mathrm{~W}$ & 24 & C-NW-SW & Ness & $|4266|$ & 429 \\
\hline WALTERS DRLG. & MAIER & $1 \mid 18 \mathrm{~s} 2$ & $24 \mathrm{~W}$ & 25 & C-SW-SW & Ness & \begin{tabular}{|c|c|}
4252 & 2
\end{tabular} & \\
\hline KERN LANDES & STIEBEN & $1 \mid 19 \mathrm{~s} / 2$ & $21 \mathrm{w}$ & 17 & NE-SW- & Ness & 4343 & 4354 \\
\hline RITCHIE EXPLORATION & REIN A-P & $19 \mathrm{~S}$ & $21 \mathrm{w}$ & 29 & & Ness & 85 & [1309] \\
\hline CITIES SERVICE & MOORE C & $119 \mathrm{~s} 2$ & $21 \mathrm{w}$ & 30 & C-SE-SW & Ness & 423 & 44 \\
\hline RITCHIE EXPLORAT & MOORE D-P & $6|19 s|_{2}^{2}$ & $21 \mathrm{~W}$ & 30 & & Ness & $|4354|$ & 43 \\
\hline RITCHIE EXPLORA & MOORE BP TWIN & $4|19 s| 2$ & $21 \mathrm{w}$ & 30 & & Ness & $|4370|$ & 4450 \\
\hline RITCHIE EXPLORAT & MOORE C-P & $4 \mid 19 \mathrm{~S}$ & $21 \mathrm{w}$ & 30 & & Ness & 4421 & 4435 \\
\hline CITIES SERVICE & FOOS A & $1 \mid 19 \mathrm{~s} / 2$ & $21 \mathrm{w}$ & 31 & C-SW-SW & Ness & 4401 & 4413 \\
\hline EXPLOR & FOOS AP TWIN & $19 \mathrm{~s} 2$ & $21 \mathrm{w}$ & 31 & & Ness & $387 \mid$ & 1440 \\
\hline RITCHIE EXPLORA & LYLE SCHABEN "P" & $19 \mathrm{~s}$ & $21 \mathrm{w}$ & 31 & & Ness & 382 & 446 \\
\hline KERN LANDES & MOORE & $1|19 \mathrm{~s}|_{2}^{2}$ & $21 \mathrm{w}$ & 34 & C-NW-NW & Ness & $|4421| 2$ & \\
\hline RITCHIE EXP. & HUMBERG AP\#3 & $19 \mathrm{~s} 2$ & $22 \mathrm{w}$ & 25 & & Ness & $\mid 4376$ & 4385 \\
\hline CITIES SERVICE & HUMBURG A & $219 \mathrm{~s}$ & $22 \mathrm{~W}$ & 25 & C-SE-SE & Ness & 4389 & 4409 \\
\hline$D_{-1}$ & ATENEN & $119 \mathrm{~s} 2$ & $24 \mathrm{~W}$ & & C-NE-NE & Ness & \begin{tabular}{|c|}
4393 \\
\end{tabular} & 4414 \\
\hline DX & BO & $19 \mathrm{~s} 2$ & $25 \mathrm{w}$ & 12 & C-NW-NE & Ness & 16 & 444 \\
\hline RITCHIE EXPLOR & HUMBURG AP & $3 \mid 19 \mathrm{~s}$ & $25 \mathrm{w}$ & 25 & & Ness & 4373 & 438 \\
\hline MOBIL & H. MOORE A & $120 \mathrm{~s} / 2$ & $21 \mathrm{w}$ & 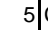 & C-NE-SW & Ness & $|4420|$ & 442 \\
\hline CITIES SERVICE & ANTENEN A & $120 \mathrm{~s} 2$ & $21 \mathrm{w}$ & 6 & C-NE-SE & Ness & 4384 & 43 \\
\hline CITIES SERVICE & O'BRIEN A & $20 \mathrm{~s} 2$ & $21 \mathrm{w}$ & & C-SE-NW & Ness & 4355 & \\
\hline & M.S & & $22 \mathrm{w}$ & 12 & C-NW-NE & Ness & 4366 & 4384 \\
\hline $\mathrm{M}$ & $\mathrm{SCH}$ & $20 \mathrm{~s} 2$ & $22 \mathrm{w}$ & 12 & C-SE-NE & Ness & 333 & 4371 \\
\hline MIDCONTINENT & J.G.COLLINS & $20 \mathrm{~s} 2$ & $26 \mathrm{~W}$ & $24 \mid$ & NW-NW-NW & Ness & $|4527| 2$ & 45 \\
\hline BEARDMORE & SHELTON A & $21 \mathrm{~s} 2$ & $24 \mathrm{~W}$ & 28 & SE-SE- & Hodgeman & $\mid 4616$ & 46 \\
\hline OASIS & ADA & $121 \mathrm{~s} 2$ & $24 \mathrm{~W}$ & 33 & C-NE-SW & Hodgeman & 4665 & 4674 \\
\hline & & & $24 \mathrm{~W}$ & 33 & & & 4594 & \\
\hline & & $21 \mathrm{~s}$ & $24 \mathrm{~W}$ & 33 & & & o & \\
\hline $\mathrm{O}$ & DE & $21 \mathrm{~s}$ & $24 \mathrm{~W}$ & 33 & C-NE-SE & Hodgeman & 4609 & 469 \\
\hline & & $21 \mathrm{~s} 2$ & $24 \mathrm{~W}$ & 33 & C-SW-SE & & \begin{tabular}{|l|l|}
4622 & \\
\end{tabular} & \\
\hline & & $21 \mathrm{~s} 2$ & $24 \mathrm{~W}$ & 33 & C-NW-SE & & $\mid 4602$ & 46 \\
\hline & DEL & $321 \mathrm{~s}$ & $24 \mathrm{~W}$ & 33 & C-NW-SW & $\mathrm{Hoc}$ & $|4625|$ & 4683 \\
\hline & & $421 \mathrm{~S} 2$ & $24 \mathrm{~W}$ & 33 & & $\mathrm{Hoc}$ & 463 & \\
\hline & $\mathrm{sc}$ & $121 \mathrm{~s}$ & $24 \mathrm{~W}$ & 33 & NW & & | $\left.4654\right|^{2}$ & | 47 \\
\hline $\mathrm{O}$ & & $21 \mathrm{~s} 2$ & $24 \mathrm{~W}$ & 34 & C-SE-SW & & $\mid 4637$ & \\
\hline & & $s \mid 2$ & $24 \mathrm{~W}$ & 34 & C-NW-SW & & 4625 & \\
\hline & & $621 \mathrm{~s}$ & $24 \mathrm{~W}$ & 34 . & C-SW-SW & & 4639 & 469 \\
\hline & & $21 \mathrm{~s} 2$ & $24 \mathrm{~W}$ & 34 & & & 46 & \\
\hline & & $s \mid 2$ & $24 \mathrm{~W}$ & 34 & & & 46 & \\
\hline & M & $\mathrm{s} 2$ & $24 \mathrm{~W}$ & 34 & SW & & 4625 & \\
\hline & & & $24 \mathrm{~W}$ & 34 & & & 4621 & \\
\hline & SALMANS A & $22 \mathrm{~s} 2$ & $22 \mathrm{~W}$ & 3 & C-SE-SE & & \begin{tabular}{|l|l|}
4432 \\
\end{tabular} & 44 \\
\hline NRAY DX & GUS MILLER & $122 \mathrm{~s} 2$ & $22 \mathrm{w}$ & 8 & C-SE-NW & Hod & 4520 & 4547 \\
\hline ERN N & & 17 & $22 \mathrm{w}$ & 17 & & & 4460 & \\
\hline & & $\left.s\right|^{2}-2$ & 24 & & vW & & 46 & \\
\hline & & $22 \mathrm{~s}$ & $24 \mathrm{~W}$ & 3 & & & $\mid 4652$ & 46 \\
\hline & DIXOI & $22 \mathrm{~s} 2$ & $24 \mathrm{~W}$ & & C-NE-NE & Hodg & \begin{tabular}{|l|l|}
$\mid 4642$ & \\
\end{tabular} & \\
\hline ORE & FEHRENBACH & $122 \mathrm{~s}$ & $25 \mathrm{~W}$ & $1]$ & C-NE-NE & Hodge & 4513 & \\
\hline (ח & CLIFTO| & & I & & NW-NE- & Hodge & 4422 & \\
\hline & & & 23 & & SW-N & & & \\
\hline Al & & S & $24 \mathrm{~W}$ & 11 & & & 4520 & \\
\hline LEETON & V.GLEASON B & $124 \mathrm{~S}$ & $21 \mathrm{w}$ & 5 & SW-NW-SE & Hodgema & 4654 & \\
\hline NORTHERN NATURAL & FRALICK A & $2|27 \mathrm{~S}| 2$ & $20 \mathrm{w}$ & 14 & C-NE-SW & Kiowa & 4818 & 48 \\
\hline ALTERS & BRENSING G & $127 \mathrm{~S} 2$ & $20 \mathrm{w}$ & 20 & C-NW-SE & Kiowa & 4874 & \\
\hline & BRENSING A & & & & SE-NM & Kiowa & 4910 & \\
\hline & & & $21 \mathrm{~W}$ & & C-NE-NW & For & & \\
\hline $\mathrm{MOB}$ & $\mathrm{M}$ & 52 & $21 \mathrm{w}$ & 16 & C-NE-NW & Ford & $\mid 4904$ & \\
\hline SINCLAIR PRAIRIE & |YOUNG & $1|27 \mathrm{~S}| 2$ & $21 \mathrm{~W}$ & & C-SL-NE & Ford & |4890| 5 & \\
\hline
\end{tabular}

4-45 
Table 4.2 Data Fields in On-line Database

\begin{tabular}{|c|c|c|}
\hline API_WELL_NUMBER & ARGILLACEOUS_CONTENT_PCT & PERMEABILITY_PLUG_INSITU_MD \\
\hline COMPLETION_DATE & BEDDING & PERMEABILITY_PLUG_KLINSITU_MD \\
\hline ELEVATION & CAPILLARY_PRESSURE & PERMEABILITY_PLUG_KLROUTINE_MD \\
\hline FIELD_NAME & CEMENT_POREFILLING_MINERAL & PERMEABILITY_PLUG_ROUTINE_MD \\
\hline INITIAL_PRODUCTION_GAS & COLOR & PERMEABILITY_PLUG_VERT_MD \\
\hline INITIAL_PRODUCTION_OIL & CONSOLIDATION_FRACTURING & PERMEABILITY_WHOLE_90_MD \\
\hline INITIAL_PRODUCTION_WATER & DEPOSITIONAL_ENVIRONMENT & PERMEABILITY_WHOLE_MAX_MD \\
\hline LEASE_NAME & DEPTH_BASE_LITH_FT & PERMEABILITY_WHOLE_VERT_MD \\
\hline OPERATOR_NAME & DEPTH_BOTTOM_CORE_FT & POROSITY_PLUG_800PSI_PCT \\
\hline PERMIT_DATE & DEPTH_TOP_CORE_FT & POROSITY_PLUG_INSITU_PCT \\
\hline RANGE & DEPTH_TOP_LITH_FT & POROSITY_PLUG_ROUTINE_PCT \\
\hline SECTION & DIGITAL_IMAGE & POROSITY_WHOLE_ROUTINE_PCT \\
\hline SPUD_DATE & FAUNAL_ASSEMBLAGE & PRINCIPAL_PORE_TYPE \\
\hline TOWNSHIP & FORMATION & PROPERTIES_UNDER_STRESS \\
\hline WELL_CLASS & FRACTURES & ROCK_TYPE \\
\hline WELL_NAME & GRAIN_DENSITY_GCC & SATURATION_OIL_PCT \\
\hline ANALYSIS_DATE & GRAIN_SIZE & SATURATION_WATER_PCT \\
\hline ARCHIE_CEMENTATION_AM & LABORATORY & STRATIGRAPHIC_UNIT \\
\hline ARCHIE_CEMENTATION_INSITU & LITHOFACIES & SUBSIDIARY_PORE_TYPE \\
\hline ARCHIE_SATURATION_AMBIENT & LITHOLOGIC_CLASSIFICATION & THIN_SECTION \\
\hline ARCHIE_SATURATION_INSITU & NMR & WATER_DEPTH \\
\hline
\end{tabular}


Table 4.3

WATER/OIL RELATIVE PERMEABILITY DATA SUMMARY

Unsteady-State Method

Simulated Reservoir Stress: $1000 \mathrm{psi}$

Test Temperature: $74.4^{\circ} \mathrm{F}$

Constant Rate Drive: $2.0 \mathrm{~cm}^{3} /$ minute

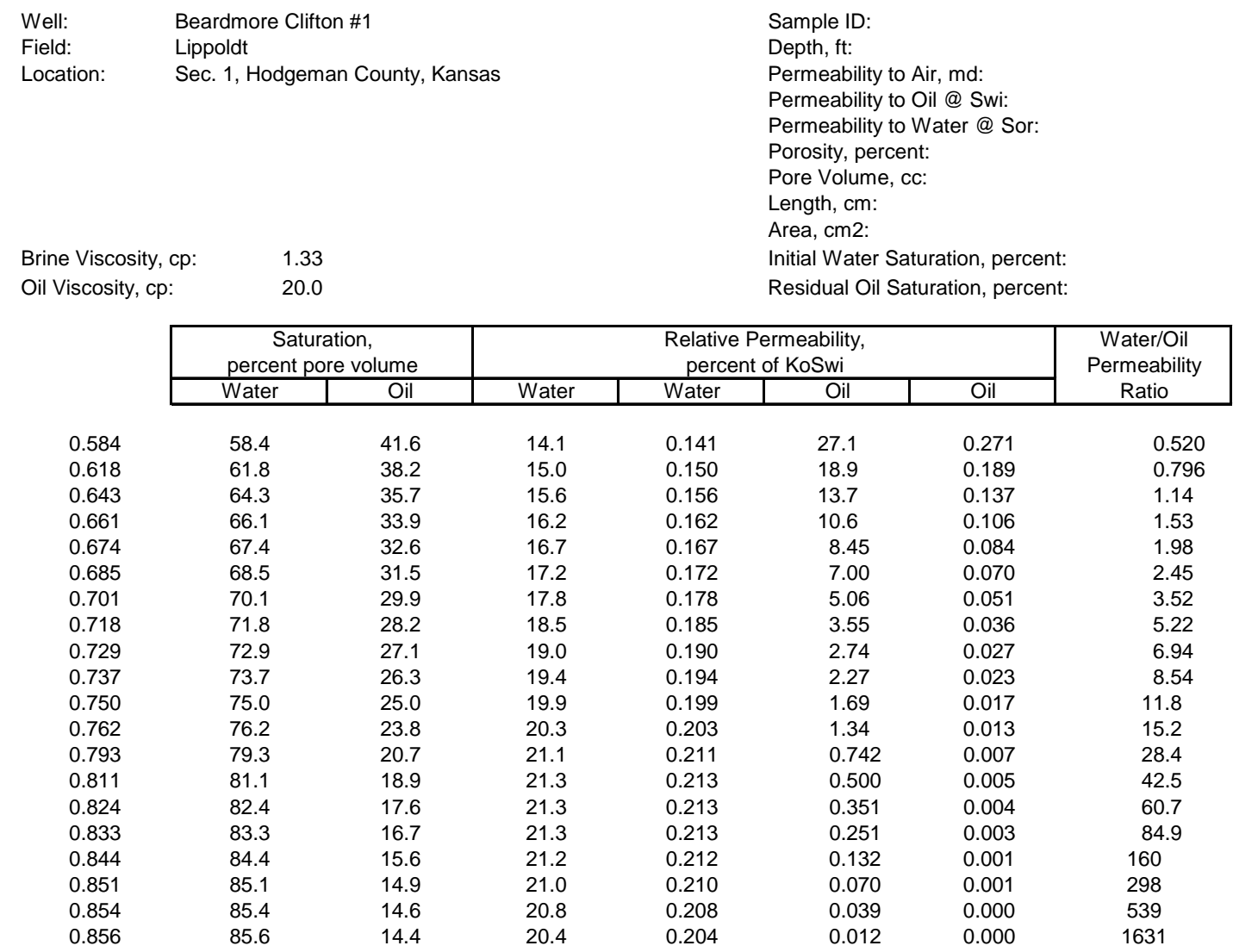




\section{Sensitivity Studies on Select Candidate Fields}

Sensitivity studies were conducted to identify field input parameters that play a critical role in affecting performance prediction from infill wells in 2 short-listed fields. Like many mature areas, the Mississippian fields of Kansas often do not have a complete set of wireline log, core, and production/pressure data. Few mature fields have a complete set of wireline log data from every well. Well-level production data often have limited information about produced water, while flowing and shut-in pressure data are recorded sporadically at a few wells. Such data limitations require assumptions to be made particularly in mapping the constituent layers of the pay zone and in populating them with petrophysical properties. Thus, it is prudent to run some quick sensitivity studies to understand the effects of various assumptions made during geomodel buildup.

Single phase simulation studies were carried out using RESMOD ${ }^{\mathrm{TM}}$ on wells from 2 fields. The first field analyzed was Ness City North, Ness County, Kansas. History matching was carried on production data from 2 vertical wells from this field. Based on the history matches obtained on the vertical wells, the simulator was used to predict the performance of a horizontal well drilled in this field. This exercise was to ground-truth the ability of RESMOD ${ }^{\mathrm{TM}}$ to predict production at both vertical and horizontal wells. The second field analyzed was Judica, Ness County, Kansas. Two vertical wells were history matched in this field followed by identification of critical parameters that influence predicted performance of a hypothetical infill horizontal well located in this field.

\subsection{Reservoir Input Parameters}

\section{Drive Mechanism Scaling Factor}

One of the major factors that affect production is the drive mechanism charging the reservoir. This is particularly important for reservoirs that are being considered as candidates for infill horizontal drilling. Infill horizontal wells in mature reservoirs perform better when reservoir pressure is not depleted. One criterion used to short list 
fields in this project was evidence of pressure support in the reservoir. One of the ways RESMOD $^{\mathrm{TM}}$ inputs this influence of drive mechanism is through the specification of the drive-mechanism scaling-factor (DMSF). The user manual of RESMOD ${ }^{\mathrm{TM}}$ defines DMSF as a fraction that "characterizes the combined drive mechanism of a reservoir, where 0 corresponds to solution-gas drive and 1 corresponds to active water drive.” The model assumes that active water drives result in highest recoveries while solution-gas drives result in the lowest recoveries.

For vertical wells producing from reservoirs under active water drive, RESMOD $^{\mathrm{TM}}$ assumes an exponential decline where oil depletion is proportional to remaining producible oil-in-place. Exponential and harmonic declines are end-member cases of the set of possible hyperbolic declines with the decline exponent " $n$ " being equal to zero in first case and equal to 1 in the later case. As RESMOD ${ }^{\mathrm{TM}}$ uses exponential decline to model vertical well production, it provides a conservative estimate of the production capability of the well. The fractional value of the DMSF can therefore be varied by the user during the process of history matching to represent drive mechanisms of different strengths, combinations, and/or types. RESMOD ${ }^{\mathrm{TM}}$ by default calculates the well performance under the bounding conditions, i.e., DMSF $=0$ and DMSF $=1$, and the user can select 3 other DMSF values within this range during each run.

For horizontal wells placed in actively water driven reservoirs, RESMOD ${ }^{\mathrm{TM}}$ assumes 2 large edge aquifers that are parallel to the horizontal well. The DMSF factor used to obtain a history match with production volumes recorded at the well also takes into account the effects of relative permeability on the flow of oil because the history of produced oil volumes is the result of multi-phase fluid flow (oil and water) that is taking place in the real life reservoir. Thus, DMSF combines the effects of both the strength of the reservoir drive and relative permeability affecting oil flow.

The suggested DMSF values in the RESMOD ${ }^{\mathrm{TM}}$ user manual are shown in Table 5.1 as fractions. The DMSF factor for each field was determined through the process of history matching the production of select vertical well(s) in a field. In the limited number 
of wells that have been studied in this report, it was observed the DMSF factor required to history match vertical well performance varied only slightly between wells in a field. This implies that the DMSF factor, which encapsulates the combined effect of reservoir drive and relative permeability of the reservoir rock, is a field-level property, and once determined by history matching vertical wells can be applied to predict performance of horizontal wells within the field.

\section{Drainage Area}

For horizontal wells, 3 types of drainage areas are commonly mentioned in literature: an ellipse, a rectangle capped with semicircular ends, and a rectangle whose length coincides with that of the well. Factors that critically affect production from a horizontal well are the area that the well drains, the length of the producing horizontal section of the well, and the thickness of the reservoir. The area drained by a horizontal well in an unlimited reservoir generally approximates that of an ellipse. Thus, this model is recommended for cases where the drainage radius is limited only by formation properties (such as permeability and porosity) and fluid viscosity. Rectangle model is recommended when the producing horizontal section of the well extends over the entire length of the pay, thereby making axial drainage into the ends of the well negligible. The capped rectangle model is recommended when the drainage is limited by boundaries that run parallel to the well and not by boundaries at the end of the well. In the fields/wells considered for this study, drainage has been mostly limited by geologic heterogeneity, and, therefore, the elliptical model of drainage was used.

\section{$\underline{\text { Skin Factor }}$}

Conventionally, a unit change in the skin value results in a $15 \%$ change in flow rate in a vertical well and about a 50\% change in the flow rate from a horizontal well. RESMOD $^{\mathrm{TM}}$ provides 2 options, namely the Joshi and Hall models, to input the skin values. The skin includes effects of both formation damage around the wellbore and also the dynamic effects arising out of fluid flow into the well. 
The Hall model treats skin as a unit of pressure loss and decreases horizontal well productivity by the same relative magnitude as it would for a vertical well. Thus, if a skin factor of 1 reduces vertical well productivity by 20\%, its use will also reduce the horizontal well productivity by $20 \%$. The Hall model distributes this loss in production over the length of the horizontal well. The Joshi model theorizes that since the skinrelated pressure drop in a vertical well is proportional to the flow rate per unit length $(\mathrm{q} / \mathrm{h})$ of a vertical well, the pressure loss due to skin in a horizontal well is proportional to flow rate per unit length $(\mathrm{q} / \mathrm{L})$ of the well. Thus, use of Joshi skin model results in significantly lower pressure losses for horizontal wells than in vertical wells.

It is not uncommon for the skin factor input to be used as a "fudge factor" to match the predicted rates with the history. The Hall skin model is more conservative than Joshi's model, and was used to predict performance of horizontal wells in this study. For each field, the skin factor in a vertical well was estimated by history matching the production from the well. This skin factor, or one close to it in value, was then used to predict the performance of the infill horizontal well. The sensitivity of production from a horizontal well on the skin factor was determined by running the model with different skin values around the initial assumed value.

\section{External Drainaqe Radius}

The user manual recommends that the external drainage radius should represent the circular external boundary of the area drained by a vertical well, and be the semiminor axis of the elliptical area drained by a horizontal well. As per reservoir engineering conventions, drainage radius represents the distance from the well where the pressure transient, created by drawdown at the well, is unable to move fluids towards the well. In real geologic settings, the drainage is seldom circular in shape. In this study, an initial approximation of the drainage radius was obtained by volumetrics, i.e., by determining the volume of the reservoir that needs to drain in order to account for the cumulative production recorded at the well assuming uniform petrophysical properties within the drainage. In the volumetric calculation, these properties were set equal to that obtained 
from log analysis at the respective vertical well. If needed, this initial estimate of drainage radius was varied during the process of history matching.

\section{$\underline{\text { Permeability }}$}

Permeability measured on core samples from Mississippian carbonate reservoirs varied significantly at same (similar) porosity values. Permeability is heavily influenced by lithofacies, and at this preliminary screening stage detailed information about the reservoir rock was unavailable. The user manual recommends input of single-phase horizontal permeability. However, it is the opinion of the author that input of effective (horizontal) permeability to oil is more appropriate in history matching or predicting oil production in a single-phase simulator like RESMOD ${ }^{\mathrm{TM}}$. This would perhaps reduce unwarranted modification of different petrophysical parameters during the history matching exercise. The best estimate of effective permeability to oil at the input porosity (representative over the drainage area) was entered in each case. Lacking measured data, the vertical permeability was assigned to be $10 \%$ of the horizontal permeability value.

\section{Formation Thickness}

The value entered in each case was the best estimate of the effective thickness of the producing zone, i.e., the net pay. Even for partially penetrating wells, the value entered was the effective thickness of the reservoir rock.

\section{$\underline{\text { Residual Oil Saturation }}$}

A constant value of $30 \%$ was assigned in each case. From past and current studies at the Kansas Geological Survey, this value was estimated to be representative of many Mississippian reservoir rocks in Kansas. The initial oil saturation was assumed to be 65\% in the inter-well prospective regions. 


\section{Length of Horizontal Well}

This is the length of the horizontal well that is exposed to the producing formation. In consultation with the industry partner Mull Drilling Company Inc. (MDCI), a well length of $500 \mathrm{ft}$ was assumed in each case.

\section{Bottom Hole Pressure}

The height of fluid column above the perforation varies during the producing life of a well, and these data are often hard to obtain in the mature fields of the midcontinent. A set of guidelines, based on the prevalent operating practices of the region, was developed in consultation with MDCI in order to assign BHPs in producing wells where recorded data were unavailable. These guidelines stipulate that wells with cumulative production less than 75 MSTB can be assumed to produce under pumped off conditions while wells whose cumulative production exceeded 75 MSTB it is reasonable to assume a standing fluid column in the producing well.

\section{Production History}

RESMOD $^{\mathrm{TM}}$ uses the IP value and an exponential decline to calculate the production history of a vertical well in aquifer driven reservoirs. Decline analyses are valid when a well produces under near constant BHP and when no changes occur in the near wellbore region (i.e., no stimulation jobs are carried out to result in permeability changes) or the production from a newly drilled neighboring well does not cause interference. Thus, the production data entered for history matching included data for the period where an uninterrupted decline was visible without any intervening production spikes. Also, the production data spikes were smoothened by annually averaging the recorded monthly production volumes. 


\section{$\underline{\text { Oil Viscosity }}$}

The API of the oil produced from the studied fields is around 40 degrees. The reservoir temperatures for these fields are close to $120^{\circ} \mathrm{F}$. Using standard correlation charts, the dead oil viscosity for such oils was estimated to be $2 \mathrm{cp}$. Most wells in this area have reported some gas production at the surface. However, gas produced is normally in quantities that did not merit metering or flaring. No data were available regarding the solution-gas-oil ratios in these fields. Thus, a low solution-gas-oil ratio of $200 \mathrm{scf} / \mathrm{stb}$ was assumed to have existed in these fields at bubble point pressure. Using this GOR, standard correlations were used to normalize the dead oil viscosity to an in situ viscosity of $1.1 \mathrm{cp}$.

\section{$\underline{\text { Economic Parameters }}$}

These included \$200,000 to drill and complete a vertical well and \$100/day fixed operating costs. It also included $\$ 400,000$ to drill and complete a horizontal well and $\$ 125 /$ day fixed well operating costs. The discount rate was assumed as $17.5 \%$ and the net sale price for the produced oil was assumed to be $\$ 19 /$ barrel (valid at the time of study in 2002).

\subsection{Calibration of RESMOD ${ }^{\mathrm{TM}}$}

For each selected vertical well, different petrophysical properties representative over the drainage area were estimated from available wireline logs and DST data. Inputs to RESMOD ${ }^{\mathrm{TM}}$ included these parameters along with the production history. Iterative runs were carried out to obtain a history match on the production data with minimal modifications of original input data. Initial flush production in the production history was neglected. A match was deemed OK when the calculated IP, cumulative production, and shape of the cumulative curve (with time) matched historic values. This exercise helped to determine the field-level parameter - DMSF. The universality of the DMSF was 
checked by history matching production from 2 vertical wells within a field. As will be discussed later, in the 2 fields that were studied and reported here, similar DMSF values were used to attain history matches at different vertical wells from the same field. This field-specific DMSF value was then input along with other petrophysical values relevant to specific locations in order to predict the performance of infill horizontal wells.

\section{Ness City North Field}

The first field that was studied using RESMOD ${ }^{\mathrm{TM}}$ was Ness City North Field, Ness County, Kansas. This field had been characterized and simulated, using Computer Modeling Group's IMEX simulator, as a part of this project (and is detailed later in Section 7). An infill horizontal well was also drilled in this field. The horizontal section of this well was left open hole due to restrictions inherent in re-entering an existing wellbore. The well produced for about 2 months at an average rate of 60 bopd with a 50\% water cut. Thereafter, a sudden collapse occurred in the wellbore shutting off production of all fluids. All efforts to reclaim the well failed resulting in abandonment of the wellbore.

Ummel \#1 is the best vertical producer in Ness City North, and it is the well immediately to the north of the horizontal well. Petrophysical properties input to RESMOD $^{\mathrm{TM}}$ were representative of the drainage area of this well. These input parameters were adjusted in order to history match (Figure 5.1) the production profile of Ummel \#1. The final set of parameters used to obtain this match is listed in the match column of Table 5.2. The history match was obtained when a DMSF $=0.5$ was assumed for Ummel $\# 1$.

Being a single-phase close tank model, RESMOD ${ }^{\mathrm{TM}}$ predicts well production by using a calculated IP and an exponential decline. One of the basic assumptions behind modeling any production decline profile, here exponential, is that the producing conditions must remain unchanged, i.e., BHP and/or skin or permeability cannot be changed. The production history entered in RESMOD ${ }^{\mathrm{TM}}$ was pre-1995 because a single 
decline was evident in the annual oil production till 1995. Post 1995, the oil production from the well showed an abrupt increase followed by another decline. It is interesting to note that the match, though admittedly non-unique, was attained with a BHP (bottom hole pressure at the well) equal to 900 psi. There is no record of BHPs in this well. The simulation study (reported later in Section 7) showed that the average BHP for most of the producing life of the well, before 1995, was around 700 psi. Upon consultation with the MDCI - the operator of Ness City North field, it was learned that Ummel \#1 was a high fluid producing well, and thus a heavy-duty pump was installed at the well some time in 1995. Since the installation of this pump, low fluid columns had been maintained at the well. However prior to 1995, MDCI opined that significant fluid columns existed in Ummel \#1, and given their experience in operating this well they confirmed that a fluid column that resulted in a BHP of 900 psi was reasonable for this well. Upon history matching, production estimated by RESMOD ${ }^{\mathrm{TM}}$ is compared with the recorded data for Ummel \#1 in Table 5.3.

The DMSF is a field-level parameter. Thus, it is expected that another vertical well in Ness City North, such as Ummel \#2, should be history matched in RESMOD ${ }^{\mathrm{TM}}$ by using a DMSF value close to 0.5. Ummel \#2 is the closest well south of the infill horizontal well. Also, it is one of the mediocre producers in the field. Starting petrophysical parameters representative of the drainage area of this well are listed under match column in Table 5.4. The resultant history match (Figure 5.2) was obtained using a $\mathrm{BHP}=850$ psi and a DMSF $=0.4$. Thus, the DMSF factors obtained from history matching two of the closest neighbors, Ummel \#1 and Ummel \#2, of the horizontal well are 0.5 and 0.4 respectively. MDCI also confirmed that this well was a high fluid producer, and thus it might have produced against a significant fluid column in the well. Table 5.5 compares the estimated production numbers with the historic values in Ummel \#2.

History matching vertical well production in RESMOD ${ }^{\mathrm{TM}}$ enabled estimation of the DMSF range that is applicable for Ness City North field. A DMSF of 0.45 was used to predict the performance of the horizontal well in this field. The petrophysical 
parameters representative of the drainage area of this well are listed in Table 5.6. The gamma ray log from this well revealed that the effective productive length of the horizontal leg in the well was about $450 \mathrm{ft}$. For most of the life of the well (the first 60 days), the standing fluid column in the well varied between 800 to $1200 \mathrm{ft}$. Table 5.7 summarizes the production profile that RESMOD ${ }^{\mathrm{TM}}$ predicts for the horizontal well in Ness City North. The production rate predicted for the initial months is comparable to that recorded during the brief life of the well.

Thus with limited available data, RESMOD ${ }^{\mathrm{TM}}$ was able to history match production data from vertical wells in a field using consistent DMSF values. Having defined the narrow range of possible DMSF values applicable for the field, it was used to predict at least the IP of an infill horizontal well. Thus, RESMOD ${ }^{\mathrm{TM}}$ could similarly be used as a screening tool for evaluating candidate reservoirs for horizontal infill drilling by calibrating it first on data from neighboring vertical well(s).

\subsection{Sensitivity Studies on Judica Field}

One of the short-listed fields in the PUMP project was Judica Field, Ness County, Kansas. Two vertical wells, namely Thornburg $\mathbf{M}$ (hence onward called as Well $\mathbf{M}$ ) and Thornburg L (hence onward called as Well L), were selected from this field for history matching in RESMOD ${ }^{\mathrm{TM}}$, and, thus, to estimate the DMSF range applicable for the chosen field. Based on the distribution of lease holdings, MDCI, the field operator, was interested in evaluating the potential of a targeted horizontal infill well in the general vicinity of these wells. Well $\mathrm{M}$ is one of the most prolific producers of the field while Well L represents one of the poorer producers.

A detailed 3D geologic model was developed for this field by integrating all the available data - wireline logs, DST, production data, and core analysis from analog neighboring wells (described in Section 7). Based on this geomodel, the representative petrophysical properties for the drainage area of Wells L and M were obtained. These 
properties are tabulated in Tables 5.8 and 5.9 respectively. Figure 5.3 shows the history match obtained in RESMOD ${ }^{\mathrm{TM}}$ for Well $\mathrm{M}$.

Table 5.10 compares the IP and cumulative production predicted by RESMOD ${ }^{\mathrm{TM}}$ for this well with that recorded in production history. The match for Well $\mathrm{M}$ was obtained by using a DMSF $=0.8$ and with a $\mathrm{BHP}=170$ psi. Fluid level data during the producing life of the well was unavailable. Currently, this well is producing under pumped-off conditions. As per (initial) suggestions from MDCI in accordance to prevalent field practices, it was decided for simulation purposes that low oil producers (cumulative production $<75,000 \mathrm{bbl}$ ) would be assumed to be produced under pumped off conditions while high oil producers (cumulative production $>75,000 \mathrm{bbl}$ ) would be assumed to be produced with some fluid column in the well. It is common practice to produce a well under a backpressure in order to reduce the increasing water cuts, and water cuts in Mississippian wells normally increase with time. Thus, when a highly productive well is being produced under pumped-off conditions today, it is likely that it has always produced with low fluid levels. Thus, an average BHP of 170 psi may be a reasonable assumption for a high producing well.

Figure 5.4 shows the match obtained for Well L. Here, the match was obtained using DMSF $=0.8$ and a BHP $=20$ psi. Well L is a low oil producer, and, thus, it is reasonable to assume that it was produced under pumped-off conditions. Table 5.11 compares the production volumes and IPs calculated by RESMOD ${ }^{\mathrm{TM}}$ against that recorded in the field for Well L. Like in the Ness City North field, this exercise on Judica field also showed that production data from two different vertical wells could be history matched in RESMOD ${ }^{\mathrm{TM}}$ using same/similar DMSF values.

Based on the geologic model constructed for this field, representative petrophysical properties were determined for a drainage area, which MDCI wanted to evaluate for its potential for an infill horizontal well in Judica. The input parameters are listed under the column named as "Base" in Table 5.12. Using a DMSF =0.8, a BHP = $300 \mathrm{psi}$, remaining oil saturation $=55 \%$, a producing length $=500 \mathrm{ft}$, and a skin factor $=$ 
2.0, RESMOD ${ }^{\mathrm{TM}}$ predicted that the IP from such an infill well will be close to $150 \mathrm{bbl} / \mathrm{d}$. Economic factors input into the model include $\$ 400,000$ as cost of drilling the well, oil price $=\$ 19$, and fixed operation costs $=\$ 120 /$ day. The RESMOD ${ }^{\mathrm{TM}}$ model predicted that based on the above data, the producing life of the well would be about 40 months and the cumulative production obtained from this well would be about 60 Mbbls.

Tables 5.12a and 5.12b summarize the results of a series of sensitivity studies carried out on the input parameters for the above horizontal infill well in Judica. In each case, only one parameter was varied, within a range thought to be relevant for this field, relative to the "Base" data, and its effect on IP, well life, and cumulative production was tabulated. Table 5.13 summarizes the sensitivity of total cumulative production (estimated over the economic life of the horizontal well) on different input parameters. It shows that when the drainage radius is changed from 500 to $700 \mathrm{ft}$, the cumulative production calculated by RESMOD ${ }^{\mathrm{TM}}$ for the horizontal well changed from 43 to 79.7 Mbbl, i.e., resulted in an increase of $85.3 \%$. As is evident from Table 5.13, the parameters that most affect cumulative production include drainage radius, initial oil saturation, average pay thickness, average porosity, and the DMSF factor. Within the limits of the range of data (for each parameter) stated in Table 5.13, it appears that factors such as well length, permeability, external drainage pressure, and skin have relatively lesser effects on the cumulative production of the proposed horizontal infill well. It is to be noted that these initial studies were carried out under the assumption that wells from all over Judica field produced under a strong active water drive. For reasons mentioned later (Section 10), this assumption was discarded in the final stages of this project. 

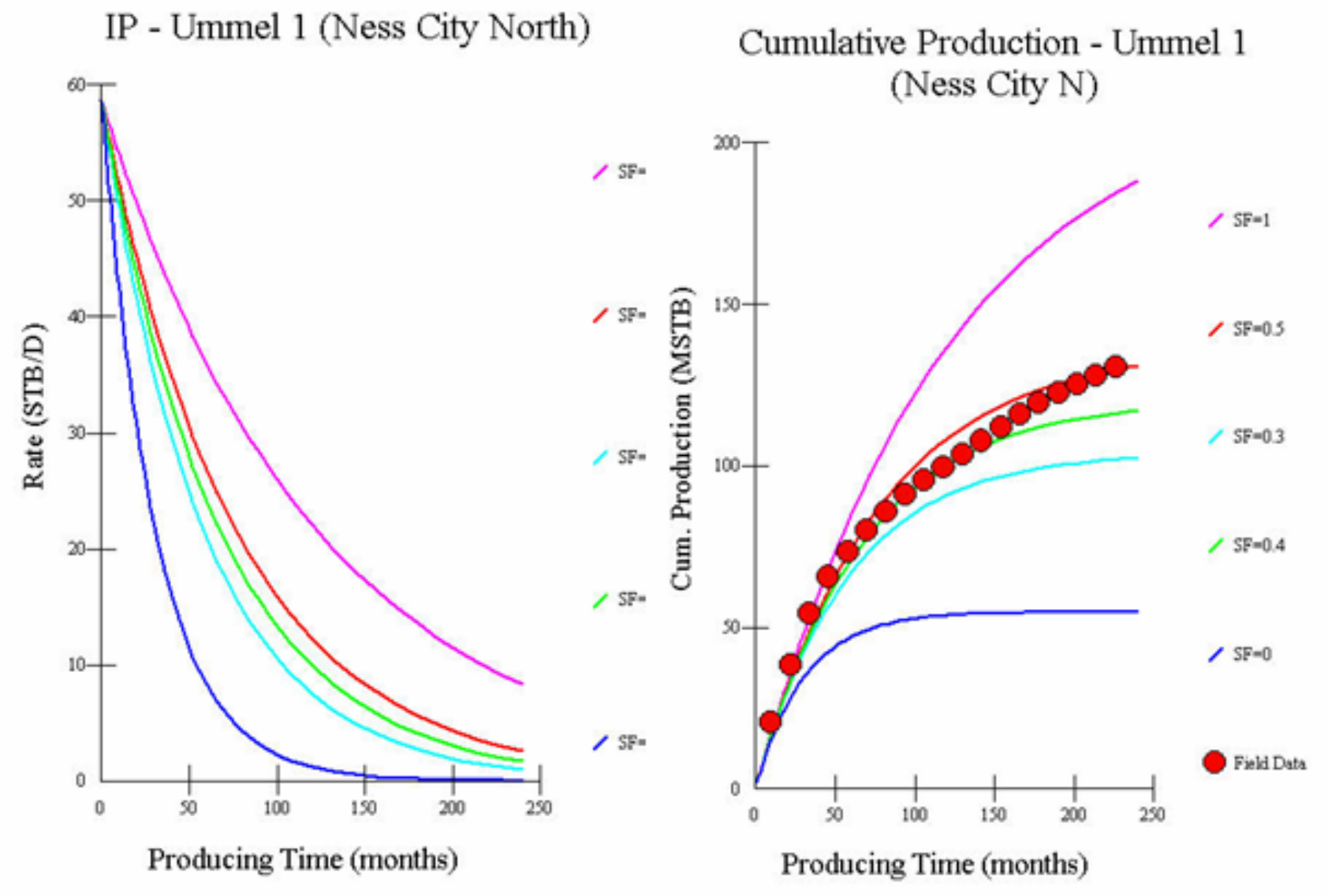
Cumulative Production - Ummel 1 (Ness City N)

Figure 5.1: History match of cumulative production for Ummel 1 well (Ness City North Field) and RESMOD ${ }^{\text {TM }}$ predicted initial production rates. 

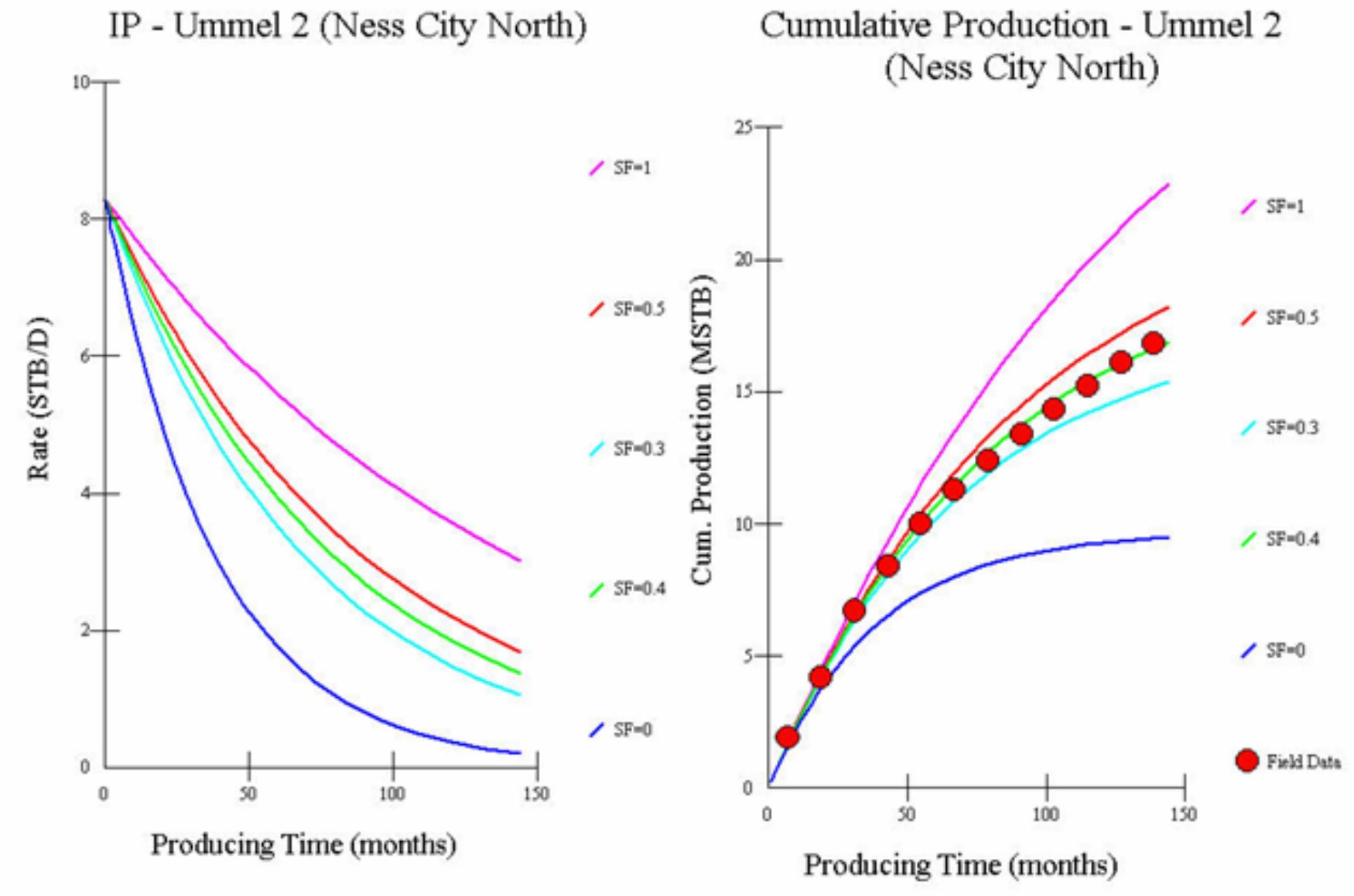

Figure 5.2: History match of cumulative production for Ummel 2 (Ness City North Field) and RESMOD ${ }^{\mathrm{TM}}$ predicted initial production rates. 

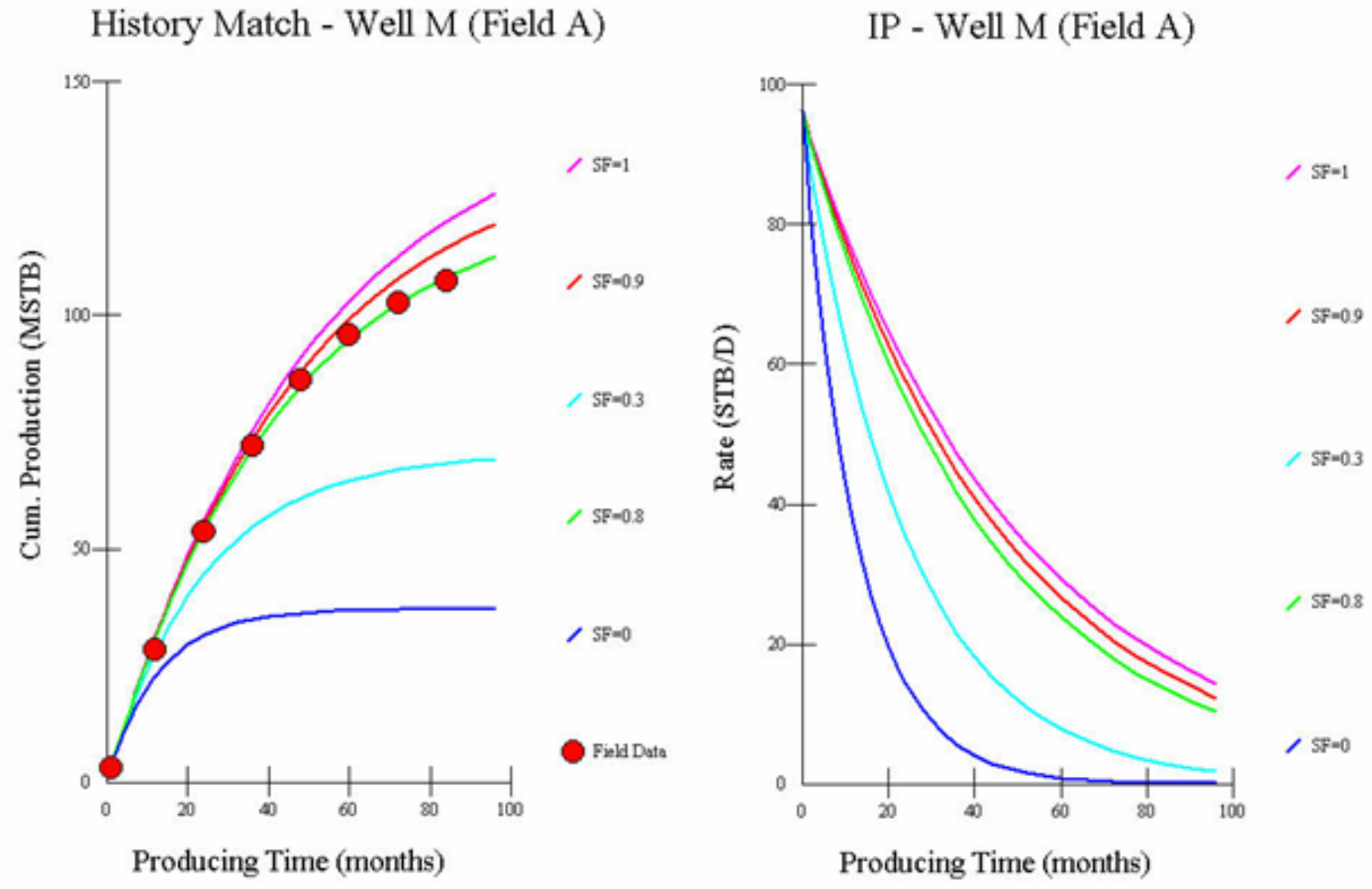

Figure 5.3: History match of cumulative production for Well M (Thornburg M, Judica Field) and RESMOD ${ }^{\mathrm{TM}}$ predicted initial production rates. 
History match - Well L (Field A)

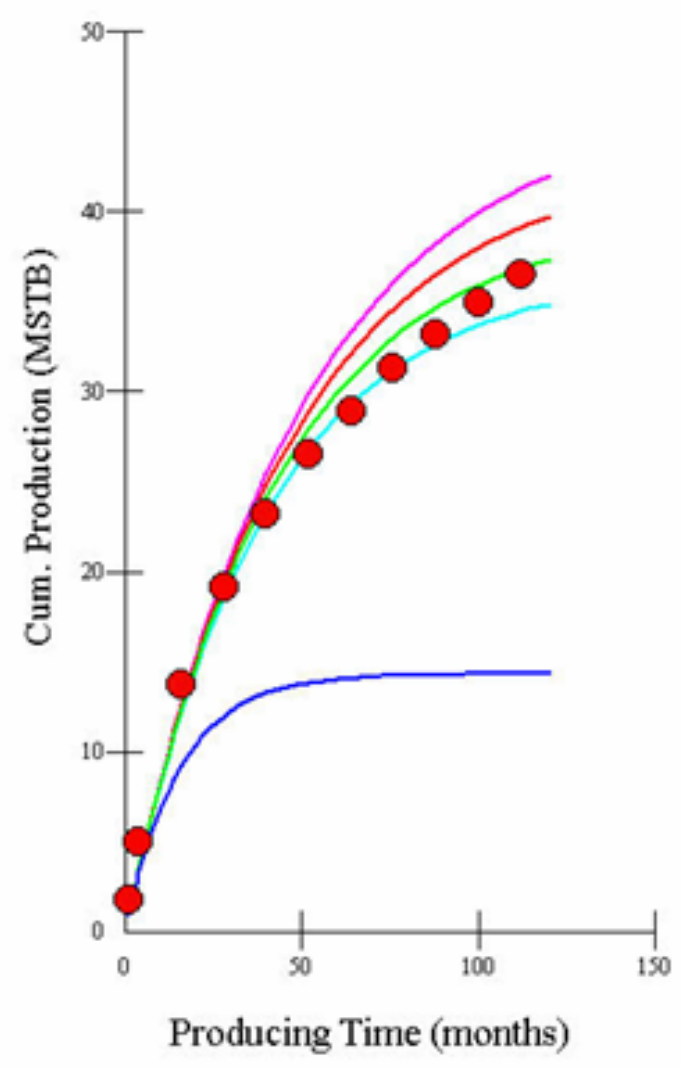

IP - Well L (Field A)

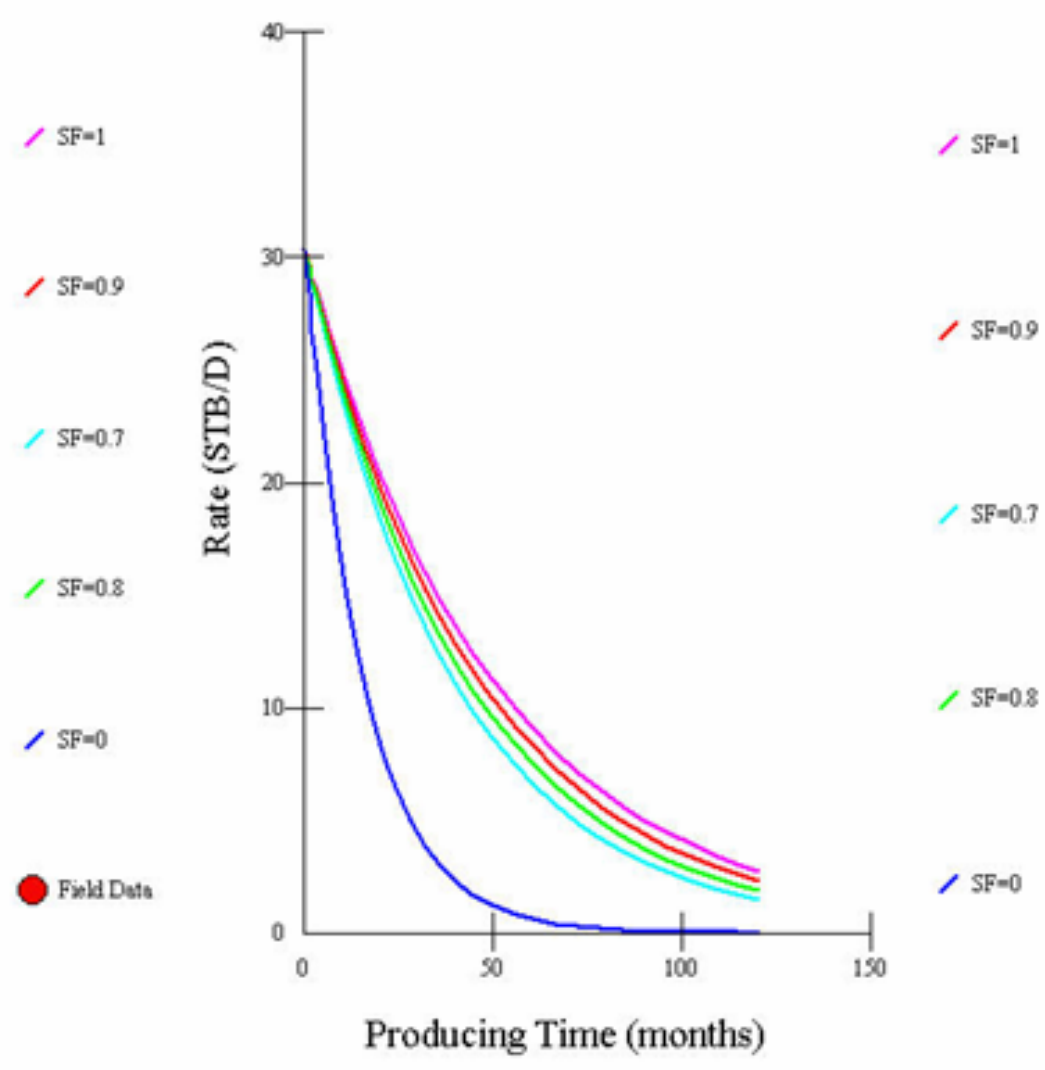

Figure 5.4: History match of cumulative production for Well L (Thornburg L, Judica Field) and RESMODTM predicted initial production rates. 


\begin{tabular}{|l|r|r|}
\hline & DMSF & \multicolumn{2}{l|}{ DMSF } \\
\hline Drive mechanism & from & to \\
\hline \hline Weak water drive & 0.1 & 0.3 \\
\hline Partial pressure maintanence & 0.1 & 0.4 \\
\hline Horizontal well under one edge water drive & 0.2 & 0.4 \\
\hline Natural depletion followed by water injection & 0.05 & 0.4 \\
\hline
\end{tabular}

Table 5.1: Recommended DMSF values from REMOD ${ }^{\mathrm{TM}}$ user manual for different reservoir drive mechanisms. 


\begin{tabular}{|c|c|c|}
\hline Field - Ness City North & & \\
\hline Well - Ummel 1 & & \\
\hline Data input to history match & Resmod & \\
\hline & Match & \\
\hline Rock Properties & & \\
\hline Drainage Radius, $\mathrm{ft}$ & 700 & \\
\hline Formation Thickness, $\mathrm{ft}$ & 10 & \\
\hline Horizontal K, md & 25 & \\
\hline Vertical $\mathrm{K}$, md & 2.5 & \\
\hline Porosity, \% & 24 & \\
\hline External Drainage Pr, psi & 1350 & \\
\hline Fluid Properties & & \\
\hline Oil Viscosity, cp & 1.1 & \\
\hline Initial oil saturation, \% & 65 & \\
\hline Formation volume factor, RB/STB & 1.05 & \\
\hline Drive Mechanism Scaling factor (DMSF) & 0.5 & \\
\hline$(D M S F=1$ for active water drive, $D M S F=0$ & for solution & gas drive) \\
\hline Vertical well data & & \\
\hline Skin factor & 4 & \\
\hline BHP, psi & 900 & \\
\hline Residual oil saturation, \% & 30 & \\
\hline Well bore radius, inch & & \\
\hline Well cost, $1000 \$$ & & \\
\hline Fixed Operational cost/day, \$ & & \\
\hline
\end{tabular}

Table 5.2: Petrophysical properties used to obtain history match at Ummel 1 well in Ness City North Field. 


\begin{tabular}{|l|r|r|l|r|r|}
\hline DMSF & $\mathbf{0 . 5}$ & & & \\
\hline Ummel 1 & & & & & \\
\hline RESMOD results & & & Actual well performance & & \\
\hline & bopd & MBBL & & bopd & MBBL \\
\hline & & & & & \\
\hline Starting production rate & 58.6 & & Avg first production (1st 10 months) & 69.1 & \\
\hline & & & Avg Production from 11 to 23 months & 49.1 & \\
\hline Rate after 204 months & 4.1 & & Rate after 202 months & 6.9 & \\
\hline Cumulative production after 204 months & & 127.5 & Cumulative production after 202 months & & 125.2 \\
\hline
\end{tabular}

Table 5.3: RESMOD ${ }^{\mathrm{TM}}$ predicted production volumes compared with historic records at Ummel 1, Ness City North Field. 


\begin{tabular}{|c|c|c|}
\hline \multirow{2}{*}{\multicolumn{3}{|c|}{\begin{tabular}{|l|} 
Field - Ness City North \\
Well - Ummel 2 (production well)
\end{tabular}}} \\
\hline & & \\
\hline \multirow[t]{2}{*}{ Data input to history match } & Resmod & \\
\hline & Match & \\
\hline \multicolumn{3}{|l|}{ Rock Properties } \\
\hline Drainage Radius, $\mathrm{ft}$ & 500 & \\
\hline Formation Thickness, $\mathrm{ft}$ & 6 & 6 \\
\hline Horizontal K, md & 8 & 3 \\
\hline Vertical K, md & 0.8 & \\
\hline Porosity, \% & 15 & \\
\hline External Drainage Pr, psi & 1200 & \\
\hline \multicolumn{3}{|l|}{ Fluid Properties } \\
\hline Oil Viscosity, $\mathrm{cp}$ & 1.1 & \\
\hline Initial oil saturation, \% & 60 & \\
\hline Formation volume factor, RB/STB & 1.05 & \\
\hline Drive Mechanism Scaling factor (DMSF) & 0.4 & \\
\hline \multicolumn{3}{|c|}{ (DMSF $=1$ for active water drive, DMSF $=0$ for solution gas drive) } \\
\hline \multicolumn{3}{|l|}{ Vertical well data } \\
\hline Skin factor & 5 & 5 \\
\hline BHP, psi & 850 & \\
\hline Residual oil saturation, \% & 30 & \\
\hline Well bore radius, inch & 3.5 & \\
\hline Well cost, $1000 \$$ & 200 & \\
\hline Fixed Operational cost/day, $\$$ & 100 & \\
\hline
\end{tabular}

Table 5.4: Petrophysical properties used to obtain history match at Ummel 2 well in Ness City North Field. 


\begin{tabular}{|l|r|r|l|r|r|}
\hline DMSF & $\mathbf{0 . 4}$ & & & \\
\hline Ummel 2 & & & & & \\
\hline RESMOD results & & & Actual well performance & \\
\hline & bopd & MBBL & & bopd & MBBL \\
\hline & & & & & \\
\hline Starting production rate & 8.3 & & Avg first production (1st 7 months) & 8.9 & \\
\hline & & & Avg Production from 8 to 20 months & 6.5 & \\
\hline Rate after 132 months & 1.6 & & Rate after 139 months & 1.9 & \\
\hline Cumulative production after 132 months & & 16.3 & Cumulative production after 139 months & & 16.8 \\
\hline
\end{tabular}

Table 5.5: RESMODTM predicted production volumes compared with historic records at Ummel 2, Ness City North Field. 


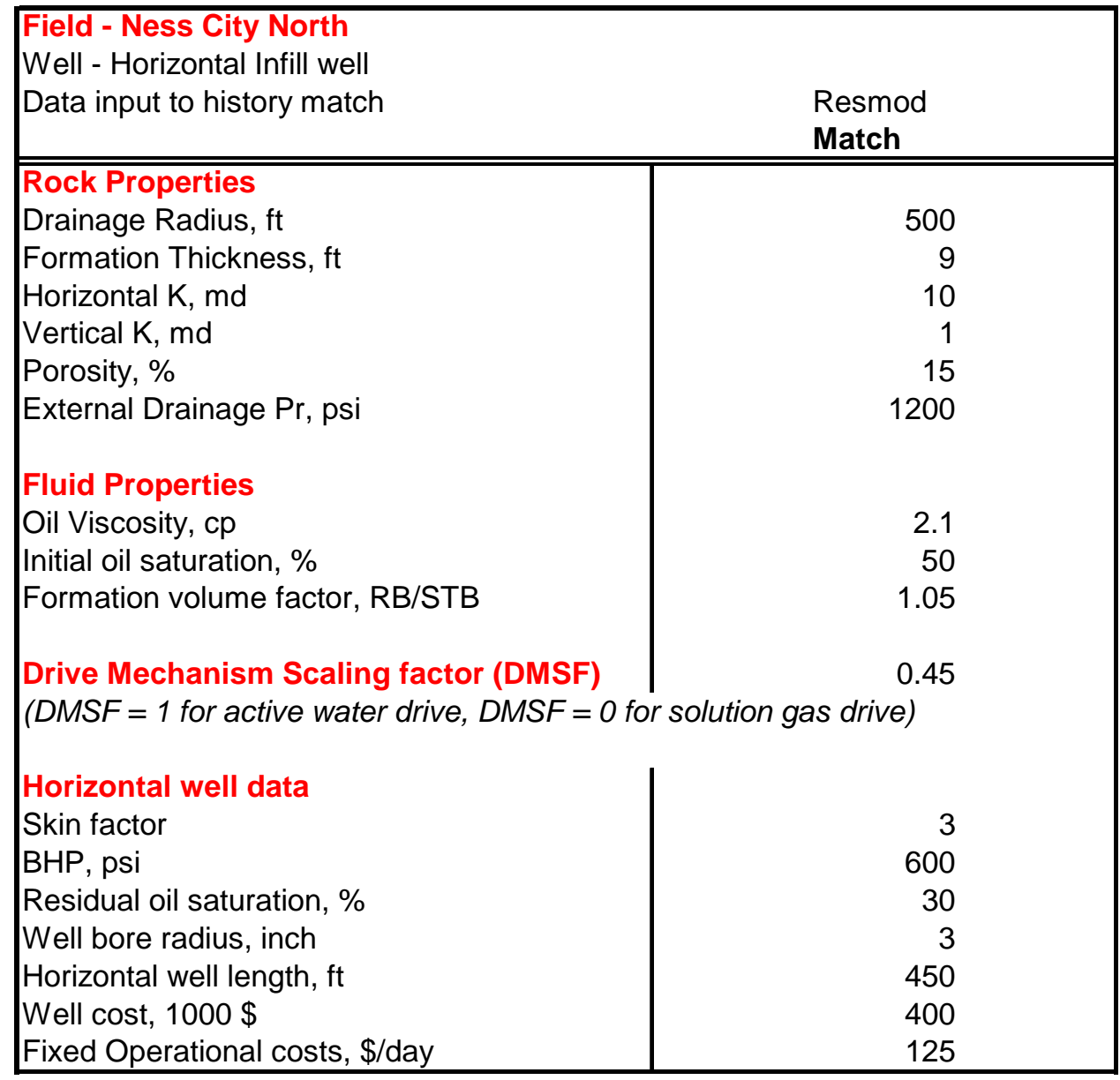

Table 5.6: Estimated average petrophysical parameters in the drainage area around the location of the horizontal well drilled in Ness City North Field. 


\begin{tabular}{|l|r|r|l|l|l|}
\hline DMSF & $\mathbf{0 . 4 5}$ & & & \\
\hline BHP, psi & $\mathbf{6 0 0}$ & & & & \\
\hline RESMOD results & & & Actual well performance & & bopd \\
\hline & bopd & MBBL & & MBBL \\
\hline & & & & 60 & \\
\hline Starting production rate & 66.1 & & Avg first production (1st 2 months) & & \\
\hline & & & & & \\
\hline Life of well, months & 24 & & & & \\
\hline Cumulative production after 24 months & & 21.7 & & & \\
\hline
\end{tabular}

Table 5.7: RESMOD ${ }^{\mathrm{TM}}$ predicted production performance from a horizontal well drilled in Ness City North Field. 


\begin{tabular}{|l|r|}
\hline Field - A \\
Well - M \\
Data input to history match \\
\hline \hline Rock Properties \\
Drainage Radius, $\mathrm{ft}$ & 750 \\
Formation Thickness, ft & 7 \\
Horizontal K, md & 20 \\
Vertical K, md & 2 \\
Porosity, \% & 20 \\
External Drainage Pr, psi & 1250 \\
& \\
Fluid Properties & 1.1 \\
Oil Viscosity, cp & 65 \\
Initial oil saturation, \% & 1.04 \\
Formation volume factor, RB/STB & 0.8 \\
& \\
Drive Mechanism Scaling factor (DMSF) & \\
(DMSF = 1 for active water drive, DMSF = 0 for solution gas drive) \\
Vertical well data \\
Skin factor \\
BHP, psi \\
Residual oil saturation, \% \\
Well bore radius, inch \\
Well cost, 1000 \$ \\
Fixed Operational cost/day, \$ \\
\end{tabular}

Table 5.8: Average petrophysical properties in the drainage area of Thornburg M (Well M) in Judica Field. 


\begin{tabular}{|l|r|}
\hline Field - A & \\
Well L & \\
Data input to history match & \\
\hline \hline Rock Properties & 550 \\
Drainage Radius, $\mathrm{ft}$ & 7.1 \\
Formation Thickness, $\mathrm{ft}$ & 5 \\
Horizontal K, md & 0.5 \\
Vertical K, md & 20 \\
Porosity, \% & 1250 \\
External Drainage Pr, psi & \\
& \\
Fluid Properties & 1.1 \\
Oil Viscosity, cp & 50 \\
Initial oil saturation, \% & 1.04 \\
Formation volume factor, RB/STB & \\
& \\
Drive Mechanism Scaling factor (DMSF) & \\
(DMSF = 1 for active water drive, DMSF $=0$ for solution gas drive) \\
Vertical well data & \\
Skin factor & 1.5 \\
BHP, psi & 20 \\
Residual oil saturation, \% & 30 \\
Well bore radius, inch & 3.95 \\
Well cost, 1000 \$ & 200 \\
Fixed Operational cost/day, \$ & 100 \\
& \\
\hline
\end{tabular}

Figure 5.9: Average petrophysical properties in the drainage area of Thornburg L (Well L) in Judica Field. 


\begin{tabular}{|l|r|l|l|r|r|}
\hline Well M & & & & \\
\hline DMSF & $\mathbf{0 . 8}$ & & & \\
\hline BHP & $\mathbf{1 7 0}$ & $\mathbf{p s i}$ & & & \\
\hline RESMOD results & & & Actual well performance & & \\
\hline & bopd & MBBL & & bopd & MBBL \\
\hline & & & & & \\
\hline Starting production rate & 96.3 & & Avg first production (1st month) & 98.1 & \\
\hline & & & Avg Production from 2 to 12 months & 76.1 & \\
\hline Rate after 84 months & 13.6 & & Rate after 84 months & 12.7 & \\
\hline Cumulative production after 84 months & & 108.2 & Cumulative production after 84 months & & 107.2 \\
\hline
\end{tabular}

Table 5.10: RESMOD ${ }^{\mathrm{TM}}$ predicted production performance from Well M (Thornburg M) in Judica Field. 


\begin{tabular}{|l|r|r|l|r|r|}
\hline Well L & & & & \\
\hline DMSF & $\mathbf{0 . 8}$ & & & & \\
\hline BHP & $\mathbf{2 0}$ & psi & & & \\
\hline RESMOD results & & & Actual well performance & & \\
\hline & bopd & MBBL & & bopd & MBBL \\
\hline & & & & & \\
\hline & & & Avg first production (1st month) & 57.6 & \\
\hline Starting production rate & 30.3 & & Avg Production from 2 to 4 months & 36.4 & \\
\hline Rate after 114 months & 2.1 & & Rate after 112 months & 4.3 & \\
\hline Cumulative production after 114 months & & 37 & Cumulative production after 112 months & & 36.5 \\
\hline
\end{tabular}

Table 5.11: RESMOD ${ }^{\mathrm{TM}}$ predicted production performance from Well L (Thornburg L) in Judica Field. 


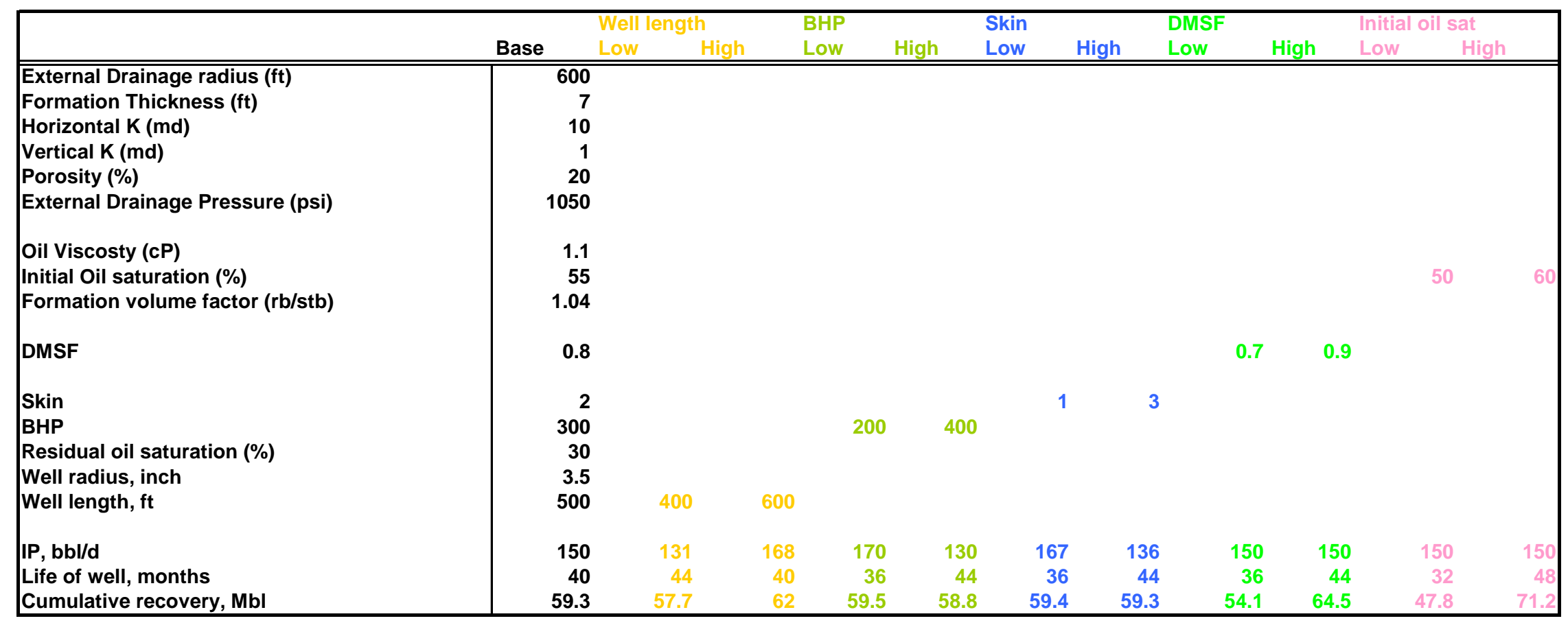

Table 5.12a: Part A - Results of sensitivity studies, on petrophysical and other inputs, on predicted productivity of an infill horizontal well in Judica Field. 


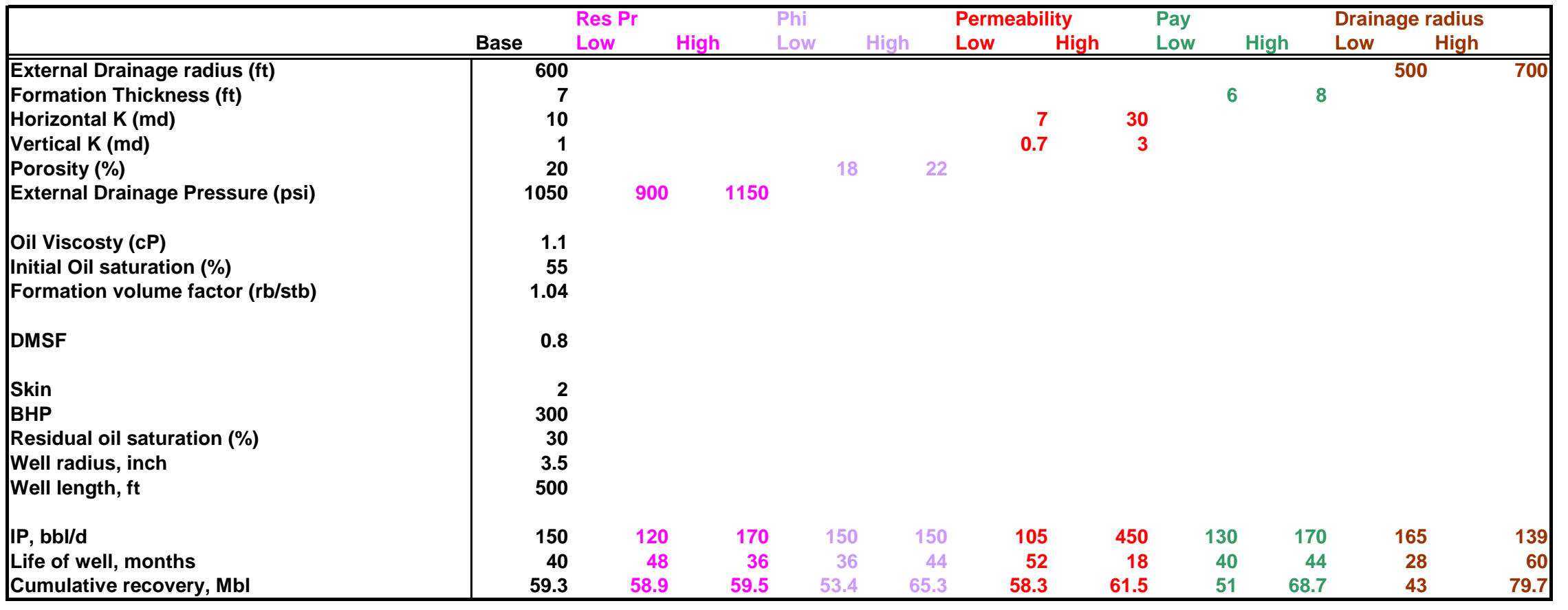

Table 5.12b: Part B - Results of sensitivity studies, on petrophysical and other inputs, on predicted productivity of an infill horizontal well in Judica Field. 


\begin{tabular}{|l|r|r|r|r|r|r|}
\hline & & & Cum, Mbbl & Cum, Mbbl \\
\hline Change in & From & To & & From & To & change \\
\hline \hline Drainage radius, ft & 500 & 700 & 43 & 79.7 & 85.3 \\
\hline Initial oil saturation, \% & 50 & 60 & 47.8 & 71.2 & 49.0 \\
\hline Pay, ft & 6 & 8 & 51 & 68.7 & 34.7 \\
\hline Porosity, \% & 18 & 22 & 53.4 & 65.3 & 22.3 \\
\hline DMSF & 0.7 & 0.9 & 54.1 & 64.5 & 19.2 \\
\hline Well length, ft & 400 & 600 & 57.7 & 62 & 7.5 \\
\hline Permeability, md & 7 & 30 & 58.3 & 61.5 & 5.5 \\
\hline External drainage pressure, psi & 900 & 1150 & 58.9 & 59.5 & 1.0 \\
\hline Skin & 1 & 3 & 59.4 & 59.3 & -0.2 \\
\hline BHP, psi & 200 & 400 & 59.5 & 58.8 & -1.2 \\
\hline
\end{tabular}

Table 5.13: Sensitivity of estimated cumulative production, from a horizontal infill well, to various input parameters. 


\section{General Geology of Mississippian Oil Fields - Central Kansas}

\subsection{Geologic Setting}

The dominant reservoirs in this study are Mississippian marine carbonates (Figure 6.1) deposited on the shallow Kansas shelf region of the Hugoton Embayment of the Anadarko Basin (Figure 4.2). The 3 fields modeled, McDonald, Ness City North, and Judica, are situated on the southwest flank of the Central Kansas Uplift, a structural high that is predominately a post-Mississippian, pre-Pennsylvanian structural feature. Older Paleozoic rocks were eroded from the uplifted area and the subcrop belts of stratigraphic intervals get older towards the uplift (Figures 4.2, 4.3, and 6.2). Mississippian production

in central Kansas is from the Spergen-Warsaw (Meramecian) and Osagean-aged rocks where they subcrop beneath the regional post-Mississippian, pre-Pennsylvanian unconformity. The three fields modeled in this study produce from undifferentiated Spergen-Warsaw.

Spergen-Warsaw sediments were deposited on the shallow portion of a gently dipping ramp that steepened in a southerly direction near the Kansas-Oklahoma state line. Ness County, Kansas, is situated in the upper portion of the main shelf to the inner shelf and its position is shown in Figure 6.2. Sediment textures ranged from carbonate muds to fine to coarse carbonate sands depending upon bathymetry and sediment supply. Slight changes in relative sea level resulted in shifting depositional environments and relatively thin, 6 to 20 feet, stacked shoaling upward parasequences. Later dolomitization and dissolution of bioclasts yielded the porous pay reservoirs of the Spergen-Warsaw with highly variable permeability and water saturations, dependant upon pore geometry.

\subsection{Reservoir Geology}

Mississippian oil in Ness County, Kansas, is produced from small, low relief structural features having 20 to 50 feet of closure (Figure 6.3). Oil can be produced commercially through perforations immediately above the oil-water contact that is 
generally horizontal for a given trap. Though the reservoir above the oil-water contact has an appearance of being continuous pay, it is generally thinly layered with properties for each layer being dependant on the dominant pore type and pore throat geometry for the layer. In the 3 areas modeled, thin, 3 to 15 foot, pay layers could be traced within the 20 to 40 foot thick reservoir. However, these pay layers cannot be traced regionally.

Recognition of distinct lithofacies in Spergen-Warsaw dolomites and their stacking relationships in electric logs facilitates reservoir characterization for the identification and exploitation of bypassed reserves through placement of vertical and horizontal infill wells. Rock properties (porosity, permeability, and capillary pressure) and water saturations are facies dependent. Dolomites with grainier primary textures tend to have higher permeability for a given porosity, lower oil threshold entry pressure, and lower water saturations than do dolomites with muddier primary textures. Dolomitized mudstone pore systems are dominated by microporosity and small pore throats, which result in higher initial water saturations. In a gross pay interval (above oil-water contact) with similar porosity throughout, thin beds of dolomitized packestones are recognized by higher resistivity (lower water saturation, pay). This facies is often interbedded with thin dolomitized mudstones that exhibit low resistivity (higher water saturation, non pay). Very few modern log suites are available in the study area. Predominately, radiation Guard or "RAG" logs are available for a majority of the wells in these fields. However, both old and modern logs, most often, provide sufficient resolution to discriminate facies in the Mississippi dolomites of central Kansas, particularly when augmented with sample descriptions from geological reports.

In the Judica area, for example, the reservoir was subdivided into five main layers that were traceable within the modeled area (Figure 6.4). Primary rock texture of the layers was determined from sample descriptions and electric log character correlated with other Mississippian cores. The pay zones, Layers 1, 3 and 5, are dominated by grainier textures (wackestones and packstones) while carbonate mudstone dominates the non-pay Layers 2 and 4. All 5 layers were dolomitized to fine to medium crystalline, sucrosic porosity. However, relatively large bioclast molds in the grainier Layers 1, 3, and 5 are 
the dominant controls on flow capacity. Larger pore throats prevalent in these layers result in capillary pressures that allow higher initial oil saturations as well. All 5 layers in the pay interval in the Thornburg Q1 well have approximately 20\% porosity, though the resistivities are much higher and the water saturations lower in the 3 pay layers (Figure 6.5). Each of the 3 fields modeled exhibited similar layering. However, these layers are not necessarily traceable outside their respective field areas. In the McDonald Field the reservoir was subdivided into three layers, while the Ness City North and Judica fields were subdivided into 4 and 5 layers respectively. Layering schemes for 2 model areas are illustrated in Figures 6.6 to 6.9 while that for the third is depicted in Figure 7.2.11.

\subsection{Static Model Building Procedure}

Static cellular models were constructed in much the same manner for 3 field areas,

utilizing all available electric logs, drill stem tests, and geologic reports. For fields such as McDonald and Judica, which did not have a core available within the field limits, lithofacies in nearby core were calibrated to $\log$ character to facilitate lithofacies estimation in wells having logs. The following workflow was implemented for building the static models:

1. Identify lithofacies using logs and sample descriptions.

2. Correlate lithofacies between wells and develop layering system.

3. Layer the main reservoir into "pay" and "non-pay" layers.

4. Generate structural grid on top layer.

5. Generate isopach grids of all layers.

6. Generate average porosity grids for each layer based on electric log values.

7. Generate water saturation grids for each layer based on log calculations.

8. Export grids in Z-map plus format for simulation.

Electric logs with adequate reservoir coverage were available for most wells in each model area to map the reservoir. However, most available wireline logs were Radiation Guard Logs (neutron porosity and guard resistivity). After estimating the vertical stacking 
of lithofacies at each well from electric log character, sample descriptions, drillstem tests, and completion responses, the reservoirs were subdivided into the minimum number of layers necessary to distinguish between pay and non-pay. Then these layers were correlated from well to well. Average porosity and water saturations were calculated at each well using available electric logs. A structural grid was generated for the top layer and thickness, average porosity and water saturation grids were generated for all layers. Geoplus Petra ${ }^{\mathrm{TM}}$ was the application used for these operations. Grid xy dimensions were 100 feet and a "highly connected (least squares)" contouring algorithm was used. Grids were then exported for simulator inputs.

\subsection{Ness City North Field Geology}

A horizontal well, Mull Ummel \#4H, was drilled in April 2000 out of a previously drilled vertical well called Mull Ummel \#4 which turned out to be dry and thus abandoned after extensive testing in Ness City North Field, Ness County, Kansas. The Ummel \#4H well had a horizontal displacement of 628 feet and a lateral length of 533 feet within the reservoir interval. A gamma-ray log was run along with the drilling tool and it showed numerous near-vertical shale intervals along the lateral length of the well. These vertical shale intervals reduced the effective productive length of the horizontal well, and may have been the cause for stability problems within the openhole completed lateral. The clean and effective productive length in the lateral was approximated at 440 feet.

An earlier report (Carr et al., 2001) details the geologic interpretation of the reservoir around the Ummel \#4H well. The vertical shale intervals were interpreted as solution-enhanced fractures extending down from the karst erosional surface that defines the top of the Mississippian reservoir. Based on cuttings and the MWD gamma ray log, the vertical shale intervals were found to be filled with lithologies similar to the overlying Pennsylvanian Cherokee Shale. The vertical shale intervals vary in width from a few inches to more than 6 feet. In addition to creating stability problems in open hole laterals, 
the vertical shale intervals were believed to create barriers to fluid flow in the reservoir and, thereby, limiting drainage from vertical wells.

The Ummel \#4H well produced for about a month averaging 54 bopd and 50 bwpd against an average bottom hole pressure of about 650 psi. Thereafter, the well rates rapidly decreased to near zero (1 bopd, 3 bwpd). It appeared, and was subsequently confirmed during later remedial workover operations, that the vertical shale intervals collapsed into the openhole lateral because of inherent lack of stability. The remedial coiled tubing operations in Ummel \#4H were unsuccessful in cleaning out the lateral and restoring production from the well. 


\begin{tabular}{|c|c|c|c|}
\hline Era & System & Series & Stratigraphic Un it \\
\hline \multirow{21}{*}{$\begin{array}{l}\frac{0}{0} \\
N \\
0 \\
\frac{D}{\pi} \\
0\end{array}$} & \multirow{8}{*}{ 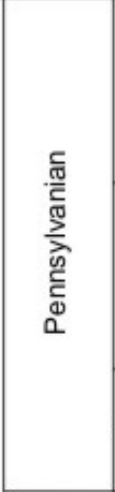 } & \multirow{3}{*}{ Virgilian } & Wabunsee Group \\
\hline & & & Shawnee Group \\
\hline & & & Douglas Group \\
\hline & & \multirow{3}{*}{ Missourian } & Lansing Group \\
\hline & & & Kansas City Group \\
\hline & & & Pleasanton Group \\
\hline & & \multirow{2}{*}{ Desmoinesian } & Marmaton Group \\
\hline & & & Cherokee Group \\
\hline & \multirow{7}{*}{ 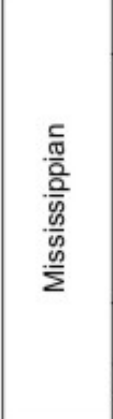 } & Chesteran & \\
\hline & & \multirow{4}{*}{ Meramecian } & St. Genevieve Ls. \\
\hline & & & St. Louis Ls. \\
\hline & & & Salem (Spergen) Ls? \\
\hline & & & Warsaw Ls. \\
\hline & & Osagean & \\
\hline & & Kinderhookian & \\
\hline & \multirow{4}{*}{ 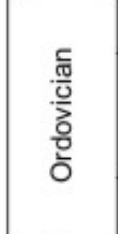 } & Upper & Maquoketa Shale \\
\hline & & \multirow{2}{*}{ Middle } & Viola Limestone \\
\hline & & & Simpson Group \\
\hline & & Lower & \multirow{2}{*}{ Arbuckle Group } \\
\hline & \multirow{2}{*}{ 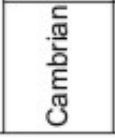 } & \multirow{2}{*}{ Upper } & \\
\hline & & & Reagan Sandstone \\
\hline \multicolumn{3}{|c|}{ Precambrian } & Granite, Schist \\
\hline
\end{tabular}

Figure 6.1: Generalized stratigraphic section for Kansas. The 3 fields that were characterized and simulated in this study produce from the Spergen-Warsaw formations. Figure is modified from Nissen and Carr, 2005. 


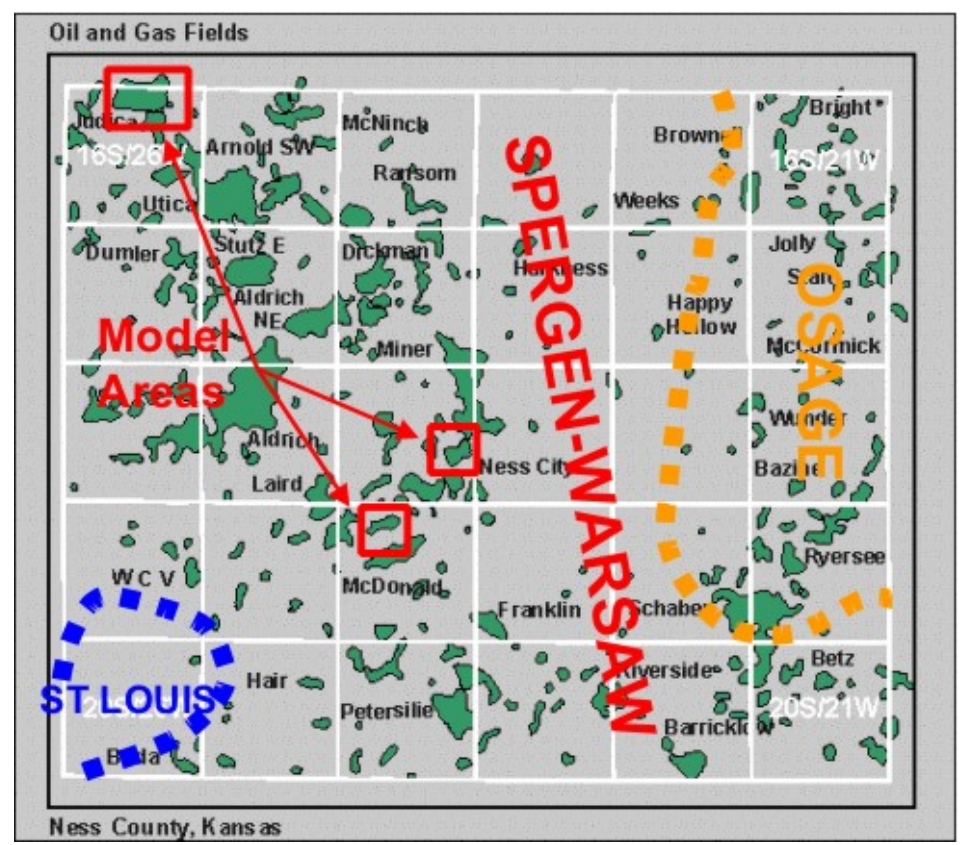

Figure 6.2: Map showing modeled areas located in the Spergen-Warsaw subcrop belt. 


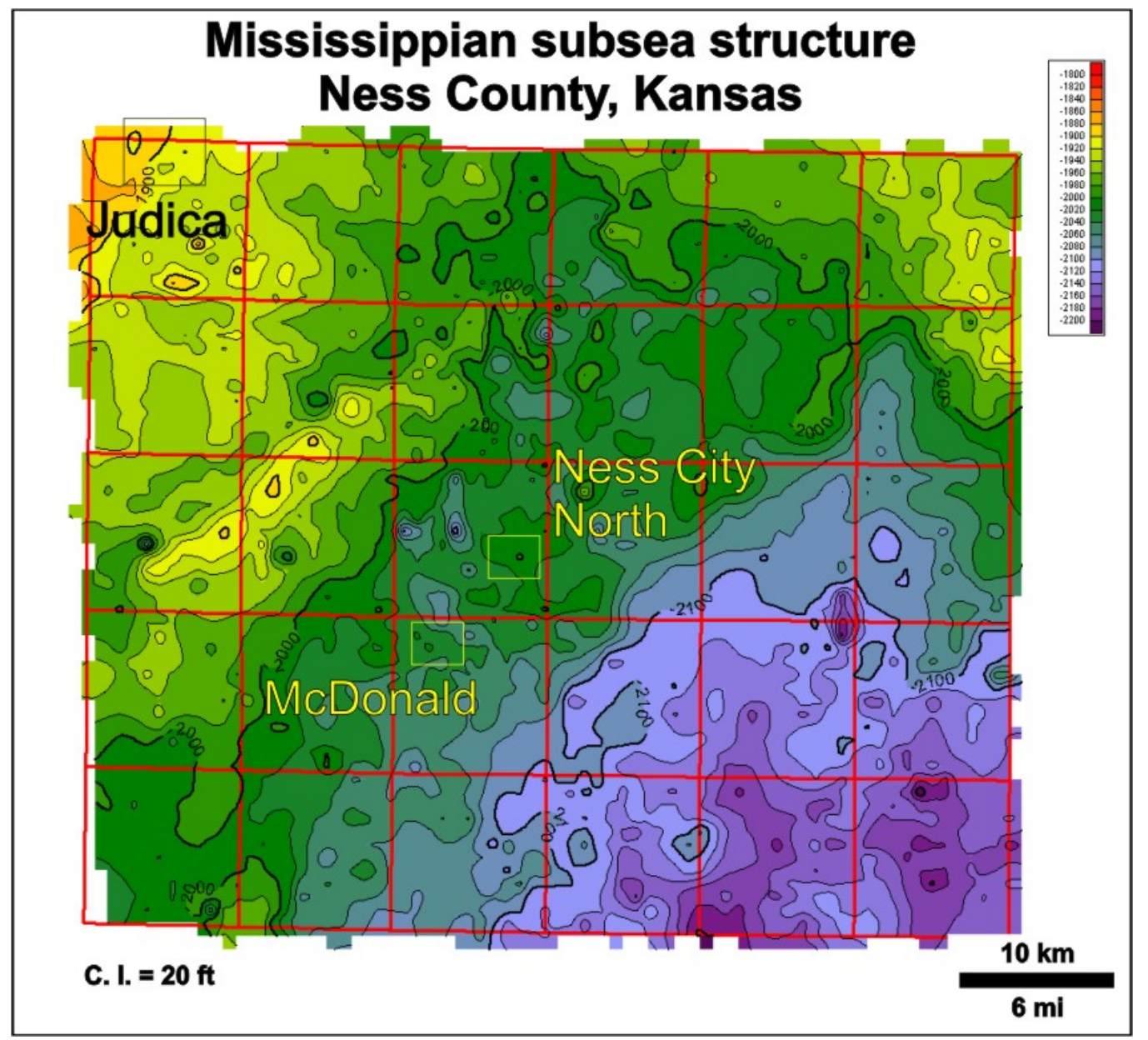

Figure 6.3: Mississippian sub-sea structure map of Ness County, Kansas. (Nissen and Carr, 2005) 


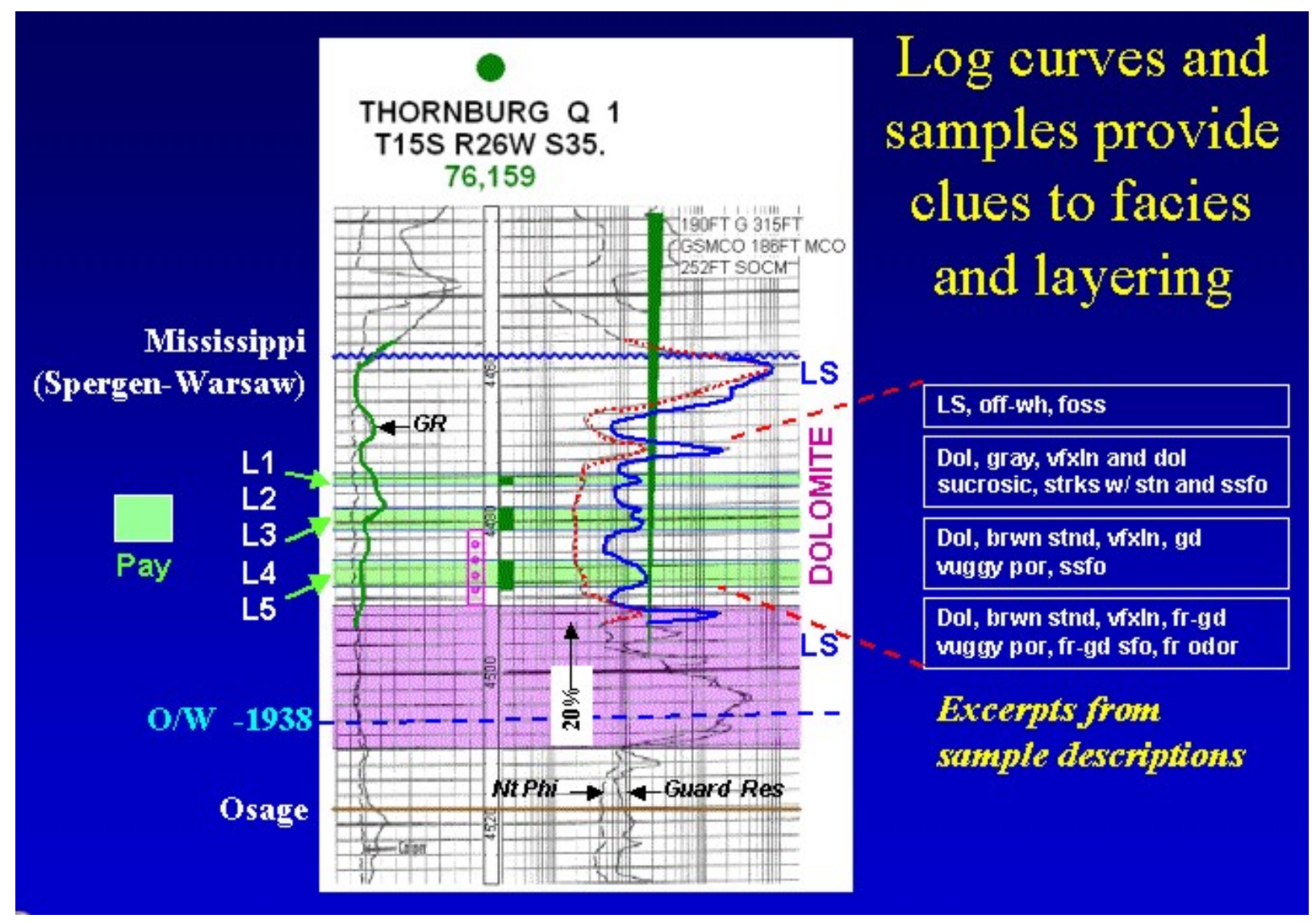

Figure 6.4: Judica area layering in the Spergen-Warsaw reservoir. Layers 1, 3, and 5, are the 3 pay intervals and are made up of dolomitized wackestones and packstones while the non-pay layers 2 and 4 are fine crystalline dolomitized mudstones. (Dubois et al., 2003) 


\begin{tabular}{|rrrrr|}
\hline & $\begin{array}{r}\text { Probable } \\
\text { Facies }\end{array}$ & Phi & Rt & $\begin{array}{r}\text { Archie } \\
\text { SW }\end{array}$ \\
L1 & Wk-Pkst & 0.18 & 17 & 0.467 \\
L2 & Mudstone & 0.19 & 7 & 0.689 \\
L3 & Wk-Pkst & 0.2 & 15 & 0.447 \\
L4 & Mudstone & 0.2 & 5 & 0.775 \\
L5 & Packstone & 0.19 & 18 & 0.430 \\
& & $R w=0.12$ & $m \& n=2$ \\
\hline
\end{tabular}

Figure 6.5: Electric log calculations for Thornburg Q1 Spergen-Warsaw (layers 1 to 5) from the Judica Field. 


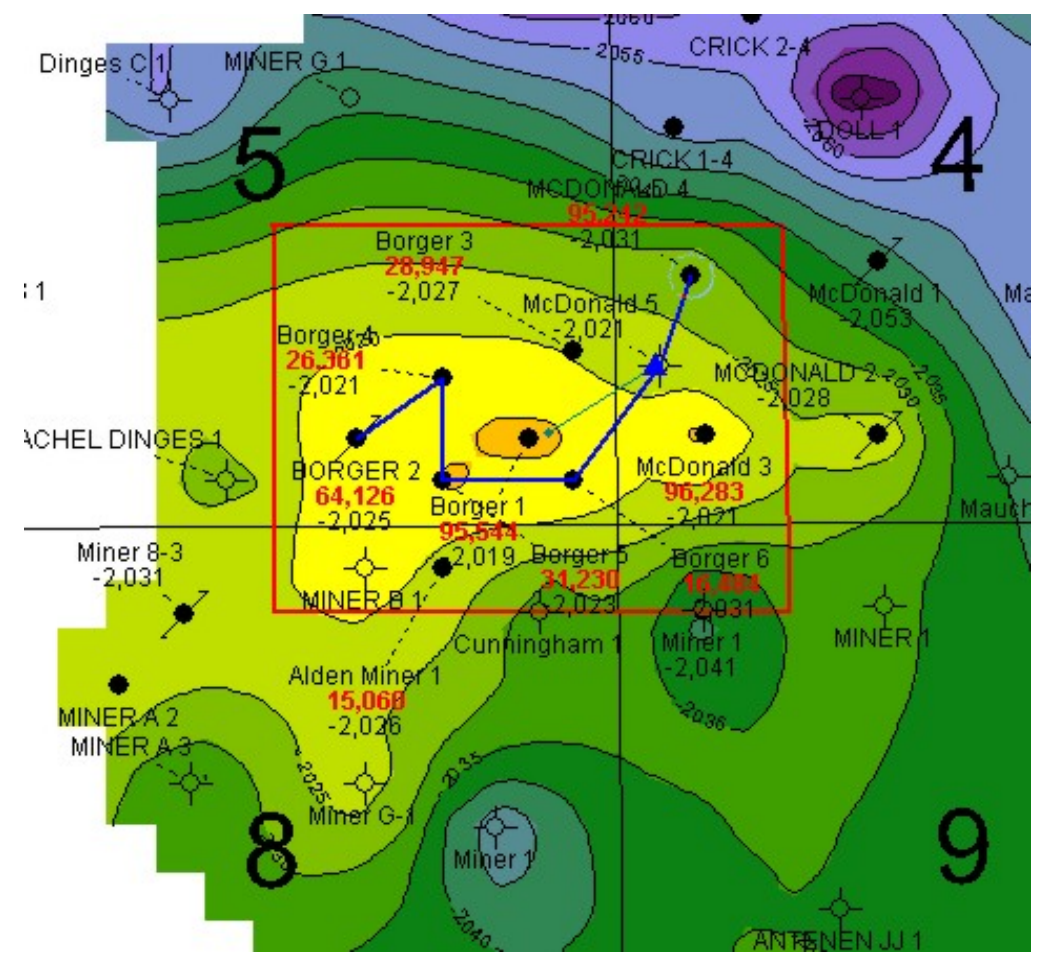

Figure 6.6: McDonald area index map showing locations of wells in the cross section (shown in Figure 6.7). 


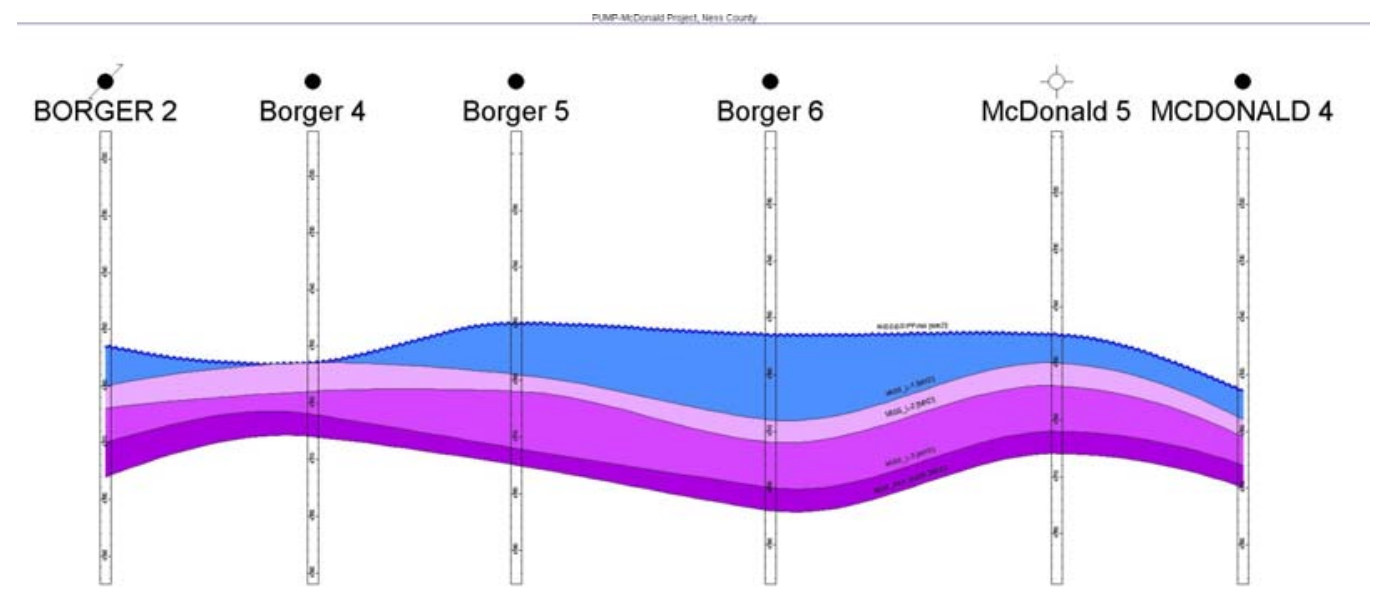

Figure 6.7: Example structural cross section in McDonald field. Three layers modeled are shown in shades of magenta. Area shaded blue is "non pay" Mississippi above the main reservoir. 


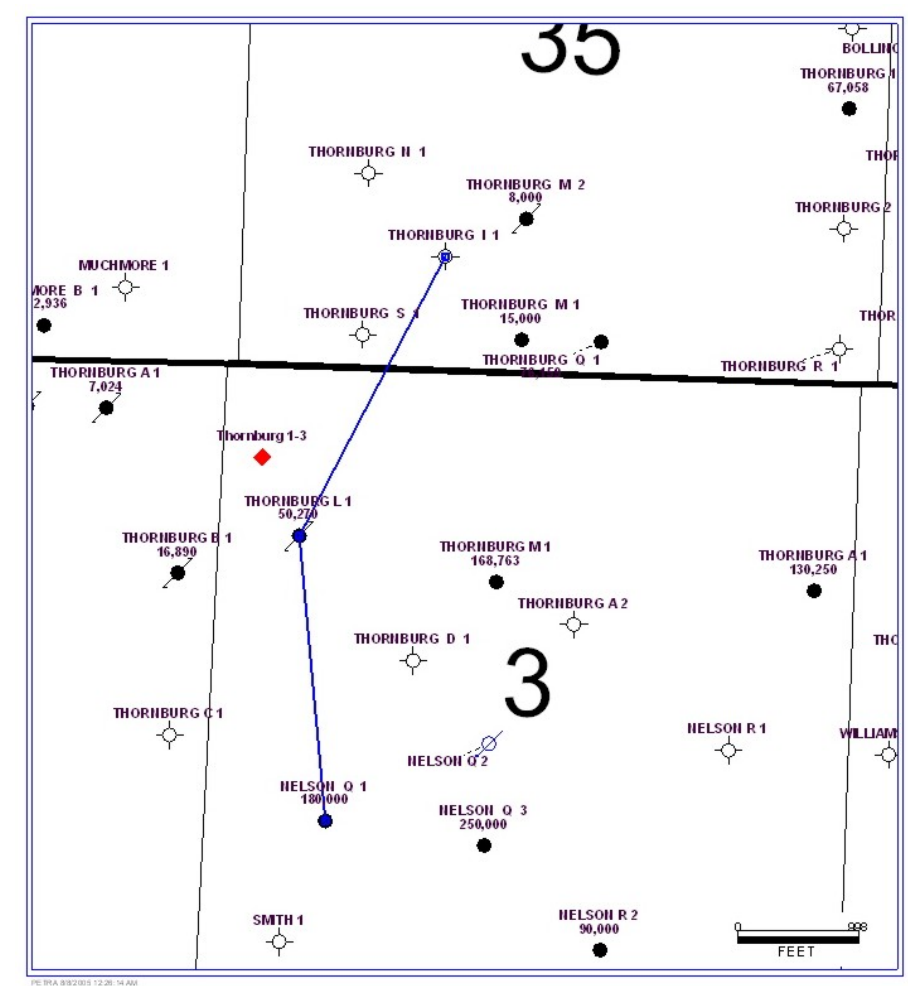

Figure 6.8: Judica area, index map showing locations of wells in the cross section. 


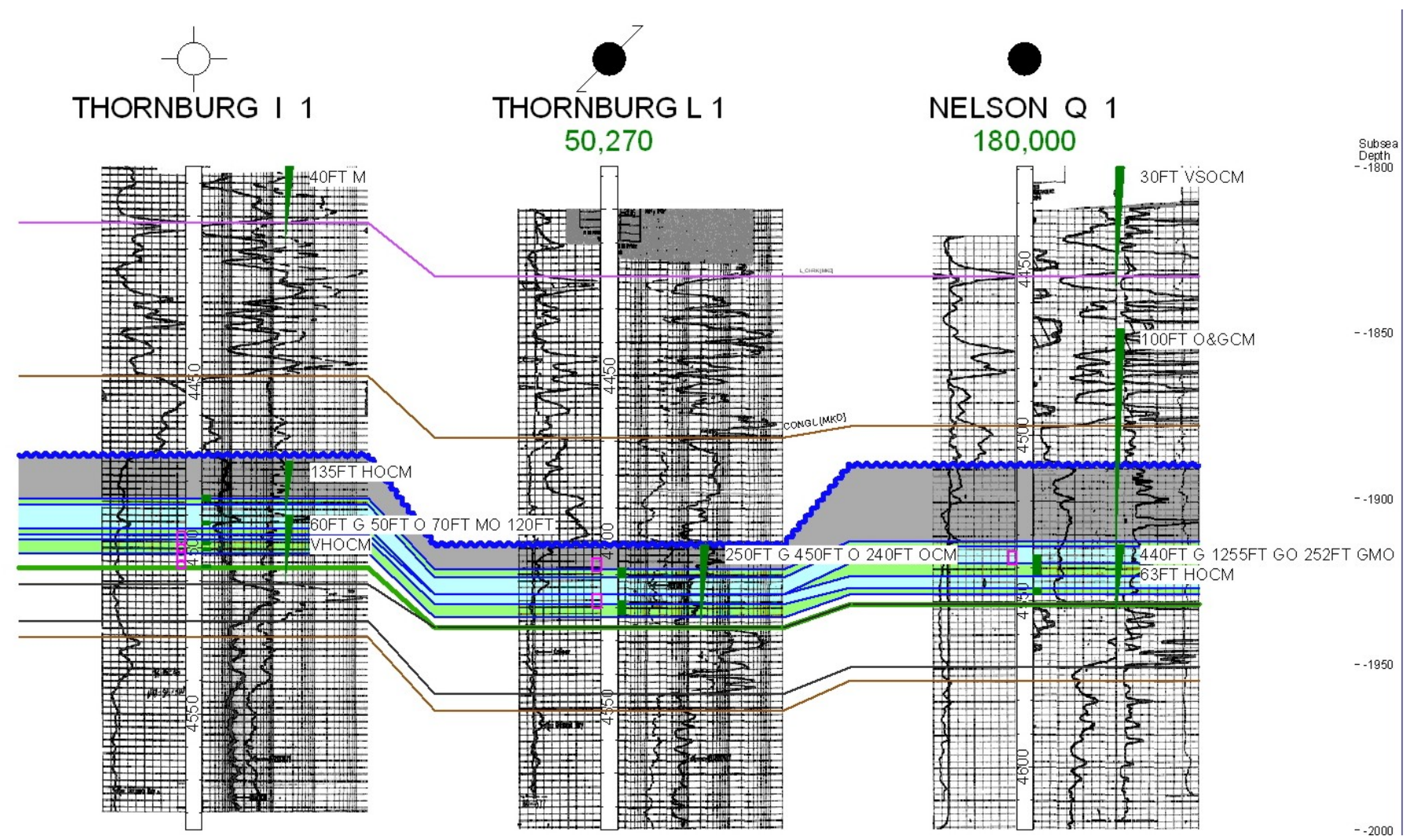

Figure 6.9: Example structural cross section through Judica area. Three "pay" layers are shown in green while "non pay" zones are indicated in blue. Mississippi unconformity surface is indicated by the heavy blue wavy line. Area shaded gray is "non pay" Mississippi above the main reservoir. 


\section{3-D Reservoir Modeling and Simulation - 3 Candidate fields}

\subsection{Reservoir Characterization and Simulation of McDonald Field, Kansas}

\subsubsection{Introduction}

An integrated reservoir characterization study was carried out on McDonald field, Ness County, Kansas, to build a 3D-geomodel, which served as the basis for reservoir simulation. McDonald produces from a Mississippian carbonate reservoir with production commencing in February 1977. Simulation studies were initially carried out to history-match well-level fluid production. Upon completion of history matching, a map of remaining reserves was generated for the field. Thereafter, the remaining reserves map was used to spot different targeted horizontal infill trajectories. Simulation studies were carried out to evaluate the production potential of each of these infill horizontal wells. For a comparative evaluation of productivity, a vertical infill well was also simulated.

\subsubsection{Geologic Model}

Figure 7.1.1 shows the location and the boundary (area bounded by the red rectangle) of the study area for this project. Petrophysical well logs, seismic data, cutting description, DST test results, and geologic reports from wells within and around the study area were used to build a geomodel for the reservoir. Tops of marker beds above and below the reservoir interval and the layers describing the reservoir were identified at each well within and around the study area. A series of cross-sections were generated from different directions and this helped to crosscheck and fine tune the geomodel. For the simulation study, 3 layers were used to model the reservoir. In accordance with the workflow defined in section 6.3, the reservoir was subdivided into layers (Figures 6.6 and 6.7) that were correlated from well to well and average properties estimated at each well. The static model was populated with layer thickness, porosity, and water saturation by layer through simple interpolation between wells, and grids were exported for simulator 
input. All the three layers are productive and intervening shale streaks are not evident. The field has no recorded gas production. Based on reservoir pressure data from development wells it appears that the reservoir produces under an active water drive. Thus in order to model fluid saturation changes due to fluid flow in the vertical direction, more than one layer was used to represent the reservoir.

Figure 7.1.2 shows study area from close. The wells with a full suite of petrophysical logs are circled in red. Also, cumulative oil production from each well is stated below the name of the well. Figure 7.1.3 displays the subsea structure (feet) of the top layer (Layer 1) and the grid used in reservoir simulation. Figures 7.1.4 to 7.1.12 display the isopach, porosity, and initial water saturation (Sw) maps of each of the 3 reservoir layers, i.e., L1, L2, and L3 respectively.

\subsubsection{Production Data Analysis}

This field was discovered and developed by Mull Drilling Company (MDC), and unlike many other independent operators of the mid-continent this company carried out production tests at regular intervals on most of their wells. Thus, a complete fluid production history was available for all but 3 wells, namely, McDonald \#3 (MDC, Sec 4), Borger \#1 and Borger \#2 (MDC, Sec 5). These were relatively older wells and regular production test data were not available. Thus, decline curve analyses was used to match the initial production (IP) rate and the later recorded (tested) oil rates and thereby generate the decline equation for the well. This equation was then used to estimate the missing oil production rates.

For wells with a complete production history, monthly production volumes of both oil and water were available. For each well, an average annual production rate (barrels per day, BPD) was calculated from the monthly oil and water production volumes. Figure 7.1.13 tabulates the cumulative oil production from each well within the study area. 


\subsubsection{Decline Curve Analysis}

One of the critical inputs to a simulation model for history matching is the bottom-hole pressure (BHP) history under which a well is produced over its life. This field was owned and managed by MDC from the beginning and based on the operating policy of the company it was possible to determine that all the wells were produced under minimal standing fluid columns. Thus, it was assumed that each well was produced under a bottom hole pressure (BHP) of 100 psi throughout their life. Hence, decline curves were not applied to determine if wells were produced under unchanging bottom hole conditions. Rather as mentioned earlier, decline curve analyses was carried out to fill in missing oil production at 4 wells.

At each of the wells with missing oil production rates, decline curve analysis was carried out by plotting the IP and the available average annual oil production rates on a plot whose axes coincided (in cycle-length) with that of the standard Fetkovich decline curve (SPE-AIME, 1980). Figure 7.1.14 shows the results for Borger \#1 and \#2 (MDC, Sec 5). Single decline curves (blue line) were found to represent the available well production histories (red circles) in case of both wells. It is evident from Figure 7.1.14 that no oil production rates were available between the month 1 and the 60th month. The decline equation for each well was used to estimate production during this missing period for each well. A similar exercise (Figure 7.1.15) was carried out for McDonald \#3 and \#4 (MDC, Sec 4). For McDonald \#4 (MDC, Sec 4), an increase in production took place during the 261st month from 1.8 to 9.4 BOPD. Lacking additional information, it was assumed that a single decline equation (shown by the blue line) affected production between the 1st and the 260th month, and this equation was used to estimate the missing oil production rates for McDonald \#4 (MDC, Sec 4). A linear equation that fit the IP water-oil ratio (WOR) and the first recorded WOR from barrel test were used to estimate water production rate corresponding to the period of missing oil production rates. 


\subsubsection{Petrophysical Log Analysis - Super-Pickett Plots}

Wells with a complete suite of petrophysical logs are marked in Figure 7.1.2. Super-Pickett cross-plots (Figures 7.1.16 to 7.1.20) were used to analyze available petrophysical logs. Standard values of $m(=2.0)$ and $n(=2.0)$ were used to analyze the logs. Based on the water salinity information $\left(\mathrm{Cl}^{-} \mathrm{ppm}\right.$ of 17,000) from Borger \#4 (MDC, Sec 5), the formation water resistivity ( $\mathrm{Rw}$ ) was calculated as 0.14 . It appears that bulk volume water (BVW) values have to be less than 0.07 for water-free production or production with minimal water (Figures 7.1.16 and 7.1.18). Perforated zones with BVW values greater than 0.07 (Figures 7.1.17, 7.1.19, 7.1.20, and 7.1.21) produce significant quantities of water in comparison to the produced oil rate. Average values for porosity, effective pay, and initial water saturations (Sw) were obtained from the Super-Pickett analysis at each of the well. These values were used to map the distribution pay, porosity, and initial saturations (Figures 7.1.4 to 7.1.12) in the 3 layers that describe the reservoir.

\subsubsection{DST Analysis}

DST (pressure-time) data were available for 9 wells within the study area and they were analyzed to estimate initial pressure and permeability. Figure 7.1.22 shows the initial pressure $(\mathrm{Pi})$ psi calculated from DST test analysis. Based on this pressure profile, the initial reservoir pressure was assumed to be 1350 psi.

\subsubsection{PVT and Relative Permeability/Capillary Pressure Inputs}

Table 7.1.1 summarizes the PVT inputs to the simulation model. There is no mention of any gas production at McDonald field, and MDC operates most wells under minimal standing fluid columns. Thus, the bubble point pressure is low given that no gas production has been recorded at the wells even when they are produced under pumpedoff conditions. The reservoir produces under a strong water drive. Within the simulation model, each well is produced under a BHP of 100 psi and to prevent any three-phase flow from occurring a low bubble point of 50 psi was assumed (at subsea -2031 feet) in this 
study. No measured bubble point data were available. Other oil PVT properties are listed in Table 7.1.1. Bubble point pressure, reservoir temperature, and oil and gas gravities were input to the inbuilt PVT calculator within the reservoir simulator (Computer Modeling Group’s IMEX) to generate other necessary PVT tables.

No cores were available from McDonald field. However, a Mississippian core from McClure Antenen \#1 well (Sec 6, T19S, R24W, Ness County, Kansas) was available from a neighboring field. Routine and advanced core analyses were carried out on this core to develop representative permeability-porosity correlation (Table 7.1.2) for both the reservoir and non-reservoir rock. Also, capillary pressure measurements were carried out on representative core plugs along with recordings of end-point saturations. Data collected from these core studies were integrated with the data set on Mississippian core plugs that has been built by virtue of studies carried out at the KGS on other Mississippian fields of the mid-continent. Porosity was found to correlate with end-point saturations such as Swi (irreducible water saturation) and Sorw (irreducible oil saturation to water). Using these correlations and measured capillary pressure curves, relativepermeability/capillary pressure calculator was created using Corey-type equations. This type of interactive calculator helped to input a consistent set of relativepermeability/capillary pressure tables into the simulator upon making changes in effective permeability over the drainage area of a well during the history-matching phase. Thus, changing the permeability input in the calculator resulted in updating the table by changing the saturation end points while conforming to the shape of the capillary pressure curve. Also, the relative permeability exponents ( $m$ and $n$ ) enable changing the relative ease of flow between the two fluid phases in the reservoir, i.e., the oil and water, especially during history-matching well-level production. Table 7.1.2 shows the calculator for the reservoir rock (Layers 1, 2, and 3).

Figure 7.1.23 compares the calculated permeability from DST analyses and the corresponding (log-derived) porosity of the tested interval with the permeability-porosity values measured on Antenen core plugs. The permeability-porosity values from the DST analyses fits within the body of corresponding data obtained from the core plugs. Such a 
match indicates that the heterogeneity captured by the core plugs are representative of that existing at a larger scale, i.e., within the drainage area of the wells. Thus, core plug measurements can be considered representative of effective reservoir properties.

\subsubsection{Simulation Study - History Matching}

The reservoir was simulated as a 3-layer model using 110 feet by 110 feet grid cells and an analytical bottom aquifer. The aquifer properties were fine-tuned so that the calculated current reservoir pressure was close to 1000 psi. Initial saturation (Sw) and pressure distributions in the drainage area of each well was input with the help of capillary pressure curves and having the simulator perform gravity-capillary equilibrium calculations. The initial permeability in each layer was populated using the permeabilityporosity correlations generated from core analysis. Each well was produced under a constant BHP $=100$ psi throughout its life with the simulator calculating the oil and water production at the end of every time step. Parameters that were fine-tuned to history- match individual well performance included effective permeability in the drainage area of the well and relative permeability exponents " $m$ " and "n". Table 7.1.3 summarizes the layers each well was perforated within the simulator and is based on recorded perforation depth range(s) and the top and bottom of each of the reservoir layers.

Figures 7.1.24 to 7.1.30 show the history matches obtained at each well in the study area. History matching was started with Borger \#3 (MDC, Sec 5) and proceeded in a counter-clockwise direction by following Borger \#4 (MDC, Sec 5), Borger 2 (MDC, Sec 5), Borger \#5 (MDC, Sec 5), and Borger \#6 (MDC, Sec 5). Upon completion of production history matches at the above wells, the simulator was directed to output its calculated production history for Borger \#1 (MDC, Sec 5) without making any additional modifications. Figure 7.1.29 shows match obtained for Borger \#1 (MDC, Sec 5). The match appears to be reasonable given the fact that it had not necessitated any modifications of the model within the related drainage areas. Also, Borger \#4 (MDC, Sec

5) has historically produced significantly high water volumes (Figure 7.1.25), compared 
to other wells in the field, and MDC suspects that it is the result of a bad cement job. Under such circumstances, part of the water produced at this well is coming from a layer (zone) outside the purview of this model. The history match obtained for McDonald \#4 (MDC, Sec 4) is shown in Figure 7.1.31. Water production records from the onset of production till 1989 are unavailable. The simulator is able to reasonably predict the initial water production, the few available measured data points, but fails to match the increased water production after 1992. MDC carried out a major stimulation job at this well in 1992-93, which resulted in a significant increase in produced fluid volumes. Though no records are available, MDC suspects that the well produced with a significant standing fluid column for some time after the stimulation job. At present, the well produces under pumped-off conditions. Lacking any recorded history of how the standing fluid column varied over time in this well, a constant BHP = 100 psi was used in the simulation study and it proved to be insufficient to model the recorded water production history.

Figure 7.1.32 shows the calculated distribution of reservoir pressure as of January 2003. The average reservoir pressure is around 850 psi. MDC's records indicate that a shut-in fluid level measurement was carried out at Borger \#1 (MDC, Sec 5) in the recent past (exact date unavailable) and it recorded about 2300 feet of standing fluid column above the perforations. Thus, MDC estimates that the current reservoir pressure is the range between 1000 and 1100-psi. However, lacking the exact date of the above shut-in test it is difficult to fine-tune the aquifer strength in the simulator model. A current shutin fluid column record is awaited and based on its results the current model will be finetuned to increase the average reservoir pressure from 850 psi to that which is determined as more representative of the reservoir.

\subsubsection{Performance Evaluation of Different Horizontal Infill Trajectories}

Upon completion of well history matches, a map of residual reserves (oil-ft, product of porosity, oil saturation, and grid thickness) was generated as of January 2003. Figure 7.1.33 maps the remaining potential (oil-ft - product of porosity, oil saturation, and pay thickness) as of January 2003 in McDonald field. Figures 7.1.34 and 7.1.35 show 
the distribution of remaining potential in layers 2 and 1, and it becomes apparent that most of the remaining potential resides in Layer 2. Based on this map (Figure 7.1.36), the productive potential of two infill horizontal trajectories, namely "Hwell 1" and "Hwell 2”, was studied. In each case, the horizontal well was assumed to be 6 inches in diameter and to have been produced for 5 years (starting January 1, 2003) under a constant BHP = 100 psi and a skin factor of 1.5 .

The expected drainage of residual reserves by "Hwell 1" over 5 years of production is shown in Figure 7.1.37. The expected production from this well is plotted in Figure 7.1.38. Simulation studies indicate that after 5 years the expected cumulative production from this well will be in the range of 30 MSTB as it produced about 400 MSTB of water. Figures 7.1.39 and 7.1.40 plot the productive potential of the second horizontal infill trajectory "Hwell 2", and this well is expected to produce about 25 MSTB after 5 years of production.

As of July 1994, a 3-day shut-in test was carried out at this well and the fluid level was found to be only 122 feet above the pump at the end of the test. Thereafter, the well was acidized resulting in a significantly higher standing fluid column in the well. MDC anticipates that the acid treatment opened up communication with the underlying aquifer. Thus, MDC believes that Borger 3 (MDC, Sec 5) drained from a pocket (before the acid treatment) that is isolated from the main reservoir.

The above simulation studies indicate that most of the remaining potential is in an area lying among and around the wells Borger \#1, \#2, and \#3 (MDC, Sec 5). However, production and pressure data collected by MDC from Borger \#3 (MDC, Sec 5) indicate that the drainage area of this well was originally isolated from the main body of the reservoir in McDonald field. Added geologic complexities, such as the flow barrier existing between the drainage area of Borger \#3 (MDC, Sec 5) and the rest of the reservoir, further reduces the productive potential of any horizontal trajectories placed within this area. 


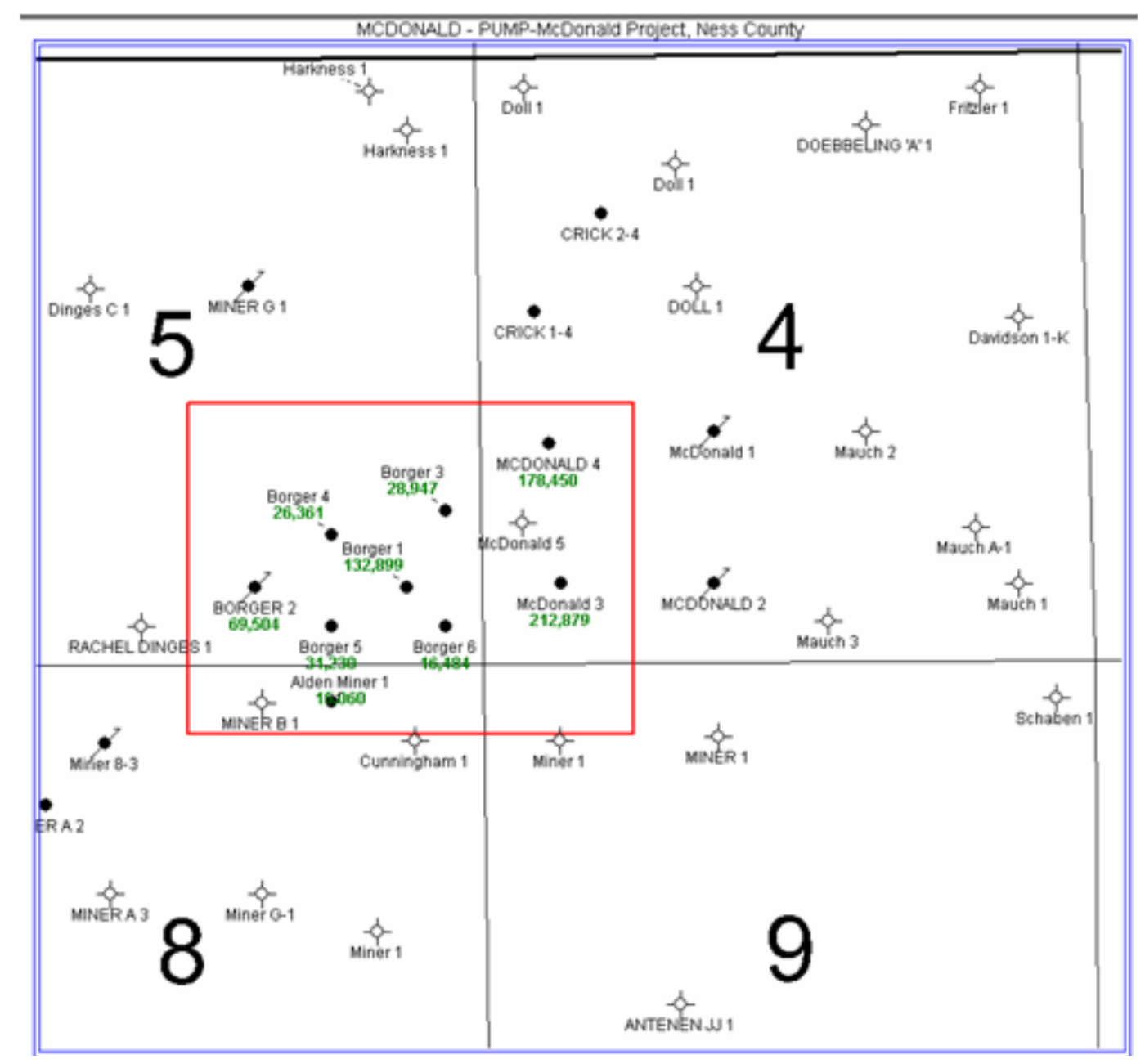

Figure 7.1.1: Location and boundary of McDonald Field, Ness County, Kansas. 


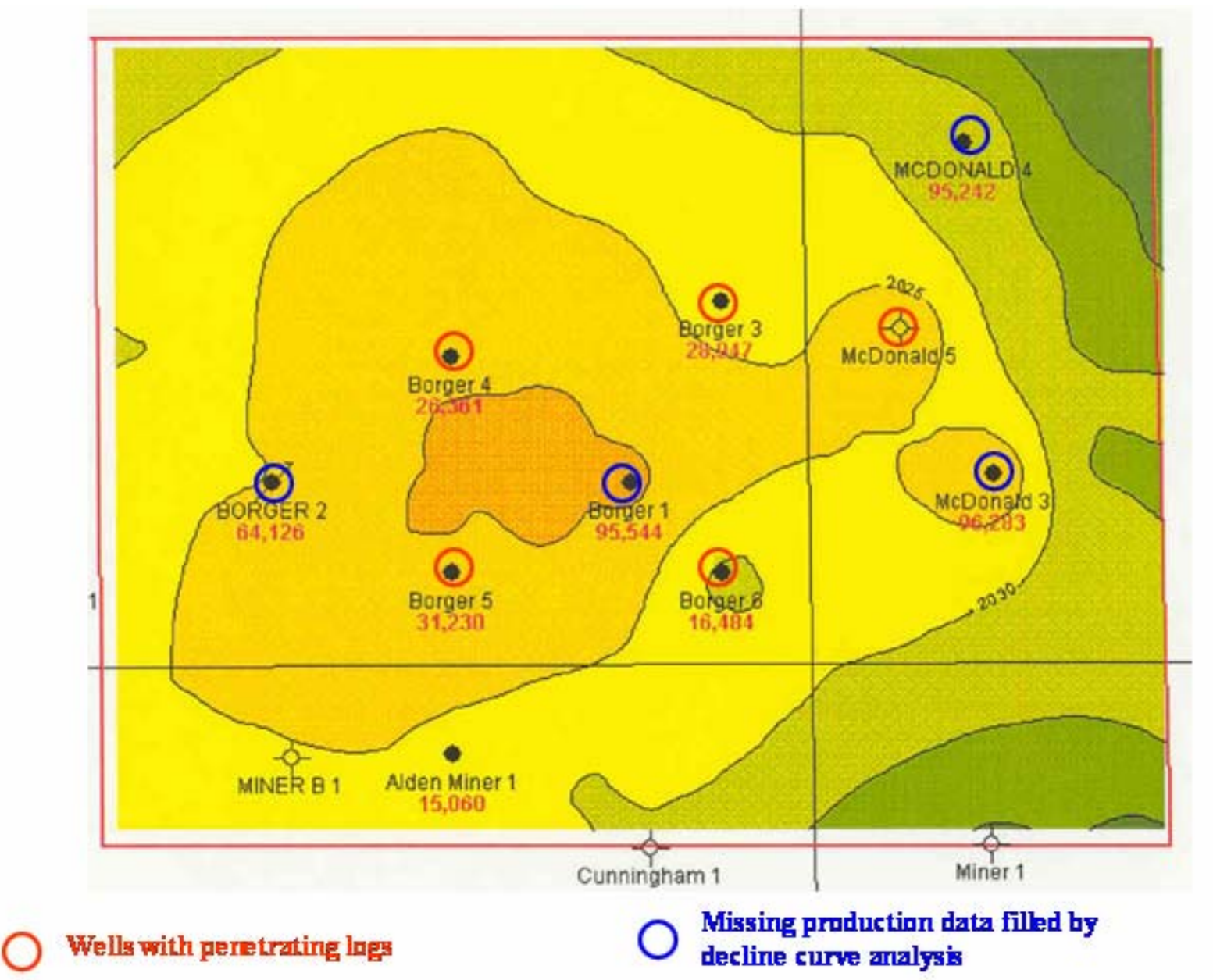

Figure 7.1.2: Location of wells with wireline logs and those with incomplete production histories in McDonald Field. 
MSS L-1 Structure

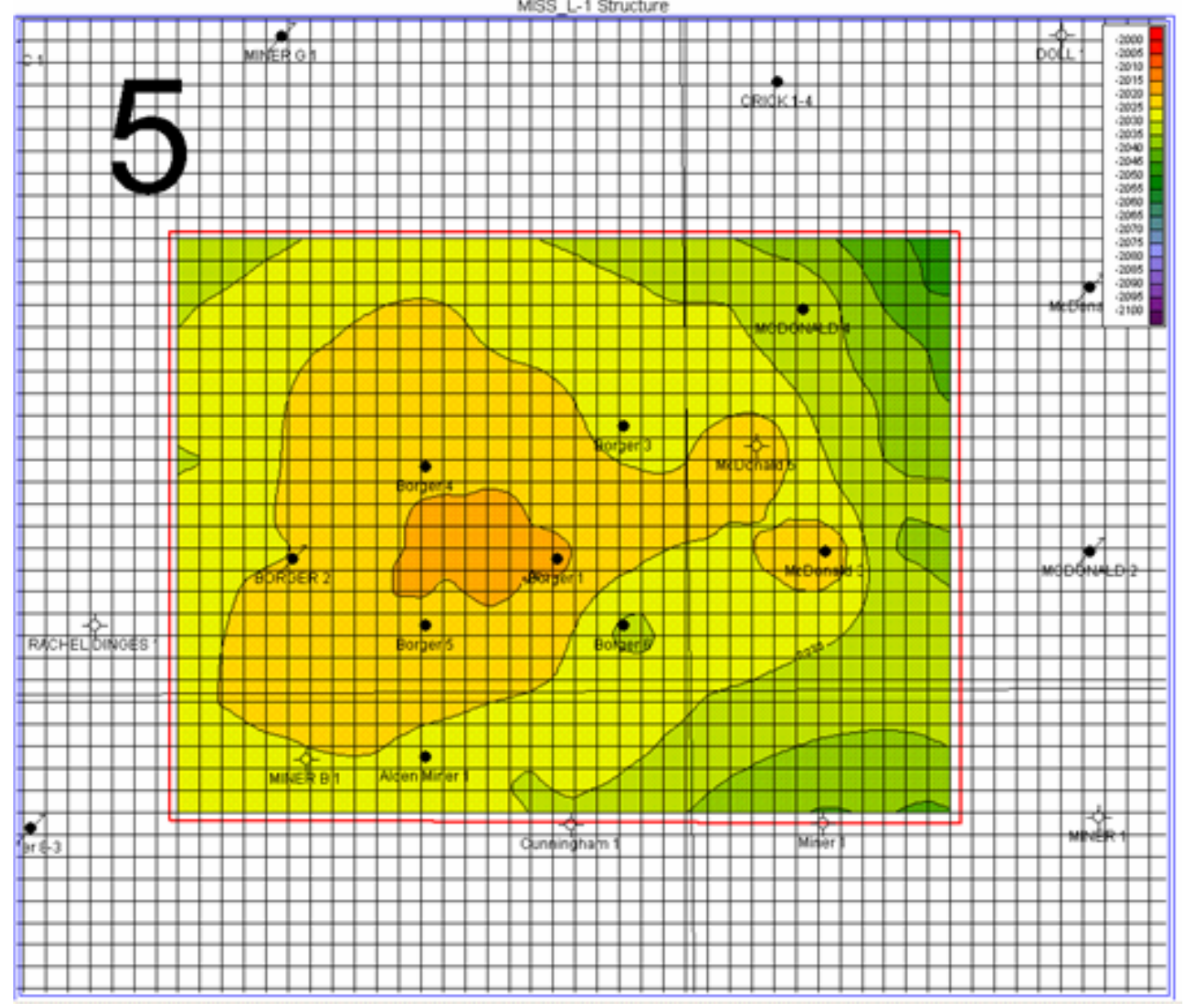

Figure 7.1.3: Subsea structure (feet) map on top of pay (Layer 1) in McDonald Field. 


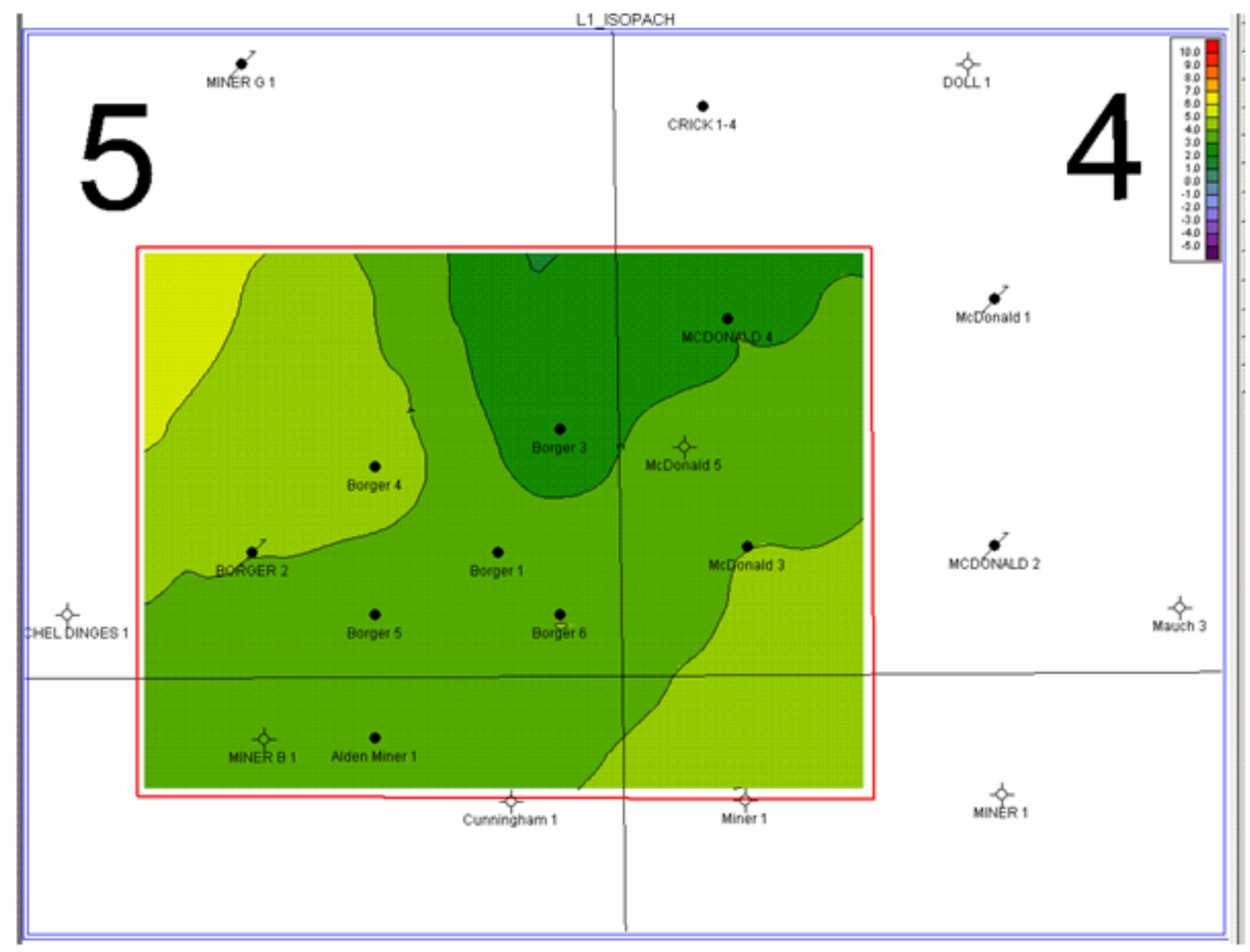

Figure 7.1.4: Isopach (feet) of Layer 1 (L1) in McDonald Field. 


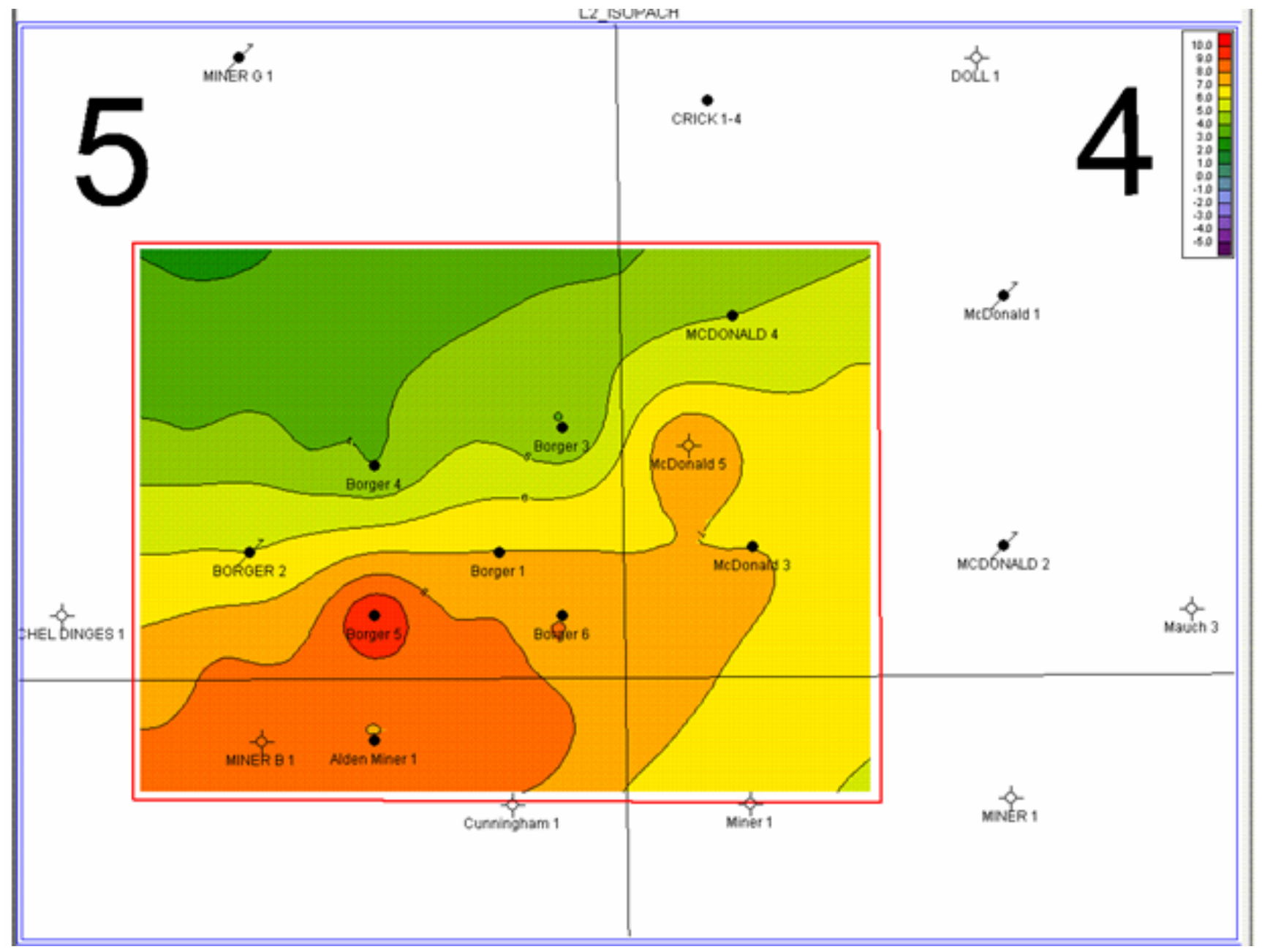

Figure 7.1.5: Isopach (feet) of Layer 2 (L2) in McDonald Field. 


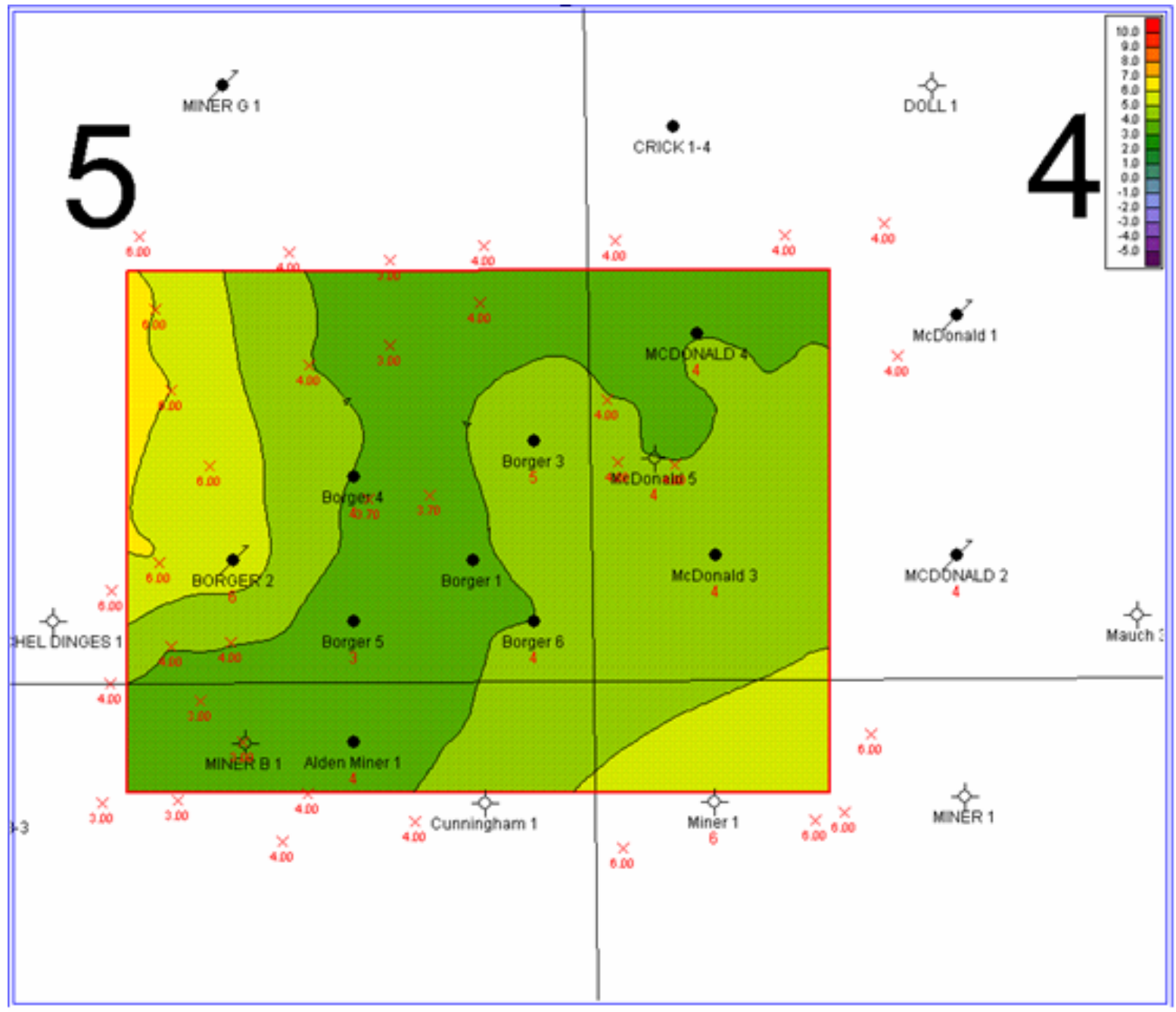

Figure 7.1.6: Isopach (feet) of Layer 3 (L3) in McDonald Field. 


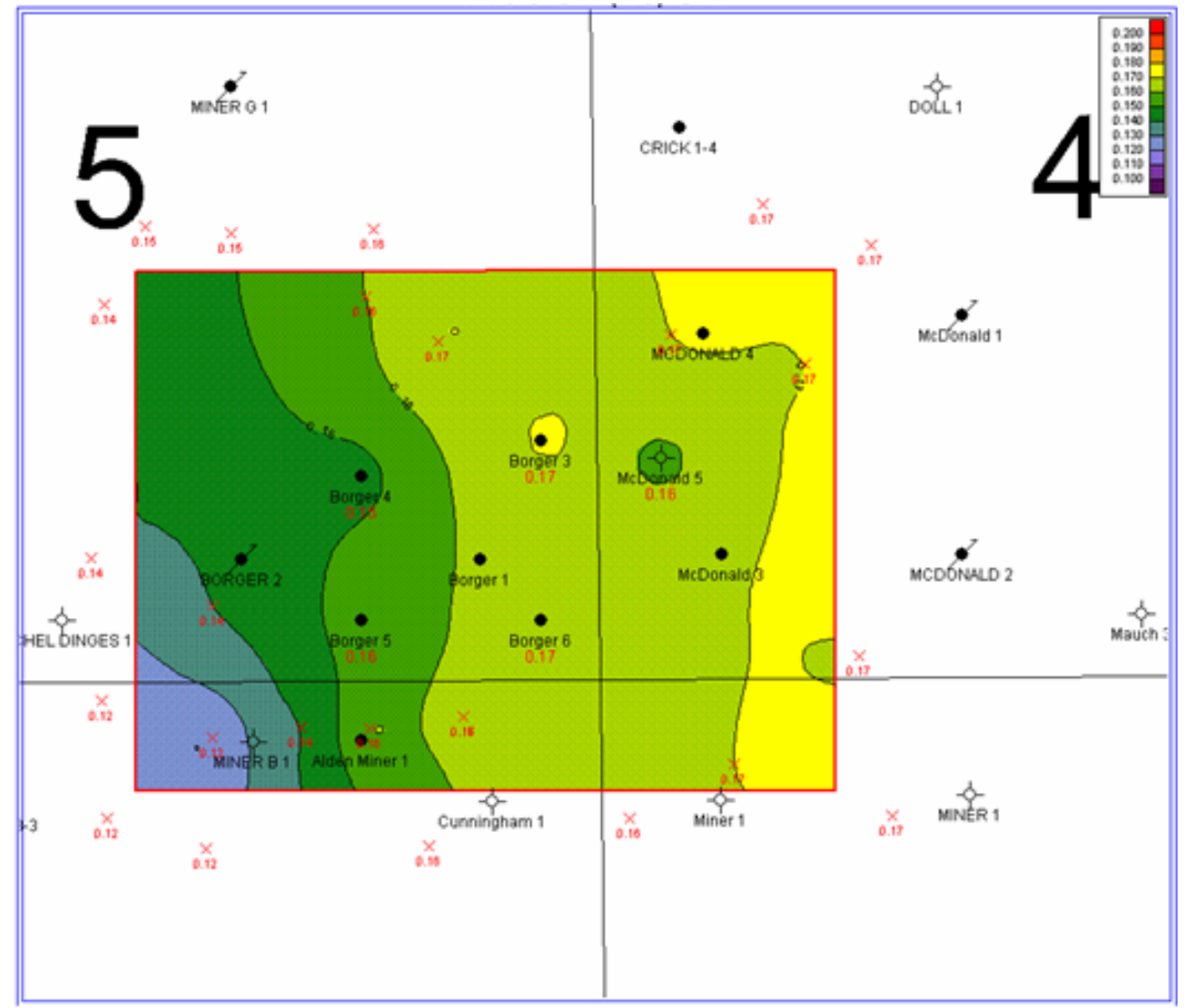

Figure 7.1.7: Porosity (fraction) distribution in Layer 1 (L1) in McDonald Field. 


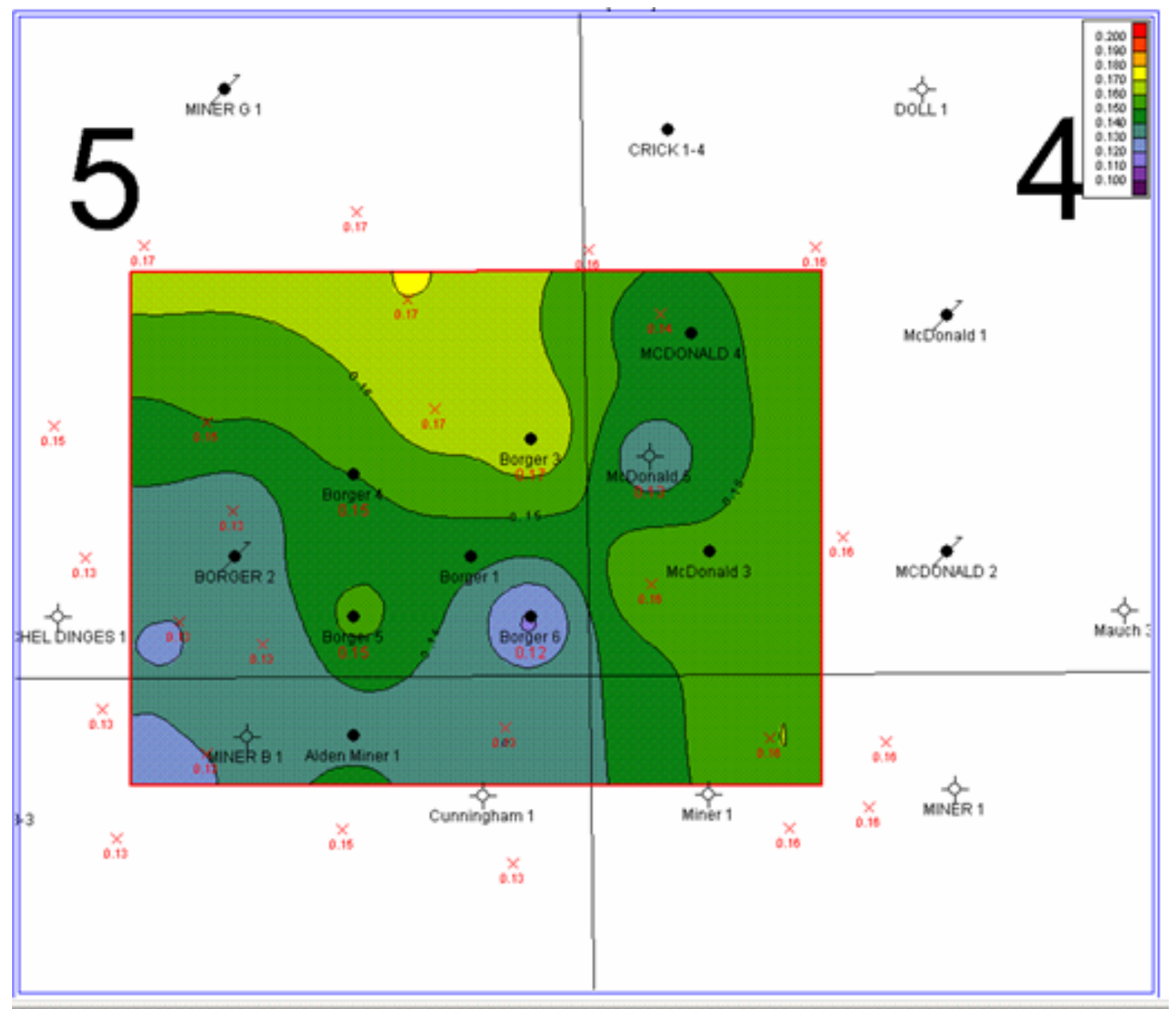

Figure 7.1.8: Porosity (fraction) distribution in Layer 2 (L2) in McDonald Field. 


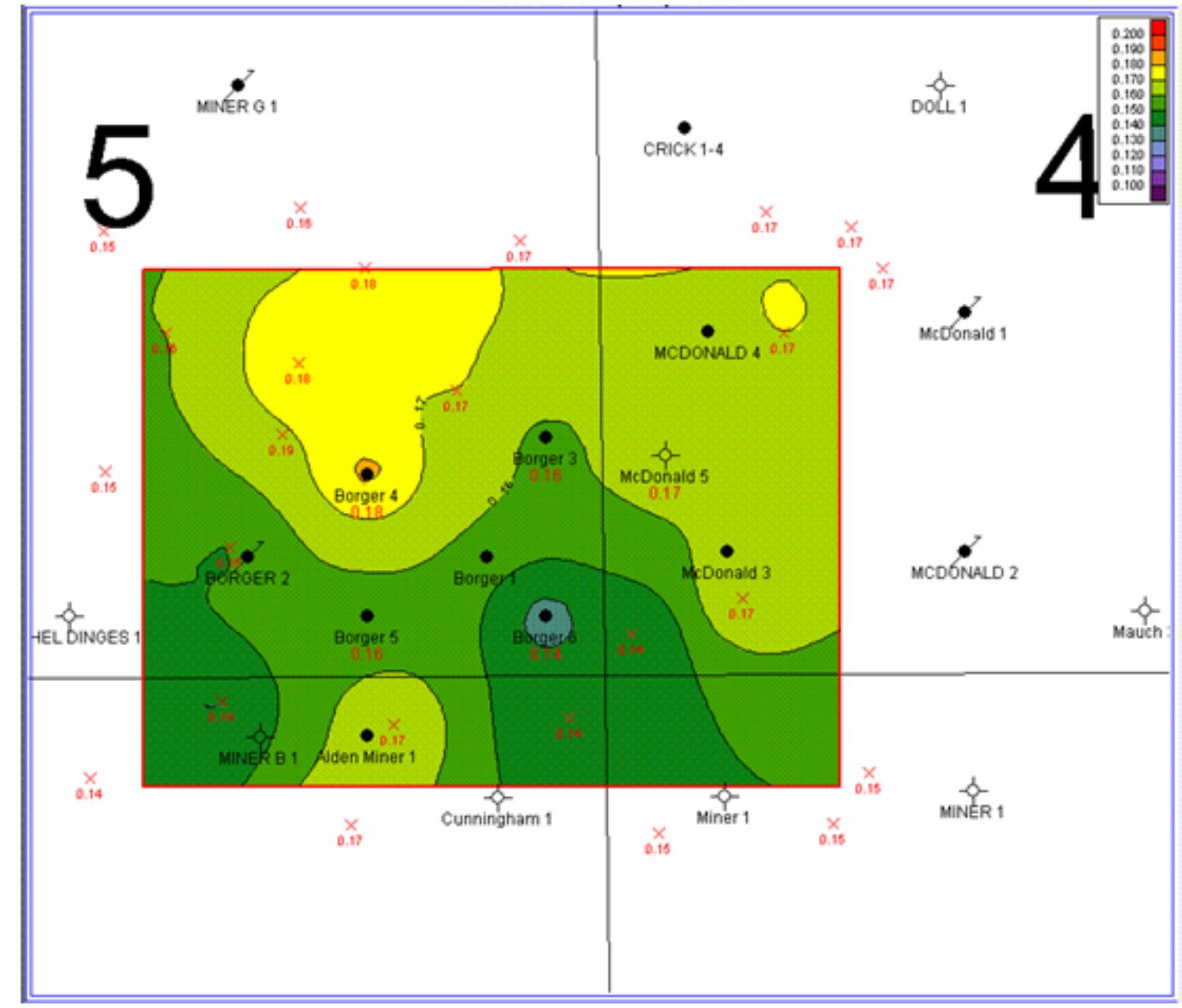

Figure 7.1.9: Porosity (fraction) distribution in Layer 3 (L3) in McDonald Field. 


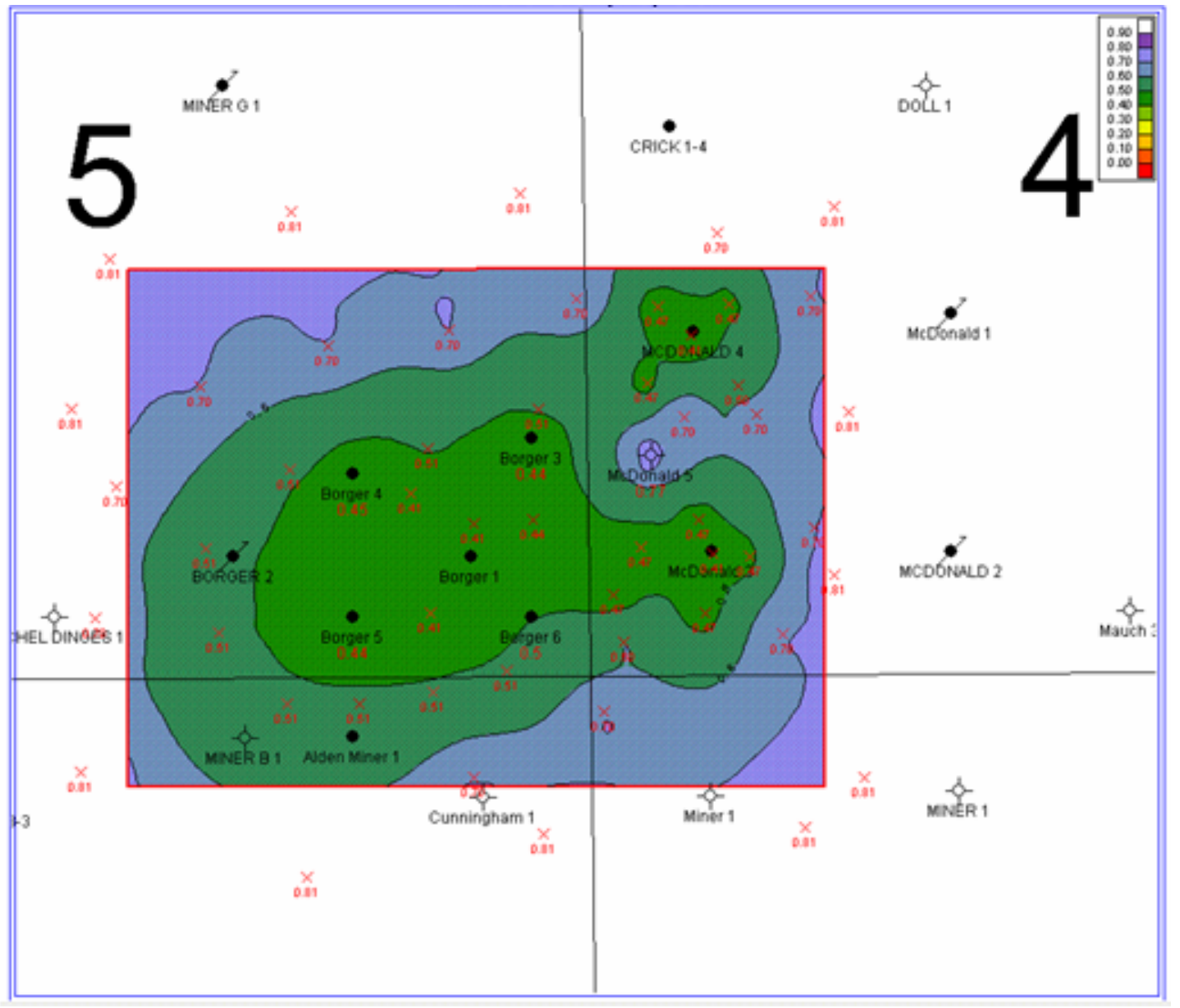

Figure 7.1.10: Distribution of initial water saturation in Layer 1 (L1) in McDonald Field. 


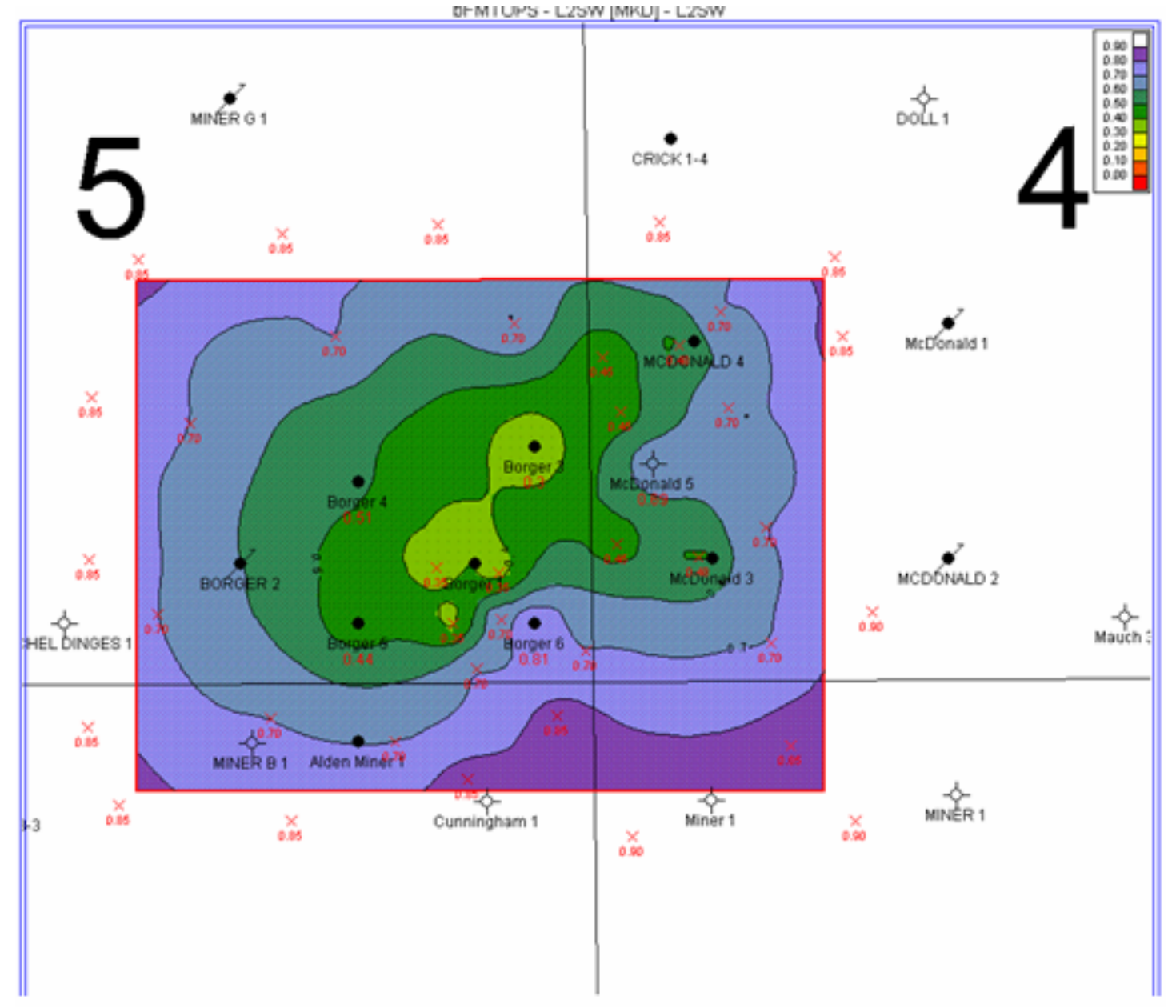

Figure 7.1.11: Distribution of initial water saturation in Layer 2 (L2) in McDonald Field. 


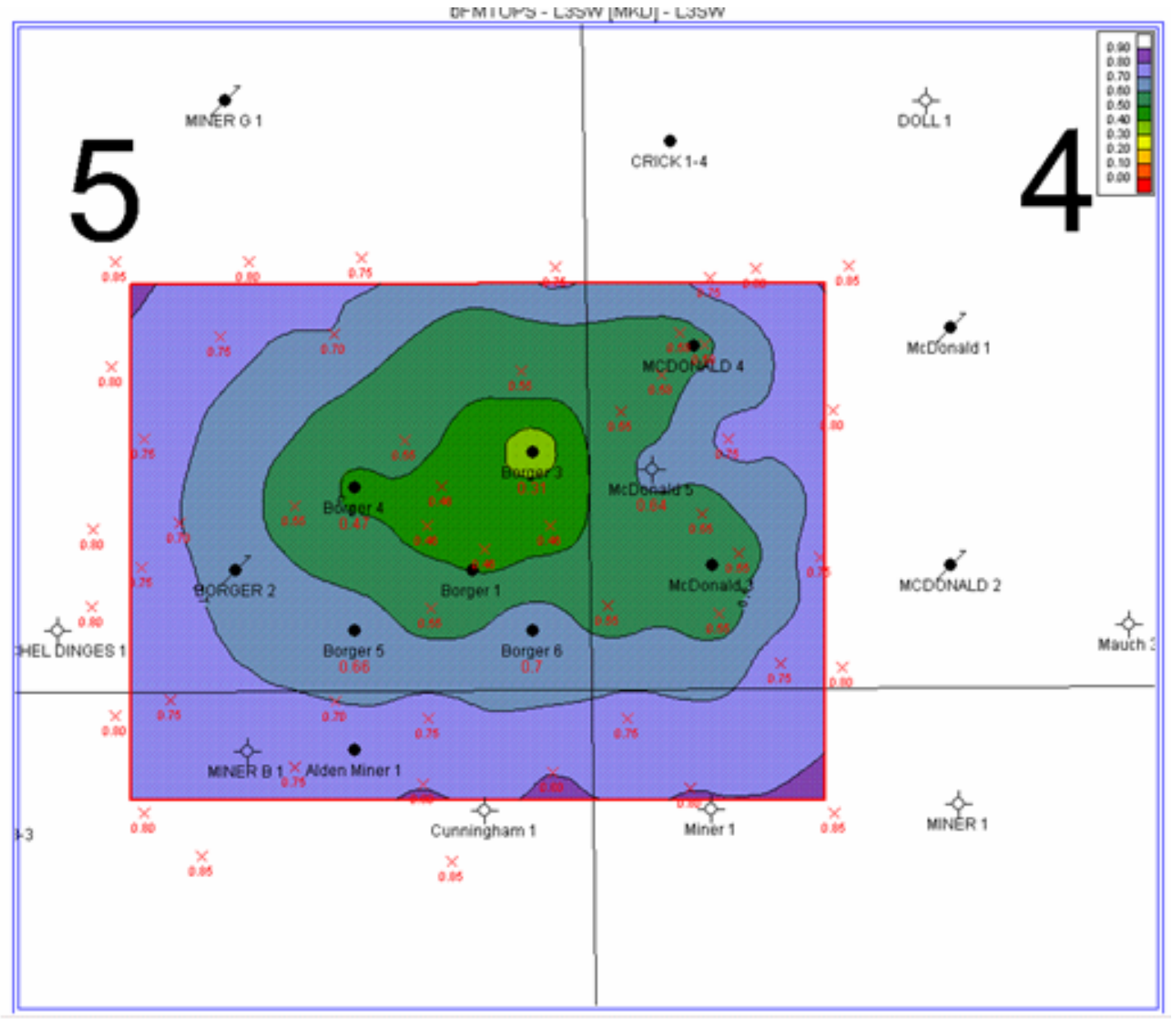

Figure 7.1.12: Distribution of initial water saturation in Layer 3 (L3) in McDonald Field. 


\begin{tabular}{|l|r|r|r|}
\hline Well & Cum Oil, bbls & Prod start \\
\hline \hline Borger 1 & & & \\
\hline Borger 2 & 95,544 & $8 / 1 / 1971$ \\
\hline Borger 3 & 64,126 & $1 / 1 / 1972$ \\
\hline Borger 4 & 28,947 & $4 / 1 / 1993$ \\
\hline Borger 5 & 26,361 & $12 / 1 / 1993$ \\
\hline Borger 6 & 31,230 & $5 / 1 / 1995$ \\
\hline & 16,484 & $12 / 1 / 1996$ \\
\hline McDonald 3 & 96,283 & $4 / 1 / 1971$ \\
\hline McDonald 4 & 95,242 & $4 / 1 / 1971$ \\
\hline & & & \\
\hline Alden Miner 1 & 15060 & $8 / 1 / 1997$ \\
\hline
\end{tabular}

Figure 7.1.13: Well-level cumulative oil production from McDonald Field. 

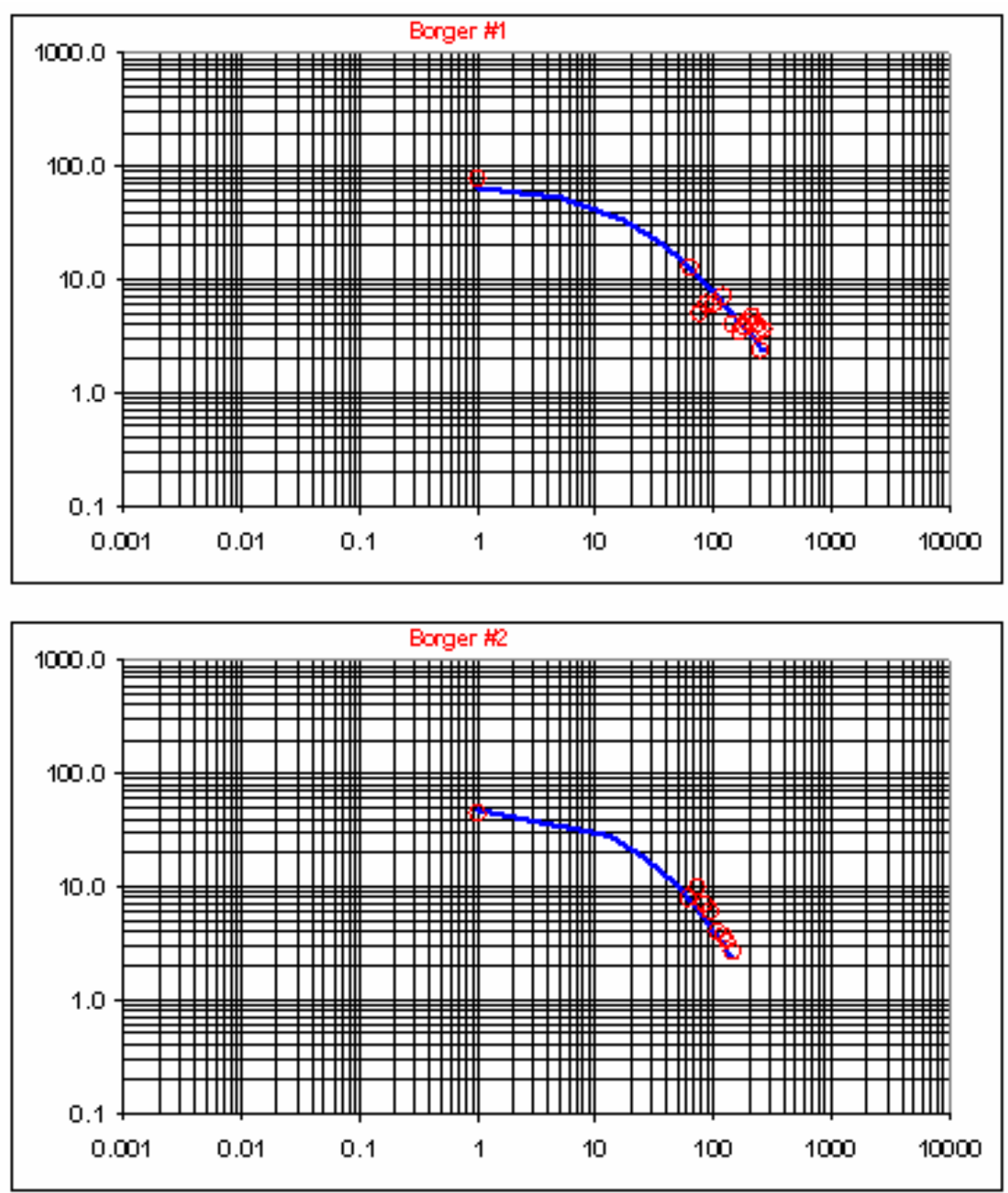

Figure 7.1.14: Decline curve analysis for Borger \#1 and Borger \#2 wells in McDonald Field. 

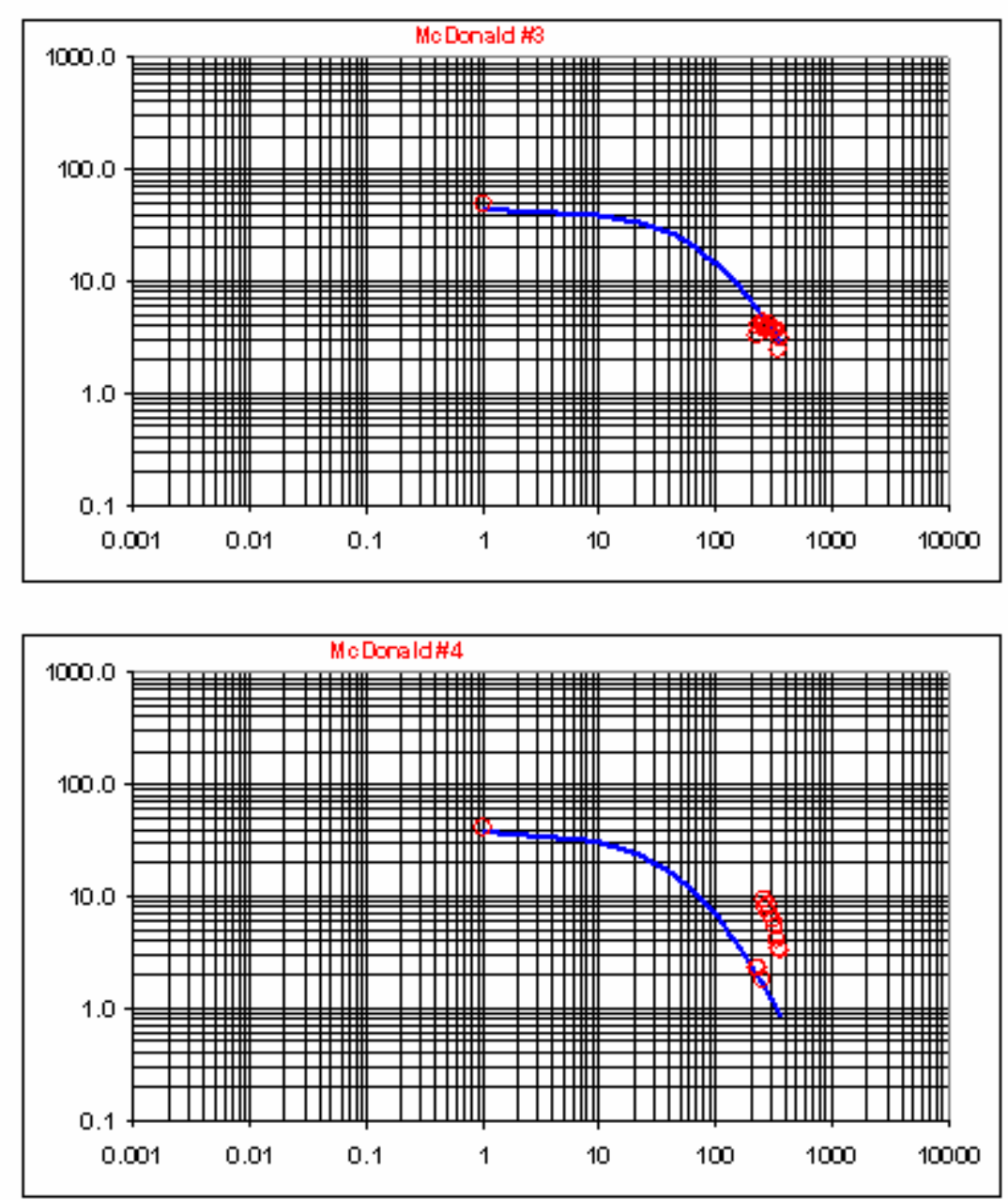

Figure 7.1.15: Decline curve analysis for McDonald \#3 and McDonald \#4 wells in McDonald Field. 


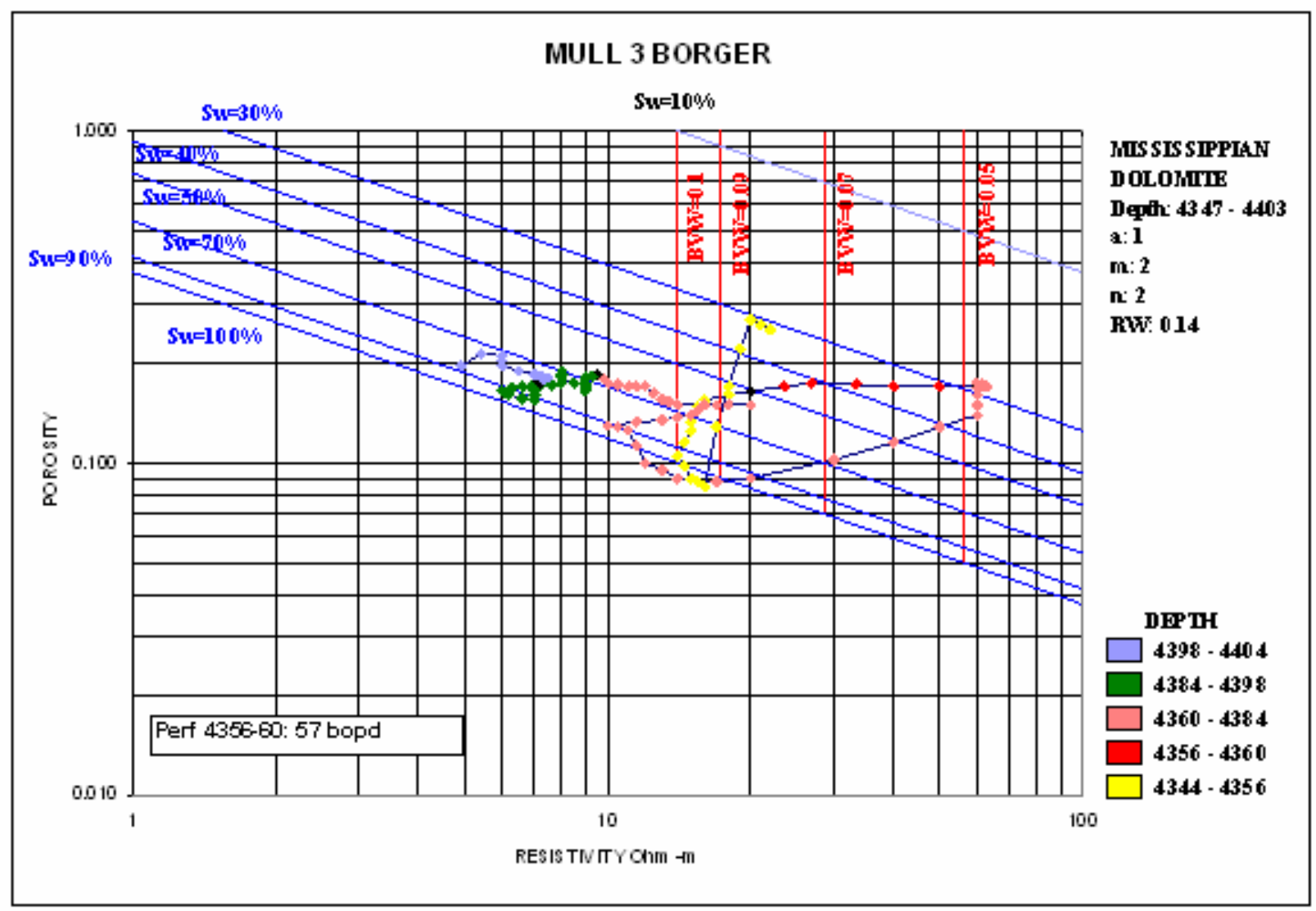

Figure 7.1.16: Super-Pickett analysis of wireline log data from Borger \#3 well. 


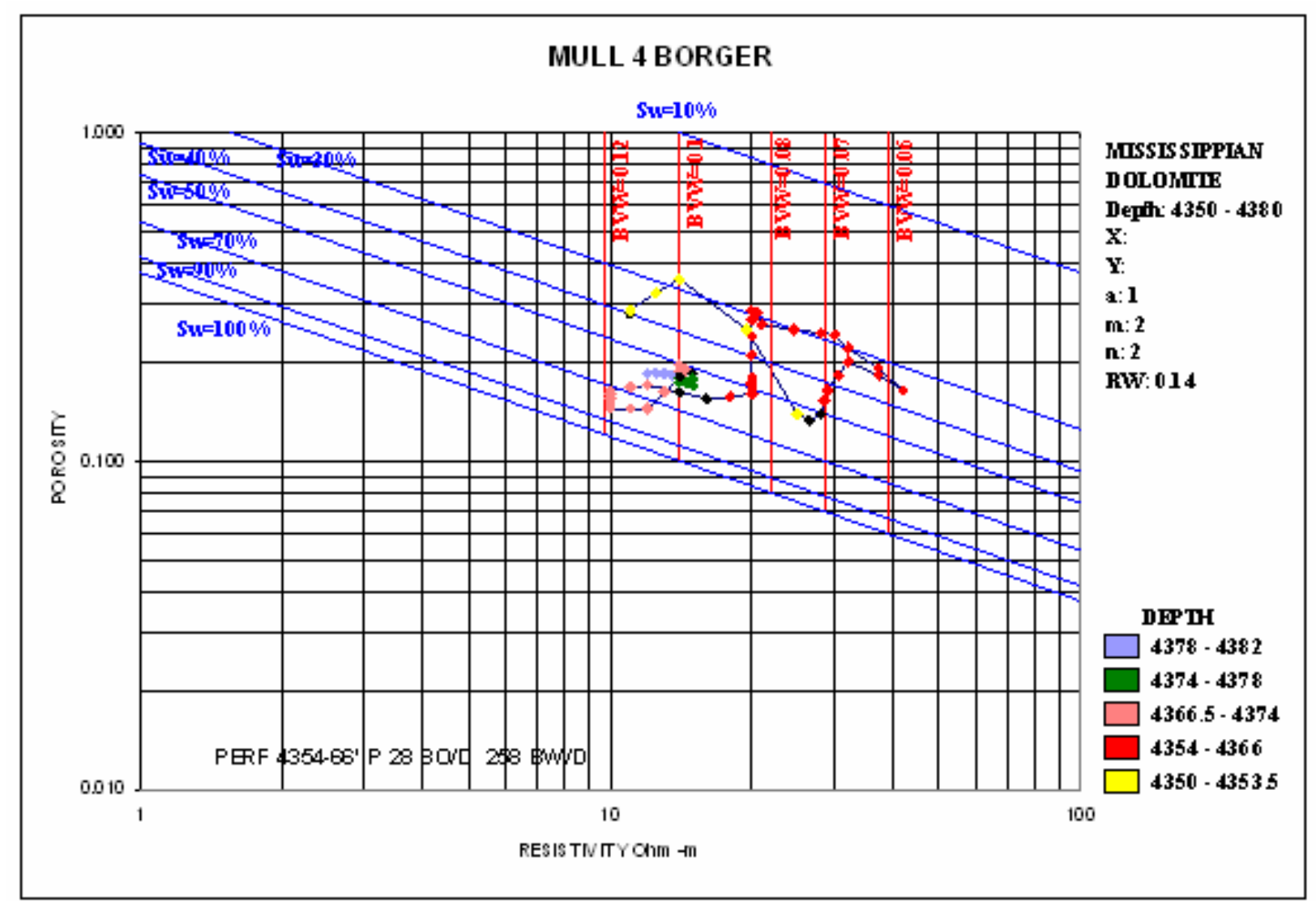

Figure 7.1.17: Super-Pickett analysis of wireline log data from Borger \#4 well. 


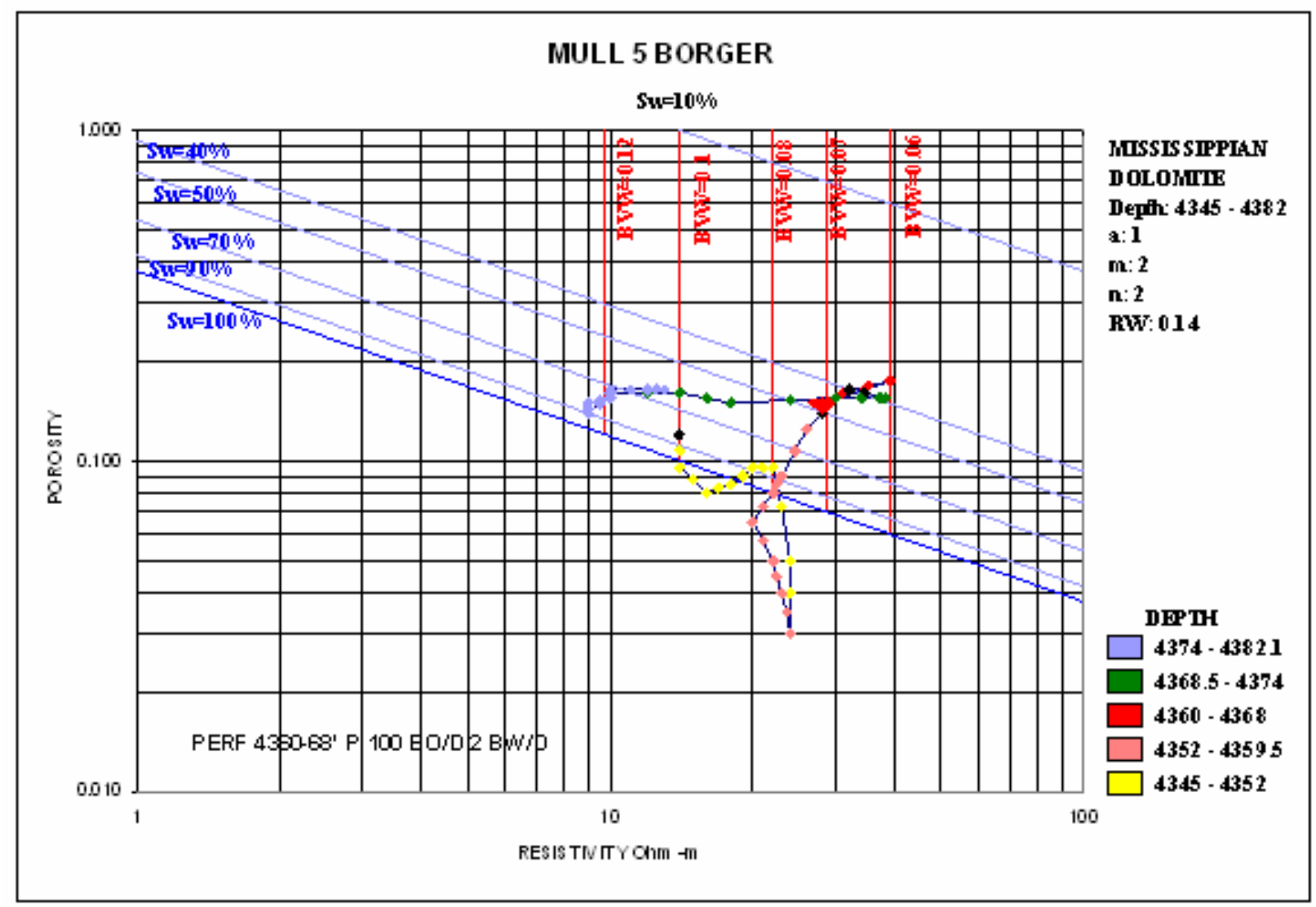

Figure 7.1.18: Super-Pickett analysis of wireline log data from Borger \#5 well. 


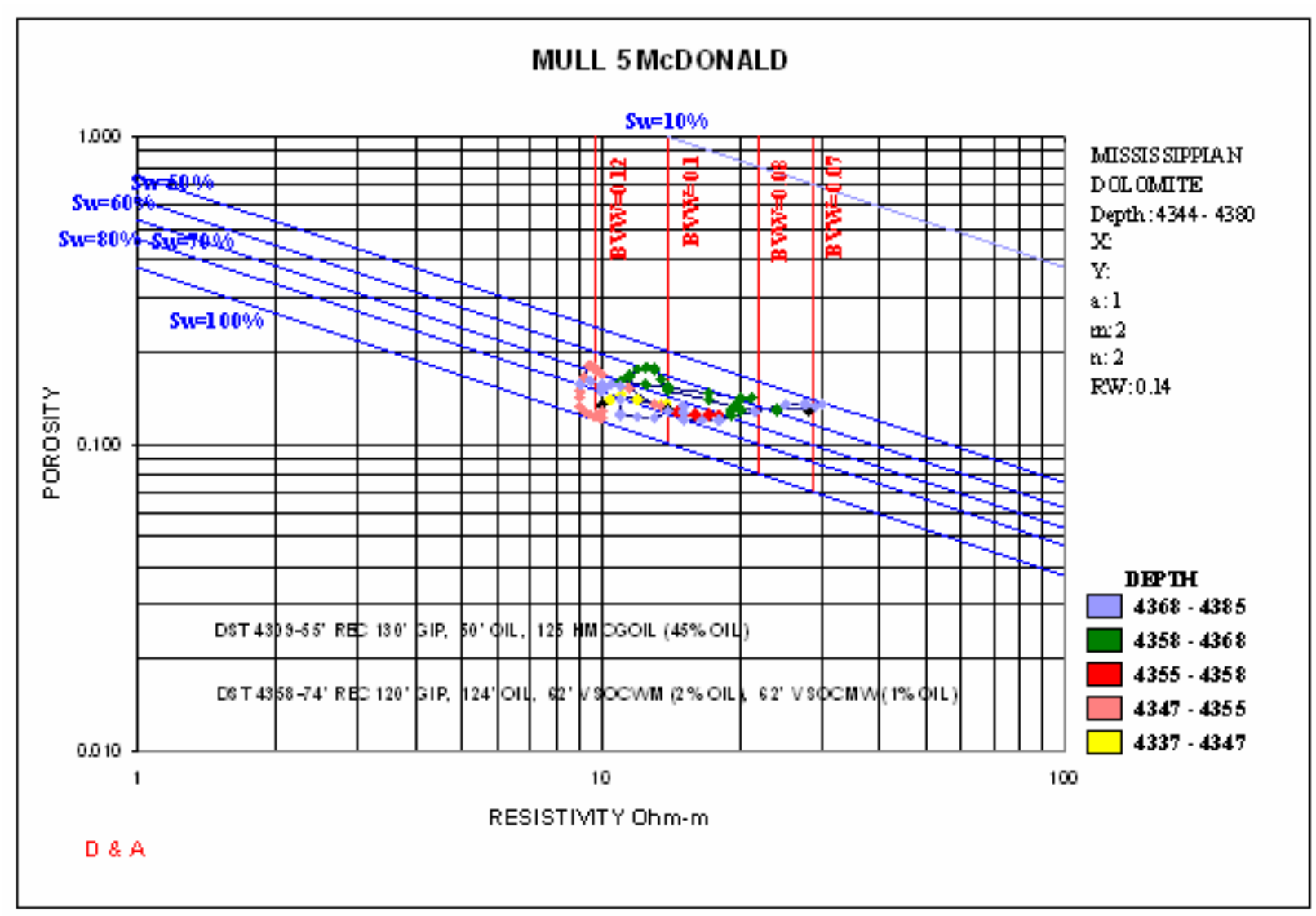

Figure 7.1.19: Super-Pickett analysis of wireline log data from McDonald \#5 well. 


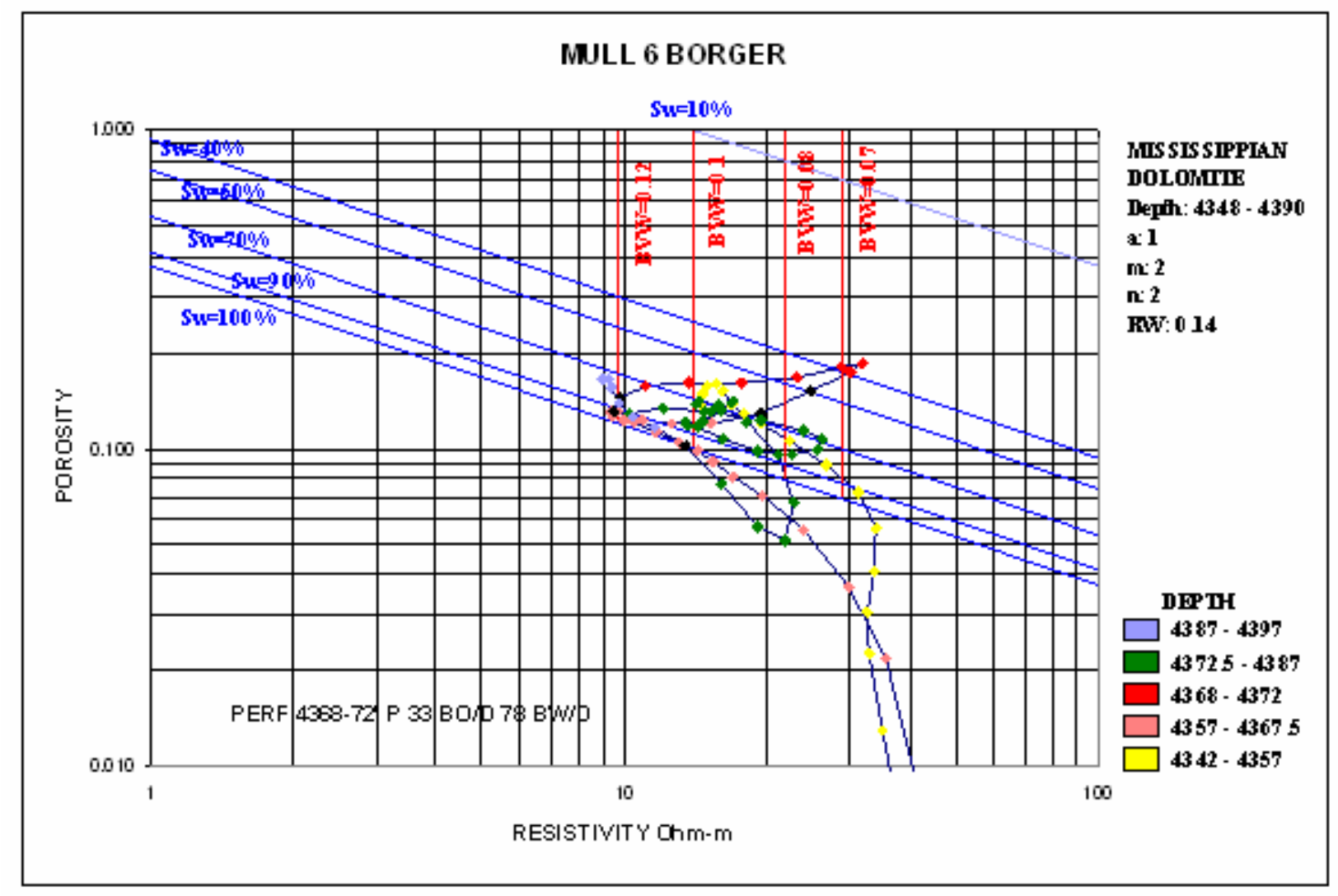

Figure 7.1.20: Super-Pickett analysis of wireline log data from Borger \#6 well. 


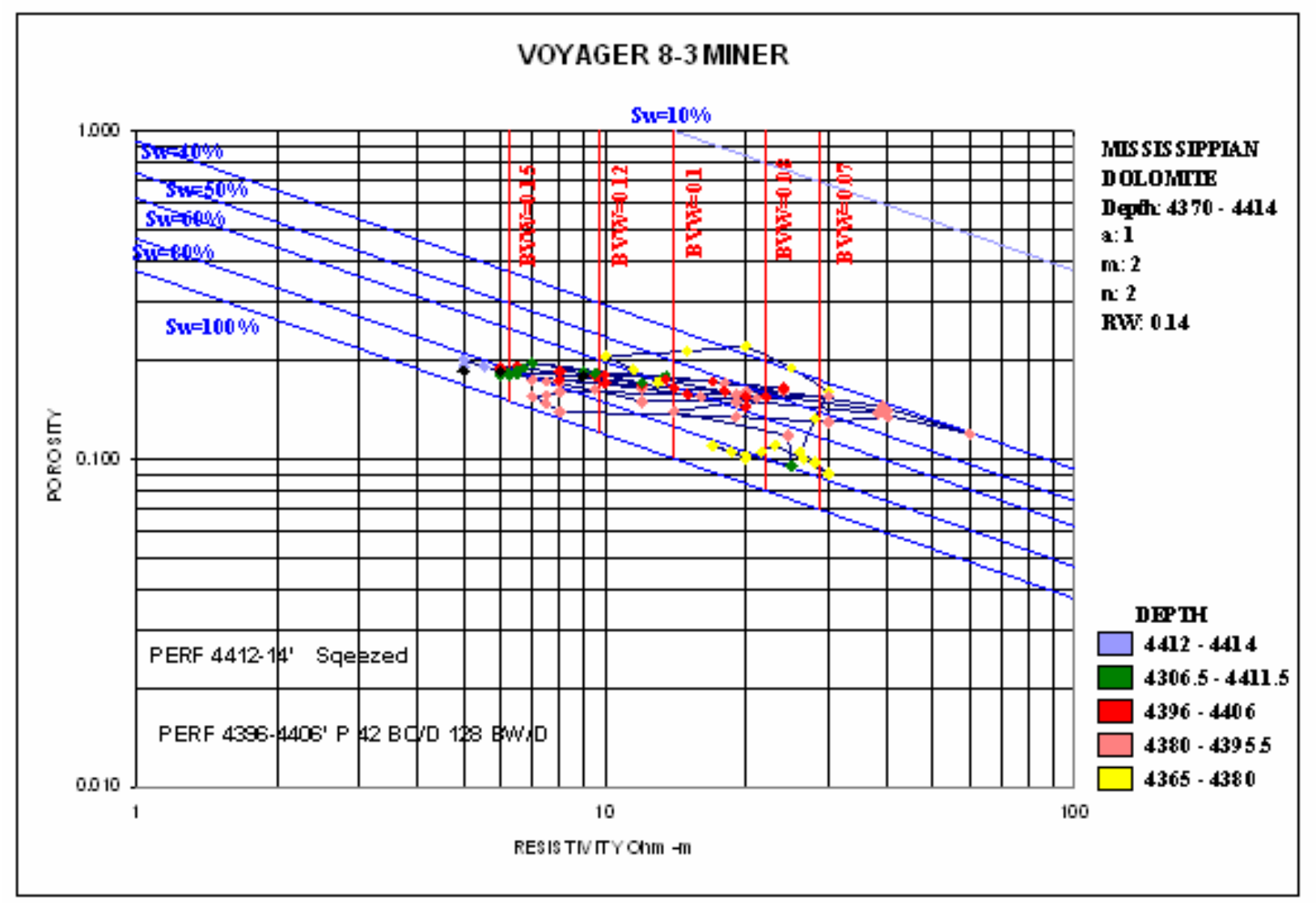

Figure 7.1.21: Super-Pickett analysis of wireline log data from Voyager \#8-3 Miner well. 


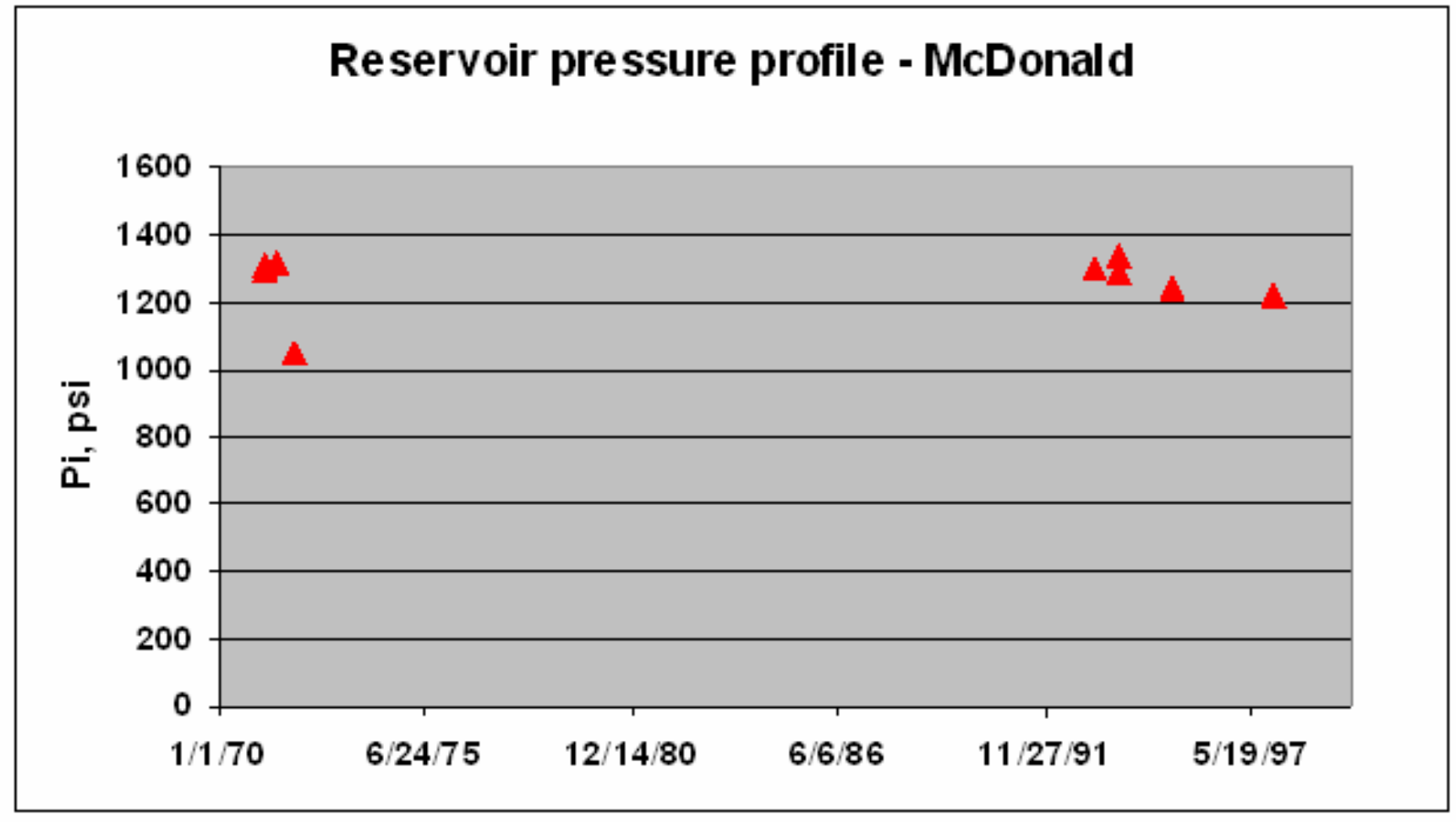

Figure 7.1.22: Plot of reservoir pressure from available DSTs in McDonald Field. 


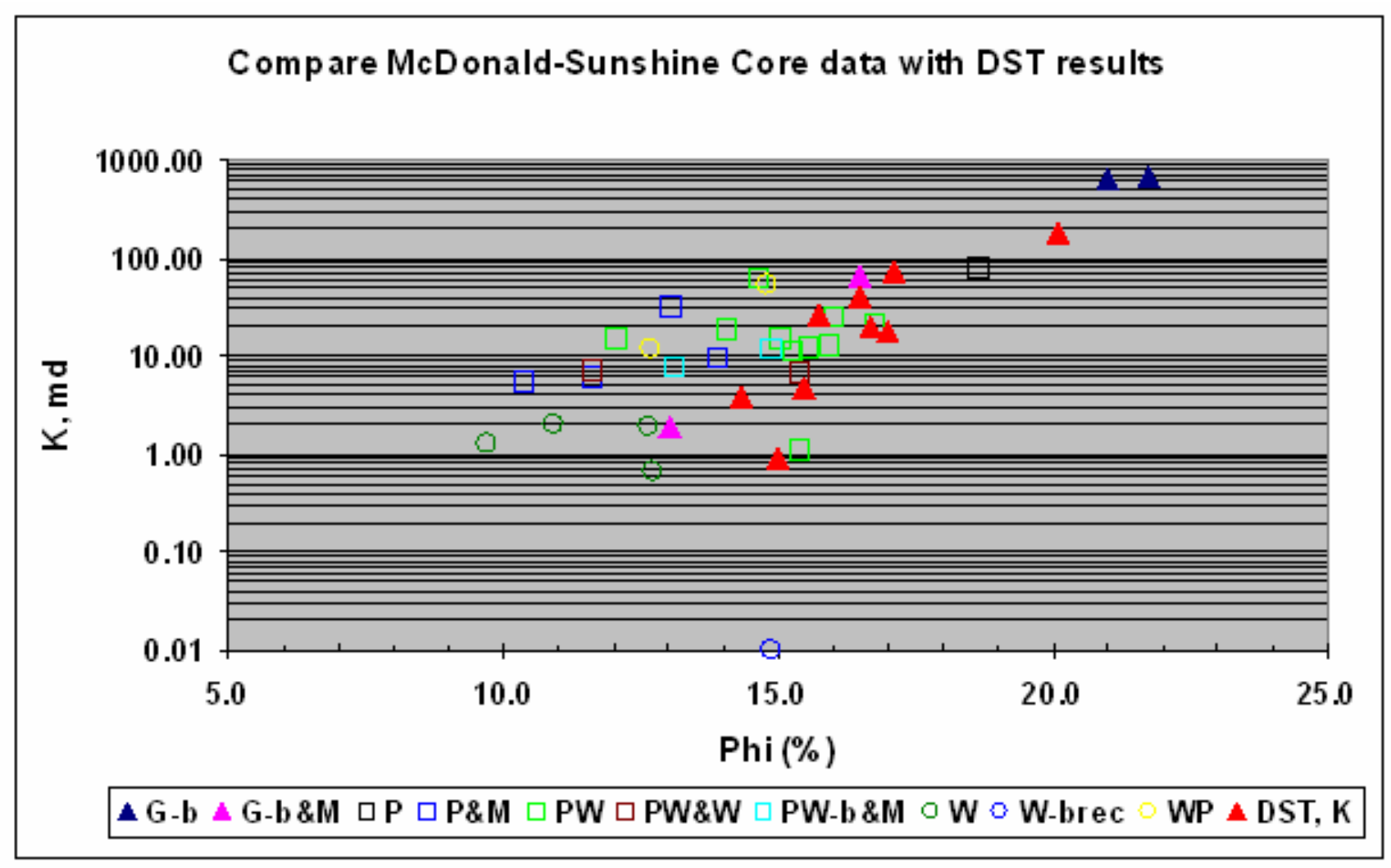

Figure 7.1.23: Comparison of DST- and core plug-derived permeability in McDonald Field. 


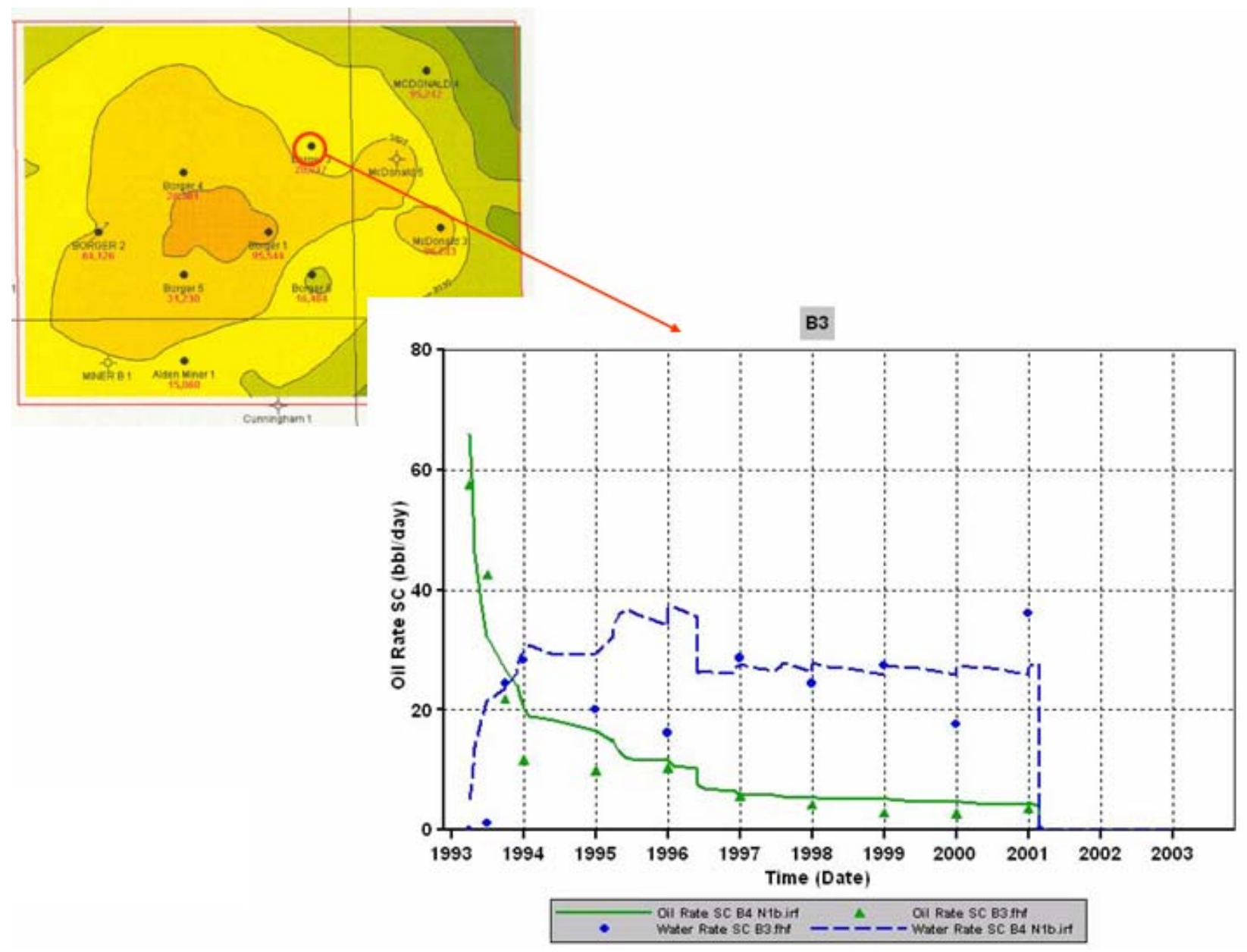

Figure 7.1.24: Production history match at Borger \#3 well in McDonald Field. 


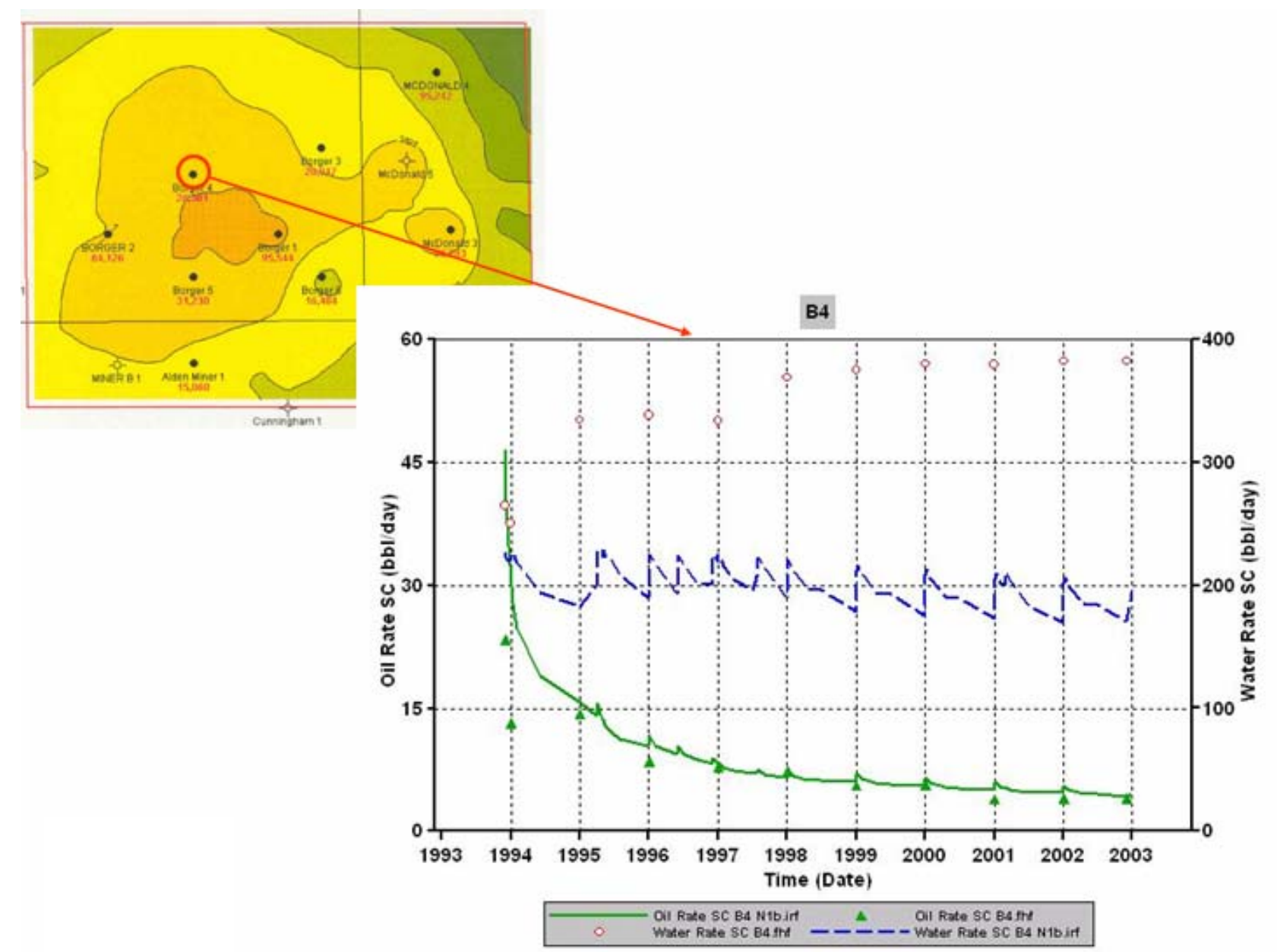

Figure 7.1.25: Production history match at Borger \#4 well in McDonald Field. 


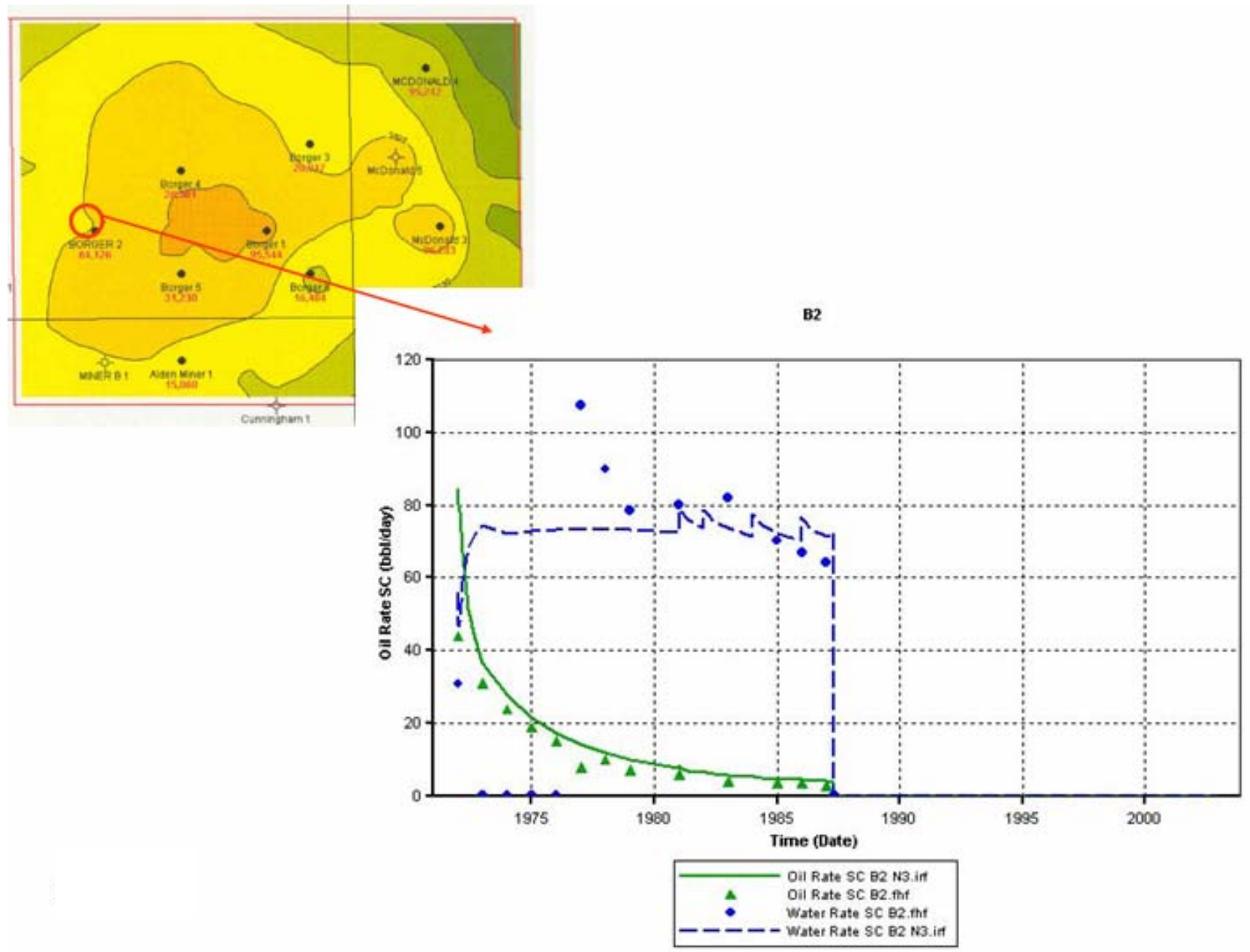

Figure 7.1.26: Production history match at Borger \#2 well in McDonald Field. 


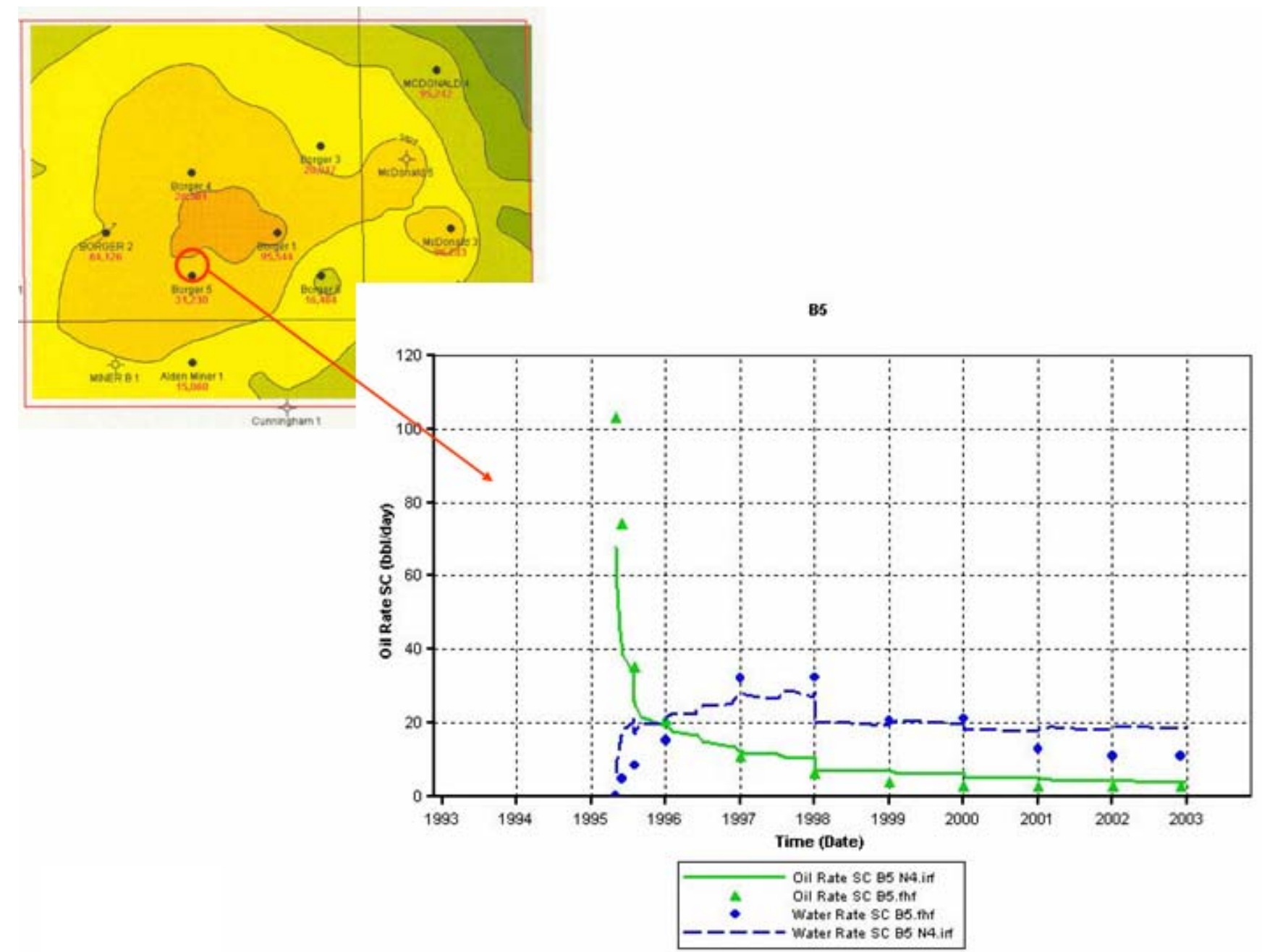

Figure 7.1.27: Production history match at Borger \#5 well in McDonald Field. 


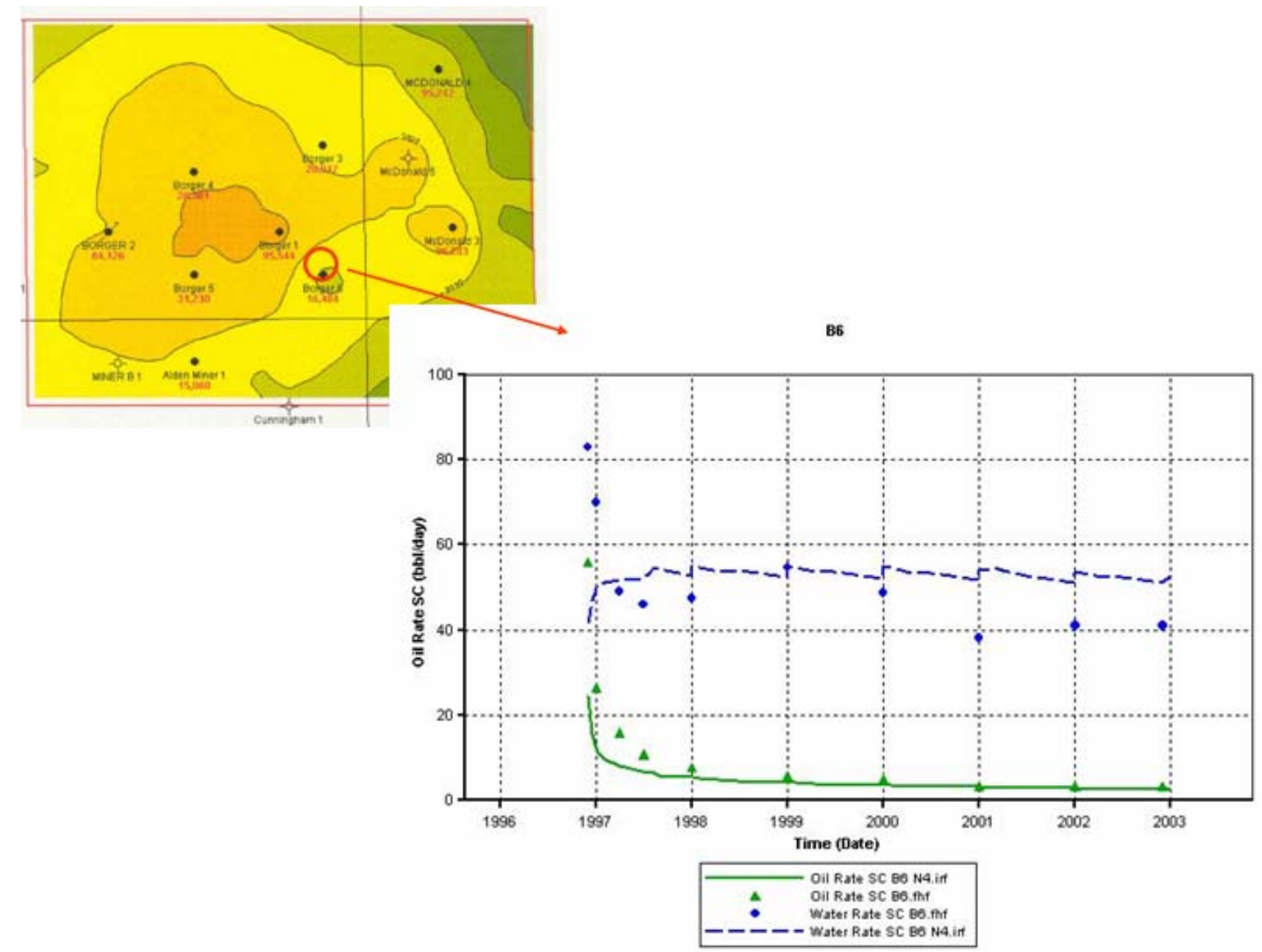

Figure 7.1.28: Production history match at Borger \#6 well in McDonald Field. 


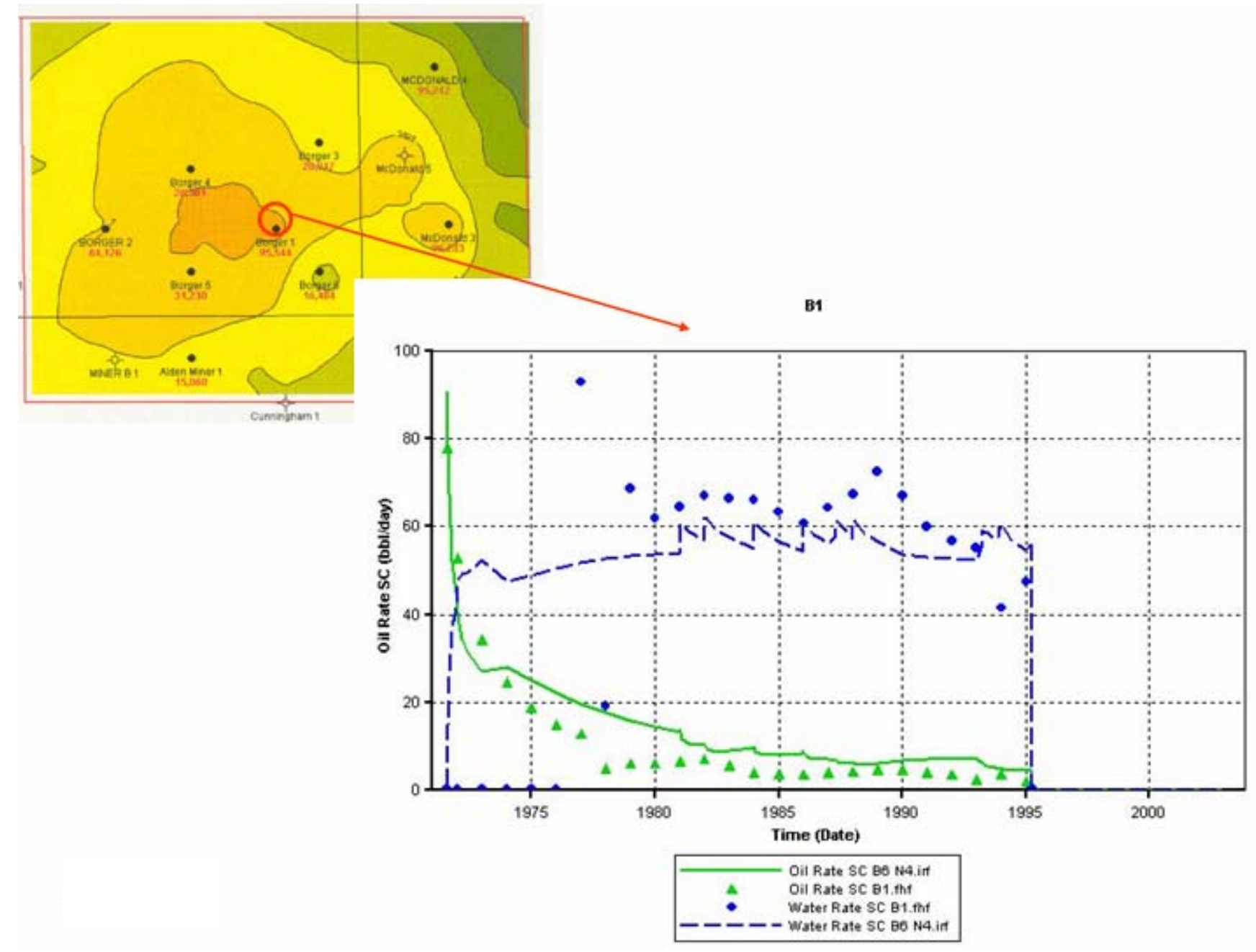

Figure 7.1.29: Simulator calculated fluid production matched against historic records at Borger \#1 well in McDonald Field. 


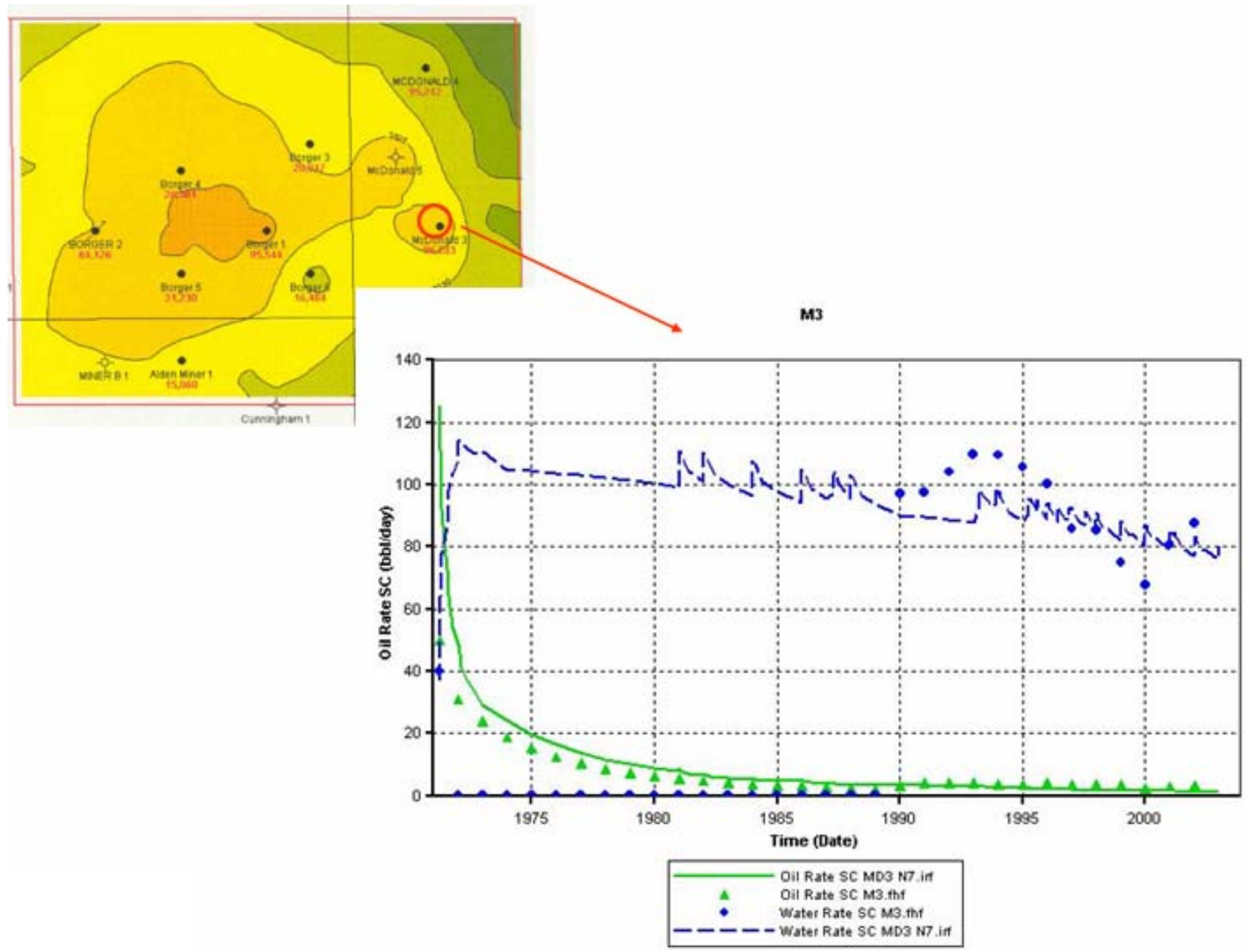

Figure 7.1.30: Production history match at McDonald \#3 well in McDonald Field. 


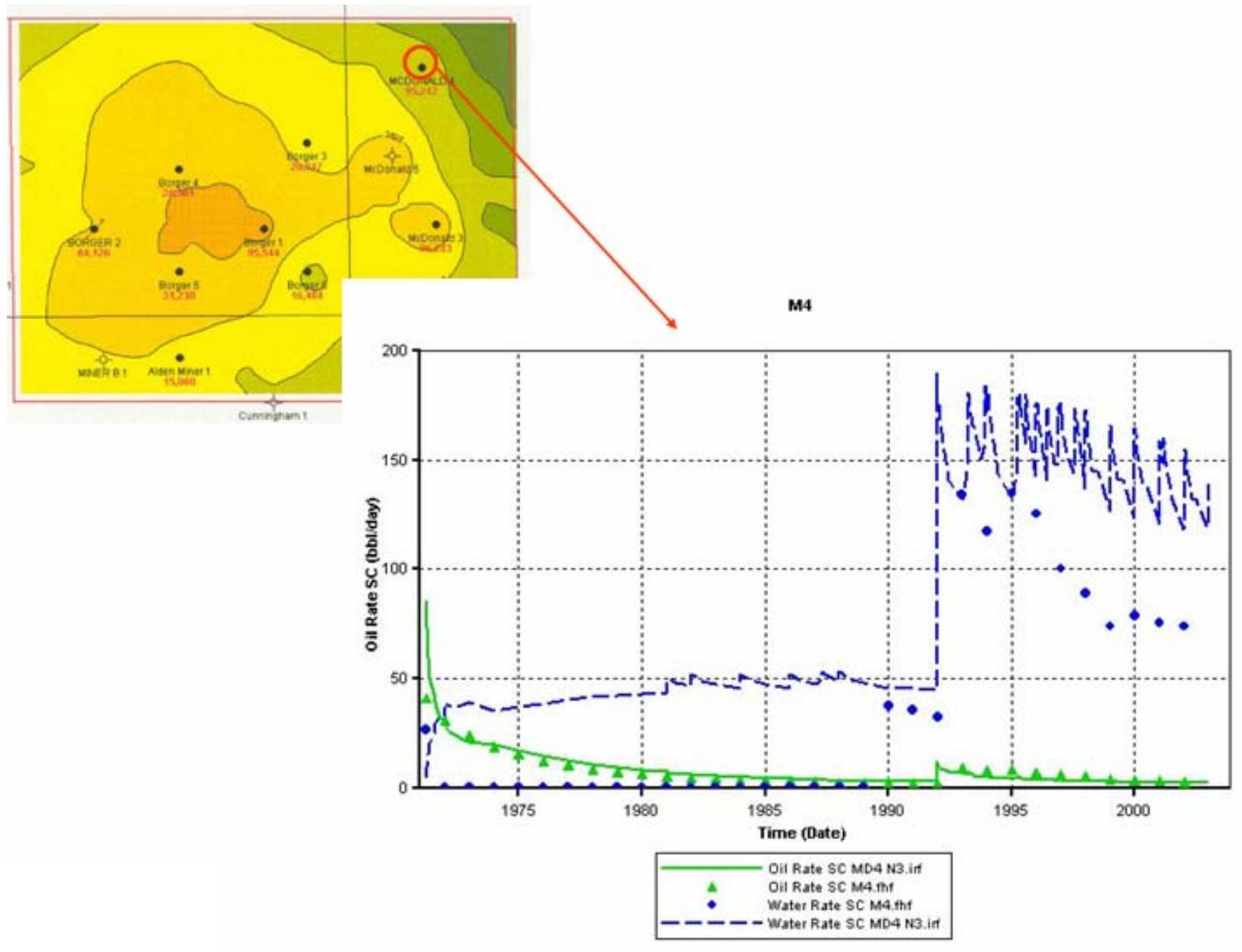

Figure 7.1.31: Production history match at McDonald \#4 well in McDonald Field. 


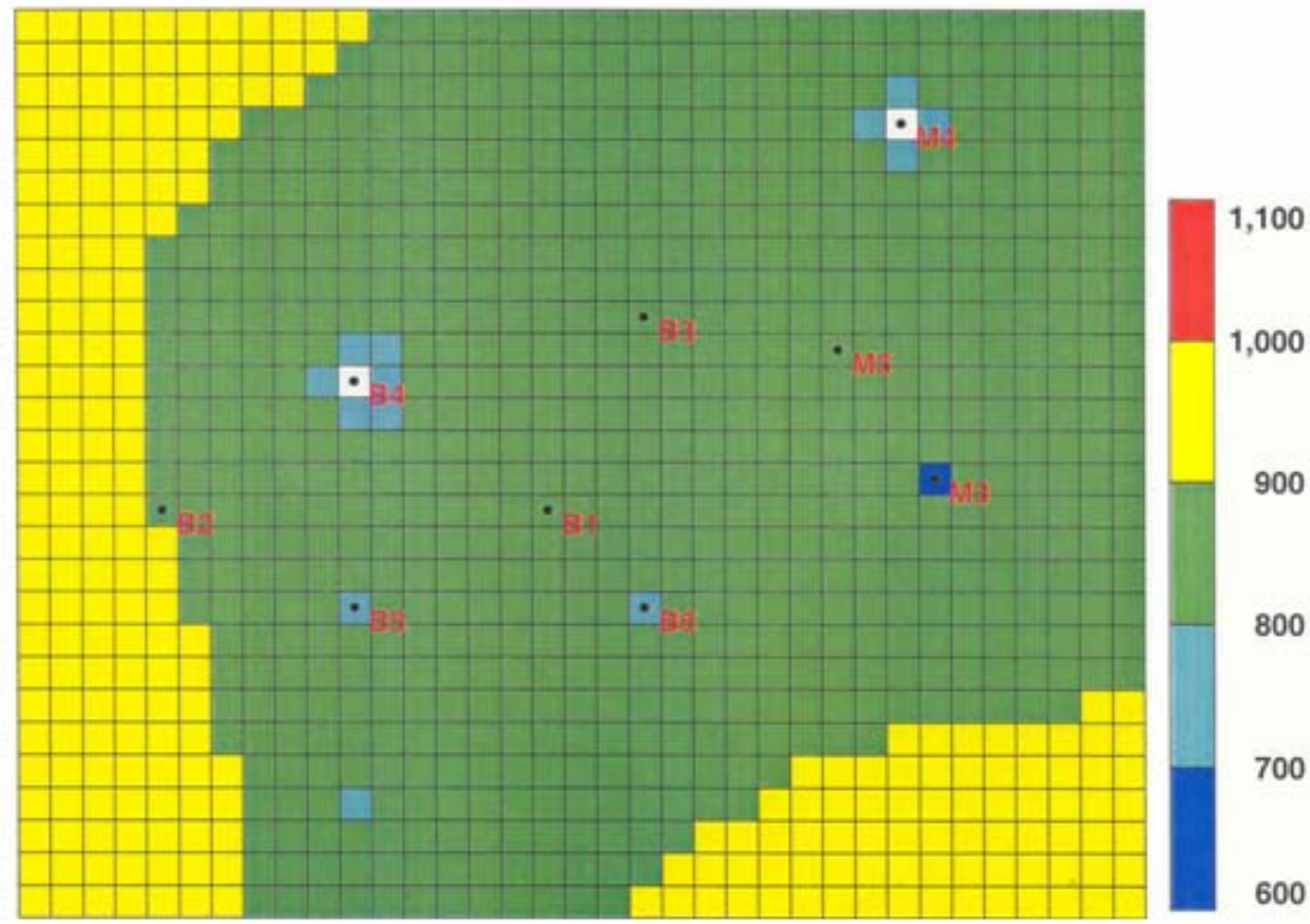

Figure 7.1.32: Simulator calculated reservoir pressure distribution as of January 2003 in McDonald Field. 


\section{Area of remaining potential}

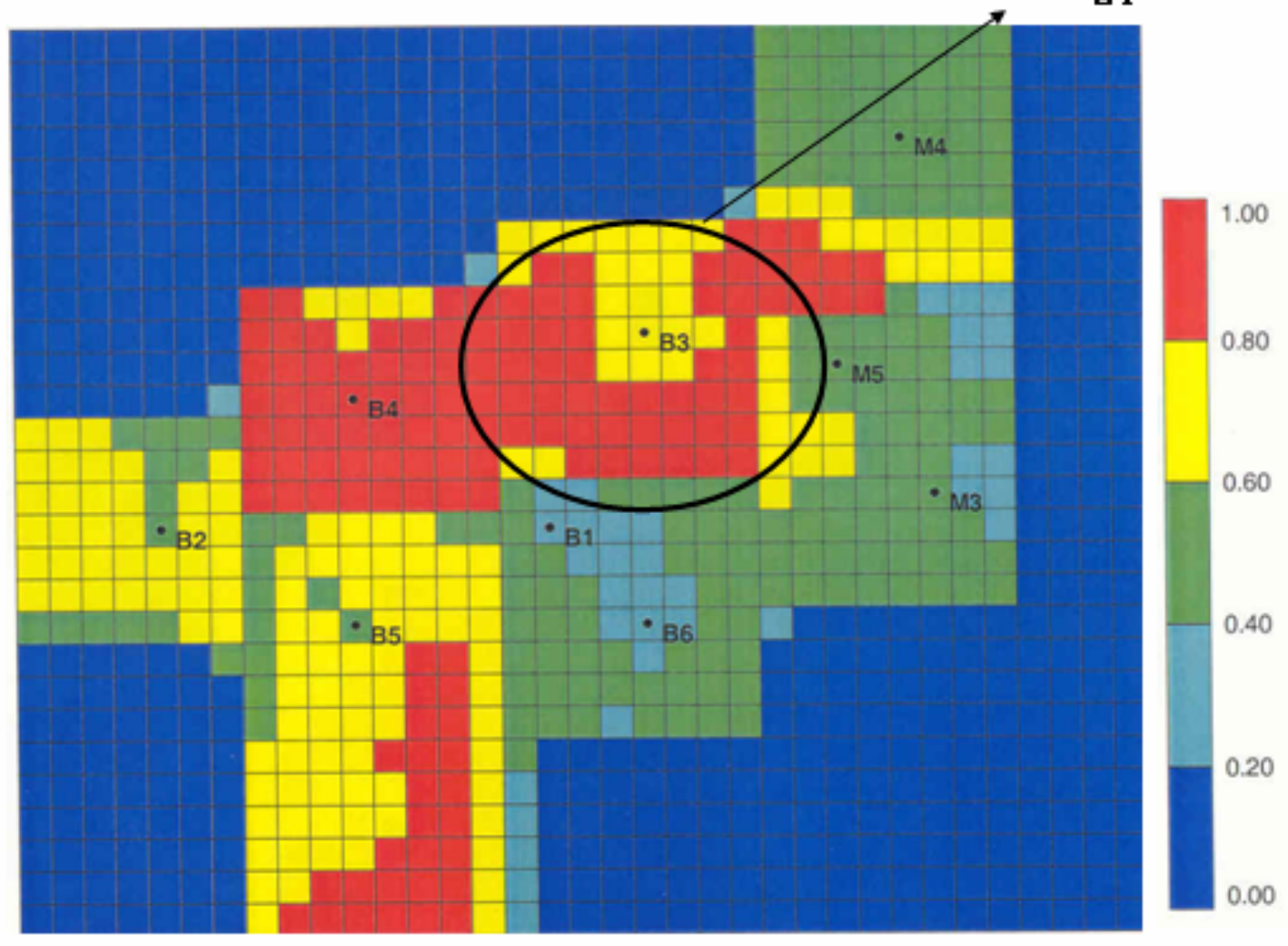

Figure 7.1.33: Map of remaining potential (porosity*oil saturation*pay) in McDonald Field as of January 2003. 


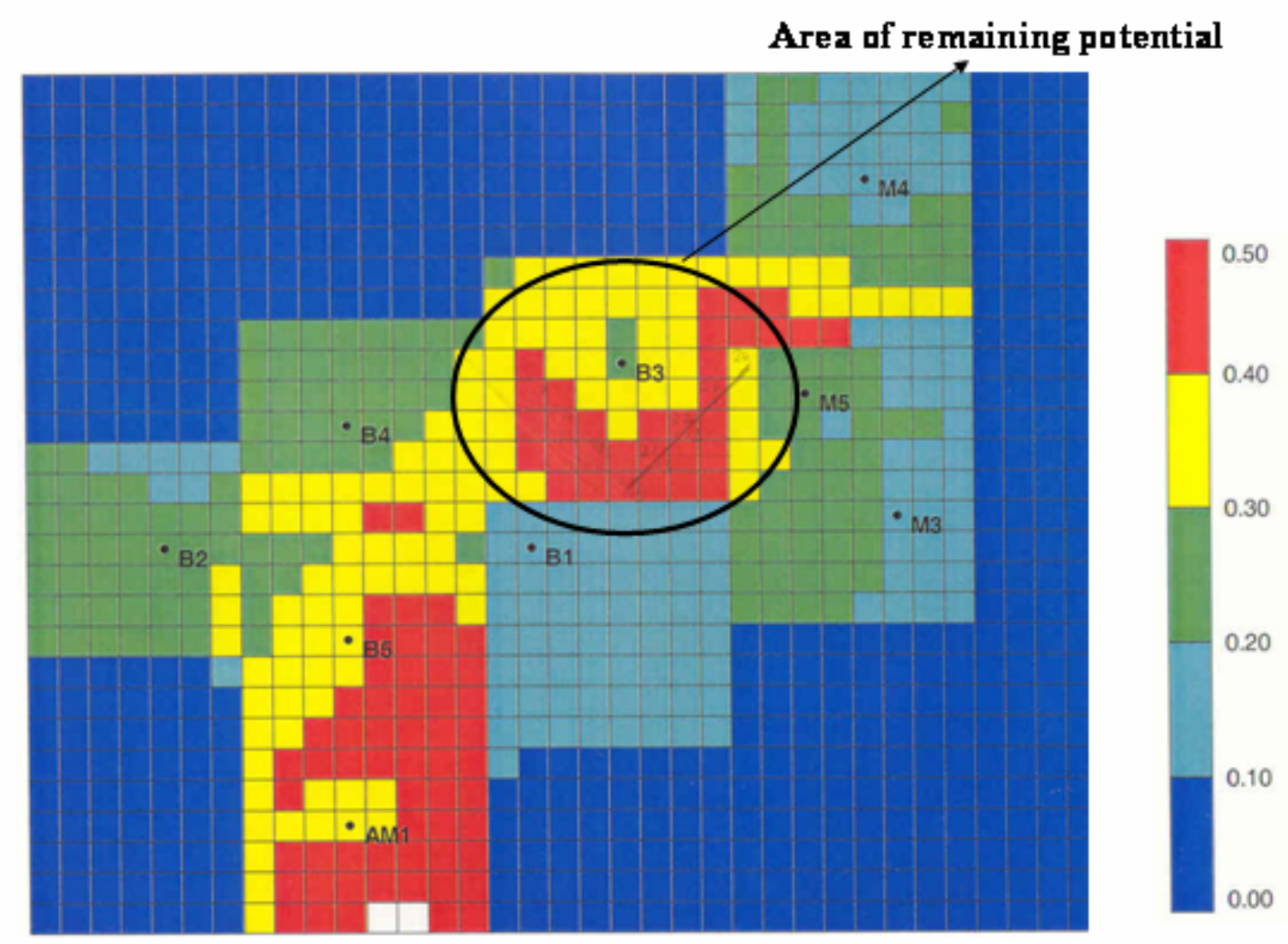

Figure 7.1.34: Map of remaining potential (porosity*oil saturation*pay) in L2 (Layer 2) in McDonald Field as of January 2003. 


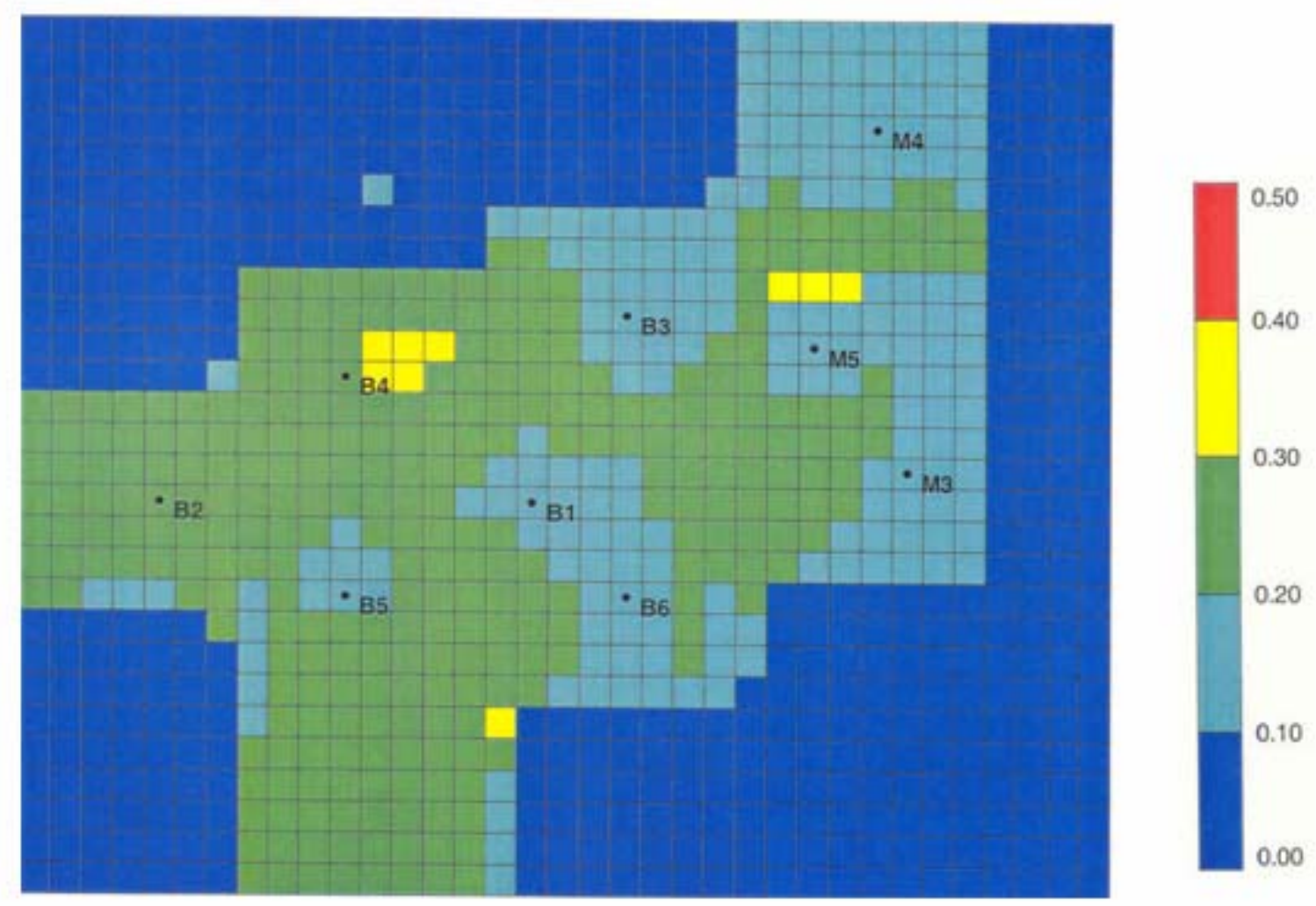

Figure 7.1.35: Map of remaining potential (porosity*oil saturation*pay) in L1 (Layer 1) in McDonald Field as of January 2003. 


\section{Remaining-oil-in-place (phi*So*H, ft) in Layer 2 - Jan 2003}

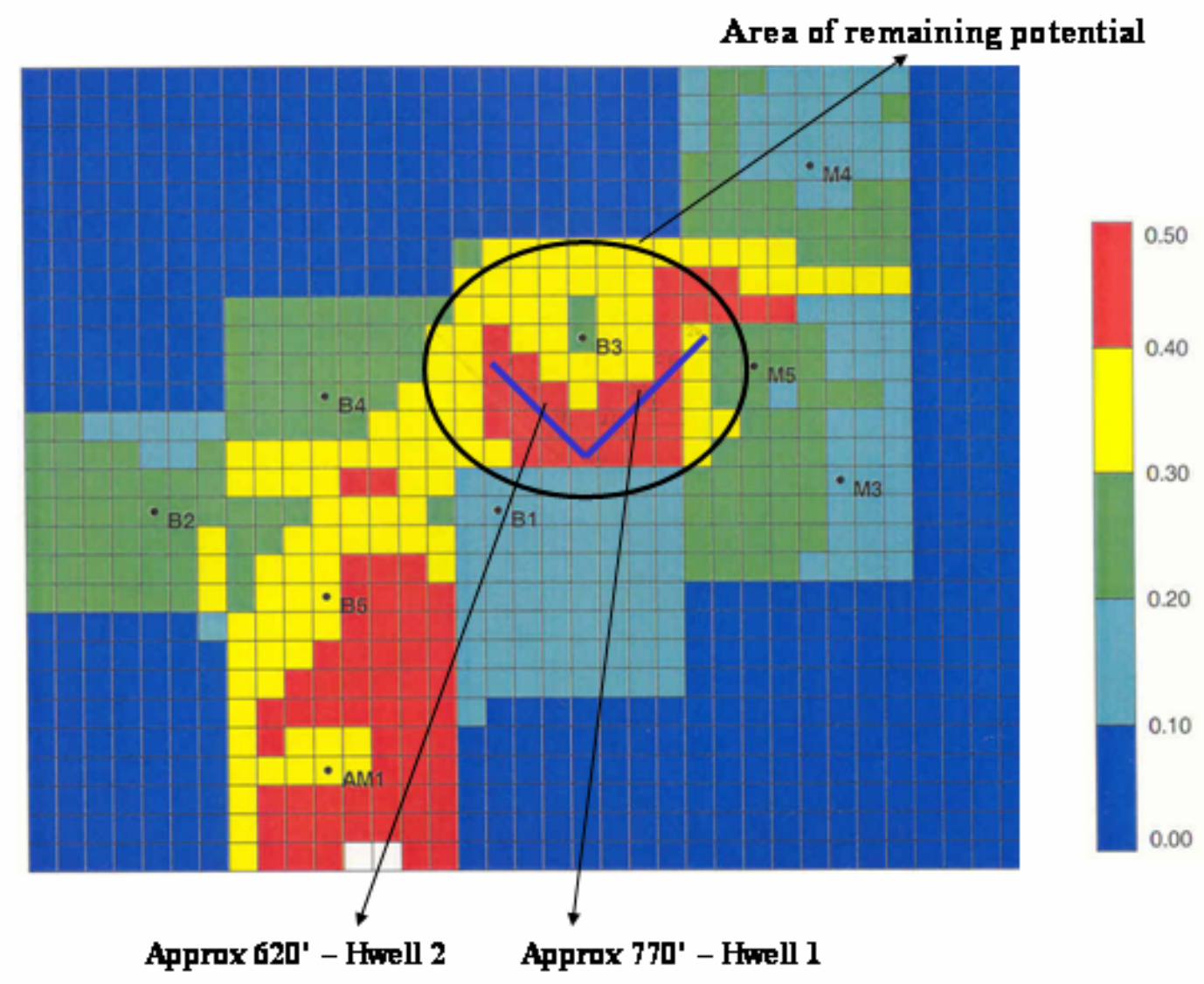

Figure 7.1.36: Trajectories of two possible horizontal infill applications in McDonald Field. 
Hwell 1 - NE to SW - recavery of remaining reserves

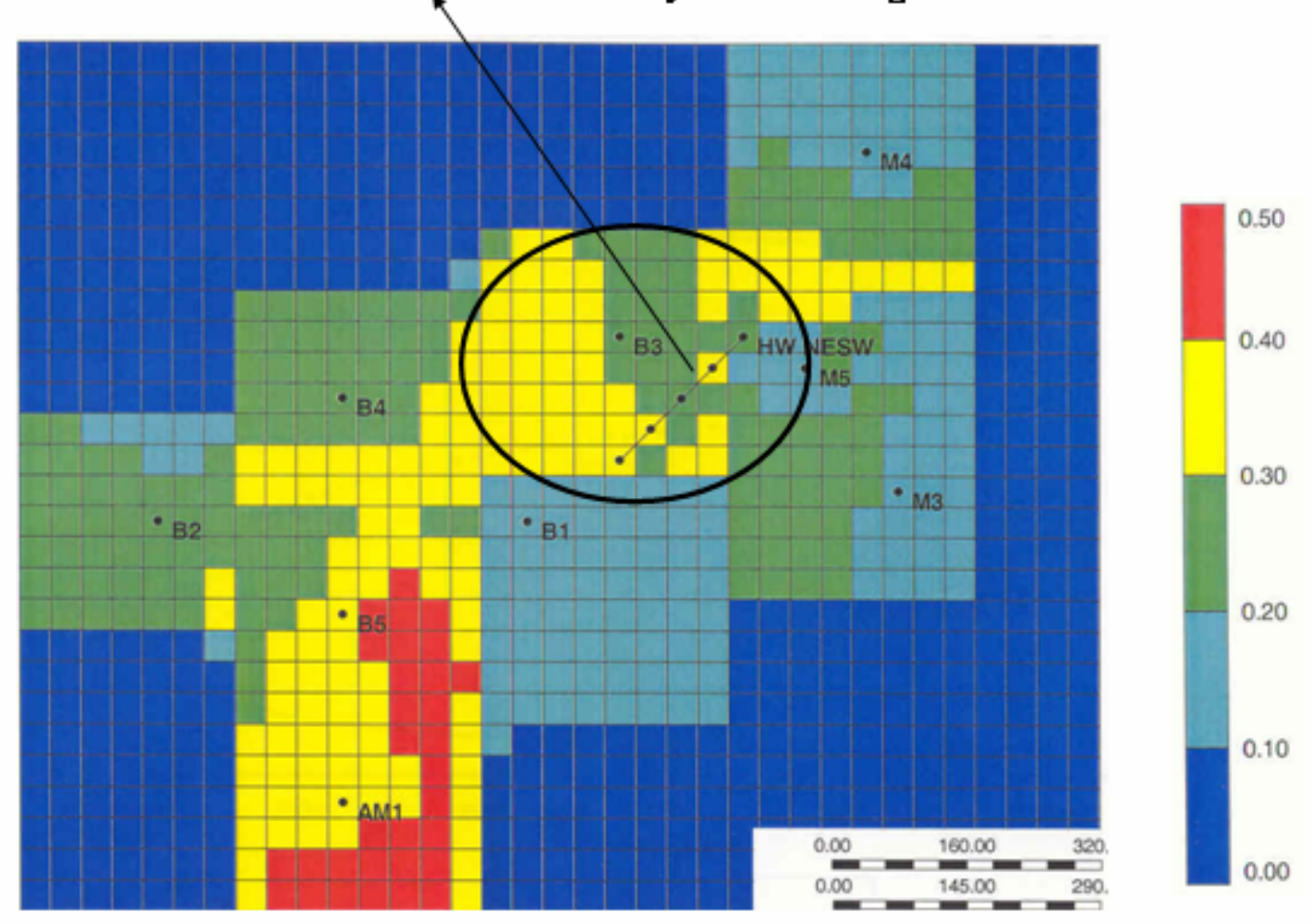

\section{Shows incremental recovery by Hwell 1 after 5 yrs.}

Figure 7.1.37: Effects of drainage on residual reserves, oil-feet (porosity*oil saturation*pay), as of January 2008 due to production from Hwell 1 - a North-East to South-West trajectory. 
Hor Infill well - NEtoSW

Skin $=1.5$, Diam $=6$ inch, Pwf $=100 \mathrm{psi}$

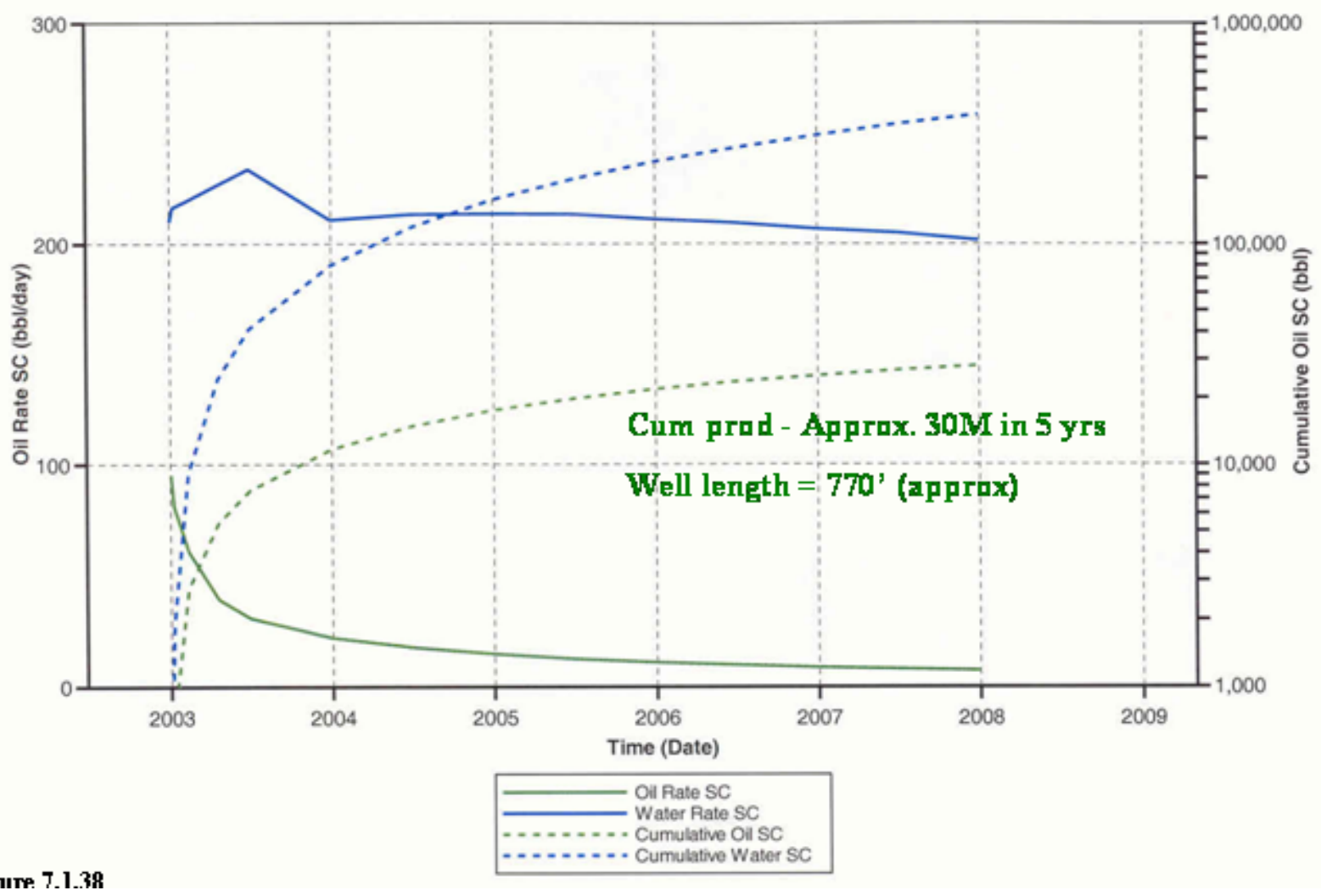

Figure 7.1.38: Simulator calculated expected production from Hwell 1 - a North-East to South-West trajectory. 


\section{Hwell 2 - SE to NW - Recovery of remaining reserves}

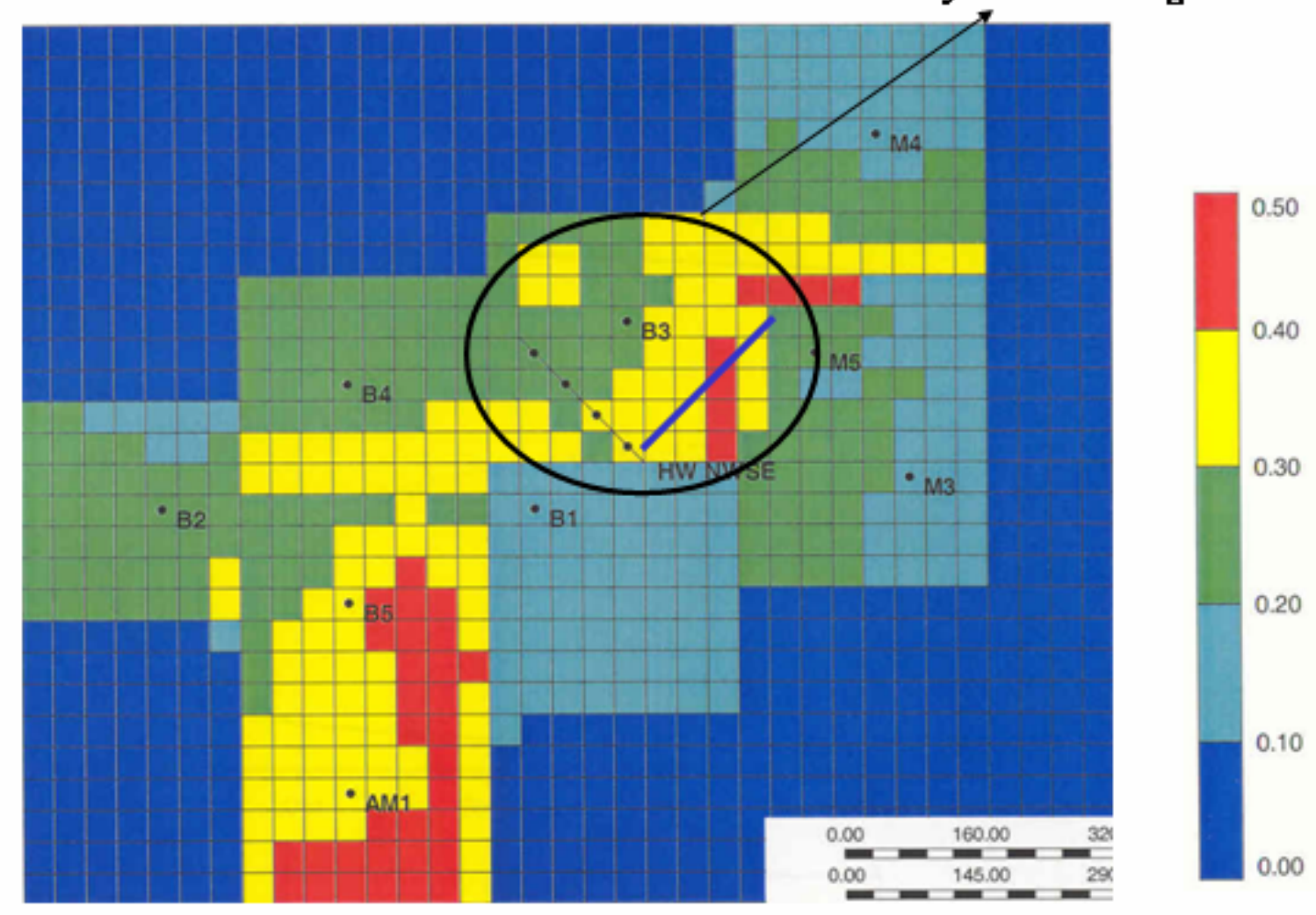

Figure 7.1.39: Effects of drainage on residual reserves, oil-feet (porosity*oil saturation*pay), as of January 2008 due to production from Hwell 2 - a South-East to North-West trajectory. 
Hor Infill well - NWtoSE

Skin=1.5, Diam $=6$ inch, Pwf $=100$ psi

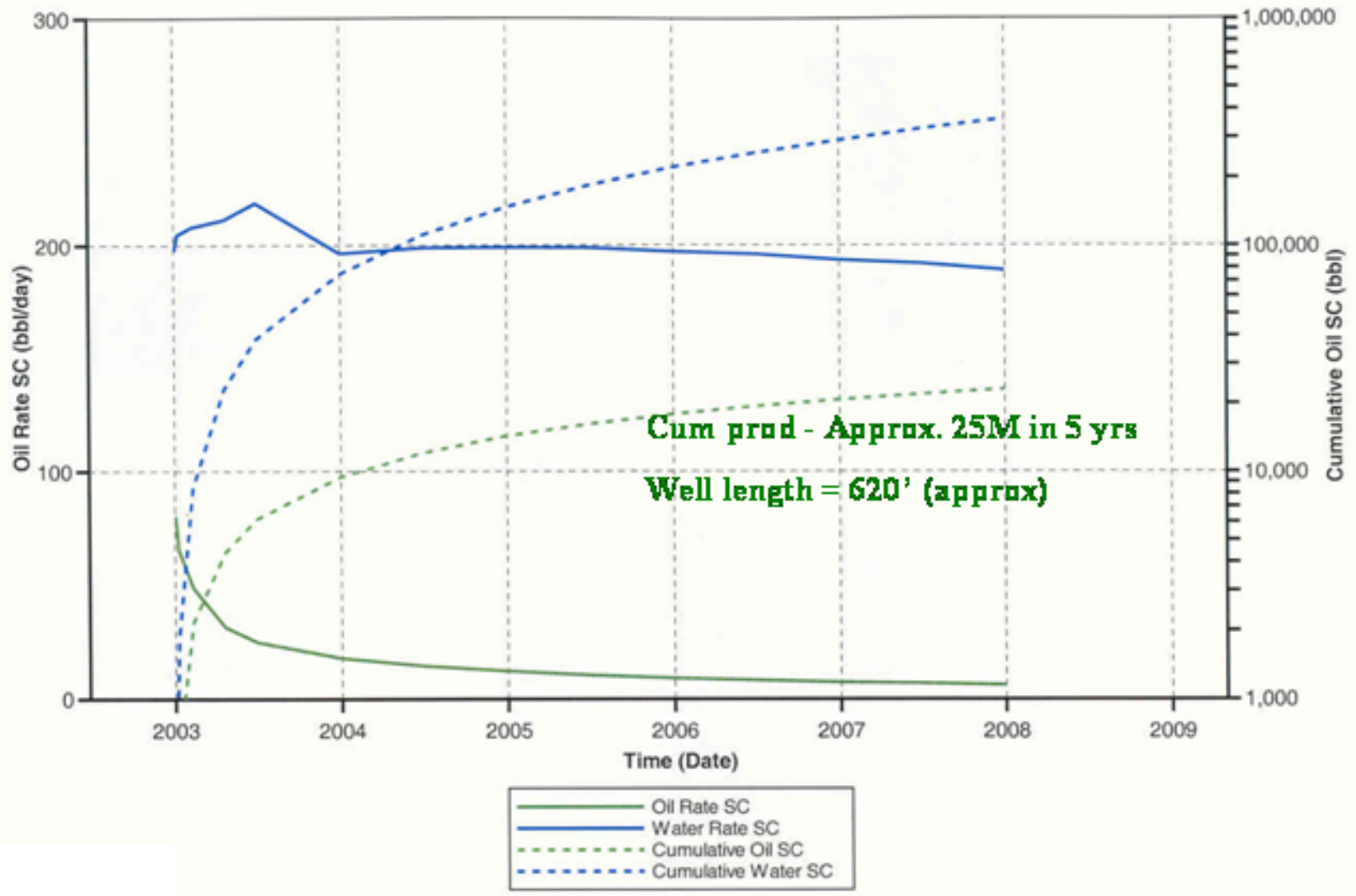

Figure 7.1.40: Simulator caıcuıarea expected production from Hwell 2 - a South-East to North-West trajectory. 


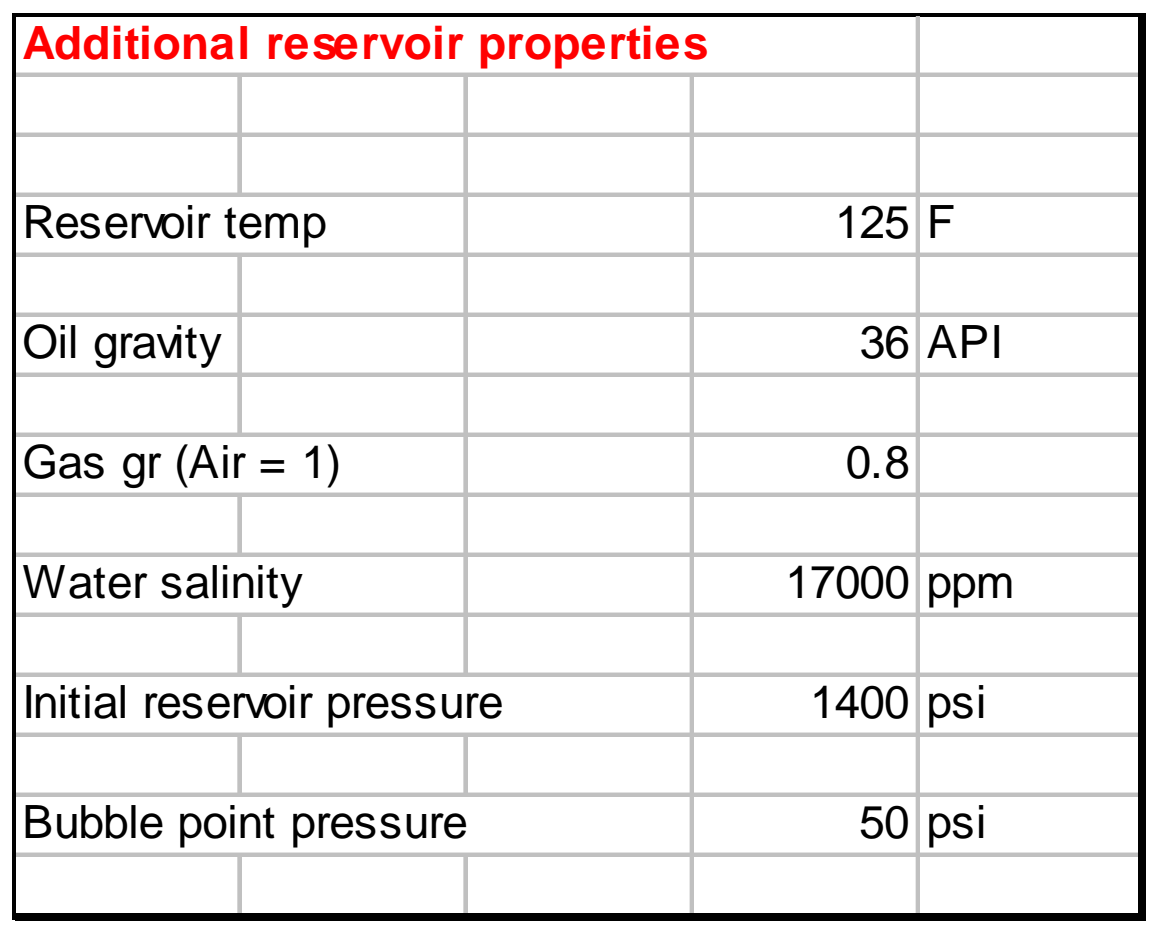

Table 7.1.1: Input PVT properties for McDonald Field simulation study. 


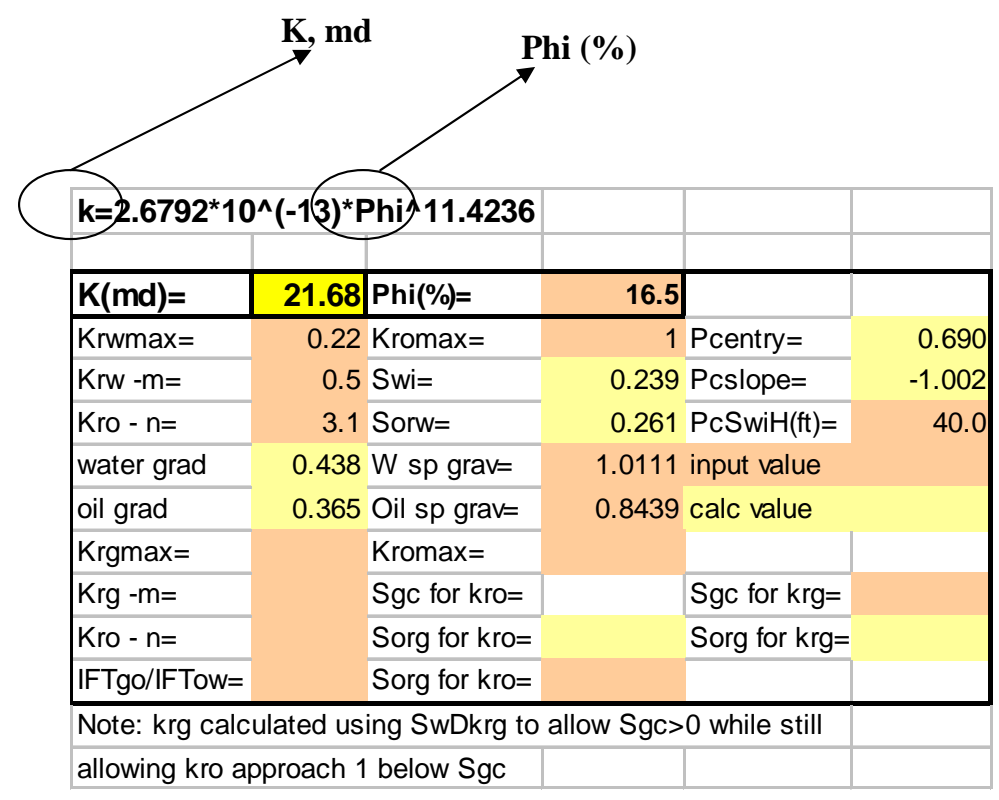

\begin{tabular}{|}
\hline \multicolumn{2}{|c|}{ Calculator for McDonald/Sunshine Fields } \\
\hline \\
\hline
\end{tabular}

Table 7.1.2: Relative permeability - capillary pressure calculator for McDonald Field. 


\begin{tabular}{|c|c|c|c|c|c|c|c|c|c|c|c|c|}
\hline \multirow[t]{2}{*}{ WELLNAME } & \multirow[t]{2}{*}{ Miss L1 } & \multirow[t]{2}{*}{ Miss L2 } & \multirow[t]{2}{*}{ Miss L3 } & \multirow{2}{*}{\begin{tabular}{|l|} 
Base \\
Miss \\
\end{tabular}} & \multirow[b]{2}{*}{ Perf T } & \multirow[b]{2}{*}{ Perf B } & \multirow[b]{2}{*}{ KB } & \multirow[b]{2}{*}{ Perf T } & \multirow[b]{2}{*}{ Perf B } & \multicolumn{2}{|c|}{ Perforations } & \\
\hline & & & & & & & & & & in Sim & & \\
\hline McDonald 3 & -2021 & -2025 & -2032 & -2036 & 4349 & 4357 & 2332 & -2017 & -2025 & L1 & L2 & \\
\hline McDonald 4 & -2031 & -2034 & -2039 & -2043 & 4358 & 4370 & 2327 & -2031 & -2043 & L1 & L2 & L3 \\
\hline McDonald 5 & -2021 & -2025 & -2033 & -2037 & & & 2329 & 2329 & 2329 & & & \\
\hline Borger 1 & -2019 & -2022 & -2030.2 & -2033.8 & 4341 & 4351 & 2326 & -2015 & -2025 & L1 & L2 & \\
\hline Borger 2 & -2025 & -2029 & -2035 & -2041 & 4360 & 4370 & 2335 & -2025 & -2035 & L1 & L2 & \\
\hline Borger 3 & -2027 & -2029 & -2033 & -2038 & 4356 & 4360 & 2329 & -2027 & -2031 & L1 & L2 & \\
\hline Borger 4 & -2021 & -2026 & -2030 & -2034 & 4354 & 4366 & 2332 & -2022 & -2034 & L1 & L2 & L3 \\
\hline Borger 5 & -2023 & -2026 & -2036 & -2039 & 4360 & 4368 & 2336 & -2024 & -2032 & L1 & L2 & \\
\hline Borger 6 & -2031 & -2035 & -2043 & -2047 & 4368 & 4372 & 2337 & -2031 & -2035 & L1 & & \\
\hline Alden Miner 1 & -2026 & -2030 & -2038 & -2042 & 4370 & 4374 & 2340 & -2030 & -2034 & & L2 & \\
\hline
\end{tabular}

Table 7.1.3: Well completion summary in McDonald Field. 


\subsection{Reservoir Characterization and Simulation of Ness City North Field, Kansas}

\subsubsection{Introduction}

An integrated reservoir characterization study was carried out on Ness City North field, Ness County, Kansas, to build a 3D-geomodel, which served as the basis for reservoir simulation. An infill horizontal well was drilled, logged, and produced for a short period in this field in April 2000. A gamma-ray log that was run along with the MWD (measurement while drilling) tool was able shed new light on the reservoir geology of this field. Inputs from this horizontal well along with cuttings descriptions and geologic drilling reports from wells in and around the field were assimilated with log and core data available from the field to build a new reservoir geomodel for the Ness City North Field. This field produces from a Mississippian carbonate reservoir with production commencing in August 1963. Simulation studies were initially carried out to history-match fluid production from the vertical wells while also matching the limited available pressure decline. Upon completion of history matching on vertical wells, the simulator model predicted the performance of the infill horizontal well that was drilled in 2000. Only a slight local adjustment in the effective permeability was required for the simulator output to closely match the available production data from this infill well. Thereafter, a map of remaining reserves was generated for the field, and was used to spot 2 additional horizontal infill trajectories. Simulation studies were carried out to evaluate the production potential of each of these infill horizontal wells.

\subsubsection{Geologic Model}

Figure 7.2.1 shows the location and the boundary of the study area for this project. Petrophysical well logs, core data (from two wells in the field), cuttings description, DST test results, and geologic reports from wells within and around the study area were used to build a geomodel for the reservoir. Tops of marker beds above and below the reservoir interval and the layers describing the reservoir were identified at each well within and around the study area. A series of cross-sections were built from different 
directions to cross-check and fine-tune the geomodel. In accordance with the workflow defined in section 6.3, the reservoir was subdivided into layers (Figures 6.11 and 6.12) that were correlated from well to well and average properties estimated at each well. The static model was populated with layer thickness, porosity, and water saturation by layer by simple interpolation between wells and grids were exported for simulator input. The reservoir was modeled with 4 layers, and Figure 7.2.2 shows that subsea structure top (feet) of the top layer (Layer 1). Layers 1 and 3 contribute to the production while the intermediate Layers 2 and 4 are tight water-saturated non-productive shale-rich layers. Of the 2 productive layers, Layer 3 is more pervasive over the study area and has greater potential than Layer 1. Figures 7.2.3 to 7.2.10 display the isopach, porosity, and initial water saturation (Sw) maps of each of the 4 reservoir layers. Few logs penetrate Layer 4 , and corresponding porosities average between 0.15 and 0.16 . Thus, a uniform porosity of 0.15 was assigned to Layer 4 in the simulation model. Few Sw values were available for Layer 4, and an approximate Sw distribution was mapped (Figure 7.2.10) for this layer by projecting the known Sw values down dip to the oil-water contact (OWC). Figure 7.2.11 is an example cross-section across the field with the productive layers shown in green while the intervening non-productive layers are shown in blue.

\subsubsection{Production Data Analysis}

The Ummel lease (Sec 23) was drilled and developed by Mull Drilling Company (MDC). Records of regular barrel tests were available for the Ummel wells, and these were used to recreate the oil and water production histories of these wells. Water production data from wells in the Pfannenstiel and Pember leases were not available. Only well level oil production histories were available for these wells. Ummel \#1 (MDC, Sec 23) is the most productive well in the lease with a cumulative production of 174 MSTB. This well is also characterized by the lowest WOR. Ummel \#2 shows a mediocre WOR vs. cumulative production profile while Ummel \#3 has always produced water volumes far in excess of that from any of the other wells in the field. Figure 7.2.12 plots WOR against cumulative production for Ummel \#1 and \#3 (MDC, Sec 23) wells. Limited water production data (after 1998) were available from Pfannenstiel \#2A-24 (MDC, Sec 
24), and upon plotting in Figure 7.2.12 was found to closely match the trend established by Ummel \#2 (MDC, Sec 23). Thus, the linear equation best fitting the WOR vs. cumulative production for Ummel \#2 (MDC, Sec 23) was used to estimate water production from Pfannenstiel \#1 (Sun Oil, Sec 24), Pfannnenstiel \#2 (Associates O\&G, Sec 24), and Pember \#A5 (Mineral Exploration, Sec 25). Table 7.2.1 lists the cumulative oil production from each well within the study area.

\subsubsection{Decline Curve Analysis}

One of the critical inputs to a simulation model for history matching is the bottom-hole pressure (BHP) history under which a well is produced over its life. Unfortunately, a regular record of BHPs was not available for any well in the study area. The industry partner in this project, an operator of some wells within and around the study area, advised as per prevalent practices that given the volumes of oil produced from each well it would not be uncommon for these wells to be produced under minimal BHPs (back pressure in the range of $100 \mathrm{psi}$ ). To test this assumption, decline curve analysis was carried out by plotting the average annual oil production rate at each well on a plot whose axes coincided (in cycle-length) with that of the standard Fetkovich decline curve. Figure 7.2.13 shows the results for Pfennestiel \#1 (Associates O\&G, Sec 35). A single decline curve was found to represent most of the well production history neglecting the production increases after the 70th month. Records are insufficient to explain the reasons behind each of these production increases. Based on standard operating practices in this area, stimulation and/or pump change(s) are likely causes of these production increases. However, without proper documentation of the changes, it is not possible to include these changes in well operation in the simulation model for this well. The decline curve indicates that significant cumulative production is not associated with these production bumps as the well production rates are below 3 BPD, and therefore material balance of fluid withdrawal from the reservoir will not be affected if a uniform decline in production (blue line) was assumed for this well. Figures 7.2.14 to 7.2.19 show the decline curves best fitting the oil production data for the other wells. For most wells, a single decline curve is able to represent most of the production history except the very last segment 
when production increases stray from the decline curve. Thus for most of the well history, it is not unreasonable to assume that the well produced under unchanging bottom hole conditions, i.e., the skin and bottom hole pressure (BHP) remained mostly unchanged.

\subsubsection{Petrophysical Log Analysis}

A complete suite of petrophysical logs was available from only two wells. Figures 7.2.20 to 7.2.21 summarize the Super-Pickett analysis. Standard values of $m(=2.0)$ and $n$ $(=2.0)$ were used to analyze the logs. Based on the water salinity information $\left(\mathrm{Cl}^{-} \mathrm{ppm}\right.$ of $19,500)$ the formation water resistivity $(\mathrm{Rw})$ was calculated as 0.13 . From the limited data, it appears that bulk volume water (BVW) values have to be less than 0.07 for waterfree production or production with minimal water (Figure 7.2.21). Perforated zones with BVW values greater than 0.07 (Figure 7.2.20) result in a non-commercial well such as Ummel \#4 (MDC, Sec 23). A Rhomma-Umma plot (Figure 7.2.22) on data from Pfannenstiel \#2A-24 (MDC, Sec 24, and previously called Pfannenstiel 1-24) indicates that the reservoir rock is cherty-dolomite like many other Mississippian fields (such as Schaben field) in this area.

\subsubsection{DST Analysis}

DST pressure-time data were available for 5 wells within the study area. Figure 7.2.23 shows the initial pressure (Pi) psi calculated from the available DST data. Based on this pressure profile, the initial reservoir pressure was assumed to be 1350 psi. Producing fluid levels from the horizontal infill well, Ummel \#4H (MDC, Sec 23), drilled in 2000, gives some indication as to the current reservoir pressure. This well produced 57 BOPD and 52 BWPD against a standing fluid column of 1860 feet above the perforations. Thus, as of mid-2000, the reservoir pressure must have been greater than 950 psi. 


\subsubsection{PVT and Relative Permeability/Capillary Pressure Inputs}

Table 7.2.1 summarizes the PVT and other field-wide inputs to the simulation model. There is no mention of any gas production at Ness City North field wells. Thus, the bubble point pressure is low given that no gas production has been recorded at the wells even when they are produced under pumped-off conditions. The reservoir produces under a strong water drive. Within the simulation model, each well is produced at least under a BHP of 100 psi and to prevent any three-phase flow from occurring a low bubble point of 100 psi was assumed (at subsea -1996 feet) in this study. There was no measured bubble point data available. Oil PVT properties are listed in Table 7.2.2. Bubble point pressure, reservoir temperature, and oil and gas gravities were input to the inbuilt PVT calculator within the reservoir simulator (Computer Modeling Group's IMEX) to generate other necessary PVT tables. Other field wide assumptions, particularly relating to each well, that were input to the simulator are listed in Table 7.2.2.

A Mississippian core was available from Pfannenstiel 2 (Sun Oil, Sec 24) located within the field. Also, 2 other cores from just outside the field were available, namely from Ummel \#1 (Sun Oil, Sec 23) and Pfannenstiel \#1 (Sun Oil, Sec 24). Details of routine core analyses have been described in a previous study (Bhattacharya et al., 1999b). Core plug measurements were used to develop representative permeabilityporosity correlations (Tables 7.2.3 \& 7.2.4) for both the reservoir and non-reservoir rock. Also, capillary pressure measurements were carried out on representative core plugs along with recordings of end-point saturations. Data collected from these core studies were integrated with the data set on Mississippian core plugs that has been built by virtue of studies carried out at the KGS on other Mississippian fields of the Mid-continent. Porosity was found to correlate with end-point saturations such as Swi (irreducible water saturation) and Sorw (irreducible oil saturation to water). Using these correlations and measured capillary pressure curves, a "new” relative-permeability/capillary pressure calculator was created using Corey-type equations. These calculators help to input a consistent set of relative-permeability/capillary pressure tables into the simulator upon making changes in effective permeability over the drainage area of a well during the 
history-matching phase. Thus, changing the permeability input updates the table by changing the saturation end points while preventing dramatic changes in the capillary pressure curve shapes. Also, the relative permeability exponents ( $m$ and $n$ ) enable changing the relative ease of flow between the two fluid phases in the reservoir, i.e., the oil and water, especially during history-matching well-level production. Table 7.2.3 shows the calculator for the reservoir rock (Layers 1 and 3) while Table 7.2.4 displays that for the non-reservoir rock (Layers 2 and 4).

Sporadic measurements of standing fluid columns over production life were available for some of the wells. These records served as the basis for determining the BHP under which each well was flowed within the simulator. Table 7.2.5 summarizes the BHP under which each well was flowed within the simulator. In particular, Pfannenstiel 2A-24 (MDC, Sec 24) was initially flowed under pumped-off conditions when it was perforated only in Layer 1. Later in January 2001, its perforations were extended to Layer 3 and the well was produced under significant standing fluid column. It was due to a pump change in November 2002 that the well started to produce under a lower BHP.

\subsubsection{Simulation Study - History Matching}

The reservoir was simulated as a 4-layer model with 110 feet by 110 feet grid cells and an analytical bottom aquifer. The aquifer properties were fine-tuned so that the calculated current reservoir pressure was around 1100 psi. Initial saturation (Sw) and pressure distributions in the drainage area of each well was input with the help of capillary pressure curves and having the simulator perform gravity-capillary equilibrium calculations. The initial permeability in each layer was populated using the permeabilityporosity correlations generated from core analysis. The correlation for the reservoir rock is stated in Table 7.2.3 while Table 7.2.4 shows the relevant correlation for the nonreservoir rock. Each well was produced under a constant/variable BHP (Table 7.2.5) with the simulator calculating the oil and water production at the end of every time step. Parameters that were fine-tuned to history-match individual well performance included 
effective permeability in the drainage area of the well and relative permeability exponents "m" and "n".

Table 7.2.6 shows the layers that each well was perforated inside the simulator model. Figures 7.2.24 to 7.2.29 show the history matches obtained at each of the original vertical wells in the field. After completion of history matches of the original vertical wells, the simulator was instructed to predict the performance of the vertical infill well Pfannenstiel 2A-24 (MDC, Sec 24). Figure 7.2.30 compares the simulator output with the recorded production from this well. The match during the initial period of the well's life (pre-2001) is modest, but improves after extension of the perforations in 2001. Only limited information is available about production practices prior to 2001, and additional information is required to improve the match. Finally, the simulator model was used to predict the performance of the horizontal infill well Ummel 4H (MDC, Sec 23) drilled in 2000. Figure 7.2.31 shows that the simulator predicted average initial production is close to that recorded at the well during its brief (1 month) life before the well stopped production due to formation collapse along its uncased lateral length. In the simulation model, this horizontal infill well is located within the drainage area of Ummel 1 (MDC, Sec 23). The only parameter that was locally modified to obtain this match was changing the horizontal permeability to $15 \mathrm{md}$ from $25 \mathrm{md}$. The simulator calculated average reservoir pressure as of January 2003 was 1185 psi.

\subsubsection{Performance Evaluation of Different Horizontal Infill Trajectories}

Upon completion of well history matches, a map of residual reserves (oil-ft, product of porosity, oil saturation, and grid thickness) was generated as of January 2003. Most of the remaining potential was found to reside in Layer 3 (L3), and the remaining oil-ft map as of January 2003 is shown in Figure 7.2.32. Productive potential of 2 infill trajectories was studied. In each case, the horizontal well was assumed to be 6 inches in diameter and to have been produced for 10 years (starting January 1, 2003) under a constant BHP $=200$ psi and a skin factor of 1.5. One of the first infills, a 990-feet EastWest well that was evaluated, is shown in Figure 7.2.33. The drainage capability of this 
well is shown in the residual reserve (oil-ft) map (Figure 7.2.33) as of January 2013 compared to that of January 2003. The expected production from this well is tabled and plotted in Figure 7.2.34. Simulation studies indicate that after 10 years the expected cumulative production from this well will be in the range of 60 MSTB while producing about 1000 MSTB of water. This infill well is located near 2 producing wells, namely Ummel \#1 (MDC, Sec 23) and Pfannenstiel \#2A-24 (MDC, Sec 24). Interference effects of this infill well on the production of the above 2 wells are shown in Table 7.2.7. Figures 7.2.35 and 7.2.36 and Table 7.2.8 show the drainage effects of a second infill trajectory (south-west to north-east diagonal well), along with its cumulative production and interference on Ummel \#1 (MDC, Sec 23) and Pfannenstiel \#2A-24 (MDC, Sec 24). The infill well is expected to produce about 76 MSTB (Figure 7.2.36) over 10-year production life but also result in an estimated total production loss of 30 MSTB (Table 7.2.8) at Pfannenstiel \#2A-24 (MDC, Sec 24). 


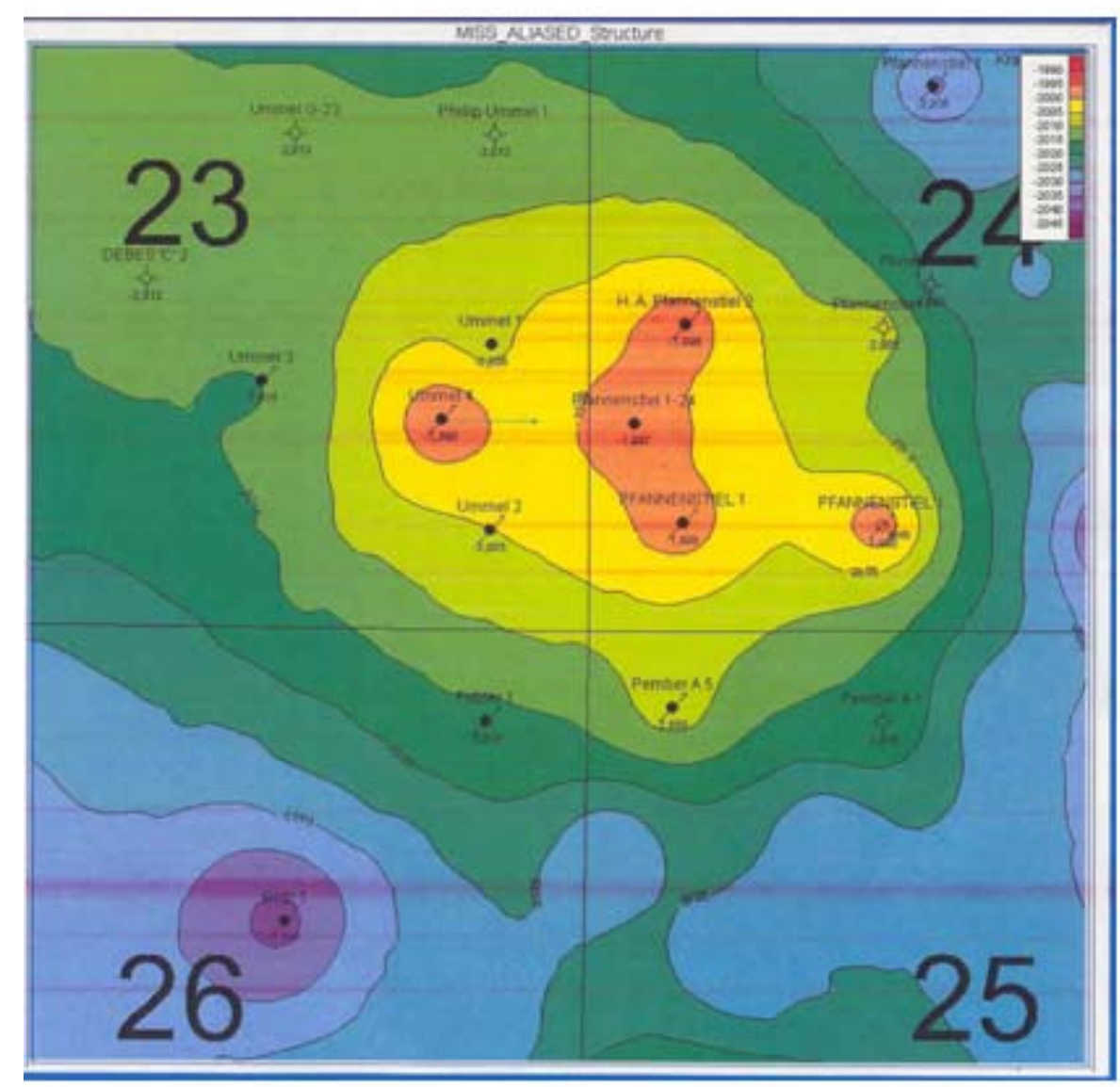

Figure 7.2.1: Location and boundary of the Ness City North Field, Ness County, Kansas. 


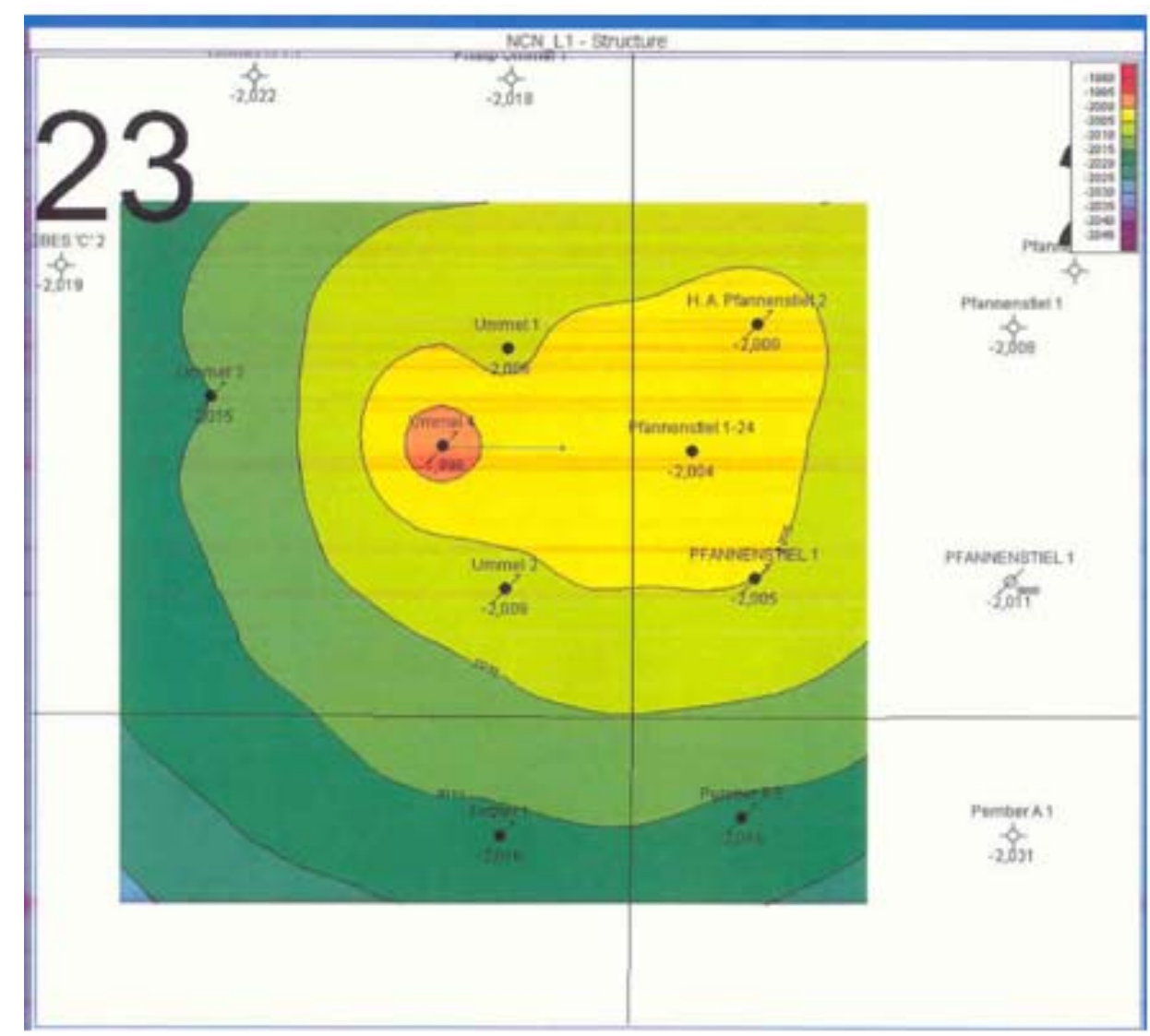

Figure 7.2.2: Subsea structure (feet) on top of pay, Layer 1 (L1), in Ness City North Field. 


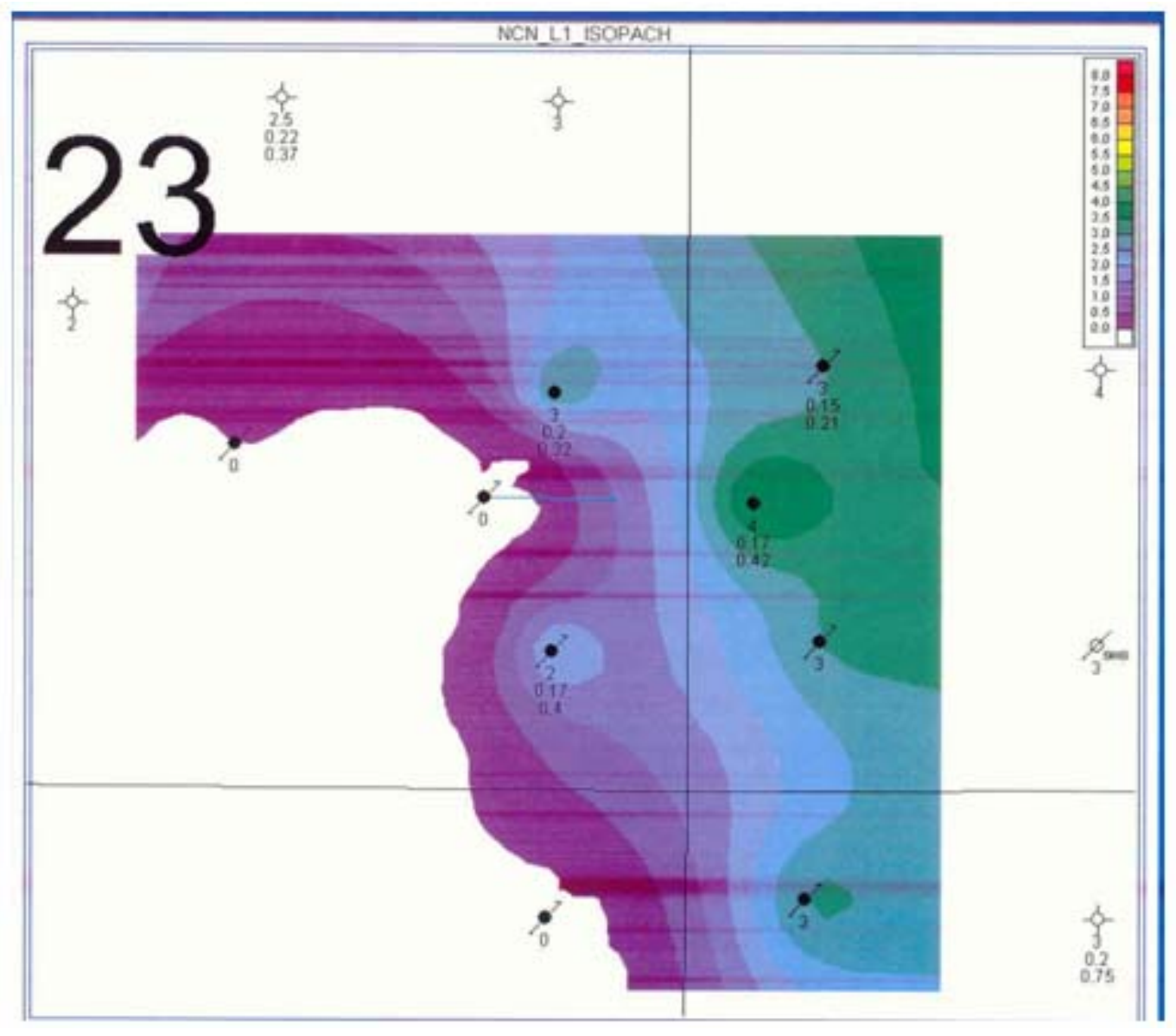

Figure 7.2.3: Isopach (feet) of Layer 1 (L1) in Ness City North Field. 
Porosity - Layer 1

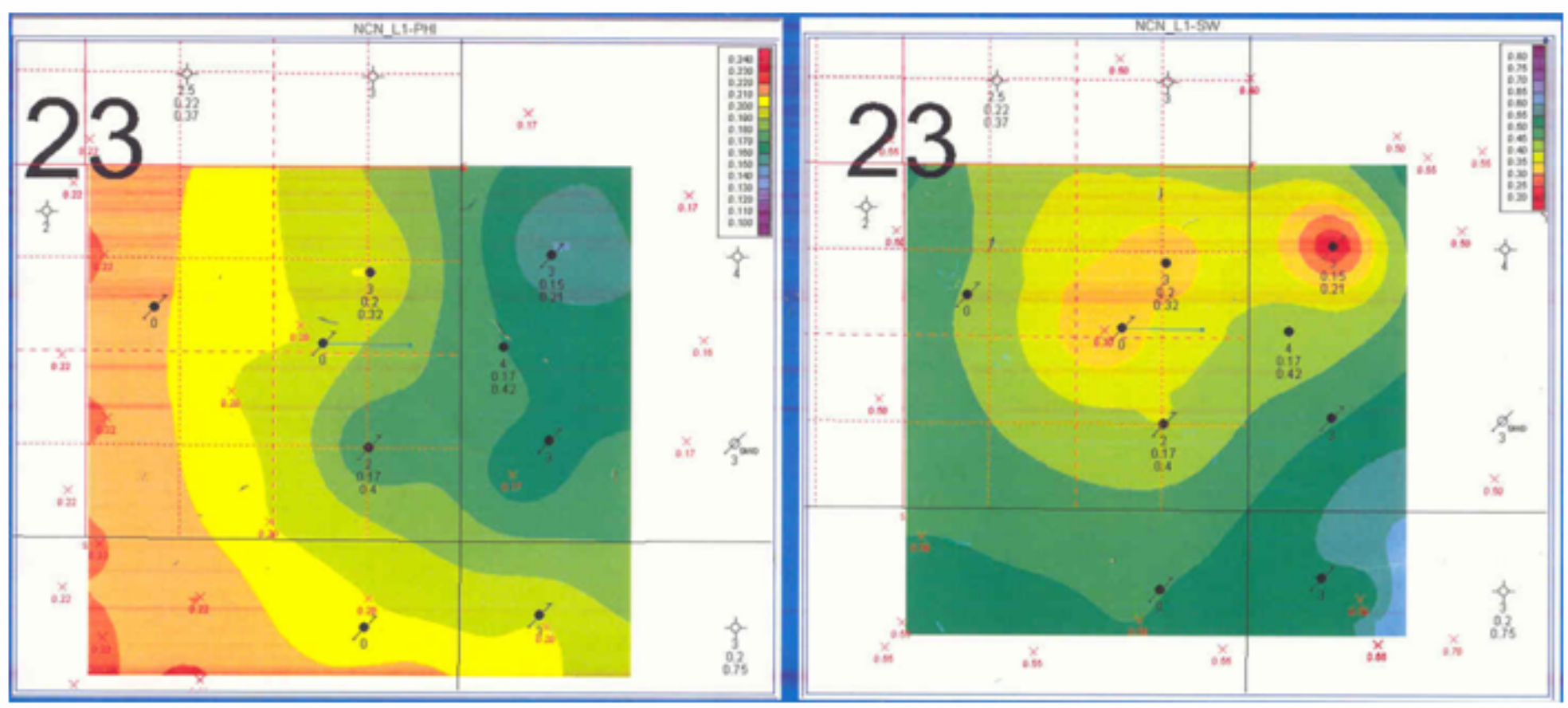

Figure 7.2.4: Distribution of porosity (fraction) and initial water saturation (fraction) in Layer 1 (L1) in Ness City North Field. 


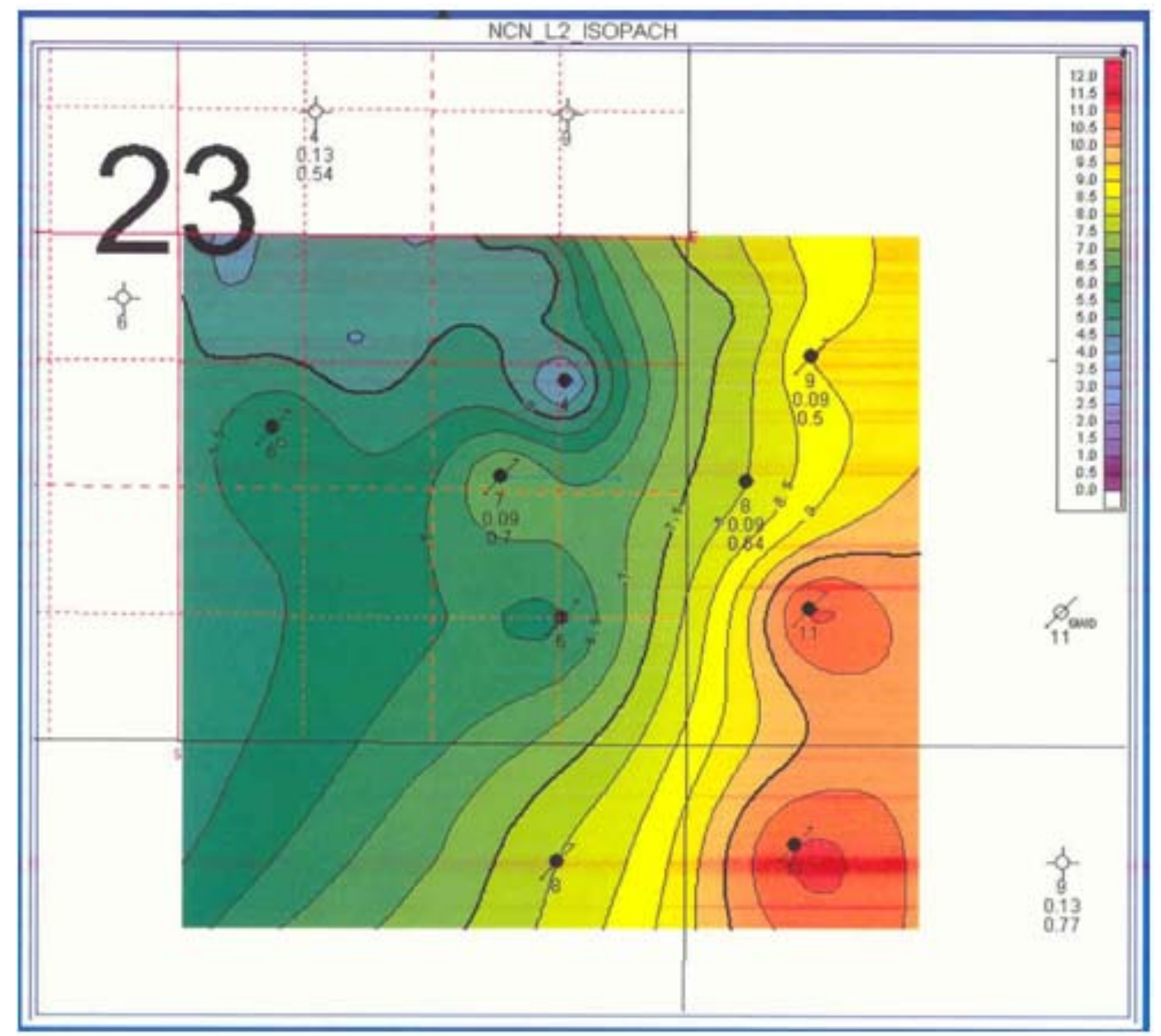

Figure 7.2.5: Isopach (feet) of Layer 2 (L2) in Ness City North Field. 


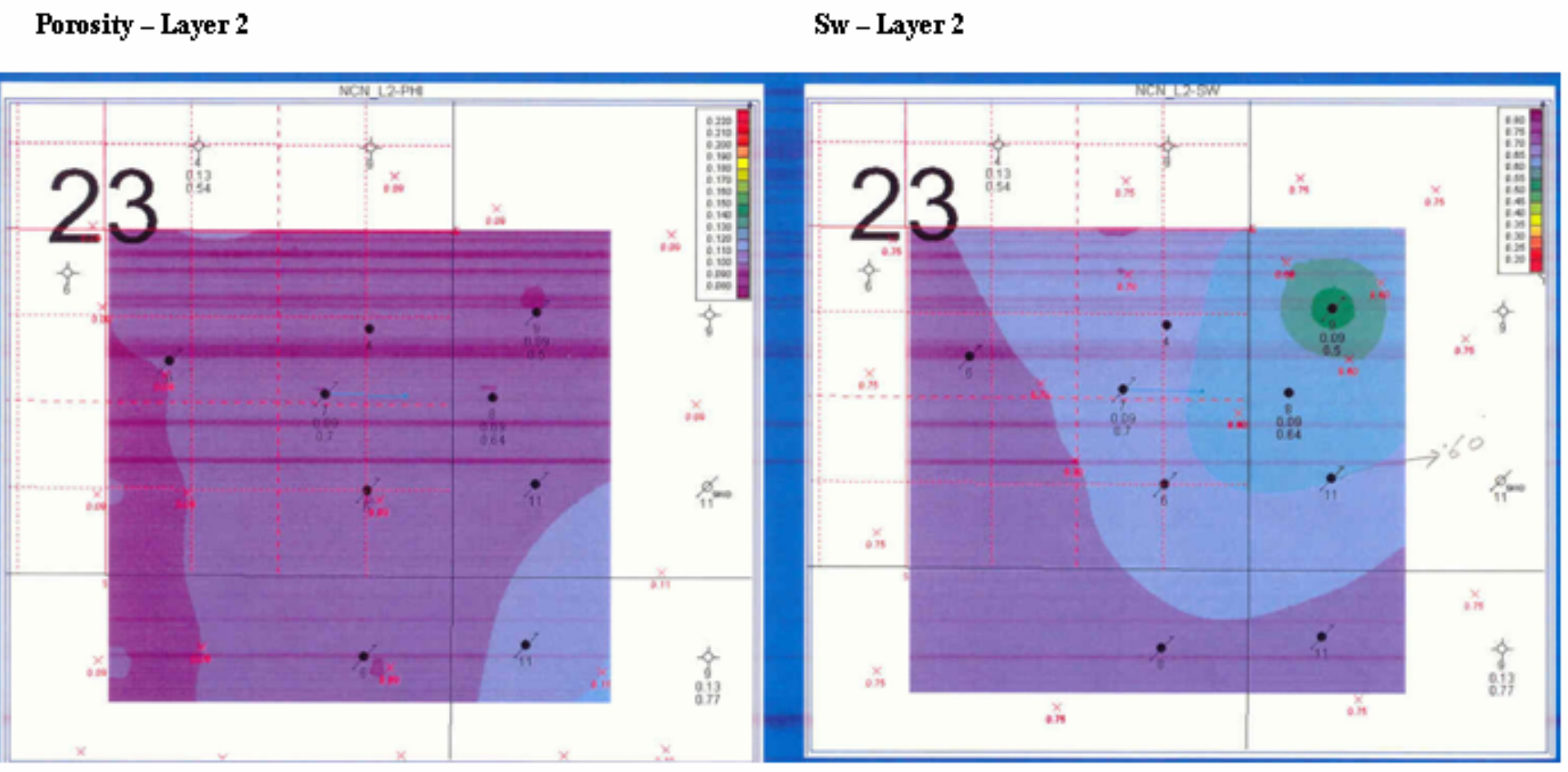

Figure 7.2.6: Distribution of porosity (fraction) and initial water saturation (fraction) in Layer 2 (L2) in Ness City North Field. 


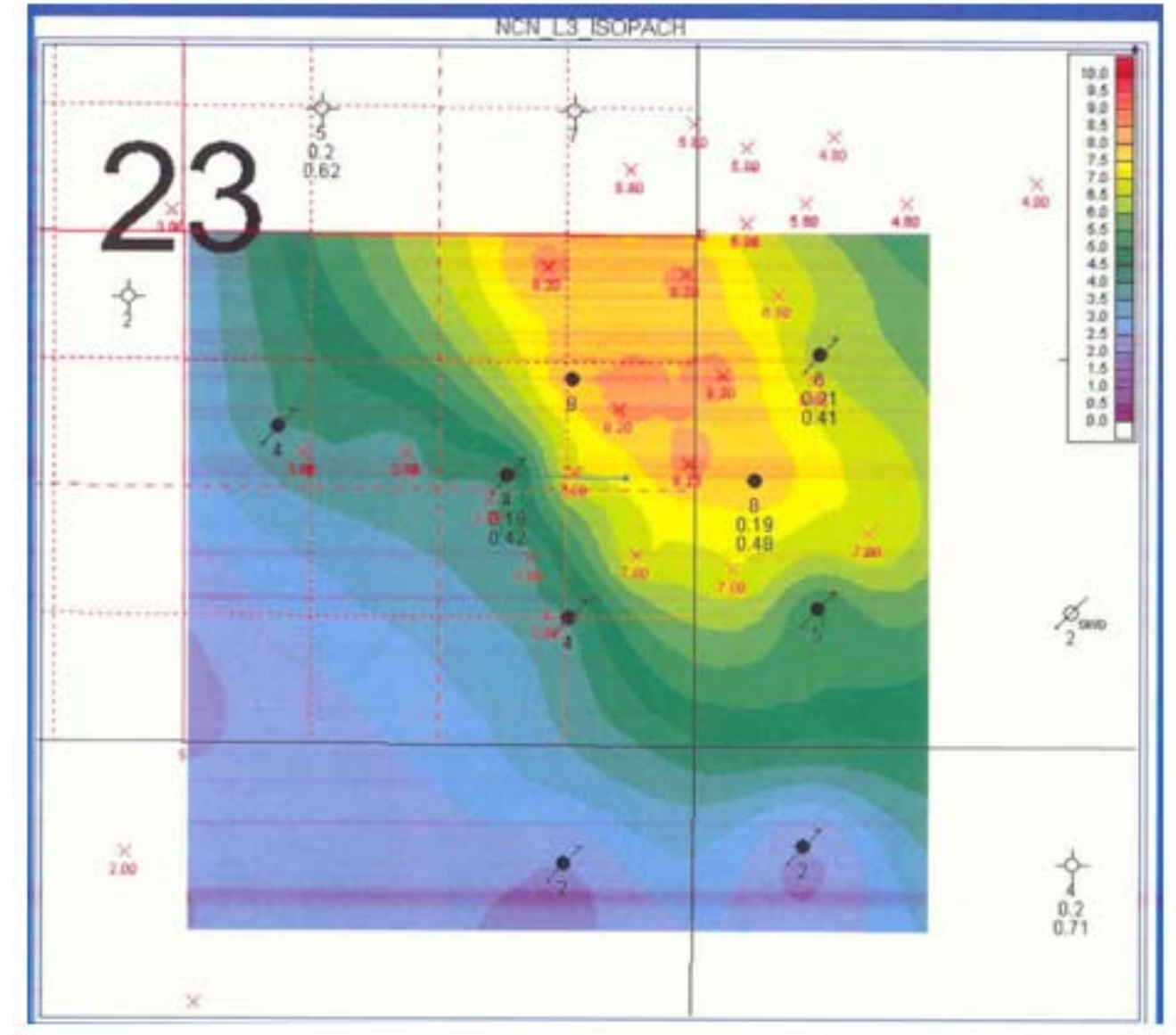

Figure 7.2.7: Isopach (feet) of Layer 3 (L3) in Ness City North Field. 


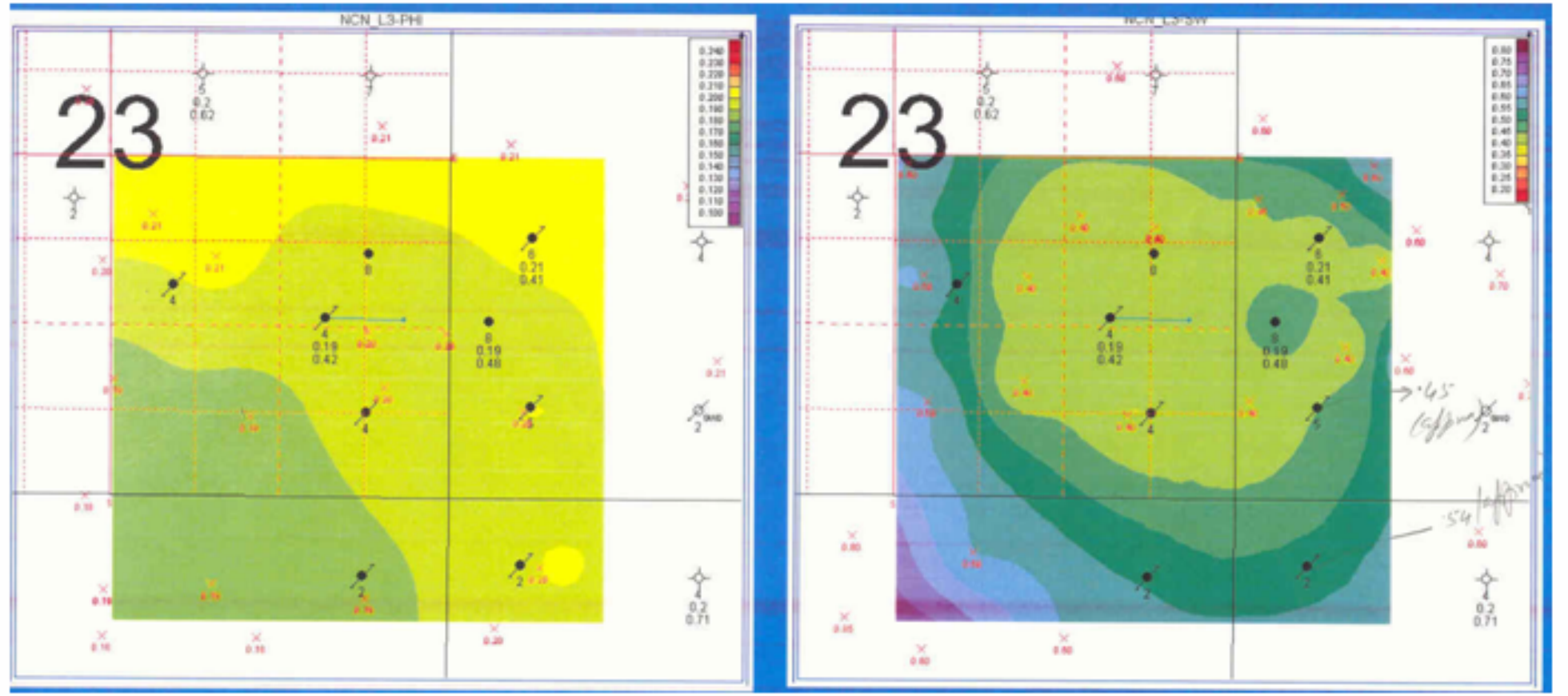

Figure 7.2.8: Distribution of porosity (fraction) and initial water saturation (fraction) in Layer 3 (L3) in Ness City North Field. 


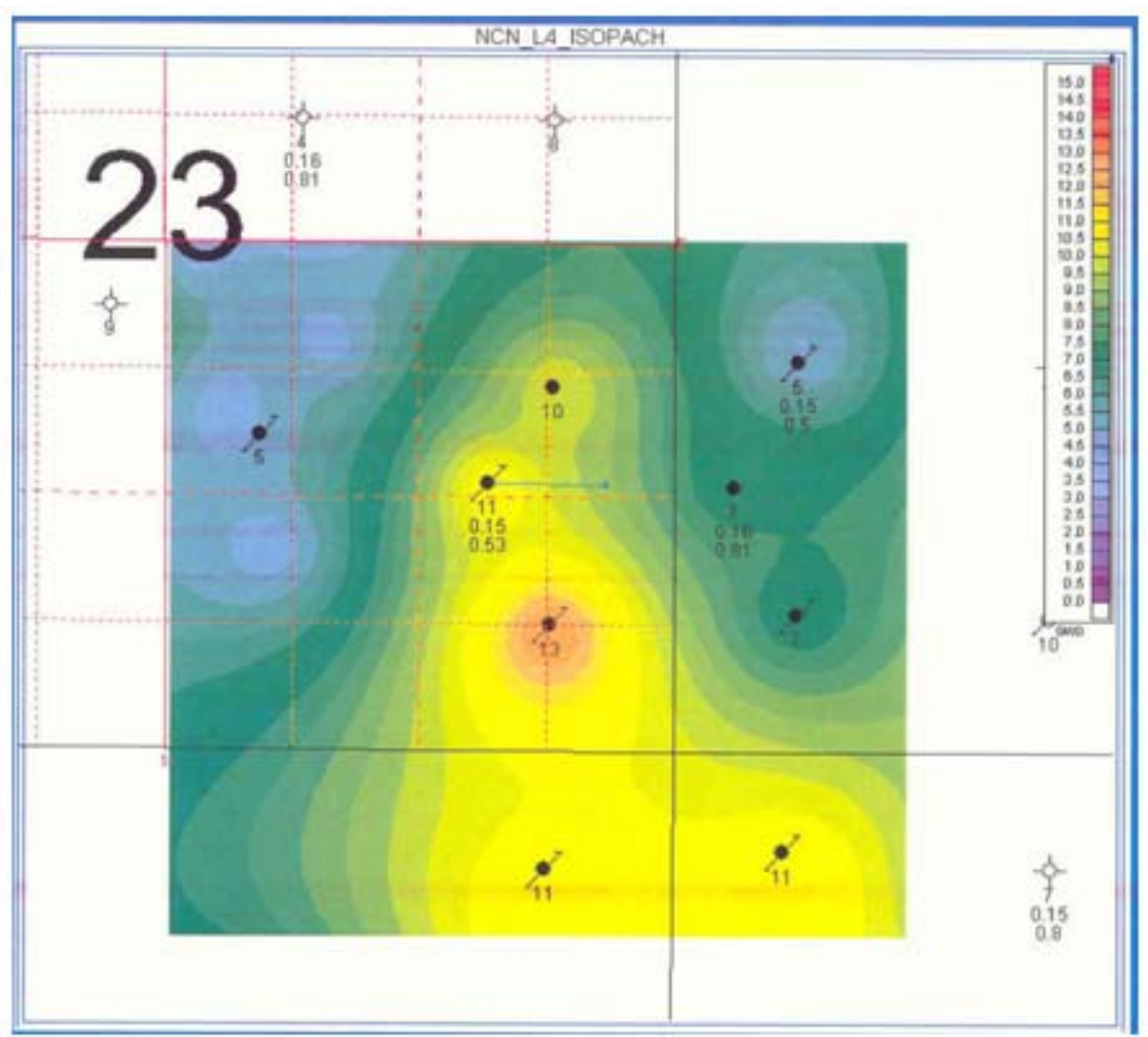

Figure 7.2.9: Isopach (feet) of Layer 4 (L4) in Ness City North Field. 


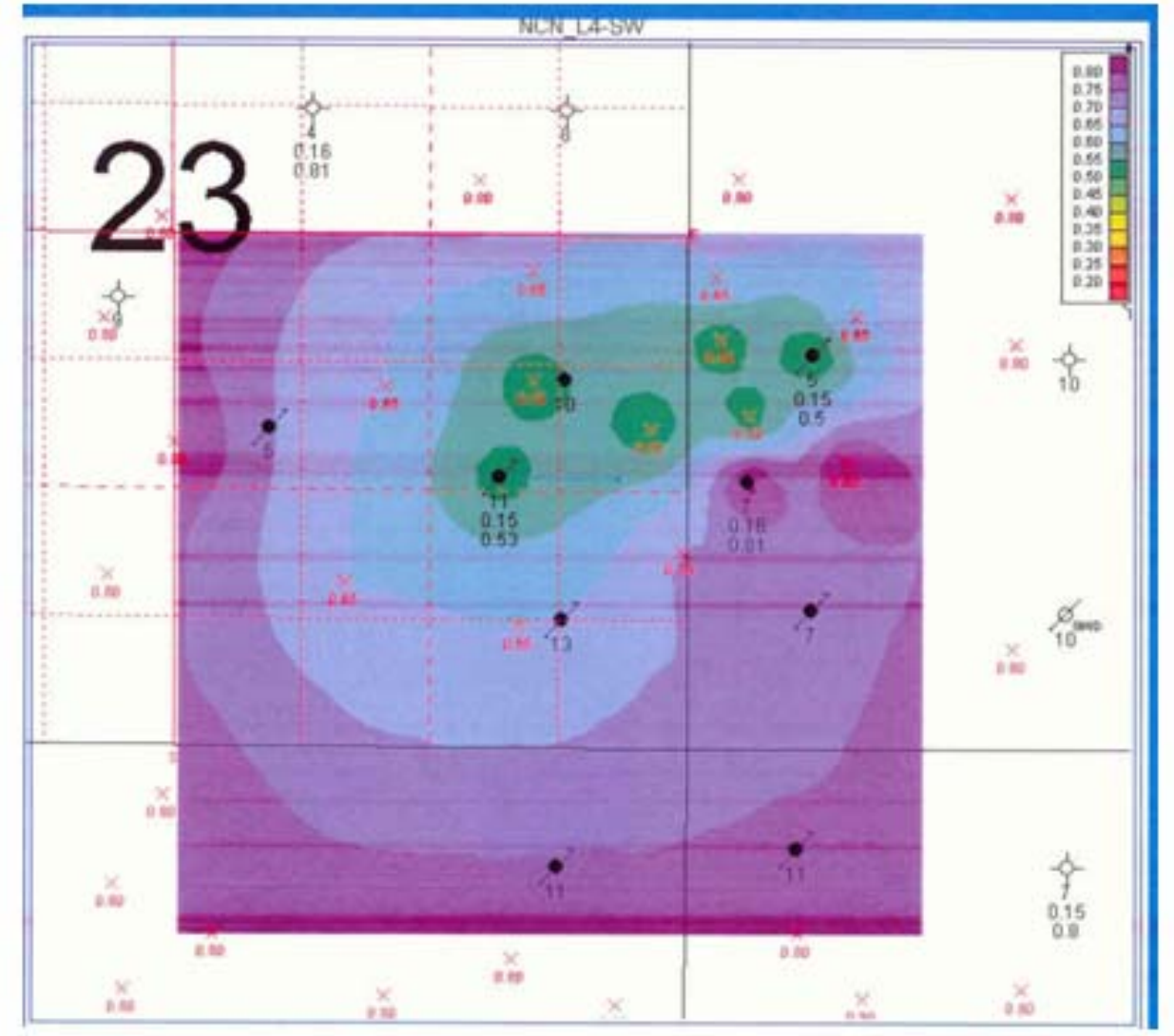

Figure 7.2.10: Distribution of initial water saturation (fraction) in Layer 4 (L4) in Ness City North Field. 


\section{Example cross section}
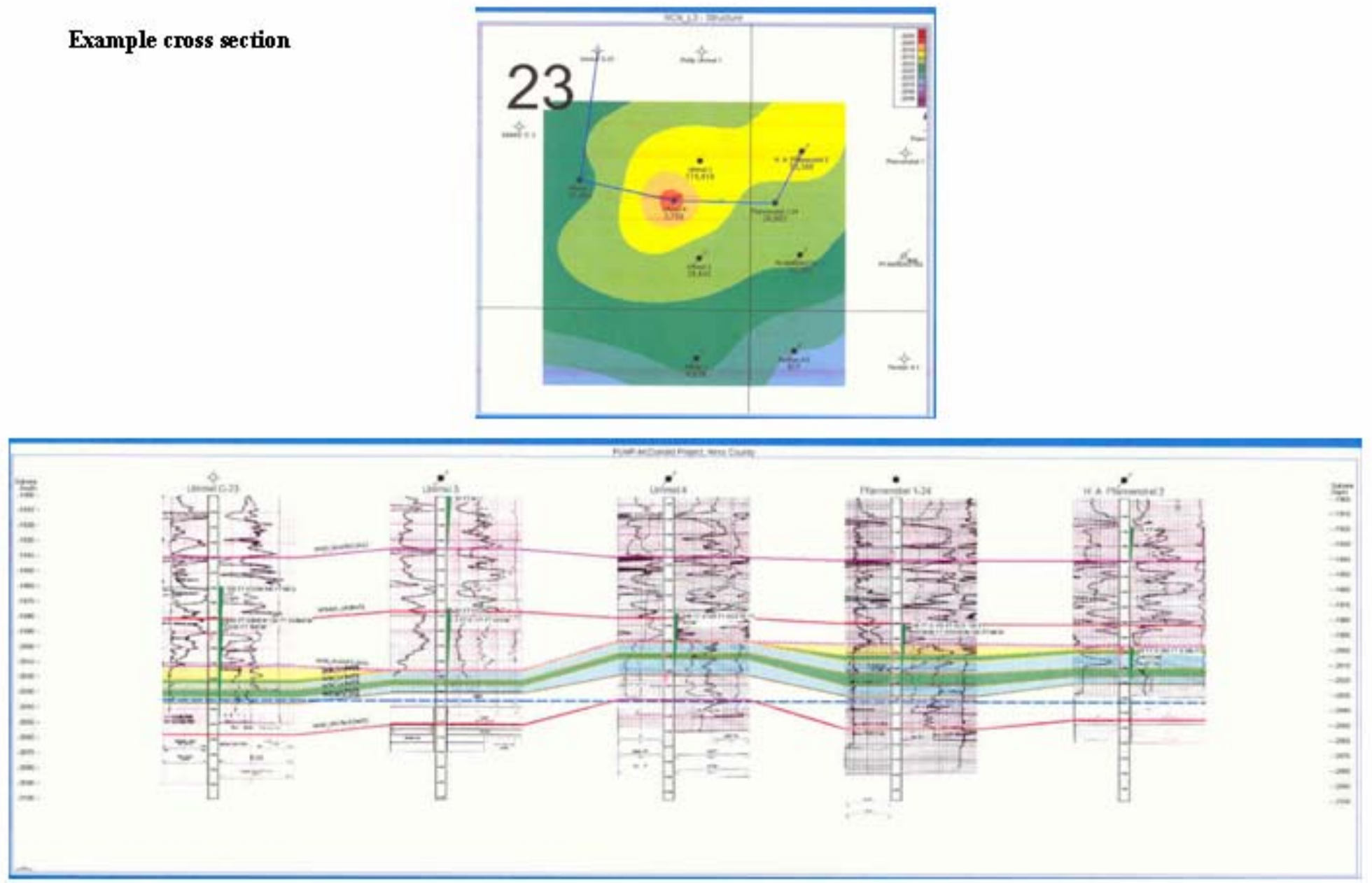

Figure 7.2.11: Example cross section from Ness City North Field. 


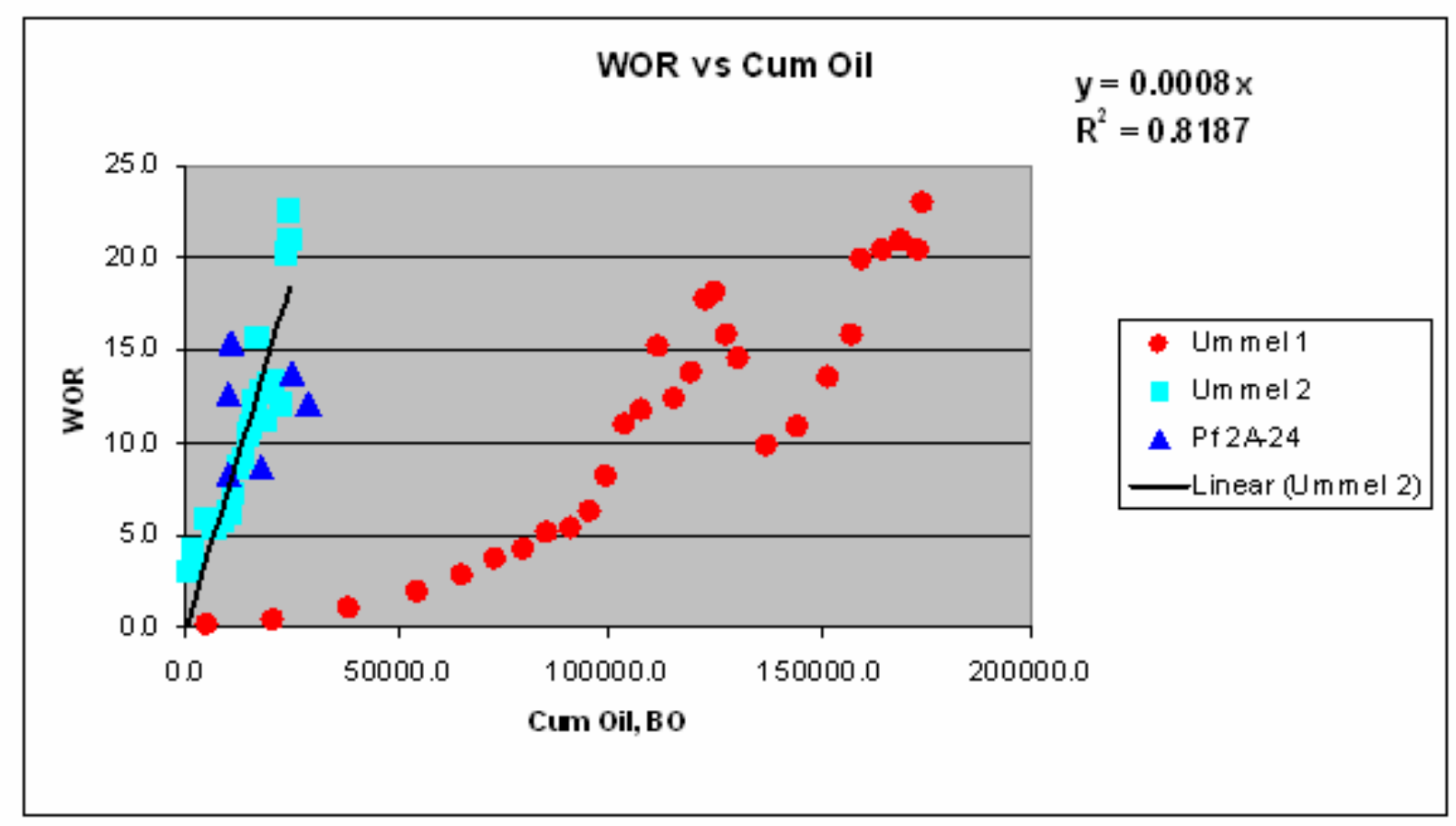

Figure 7.2.12: Trends of water-oil-ratio (WOR) with cumulative production in Ness City North Field. 


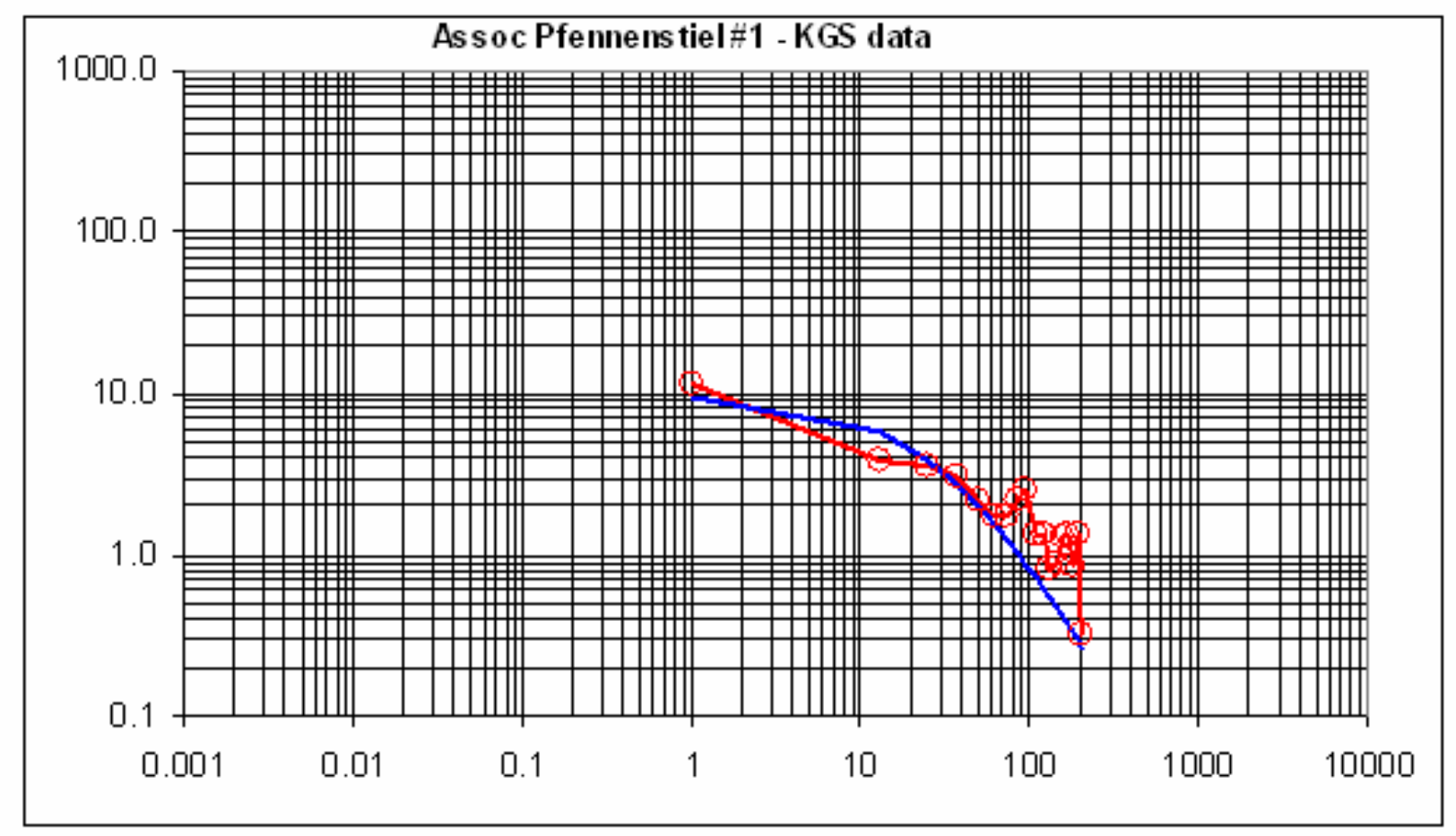

Figure 7.2.13: Decline curve analysis at Pfennenstiel \#1 well in Ness City North Field. 


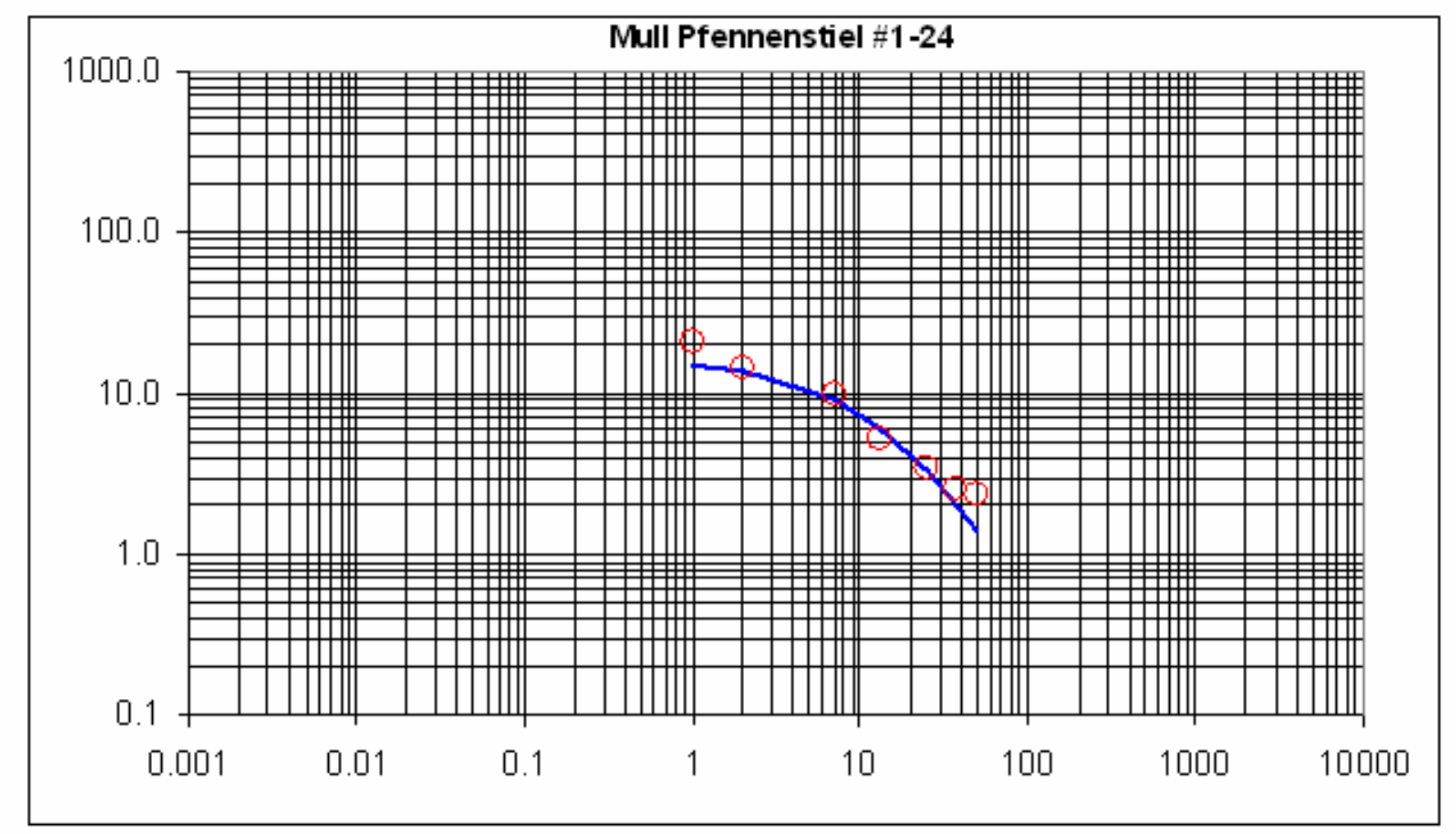

Figure 7.2.14: Decline curve analysis at Pfennenstiel \#1-24 well in Ness City North Field. 


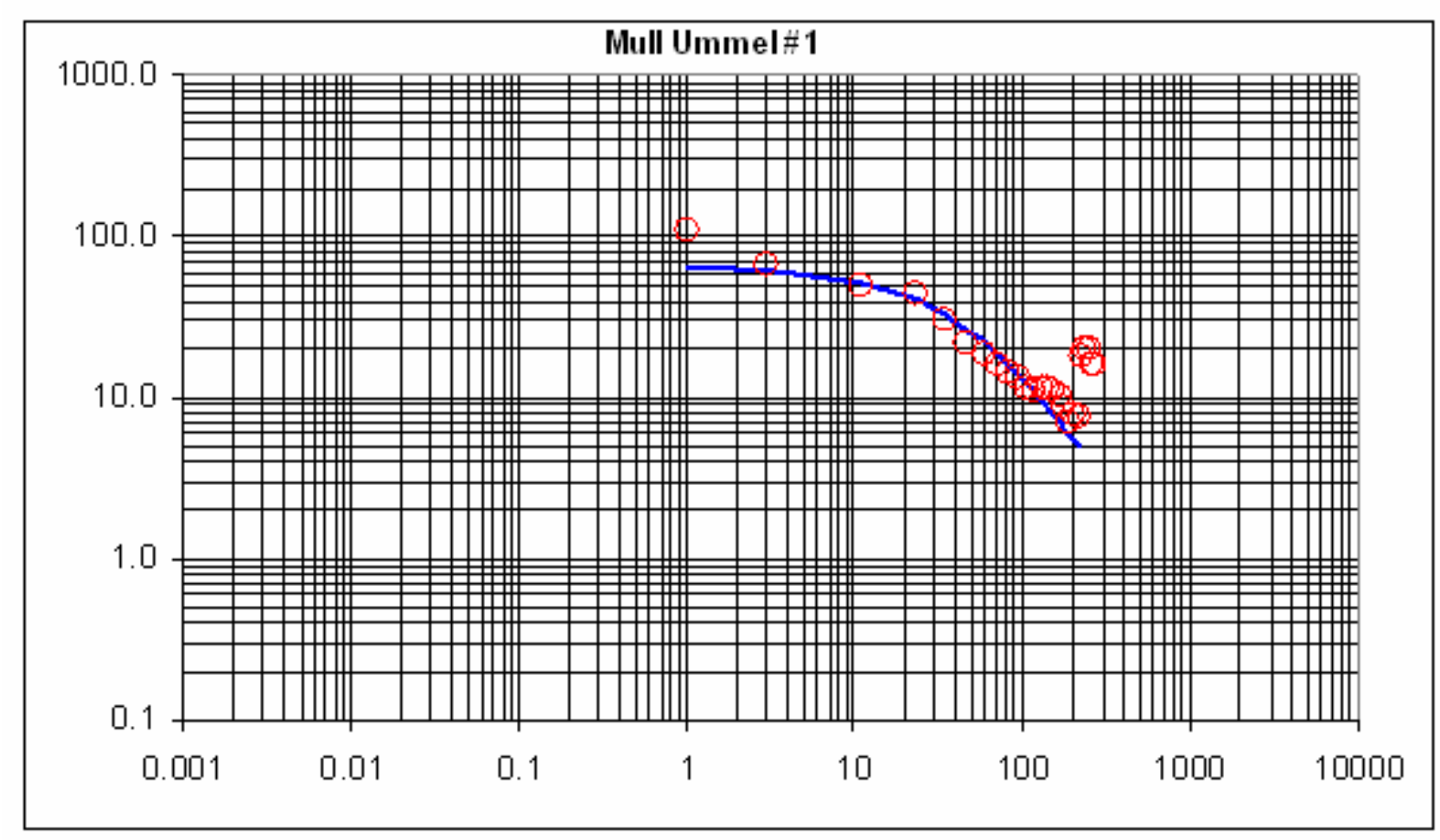

Figure 7.2.15: Decline curve analysis at Ummel \#1 well in Ness City North Field. 


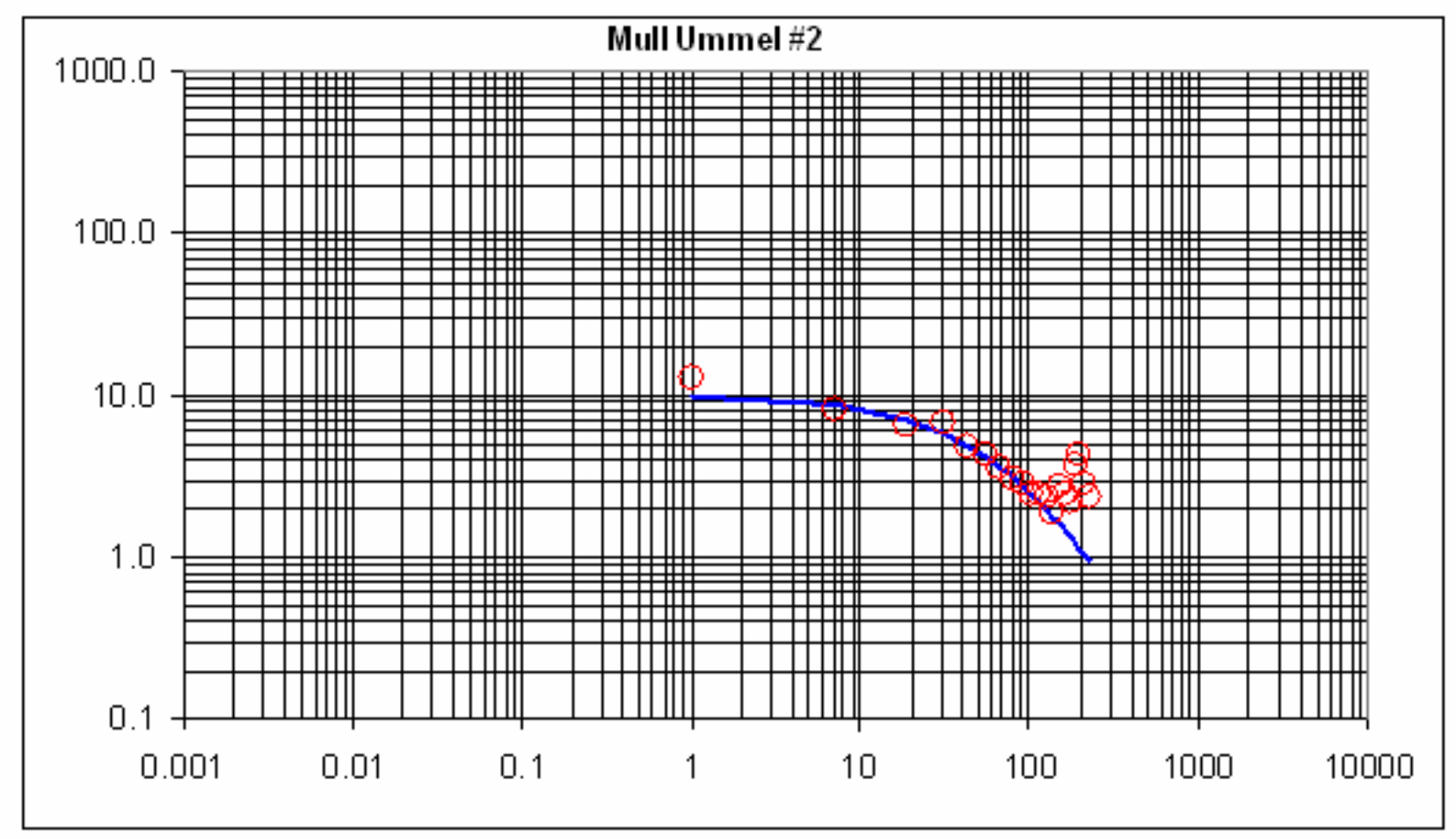

Figure 7.2.16: Decline curve analysis at Ummel \#2 well in Ness City North Field. 


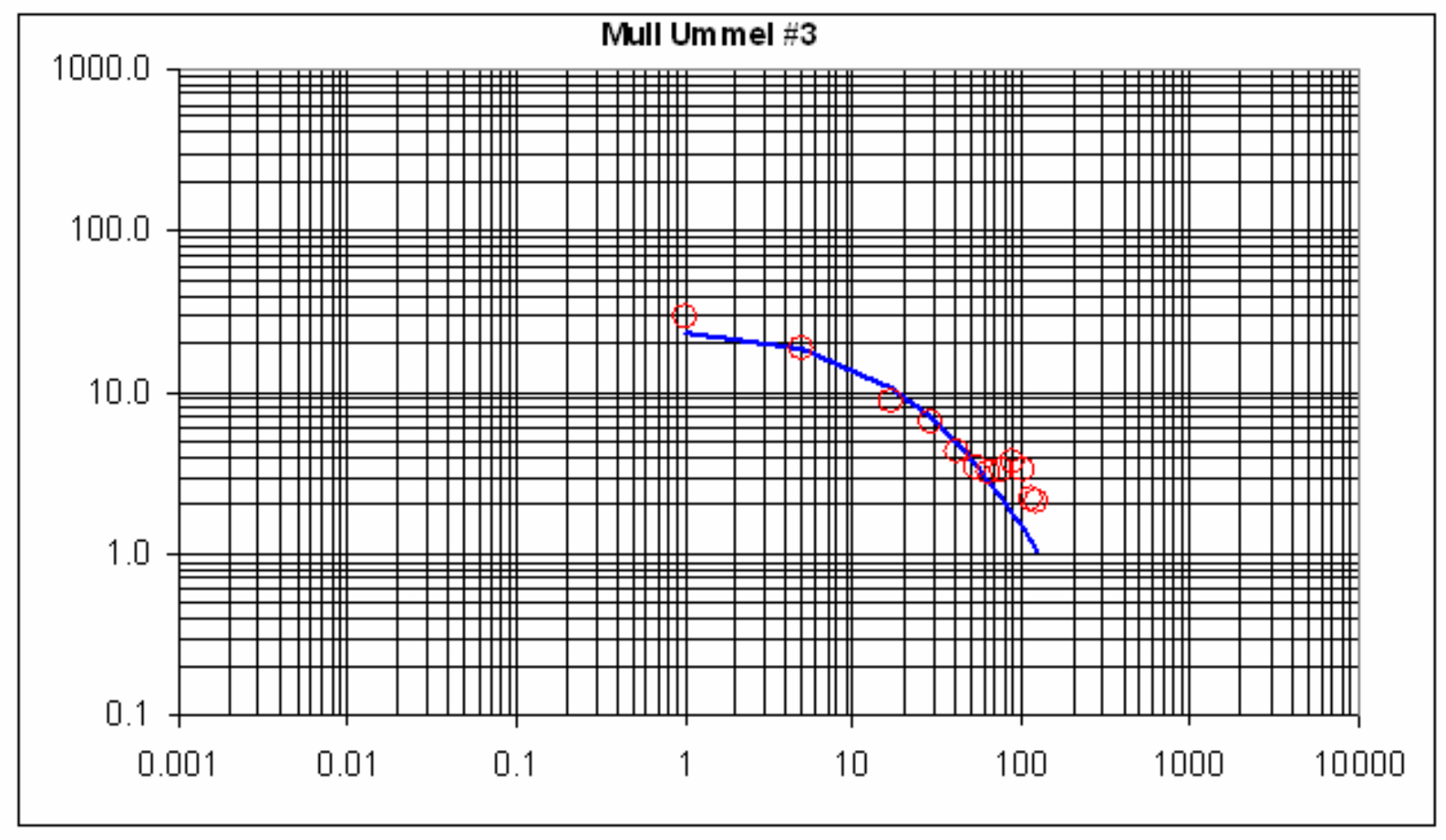

Figure 7.2.17: Decline curve analysis at Ummel \#3 well in Ness City North Field. 


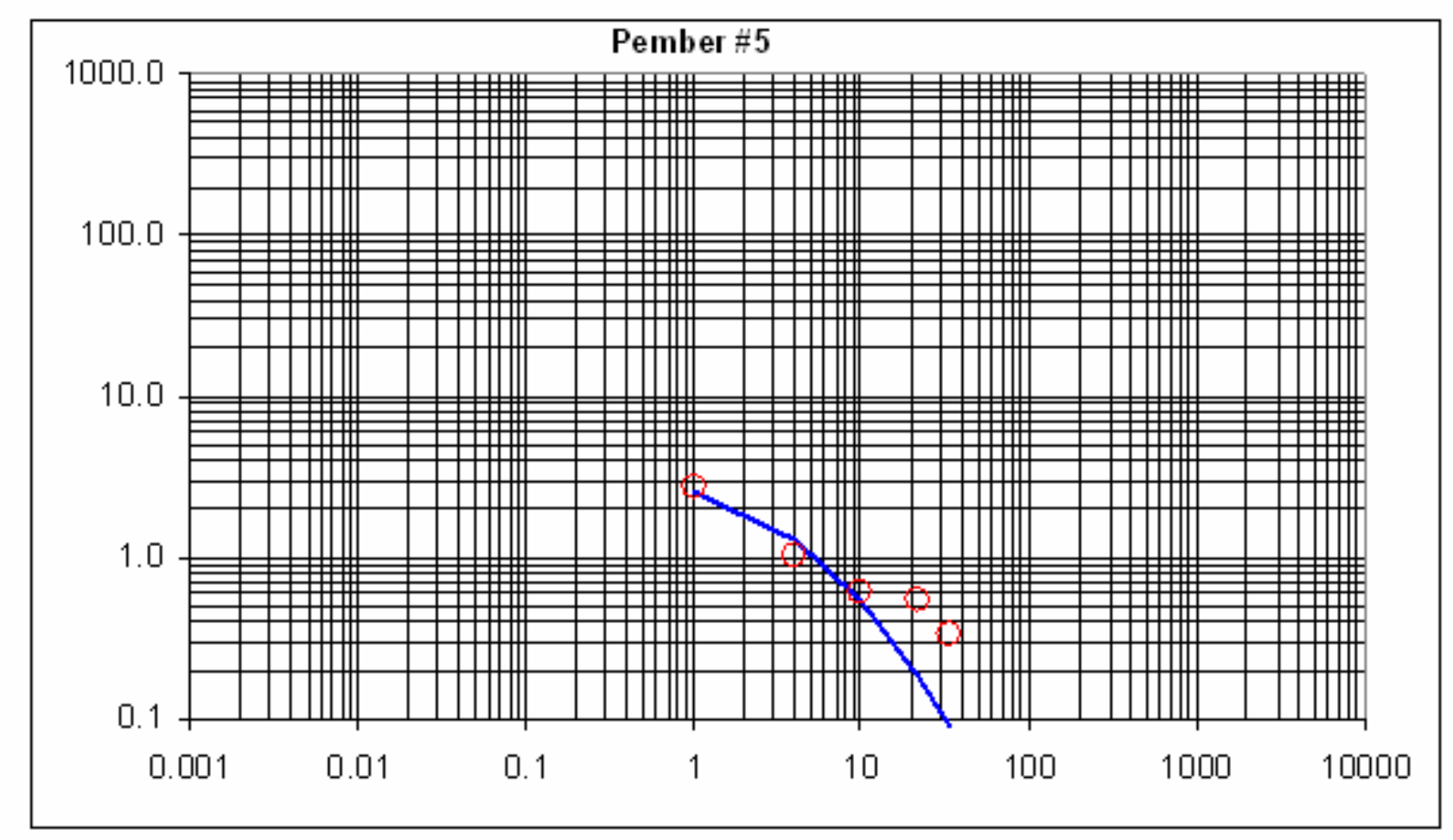

Figure 7.2.18: Decline curve analysis at Pember \#5 well in Ness City North Field. 


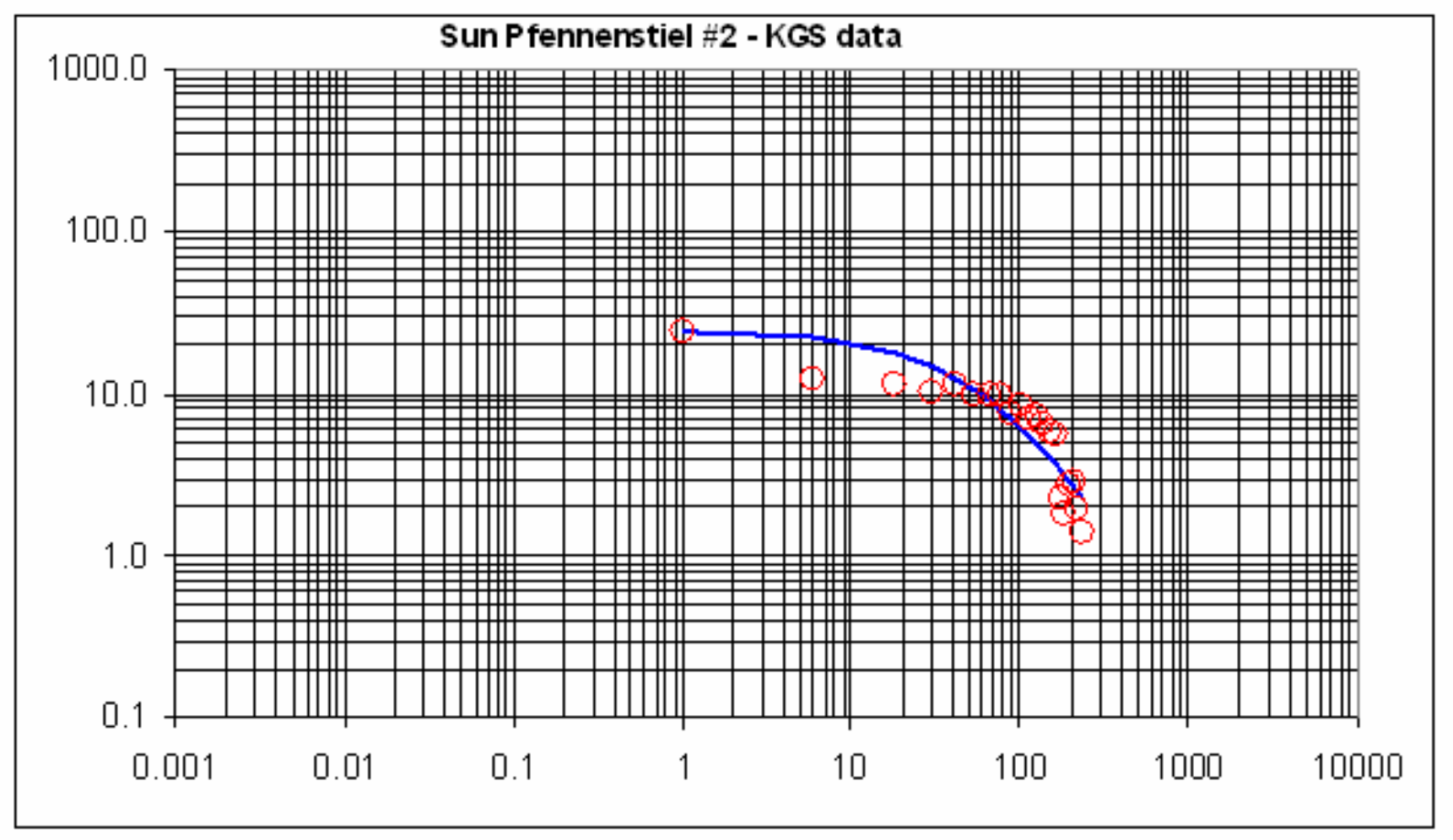

Figure 7.2.19: Decline curve analysis at Pfennenstiel \#2 (Sun) well in Ness City North Field. 


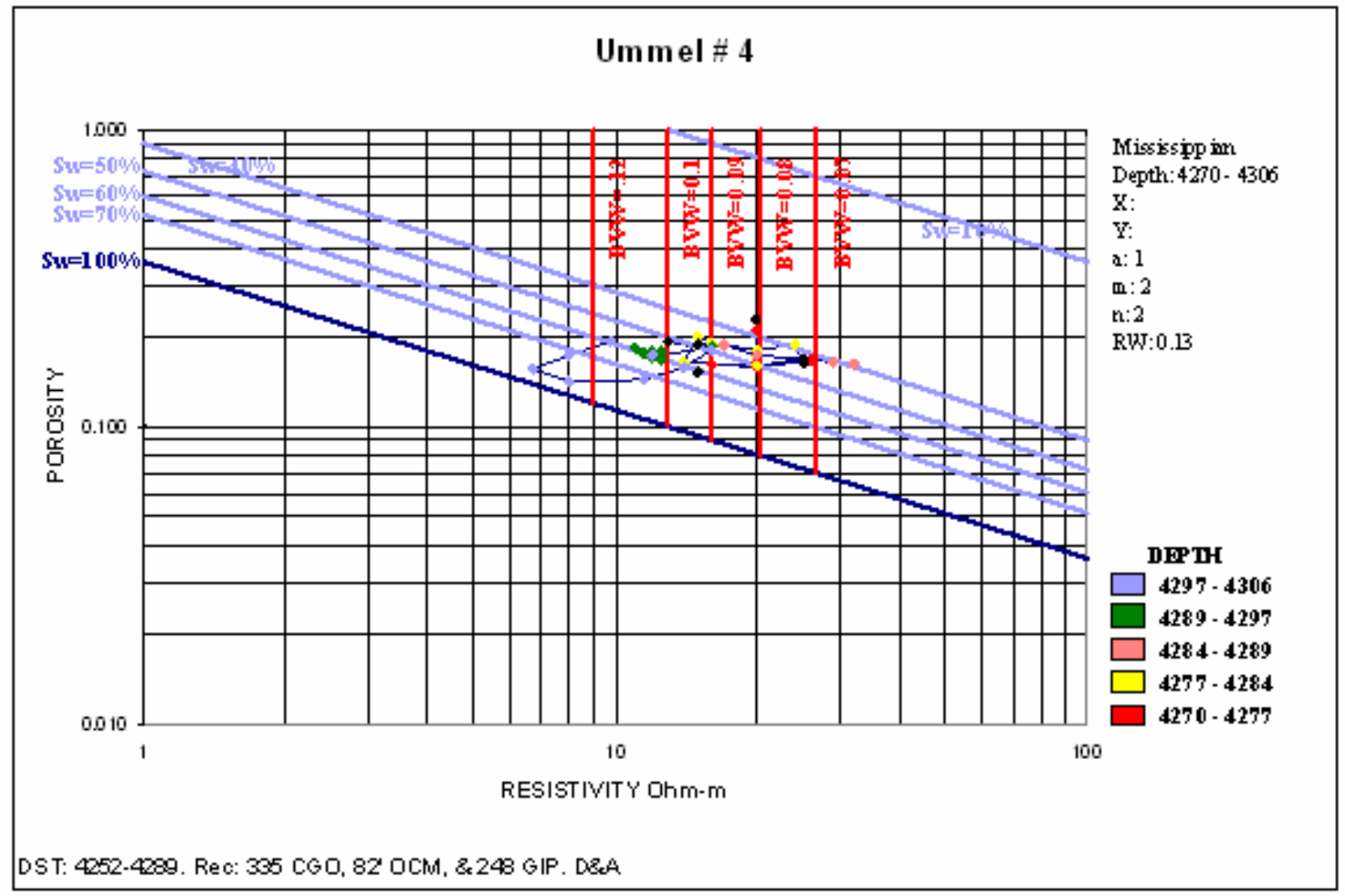

Figure 7.2.20: Super-Pickett analysis of wireline data from Ummel \#4 well in Ness City North Field. 


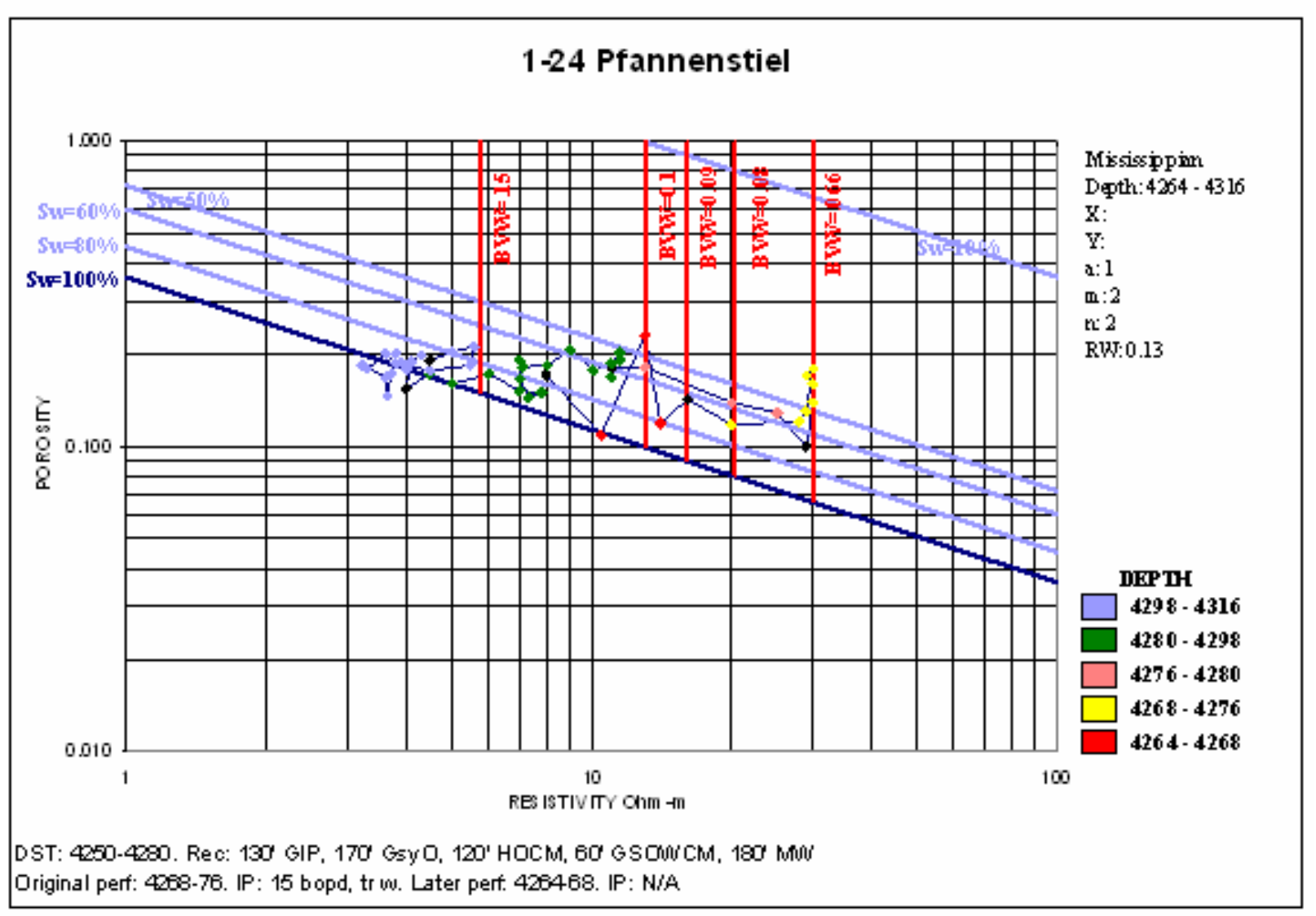

Figure 7.2.21: Super-Pickett analysis of wireline data from Pfannenstiel \#1-24 well in Ness City North Field. 

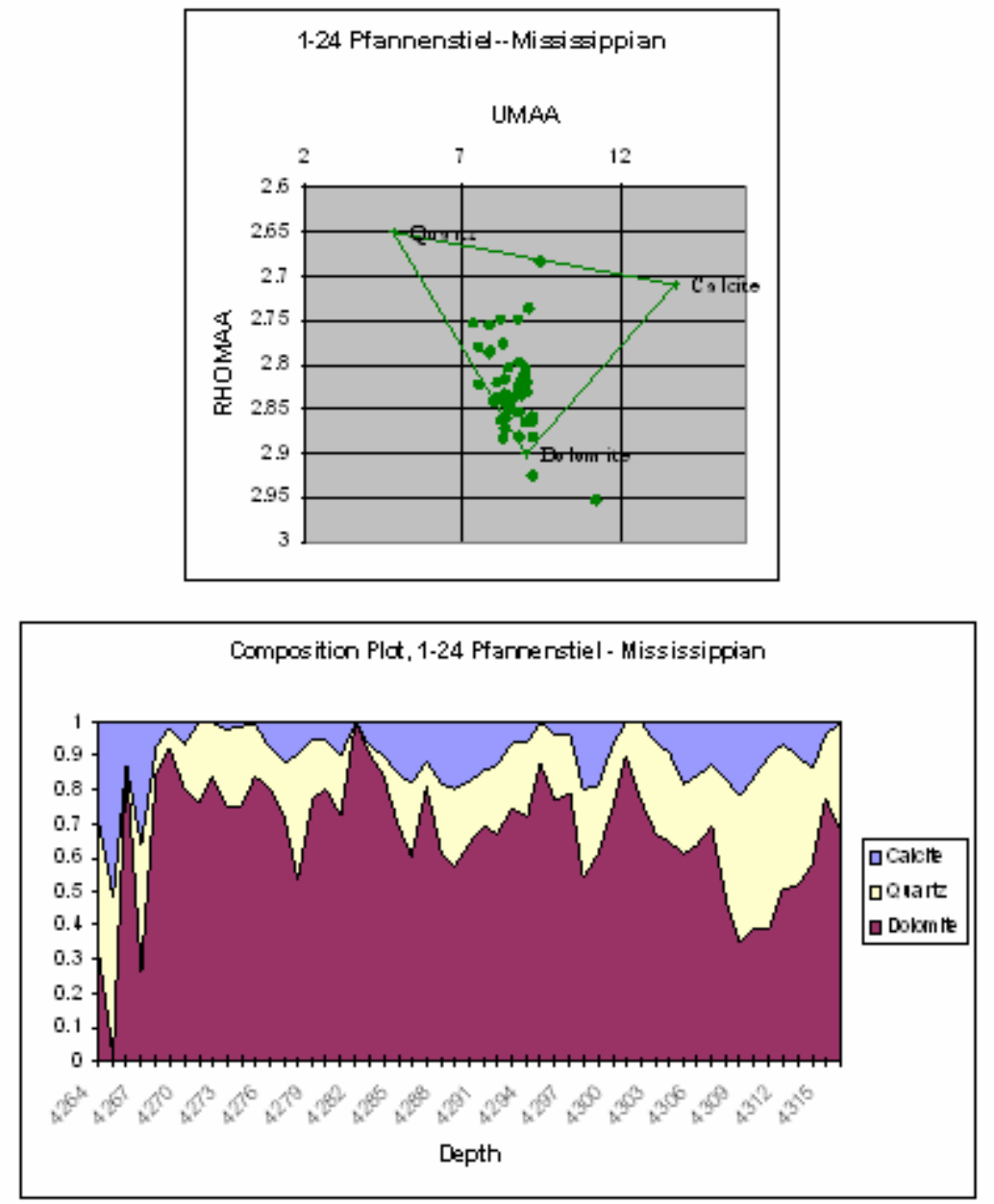

Figure 7.2.22: A Rhomma-Umaa plot using wireline log data from Pfannenstiel \#1-24 well in Ness City North Field. 


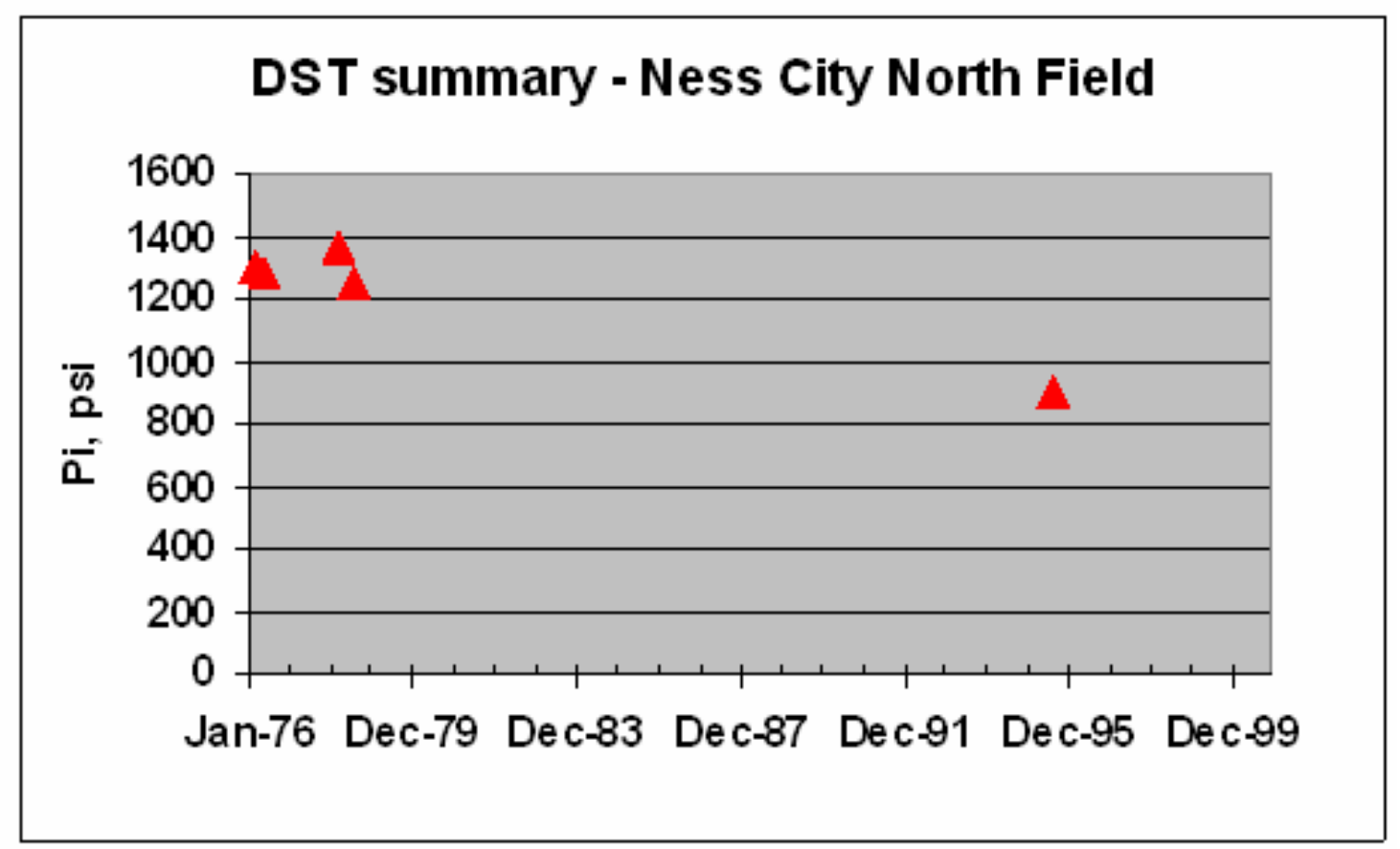

Figure 7.2.23: Plot of reservoir pressure from available DSTs in Ness City North Field. 


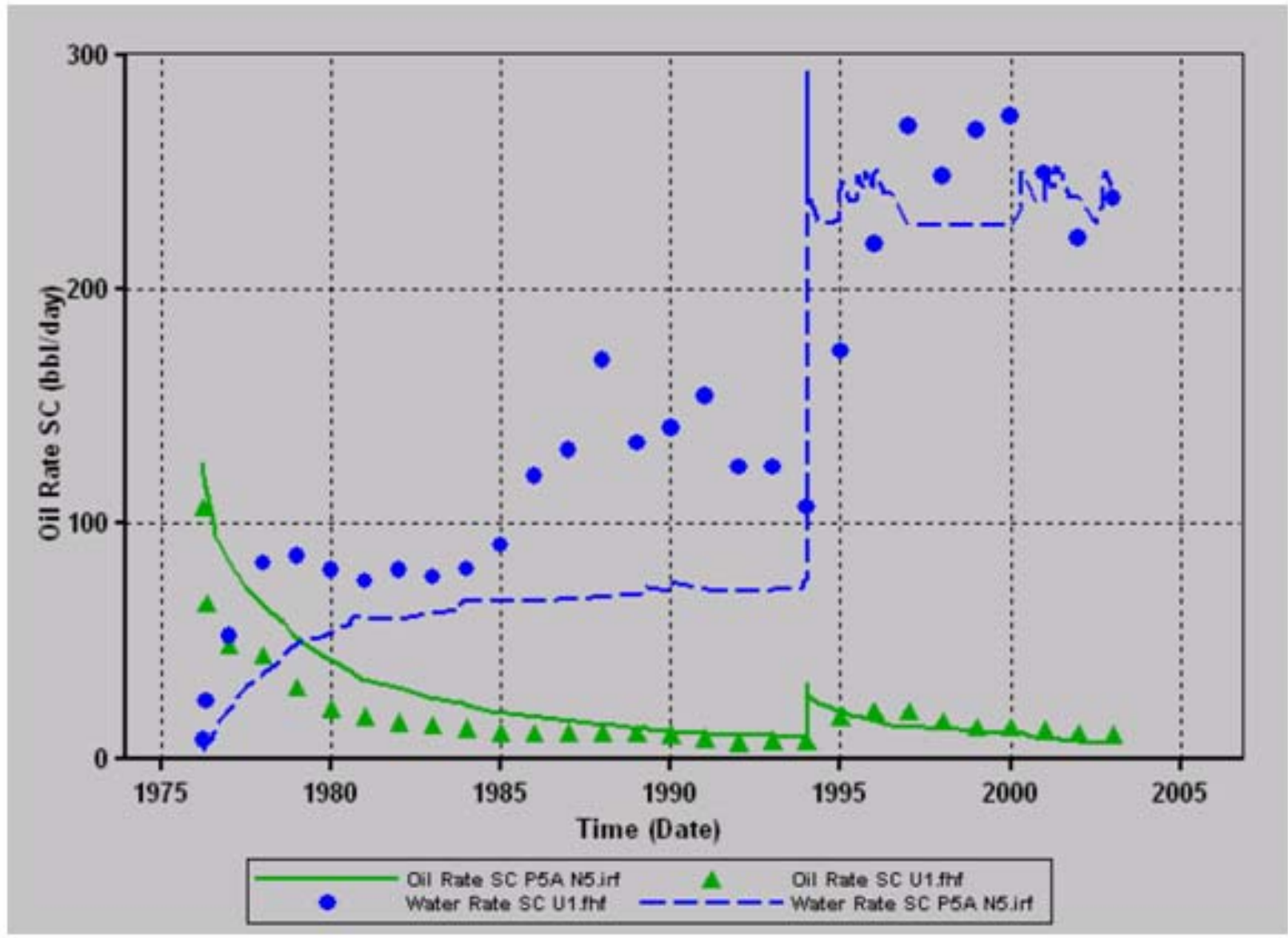

Figure 7.2.24: Production history match at Ummel \#1 well in Ness City North Field. 


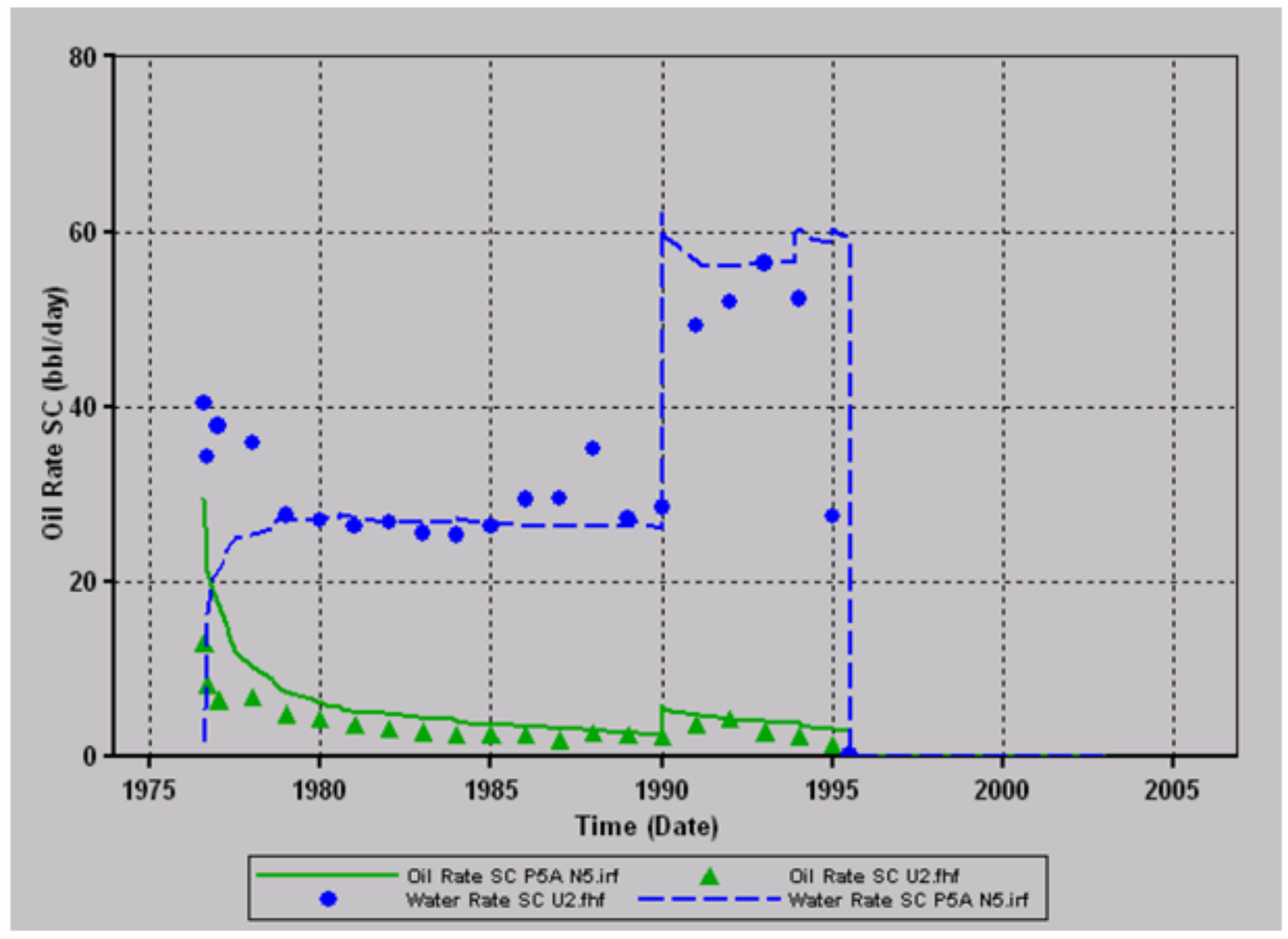

Figure 7.2.25: Production history match at Ummel \#2 well in Ness City North Field. 


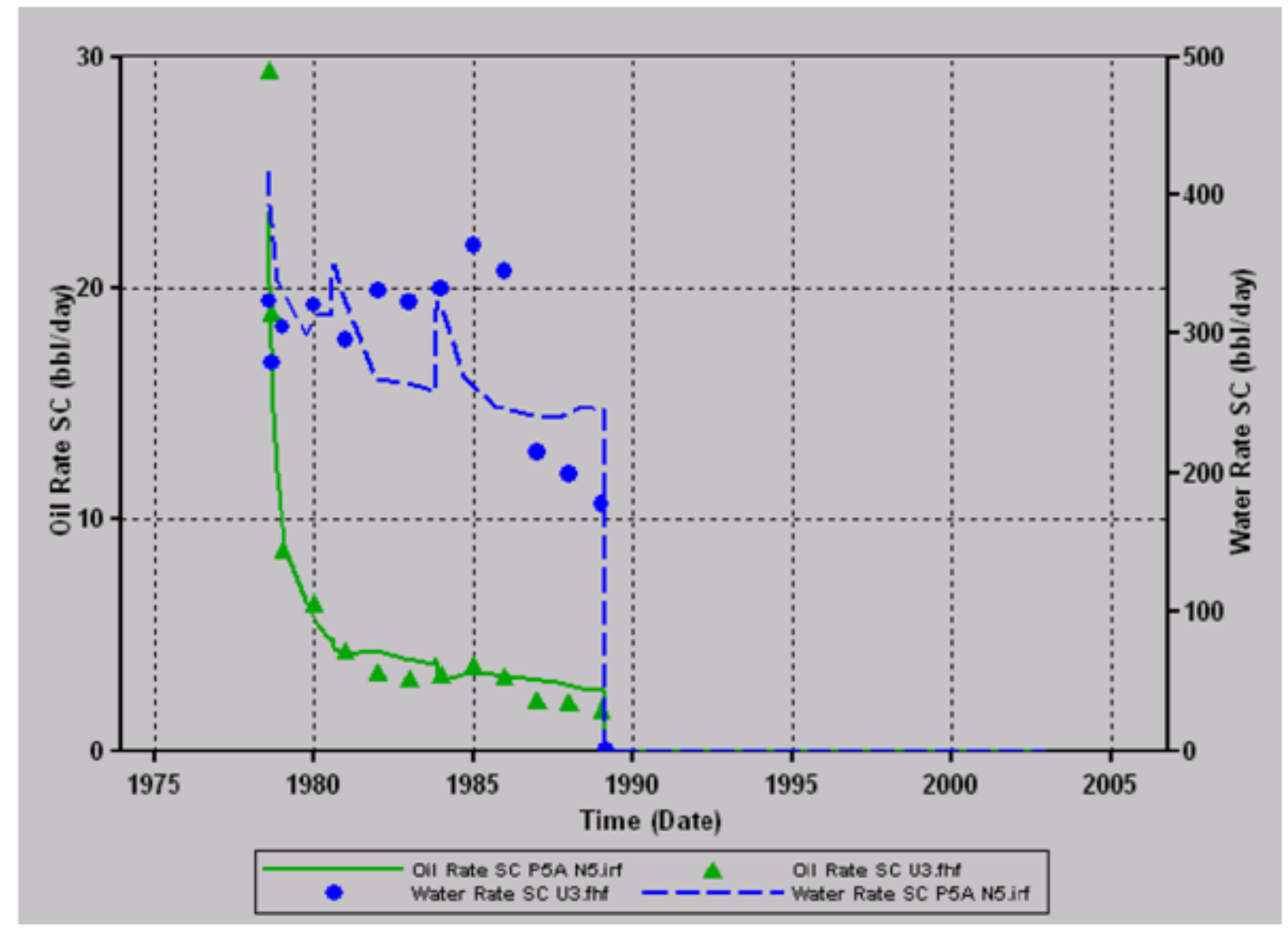

Figure 7.2.26: Production history match at Ummel \#3 well in Ness City North Field. 


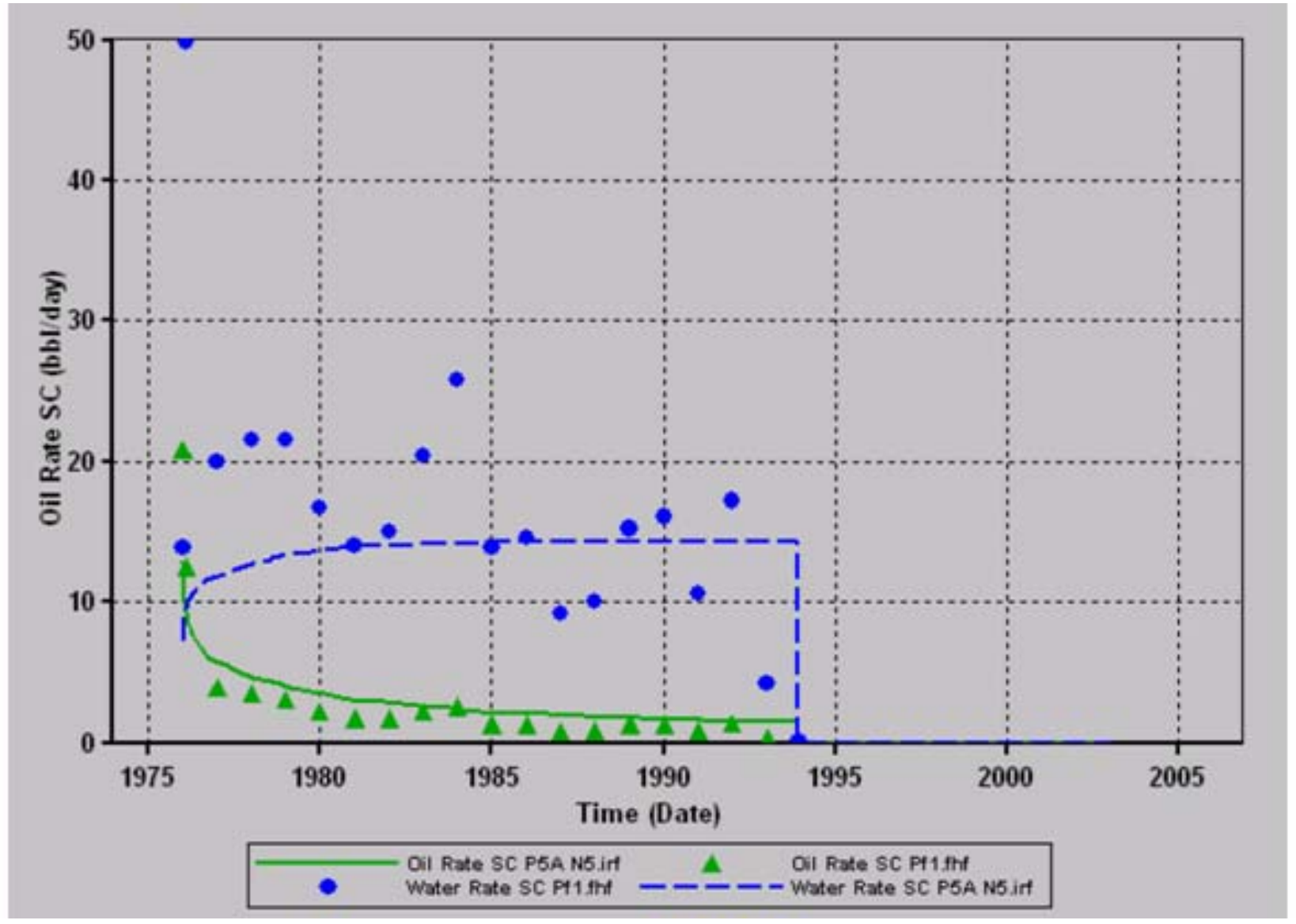

Figure 7.2.27: Production history match at Pfannenstiel \#1 well in Ness City North Field. Water production history was not available at this well. Water production estimated using WOR vs. cumulative oil from Ummel \#2 well. 


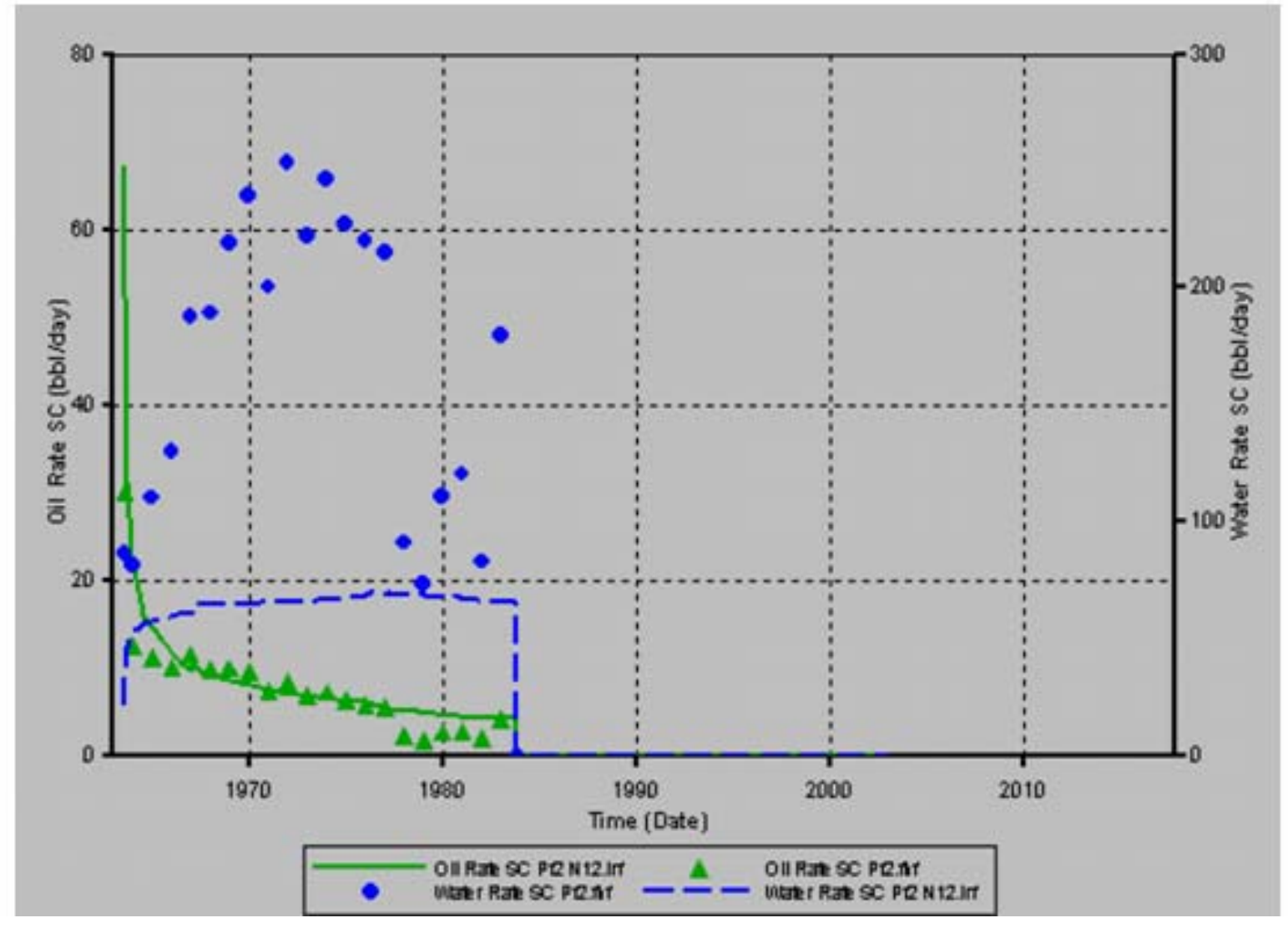

Figure 7.2.28: Production history match at Pfannenstiel \#2 well in Ness City North Field. Water production history was not available at this well. Water production estimated using WOR vs. cumulative oil from Ummel \#2 well. 


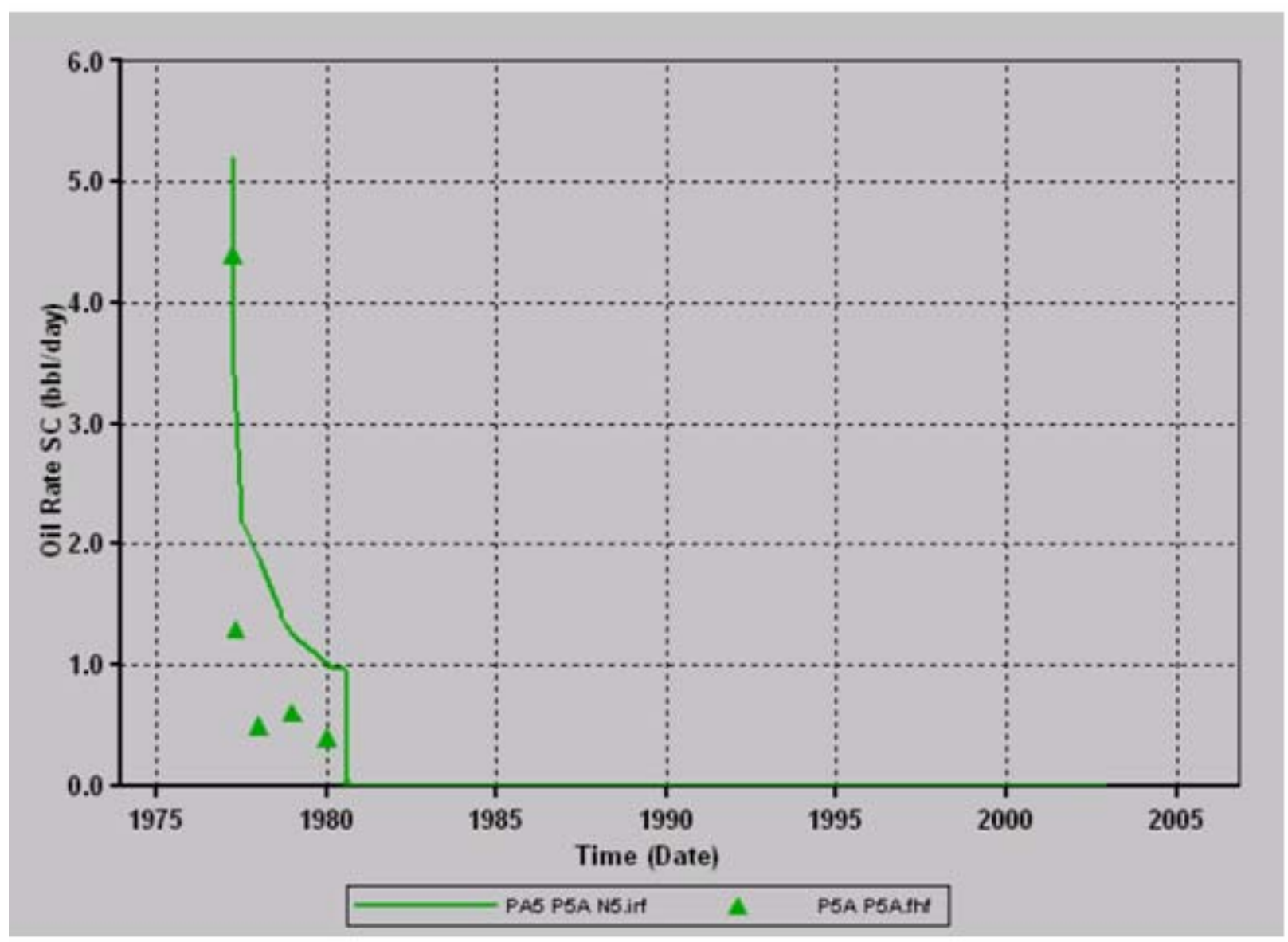

Figure 7.2.29: Production history match at Pember \#5A well in Ness City North Field. Water production history was not available at this well. 
Sw at Pf 2A-24 from logs at Jan 1994:

$\mathrm{Ll}=0.42, \mathrm{~L} 2 \mathrm{2}=0.64, \mathrm{~L} 3=$ $0.48, \mathrm{~L} A=0.81$

Sw at Pf $2 A-24$ calculated by simulation at Jan 1994:

$\mathrm{Ll}=0.41, \mathrm{~L} 2 \mathrm{2}=0.52, \mathrm{~L} 3=$ $0.46, \mathrm{~L} A=0.73$

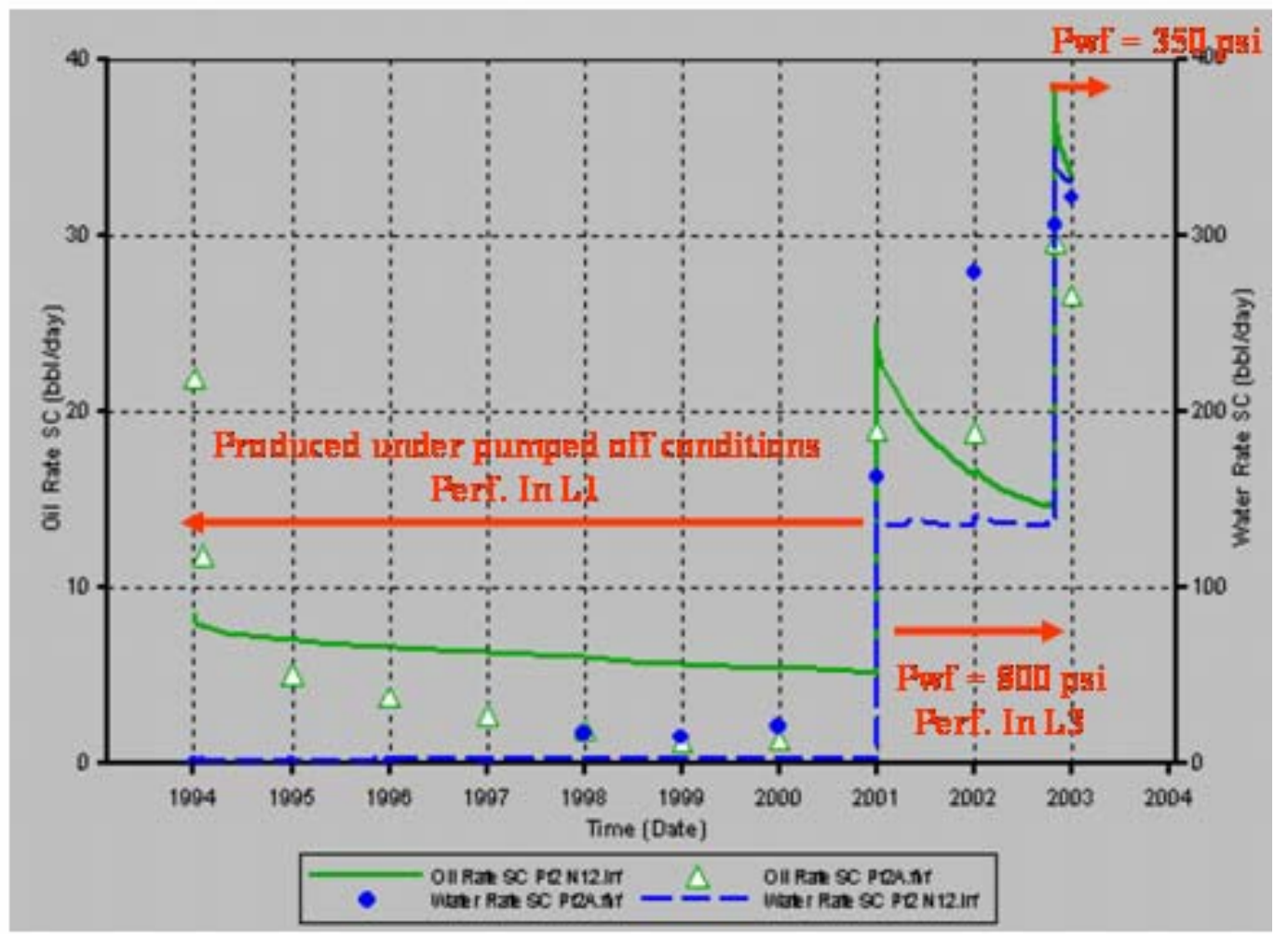

Figure 7.2.30: Simulator calculated fluid production at Pfannenstiel \#2A-24 well matched with historically recorded production volumes. 


\begin{abstract}
Well produced for 1 year in the simulator to estimate production decline. Under field conditions, this well produced for 1 month only before mechanical collapse. For history matching, horinontal permeability (Kxy) was modified. Ummel $1 \mathrm{Kxy}=25 \mathrm{md}$. Ummel $4 \mathrm{H}$
\end{abstract}

$\mathrm{Kxy}=15 \mathrm{md}$

Simulatar calculated

Initial IPs:

Qu $=52$ bopd

$Q w=65$ bwpd

Pwf $=550$ psi.

Skin $=1.5$

Well diameter $=6$ inches

Well length $=330 \mathrm{ft}$

Prad. Rates actually abgerved:

Averaged aver lst month:

Avg Qa $=59$ bopd

Avg Qw $=55$ bwpd

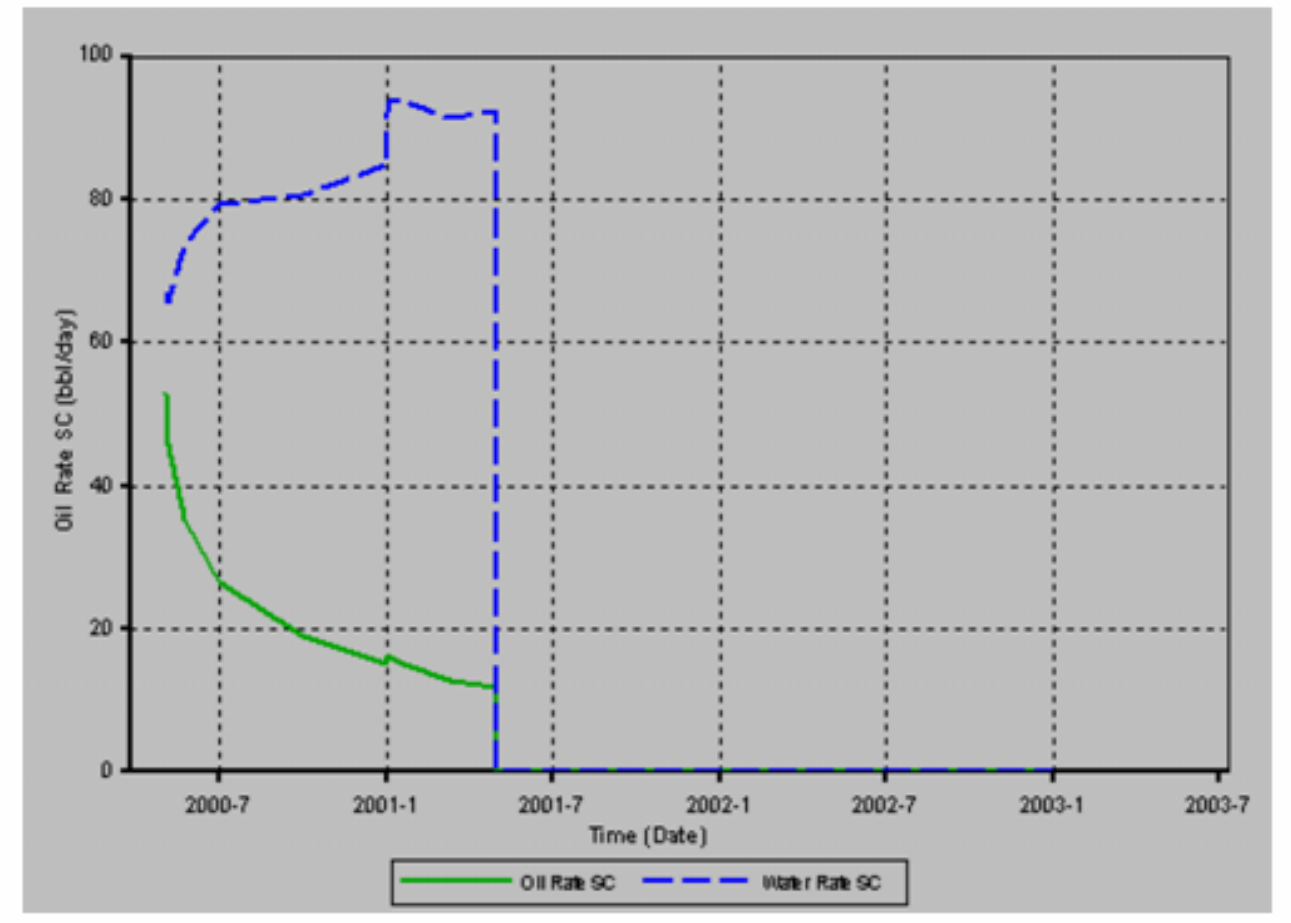

Figure 7.2.31

Figure 7.2.31: Simulator-calculated fluid production at the infill horizontal well (Ummel \#4H) drilled in Ness City North Field. 


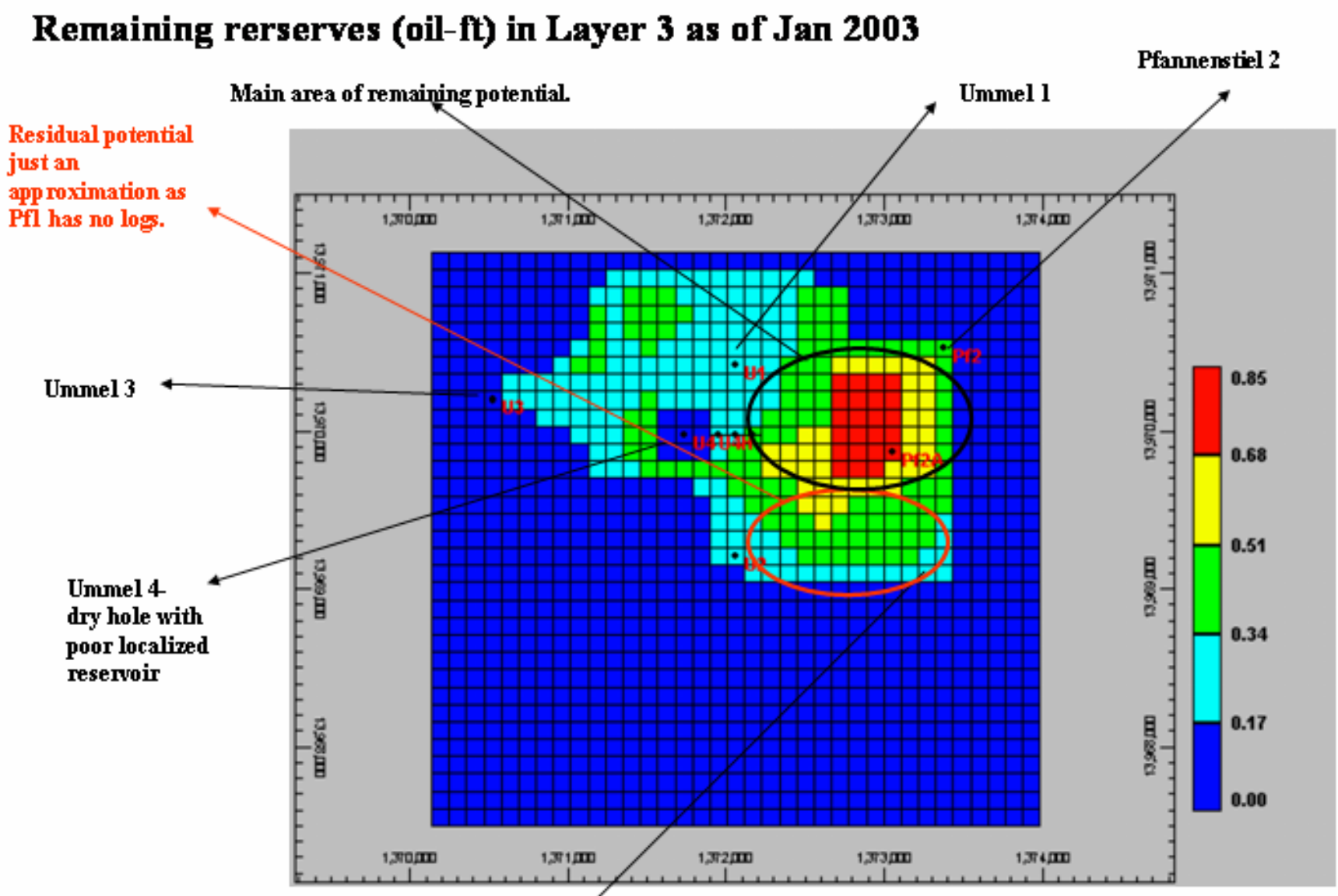

Figure 7.2.32

Pfannenstiel 1 -perf in Ll only. No log available for this well Pay thickness, porosity and Sw estimated in Ll to $\mathrm{L} A$ from regional cross sections.

Figure 7.2.32: Remaining reserve (porosity*oil saturation*pay), oil-feet, in Layer 3 (L3) as of January 2003 in Ness City North Field. 


\section{Horizontal Infill well}

East- West

Oil-ft in Layer 3 as of Jan 2003

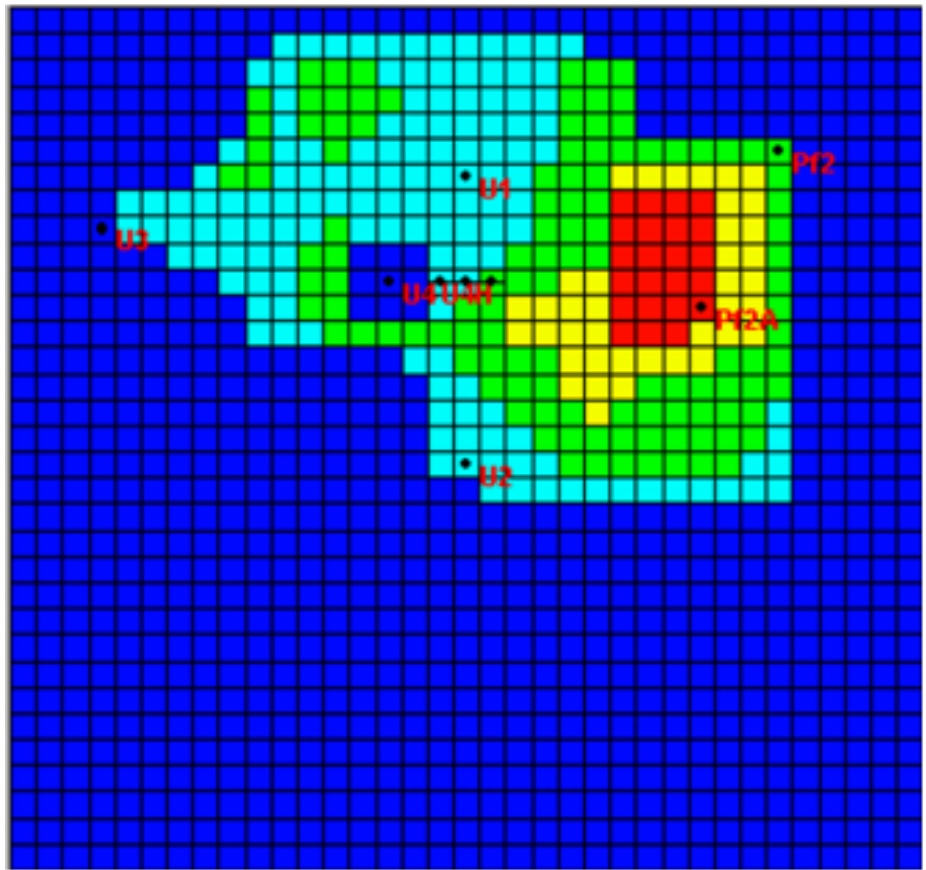

Oil-ft in Layer 3 as of Jan 2013

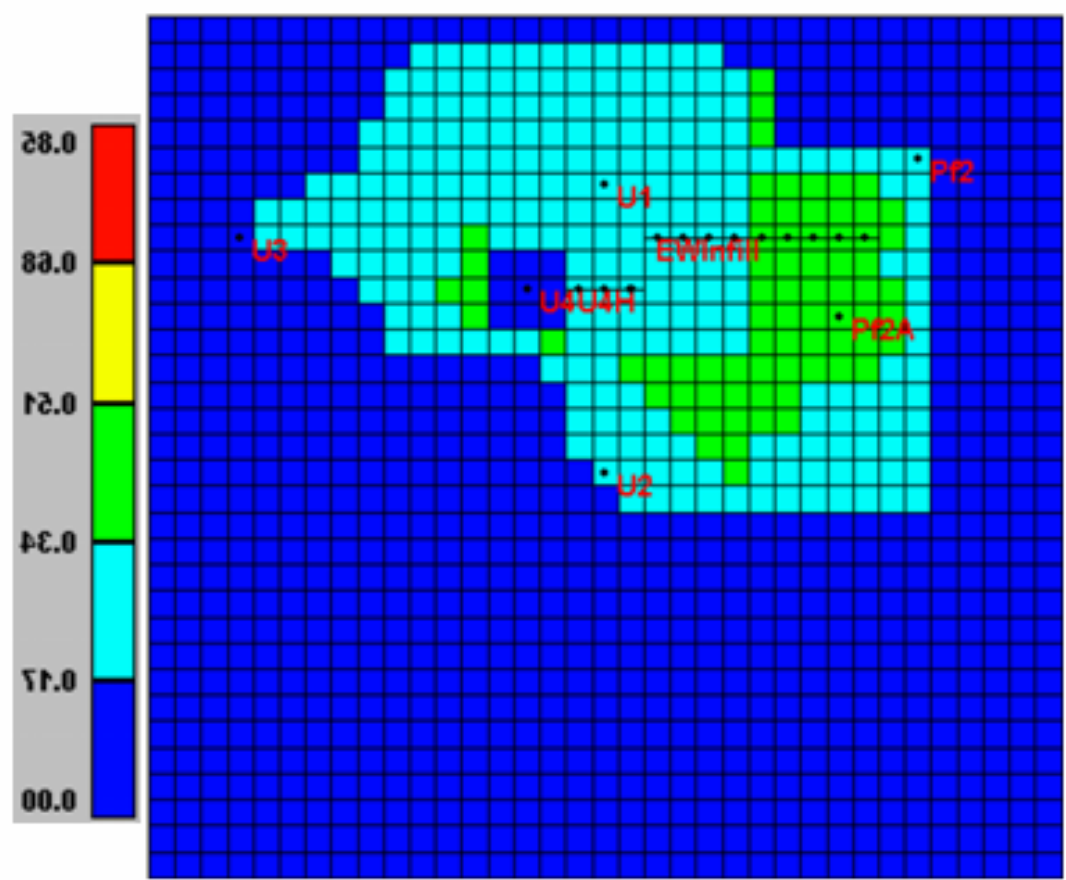

Figure 7.2.33: Simulator-calculated drainage, expressed as oil-feet (porosity*oil saturation*pay), by a targeted horizontal infill, EWInfill, in Ness City North Field between January 2003 and January 2013. 


\section{Performance prediction - East-West Horizontal Infill well}

Cum oil produced over 10 years $=71272 \mathrm{bbls}$.

Well length $=990 \mathrm{ft}$, skin $=1.5$, Pwf $=200$ psi, well diameter $=6$ inch

\begin{tabular}{|r|r|r|}
\hline Year end & Cum Oil, BO Cum Wir, BN \\
\hline \hline $\mathbf{2 0 0 3}$ & 17,723 & 109,401 \\
\hline $\mathbf{2 0 0 4}$ & 27,946 & 220,121 \\
\hline $\mathbf{2 0 0 6}$ & 40,956 & 441,753 \\
\hline $\mathbf{2 0 0 8}$ & 49,478 & 659,336 \\
\hline $\mathbf{Z 0 1 3}$ & 60,572 & $1,074,080$ \\
\hline
\end{tabular}

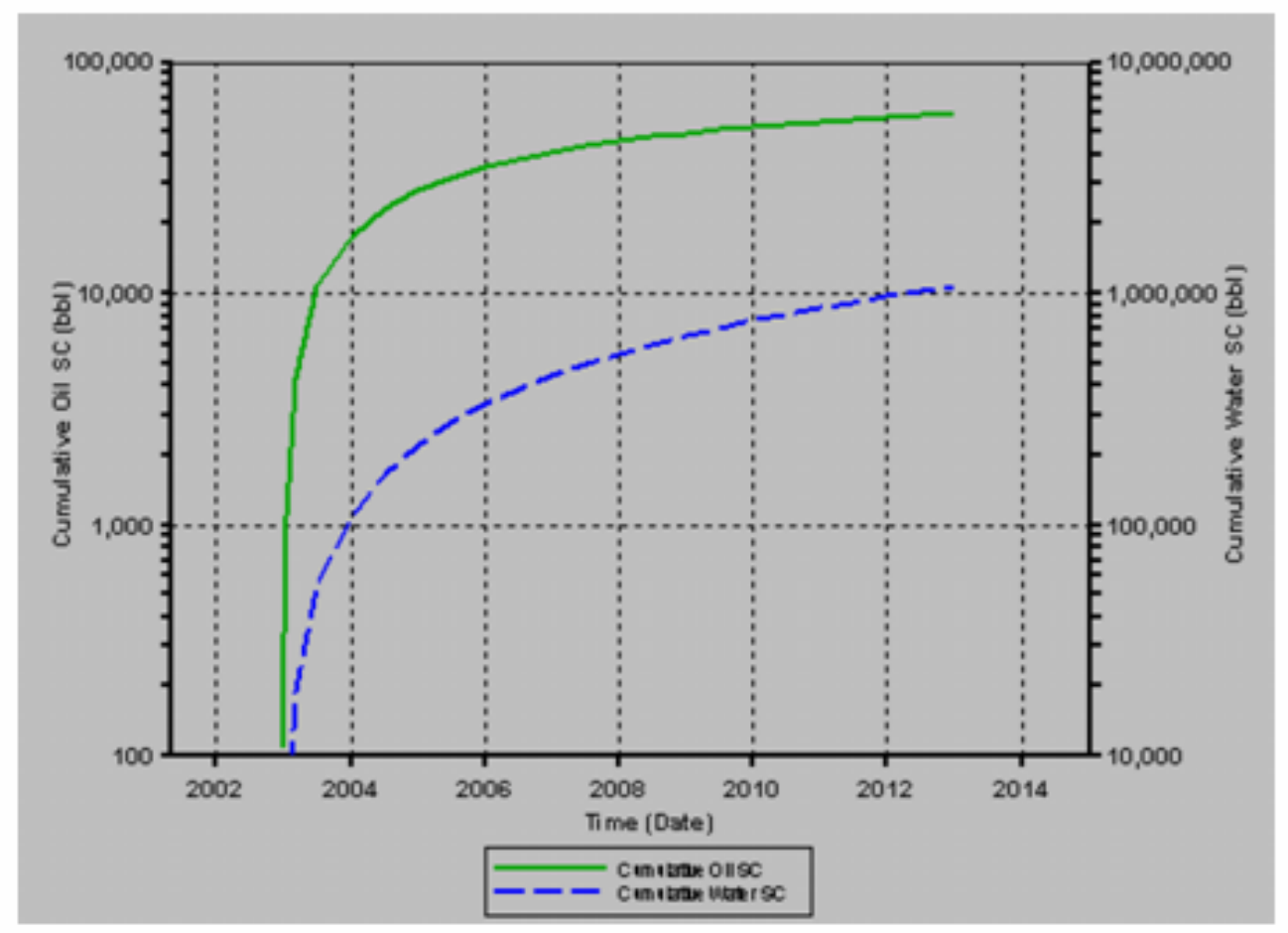

Figure 7.2.34: Simulator-calculated production from a targeted horizontal infill, EWInfill, in Ness City North Field. 


\section{Performance prediction}

Horizontal Infill well -

North-East to South-West (diagonal)

Oil-ft in Layer 3 as of Jan 2003

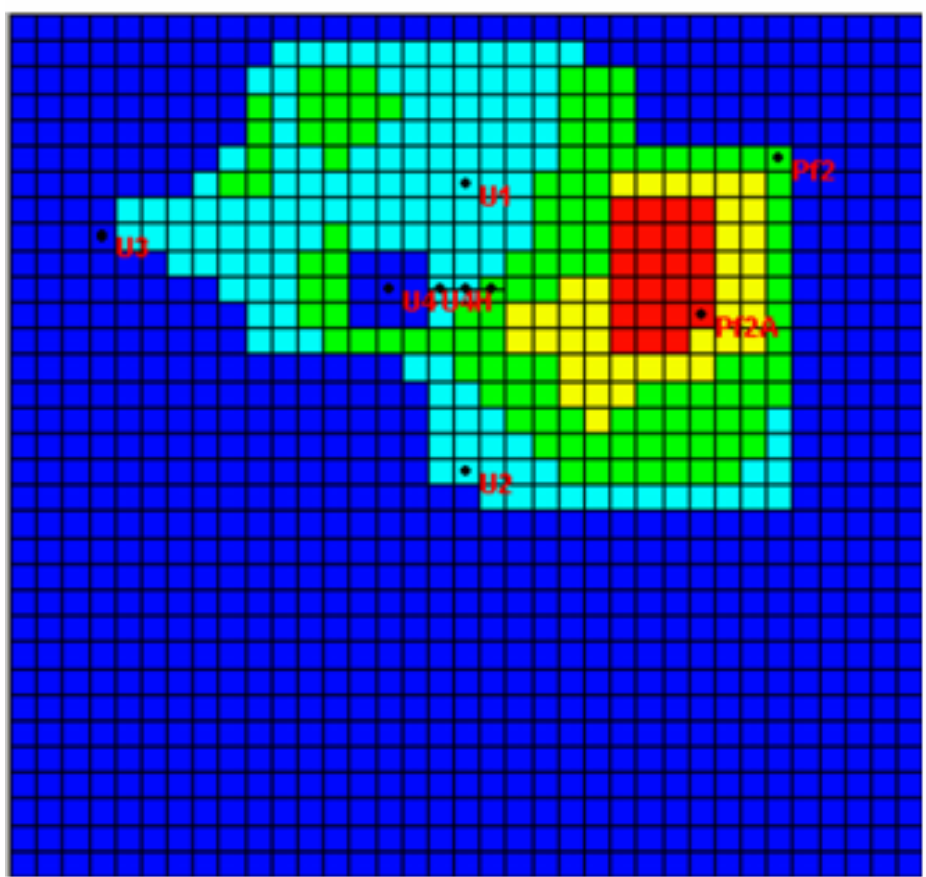

Oil-ft in Layer 3 as of $\operatorname{Jan} 2013$

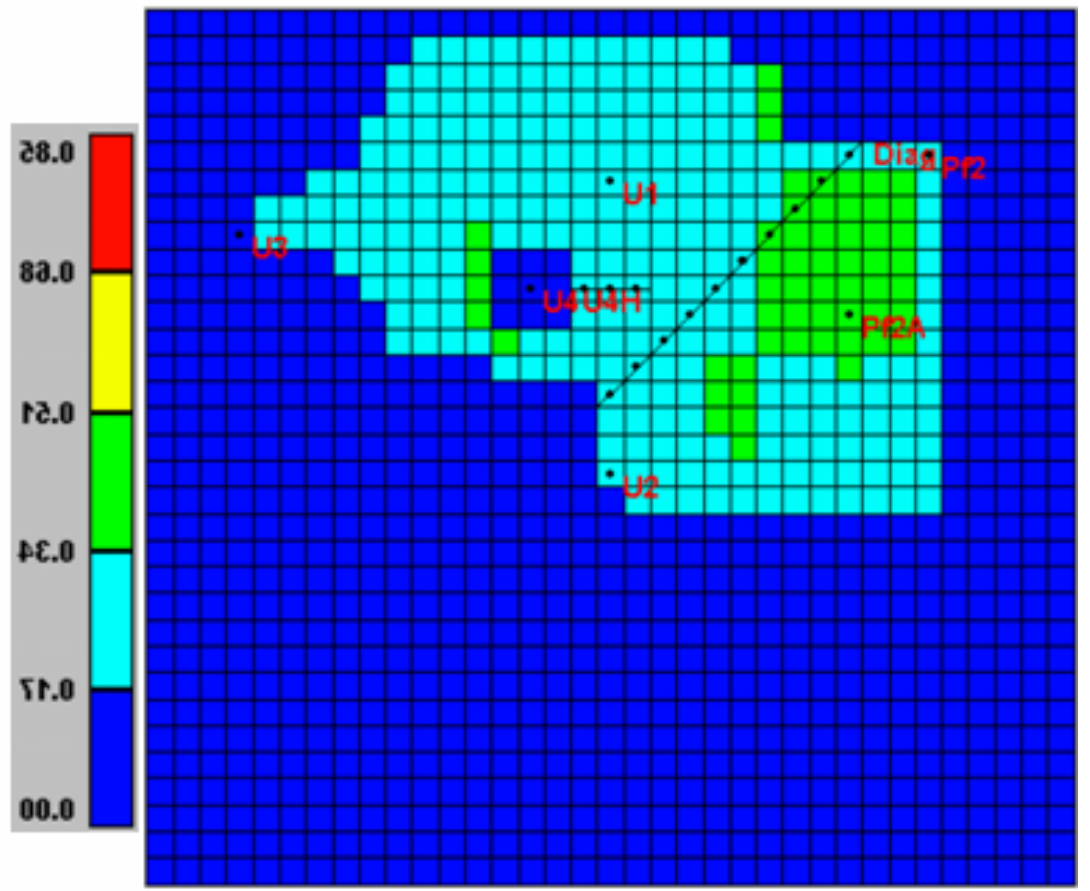

Figure 7.2.35: Simulator-calculated drainage, expressed as oil-feet (porosity*oil saturation*pay), by a targeted horizontal infill, Dia - a North-East to South-West trending well, in Ness City North Field between January 2003 and January 2013. 


\section{Performance prediction}

\section{NE to SW Horizontal Infill well}

Cum oil produced over 10 years $=83922 \mathrm{bbls}$.

Well length $=1100 \mathrm{ft}$ skin $=1.5$, Pwf $=200 \mathrm{psi}$, well diame ter $=6$ inch

\begin{tabular}{|r|r|r|}
\hline Year end & Cum Oil, BO Cum Wtr, BW \\
\hline \hline $\mathbf{2 0 0 3}$ & 29,327 & 190,629 \\
\hline $\mathbf{2 0 0 4}$ & 41,359 & 377,940 \\
\hline $\mathbf{2 0 0 6}$ & 55,800 & 747,658 \\
\hline $\mathbf{2 0 0 8}$ & 64,850 & $1,104,510$ \\
\hline $\mathbf{2 0 1 3}$ & 76,399 & $1,769,580$ \\
\hline
\end{tabular}

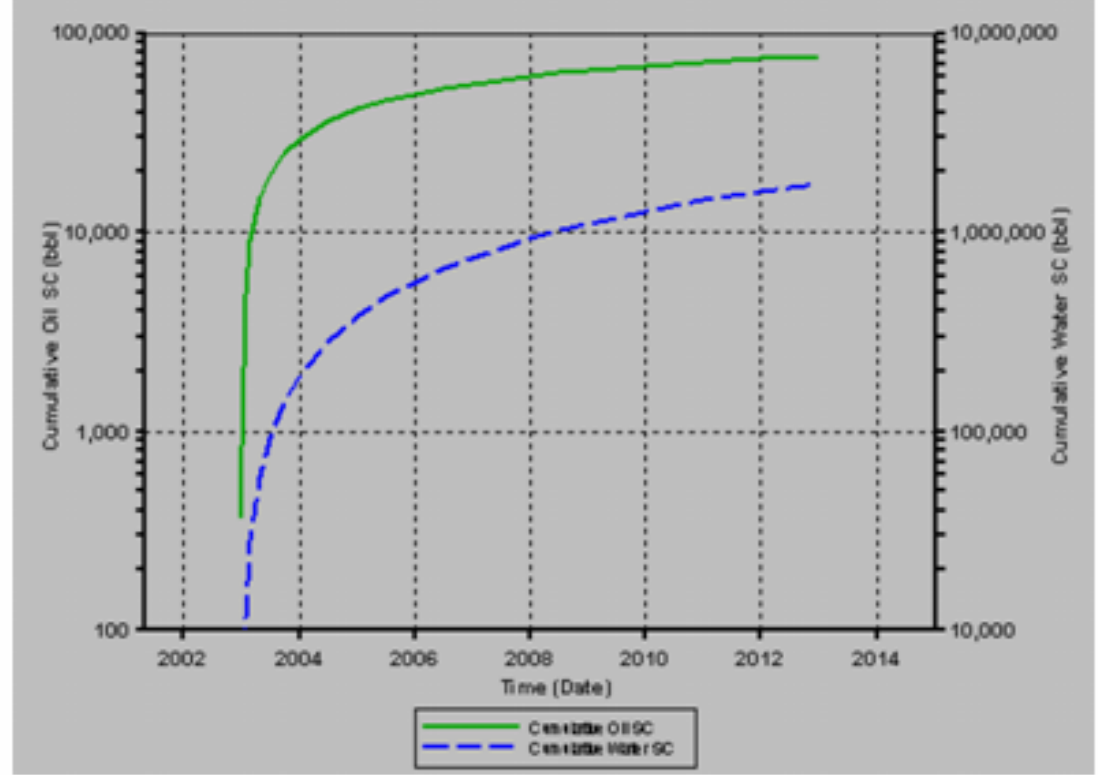

Figure 7.2.36: Simulator-calculated production from a targeted horizontal infill, Dia - a North-East to South-West trending well, in Ness City North Field. 


\begin{tabular}{|lr|}
\hline Well & Cumulative oil production, bbls \\
\hline \hline Ummel 1 & 174,419 \\
Ummel 2 & 24,445 \\
Ummel 3 & 17,993 \\
& \\
Pfannenstiel 2 & 53,388 \\
Pfannenstiel 1 & 16,056 \\
Pfannenstiel 2A-24 & 26,088 \\
& \\
Pember A5 & 917 \\
\hline
\end{tabular}

Table 7.2.1: Well-level cumulative production from Ness City North Field. 


\begin{tabular}{|lc|}
\hline PVT properties & \\
Reservoir temperature & $116 \mathrm{~F}$ \\
API & 37 degrees \\
Gas gravity (Air = 1.0) & 0.75 \\
Water salinity & $19,500 \mathrm{ppm}$ \\
Water resistivity & $0.13 \mathrm{ohm}-\mathrm{m}$ \\
Reference initial reservoir pressure & $1350 \mathrm{psi}$ \\
Depth of reference pressure (subsea, feet) & -1996 \\
\hline
\end{tabular}

Table 7.2.2: PVT inputs to reservoir simulation study of Ness City North Field. 


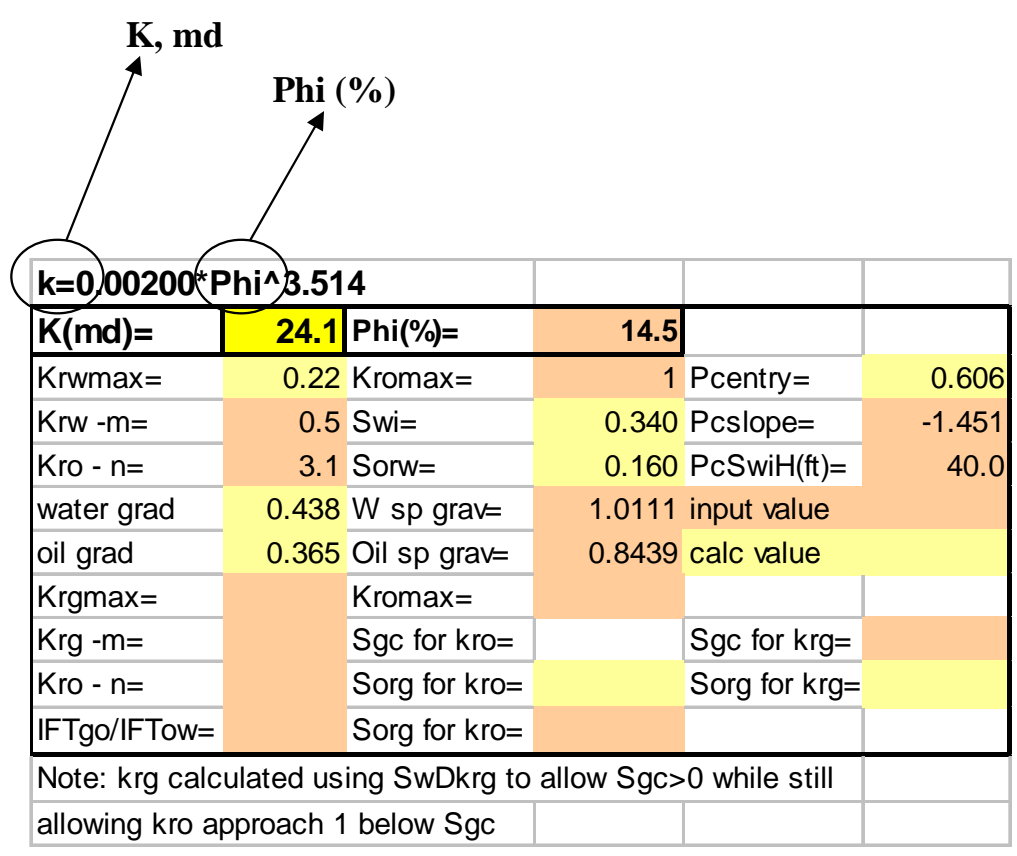

Calculator for Ness City North Field

\begin{tabular}{|c|c|c|c|c|c|}
\hline & & & & Height above & \\
\hline SW & KRW & KROW & PCOW & free water (ft) & SwD \\
\hline 0.3400 & 0.000000 & 1.000000 & 2.896 & 40.00 & 0.00000 \\
\hline 0.3500 & 0.031058 & 0.939501 & 2.777 & 38.36 & 0.01993 \\
\hline 0.4000 & 0.076188 & 0.672983 & 2.288 & 31.60 & 0.11993 \\
\hline 0.4500 & 0.103173 & 0.463036 & 1.929 & 26.64 & 0.21993 \\
\hline 0.5000 & 0.124437 & 0.302633 & 1.655 & 22.86 & 0.31993 \\
\hline 0.5500 & 0.142564 & 0.184837 & 1.441 & 19.91 & 0.41993 \\
\hline 0.6000 & 0.158634 & 0.102812 & 1.271 & 17.55 & 0.51993 \\
\hline 0.6500 & 0.173218 & 0.049840 & 1.131 & 15.63 & 0.61993 \\
\hline 0.7000 & 0.186667 & 0.019343 & 1.016 & 14.03 & 0.71993 \\
\hline 0.7500 & 0.199210 & 0.004919 & 0.919 & 12.70 & 0.81993 \\
\hline 0.8000 & 0.211009 & 0.000399 & 0.837 & 11.56 & 0.91993 \\
\hline 0.8500 & 0.220000 & 0.000000 & 0.767 & 10.59 & 1.00000 \\
\hline 0.9000 & 0.220000 & 0.000000 & 0.706 & 9.75 & 1.00000 \\
\hline 0.9500 & 0.220000 & 0.000000 & 0.652 & 9.01 & 1.00000 \\
\hline 1.0000 & 0.220000 & 0.000000 & 0.606 & 8.36 & 1.00000 \\
\hline 1.0000 & 0.220000 & 0.000000 & 0.606 & 8.36 & 1.00000 \\
\hline 1.0000 & 0.220000 & 0.000000 & 0.606 & 8.36 & 1.00000 \\
\hline 1.0000 & 0.220000 & 0.000000 & 0.606 & 8.36 & 1.00000 \\
\hline 1.0000 & 0.220000 & 0.000000 & 0.606 & 8.36 & 1.00000 \\
\hline 1.0000 & 0.220000 & 0.000000 & 0.606 & 8.36 & 1.00000 \\
\hline 1.0000 & 0.220000 & 0.000000 & 0.606 & 8.36 & 1.00000 \\
\hline
\end{tabular}

Table 7.2.3: Relative permeability-capillary pressure calculator for reservoir rock in Ness City North Field. 


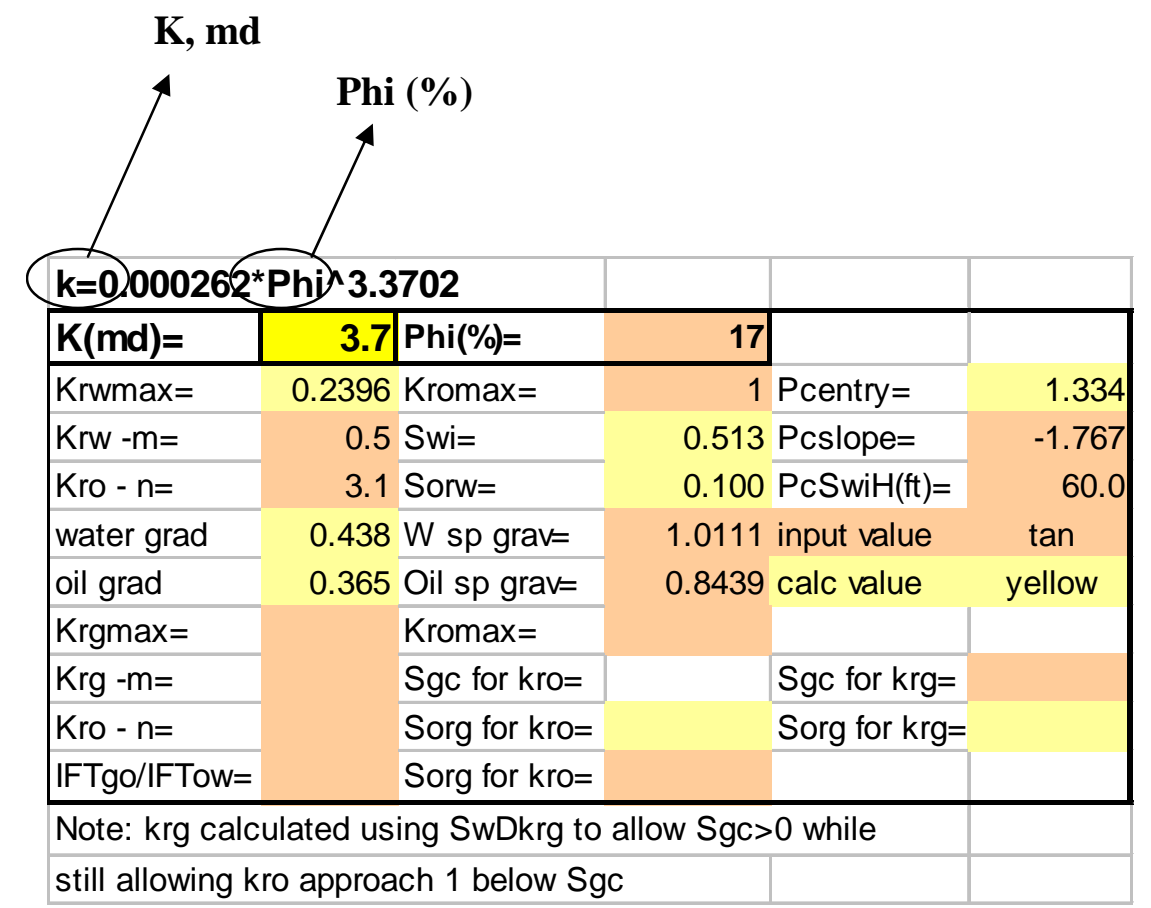

Calculator for Ness City North Field

\begin{tabular}{|c|c|c|c|c|c|}
\hline & & & & Height above & \\
\hline SW & KRW & KROW & PCOW & free water (ft) & SwD \\
\hline 0.5125 & 0.000000 & 1.000000 & 4.344 & 60.00 & 0.00000 \\
\hline 0.5500 & 0.074491 & 0.729605 & 3.835 & 52.97 & 0.09669 \\
\hline 0.6000 & 0.113816 & 0.452431 & 3.288 & 45.42 & 0.22574 \\
\hline 0.6500 & 0.142687 & 0.257093 & 2.855 & 39.43 & 0.35478 \\
\hline 0.7000 & 0.166628 & 0.128727 & 2.504 & 34.59 & 0.48383 \\
\hline 0.7500 & 0.187537 & 0.052767 & 2.217 & 30.62 & 0.61287 \\
\hline 0.8000 & 0.206338 & 0.015013 & 1.978 & 27.32 & 0.74191 \\
\hline 0.8500 & 0.223563 & 0.001751 & 1.777 & 24.55 & 0.87096 \\
\hline 0.9000 & 0.239553 & 0.000000 & 1.606 & 22.19 & 1.00000 \\
\hline 0.9500 & 0.239553 & 0.000000 & 1.460 & 20.17 & 1.00000 \\
\hline 1.0000 & 0.239553 & 0.000000 & 1.334 & 18.42 & 1.00000 \\
\hline 1.0000 & 0.239553 & 0.000000 & 1.334 & 18.42 & 1.00000 \\
\hline 1.0000 & 0.239553 & 0.000000 & 1.334 & 18.42 & 1.00000 \\
\hline 1.0000 & 0.239553 & 0.000000 & 1.334 & 18.42 & 1.00000 \\
\hline 1.0000 & 0.239553 & 0.000000 & 1.334 & 18.42 & 1.00000 \\
\hline 1.0000 & 0.239553 & 0.000000 & 1.334 & 18.42 & 1.00000 \\
\hline 1.0000 & 0.239553 & 0.000000 & 1.334 & 18.42 & 1.00000 \\
\hline 1.0000 & 0.239553 & 0.000000 & 1.334 & 18.42 & 1.00000 \\
\hline 1.0000 & 0.239553 & 0.000000 & 1.334 & 18.42 & 1.00000 \\
\hline 1.0000 & 0.239553 & 0.000000 & 1.334 & 18.42 & 1.00000 \\
\hline 1.0000 & 0.239553 & 0.000000 & 1.334 & 18.42 & 1.00000 \\
\hline
\end{tabular}

Table 7.2.4: Relative permeability-capillary pressure calculator for non-reservoir rock in Ness City North Field. 


\begin{tabular}{|ll|}
\hline Well & BHP, psi Comments \\
\hline \hline Ummel 1 & 250 \\
Ummel 2 & 150 \\
Ummel 3 & 800 \\
Ummel 4H & 650 \\
& \\
Pfannenstiel 1 & 100 \\
Pfannenstiel 2 & 100 \\
Pfannenstiel 2A-24 & 100 (from 1994 to 1999) \\
& 800 (from Jan 2001 to Oct 2002. Perforations extended to Layer 3.) \\
& 350 (from Nov 2002 to date) \\
Pember A5 & 100 \\
\end{tabular}

Table 7.2.5: Estimated bottom hole pressures (BHPs) prevalent at wells in Ness City North Field. 


\begin{tabular}{|c|c|c|c|c|c|c|c|c|c|c|c|}
\hline & & & & & Subsea & Subsea & L1 Top & L1 Bot & L3 Top & L3 Bot & Perfs in \\
\hline Well & KB & Perf top & Perf Bot & Comments & Perf Top & Perf Bot & & & & & Sim \\
\hline Ummel 1 & 2281 & 4285 & 4295 & $\mathrm{OH}$ & -2004 & -2014 & 2005.7 & 2007.7 & 2012 & 2019.4 & L1, L3 \\
\hline Ummel 2 & 2265 & 4272 & 4280 & $\mathrm{OH}$ & -2007 & -2015 & 2008.5 & 2009.8 & 2015.7 & 2019.5 & L1, L3 \\
\hline Ummel 3 & 2271 & 4286 & 4292 & $\mathrm{OH}$ & -2015 & -2021 & & & 2021.2 & 2024.9 & L2, L3 \\
\hline Ummel 4H & 2277 & 4289 & 4289 & & -2012 & -2012 & & & & & L3 \\
\hline Pfannenstiel 2 & 2268 & 4277 & 4284 & & -2009 & -2016 & 2000.5 & 2003.4 & 2012.1 & 2018.7 & L3 \\
\hline Pfannenstiel 2A-24 & 2267 & 4268 & 4276 & & -2001 & -2009 & 2003.9 & 2007.5 & 2015.4 & 2023.2 & L1 \\
\hline & 2267 & 4264 & 4276 & & -1997 & -2009 & & & & & L1 \\
\hline & 2267 & 4284 & 4291 & & -2017 & -2024 & & & & & L3 \\
\hline Pfannenstiel 1 & 2266 & 4266 & 4282 & $\mathrm{OH}$ & -2000 & -2016 & 2005 & 2007.8 & 2018.6 & 2023.7 & L1 \\
\hline Pember 5A & 2262 & 4270 & 4282 & & -2008 & -2020 & 2015.8 & 2018.4 & 2029.2 & 2031.3 & L1 \\
\hline
\end{tabular}

Table 7.2.6: Well completion summary in Ness City North Field. 


\begin{tabular}{|r|l|l|l|}
\hline & Ummel 1 & Ummel 1 & \\
\hline & Cum Oil, BO & Cum Oil, BO & Ummel 1 \\
\hline & No Infill & Infill E-W & Prod loss, BO \\
\hline Jan-2003 & 229,096 & & \\
\hline Jan-2006 & 235,530 & 233,406 & 2,124 \\
\hline Jan-2008 & 239,113 & 235,687 & 3,426 \\
\hline Jan-2013 & 246,420 & 240,369 & 6,051 \\
\hline
\end{tabular}

\begin{tabular}{|r|r|r|r|}
\hline & Pf2A-24 & Pf2A-24 & \\
& Cum Oil, BO & Cum Oil, BO & Pf2A-24 \\
\hline & \multicolumn{1}{|l}{ No Infill } & Infill E-W & Prod loss, BO \\
\hline \hline Jan-2003 & 29,224 & & \\
\hline Jan-2006 & 56,657 & 47,000 & 9,657 \\
\hline Jan-2008 & 68,616 & 53,002 & 15,614 \\
\hline Jan-2013 & 88,642 & 61,598 & 27,044 \\
\hline
\end{tabular}

Table 7.2.7: Production loss at nearby wells due to drainage from EWInfill well in Ness City North Field. 


\begin{tabular}{|r|r|l|l|}
\hline & Ummel 1 & Ummel 1 & \\
\hline & Cum Oil, BO & Cum Oil, BO & Ummel 1 \\
\hline & No Infill & Infill NE-SW & Prod loss, BO \\
\hline \hline Jan-2003 & 229,096 & & \\
\hline Jan-2006 & 235,530 & 233,939 & 1,591 \\
\hline Jan-2008 & 239,113 & 236,254 & 2,859 \\
\hline Jan-2013 & 246,420 & 240,678 & 5,742 \\
\hline
\end{tabular}

\begin{tabular}{|r|r|r|r|}
\hline & Pf2A-24 & Pf2A-24 & \\
\hline & Cum Oil, BO & Cum Oil, BO & Pf2A-24 \\
\hline \multicolumn{1}{|l|}{ No Infill } & Infill NE-SW & Prod loss, BO \\
\hline Jan-2003 & 29,224 & & \\
\hline Jan-2006 & 56,657 & 46,354 & 10,303 \\
\hline Jan-2008 & 68,616 & 51,794 & 16,822 \\
\hline Jan-2013 & 88,642 & 59,233 & 29,409 \\
\hline
\end{tabular}

Table 7.2.8: Production loss at nearby wells due to drainage from Dia, a North-East to South-West trending well, in Ness City North Field. 


\subsection{Reservoir Characterization and Simulation of Judica Field, Ness County, Kansas}

\subsubsection{Introduction}

An integrated reservoir characterization study was carried out on Judica field, Ness County, Kansas, to build a 3D-geomodel, which served as the basis for reservoir simulation. Judica produces from a Mississippian carbonate reservoir with production commencing from February 1979. Simulation studies were initially carried out to historymatch well-level fluid production while also matching the limited available pressure decline. Upon completion of history matching, a map of remaining reserves was generated for the field. Thereafter, the remaining reserves map was used to spot different targeted horizontal infill trajectories. Simulation studies were carried out to evaluate the production potential of each of these infill horizontal wells. For a comparative evaluation of productivity, a few vertical infill wells were also simulated.

\subsubsection{Geologic Model}

Figure 7.3.1 shows the location and the boundary (area bounded by the rectangle) of the study area for this project. Petrophysical well logs, analogous core data (from a neighboring well), core cuttings description, DST test results, and geologic reports from wells within and around the study area were used to build a geomodel for the reservoir. Tops of marker beds above and below the reservoir interval and the layers describing the reservoir were identified at each well within and around the study area. A series of crosssections were built from different directions to cross-check and fine-tune the geomodel. In accordance with the workflow defined in section 6.3, the reservoir was subdivided into layers (Figures 6.8 and 6.9) that were correlated from well to well and average properties estimated at each well. The static model was populated with layer thickness, porosity, and water saturation by layer by simple interpolation between wells and grids were exported for simulator input. The reservoir was modeled with 5 layers, and Figure 7.3.2 shows that subsea structure top (feet) of the top layer (Layer 1). Layers 1, 3, and 5 
contribute to the production while the intermediate Layers 2 and 4 are water-saturated shale streaks. Figures 7.3.3 to 7.3.17 display the isopach, porosity, and initial water saturation (Sw) maps of each of the 5 reservoir layers.

\subsubsection{Production Data Analysis}

As most leases in the study area are single-well leases, well-level oil sales data were available on a monthly basis from most wells. However, Thornburg M1 and M2 (Kansas Oil Corp, Section 35) belonged to the same lease and thus no record of individual production was available from these 2 wells. Lacking any other data, the Thornburg $\mathrm{M}$ lease sales data were proportioned in ratio of the initial production (IP) rates recorded at these two wells. The leases sales history includes mention of only oil volumes sold every month. An average annual production rate (barrels per day, BOPD) was calculated from the monthly sales data for each well. Available water production data included data over a 10-year period (January 1989 to July 1999) at Thornburg Q1 (Slawson, Sec 35), and current (January 2003) barrel test data from Thornburg Q1 (Slawson, Sec 35) and Thornburg M1 (Slawson, Sec 3). Figure 7.3.18 plots the wateroil-ratio (WOR) with time for the above named 2 wells that have limited water production data. It is evident from the plot for Thornburg Q1 (Slawson, Sec 35) that a best-fit linear line correlates the WOR with days from the start of production. Even the unforced best-fit line (broken line in red) passes within 365 days from the origin. Thus lacking any other data, this linear WOR-time correlation was used to estimate water production at other wells in the study area. Thornburg M1 (Slawson, Sec 3) is the highest producing well within the study area and the current measured WOR is low compared to the long production life of this well. Thus for Thornburg M1 (Slawson, Sec 3), the water production history was estimated using the WOR-time correlation depicted in well specific the WOR-time plot (Figure 7.3.18). 


\subsubsection{Decline Curve Analysis}

One of the critical inputs to a simulation model for history matching is the bottom-hole pressure (BHP) history under which a well is produced over its life. Unfortunately, a regular record of BHPs was not available for any well in the study area. The industry partner in this project, an operator of some wells within and around the study area, advised as per prevalent practices that given the volumes of oil produced from each well it would not be uncommon for these wells to be produced under minimal BHP, (back pressure in the range of $100 \mathrm{psi}$ ). To test this assumption, decline curve analysis was carried out by plotting the average annual oil production rate at each well on a plot whose axes coincided (in cycle-length) with that of the standard Fetkovich decline curve. Figure 7.3.19 shows the results for Thornburg \#1 (Foxfire, Sec 35). A single decline curve is found to represent the well production history neglecting the (minor) production increase midway through the well life. Thus lacking any other data, it is reasonable to assume that this well produced under near unchanging bottom hole conditions (skin and/or BHP). Figure 7.3.20 shows that a similar assumption is reasonable for well Thornburg \#L1 (Slawson, Sec 3). Figure 7.3.21 plots the production data from Thornburg \#M1 (Slawson, Sec 3). The production history shows 2 distinct decline trends. The value of the decline exponents (b) for the both the curves is same ( $b=0.4)$, which suggests that the production data are from the same well producing out of the same reservoir. As mentioned earlier, no information is available about the BHP under which the well produced during the first decline curve. Currently, the well produces under pumped-off conditions. Thus in absence of any BHP data, it is not unreasonable to change (reduce) the skin to history-match the increased production (second decline) while keeping the BHP unchanged at 100 psi. Thornburg \#Q1 (Slawson, Sec 35) shows a similar behavior (Figure 7.3.22). Thus, all wells in the simulation study were produced under a constant $\mathrm{BHP}=100$ psi, and production increases (bumps) were matched by changing the skin. 


\subsubsection{DST Analysis}

DST pressure-time data were available for 3 wells within the study area, namely Thornburg \#M1 (Slawson, Sec 3), Thornburg \#B1 (Kansas Oil Corp, Sec 4) and Thornburg \#Q1 (Slawson, Sec 35). DST data were available from 2 others wells, namely Thornburg \#N2 (Slawson, Sec 4) and Muchmore (Slawson, Sec 34) immediately outside the study area, and they were also analyzed with those from the study area in order to estimate initial reservoir pressure in the field. Figure 7.3.23 shows the initial pressure (Pi) psi calculated from the DSTs along with the final shut in pressures (FSIPs) from the above wells. Based on this pressure profile, the initial reservoir pressure was assumed to be 1350 psi. The most current pressure data is from Thornburg \#F1 (Kansas Oil Corp, Sec 4). Static fluid column was recorded at this well after a 5-day shut-in in November 2002, and it revealed a reservoir pressure of 1030.5 psi. Though this well is located just outside the study area, this pressure was used as an estimate of current reservoir pressure in Judica lacking any other available data.

\subsubsection{PVT and Relative Permeability/Capillary Pressure Inputs}

There is no record of any gas production at Judica. Thus, the bubble point pressure is low given that no gas production has been recorded at the wells even when they are produced under pumped-off conditions. The reservoir produces under a strong water drive. Within the simulation model, each well is produced under a BHP of 100 psi, and to prevent any three-phase flow a low bubble point of 100 psi was assumed (at subsea -1938 feet) in this study. No measured bubble point data were available. Other oil PVT properties are listed in Table 7.3.1, while the water PVT properties are listed in Table 7.3.2. Bubble point pressure, reservoir temperature, and oil and gas gravities were input to the inbuilt PVT calculator within the reservoir simulator (Computer Modeling Group’s IMEX) to generate other necessary PVT tables. Other field-wide assumptions, particularly relating to each well, that were input to the simulator are listed in Table 7.3.1. Given the nature of the reservoir rocks, all wells were perforated in Layers 1, 3, and 5, if present, within the simulator during the history matching. 
No cores were available from Judica field. However, a Mississippian core from Beardmore Clifton \#1 well (Sec 1, Hodgeman County, Kansas) was available from Lippoldt - a neighboring field. Routine and advanced core analyses were carried out on this core to develop representative permeability-porosity correlations (Tables 7.3.3 \& 7.3.4) for both the reservoir and non-reservoir rock. Also, capillary pressure measurements were carried out on representative core plugs along with recordings of end-point saturations. Data collected from these core studies were integrated with the data set on Mississippian core plugs that has been built by virtue of studies, carried out at the KGS on other Mississippian fields of the mid-continent. Porosity was found to correlate with end-point saturations such as Swi (irreducible water saturation) and Sorw (irreducible oil saturation to water). Using these correlations and measured capillary pressure curves, relative-permeability/capillary pressure calculator was created using Corey-type equations. These calculators help to input a consistent set of relativepermeability/capillary pressure tables into the simulator upon making changes in effective permeability over the drainage area of a well during the history-matching phase. Thus, changing the permeability input updates the table by changing the saturation end points while preventing dramatic changes in the capillary pressure curve shapes. Also, the relative permeability exponents ( $\mathrm{m}$ and $\mathrm{n}$ ) enable changing the relative ease of flow between the 2 fluid phases in the reservoir, i.e., the oil and water, especially during history-matching well-level production. Table 7.3.3 shows the calculator for the reservoir rock (Layers 1, 3, and 5) while Table 7.3.4 displays that for the non-reservoir rock (Layers 2 and 4).

\subsubsection{Simulation Study - History Matching}

The reservoir was simulated as a 5-layer model with 110 feet by 110 feet grid cells and an analytical bottom aquifer. The aquifer properties were fine tuned so that the calculated current reservoir pressure was between 1000 and 1100 psi. Initial saturation (Sw) and pressure distributions in the drainage area of each well was input with the help of capillary pressure curves and having the simulator perform gravity-capillary equilibrium calculations. The initial permeability in each layer was populated using the 
permeability-porosity correlations generated from core analysis. The correlation for the reservoir rock is stated in Table 7.3.3 while Table 7.3.4 shows the relevant correlation for the non-reservoir rock. Each well was produced under a constant BHP $=100$ psi throughout its life with the simulator calculating the oil and water production at the end of every time step. Parameters that were fine tuned to history match individual well performance included effective permeability in the drainage area of the well and relative permeability exponents " $m$ " and " $n$ ".

Figure 7.3.24 summarizes the data constraints under which the simulation study was performed. Only limited water production data were available at 2 wells - Thornburg \#Q1 (Slawson, Sec 35) and Thornburg \#M1 (Slawson, Sec 3). DST fluid recovery at Thornburg A1 (Slawson, Sec 3) indicates that a productive zone possibly exists atop the Layer 1. However, there is no evidence of an extension of this layer to other areas of the study area, and thus some of the production recorded at this well may come from a layer that has not been modeled in this study. Individual well production data are not available for Thornburg \#M1 and \#M2 (Slawson, Sec 35) as these wells produce to 1 lease. Finally, the current geomodel explains the existence of 3 dry wells (Thornburg \#N1, \#I1, and \#S1 in Sec 35) at the top of the structure due to low permeability resulting from degradation of porosity of the reservoir rock.

Figures 7.3.25 to 7.3.32 show the history matches obtained at each well in the study area. Figure 7.3.33 shows the calculated distribution of reservoir pressure as of January 2003. The average reservoir pressure is around $1070 \mathrm{psi}$, close to the BHP obtained at Thornburg \#F1 (Slawson, Sec 4) in November 2002 after a 5-day shut-in. Thus, from a material balance standpoint it appears that the given reservoir geomodel acting under a strong water drive can deliver the historically recorded fluid production and undergoing a pressure decline from $1350 \mathrm{psi}$ to $1070 \mathrm{psi}$. 


\subsubsection{Performance Evaluation of Different Horizontal Infill Trajectories}

Upon completion of well history matches, a map of residual reserves (oil-ft, product of porosity, oil saturation and grid thickness) was generated as of January 2003. Most of the remaining potential was found to reside in Layer 5 (L5), and the remaining oil-ft map as of January 2003 is shown in Figure 7.3.35. Productive potential of different infill trajectories was studied. In each case, the horizontal well was assumed to be 6 inches in diameter and to have been produced for 10 years (starting January 1, 2003) under a constant BHP $=200 \mathrm{psi}$ and a skin factor of 1.5. One of the first infills, an 1100 feet long North-south well, that was evaluated is shown in Figure 7.3.35. Thus, the drainage capability of this well is shown in the residual reserve (oil-ft) map as of January 2013, particularly when compared with that of January 2003. The expected production from this well is tabled and plotted in Figure 7.3.36. Simulation studies indicate that after 10 years the expected cumulative production from this well will be in the range of 76 MMSTB while producing about 962 MMSTB of water. The location of this infill is in proximity to Thornburg \#M1 (Slawson, Sec 3), and thus interference effects of this well on the production of Thornburg \#M1 is shown in Figure 7.3.37. Figures 7.3.38 and 7.3.39 show the drainage effects of a second infill trajectory (south-west to north-east) called MULL 1, its cumulative production and interference on Thornburg \#M1 (TM1s, Slawson, Sec 3). Figures 7.3.40 to 7.3.47 plot the productive potential of other horizontal infill trajectories, i.e., MULL 2 to MULL 5.

Uncertainties are inherent in any geomodel because at times boundaries between the reservoir layers are difficult to identify at some wells. Also, the interpolation technique of the mapping process relies on the assumption of depositional continuity between 2 wells and often geologic processes result in more complex depositional patterns. Finally, a horizontal well is never perfectly horizontal and thus has the possibility of not being confined within a model layer (such as Layer 5) all along its length. Thus, the effects of the infill trajectory intersecting different layers was studied by placing the well MULL 5 solely in Layer 5 (Figure 7.3.47, cumulative production around 175 MMSTB), in Layer 3 (Figure 7.3.48, cumulative production around 174 MMSTB), 
and in Layer 1 (Figure 7.3.49, cumulative production around 162 MMSTB). Thus, the production potential of trajectory MULL 2 is not significantly affected by the possibility that it was perhaps not confined to Layer 5 along its total length.

Finally, a couple of vertical infill wells were simulated in the areas where most of the horizontal infills were targeted in order to find out if the simulator predictions for the horizontal infills were within the realms of expectations. The industry partner with its significant operating experience had a general idea about the expected production potential from a vertical infill well in this type of a mature Mississippian field, and therefore wanted to validate the reservoir model by having it predict the performance of vertical infill wells. Thus, two vertical infill wells were simulated with each being located in the general areas where most of the horizontal wells had been placed. Figures 7.3.50 and 7.3.51 show the drainage and the expected production from the first vertical infill, named MULL Vertical East ("Vwell" in the residual reserve map). This well was perforated only in Layer 5 and the expected cumulative production from this well was in the range of 23 MMSTB after 10 years. Upon completing this well in Layers 1, 3, and 5, the cumulative production increased to 31.4 MMSTB (Figures 7.3.52 and 7.3.53) after 10 years. The location of the second vertical infill well, MULL Vertical West (Vwell on oil$\mathrm{ft}$ map), is shown on Figure 7.3.54. This well was completed in all the 3 reservoir layers and expected cumulative production after 10 years is 25.9 MMSTB (Figure 7.3.55). The expected cumulative production volumes for these vertical infill wells were within the range of expectation of the industry partner.

\subsection{Site Selection for Field Demonstration}

Based on the results of the detailed field characterization and simulation studies, MDCI in consultation with other consortium members (for this project) decided to select Judica field for the field demonstration of using targeted horizontal infill wells to exploit remaining potential of mature Mississippian carbonate reservoirs of Kansas. 


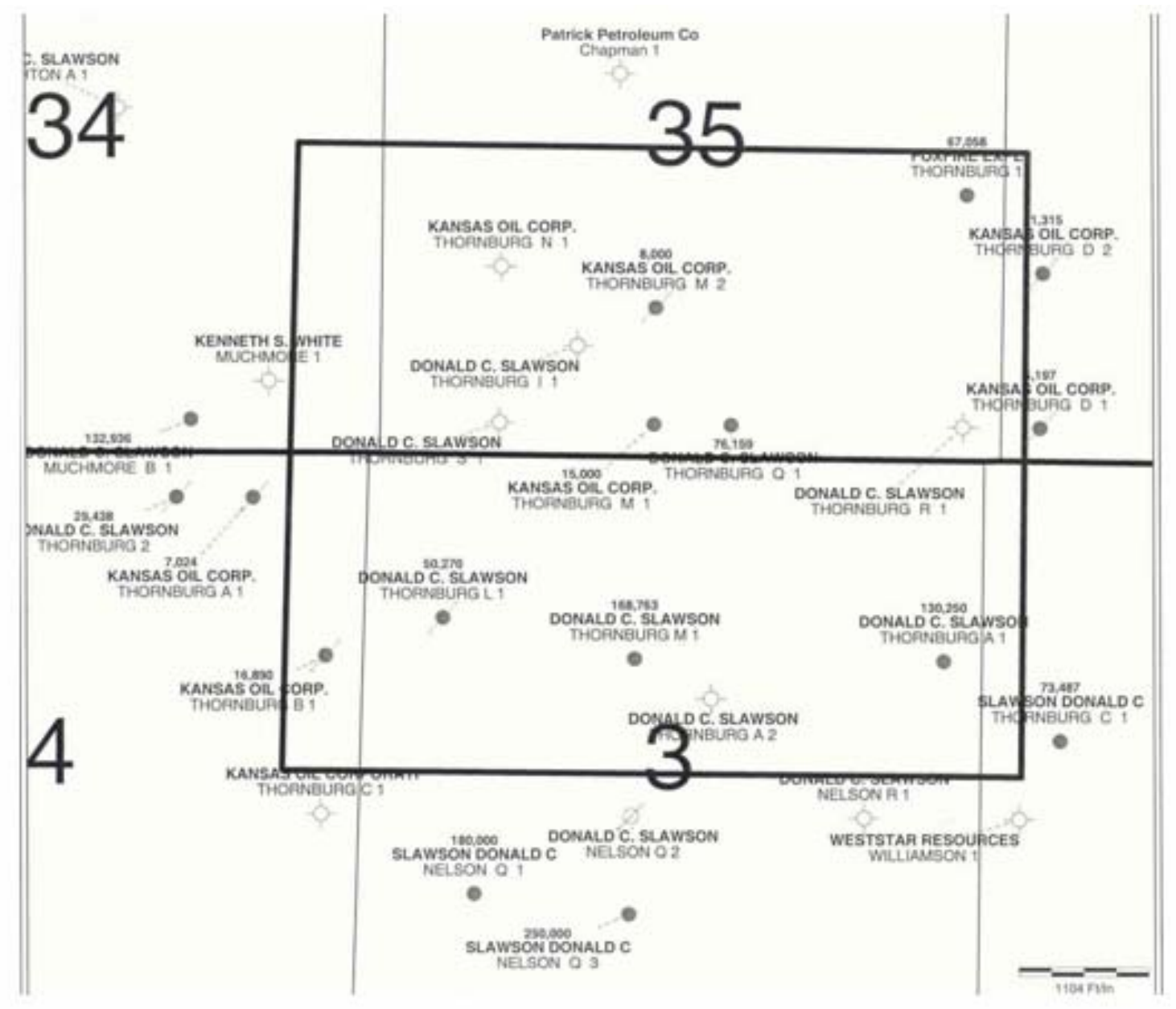

Figure 7.3.1: Location and boundary of Judica Field, Ness County, Kansas. 


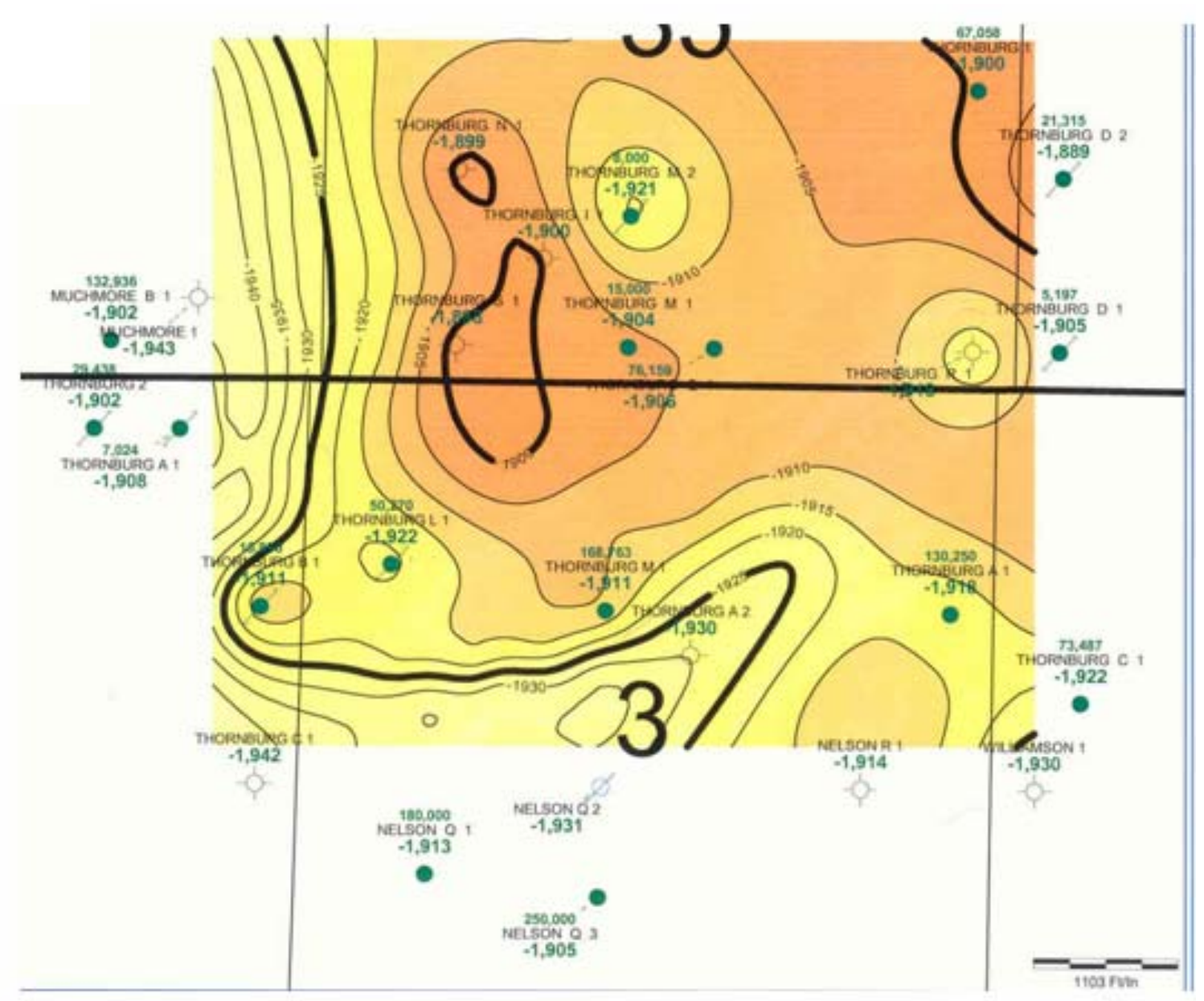

Figure 7.3.2: Subsea structure (feet) on top of pay Layer 1 (L1) in Judica Field. 


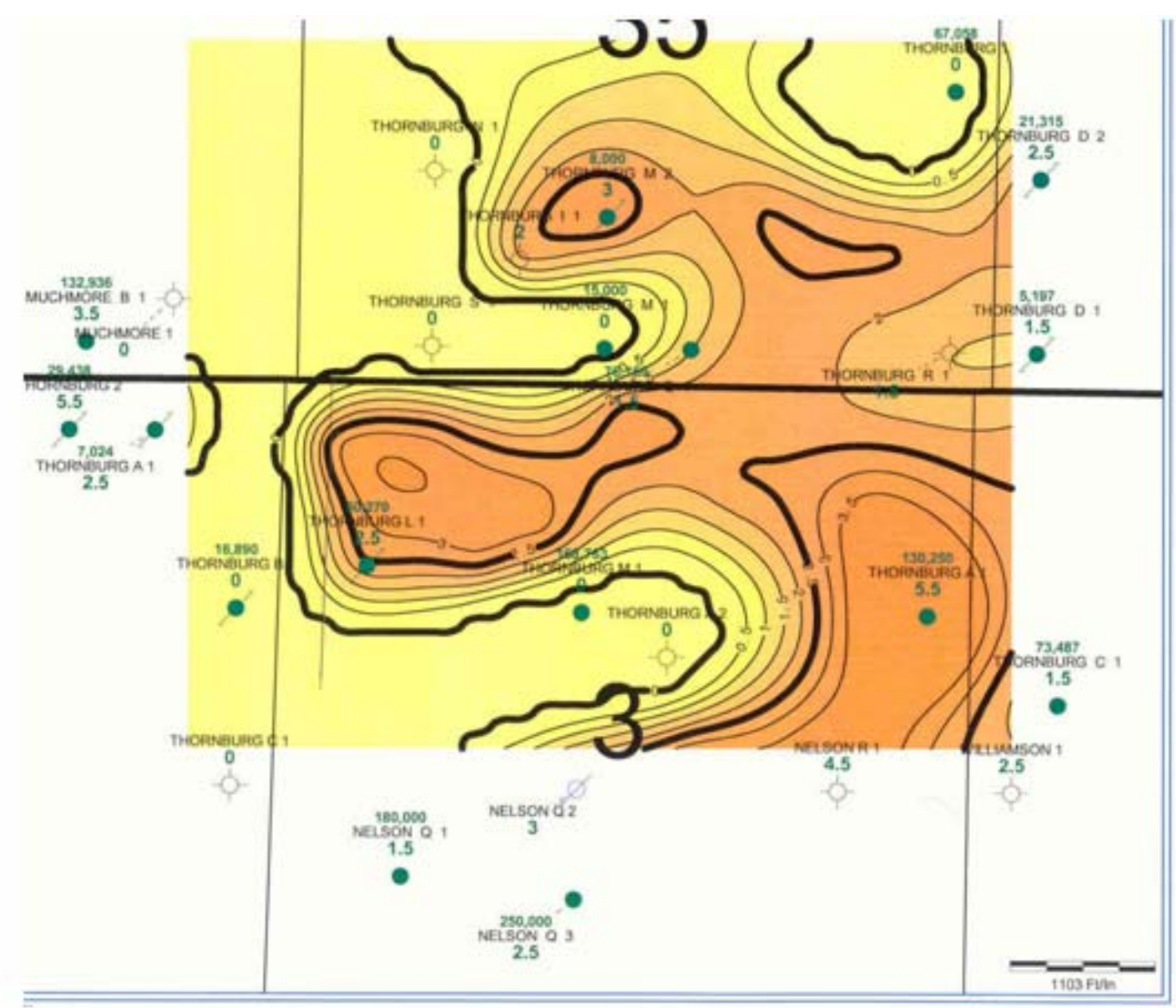

Figure 7.3.3: Isopach (feet) of Layer 1 (L1) in Judica Field. 


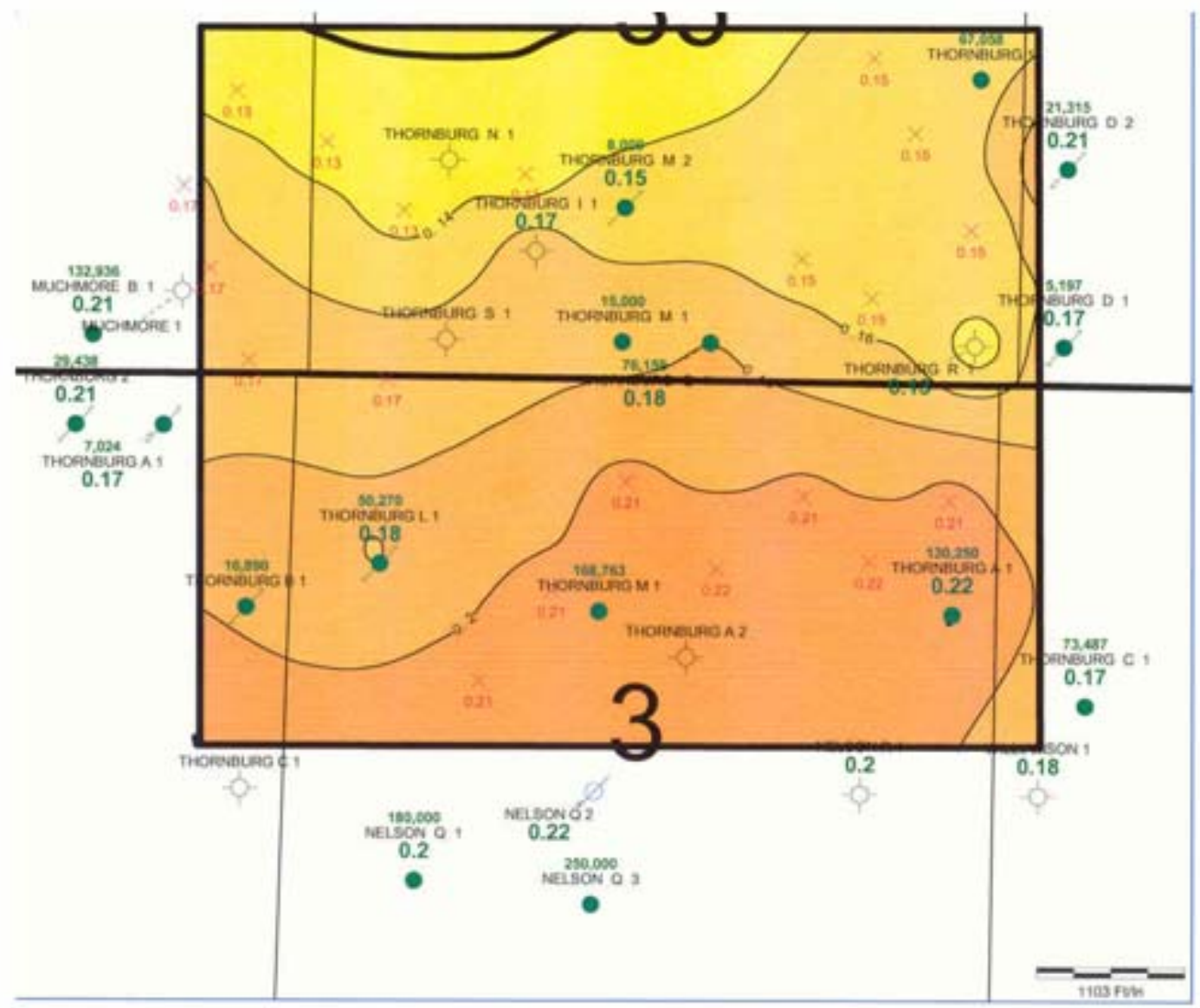

Figure 7.3.4: Porosity (fraction) distribution in Layer 1 (L1) in Judica Field. 


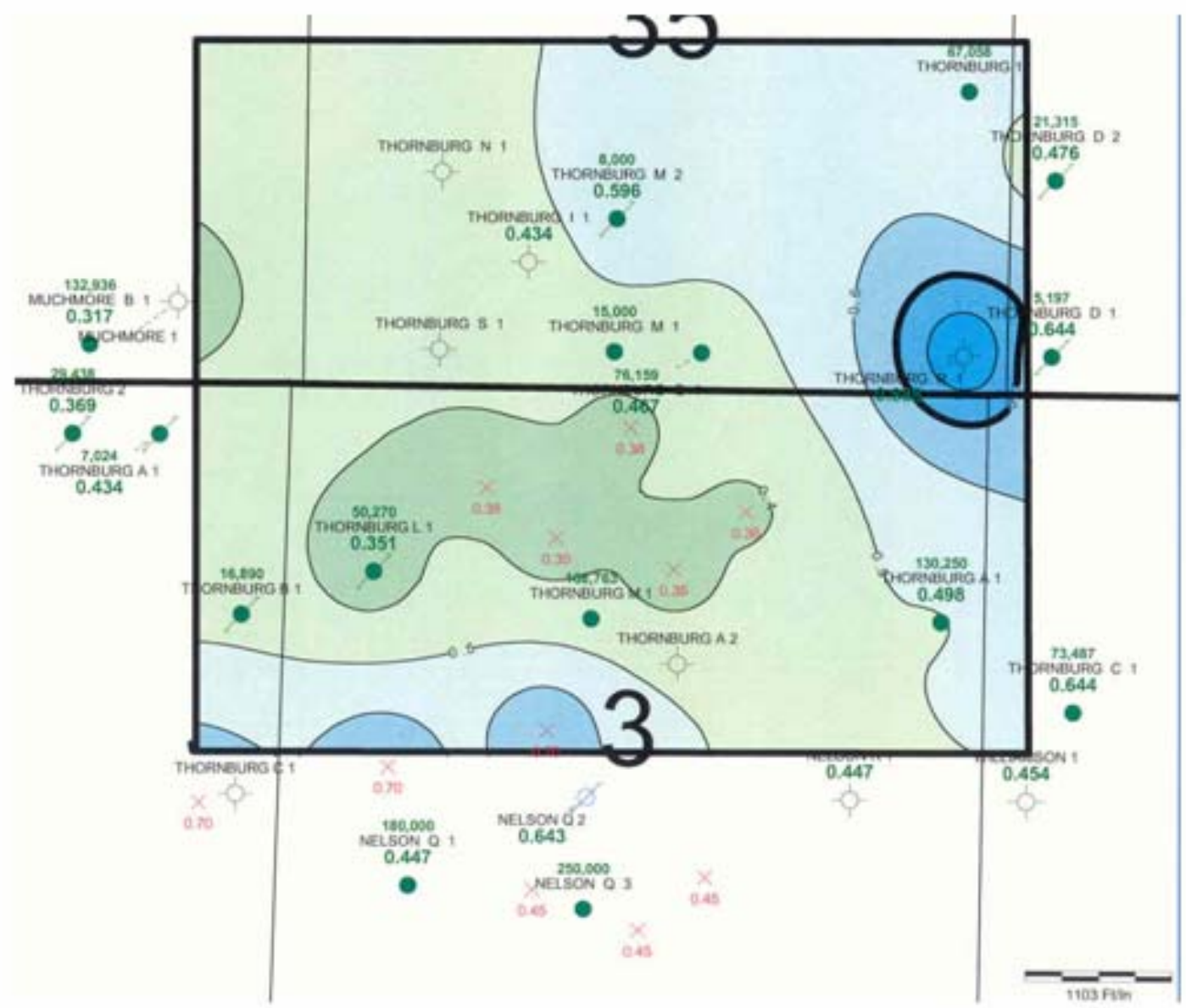

Figure 7.3.5: Initial water saturation (fraction) distribution in Layer 1 (L1) in Judica Field. 


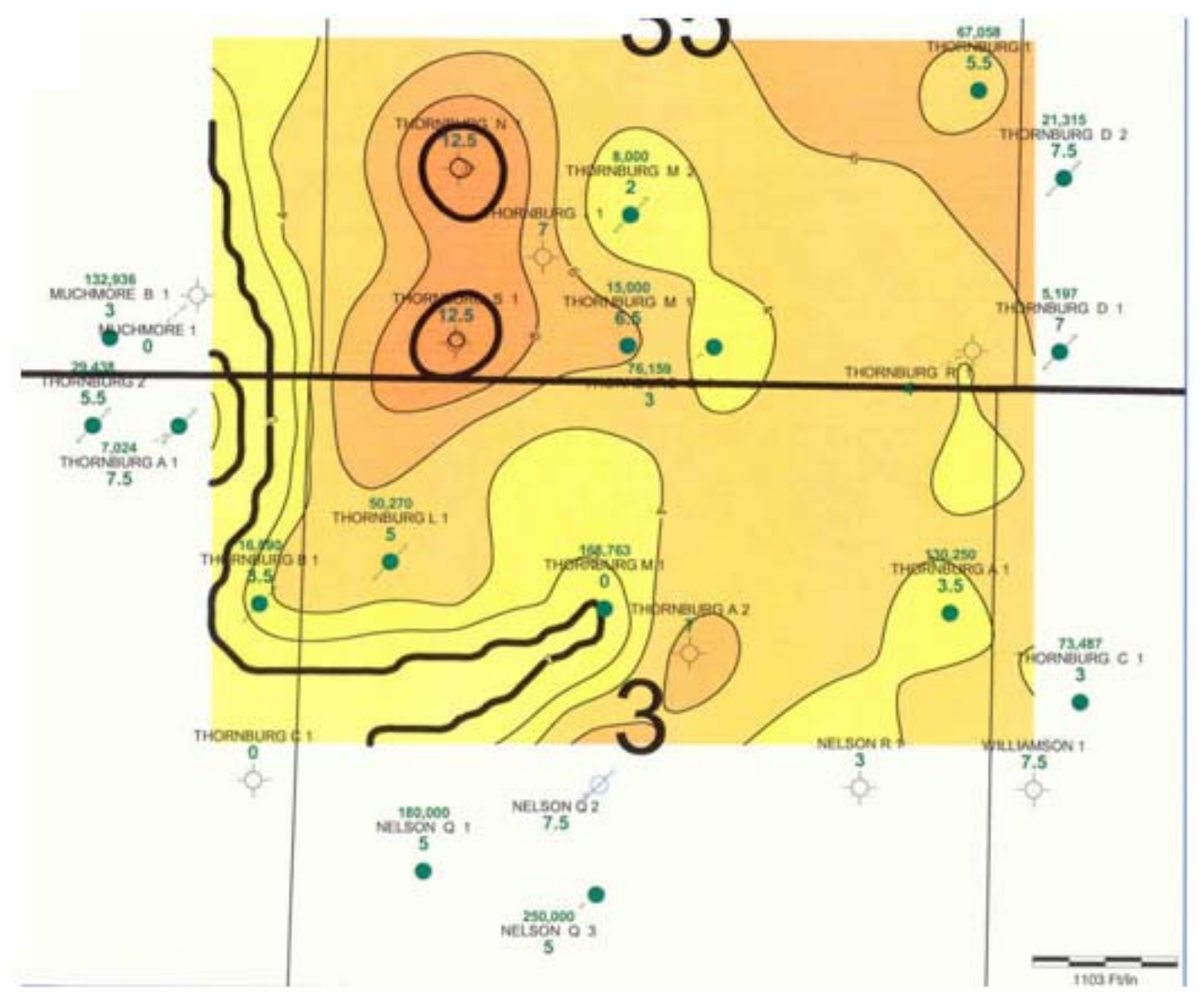

Figure 7.3.6: Isopach (feet) of Layer 2 (L2) in Judica Field. 


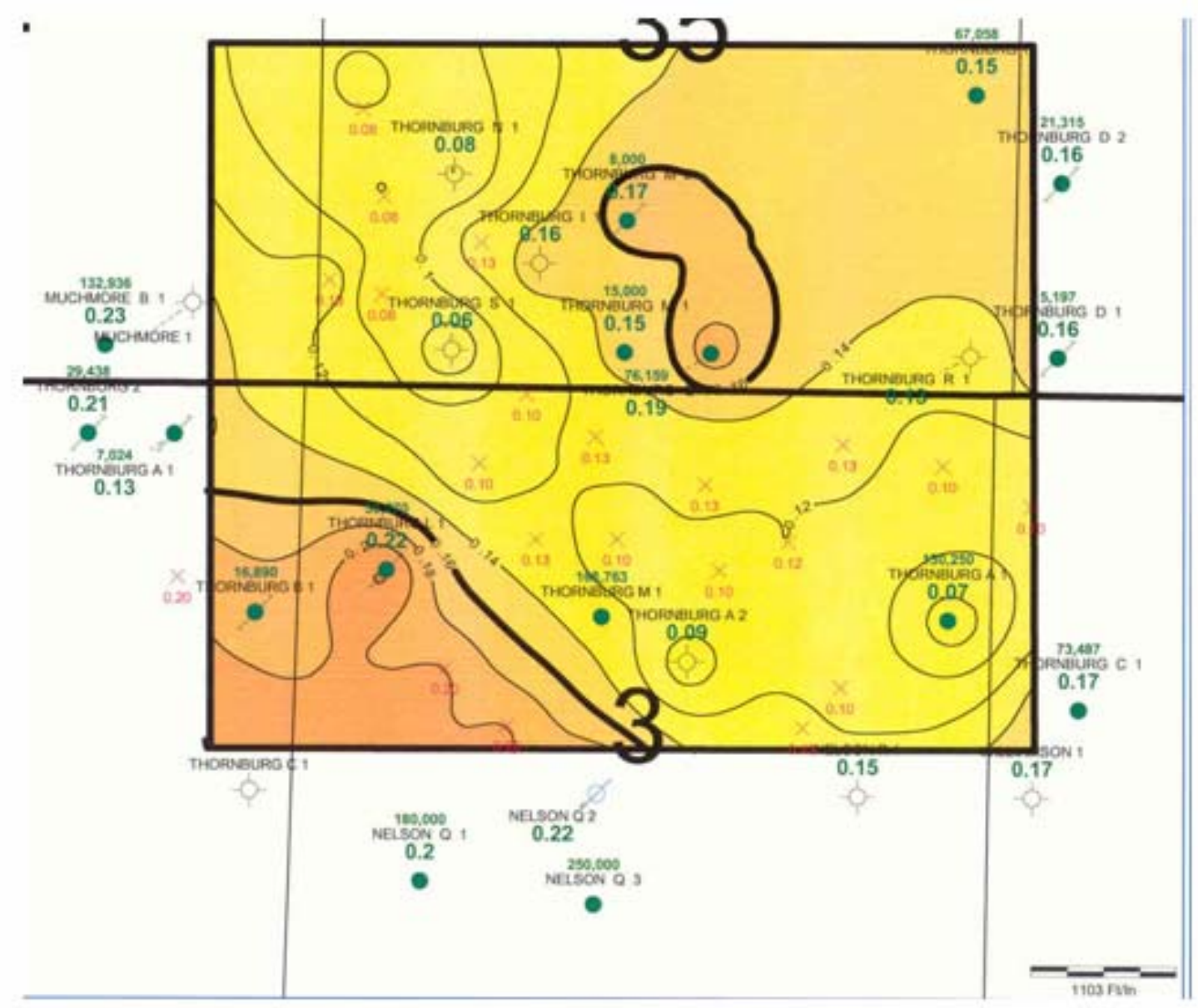

Figure 7.3.7: Porosity (fraction) distribution in Layer 2 (L2) in Judica Field. 


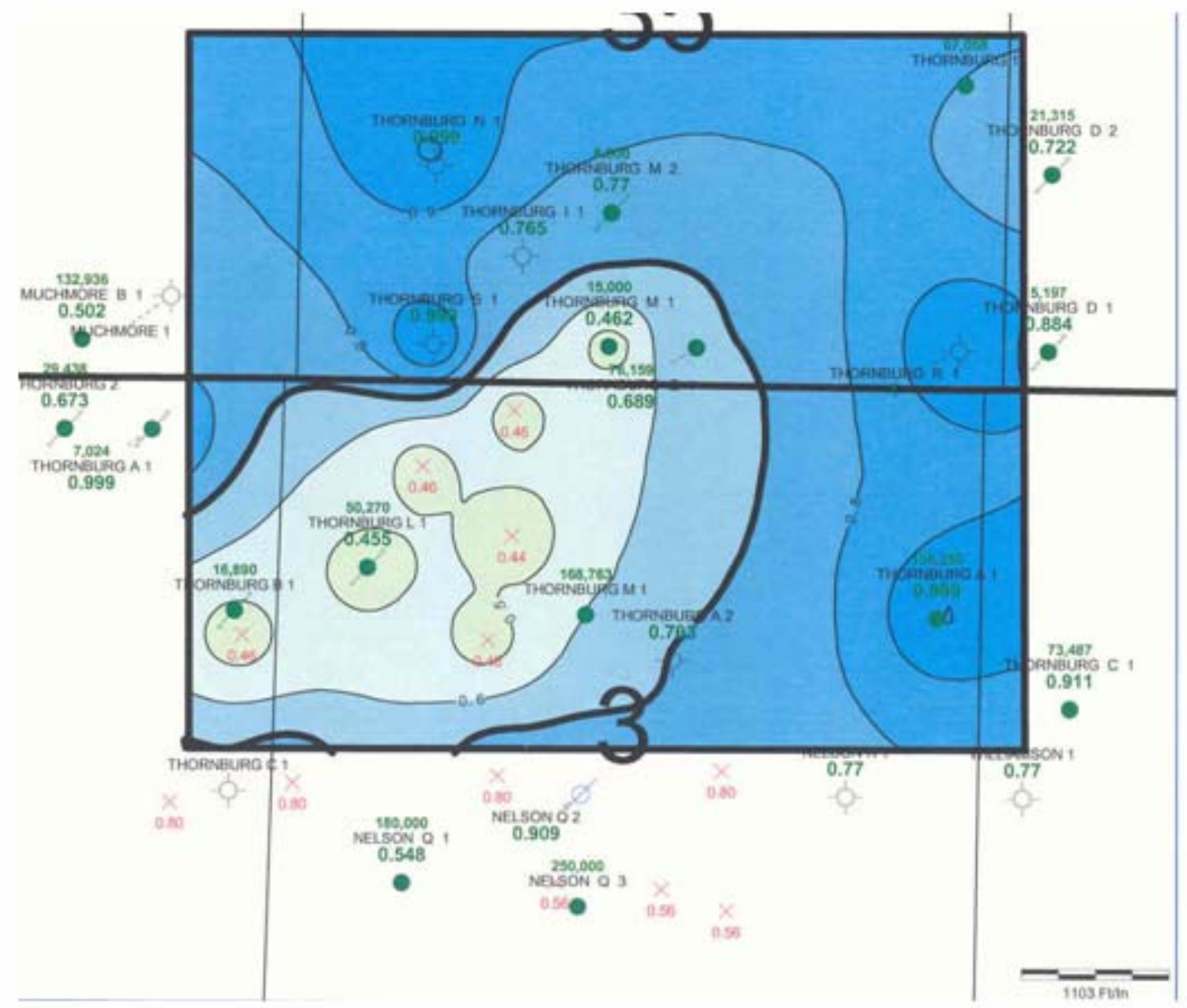

Figure 7.3.8: Initial water saturation (fraction) distribution in Layer 2 (L2) in Judica Field. 


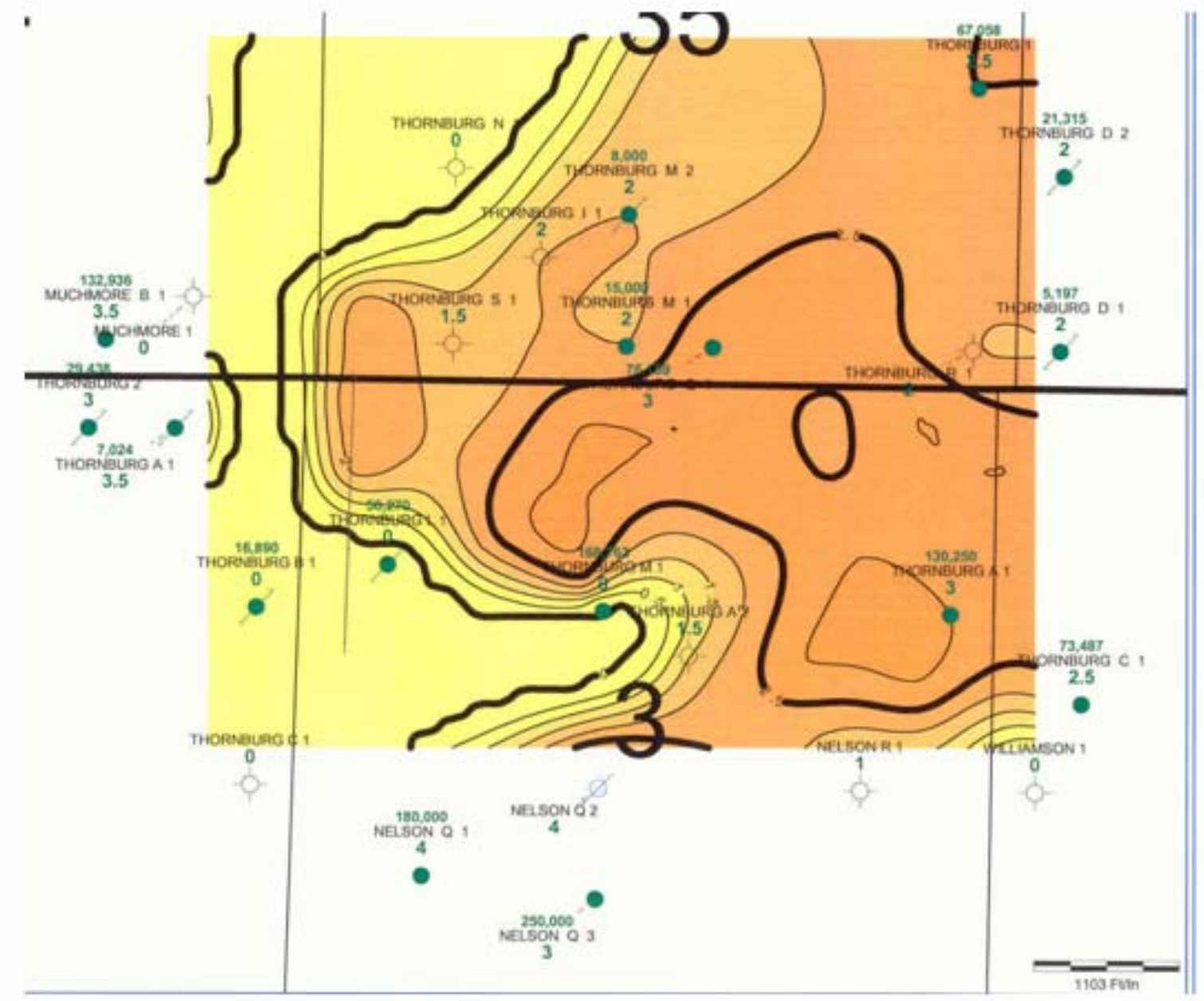

Figure 7.3.9: Isopach (feet) of Layer 3 (L3) in Judica Field. 


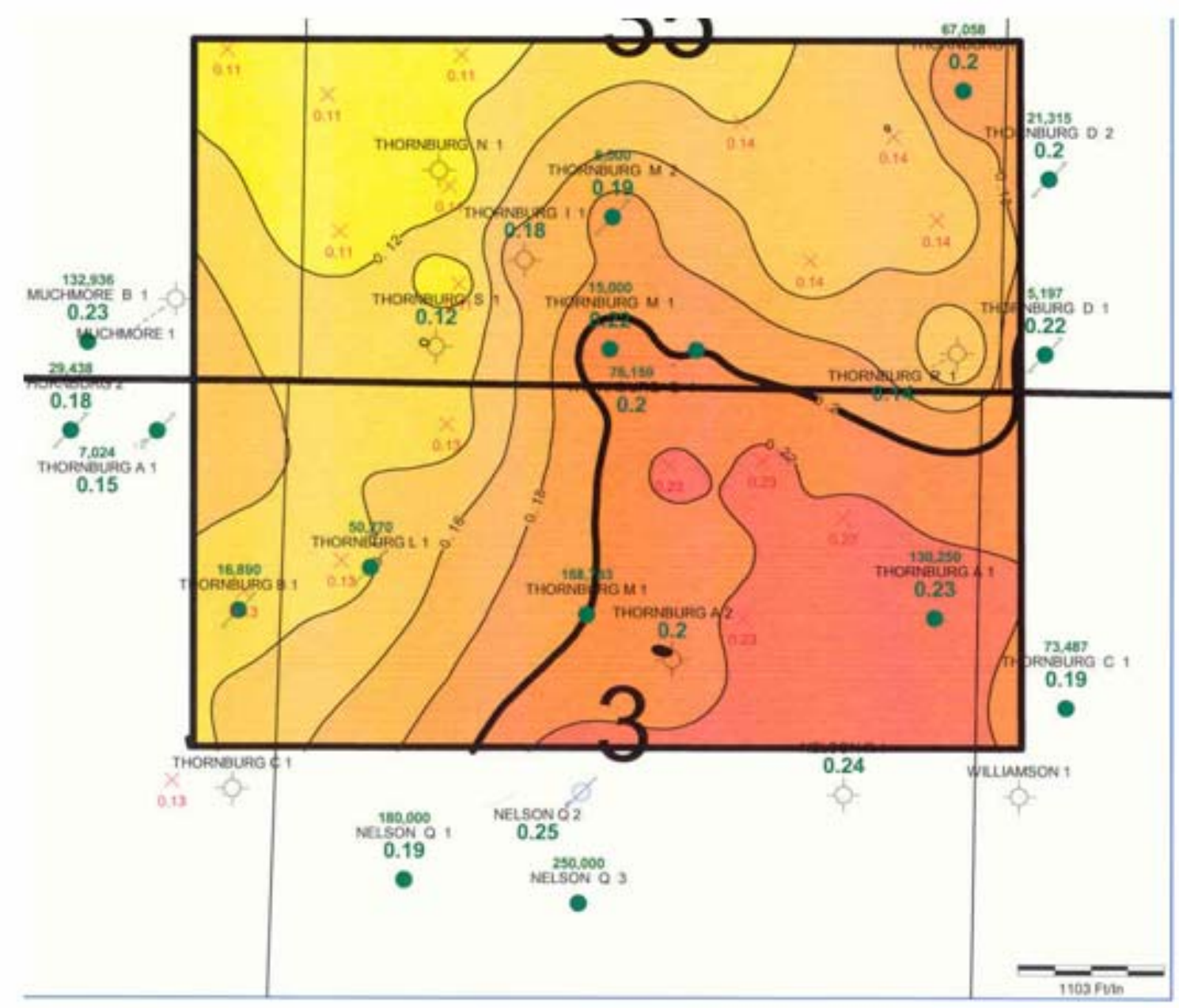

Figure 7.3.10: Porosity (fraction) distribution in Layer 3 (L3) in Judica Field. 


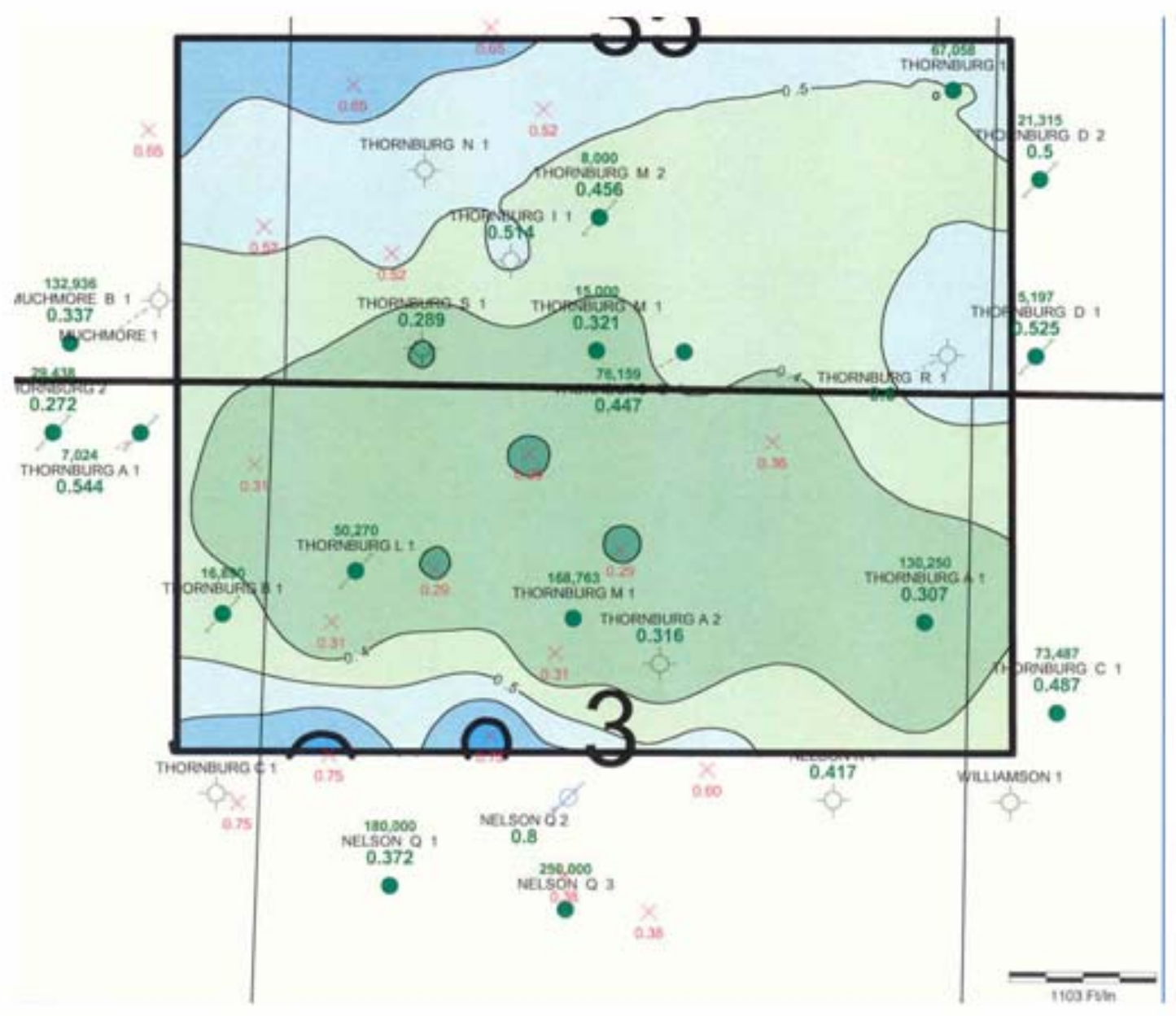

Figure 7.3.11: Initial water saturation (fraction) distribution in Layer 3 (L3) in Judica Field. 


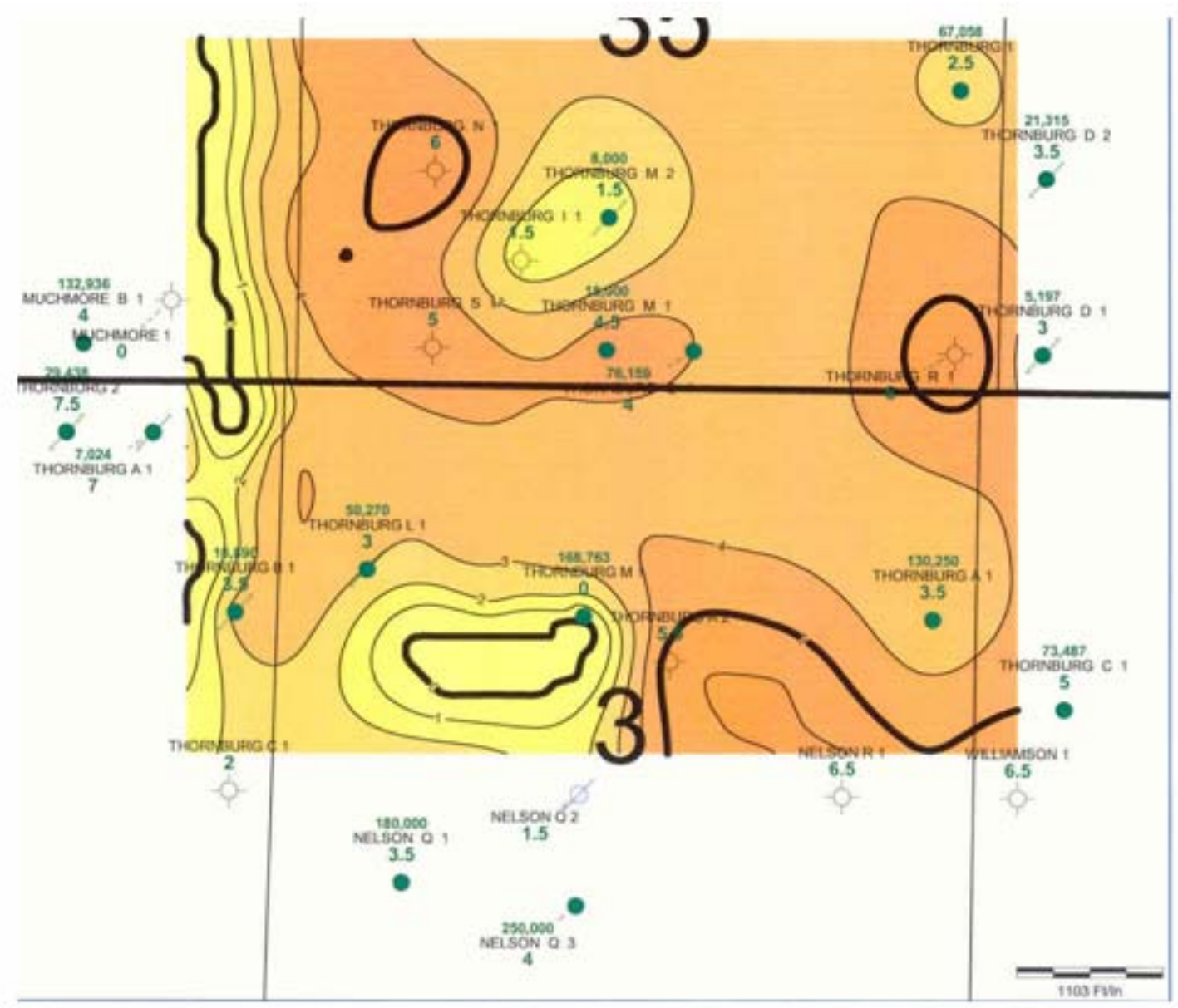

Figure 7.3.12: Isopach (feet) of Layer 4 (L4) in Judica Field. 


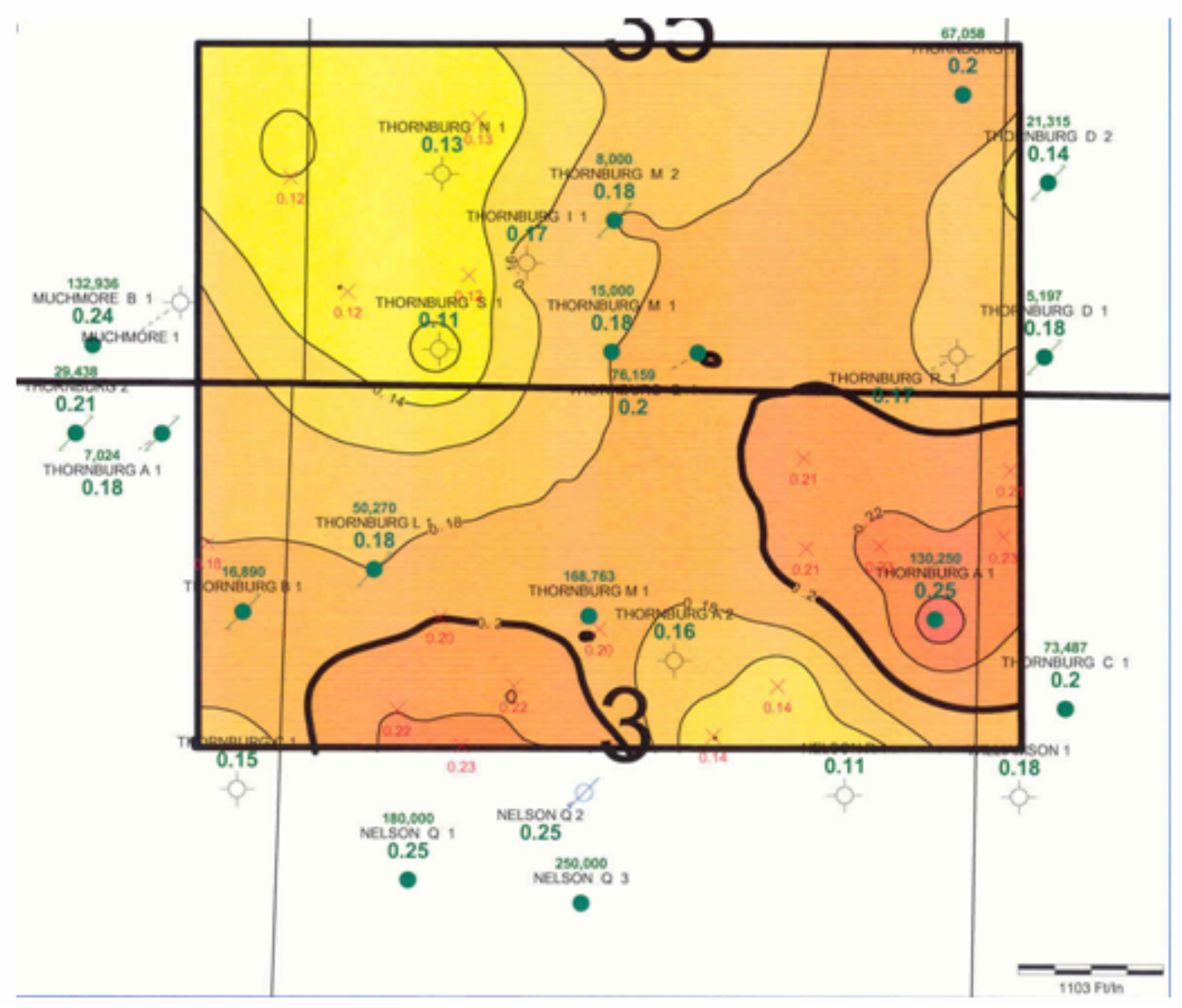

Figure 7.3.13: Porosity (fraction) distribution in Layer 4 (L4) in Judica Field. 


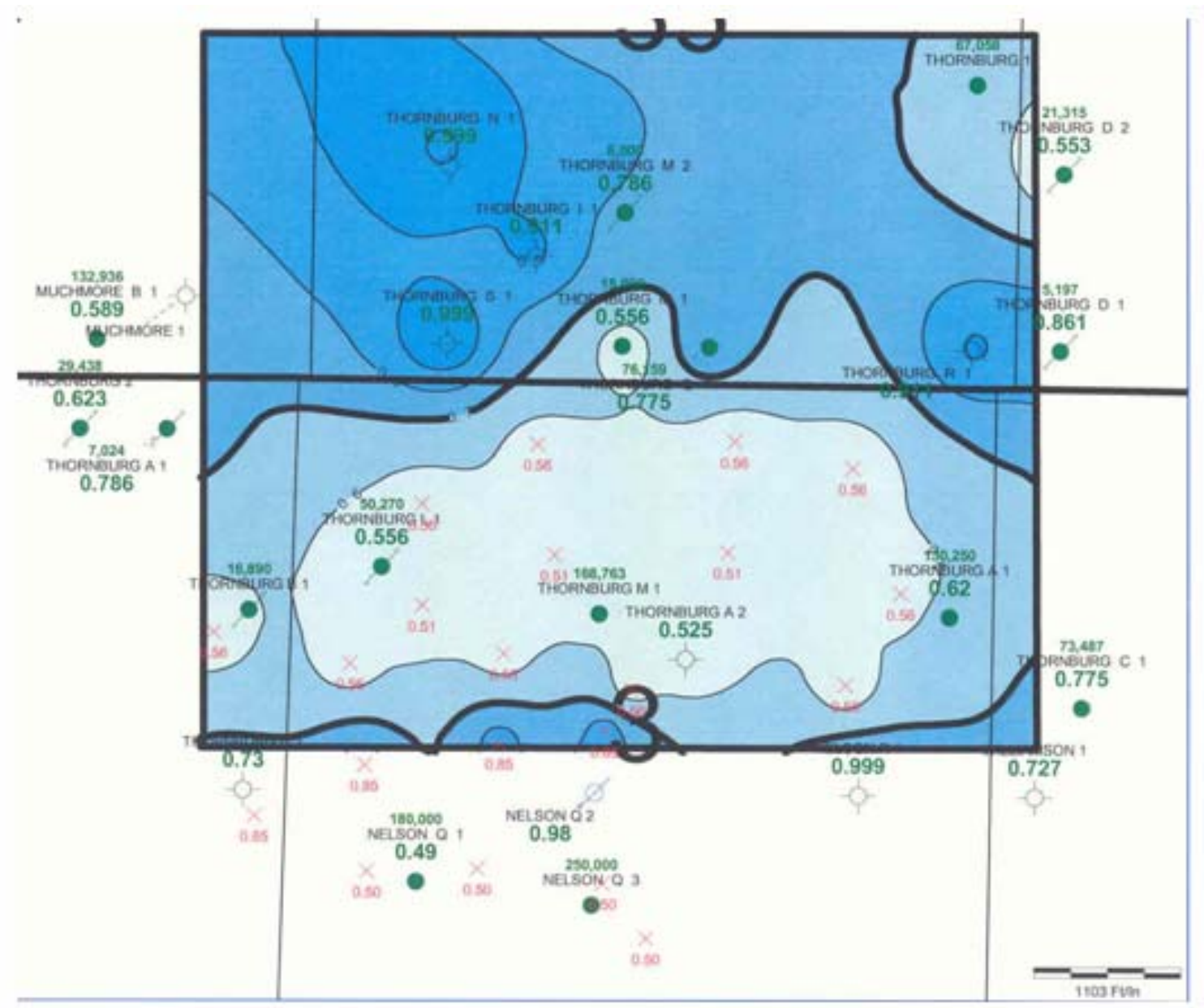

Figure 7.3.14: Initial water saturation (fraction) distribution in Layer 4 (L4) in Judica Field. 


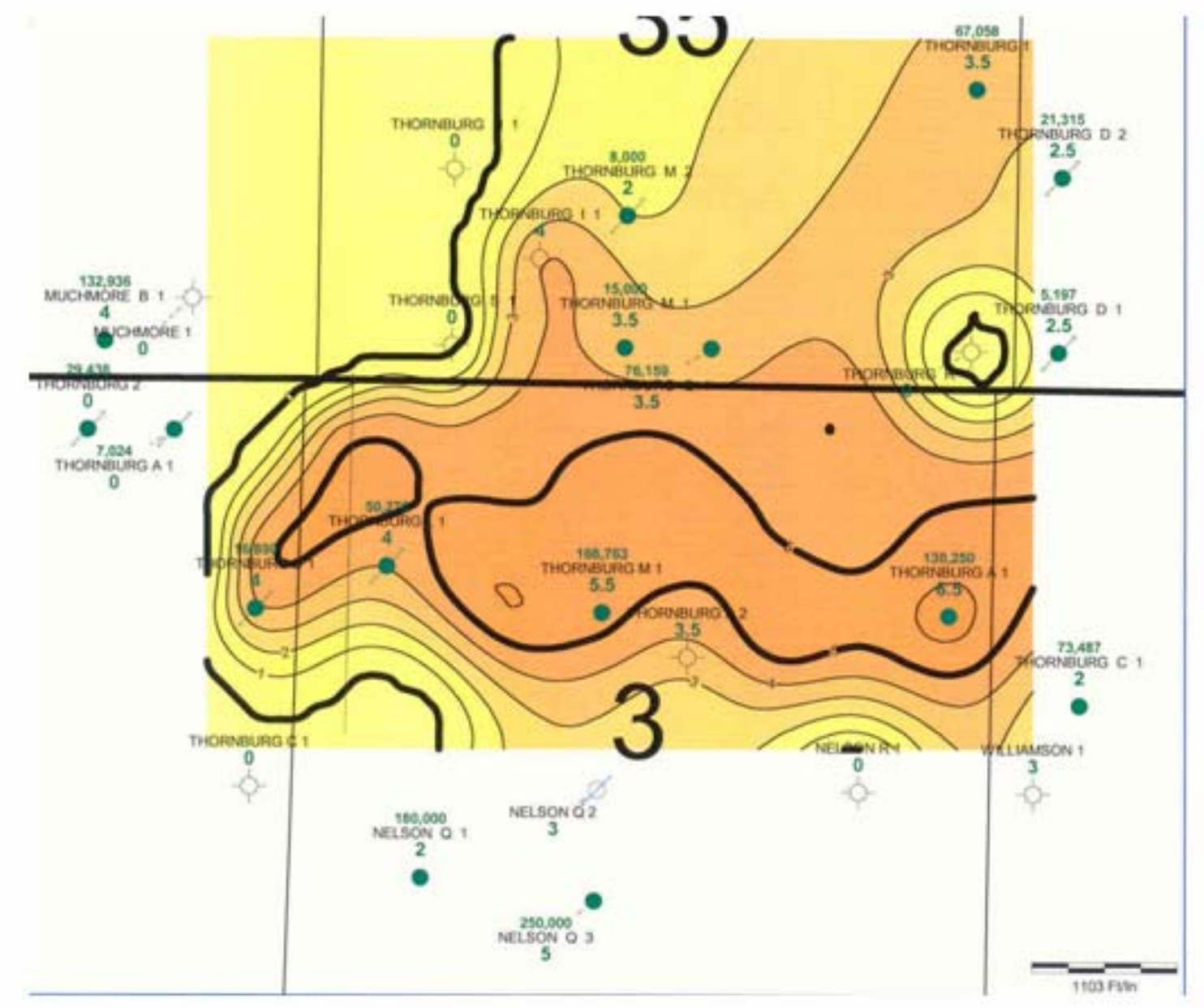

Figure 7.3.15: Isopach (feet) of Layer 5 (L5) in Judica Field. 


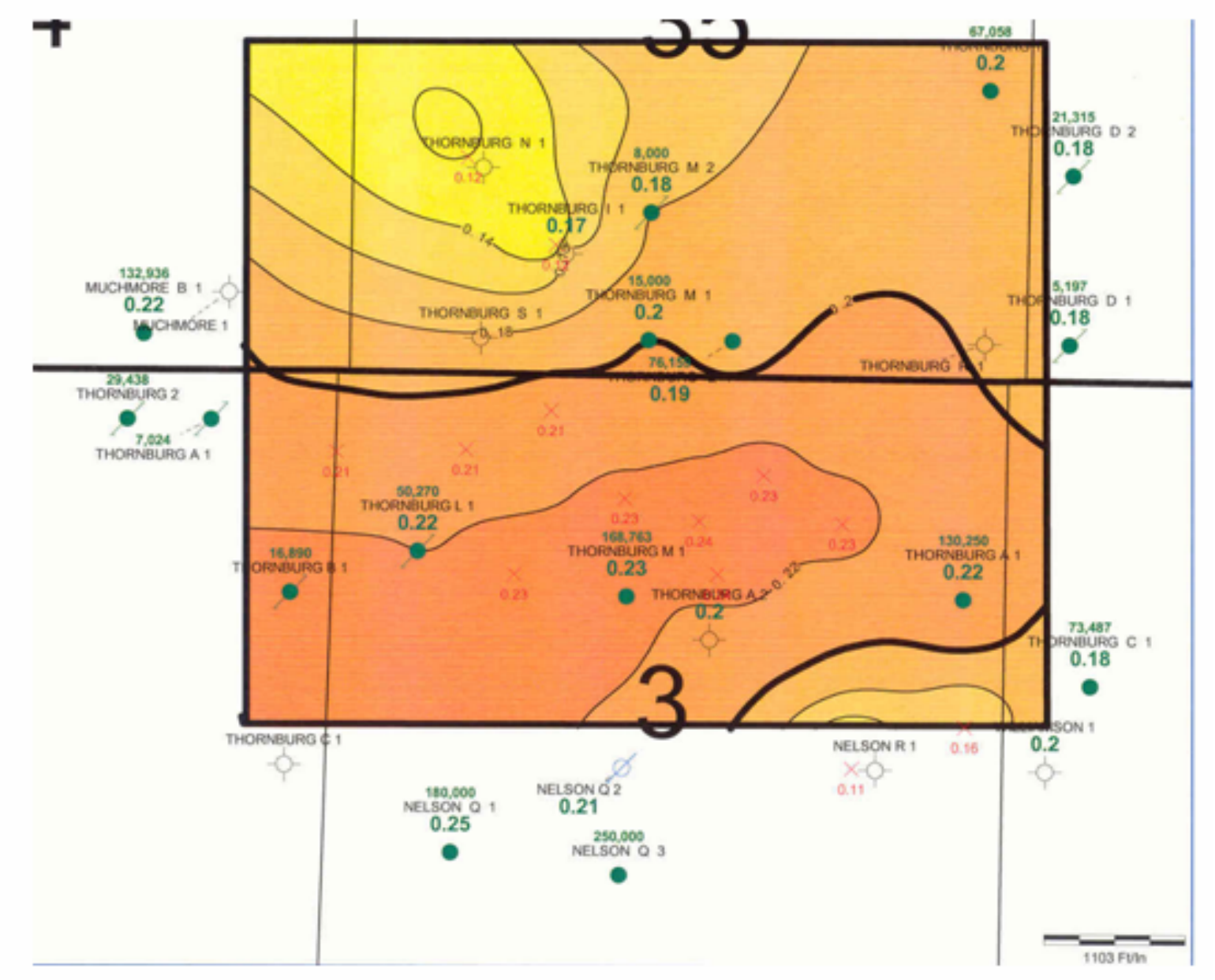

Figure 7.3.16: Porosity (fraction) distribution in Layer 5 (L5) in Judica Field. 


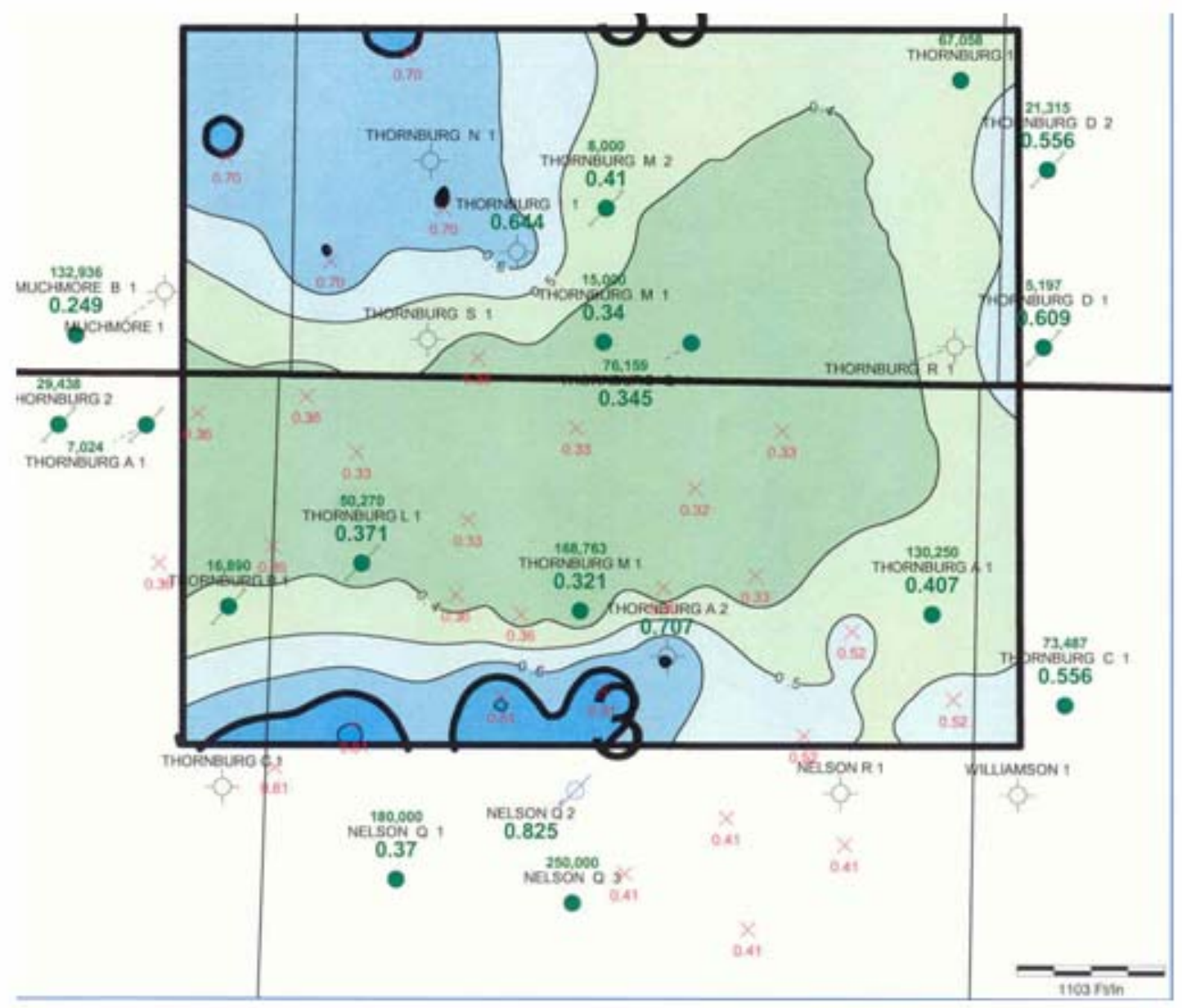

Figure 7.3.17: Initial water saturation (fraction) distribution in Layer 5 (L5) in Judica Field. 
WOR-time relationship established from TQ1 data was used to estimate the water production of all wells except TM1s (Thronburg M1 Slawson).

MULL's observation - Judica wells have historically produced less water than other Mississippian field wells.
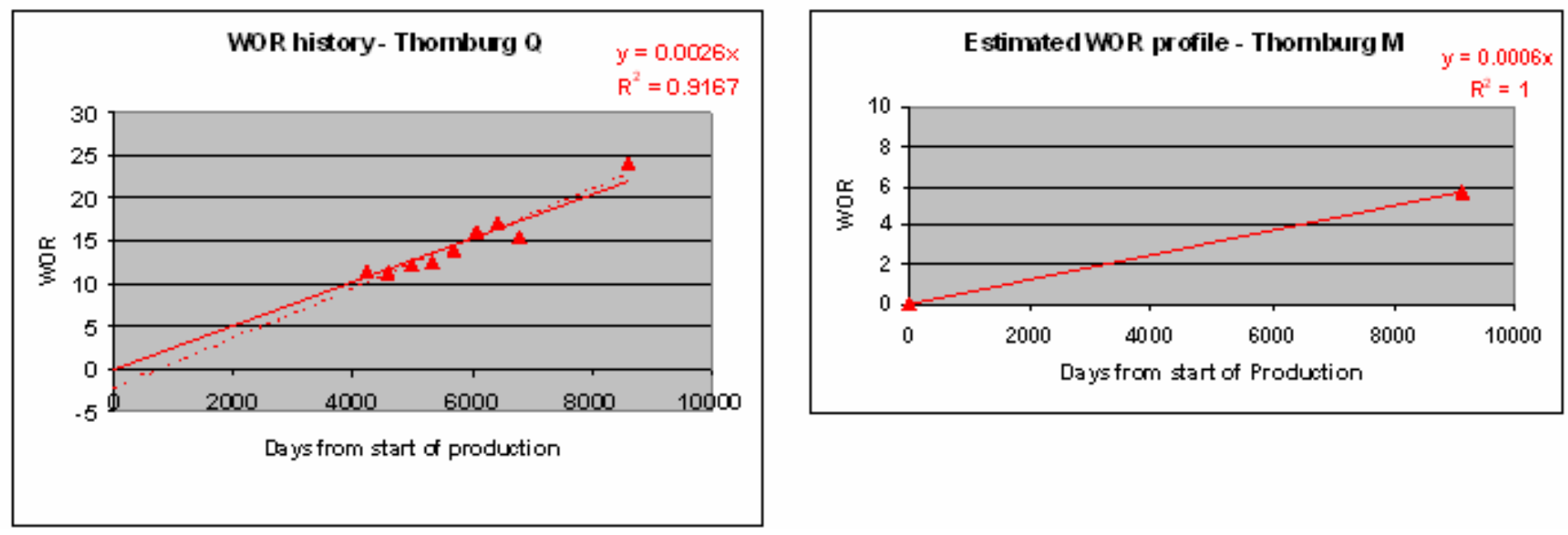

Figure 7.3.18: Plot of water-oil-ratio (WOR) versus time at Thornburg Q and Thornburg $M$ wells in Judica Field. The unforced best-fit line passes within 365 days from origin in Thornburg Q well. 


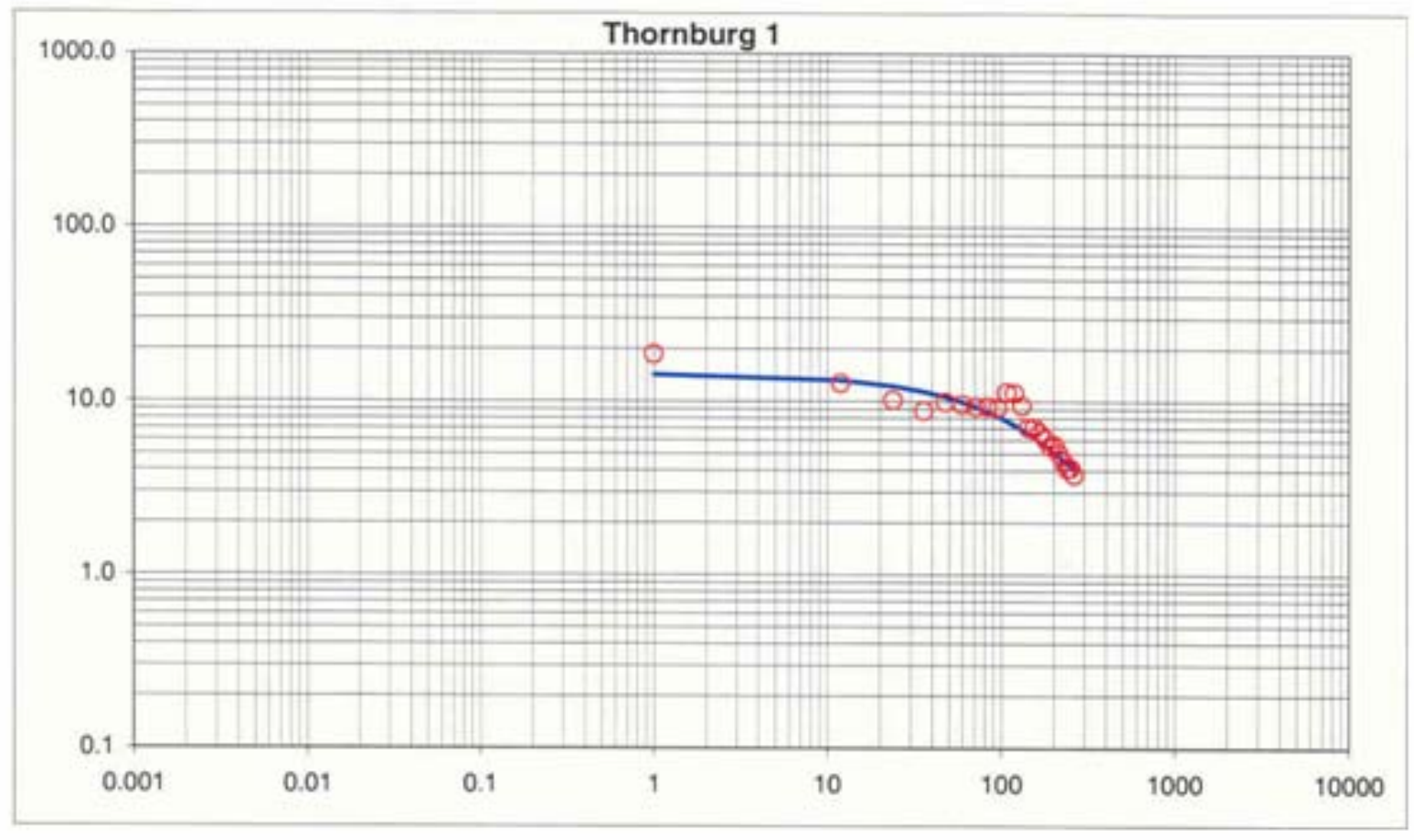

Figure 7.3.19: Decline curve analysis at Thornburg 1 well in Judica Field. A single decline curve appears to represent the production history indicating that it is not unreasonable to assume that the well (perhaps) produced under unchanging conditions (constant skin and/or flowing bottom hole pressure). 


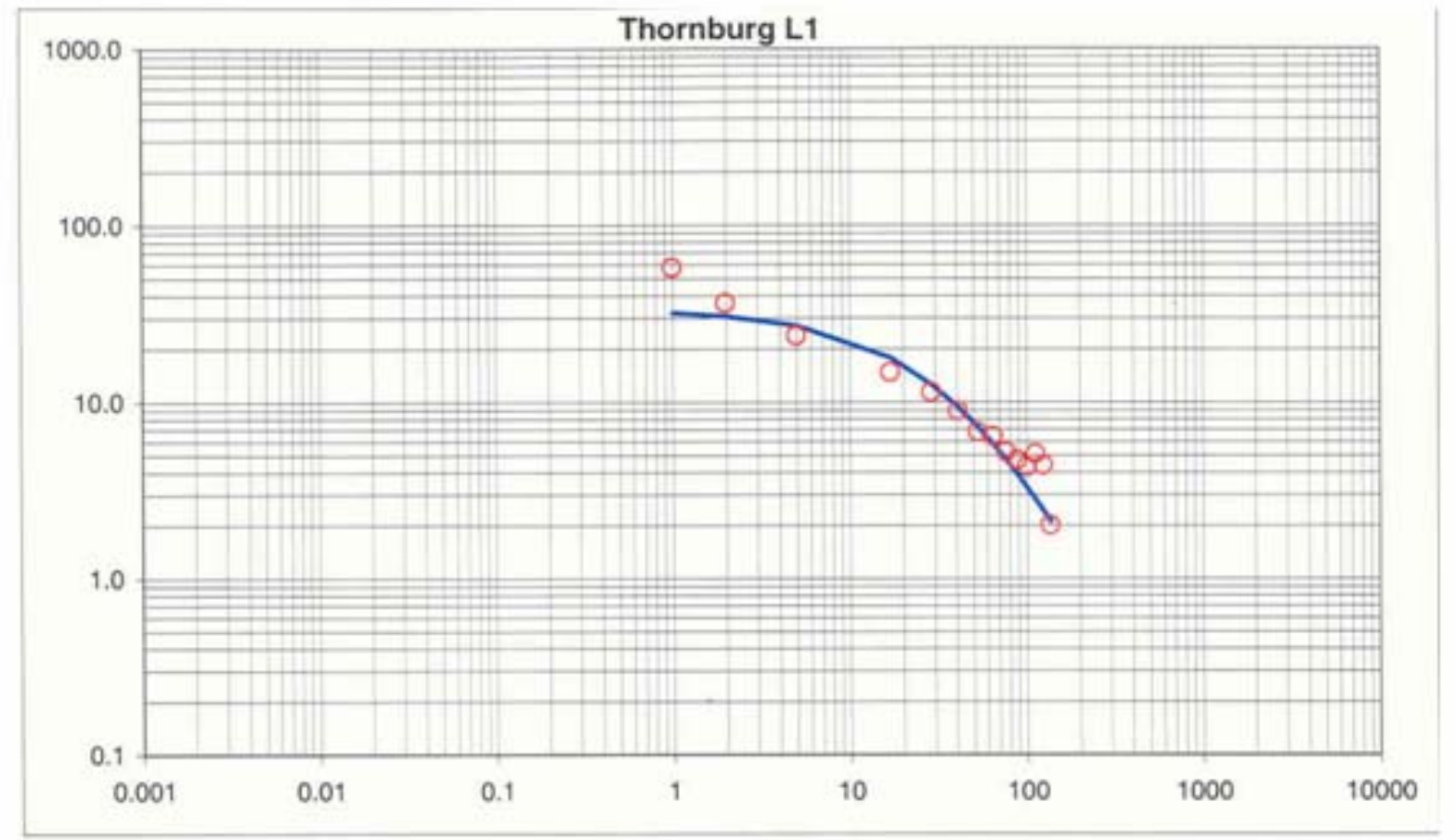

Figure 7.3.20: Decline curve analysis at Thornburg L1 well in Judica Field. A single decline curve appears to represent the production history indicating that it is not unreasonable to assume that the well perhaps produced under unchanging conditions (constant skin and/or flowing bottom hole pressure). 
Well praducing canditinns changed (qkin and/ar Pwf changed)

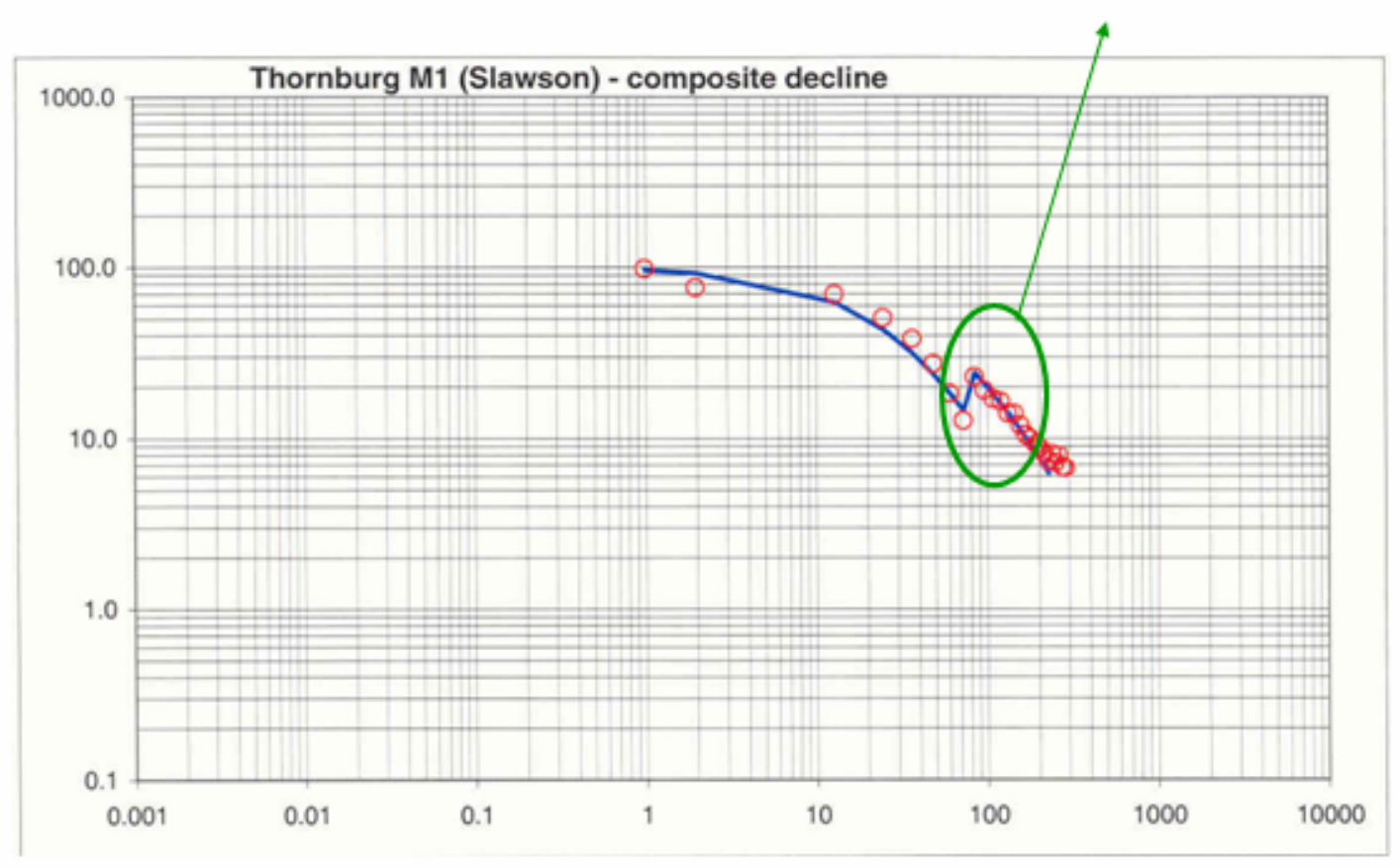

Figure 7.3.21: Decline curve analysis at Thornburg M1 (Slawson) well in Judica Field. Production history shows 2 different decline trends. The value of the decline exponents (b) for both the trends are the same $(b=0.4)$, which is suggests that the production data are from the same well and reservoir drainage volume. No information is available about flowing bottom hole pressure (Pwf) during the first decline. Currently, the well produces under pumped-off conditions. It might not be, therefore, unreasonable to history-match the second decline phase at this well by reducing skin (keeping Pwf constant) lacking any information about the Pwf. 


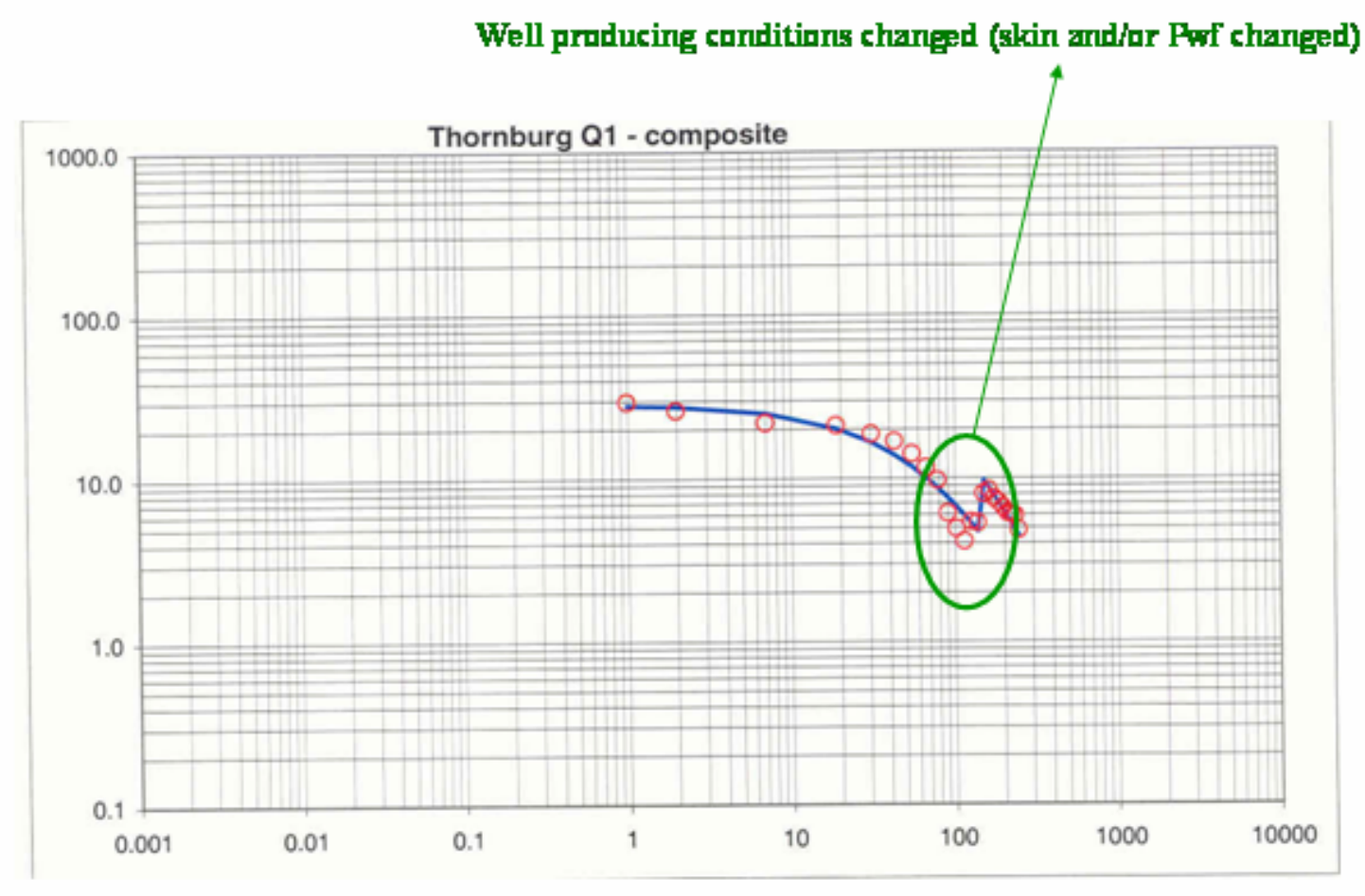

Figure 7.3.22: Decline curve analysis at Thornburg Q1 well in Judica Field. Production history shows 2 different decline trends. The value of the decline exponents (b) for both the trends are the same $(b=0.4)$, which is suggests that the production data are from the same well and reservoir drainage volume. No information is available about flowing bottom hole pressure (Pwf) during the first decline. Currently, the well produces under pumped-off conditions. It might not be, therefore, unreasonable to history match the second decline phase at this well by reducing skin (keeping Pwf constant) lacking any information about the Pwf. 
Shut-in fluid column

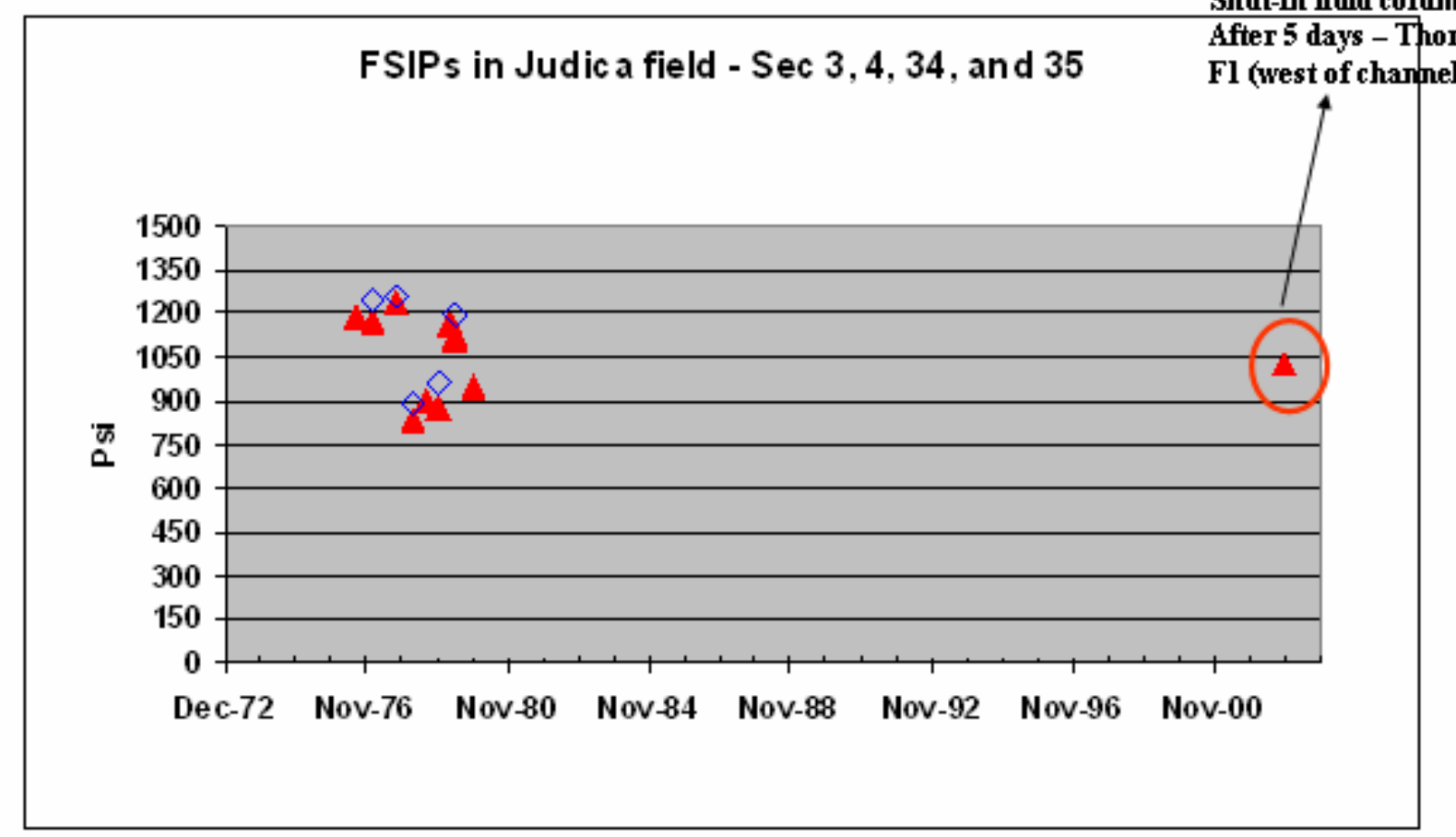

Red triangles are FSIPs while blue diamonds represent Pi calculated from actual DST pressure profiles.

Figure 7.3.23: Plot of reservoir pressure from available DST and shut-in tests in Judica Field. 


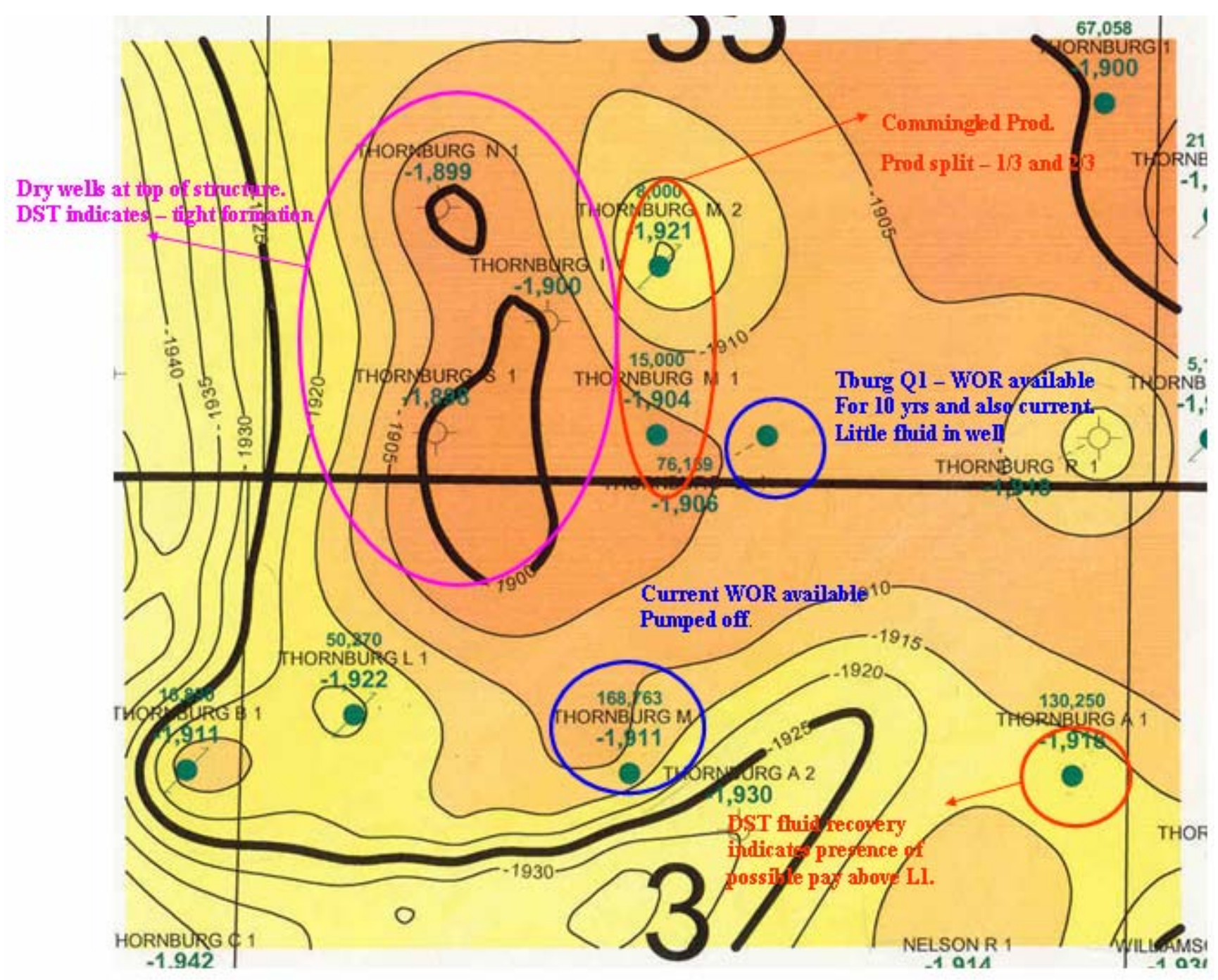

Figure 7.3.24: Map showing the area simulated in Judica Field along with well locations and a summary of data constraints. 


\section{Tharnburg Ml Slawsan (TMlg)}

Phi: Ll= absent, L3 = 0.197, L5 $=0.229$

Swi: Ll = absertt, L3 = N/a, L5 = 0.32

Mast pralific praducer. Current WOR indicates very lnw water praductinn aver the life af the well. Thus, Relative K water expanent m (= 2.5) was leed tn lawer water praductinn.

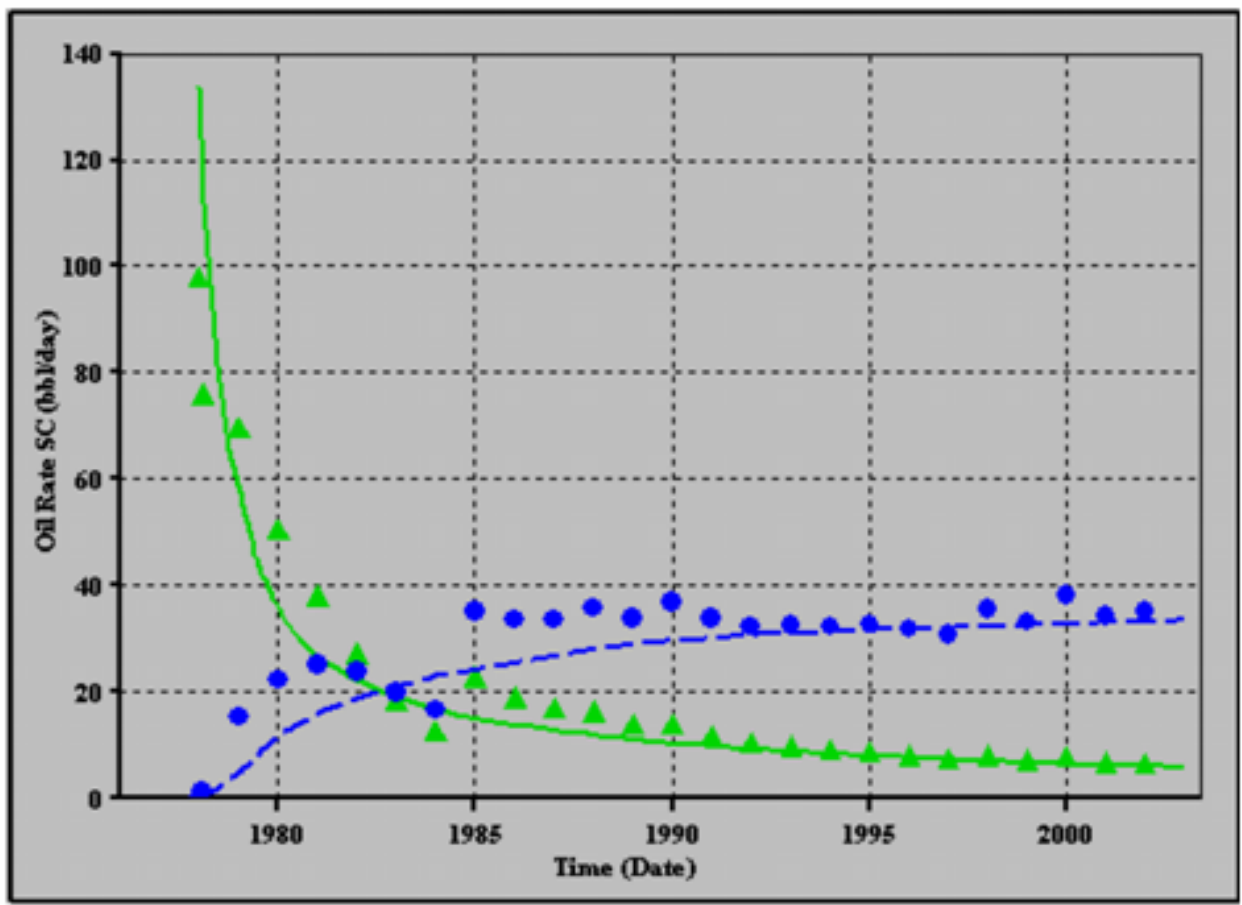

Figure 7.3.25: Production history match at Thornburg M1 (Slawson), TM1s, well in Judica Field. 
Phi: $\mathrm{Ll}=\mathrm{D} .18, \mathrm{L3}=\mathrm{absent}, \mathrm{L} 5=0.22$

Swi: L1 $=0.35$, L3 = absent, L.5 = 0.37

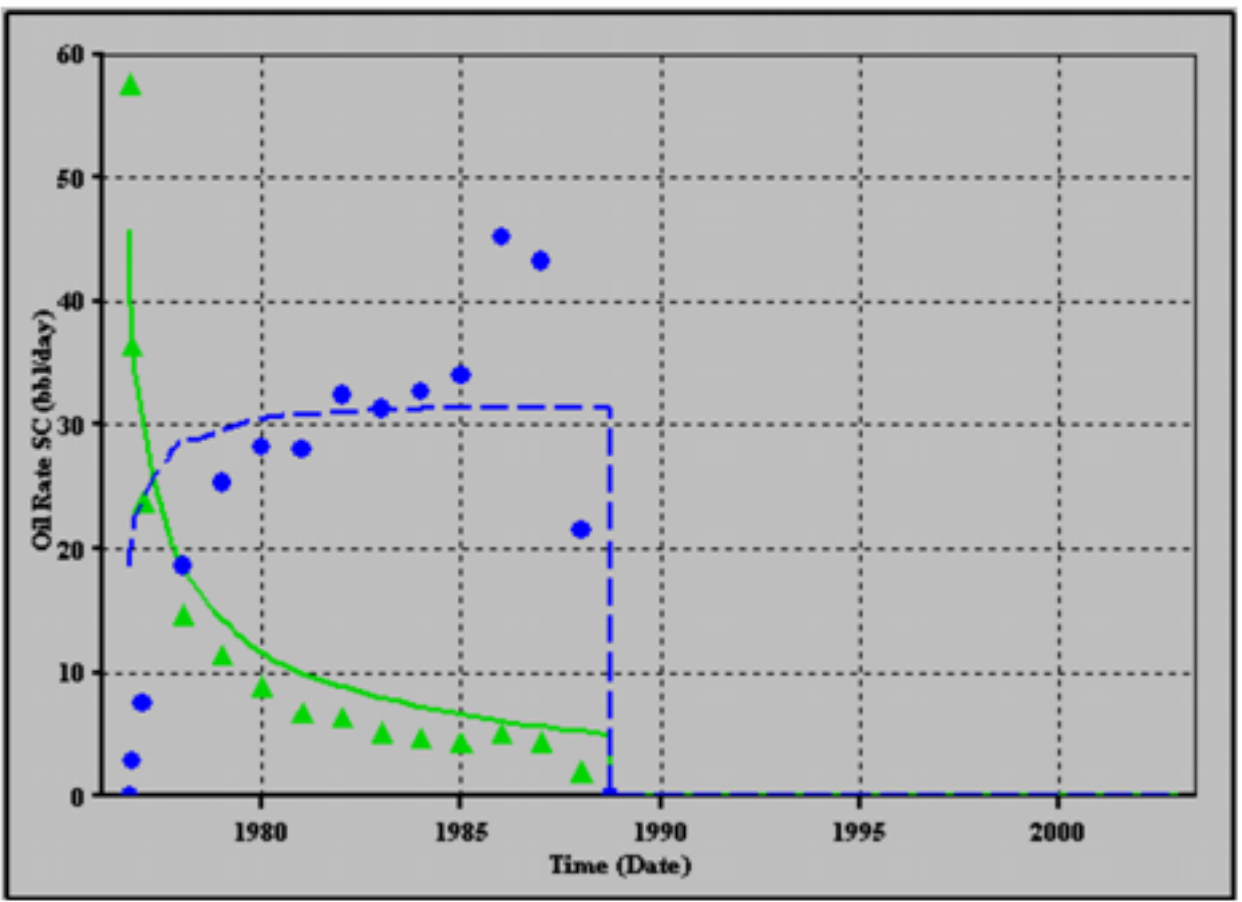

Figure 7.3.26: Production history match at Thornburg L1, TL1, well in Judica Field. 
Tharmburg Al (TAl)

Phi: $\mathrm{Ll}=0.22, \mathrm{L3}=0.23, \mathrm{LS}=\mathbf{0 . 2 2}$

Swi: L1 = 0.49, L3 = 0.30, L5 = 0.41

Gealngic madel indicates presence of pay above L1. Match abtained by allacating well praductinn tn L1, L3, s L5.

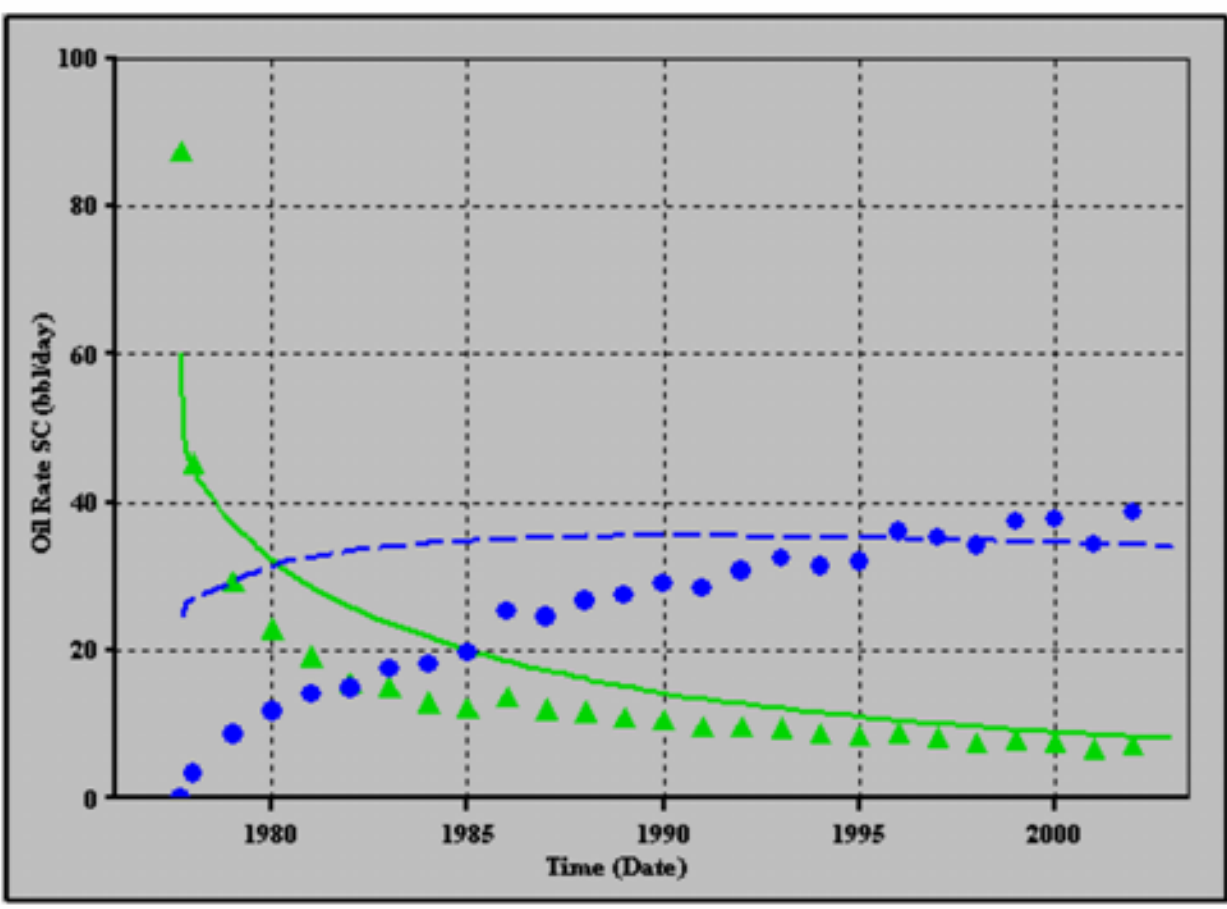

Figure 7.3.27: Production history match at Thornburg A1, TA1, well in Judica Field. 
Tharmburg 1 (T1)

Phi: $\mathrm{Ll}=$ absent, $\mathrm{L3}=0.2, \mathrm{~L} 5=0.2$

Swi: L1 = absent, L3 = N/a (zsume 0.40), L5 = N/a (agoume 0.45)

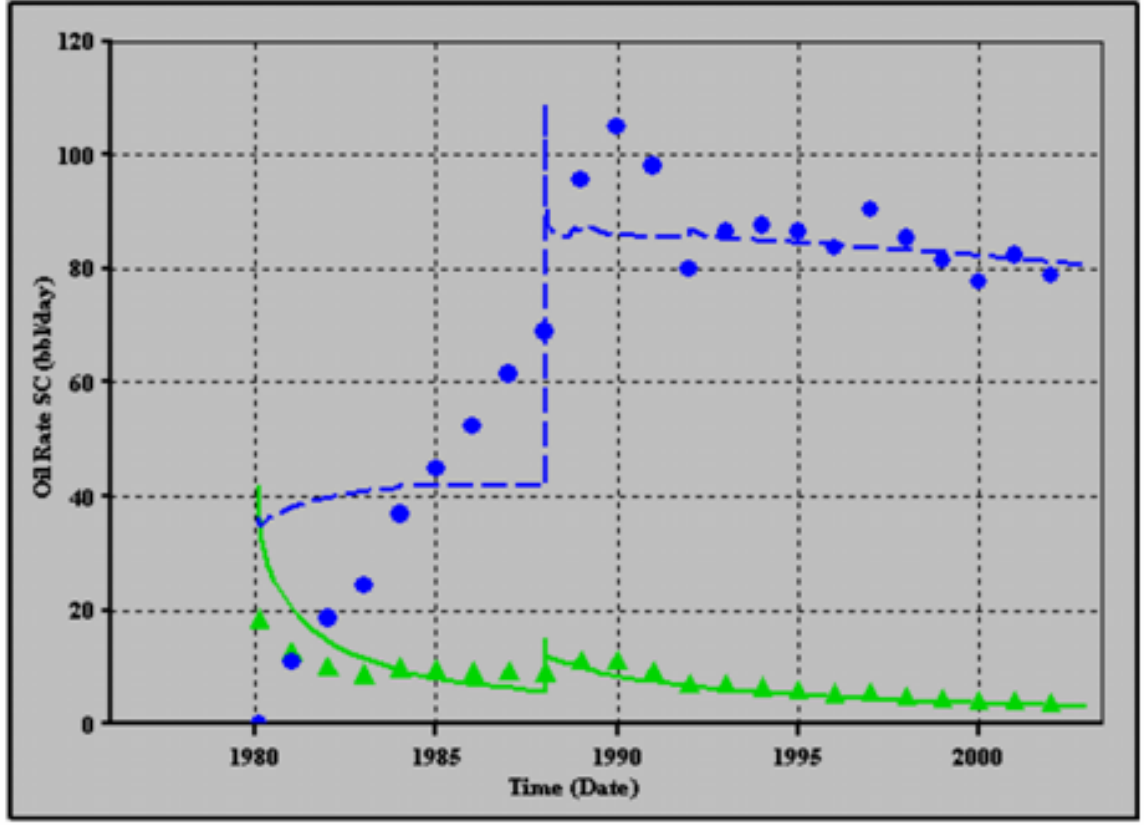

Figure 7.3.28: Production history match at Thornburg 1, T1, well in Judica Field. 
Tharnburg Bl (TBI)

Na log are available

Phi: Ll= absent, L3 = absent, L5 = 0.226 (extrapalated while mapping)

Swi: LI = absent, L3 = absent, L5 = N/a (zssume 0.55)

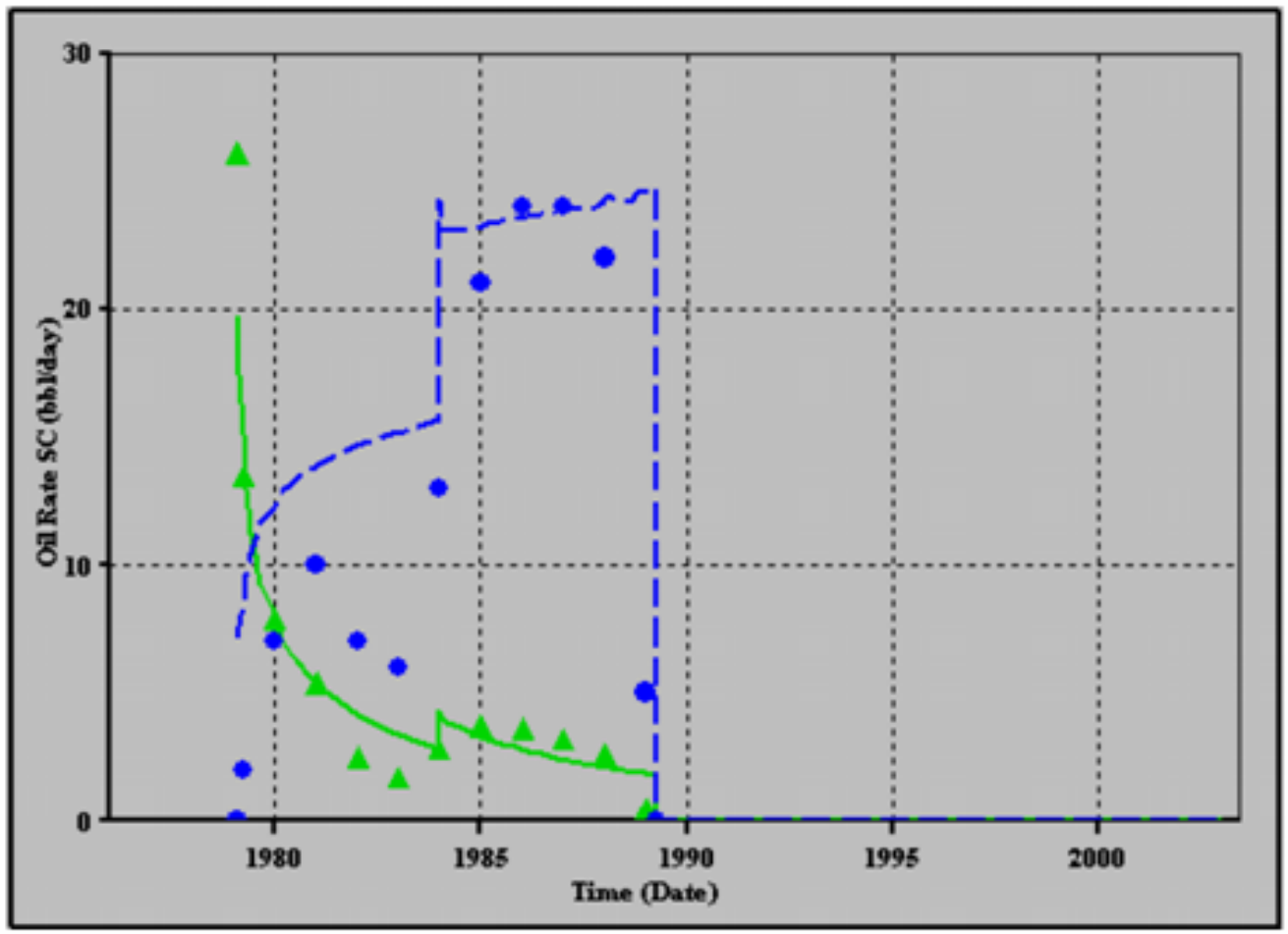

Figure 7.3.29: Production history match at Thornburg B1, TB1, well in Judica Field. 


\section{Tharnburg Ml (TMl)}

Well praductian datz N/A. Tharrbure leage praductian allacated between TML ard TH2 in ratia af la:40

Phi: $L 1=$ absent, $L 3=0.22, L 5=0.2$

Swi: L1 = absent, L3 = 0.32, L5 = 0.34

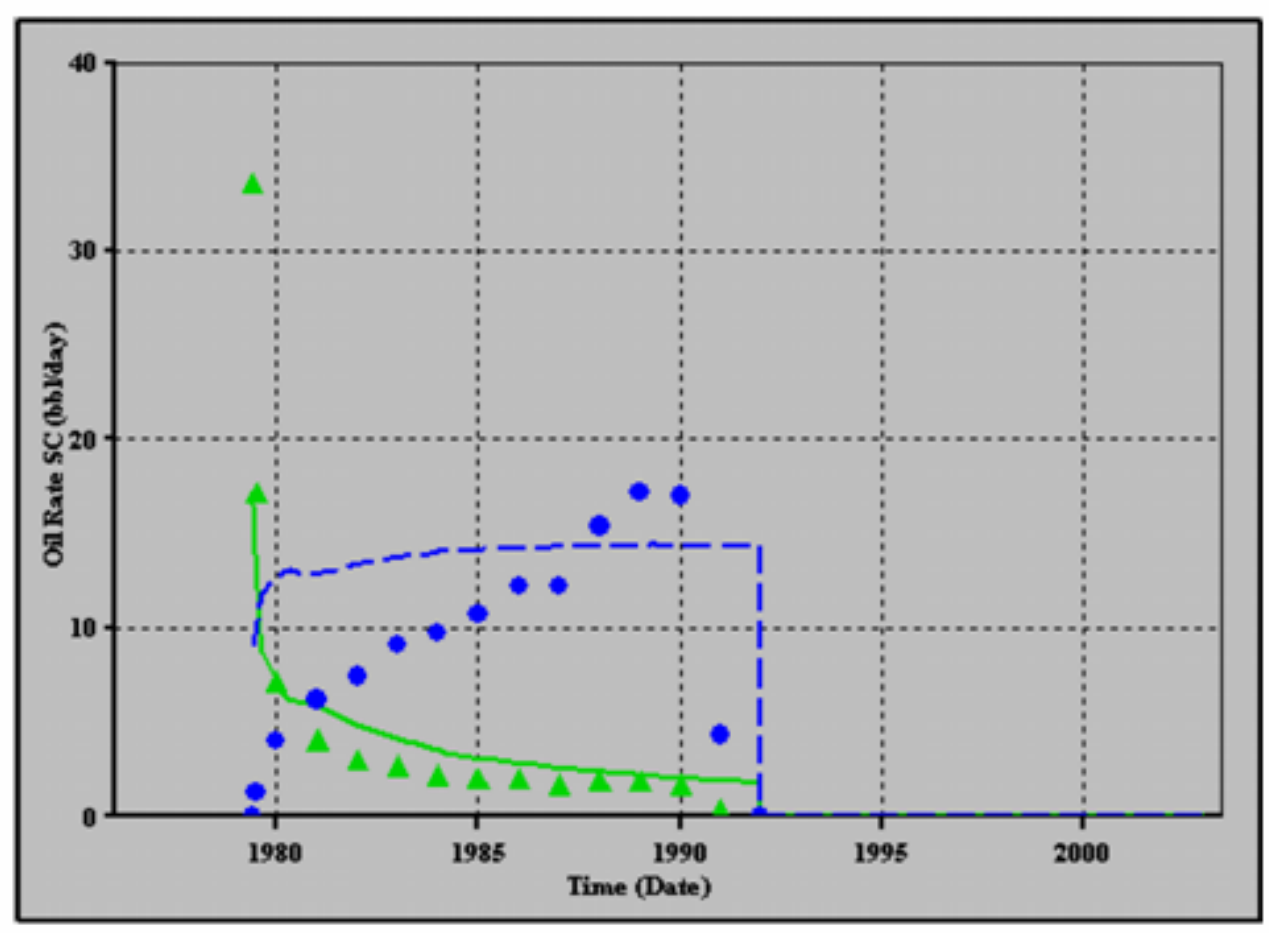

Figure 7.3.30: Production history match at Thornburg M1, TM1, well in Judica Field. 


\section{Tharnburg M2 (TM2)}

Well praductinn datz N/A. Thurnbure leage praductinn allacated between Thl ard TM2 in ratin af $60: 40$ Phi: LI= 0.15, L3 = 0.19, L5 = 0.18

Swi: L1 = 0.6口, L3 = 0.46, L5 = 0.41

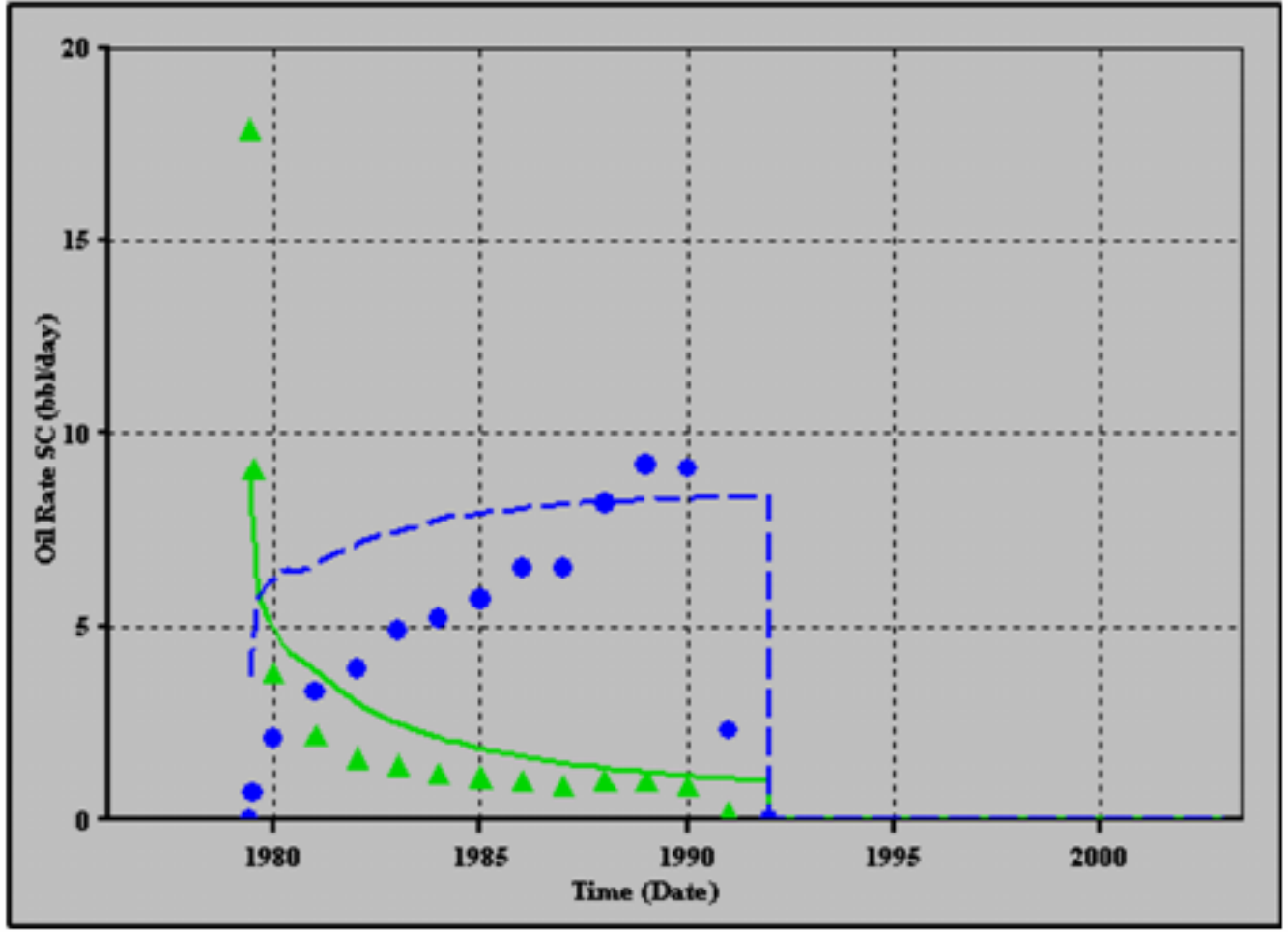

Figure 7.3.31: Production history match at Thornburg M2, TM2, well in Judica Field. 
Tharnburg Q1 (TQ1) - histary matching

TQ1 14

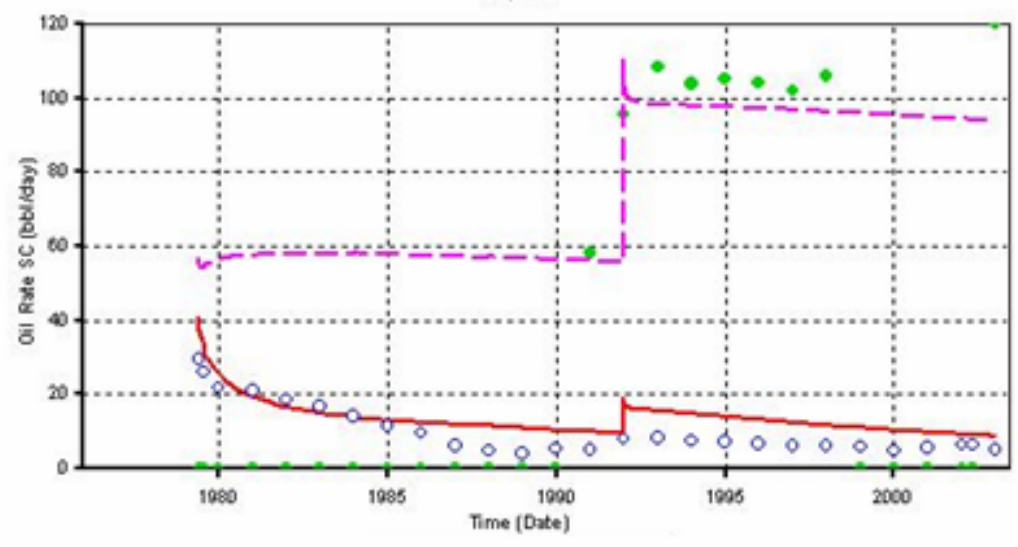

TQ1 MS

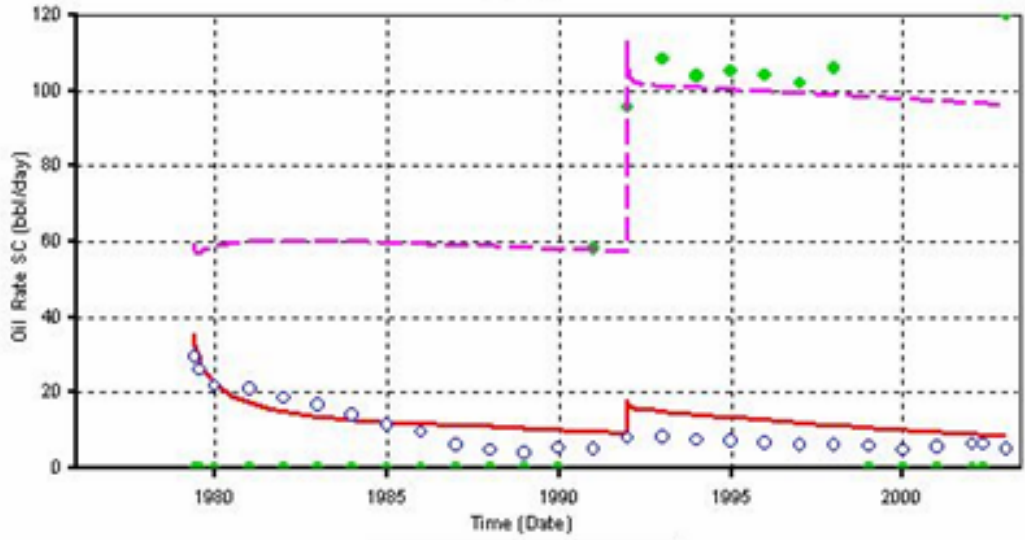

Phi: LI $=0.18, \mathrm{L3}=0.2, \mathrm{LS}=0.19$

Swi: Ll $=0.47, \mathrm{L3}=0.45, \mathrm{LS}=0.35$

\section{Initial ail saturatings - same as that} estimated from log

$\mathrm{Ll}=0.47, \mathrm{L3}=0.45, \mathrm{LS}=0.35$

Porasity - same as that estimated from logs

L1 $=0.178$, L3 $=0.198$, L5 $=0.190$

Relative permeability expanents: $\mathrm{n}=\mathbf{0 . 2}$ and $\mathrm{m}=6.0$ (mirimixe ail flum and maximize water flurs)

Fhi is L3 (口.19g) is greater than L5 (口.190) and yet Swi in L3 is ereater than L5. Maybe Stri needs to be higher in L5.

New ail saturatiars:

$\mathrm{LI}=0.47, \mathrm{~L} 3=0.45, \mathrm{~L} 5=\square .51$

Relative permeability exponents: $\mathbf{n}=\mathbf{0 . 2}$ and $m=6.0$ (minimixe ail flew and maximize water flew)

Figure 7.3.32: Initial production history match at Thornburg Q1, TQ1, well in Judica Field. 
Tharrbure Q1 (TQ1) firal - fram TQ1 NG b. dat

Initial ail saturations - same as that estimated from logs

Netigrags = 0.9 fram L1, L2, L3

Relative permeability exponents: $n=0.2$ and $\mathrm{m}=6.0$ (minimixe ail flew and maximize water flow)

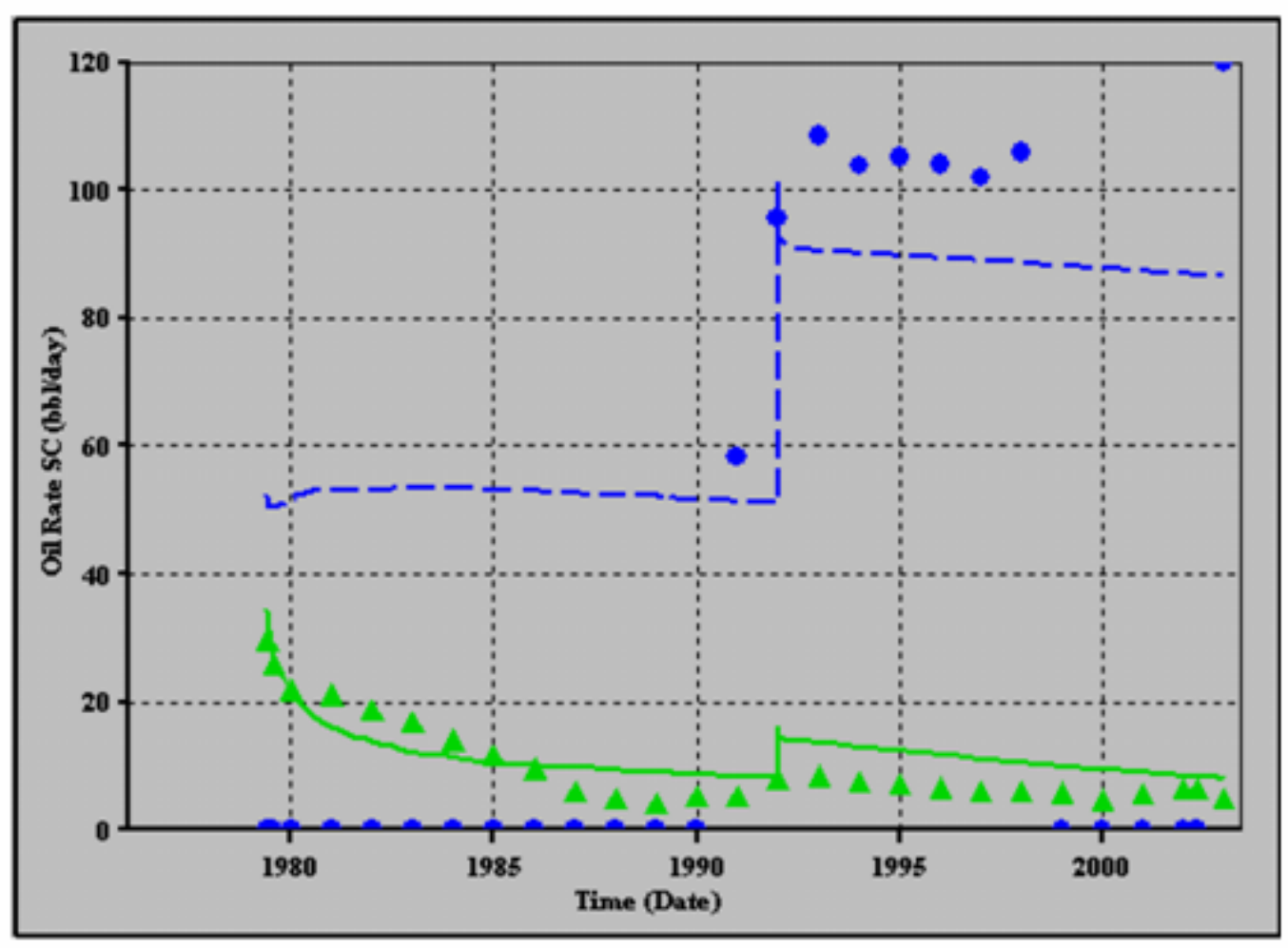

Figure 7.3.33: Final production history match at Thornburg Q1, TQ1, well in Judica Field. 


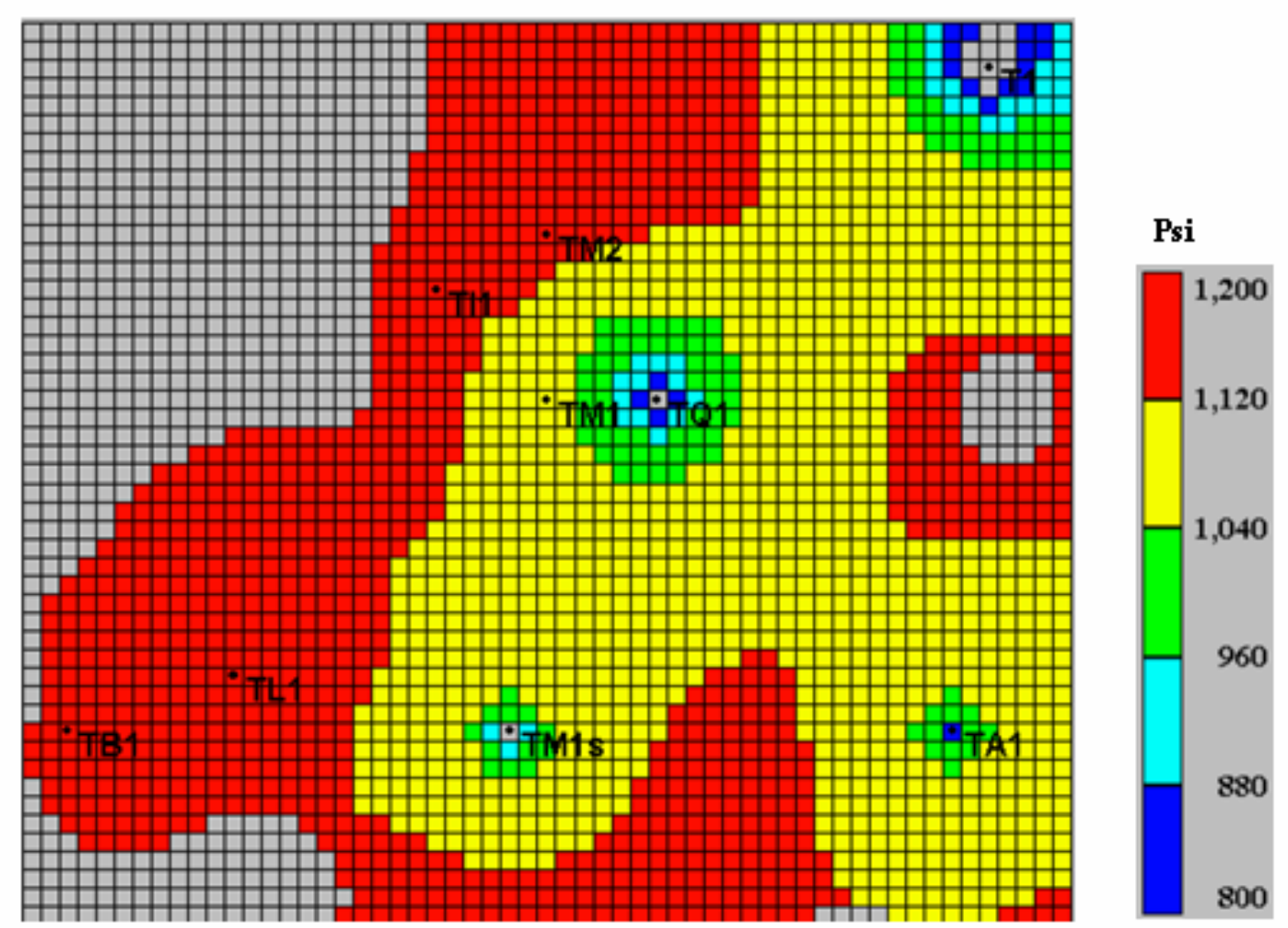

Figure 7.3.34: Simulator calculated reservoir pressure distribution in Judica Field as of January 2003. Extended shut-in test at Thornburg F1 (located west of the study area) in November 2002 indicated a reservoir pressure of 1030 psi in its drainage area. 
Jar 1, 2013 - remaining reservea (ail-ft) in layer 5

Jan 1, 2003 - remziruing reserves (quil-fț in after drilling an infill harizantal well - Hwell Layer 5 Lacatinn: $(17,31)$ to $(17,41)$
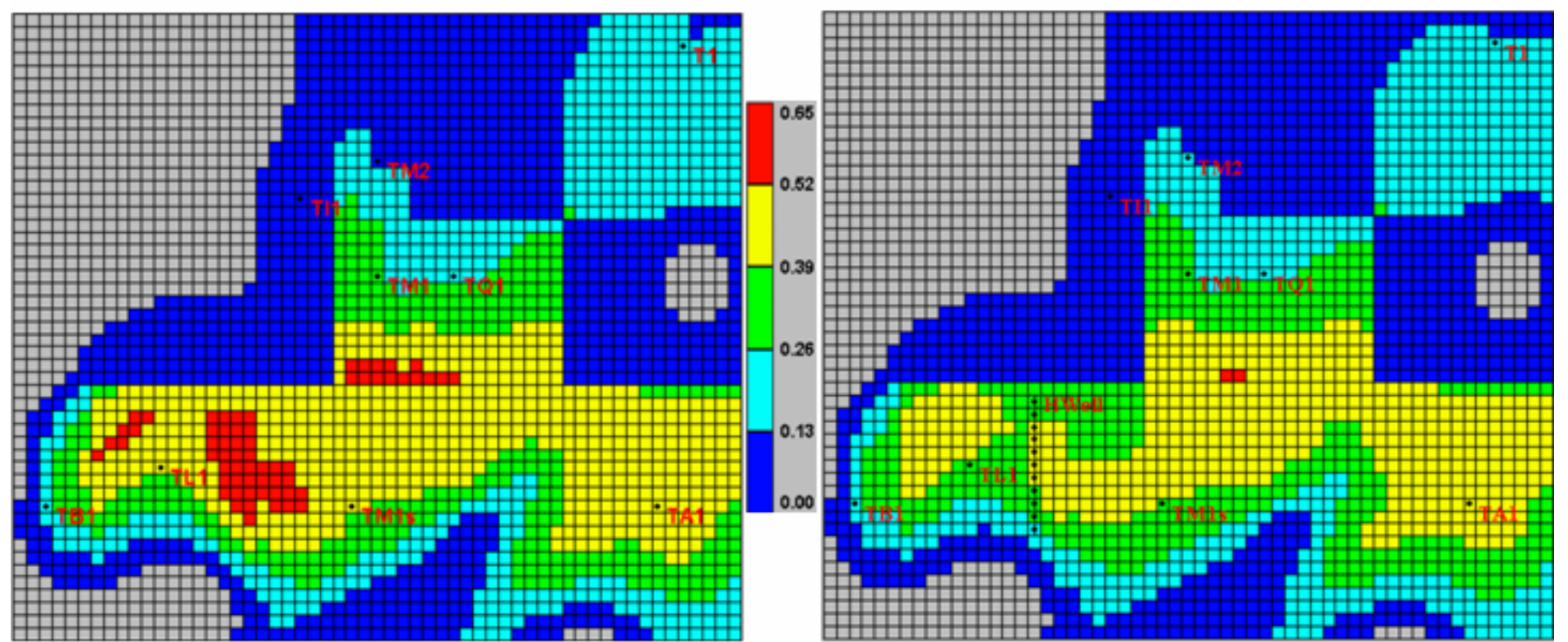

Well length $=1100 \mathrm{ft}$

skin $=1.5$

Well dizmeter $=$ G"

Enttnm hale pregiare $=200$ psi $\left(\mathrm{P}_{\mathrm{w}}\right)$

Campleted an Jan 1, 2003

Figure 7.3.35: Drainage (expressed as oil-feet) over 10 years by a targeted horizontal infill well, HWell, in Judica Field. Oil-feet calculated as the product of porosity, oil saturation, and pay thickness. 
Harizantal infill well praductivity estimate - baged an TQ1 NGb.dat

Well name: Hwell, Lacatiar: $\{17,31\}$ ta $\{17,41\}$

Lergth: 1100,

Well completed on Jan 1, 2003

\begin{tabular}{|c|c|c|}
\hline Year & Cum Oil & Cum Wtr \\
\hline & MO & MW \\
\hline 2004 & 19.1 & 98.3 \\
\hline 2006 & 40.7 & 294.5 \\
\hline 2008 & 54.8 & 490 \\
\hline 2010 & 64.9 & 682.5 \\
\hline 2012 & 72.9 & 870.1 \\
\hline 2013 & 76.2 & 962.1 \\
\hline
\end{tabular}

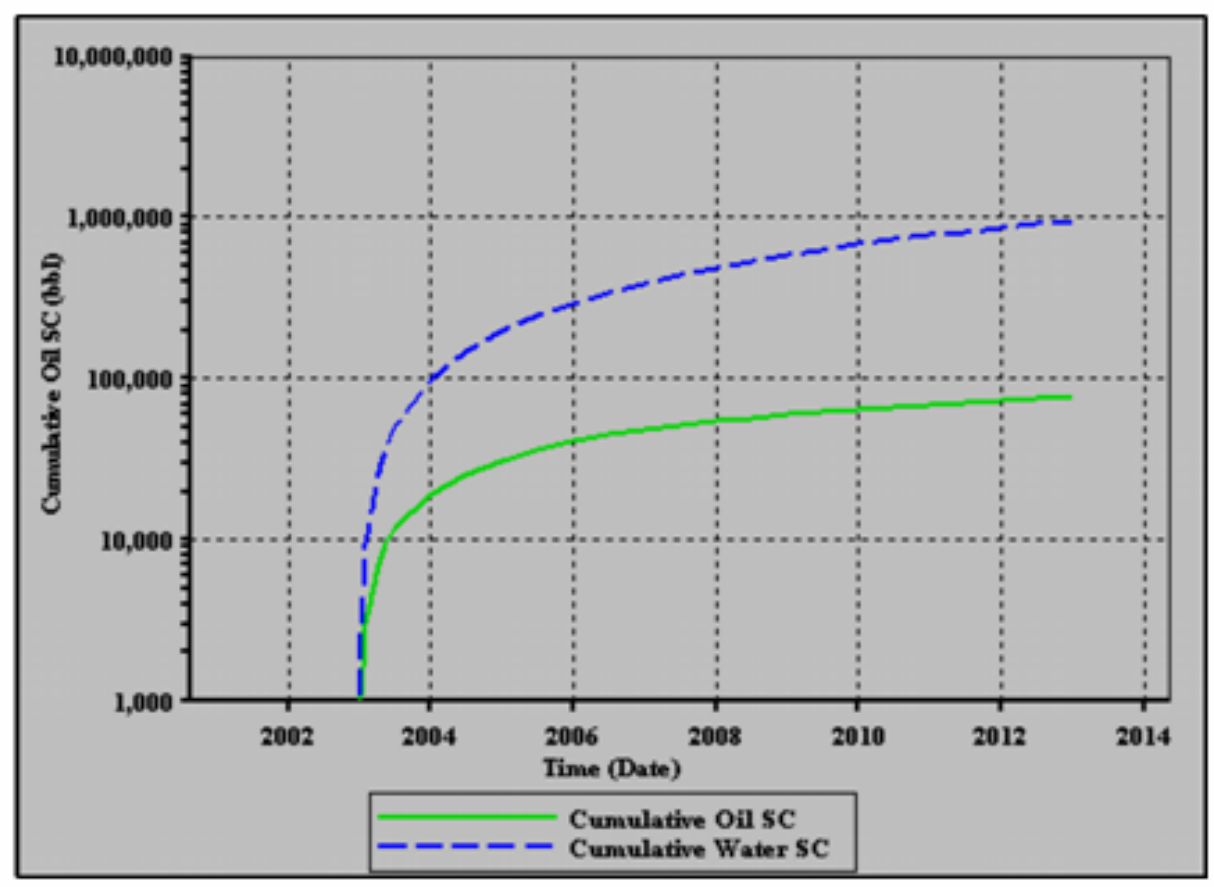

Figure 7.3.36: Simulator calculated production potential of targeted horizontal infill, HWell, in Judica Field. 


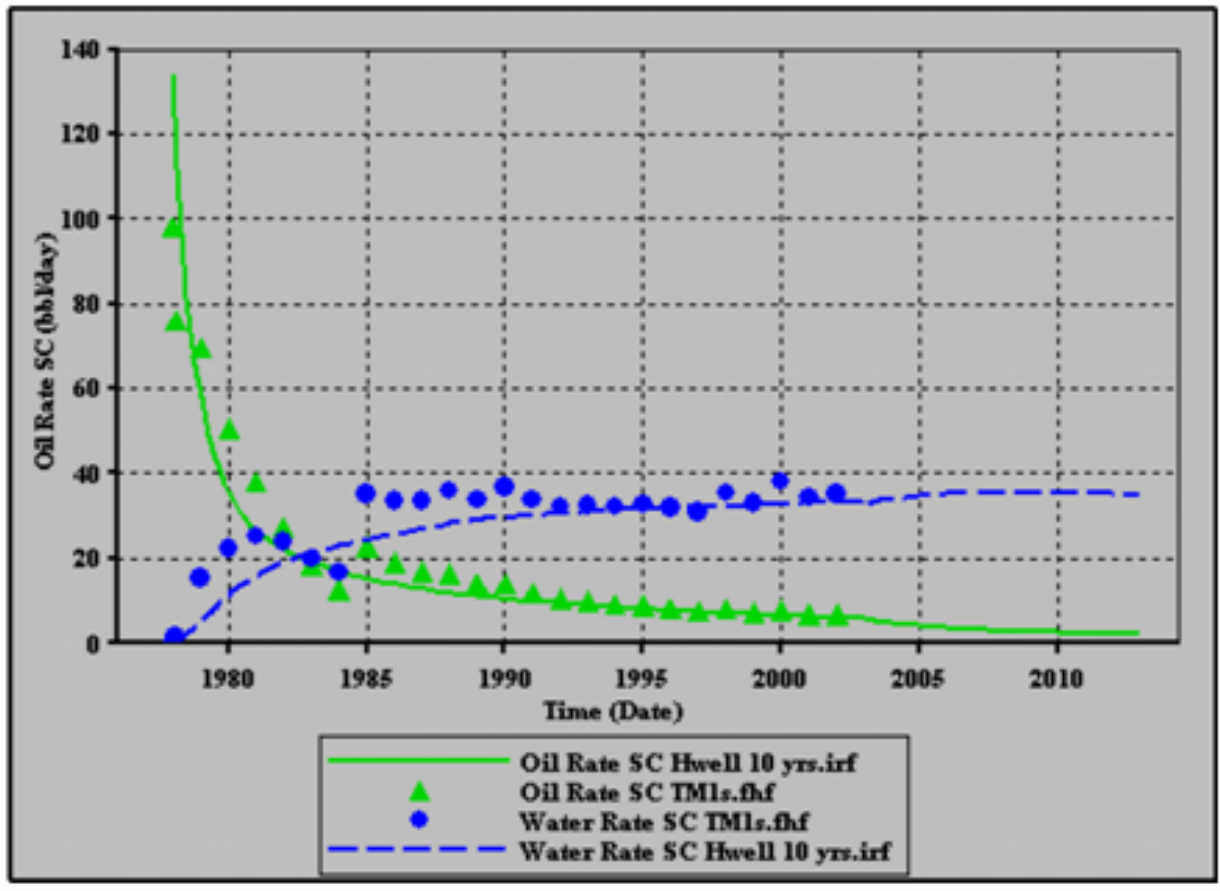

Figure 7.3.37: Interference effects resulting in production loss at Thornburg M1 (Slawson) due to drainage from horizontal infill Hwell in Judica Field. 


\section{MULL 1}

Jan 1, 2003 - remaining reserves (口il-fţ in Layer 5 (L5)
Jan 1, 2013 - L5 remzining reserves (ail-ft) after drilling an irfill harixantal well - MLLLI Lacatinr: (15,30), (14,31), (13,32), (12,33), $(11,34)$, $(10,35)$, and $(9,36)$

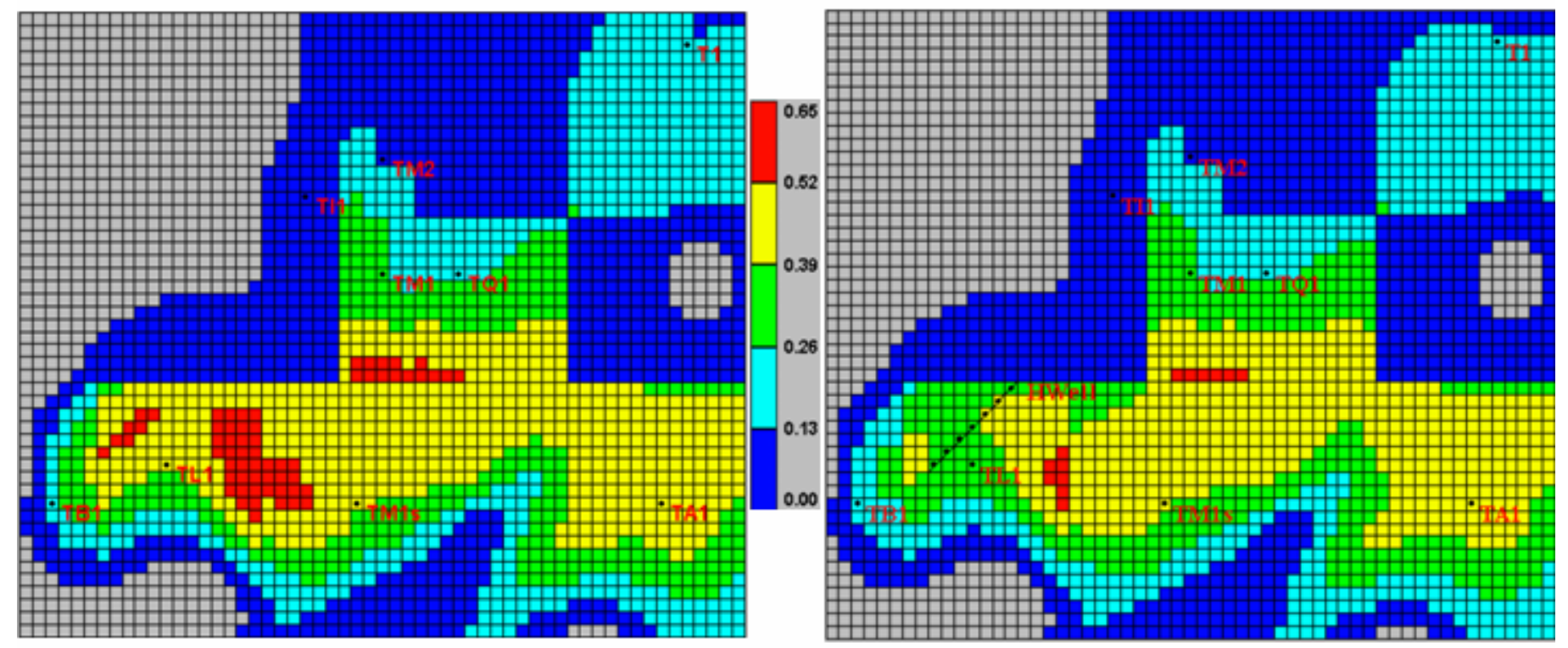

Well lergth $=109 \mathrm{ft}$

glkirl $=1.5$

Well diameter $=$ G"

Ëattum hule presaure = 200 pai $\left(\mathrm{P}_{\text {wf }}\right)$

Campleted an Jan 1, 2003

Figure 7.3.38: Drainage (oil-feet) over 10 years by a targeted horizontal infill well, MULL 1, in Judica Field. Oil-feet calculated as the product of porosity, oil saturation, and pay thickness. 
Baged an TQ1 NGb.dat

Well rame: Hwell, Lacatian: $(15,30),(14,31)$,

$(13,32),(12,33),(11,34),(10,35)$, and $(9,36)$

MULL 1

Length: 770 ,

Well completed on Jan 1, 2003

Estimated Production from Infill

\begin{tabular}{|c|c|c|}
\hline Year & Cum Oil & Cum Wtr \\
\hline & MO & MW \\
\hline 2004 & 12.5 & 99.2 \\
\hline 2006 & 26.7 & 288.4 \\
\hline 2008 & 36.8 & 473.5 \\
\hline 2010 & 44.8 & 654.2 \\
\hline 2012 & 51.2 & 829.6 \\
\hline 2013 & 53.9 & 915.5 \\
\hline
\end{tabular}

Estimated Production Loss at neighboring well

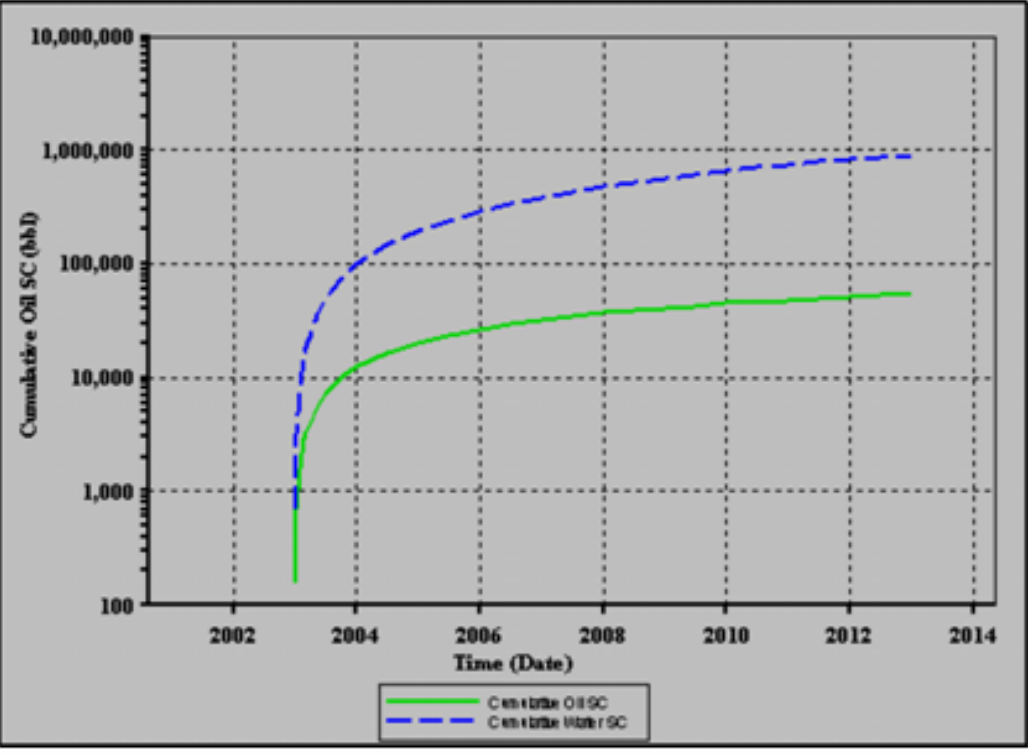

\begin{tabular}{|r|r|r|r|}
\hline & With Infill & No Infill & Prod loss at TM1s \\
\hline Year & TM1s Cum Oil, MaO & TM1s Cum Oil, MO & due to infill, MO \\
\hline \hline 2003 & 141.2 & 141.1 & \\
\hline 2004 & 143.2 & 143.3 & 0.1 \\
\hline 2005 & 145.1 & 145.3 & 0.2 \\
\hline 2010 & 152.8 & 154.6 & 1.8 \\
\hline 2013 & 156.6 & 159.6 & 3 \\
\hline
\end{tabular}

Figure 7.3.39: Simulator-calculated production potential of targeted horizontal infill, MULL 1, in Judica Field along with estimated production loss at Thornburg M1 (Slawson). 


\section{MULL 2}

Jan 1, 2003 - remaining reserves (ail-fț in Layer 5 (L5)
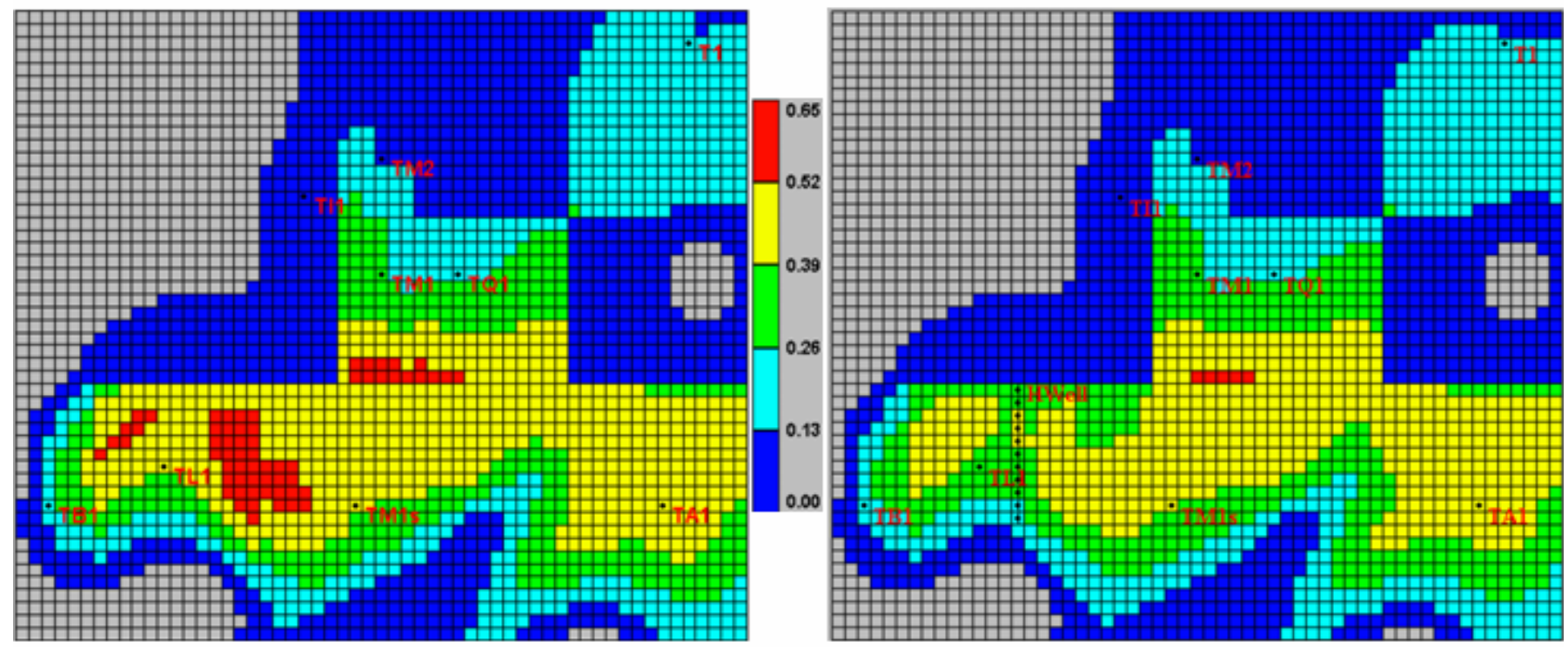

well length $=1210 \mathrm{ft}$

skin $=1.5$

well diameter = G"

Ëattum hale pressure = 200 psi $\left(\mathrm{P}_{\mathrm{wf}}\right)$

Campleted an Jar 1, 2003

Figure 7.3.40: Drainage (expressed as oil-feet) over 10 years by a targeted horizontal infill well, MULL 2, in Judica Field. Oil-feet calculated as the product of porosity, oil saturation, and pay thickness. 
Based on TQ1 N6b.dat

Well name: MULL 2, Location: $(15,30)$ to $(15,40)$

MULL 2

Length: 1210'

Well completed on Jan 1, 2003

Estimated Production from Infil

\begin{tabular}{|c|c|c|}
\hline Year & Cum Oil & Cum Wtr \\
\hline \hline 2004 & MO & MW \\
\hline 2006 & 32.4 & 103.6 \\
\hline 2008 & 44.8 & 303 \\
\hline 2010 & 54.1 & 498.5 \\
\hline 2012 & 61.5 & 889.6 \\
\hline 2013 & 64.6 & 966.3 \\
\hline
\end{tabular}

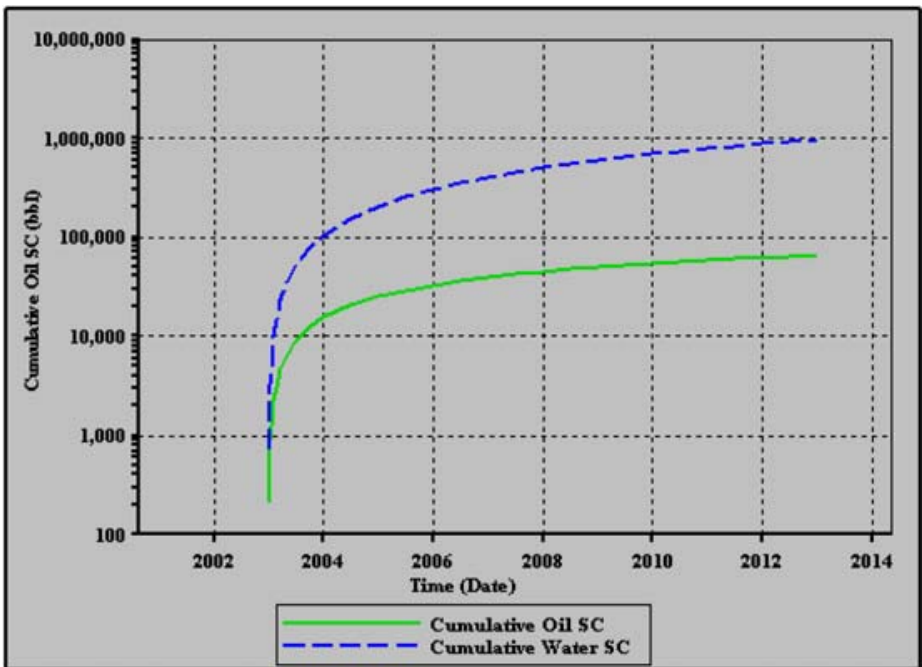

Estimated Production Loss at neighboring well

\begin{tabular}{|r|r|r|r|}
\hline & With Infill & \multicolumn{1}{l|}{ No Infill } & Prod loss at TM1s \\
\hline Year & TM1s Cum Oil, MO & TM1s Cum Oil, MO & due to infill, MO \\
\hline \hline 2003 & 141.1 & 141.1 & \\
\hline 2004 & 143.1 & 143.3 & 0.2 \\
\hline 2005 & 144.8 & 145.3 & 0.5 \\
\hline 2010 & 151.6 & 154.6 & 3 \\
\hline 2013 & 154.7 & 159.6 & 4.9 \\
\hline
\end{tabular}

Figure 7.3.41: Simulator-calculated production potential of targeted horizontal infill, MULL 2, in Judica Field along with estimated production loss at Thornburg M1 (Slawson). 


\section{MULL 3}

Jan 1, 2003 - remaining reserves (ail-ft' in Layer 5 (L5)
Jan 1, 2013 - L5 remaining reserves (quil-ft) after drilling an irfill harizantal well - MLLL3 Lacatinr: (10,32) t口 (26,32)

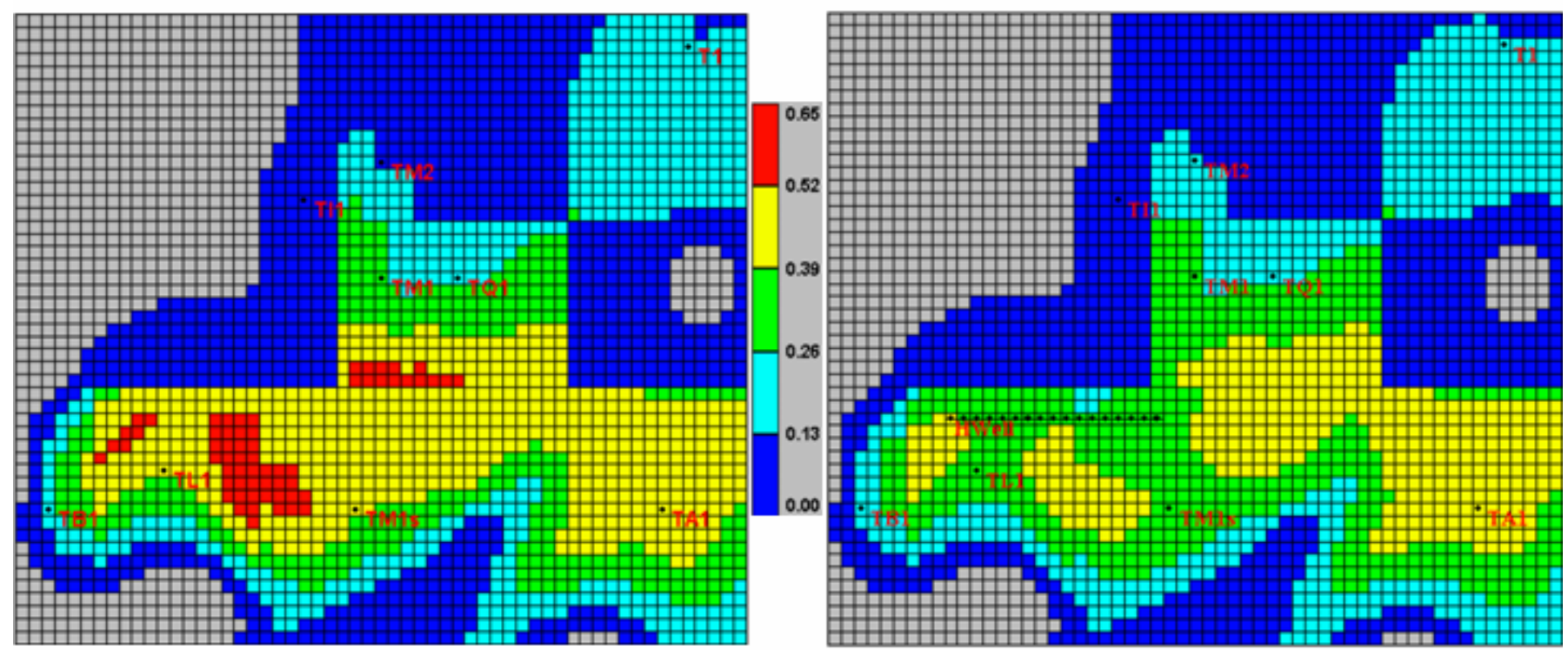

Well length $=1870 \mathrm{ft}$

skin $=1.5$

well dianeter $=$ G"

Battum hale pregaure $=200$ psi $\left(\mathrm{P}_{\mathrm{uf}}\right)$

Campleted arl Jarn 1, 2 au3

Figure 7.3.42: Drainage (expressed as oil-feet) over 10 years by a targeted horizontal infill well, MULL 3, in Judica Field. Oil-feet calculated as the product of porosity, oil saturation, and pay thickness. 
Based on TQ1 N6b.dat

Well name: MULL 3, Location: $(10,32)$ to $(26,32)$

MULL 3

Length: 1870'

Well completed on Jan 1, 2003

Estimated Production from Infill

\begin{tabular}{|c|c|c|}
\hline Year & Cum Oil & Cum Wtr \\
\hline \hline 2004 & Mo & MW \\
\hline 2006 & 70 & 149.3 \\
\hline 2008 & 99.1 & 460.8 \\
\hline 2010 & 115.5 & 775.2 \\
\hline 2012 & 127.6 & 1084.1 \\
\hline 2013 & 132.8 & 153.1 \\
\hline
\end{tabular}

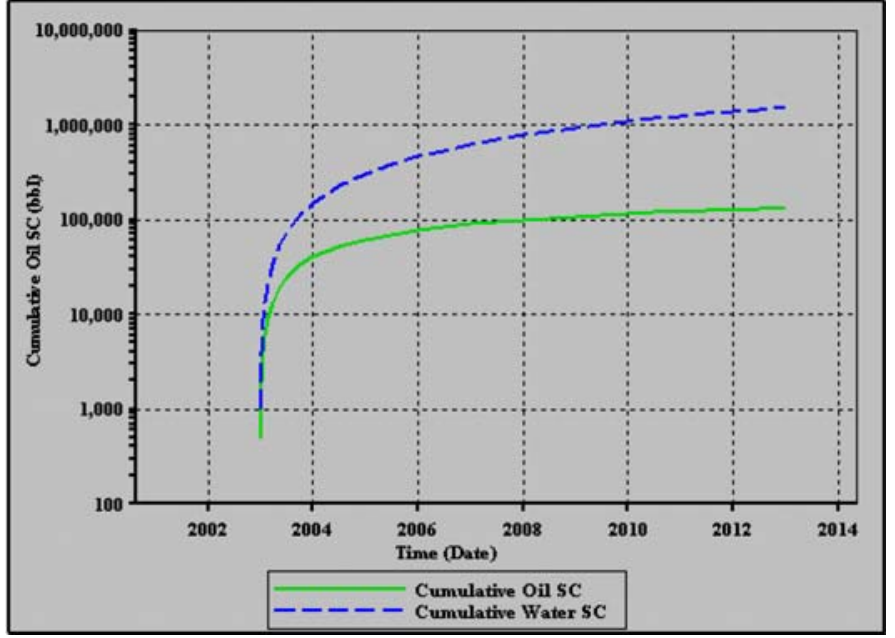

Estimated Production Loss at neighboring well

\begin{tabular}{|c|c|c|c|}
\hline & With Infill & No Infill & Prod loss at TM1s \\
\hline Year & TM1s Cum Oil, MO & TM1s Cum Oil, MO & due to infill, M0 \\
\hline 2003 & 141.2 & 141.1 & \\
\hline 2004 & 142.6 & 143.3 & 0.7 \\
\hline 2005 & 143.6 & 145.3 & 1.7 \\
\hline 2010 & 146.7 & 154.6 & 7.9 \\
\hline 2013 & 147.9 & 159.6 & 11.7 \\
\hline
\end{tabular}

Figure 7.3.43: Simulator calculated production potential of targeted horizontal infill, MULL 3, in Judica Field along with estimated production loss at Thornburg M1 (Slawson). 


\section{MULL 4}

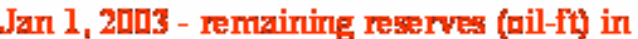
Layer 5 (L5)
Jan 1, 2 al3 - L5 remzining reserves (ail-ft) after drilling an irfill harimantal well - MLLL4

Lacatinr: (14,30), $(15,31),(16,32),(17,33),(18,34)$, $(19,35),(20,36),(21,37),(22,35),(23,39), 6$

$$
\text { (24,40) }
$$

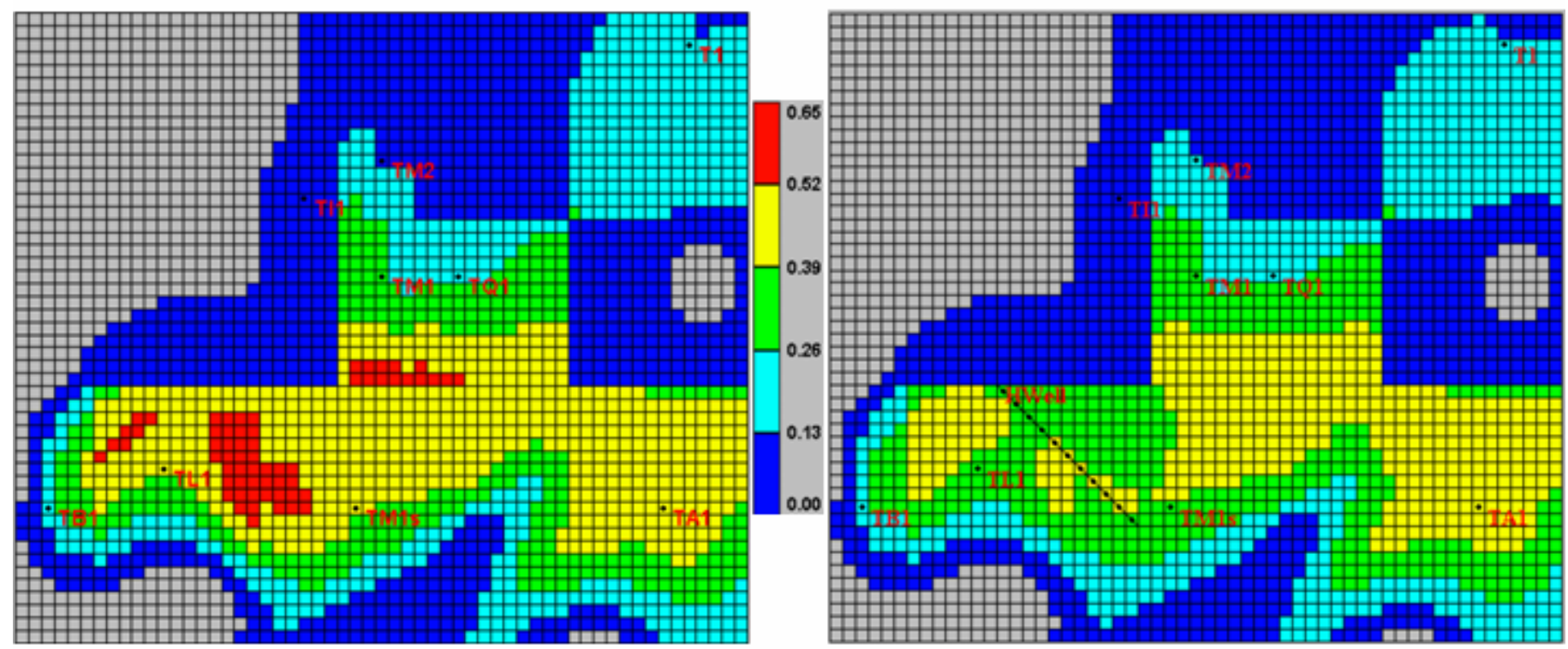

well length $=1711 \mathrm{ft}$

skin $=1.5$

well diameter $=$ G"

Fattum hale presiare = 200 psi $\left(\mathrm{P}_{\mathrm{w} f}\right)$

Campleted an Jan 1, 2003

Figure 7.3.44: Drainage (oil-feet) over 10 years by a targeted horizontal infill well, MULL 4, in Judica Field. Oil-feet calculated as the product of porosity, oil saturation, and pay thickness. 
Based on TQ1 N6b.dat

$$
\text { (14,30), (15,31), (16,32), }
$$

$(17,33),(18,34),(19,35),(20,36),(21,37)$,

$(22,38),(23,39), \&(24,40)$

Length: 1210'

Well completed on Jan 1, 2003

Estimated Production from Infill

\begin{tabular}{|c|c|c|}
\hline Year & Cum Oil & Cum Wtr \\
\hline \hline 2004 & MO & MW \\
\hline 2006 & 29.3 & 138.9 \\
\hline 2008 & 60.3 & 422.8 \\
\hline 2010 & 92.3 & 710.4 \\
\hline 2012 & 102.5 & 994.2 \\
\hline 2013 & 106.8 & 1269.9 \\
\hline
\end{tabular}

Well name: MULL 4, Location:

\section{MULL 4}

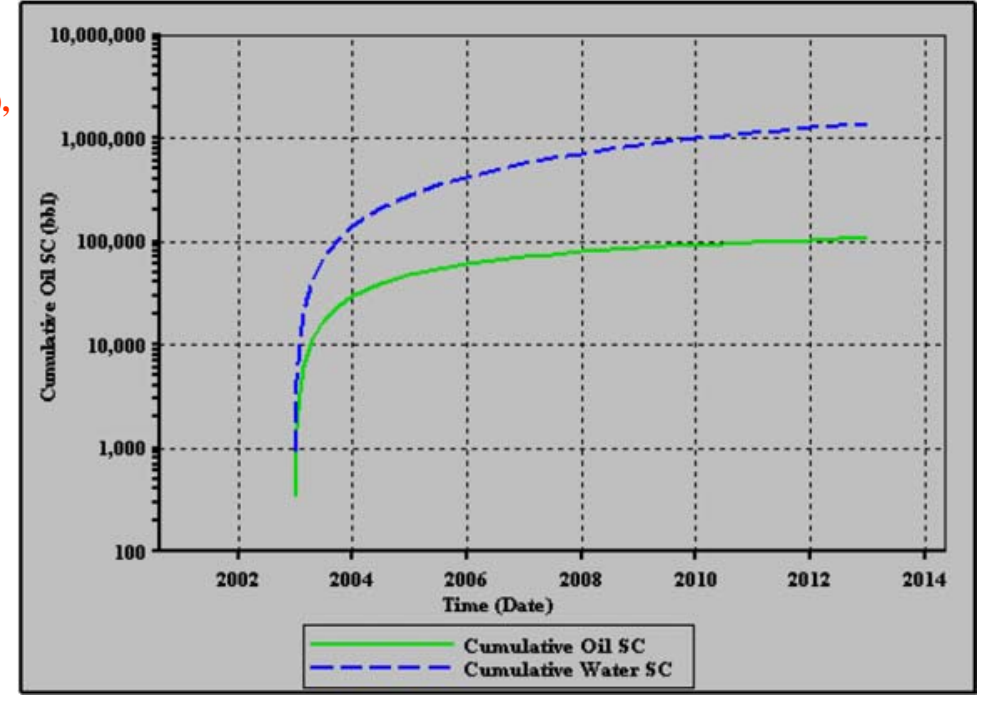

Estimated Production Loss at neighboring well

\begin{tabular}{|c|c|c|c|}
\hline & With Infill & No Infill & Prod loss at TM1s \\
\hline Year & TM1s Cum Oil, MO & TM1s Cum Oil, MO & due to infill, MO \\
\hline 2003 & 141.1 & 141.1 & \\
\hline 2004 & 142.4 & 143.3 & 0.9 \\
\hline 2005 & 143.3 & 145.3 & 2 \\
\hline 2010 & 146.1 & 154.6 & 8.5 \\
\hline 2013 & 147.2 & 159.6 & 12.4 \\
\hline
\end{tabular}

Figure 7.3.45: Simulator-calculated production potential of targeted horizontal infill, MULL 4, in Judica Field along with estimated production loss at Thornburg M1 (Slawson). 


\section{MULL 5 in L5}

Jan 1, 2003 - remaining reserves (ail-ftì in Layer 5 (L5)

Jan 1, 2 113 - L5 remaining reserves (quil-ft) after drilling an irfill harixartal well - MLLLS Lacatinr: $(33,32)$ t口 $(51,32)$

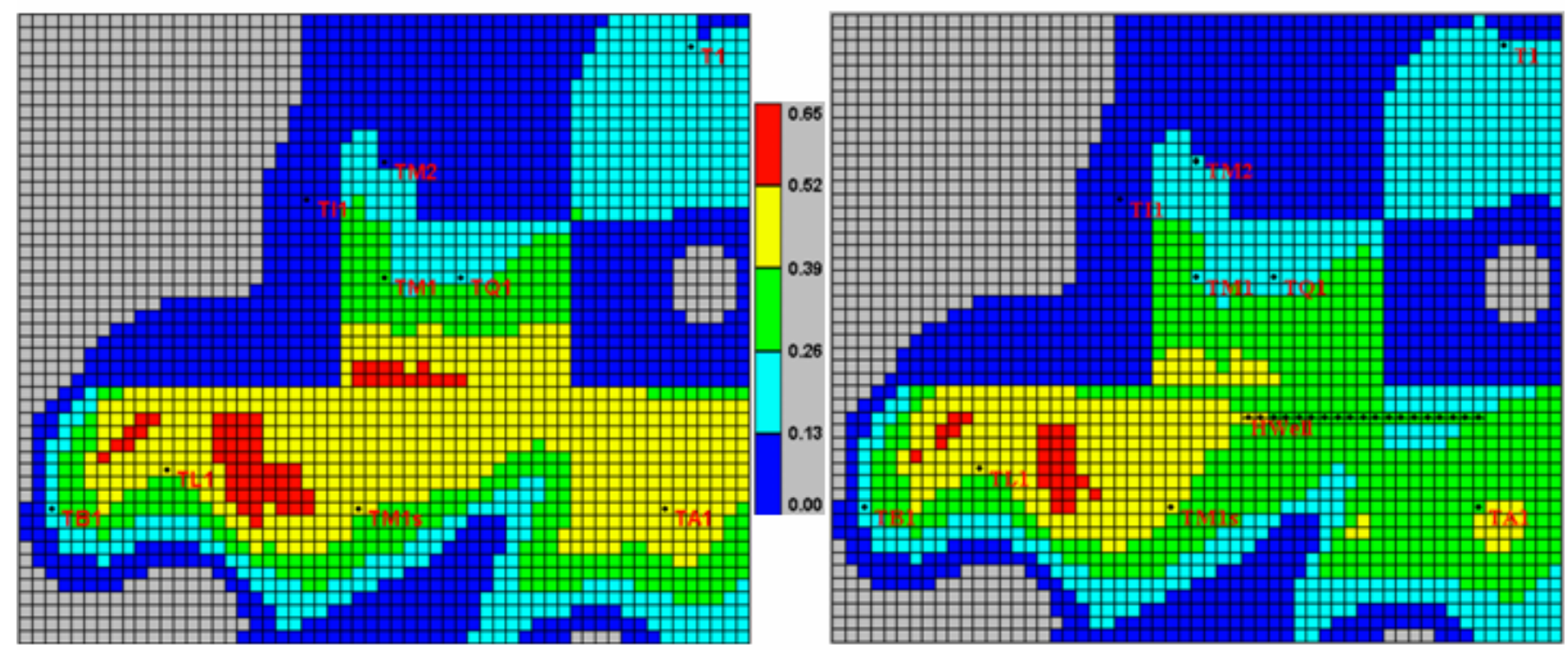

well lergth $=2$ 口g口 $\mathrm{ft}$

skin $=1.5$

well diameter $=$ G"

Eattum hale pregsure = 200 psi $\left(\mathrm{P}_{\mathrm{wf}}\right)$

Campleted an Jan 1, 2003

Figure 7.3.46: Drainage (oil-feet) over 10 years by a targeted horizontal infill well, MULL 5, in Judica Field. Oil-feet calculated as the product of porosity, oil saturation, and pay thickness. 
Based on TQ1 N6b.dat

Well Location: $(33,32)$ to $(51,32)$

Length: 2090'

Well completed on Jan 1, 2003

Estimated Production from Infill

\begin{tabular}{|c|c|c|}
\hline Year & Cum Oil & Cum Wtr \\
\hline & MO & MW \\
\hline \hline 2004 & 46 & 155 \\
\hline 2006 & 96.8 & 488.8 \\
\hline 2008 & 128.2 & 831.3 \\
\hline 2010 & 150.9 & 1169.4 \\
\hline 2012 & 168.4 & 1497.1 \\
\hline 2013 & 175.9 & 1656.7 \\
\hline
\end{tabular}

Estimated Production Loss at neighboring wells
MULL 5 in L5

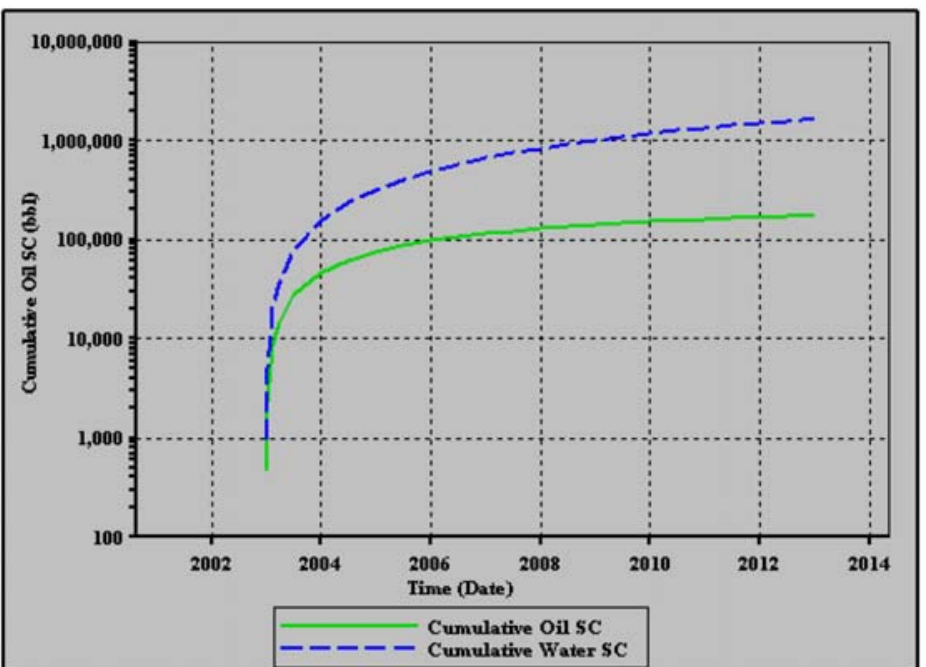

\begin{tabular}{|r|r|r|r|}
\hline & With Infill & No Infill & Prod loss at TM1s \\
\hline Year & TM1s Cum Oil, MO & TM1s Cum Oil, MO & due to infill, MO \\
\hline \hline 2003 & 141.1 & 141.1 & \\
\hline 2004 & 143.1 & 143.3 & 0.2 \\
\hline 2005 & 144.8 & 145.3 & 0.5 \\
\hline 2010 & 151.6 & 154.6 & 3 \\
\hline 2013 & 154.6 & 159.6 & 5 \\
\hline
\end{tabular}

\begin{tabular}{|r|r|r|r|}
\hline \multicolumn{1}{|l|}{ With Infill } & \multicolumn{1}{l|}{ No Infill } & \multicolumn{2}{l|}{ Prod loss at TA1 } \\
\hline Year & TA1 Cum Oil, MO & \multicolumn{1}{|l|}{ TA1 Cum Oil, MO } & due to infill, MO \\
\hline \hline 2003 & 158.3 & 158.3 & \\
\hline 2004 & 160.9 & 161.1 & 0.2 \\
\hline 2005 & 163.3 & 163.9 & 0.6 \\
\hline 2010 & 172.8 & 176.6 & 3.8 \\
\hline 2013 & 177.2 & 183.4 & 6.2 \\
\hline
\end{tabular}

Figure 7.3.47: Simulator-calculated production potential of targeted horizontal infill, MULL 5, completed in Layer 5 in Judica Field along with estimated production loss at Thornburg M1 (Slawson) and Thornburg A1 wells. 
Horizontal well productivity estimate - Based on TQ1 N6b.dat

Well Location: $(33,32)$ to $(51,32)$

Length: 2090'

\section{MULL 5 in L3}

Well completed on Jan 1, 2003

Estimated Production from Infill

\begin{tabular}{|c|c|c|}
\hline Year & $\begin{array}{c}\text { Cum Oil } \\
\text { MO }\end{array}$ & $\begin{array}{c}\text { Cum Wtr } \\
\text { MW }\end{array}$ \\
\hline \hline 2004 & 48.3 & 132.3 \\
\hline 2006 & 97.6 & 429.3 \\
\hline 2008 & 127.9 & 738.1 \\
\hline 2010 & 149.8 & 1045.6 \\
\hline 2012 & 166.7 & 1345.1 \\
\hline 2013 & 173.9 & 1491.7 \\
\hline
\end{tabular}

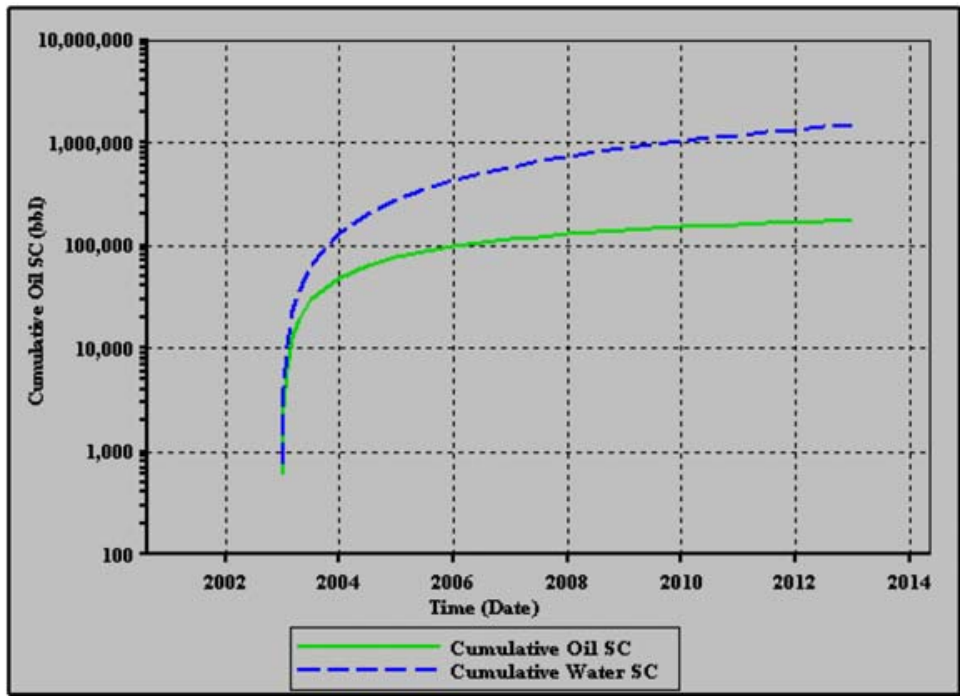

Figure 7.3.48: Simulator-calculated production potential of targeted horizontal infill, MULL 5, when completed in Layer 3 in Judica Field. 
Horizontal well productivity estimate - Based on TQ1 N6b.dat

Well Location: $(33,32)$ to $(51,32)$

Length: 2090'

MULL 5 in L1

Well completed on Jan 1, 2003

Estimated Production from Infill

\begin{tabular}{|c|c|c|}
\hline Year & $\begin{array}{c}\text { Cum Oil } \\
\text { MO }\end{array}$ & $\begin{array}{c}\text { Cum Wtr } \\
\text { MW }\end{array}$ \\
\hline \hline 2004 & 45.1 & 103.3 \\
\hline 2006 & 90.6 & 346.3 \\
\hline 2008 & 118.9 & 602.9 \\
\hline 2010 & 139.4 & 861.6 \\
\hline 2012 & 155.4 & 1116.1 \\
\hline 2013 & 162.2 & 1241.3 \\
\hline
\end{tabular}

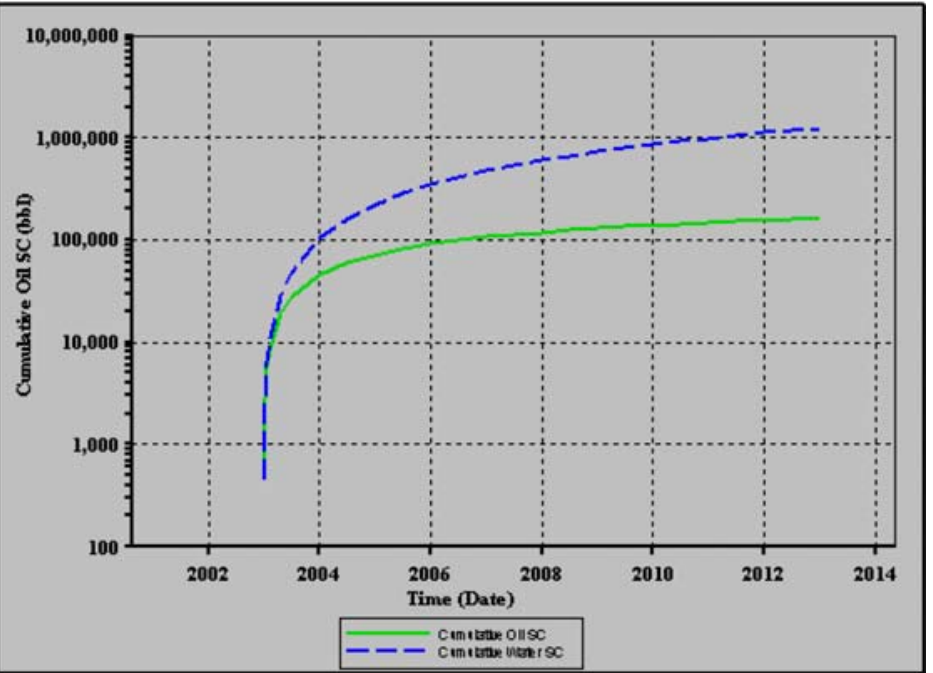

Figure 7.3.49: Simulator-calculated production potential of targeted horizontal infill, MULL 5, when completed in Layer 1 in Judica Field. 


\section{MULL Vertical (East) in L5}

Jan 1, 2043 - remainüg regerveg (nil-fţ) in Layer 5 (L.5)
Jan 1, 2013 - L5 remaining reserves (ail-ft) after drilling an irfill vertical well - Well Lacatian: $(33,32)$

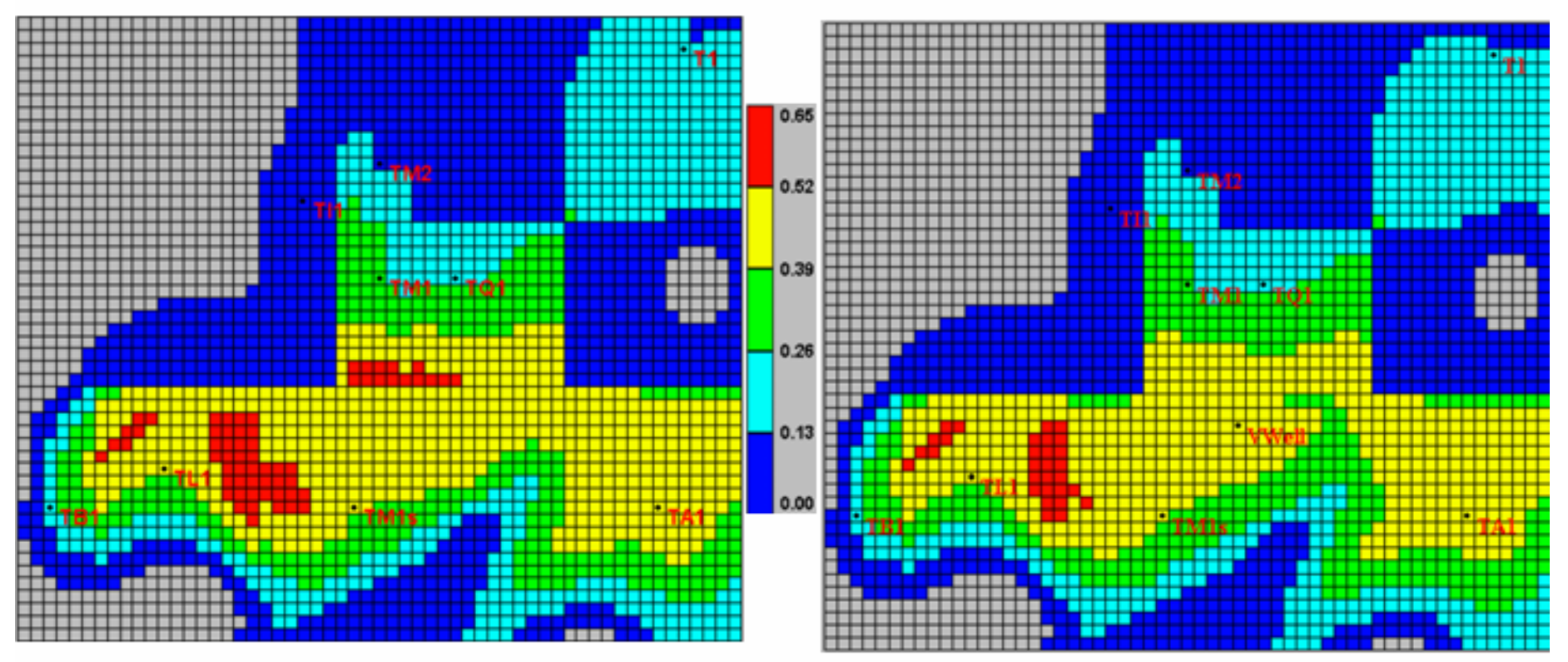

gkin $=1.5$

Well dianeter $=6 "$

Enttam hale pregaure $=200$ psi $\left(\mathrm{P}_{\mathrm{w}}\right)$

Cantpleted ar Jar 1, 2003

Figure 7.3.50: Drainage (oil-feet) over 10 years by a hypothetical vertical infill well, VWell L5 E, completed in Layer 5 in Judica Field. Oil-feet calculated as the product of porosity, oil saturation, and pay thickness. 
Vertical well productivity estimate - Based on TQ1 N6b.dat

Well name: Vwell L5 E, Location: $(33,32)$

Perforated in L5

\section{Vertical well in L5 - East location}

Well completed on Jan 1, 2003
Estimated Production from Infill
\begin{tabular}{|c|c|c|}
\hline Year & Cum Oil & Cum Wtr \\
\hline & Mo & MW \\
\hline \hline 2004 & 3.5 & 6.7 \\
\hline 2006 & 9.4 & 21.5 \\
\hline 2008 & 14.3 & 37.6 \\
\hline 2010 & 18.5 & 54.4 \\
\hline 2012 & 22.1 & 71.8 \\
\hline 2013 & 23.8 & 80.6 \\
\hline
\end{tabular}

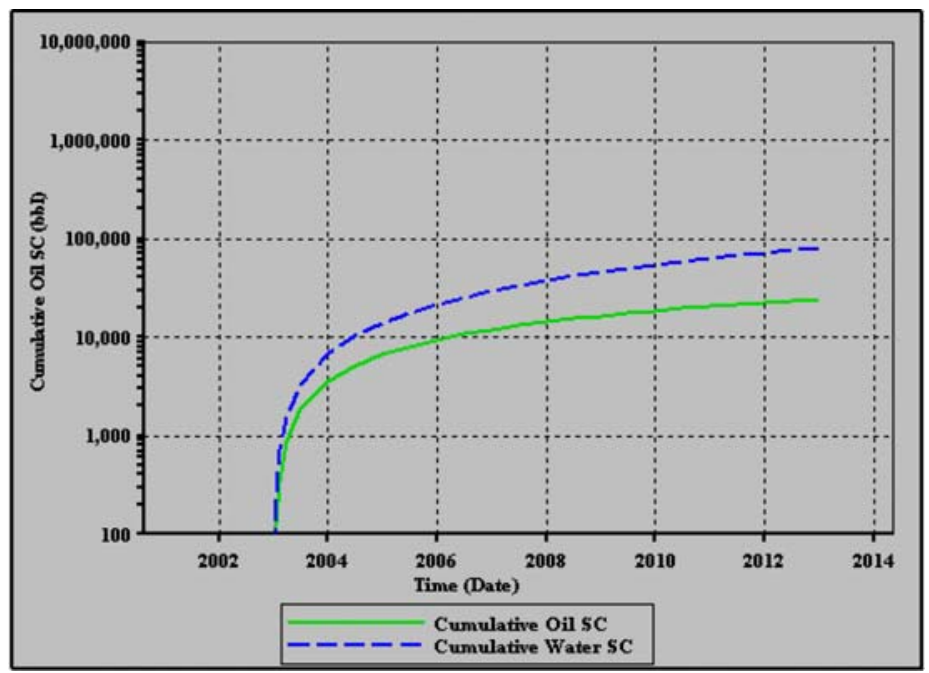

Figure 7.3.51: Simulator-calculated production potential of a hypothetical vertical infill, VWell L5 E, completed in Layer 5 in Judica Field. 


\section{MULL Vertical (East) in L1, L3, \& L5}

Jan 1, 2003 - remairing regerves (nil-fț in Layer 5 (L)
Jan 1, 2013 - L5 5 renaining reserves ('ᄆil-ft) after drilling an irfill vertical well - Well Lacatian: $(33,32)$
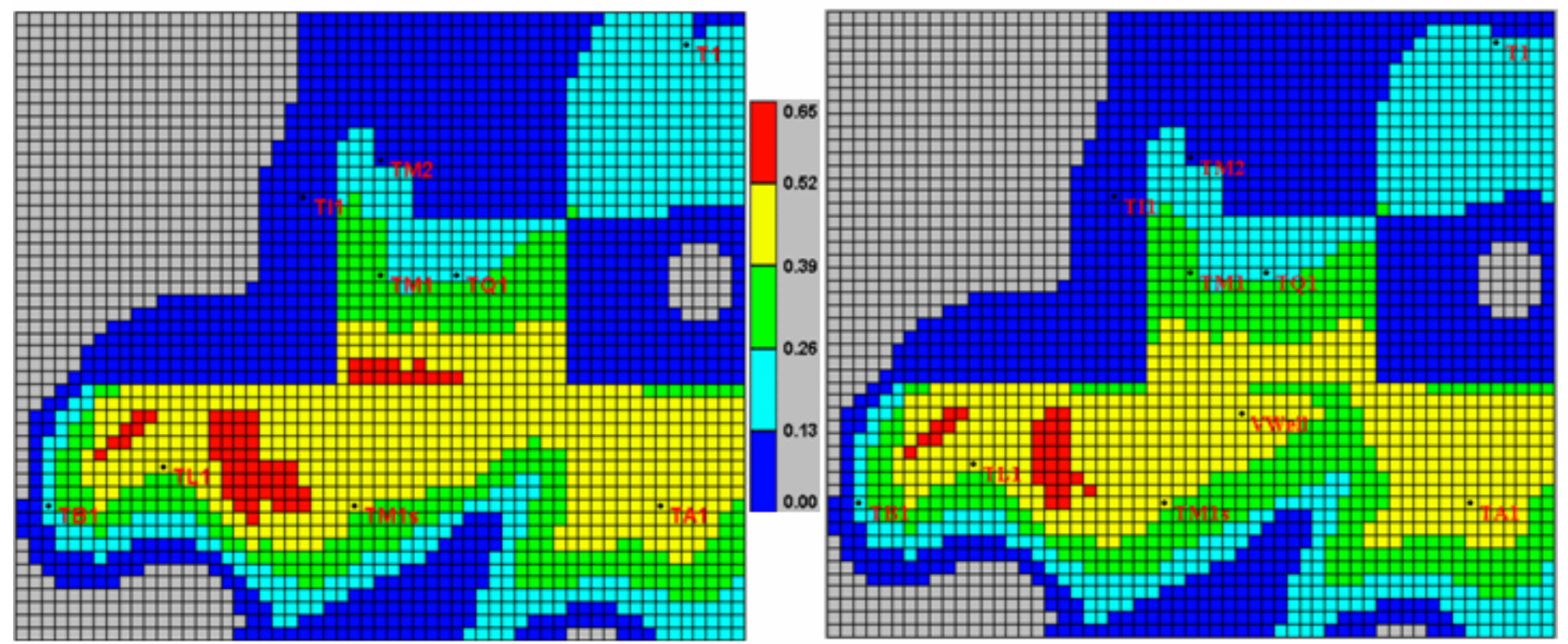

skin $=1.5$

Well dianeter $=$ G"

Battam hale presaure $=200$ psi $\left(\mathrm{P}_{\mathrm{w} f}\right)$

Canpleted an Jan 1, 2003

Figure 7.3.52: Drainage (oil-feet) over 10 years by a hypothetical vertical infill well, VWell E, completed in Layers 1 , 3 , and 5 in Judica Field. Oil-feet calculated as the product of porosity, oil saturation, and pay thickness. 
Vertical infill well productivity estimate - based on TQ1 N6b.dat

Well name: Vwell E, Location: $(33,32)$

Perforated in L1, L2, and L5

\section{Vertical well in L1, L3, \& L5 - East location}

Well completed on Jan 1, 2003
Estimated Production from Infill
\begin{tabular}{|c|c|c|}
\hline Year & Cum Oil & Cum Wtr \\
\hline & MO & MW \\
\hline \hline 2004 & 5.2 & 8.9 \\
\hline 2006 & 13.3 & 29.2 \\
\hline 2008 & 19.6 & 51.6 \\
\hline 2010 & 24.8 & 75.3 \\
\hline 2012 & 29.3 & 99.9 \\
\hline 2013 & 31.4 & 112.5 \\
\hline
\end{tabular}

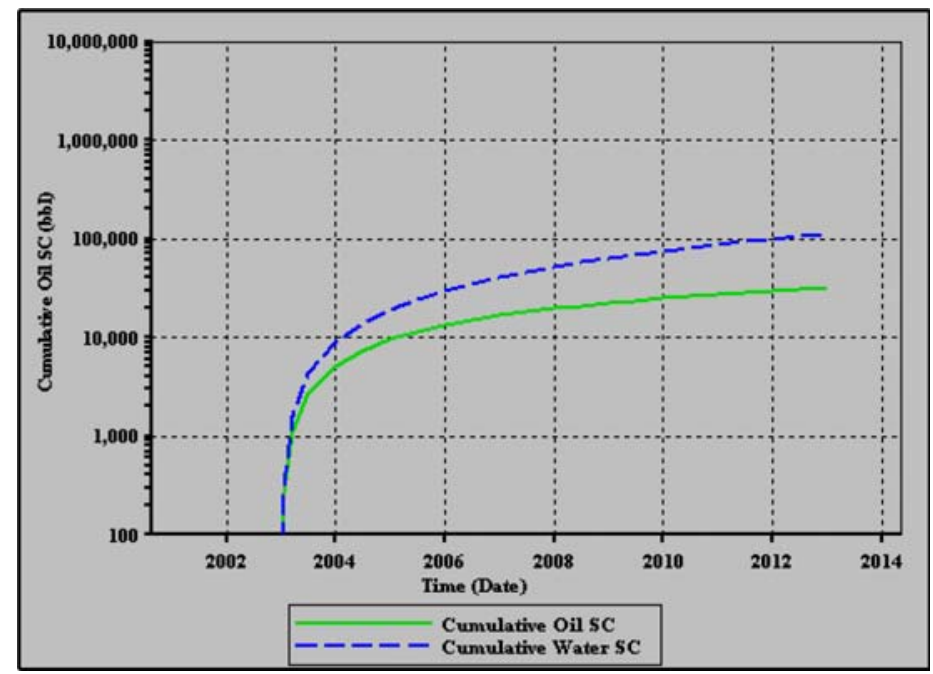

Figure 7.3.53: Simulator-calculated production potential of a hypothetical vertical infill, VWell E, completed in Layers 1, 3, and 5 in Judica Field. 


\section{MULL Vertical (West) in L1, L3, \& L5}

Jar 1,2003 - remairing regerveg (ail-fț in Layer 5 (L)
Jan 1, 2 a13 - L 5 renzining reserves (nil-ft) after drilling an irfill vertical well - Weell Lacatiarl: (18,35)

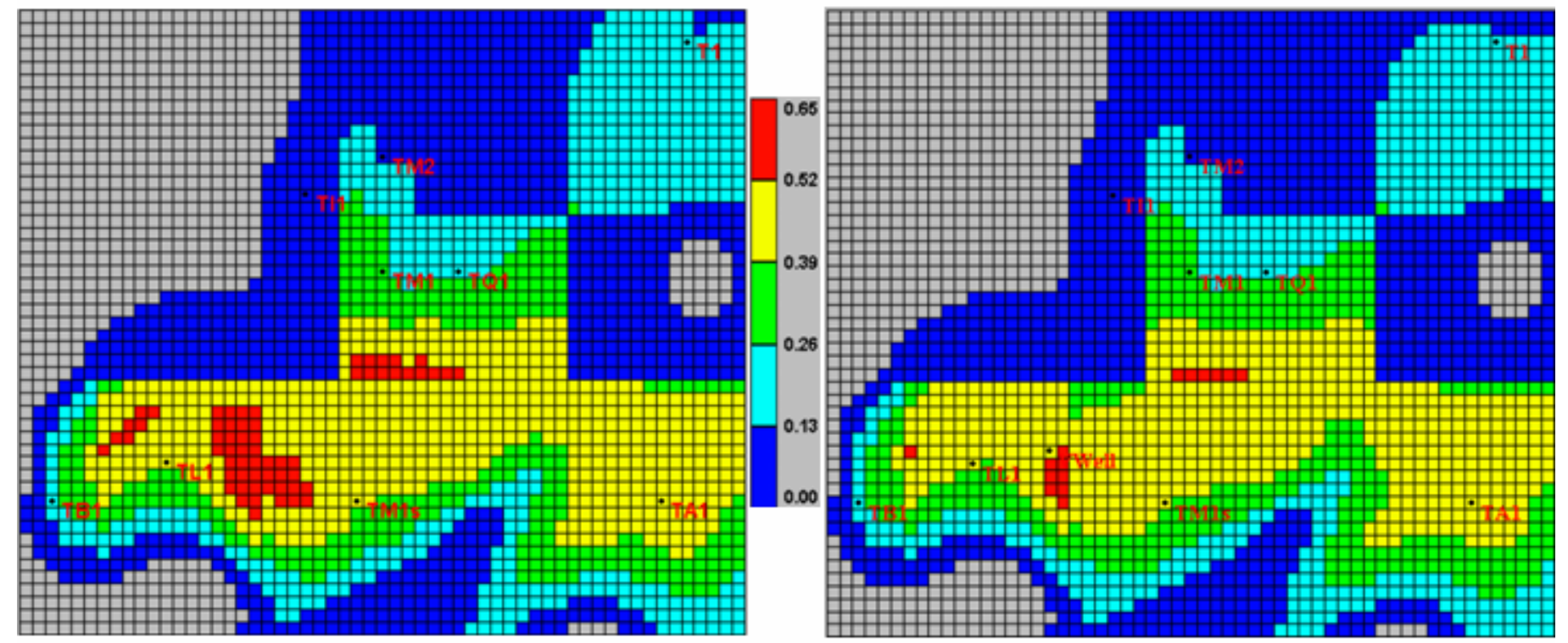

skkin $=1.5$

Well diameter $=$ G"

Enttom hale pregare $=200$ psi $\left(\mathrm{P}_{\mathrm{w} f}\right)$

Canpleted ar Jarn 1, 2003

Figure 7.3.54: Drainage (oil-feet) over 10 years by a hypothetical vertical infill well, VWell W, completed in Layers 1 , 3 , and 5 in Judica Field. Oil-feet calculated as the product of porosity, oil saturation, and pay thickness. 
Vertical well productivity estimate - Based on TQ1 N6b.dat

Well name: Vwell W, Location: $(18,35)$

Perforated in L1, L2, and L5

\section{Vertical well in L1, L3, \& L5 - West location}

Well completed on Jan 1, 2003

Estimated Production from Infill

\begin{tabular}{|c|c|c|}
\hline Year & $\begin{array}{c}\text { Cum Oil } \\
\text { MO }\end{array}$ & $\begin{array}{c}\text { Cum Wtr } \\
\text { MW }\end{array}$ \\
\hline \hline 2004 & 3.9 & 10.4 \\
\hline 2006 & 10.4 & 31.4 \\
\hline 2008 & 15.8 & 52.4 \\
\hline 2010 & 20.3 & 73.5 \\
\hline 2012 & 24.2 & 94.5 \\
\hline 2013 & 25.9 & 104.9 \\
\hline
\end{tabular}

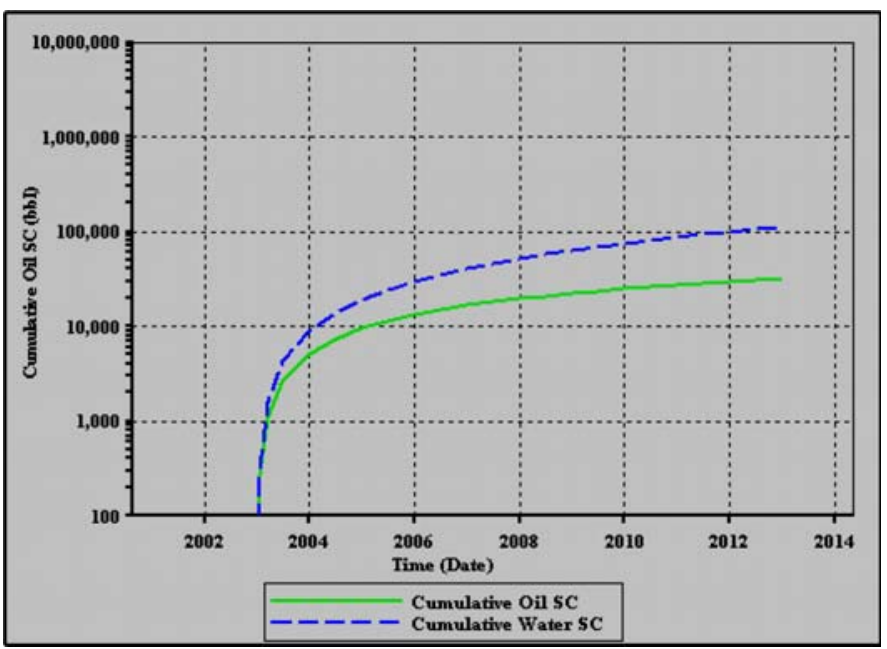

Figure 7.3.55: Simulator-calculated production potential of a hypothetical vertical infill, VWell W, completed in Layers 1, 3, and 5 in Judica Field. 


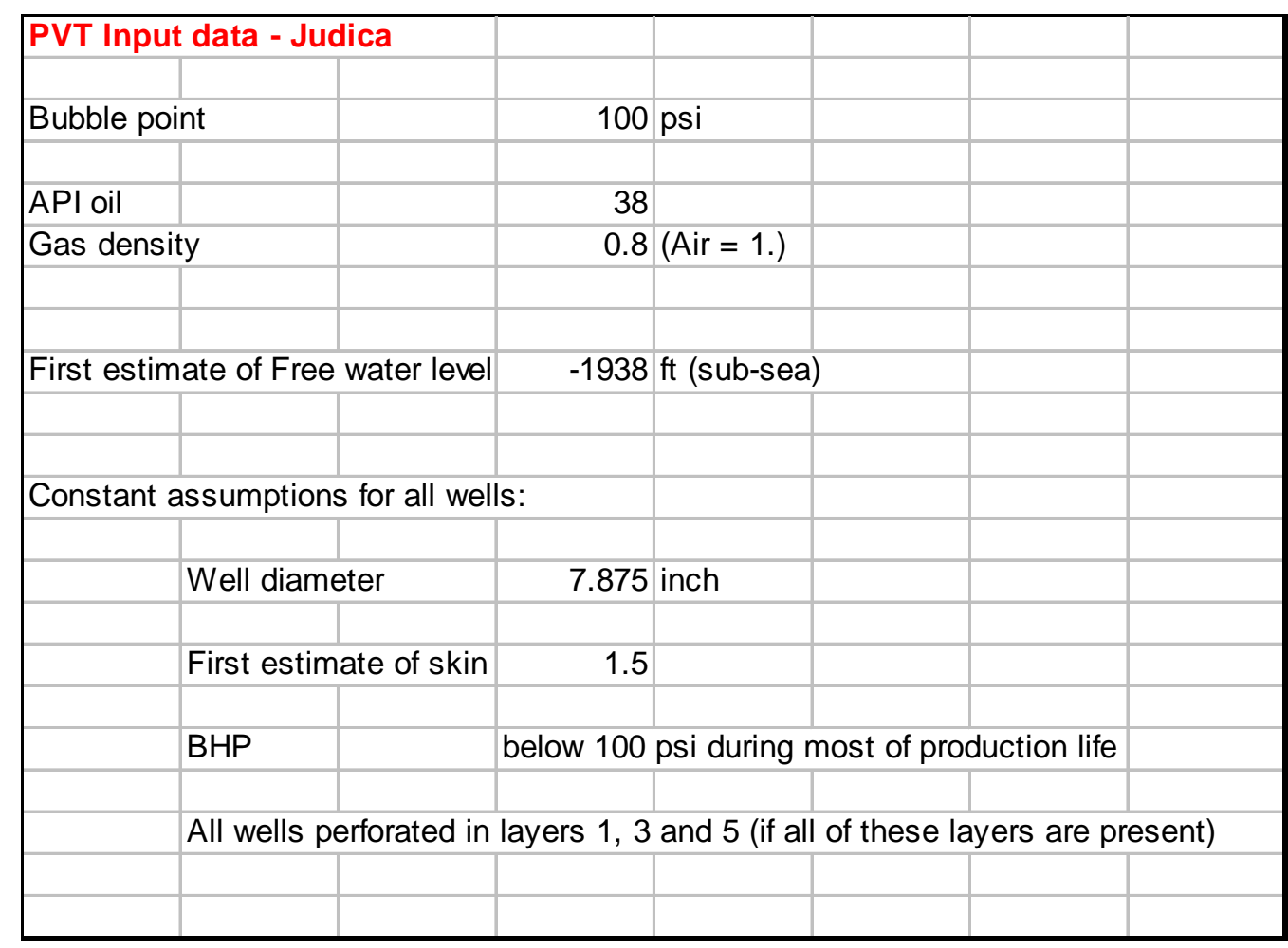

Table 7.3.1: PVT inputs to reservoir simulation study of Judica Field. 
Water PVT

(Refer: Properties of Petroleum Fluids by William D. MCCain, 2nd Edition, Pennwell Books)

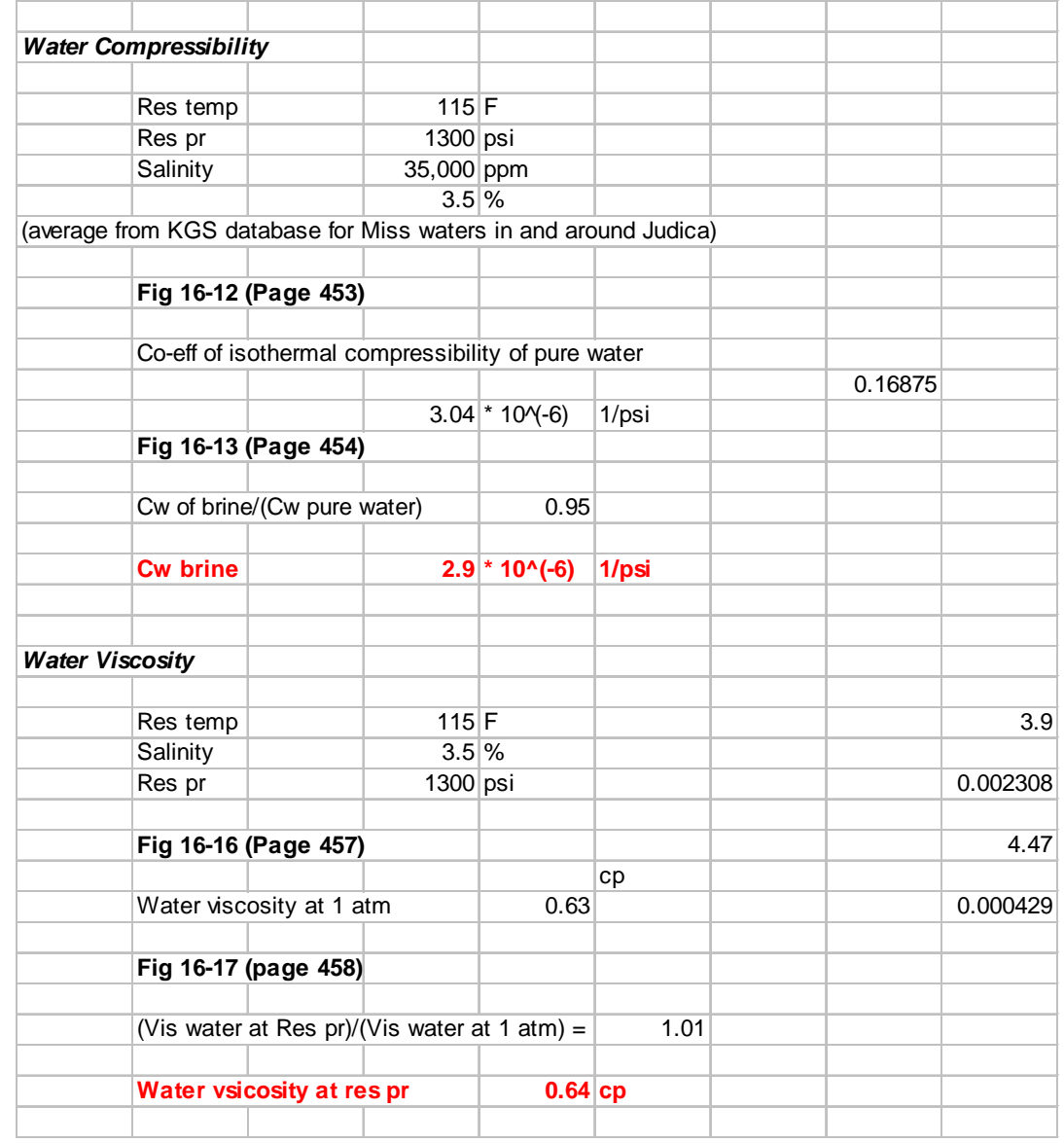

\begin{tabular}{|c|c|c|c|c|c|c|}
\hline \multicolumn{7}{|c|}{ Formation volume factor for water } \\
\hline & Res temp & & \multicolumn{2}{|c|}{$115 \mathrm{~F}$} & & \\
\hline & \multirow{2}{*}{\multicolumn{3}{|c|}{ Figure $16-6$ (page 447 ) }} & & & \\
\hline & & & & & & \\
\hline & & & & & & \\
\hline & Del Vwt & & 0.0123 & & & \\
\hline & & & & & & \\
\hline & \multicolumn{2}{|c|}{ Fig 16-7 (page 448) } & & & & \\
\hline & & & & & & \\
\hline & Res pr & 1300 & psi & & & \\
\hline & & & & & & \\
\hline & Del Vwp & & -0.0008 & & & \\
\hline & & & & & & \\
\hline & \multicolumn{4}{|c|}{ Formation volume factor of water $=$} & & \\
\hline & & & & & & \\
\hline & & & & 1.01 & 1 res bbl/sth & \\
\hline \multicolumn{7}{|c|}{ Water Density } \\
\hline & & & & & & \\
\hline & Salinity & & 3.59 & & & \\
\hline & & & & & & \\
\hline & \multicolumn{2}{|c|}{ Fig 16-8 (page 449) } & & & & \\
\hline & & & & & & \\
\hline & \multicolumn{4}{|c|}{ Brine density at $14.7 \mathrm{psi}$ and $60 \mathrm{oF}$} & 63.7 & $\mathrm{Ib} / \mathrm{cu} \mathrm{ft}$ \\
\hline & \multirow{2}{*}{\multicolumn{3}{|c|}{ Formation volume factor of water }} & & & \\
\hline & & & & \multicolumn{2}{|c|}{$1.01 \mathrm{res} \mathrm{bbl} / \mathrm{stb}$} & \\
\hline & & & & & & \\
\hline & \multicolumn{2}{|c|}{ Density of brine $=$} & & 62.9 & $9 \mathrm{lbs} / \mathrm{cu} \mathrm{ft}$ & \\
\hline
\end{tabular}

Table 7.3.2: Water PVT properties input for reservoir simulation of Judica Field. 
Note: this has a Krwmax equation for drainage

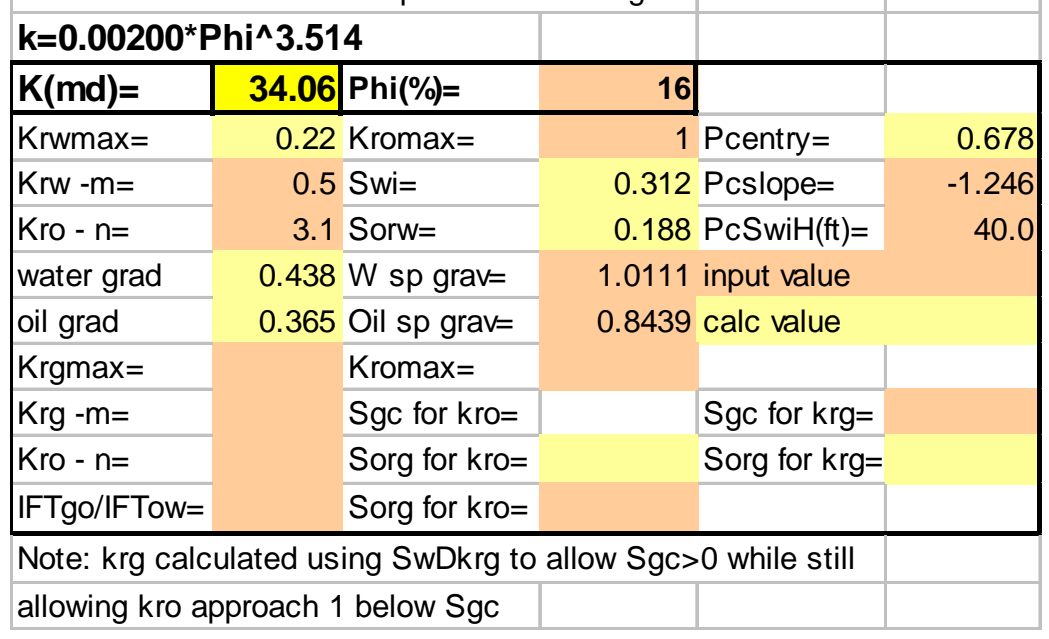

\begin{tabular}{|c|c|c|c|c|c|}
\hline Jalcı & lator fo & or Judic & za Field & & \\
\hline & & & & Heiaht ahove & \\
\hline SW & KRW & KROW & PCOW & free water (ft) & SwD \\
\hline 0.3118 & 0.000000 & 1.000000 & 2.896 & 40.00 & 0.00000 \\
\hline 0.3500 & 0.060830 & 0.781492 & 2.507 & 34.63 & 0.07645 \\
\hline 0.4000 & 0.092414 & 0.547818 & 2.123 & 29.32 & 0.17645 \\
\hline 0.4500 & 0.115673 & 0.366732 & 1.833 & 25.32 & 0.27645 \\
\hline 0.5000 & 0.134982 & 0.231258 & 1.608 & 22.21 & 0.37645 \\
\hline 0.5500 & 0.151856 & 0.134514 & 1.428 & 19.72 & 0.47645 \\
\hline 0.6000 & 0.167034 & 0.069727 & 1.281 & 17.69 & 0.57645 \\
\hline 0.6500 & 0.180943 & 0.030256 & 1.159 & 16.01 & 0.67645 \\
\hline 0.7000 & 0.193856 & 0.009617 & 1.057 & 14.60 & 0.77645 \\
\hline 0.7500 & 0.205962 & 0.001530 & 0.970 & 13.40 & 0.87645 \\
\hline 0.8000 & 0.217394 & 0.000009 & 0.895 & 12.36 & 0.97645 \\
\hline 0.8500 & 0.220000 & 0.000000 & 0.830 & 11.46 & 1.00000 \\
\hline 0.9000 & 0.220000 & 0.000000 & 0.773 & 10.68 & 1.00000 \\
\hline 0.9500 & 0.220000 & 0.000000 & 0.723 & 9.98 & 1.00000 \\
\hline 1.0000 & 0.220000 & 0.000000 & 0.678 & 9.36 & 1.00000 \\
\hline 1.0000 & 0.220000 & 0.000000 & 0.678 & 9.36 & 1.00000 \\
\hline 1.0000 & 0.220000 & 0.000000 & 0.678 & 9.36 & 1.00000 \\
\hline 1.0000 & 0.220000 & 0.000000 & 0.678 & 9.36 & 1.00000 \\
\hline 1.0000 & 0.220000 & 0.000000 & 0.678 & 9.36 & 1.00000 \\
\hline 1.0000 & 0.220000 & 0.000000 & 0.678 & 9.36 & 1.00000 \\
\hline 1.0000 & 0.220000 & 0.000000 & 0.678 & 9.36 & 1.00000 \\
\hline
\end{tabular}

Table 7.3.3: Relative permeability - capillary pressure table for reservoir rock (Layers 1, 3, and 5) in Judica Field. 
Note: this has a Krwmax equation for drainage

\begin{tabular}{|c|c|c|c|c|c|}
\hline \multicolumn{3}{|c|}{ k=0.000262*Phi^3.3702 } & \multirow[b]{2}{*}{17} & & \multirow[b]{3}{*}{1.951} \\
\hline $\mathrm{K}(\mathrm{md})=$ & 3.7 & Phi(\%)= & & & \\
\hline Krwmax= & 0.8121 & Kromax= & 1 & Pcentry= & \\
\hline $\mathrm{Krw}-\mathrm{m}=$ & 0.5 & Swi= & 0.880 & Pcslope= & -3.076 \\
\hline Kro $-\mathrm{n}=$ & 3.1 & Sorw= & 0.100 & $\mathrm{PcSwiH}(\mathrm{ft})=$ & 40.0 \\
\hline water grad & 0.438 & W sp grav= & 1.0111 & input value & $\tan$ \\
\hline oil grad & 0.365 & Oil sp grav= & 0.8439 & calc value & yellow \\
\hline Krgmax= & & Kromax= & & & \\
\hline $\mathrm{Krg}-\mathrm{m}=$ & & Sgc for kro= & & Sgc for krg= & \\
\hline Kro $-\mathrm{n}=$ & & Sorg for kro= & & Sorg for $\mathrm{krg}=$ & \\
\hline IFTgo/IFTow= & & Sorg for kro= & & & \\
\hline \multicolumn{5}{|c|}{ Note: $\mathrm{krg}$ calculated using SwDkrg to allow Sgc $>0$ while still } & \\
\hline allowing kro & & below Sgc & & & \\
\hline
\end{tabular}

\begin{tabular}{|c|c|c|c|c|c|}
\hline & & & & Height above & \\
\hline SW & KRW & KROW & PCOW & free water (ft) & SwD \\
\hline 0.8795 & 0.000000 & 1.000000 & 2.896 & 40.00 & 0.00000 \\
\hline 0.9000 & 0.812078 & 0.000000 & 2.698 & 37.27 & 1.00000 \\
\hline 0.9500 & 0.812078 & 0.000000 & 2.285 & 31.56 & 1.00000 \\
\hline 1.0000 & 0.812078 & 0.000000 & 1.951 & 26.95 & 1.00000 \\
\hline 1.0000 & 0.812078 & 0.000000 & 1.951 & 26.95 & 1.00000 \\
\hline 1.0000 & 0.812078 & 0.000000 & 1.951 & 26.95 & 1.00000 \\
\hline 1.0000 & 0.812078 & 0.000000 & 1.951 & 26.95 & 1.00000 \\
\hline 1.0000 & 0.812078 & 0.000000 & 1.951 & 26.95 & 1.00000 \\
\hline 1.0000 & 0.812078 & 0.000000 & 1.951 & 26.95 & 1.00000 \\
\hline 1.0000 & 0.812078 & 0.000000 & 1.951 & 26.95 & 1.00000 \\
\hline 1.0000 & 0.812078 & 0.000000 & 1.951 & 26.95 & 1.00000 \\
\hline 1.0000 & 0.812078 & 0.000000 & 1.951 & 26.95 & 1.00000 \\
\hline 1.0000 & 0.812078 & 0.000000 & 1.951 & 26.95 & 1.00000 \\
\hline 1.0000 & 0.812078 & 0.000000 & 1.951 & 26.95 & 1.00000 \\
\hline 1.0000 & 0.812078 & 0.000000 & 1.951 & 26.95 & 1.00000 \\
\hline 1.0000 & 0.812078 & 0.000000 & 1.951 & 26.95 & 1.00000 \\
\hline 1.0000 & 0.812078 & 0.000000 & 1.951 & 26.95 & 1.00000 \\
\hline 1.0000 & 0.812078 & 0.000000 & 1.951 & 26.95 & 1.00000 \\
\hline 1.0000 & 0.812078 & 0.000000 & 1.951 & 26.95 & 1.00000 \\
\hline 1.0000 & 0.812078 & 0.000000 & 1.951 & 26.95 & 1.00000 \\
\hline 1.0000 & 0.812078 & 0.000000 & 1.951 & 26.95 & 1.00000 \\
\hline
\end{tabular}

Table 7.3.4: Relative permeability - capillary pressure table for non-reservoir rock (Layers 2 and 4) in Judica Field. 


\section{Recommended Protocols for Coring Pilot Well of a Horizontal Infill}

Maurer Engineering Inc. was consulted to provide a summary of protocols to be followed in planning coring operations at the pilot well for the demonstration horizontal infill. The initial intent was to obtain a horizontal core in the lateral but MDCI favored a vertical core from the pilot well due to concerns about well stability and invasion problems anticipated while coring the horizontal leg. The purpose of the core acquisition in the pilot well was to provide information about the following:

- Geologic core description

- Routine saturation, porosity, and permeability data

- Well stimulation options by testing drill fluid clean-up and rock-acid compatibility

The core description will also provide a detailed log of the lateral lithologic variation away from the well, which will help determine the depositional environment and provide information on potential hydrocarbon bearing zones.

The routine core data will provide the following:

- Saturation of oil, gas, and water in the core material

- Porosity

- Permeability

- Grain density, which will provide mineralogy data and aid in core description

The routine data are also very important in correction and correlation of any log data and characterization and modeling of the reservoir. 
Laboratory stimulation testing on native core material will provide data which will aid in optimizing any wellbore cleanup due to formation damage from the drilling fluid. Tests can be performed in the laboratory with the drilling fluid and different combination of acids and other clean up fluids such as oxidizers, bleach, etc. These tests will identify and optimize stimulation options which may be employed to increase nearwellbore permeability.

It is advisable to keep the core preserved (at least refrigerated) after the routine and stimulation plugs are taken in case further testing is required.

\subsection{Coring Plan}

A 30' conventional core was planned to be taken in the vertical pilot well for the proposed horizontal well in the Judica field, Ness County, in Kansas. The core will be $3.5^{\prime}$ or smaller in diameter and will be taken at an approximate $0^{\circ}$ angle. Core depth will be approximately 5500 feet. The formation at this depth is expected to be a relatively tight carbonate sequence with the presence of light oil. Permeability should be less then $100 \mathrm{md}$. The pilot well will be drilled in an overbalanced condition and a water-based drilling fluid will be used.

\subsection{Analytical Test Procedures after Core Retrieval}

\subsubsection{Basic Rock Properties}

1. A 1.0" length by 1.0" diameter sample is to be taken at 1-foot intervals for routine analysis. The samples will be drilled using liquid nitrogen as the bit lubricant. Each end of the sample will be trimmed to a right cylinder and ends saved in a plastic bag for possible future analysis.

2. Each of the plug samples will then be weighed to the nearest 0.001 grams and loaded into a pre-boiled Dean-Stark apparatus for distillation to determine 
residual fluid saturations. Water volume in each Dean-Stark receiving tube will be monitored during the toluene-refluxing process until stabilization. A wire will be used to swab off any water droplets from the neck of the condenser. A record of time and water volumes will be kept for each sample.

3. The samples will be placed into a reflux soxhlet with methylene chloride. The samples will be cleaned until the solvent is clear and checked with an ultra violet light to insure no fluorescence exists. The methylene chloride will then be replaced with methanol. The samples will be extracted in methanol to remove any salt. The samples will be placed in a vacuum oven at a temperature of $220^{\circ} \mathrm{F}$ until a constant weight is achieved.

4. After the samples are cooled, weights will be determined. The length and diameter of each sample will be measured with digital calipers. Grain volumes will be measured in a matrix cup at ambient conditions by the Ultra Porosimeter ${ }^{\mathrm{TM}}$ using Boyle's law, with helium as the gaseous medium. Grain density will be calculated for each sample using the dry sample weight and grain volume data. During these procedures, exposure to the atmosphere will be minimized to preclude absorption of moisture.

5. Permeability and porosity will be measured using the $\mathrm{CMS}-300^{\mathrm{TM}}$ at the appropriate confining stress. A standard system leak test of the CMS-300 ${ }^{\mathrm{TM}}$ will be performed before testing to ensure correct equipment operation. A calibrated, known-volume check cylinder and a known-permeability check plug will be run with each carousel suite of samples. The Klinkenberg (slip corrected) permeability for each plug sample will be determined as a function of pressure decay (helium blow-down). A reference cell of known volume will be used to charge the sample with helium. A downstream valve will vent the sample to atmosphere as pressure changes with time are monitored. The multiple flow regime data will allow the determination of Klinkenberg permeability of the 
sample, calculated air permeability (Kair), along with parameters of helium slip factor (b) and the Forcheimer inertial resistance factor beta (ß).

6. Porosity for each plug sample will be calculated using the Boyle's law measured grain volume and the pore volume.

Fluid saturation and permeability data will be calculated and reported using the measured data. Porosity and grain-density measured values will also be reported.

\subsubsection{Stimulation Test Procedures - Drilling Fluid Cleanup}

1. The selected core sample will be evacuated of air and pressure-saturated with brine.

2. Next, the sample will be spun to initial water saturation in a high-speed centrifuge then briefly evacuated under laboratory oil.

3. The samples will be loaded into a hydrostatic core-holder. A 1/8” thick spacer ring will be utilized on the injection end of the sample to allow for the circulation of drilling mud across the face of the core.

4. A net confining pressure of 4000 psi will be applied, and a backpressure of 200 psi will be established.

5. The temperature of the system will be elevated to the appropriate reservoir temperature, crude oil injected in the production flow direction at a constant rate of $3 \mathrm{ml} / \mathrm{min}$, and effective permeability to oil at initial water saturation will be determined.

6. Drilling overbalance pressure (if any) is calculated based on the measured mud weight and the provided reservoir pressure. Drilling mud will be circulated across 
the injection face of the sample at the calculated overbalance pressure for 4 hours. Leak-off volume as a function of time will be recorded.

7. Drilling mud cleanup fluids will be circulated across the face of the core at varying rates and for varying time periods, depending on the fluid.

8. Crude oil will be injected in the original (production) flow direction at a constant rate of $3 \mathrm{ml} / \mathrm{min}$ and return permeability to oil as a function of throughput determined.

9. The test samples will be unloaded and residual fluid saturations determined by Dean Stark toluene extraction.

\subsubsection{Stimulation Test Procedures - Rock/Acid Compatibility}

1. The core sample will be loaded in a hydrostatic core-holder in an air bath oven, the appropriate reservoir net confining stress applied, and 200 psi backpressure be established. The oven temperature will be increased to reservoir conditions.

2. Base-line permeability will be established with desired completion fluid. The fluid will be pumped at $1 \mathrm{ml} / \mathrm{min}$ for 20 pore volumes to insure stability. Differential pressure, time, and produced volume will be monitored, and permeability versus throughput calculated.

3. Each acid or acid mixture ( $\mathrm{HCl}, \mathrm{HF}: \mathrm{HCl}$, Acetic acid, or mixture of previous) will be injected at the same constant rate of $1 \mathrm{ml} / \mathrm{min}$ for approximately 10 pore volumes. Other fluids such as pre- or post-flushes will also be injected depending on the particular acid system. Differential pressure, time, and produced volume will be monitored, and permeability to each fluid versus throughput calculated. 
4. The fluid used for the initial baseline measurement will be re-injected for approximately 20 pore volumes at $1 \mathrm{ml} / \mathrm{min}$. Differential pressure, time, and produced volumes will be monitored, and permeability to the baseline fluid versus throughput calculated to determine any stimulation or damage that may have occurred.

5. Following testing, each sample will be cooled and unloaded. 


\section{Pilot Well in Judica Field}

Based on the history matches of fluid production, average reservoir pressure, and predicted production volumes from targeted horizontal infill wells placed in Ness City North, McDonald, and Judica fields, MDCI decided to drill a pilot well (Thornburg 1-3), location shown in Figure 9.1, in Judica field, Ness County, Kansas as a part of the demonstration study. The intent of the pilot well was to validate the structure and thickness of Mississippian pay porosity and the extent of the channel bordering the study area in Judica field so that the field geomodel could be revised and re-simulated to determine the optimum trajectory for the horizontal well. The pilot well location was chosen at the edge of the reservoir to provide multiple options to drill horizontal laterals in various directions such as to the south, to the south-east, and/or to the east. The remaining reserves map (Figure 9.2) indicated the distribution of remaining reserves relative to the pilot well as of January 2003. A DST was carried out at the pilot well along with attempts to retrieve a core representative of the reservoir interval. The DST data at the pilot well would be used to confirm the current reservoir pressure, and retrieved core data would be tested in the laboratory to obtain representative petrophysical data - permeability-porosity correlations, relative permeability, and capillary pressure for input to the simulation model.

\subsection{Evidence of Additional Reservoir Heterogeneity}

Table 9.1 summarizes the major events that took place after the drilling of the pilot well Thornburg 1-3. The pilot well encountered the Mississippian at a structurally low position, i.e., below the field oil-water contact (OWC). Three attempts at coring resulted in the retrieval of only conglomerate fill. Also, the DST resulted in questionable shut-in pressure profiles suggesting packer failure. One of the major reasons for drilling the pilot well was to confirm the current reservoir pressure. Infill horizontal wells are successful when they are placed in reservoirs with low or minimal pressure depletion. Most of the productive wells in the study area have already been plugged. Thus, when a representative reservoir pressure from the pilot well could not be obtained, shut-in fluid 
levels were shot at Thornburg M1 Slawson (TM1s). However, it resulted in a very slow build-up that failed to stabilize after 3 days and thus was terminated prematurely. From the recovered data, it appeared that the reservoir pressure may have stabilized in the range of 500 psi, substantially less than that recorded at Thornburg F1 (TF1), i.e. around $1030 \mathrm{psi}$, located just outside the study area to the west. A shut-in fluid column survey was, therefore, carried out at the Thornburg Q1 (TQ1) well, resulting in quick stabilization of pressure to 1000 psi. Given the discrepancy between shut-in fluid columns at TQ1 and TM1s, MDCI decided to shoot a 3D-seismic survey over the study area to better understand the reservoir heterogeneity.

\subsection{D-Seismic Survey Over Judica Field Study Area}

Drilling the Thornburg 1-3 pilot well illustrated the risk of drilling without a clear view of the complexities of the Mississippian erosional and karsted surface. Though most mature Mississippian fields are developed on a 40-acre spacing in Kansas, and often multiple wells with interpretable wireline logs, this study demonstrates that the complexity and compartmentalizations in Mississippian reservoirs require additional information beyond what has been traditionally considered requisite. Thus, a 3D-seismic survey was carried out over the Judica study area to get a better understanding of the reservoir compartments affecting and limiting production from traditional vertical wells and also affecting productivity of the proposed horizontal infill well. 


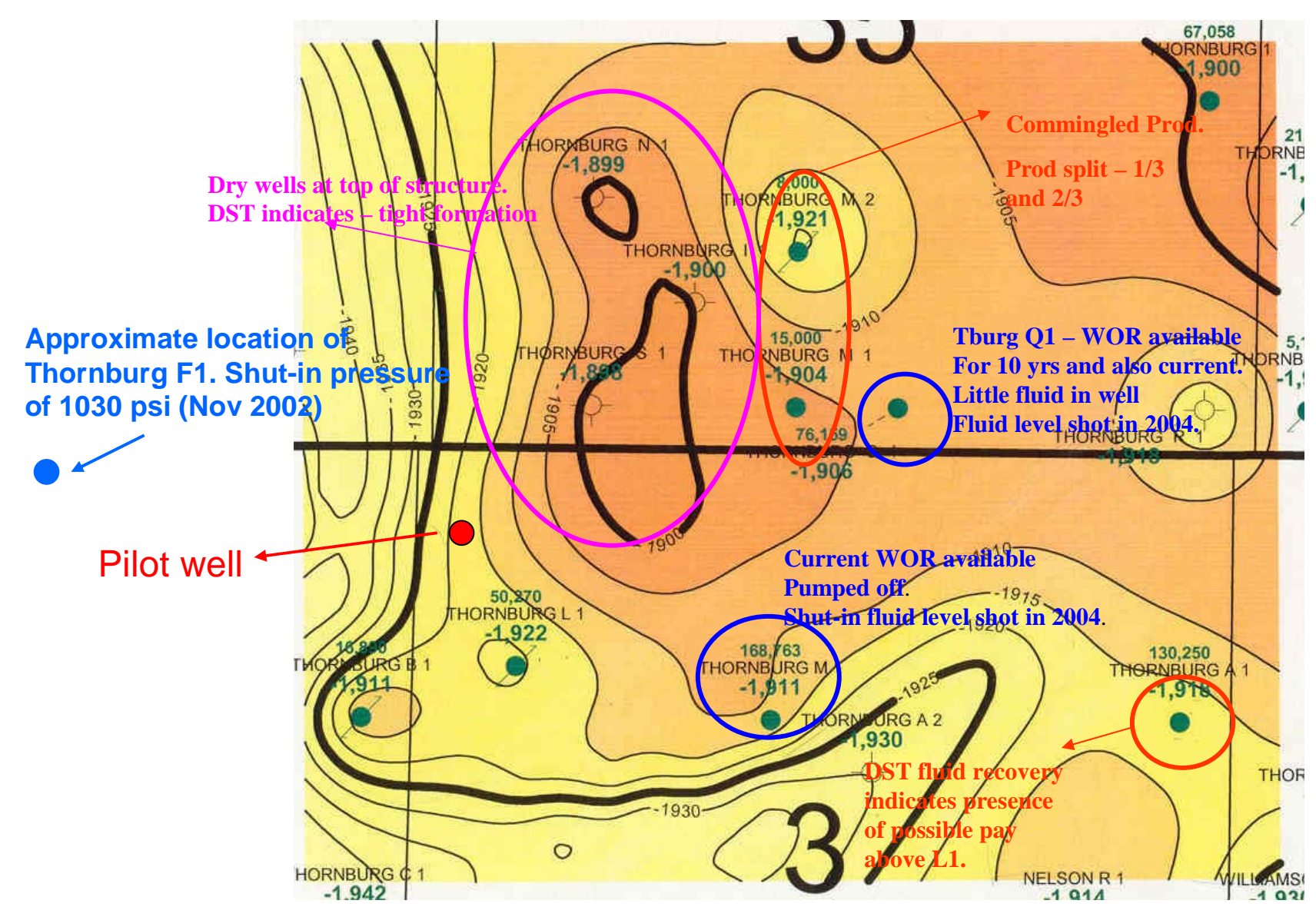

Figure 9.1: Map showing the area simulated in Judica Field along with location of the pilot well and Thornburg F1 where a 5-day shut-in test was carried out in November 2002 indicating a reservoir pressure of about 1030 psi. 


\section{Pilot well location}

Jan 1, 2003 - remaining reserves (oil-ft)

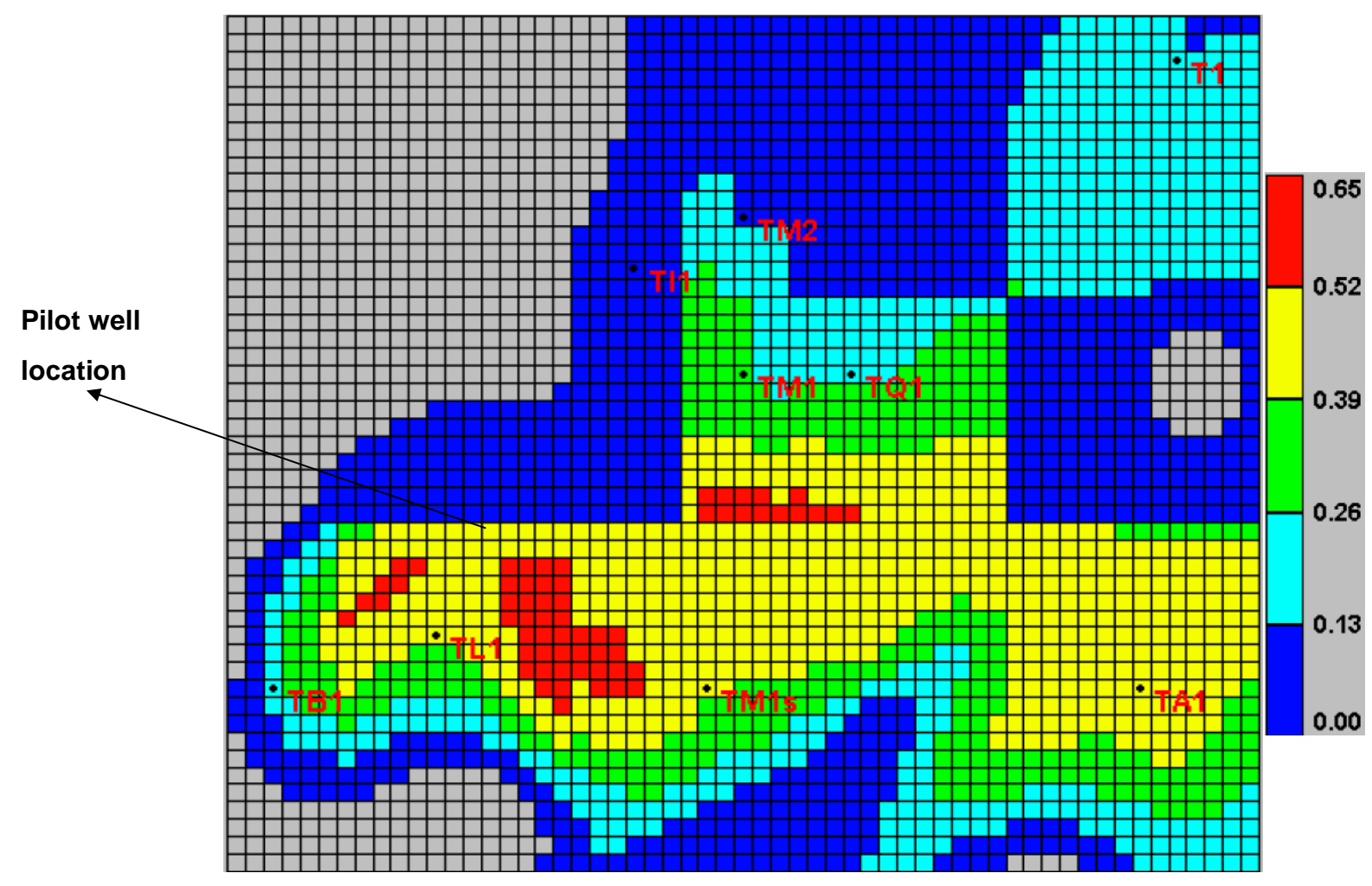

Figure 9.2: Remaining reserves, oil-feet (product of porosity, oil saturation, and pay), map as of January 2003 and the approximate location of the pilot well drilled in Judica Field. 
Tasks Accomplished - Post-pilot well

Nov 19, 2003 - Spudded Pilot well

Nov 27-28, 2003 - Attempted to core Mississippian interval

Nov 29, 2003 - DST Mississippian-Warsaw interval

Nov 30, 2003 - Rig released.

Dec 16, 2003 - Shut-in fluid levels from Thornburg M1 Slawson (TM1s) received. Very slow build-up. Test terminated before stabilization of fluid column. Suspect reservoir pressure close to $500 \mathrm{psi}$.

Jan 8, 2003 - Shut-in fluid level measurement at Thornburg Q1 (TQ1) initiated.

Jan 13, 2004 - Shut-in fluid levels at TQ1 indicates a reservoir pressure in the range of $1000 \mathrm{psi}$.

Jan 29, 2004 - MULL decides to shoot a 1 sq. mile 3D centered around the pilot well. MULL also negotiating with Pintail - operator of the adjacent TM1s lease. Tentative date for 3D survey - April 2004.

Apr 23, 2004 - Start of 3D survey in Judica.

May 21, 2004 - MULL receives results from 3D survey.

Jun 15, 2004 - Marty updates reservoir model after input from MULL (Rick).

July 6, 2004 - Present simulation results to MULL based on Marty's initial revised model. Forward 3D data for curvature analyses by Univ. of Houston.

July 26, 2004 - Obtained interpreted results from University of Houston.

Aug 19, 2004 - MULL visits KGS to review final reservoir model. Extent of reservoir compartmentalization becomes evident - pressure and reservoir compartments.

Sep 7, 2004 - Complete simulation of area of interest using current reservoir model.

Table 9.1: Summary of events at Judica Field Pilot well. 


\section{Characterization \& Simulation of Judica Field - Post 3D- Seismic Survey}

Analyses of the 3D-seismic data revealed a significantly different view of the Mississippian terrain in Judica field, Ness County, Kansas, and resulted in the development of a revised reservoir geomodel including previously unknown heterogeneities.

\subsection{Analyses of 3D-Seismic Survey Data}

Seismic reflections corresponding to the top of the Mississippian and other surfaces were interpreted across the Judica 3-D seismic survey. Grids of the seismic time horizons were converted to depth using velocities derived from well control, then imported and contoured in Petra ${ }^{\mathrm{TM}}$, a Geoplus mapping application. Earlier subsurface and post-3D Mississippi structure maps are shown in Figures 10.1A and 10.1B for comparison. Figure 10.2 is a Mississippi structure maps of the greater Judica area. The major features were recognized from previous subsurface mapping. However, the finer scale karst-related features leading to possible reservoir compartmentalization are evident in the post-3D work.

In the earlier work it was recognized that compartmentalization within the Mississippian dolomite reservoir, such as in the Ness City North Field, Ness County, Kansas, was due to reservoir heterogeneity, karst processes, and actual structure. The new data does not change these earlier conclusions, however the post-3D data do provide evidence that compartmentalization due to karst is more pervasive than earlier thought. The effect is to reduce the size of the prospective compartments (blue dashed outline in Figures 10.1 to $10.3,10.5$, and 10.7 to 10.15 ) within the lease boundaries of the operator, here MDCI.

3-D-seismic attributes provide additional insight into reservoir properties. For instance, a decrease in porosity will increase both seismic velocity and density and could 
have an observable affect on seismic amplitudes. A crossplot (Figure 10.3A) of porosityheight (phi-h) of the Judica zone from well data versus amplitude of the Base Warsaw LS horizon (the trough immediately below the peak corresponding to the top Mississippian) extracted from the 3-D-seismic survey at the well locations shows an empirical relationship between seismic amplitude and phi-h. A model of the seismic response to variation of porosity within the Judica zone, based on sonic information from the Thornburg 1-3 well, is shown in Figure 10.4. This model shows that the magnitude of the seismic amplitude extracted along the Base Warsaw LS horizon is predicted to increase by approximately $60 \%$ as average porosity in the Judica zone decreases from $25 \%$ to $5 \%$ (or as phi-h decreases from 6.0 to 1.2 porosity-ft), validating the empirical relationship. Base Warsaw LS amplitude is mapped in Figure 10.5A while Figure 10.5B shows the Mississippian structure map, with warmer colors representing lower amplitude (and therefore presumed areas of higher porosity-feet). Warmer colors on the amplitude map are associated with producing areas and are not necessarily correlated with structure. A very strong structural high in the south half of Section 35, immediately north of the target area, is non-productive due to lack of porosity in the reservoir interval. The cooler colors in the amplitude map over this area may be related to this lack of porosity in the upper Mississippian. The base Warsaw LS amplitude map in conjunction with the structural map is able to discriminate between the dry and productive wells in the greater Judica area. Thus, the above analyses of 3D-seismic data is able to trace compartment boundaries and also identify those compartments with productive potential, i.e., better porosity.

\subsection{Reservoir Simulation Using Revised Judica Geomodel}

Figure 10.6 shows the 3D volume based on the revised reservoir geomodel developed by incorporating the 3D-seismic analysis. The post-3D reservoir model assumed that the simulated compartment was charged by a weak bottom-water drive based on the estimated shut-in pressure of around 500 psi observed at the Thornburg \#M1 Slawson (TM1s) well in 2004. One of the limiting factors in the Judica field simulation has been the availability of limited water production data. The current water-oil-ratio 
(WOR) is available at TM1s while WORs were recorded at Thornburg \#Q1 (TQ1) over a period of 10 years. Figure 10.7B shows the plot of WOR against cumulative oil for TM1s and TQ1, while Figure 10.7C plots the WOR against time for TQ1. Figures 10.8B and 10.8D show the history match on cumulative oil production and daily fluid rates for the well TM1s. Figure 10.8C shows the history match obtained for this well using the pre-3D geo-model. Figures 10.9 to 10.11 show similar history matches for other wells within the simulation study area. In most cases, the post-3D model enables better history matches with well production. Figure 10.12 plots the simulator-calculated average reservoir pressure with time, and indicates that the current reservoir pressure is close to $470 \mathrm{psi}$ which is close to what the incomplete shut-in fluid column data from TM1s seem to indicate. Not having any alternate and better source of current reservoir pressure data, MDCI advised conducting incremental recovery from horizontal infills based on a current assumed reservoir pressure of $500 \mathrm{psi}$.

\subsection{Performance Prediction of Targeted Horizontal Infill Wells}

Figure 10.13 shows the distribution of calculated residual reserves (oil saturation feet) in the Judica study area. Figures 10.13B and 10.13C compare the simulated residual potential using the pre- and post-3D models, and it clearly indicates a decrease in the oil saturation-feet in the post-3D model. Figure 10.14C shows the estimated recovery from an infill horizontal trajectory (shown in Figure 10.14B). This is a 1000-feet well placed in L5 zone, and the simulator predicts a cumulative recovery of $11.5 \mathrm{MBO}$ after 5 years. An actual horizontal well will probably penetrate the thinner and thus less productive L3 zone as well. Figure 10.15 shows the simulator-calculated production output from the same horizontal infill assuming that it is perforated both in L3 and L5 along its lateral length of 1000 feet. The additional completion in L3 results in a marginal increase in cumulative production to $14 \mathrm{MBO}$ over 5 years.

One of the major drivers affecting productive potential of the infill horizontal well is the current reservoir pressure which in turn controls the available drawdown. However, lacking a definite knowledge about the current reservoir pressure in the immediate 
vicinity of TM1s, area of reach for a lateral out of the already drilled pilot, the analytical aquifer in the simulator was strengthened so that the calculated average pressure increased to about 550 psi (Figure 10.16). Figures 10.17A to 10.17D show that strengthening the analytical aquifer to the degree as suggested above did not result in major changes in the well history matches obtained using the original weaker aquifer. Figure 10.18A shows the simulator calculated cumulative production from a horizontal infill trajectory (Figure 10.18B) which is completed in both L3 and L5 zones when the underlying aquifer is assumed to be stronger than modeled in the earlier runs. The stronger aquifer simply nudged the cumulative production from the infill to $15.1 \mathrm{MBO}$.

With low calculated recoveries from the possible horizontal trajectory, MDCI evinced interest in studying the effects of drilling a longer lateral (1900 feet long) extending beyond their property lines. Figure 10.19A shows the well trajectory while Figure 10.19C plots the expected cumulative recovery after 5 years of production to be at 28.6 MBO.

\subsection{Future Plans to Identify Drilling Prospects Adjacent to Judica Field}

MDCI's estimates of current drilling expenses (as of 2004) are noted in Table 10.1, and given these economics, estimated recoveries, oil prices, and risks associated with other available targets within MDCI's portfolio, MDCI decided against drilling a lateral out of the pilot well in Judica study area. MDCI has acquired additional acerage (area colored in yellow in Figure 10.20) adjacent and to the west of Judica field and they plan to shoot 3D survey over area marked by broken blue lines in Figure 10.20 in 2005. KGS will apply interpretation techniques, developed in this study, to map reservoir compartments and to discriminate between dry and productive wells on this newly acquired 3D data to identify resource pockets that MDCI may consider exploring. Confirmation of potential in these reservoir compartments by drilling productive wells will validate techniques developed in this project to identify candidates for horizontal infilling in mature mid-continent Mississippian fields. 


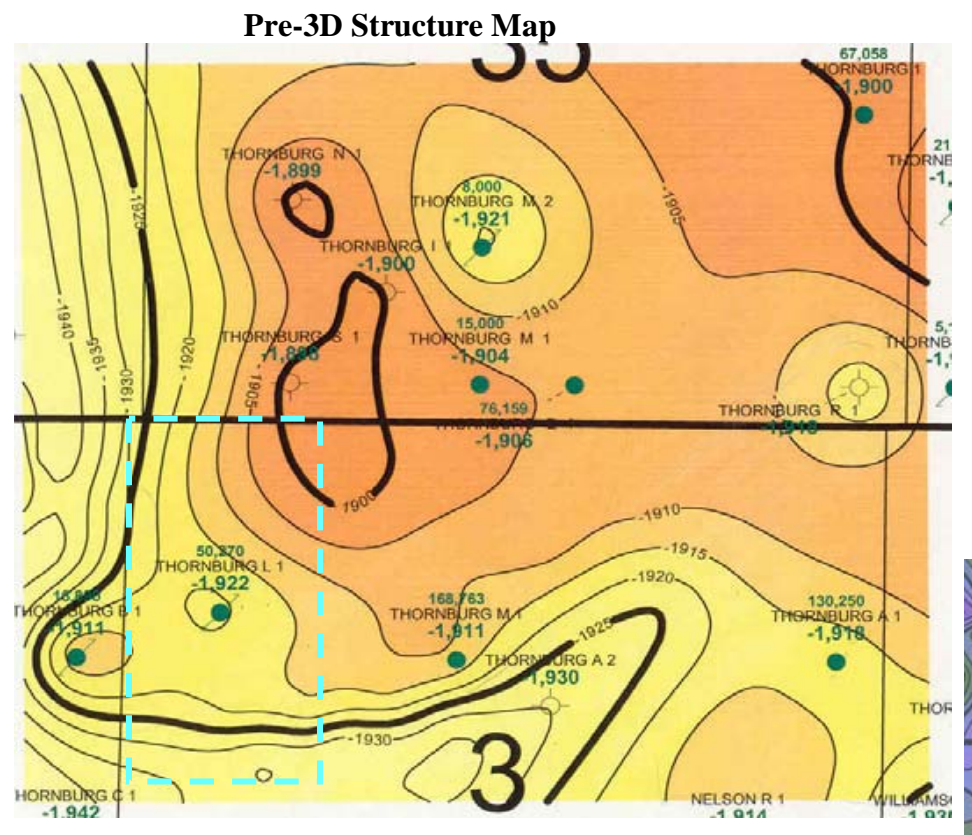

B.

Post-3D Structure Map

A.

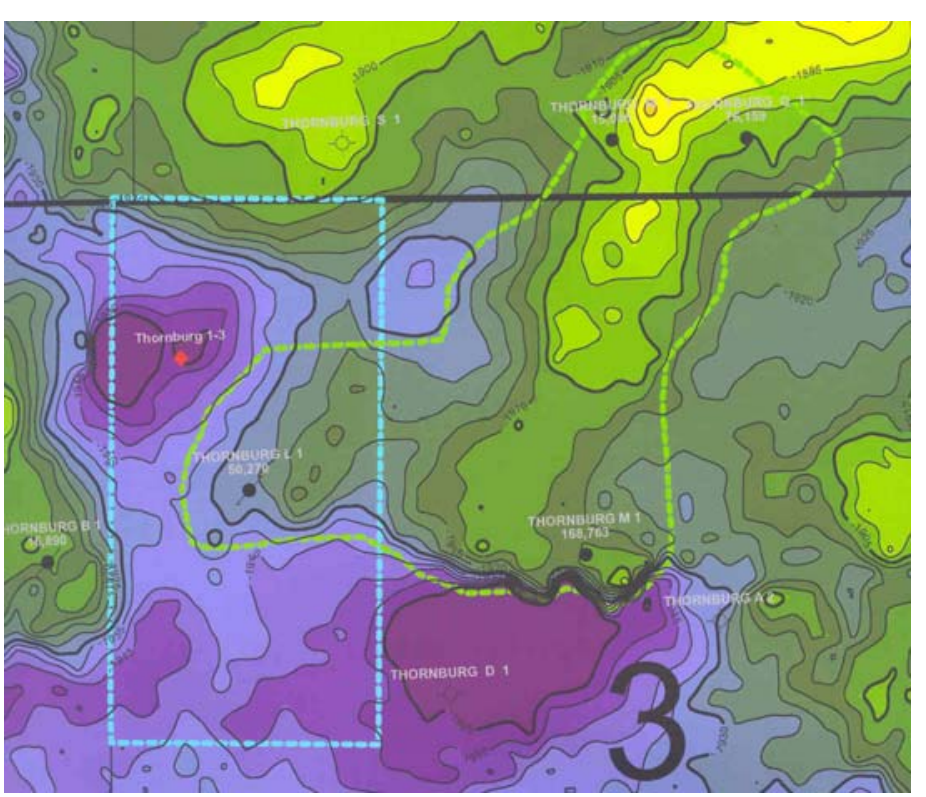

Figure 10.1: A) Structure map on Mississippian pay at Judica Field before 3D seismic survey. B) Revised structure map on Mississippian pay after incorporating 3D-seismic analyses. Thornburg \#1-3 is the location of the pilot well. The blue dashed line indicates the lease holding of the industry partner, MDCI, while the green broken line indicates the reservoir compartment modeled post-3D. 


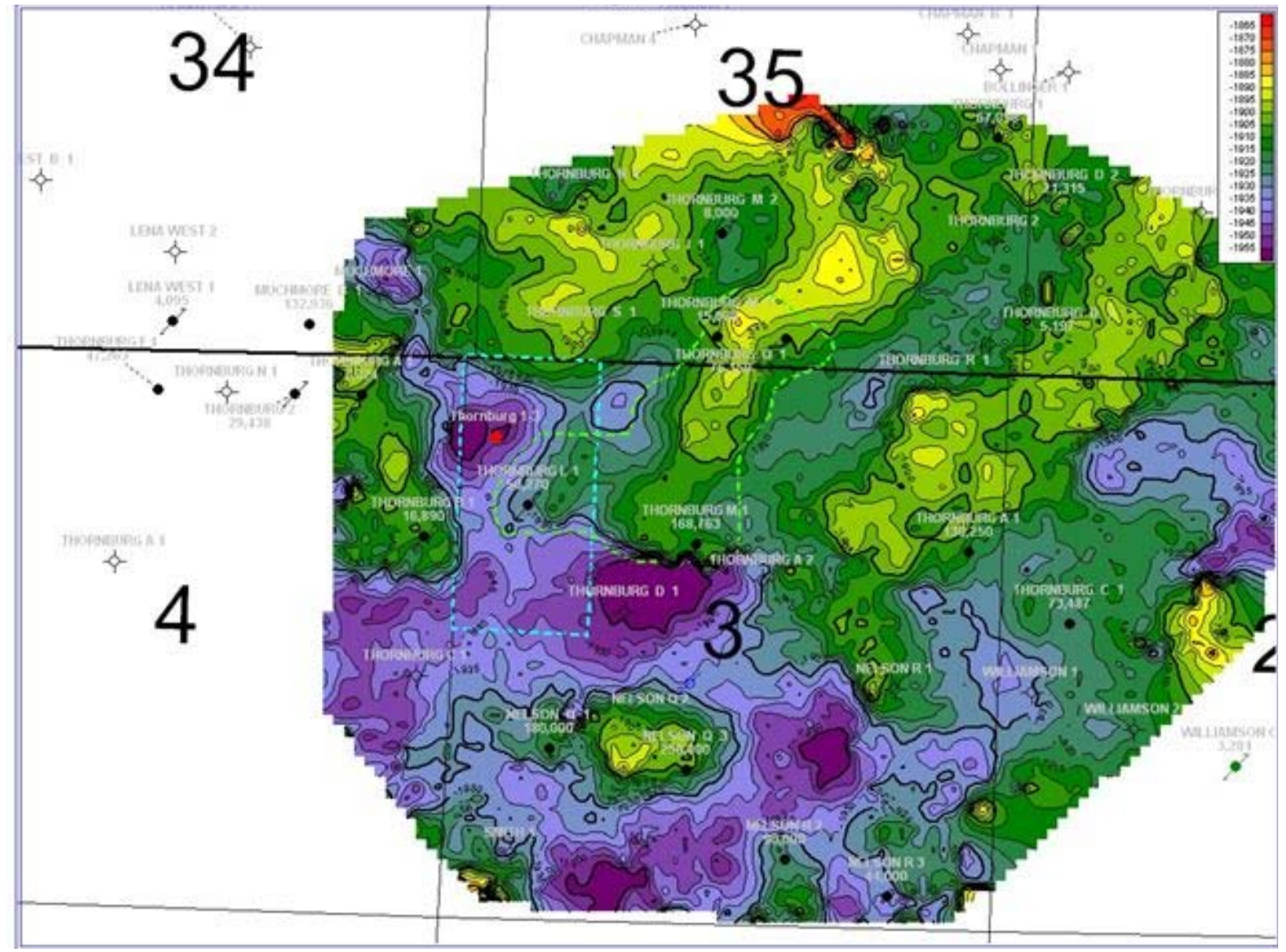

Figure 10.2: Mississippian structure map derived from 3D-seismic survey including and around the Judica Field study area. 


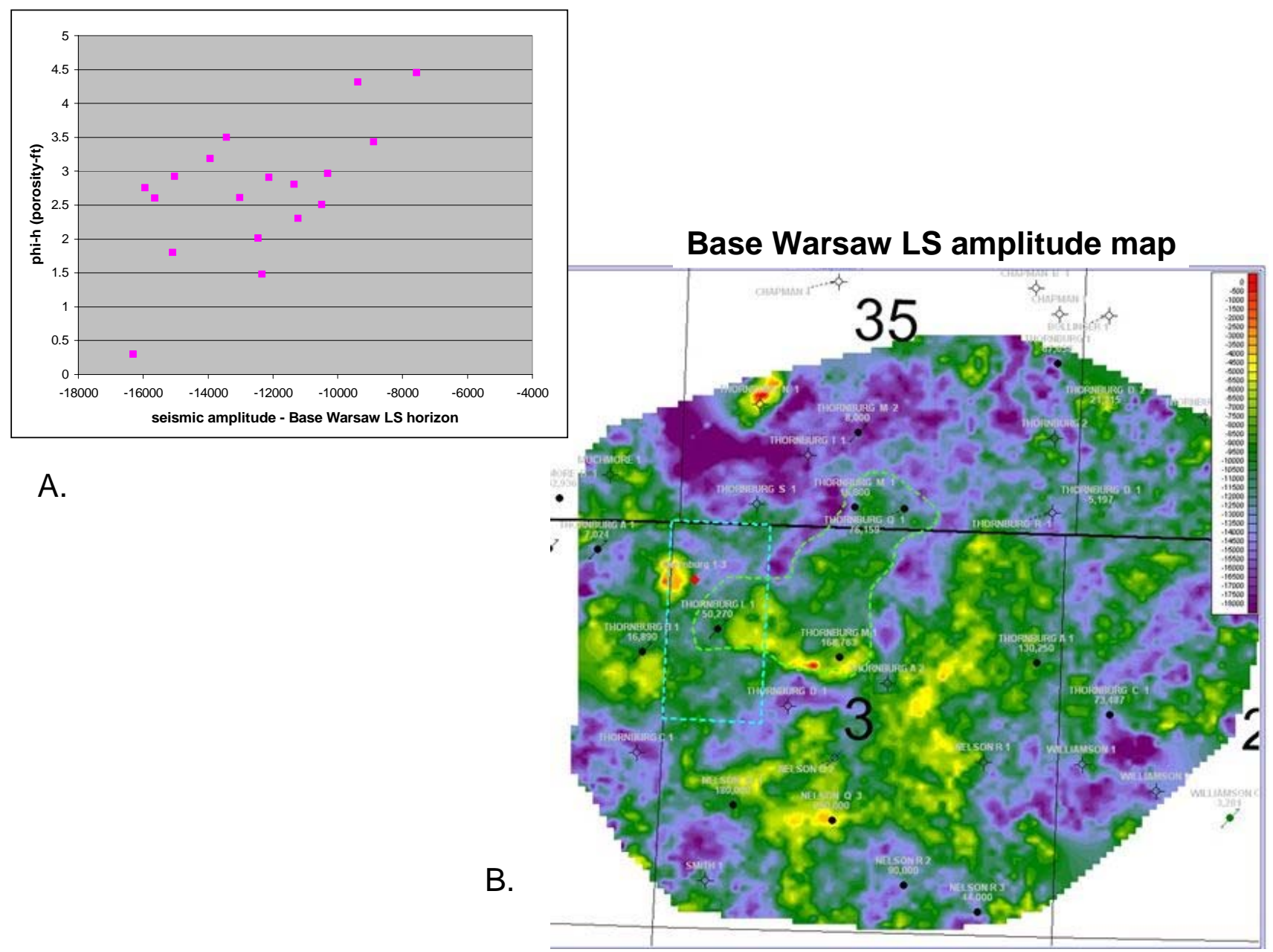

Figure 10.3: A) A crossplot of porosity-height (from well data) of the Judica zone versus amplitude of the Base Warsaw LS horizon. B) An amplitude map of Base Warsaw LS over and around Judica Field. 


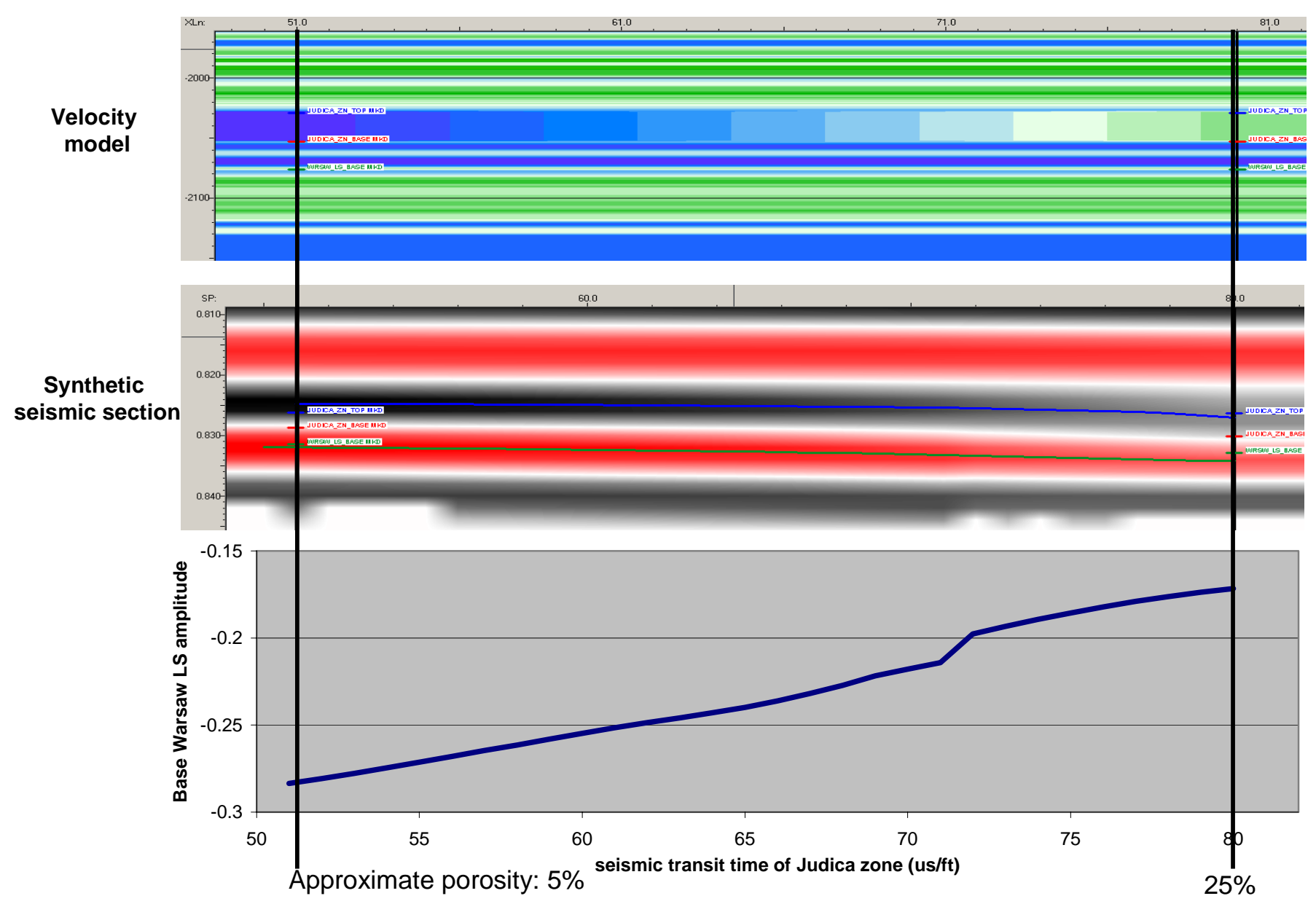

Figure 10.4: Model of variation in amplitude of Base Warsaw LS horizon due to increase in porosity of Judica zone. 

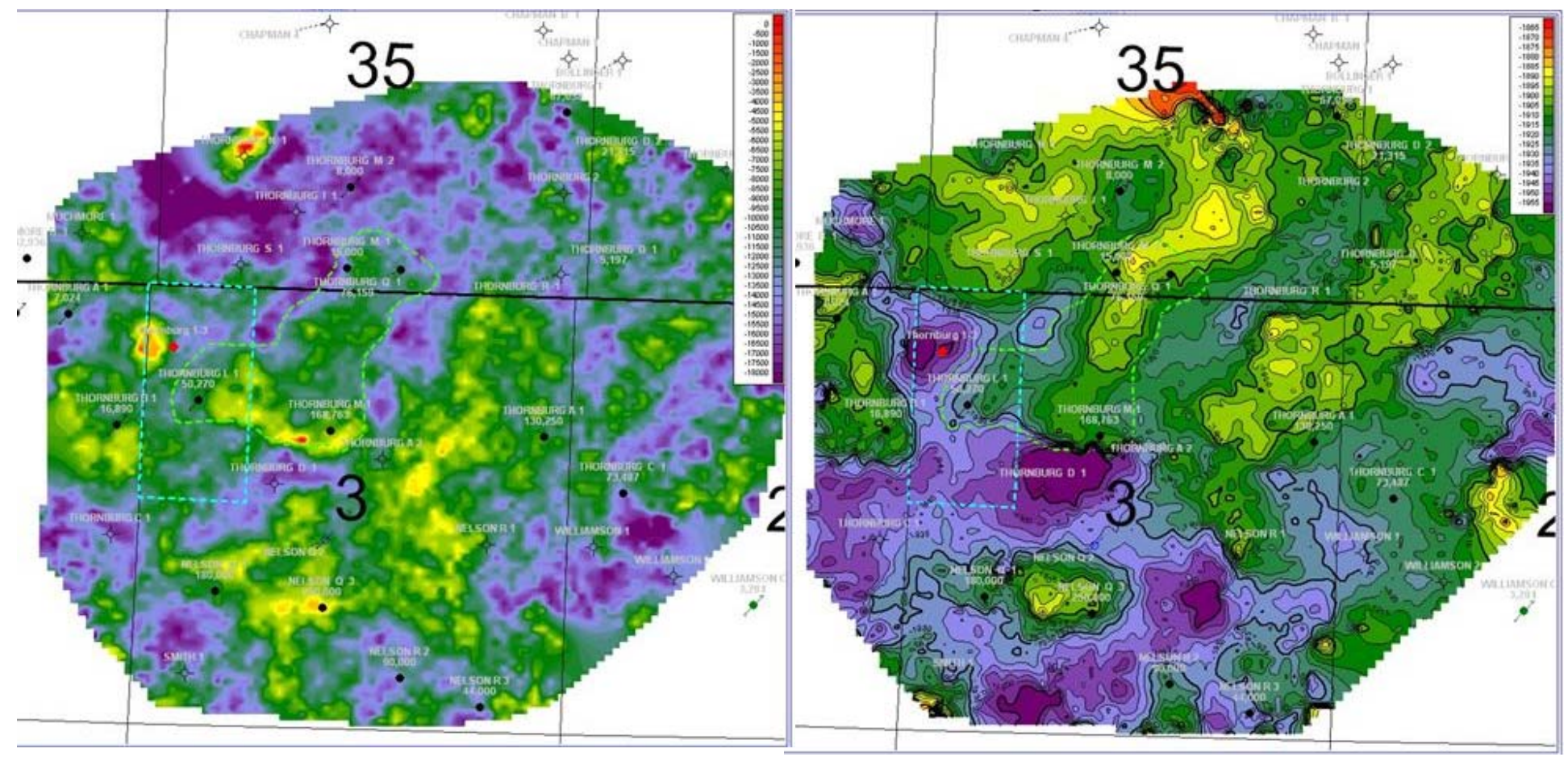

A.

B.

Figure 10.5: A) Map of Base Warsaw LS Amplitude over and around Judica Field study area. B) Post-3D Mississippian structure map over and around Judica Field study area. The area demarked by broken green line is the reservoir compartment characterized and simulated post-3D. 


\section{D Model Input to Reservoir Simulator}

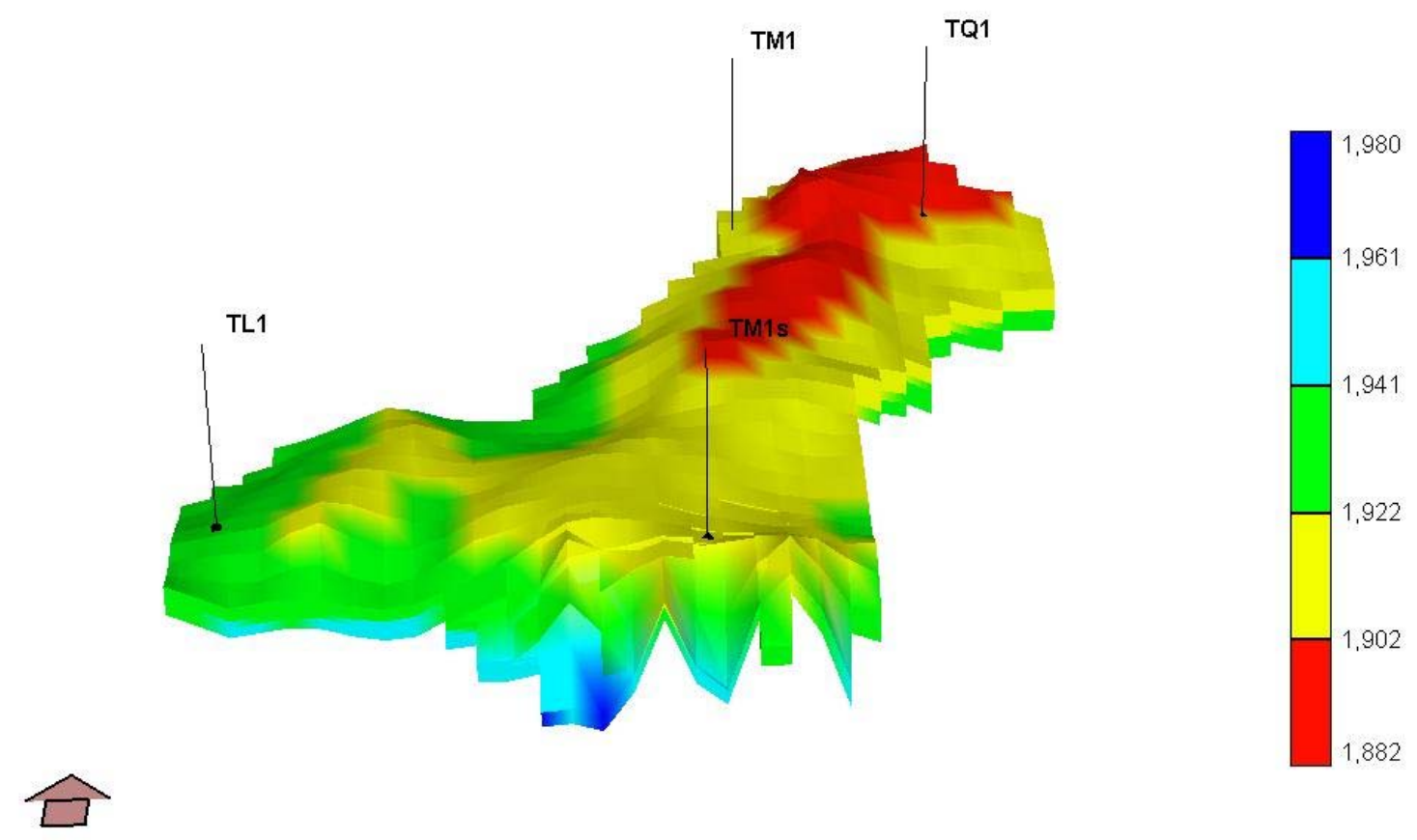

Figure 10.6: Post-3D reservoir volume (subsea, feet) around the Pilot well in Judica Field simulated to study its potential for an infill horizontal well. 


\section{Limited Water \\ Production data}

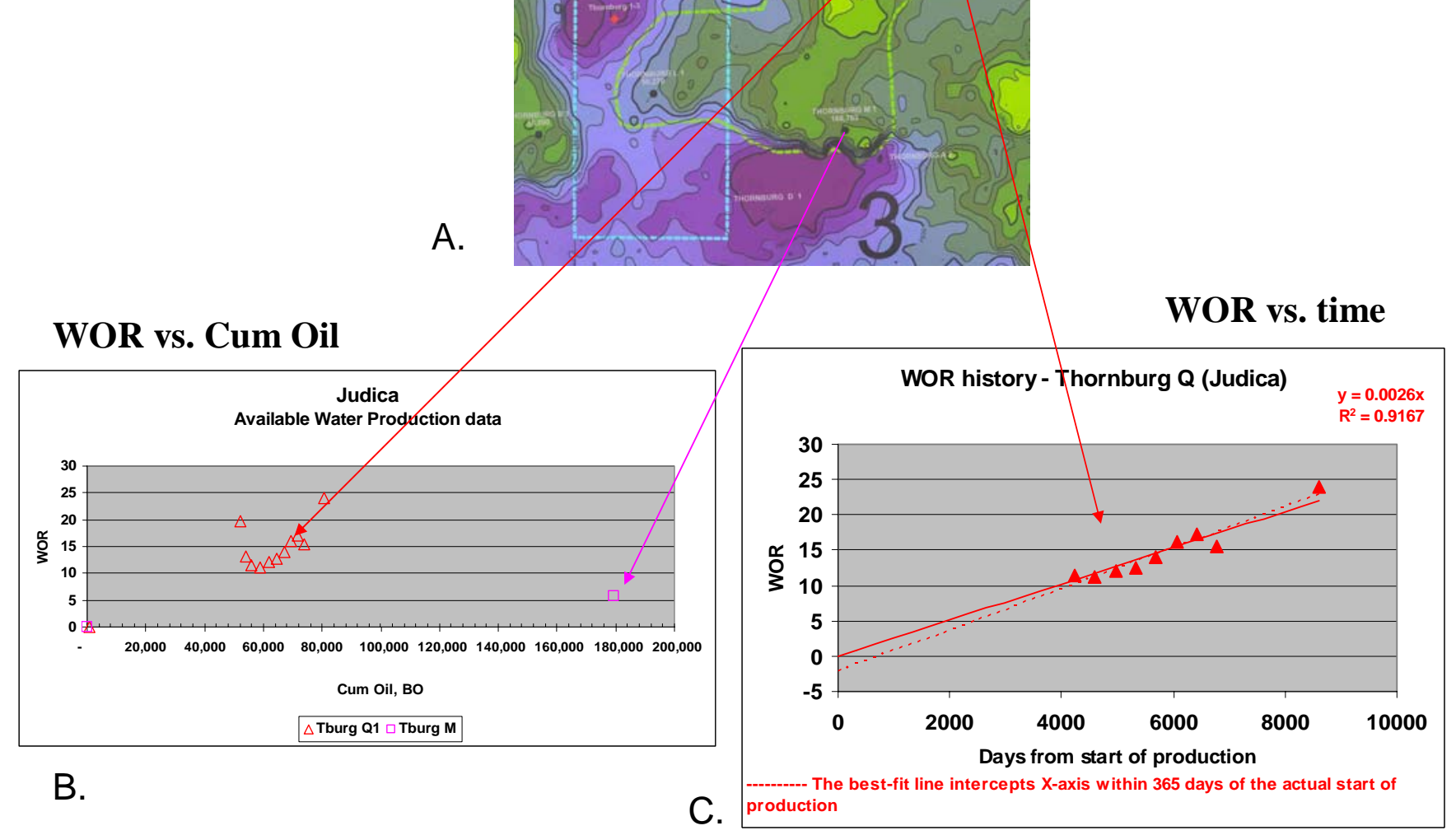

Figure 10.7: A) Boundary of the Judica Field study area shown by broken green line. B) Water-oil-ratio (WOR) versus cumulative oil production from Thornburg Q1. C) Water-oil-ratio (WOR) versus time for Thornburg Q1. 


\section{History Match - TM1s}

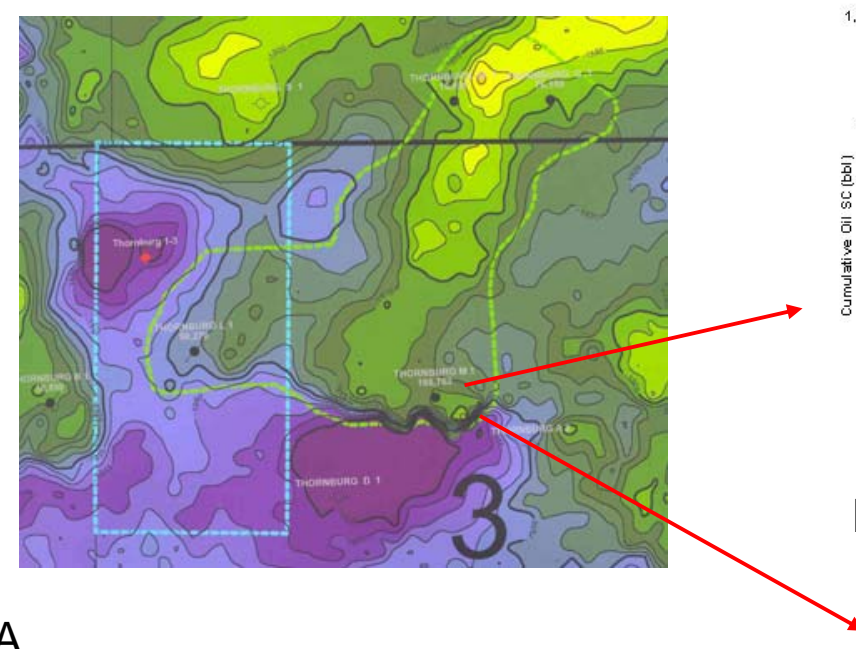

A.

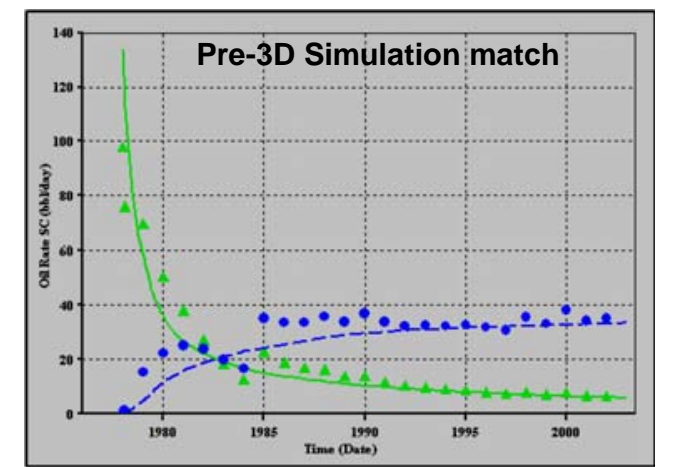

Final Model

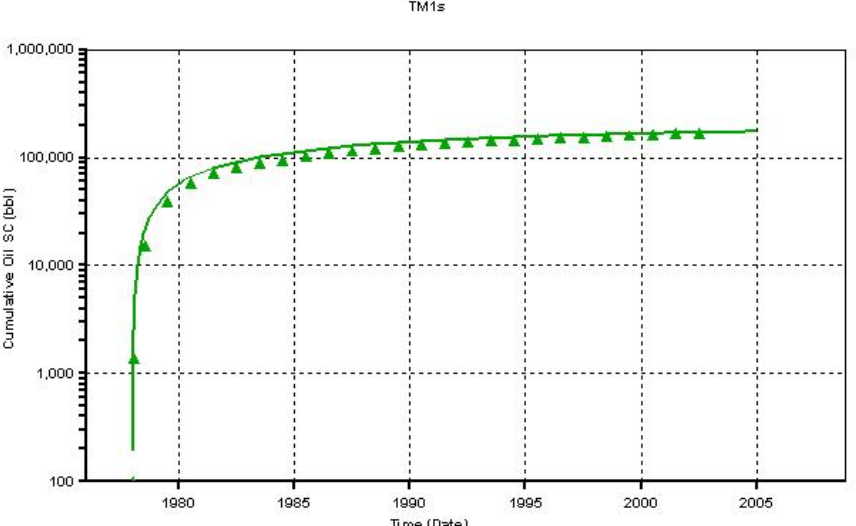

B.

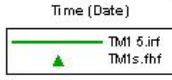

Final Model

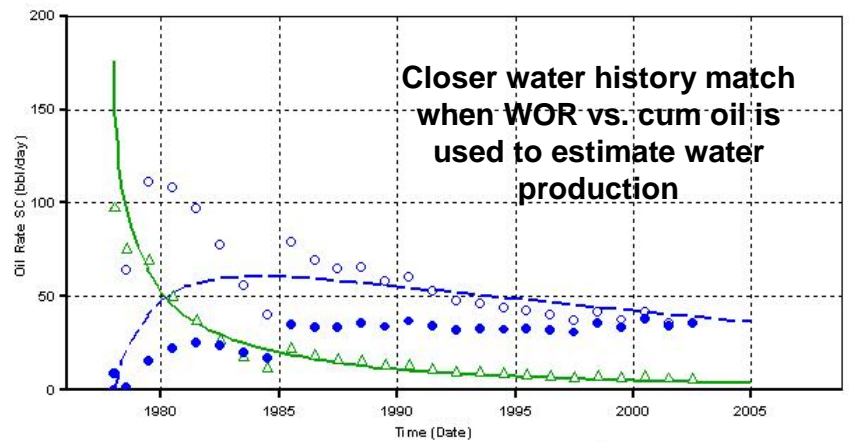

D.

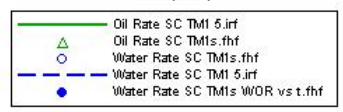

Figure 10.8: A) Boundary of the Judica Field study area demarked by broken green line. B) Production history-match for Thornburg M1 (Slawson) well. C) History match obtained from pre-3D model. D) History-match on estimated water production based on WOR vs. time and WOR vs. cumulative production. (WOR - water oil ratio). 


\section{History Match - TL1}

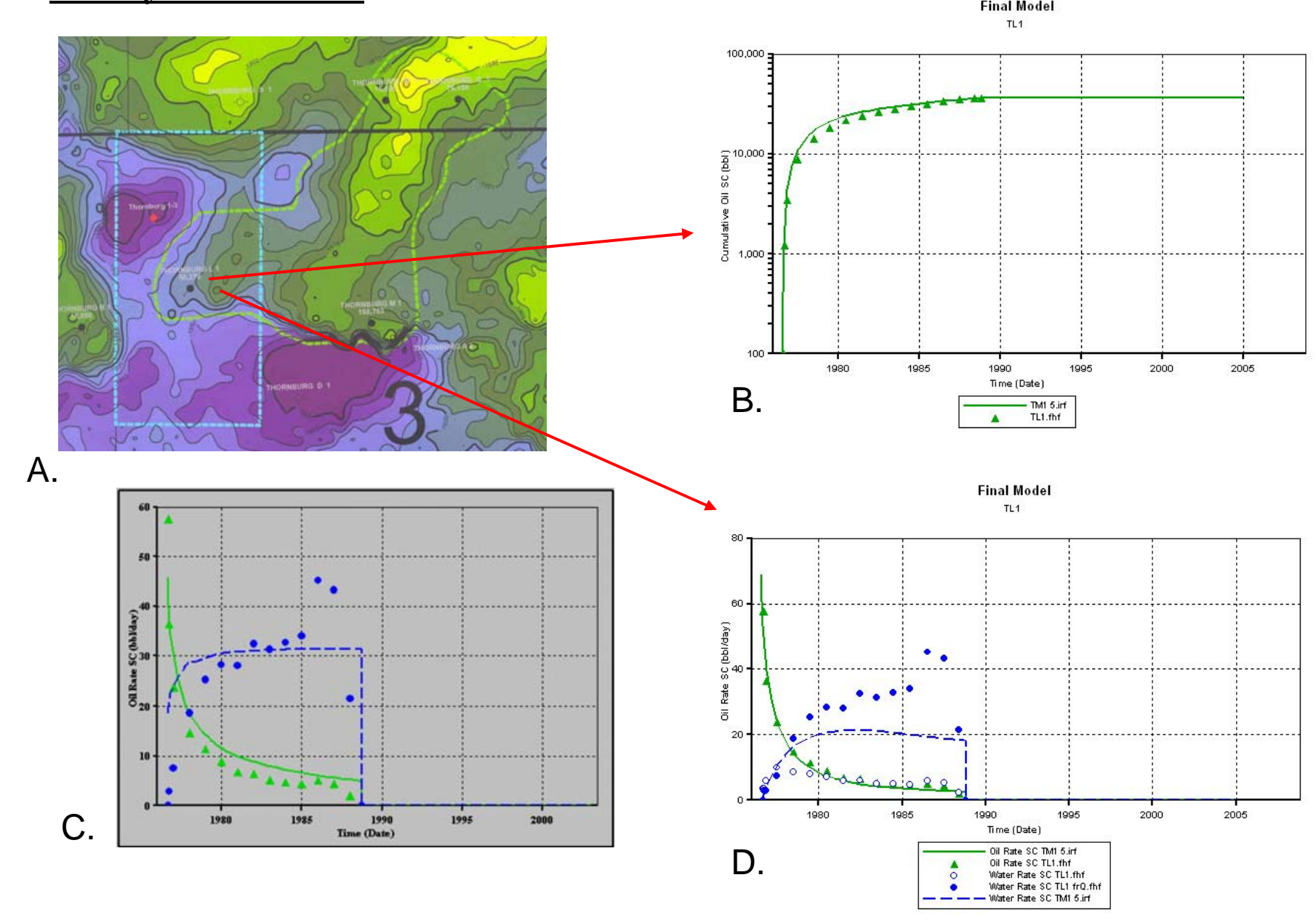

Figure 10.9: A) Boundary of the Judica Field study area demarked by broken green line. B \& D) Production history match for Thornburg L1 well. C) History match obtained from pre-3D model. 


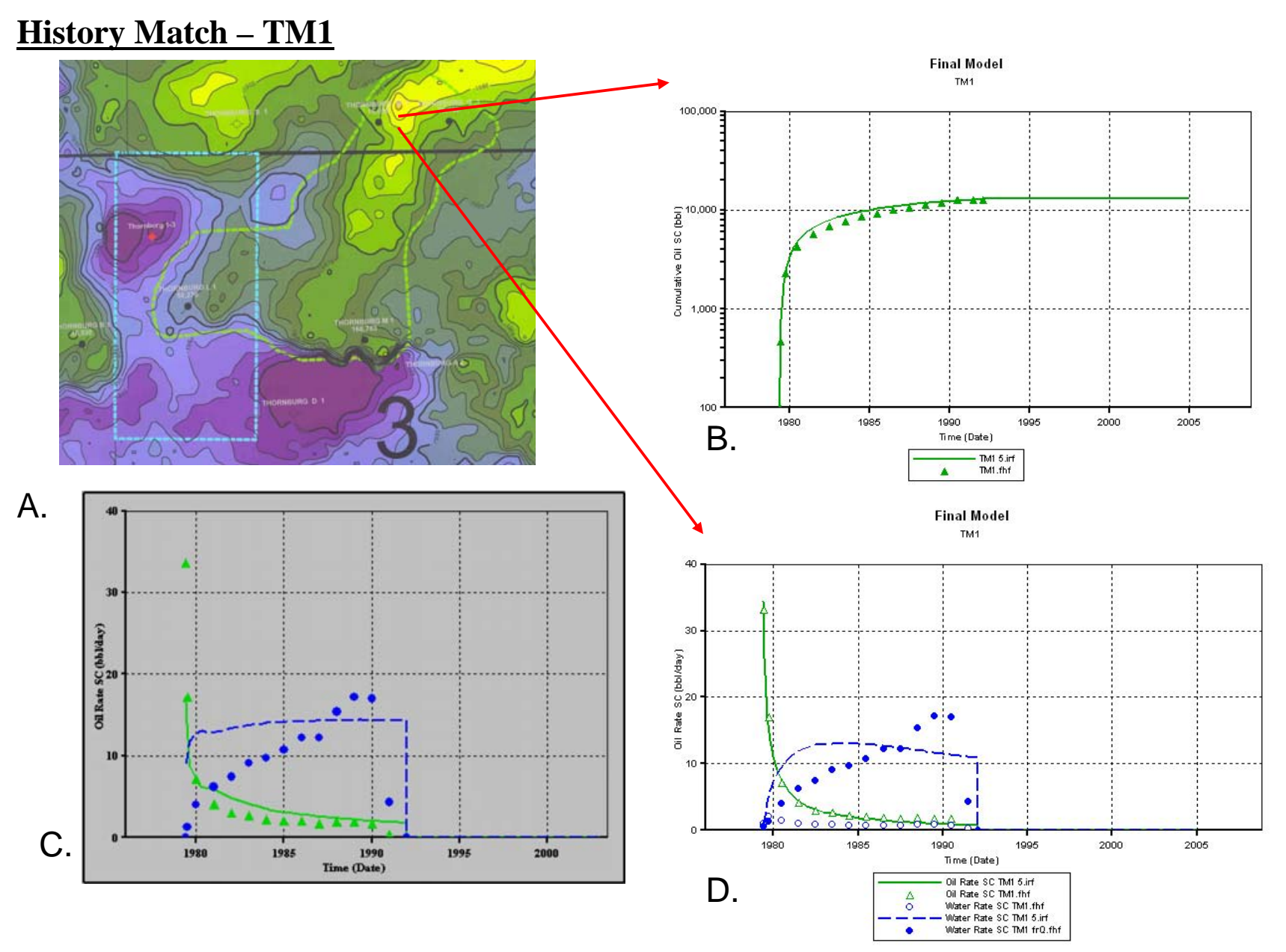

Figure10.10: A) Boundary of the Judica Field study area demarked by broken green line. B \& D) Production history match for Thornburg L1 well. C) History match obtained from pre-3D model. 


\section{History Match - TQ1}

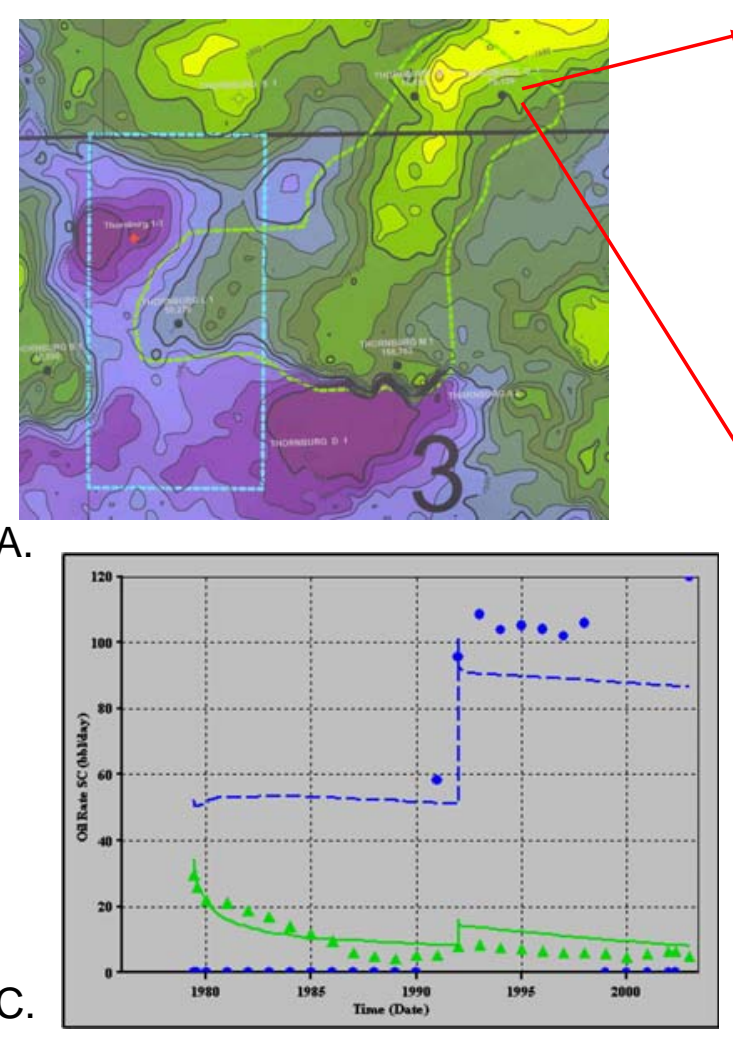

Final Model

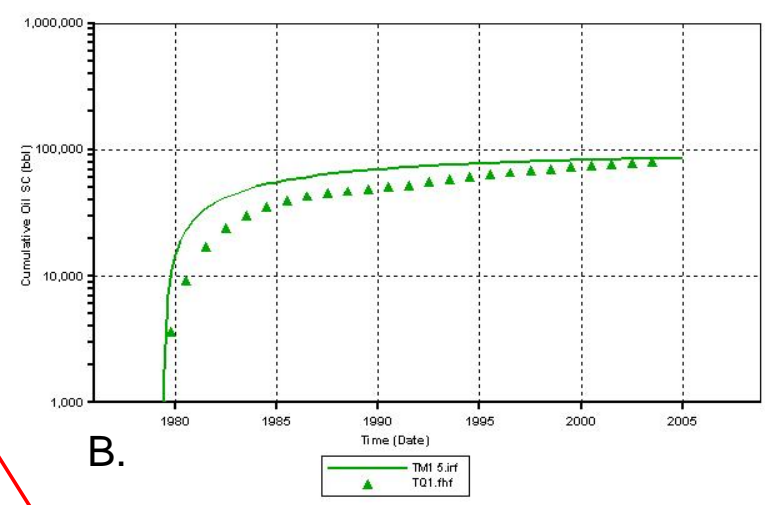

Final Modet

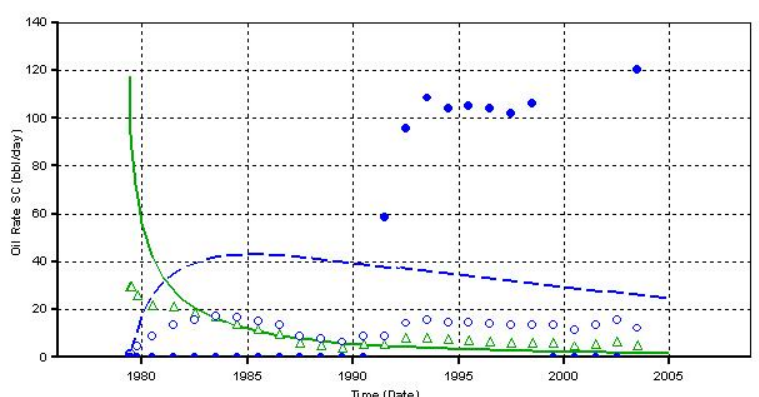

D.

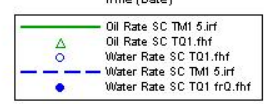

Figure 10.11: A) Boundary of the Judica Field study area demarked by broken green line. B \& D) Production history match for Thornburg Q1 well. C) History match obtained from pre-3D model. 


\section{$\underline{\text { Average Reservoir Pressure Decline }}$}

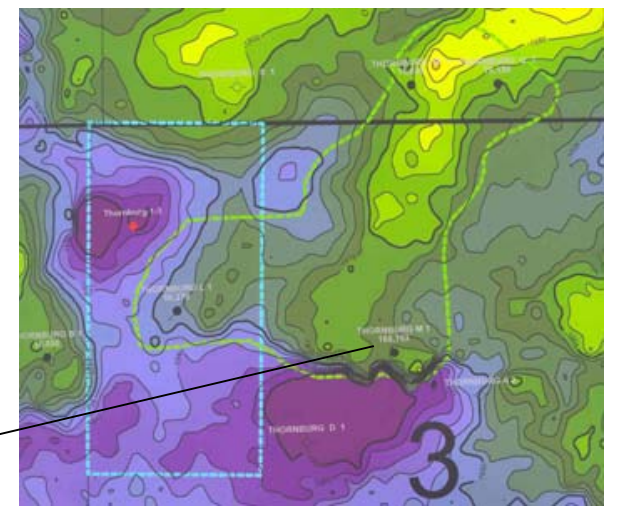

Estimated pressure from

Final Model

shut-in test is around 500

PRES Average Reservor Pressure. TM1 5 irt

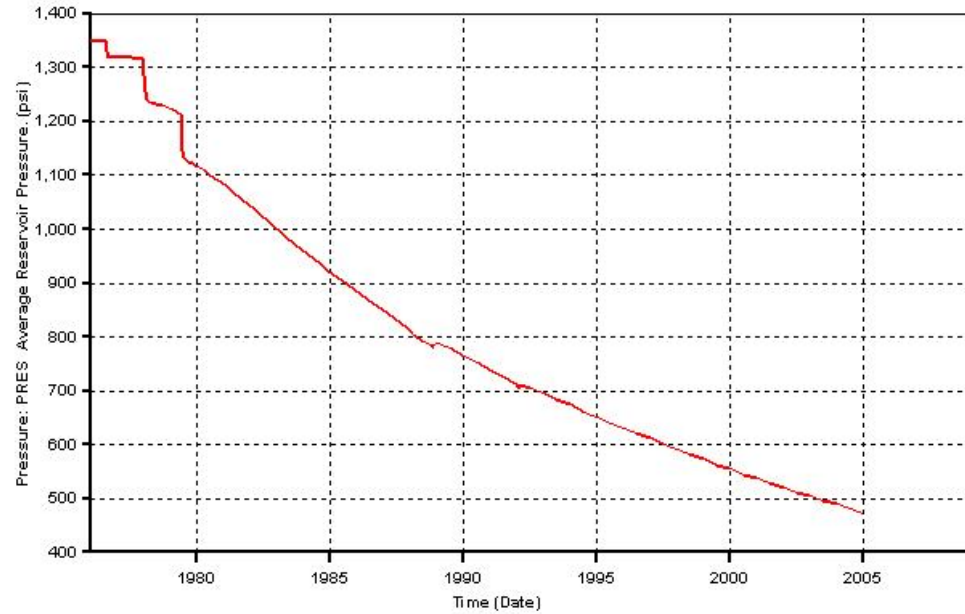

Figure 10.12: A) Boundary of the Judica Field study area demarked by broken green line. B) Simulator-calculated decline on average reservoir pressure with time. 
A.

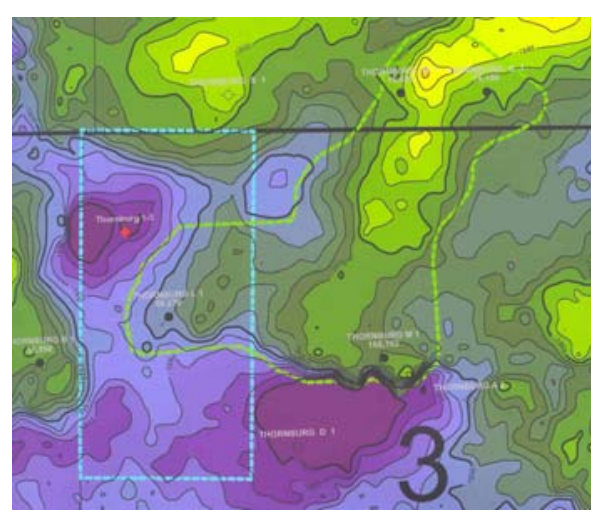

B.
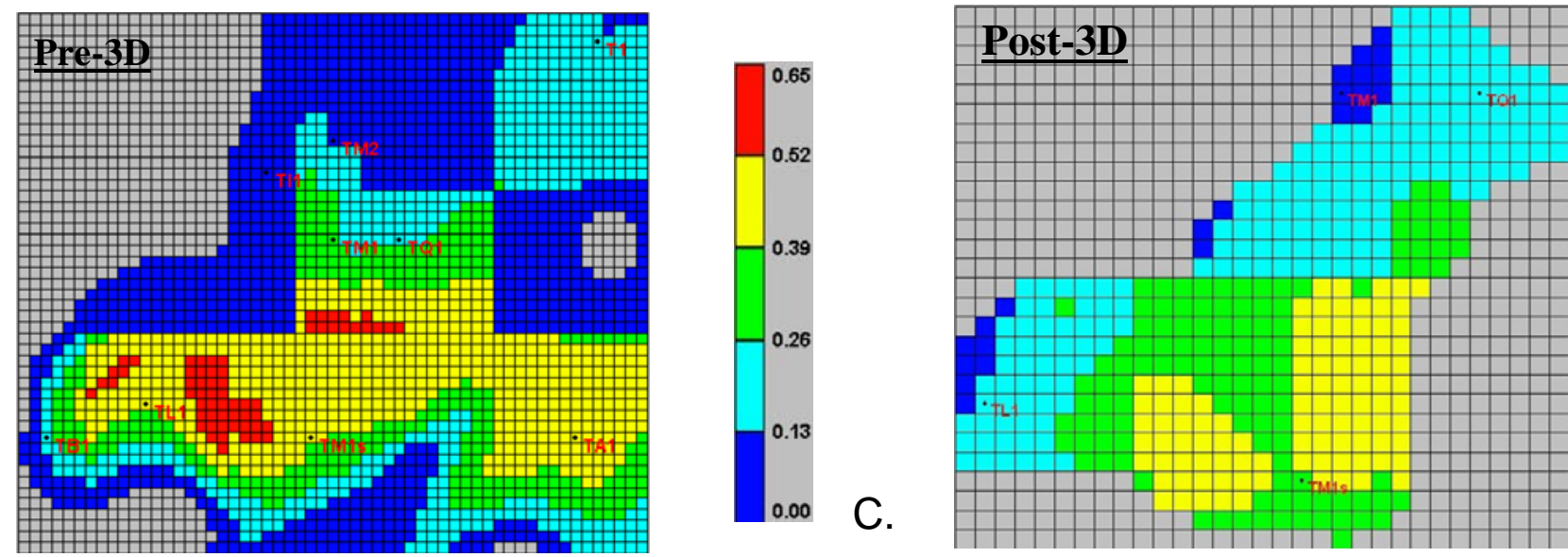

Figure 10.13 A) Boundary of the Judica Field study area demarked by broken green line. B \& C) Remaining reserves (oil-feet, product of porosity, oil saturation, and pay) as of January 2005 using pre-3D and post-3D models. 


\section{Potential of Horizontal Infill - L5}

A.

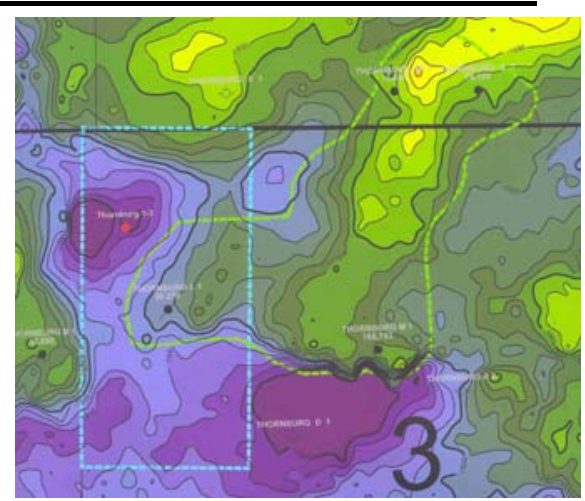

Final Model
Hor Hor Infilli.irf

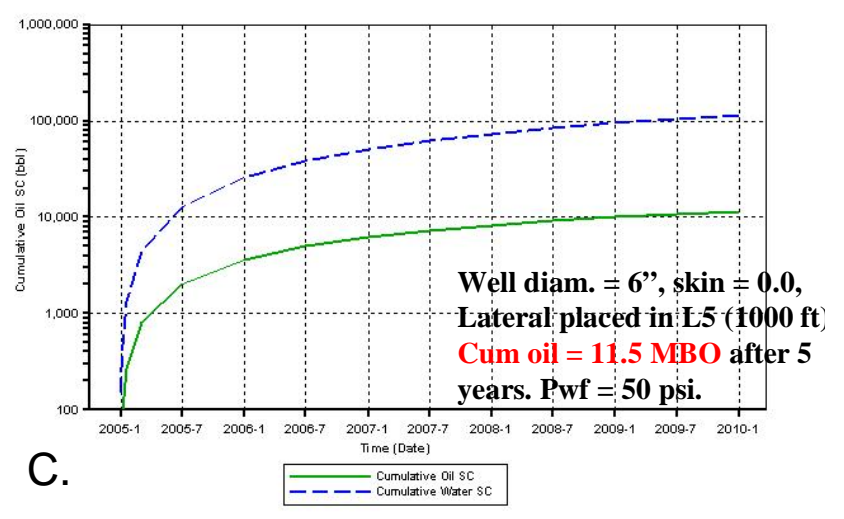

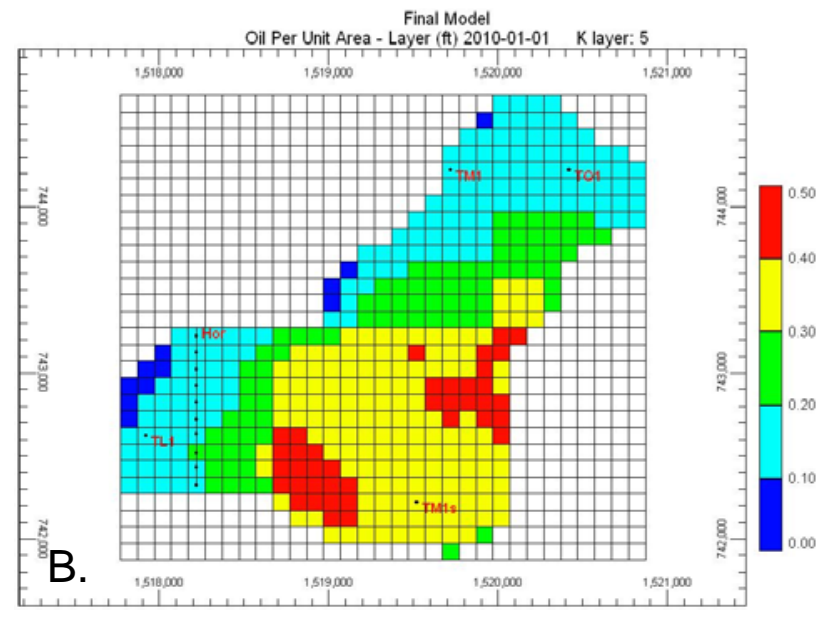

Final Model
Oil Per Unit Area - Layer (t) 2010-01-01

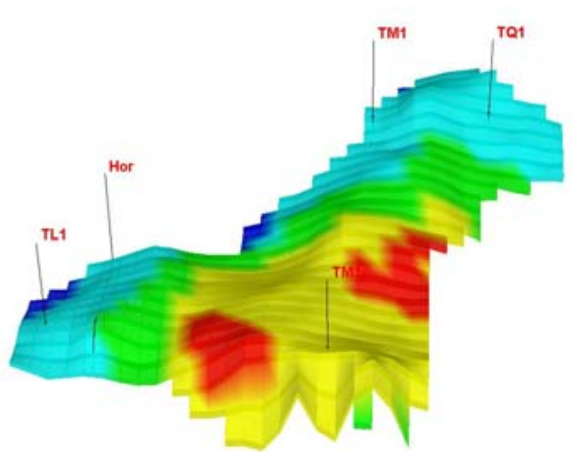

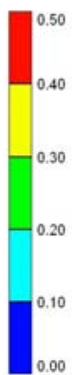

D.

Figure 10.14: A) Boundary of the Judica Field study area demarked by broken green line. B) Location of infill horizontal trajectory. C) Simulator-estimated production potential of the infill horizontal well. D) Estimated drainage (oil-feet, product of porosity, oil saturation, and pay) by infill horizontal well after 5 years of production (January 2010). 


\section{Potential of Horizontal Infill - L5 \& L3}

Well diam. $=6$ "

Skin $=\mathbf{0 . 0}$

Lateral placed in L3 and

L5.

Cum oil = $14 \mathrm{MBO}$ after

5 years.

Pwf $=60$ psi.

Average reservoir

pressure @ Jan $2010=$

297 psi.

Lateral length $=1000 \mathrm{ft}$.

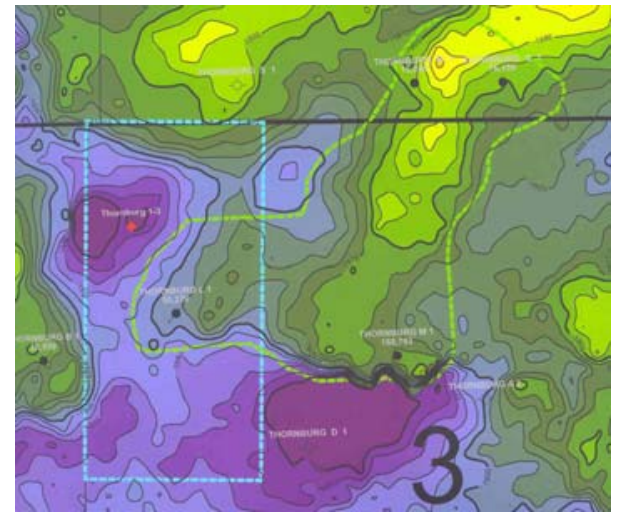

Final Model

Lateral in L3 and L5

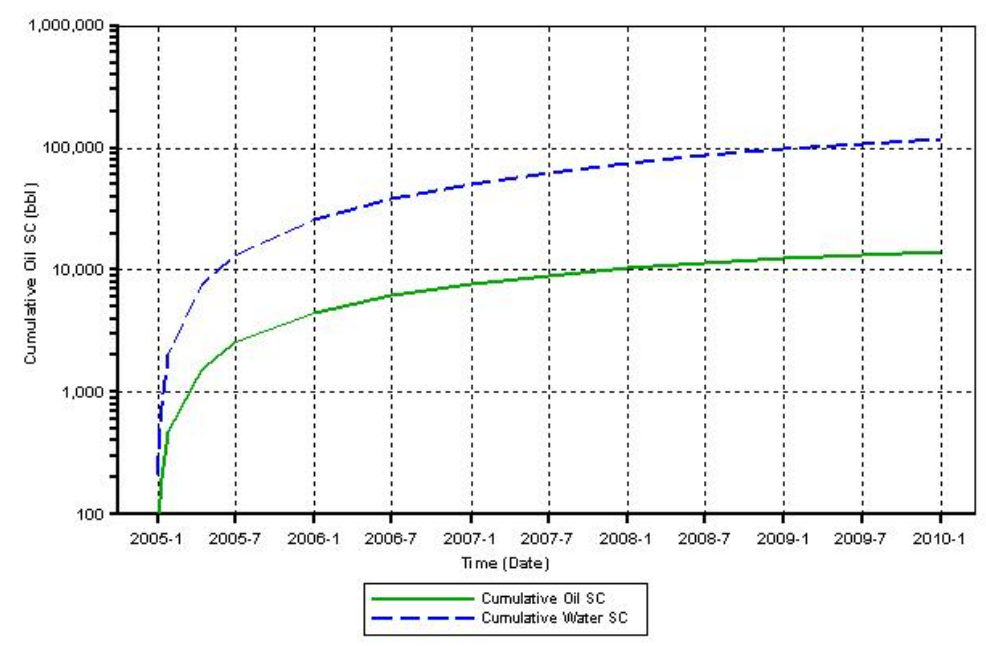

Figure 10.15: A) Boundary of the Judica Field study area demarked by broken green line. B) Simulator-calculated production output from the horizontal infill well if completed in Layers 3 and 5 (L3 and L5). 


\section{Aquifer Strengthening}

Average Reservoir Pressure $=550$ psi (Jan 2005)

Stronger Aquifer

PRES Average Reservoir Pressure. Strong Aq.irf

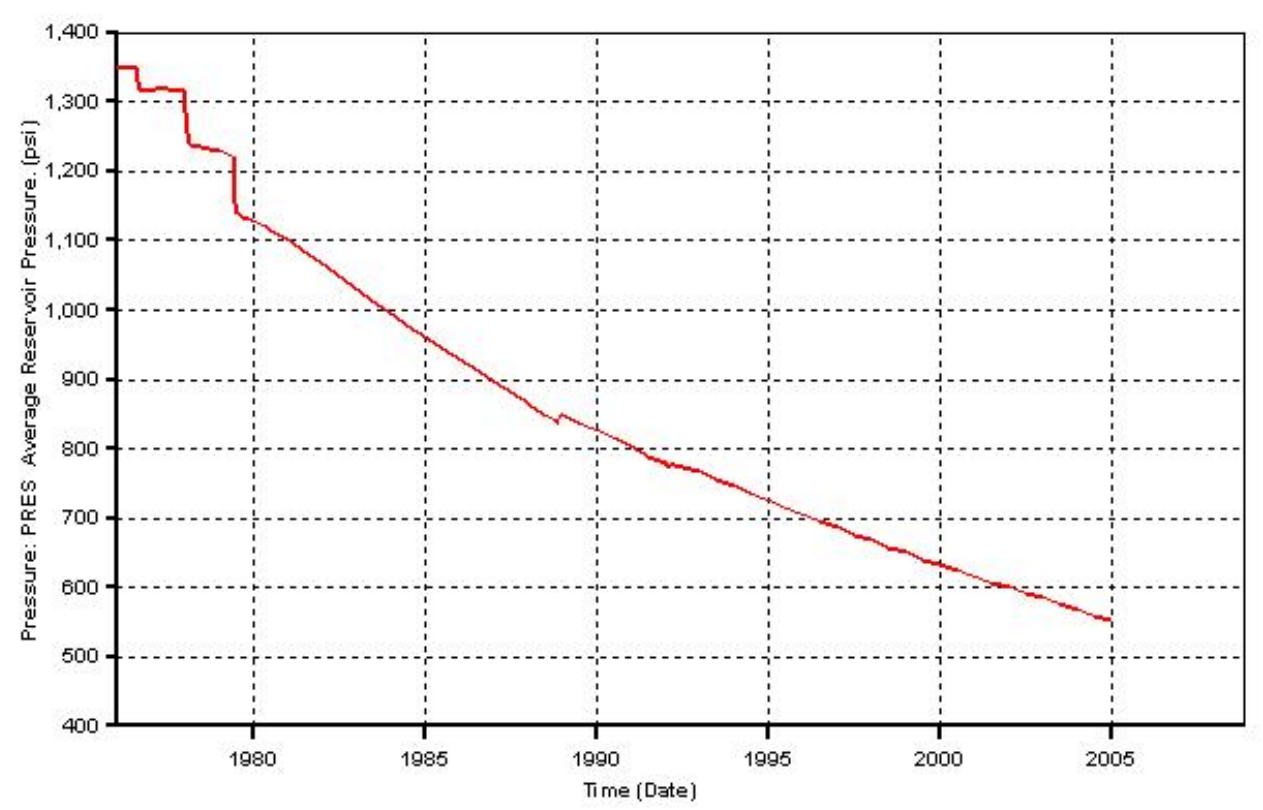

Figure 10.16: Effects of strengthening analytical aquifer on simulator-calculated average reservoir pressure decline. 


\section{History Matches - Stronger Aquifer}
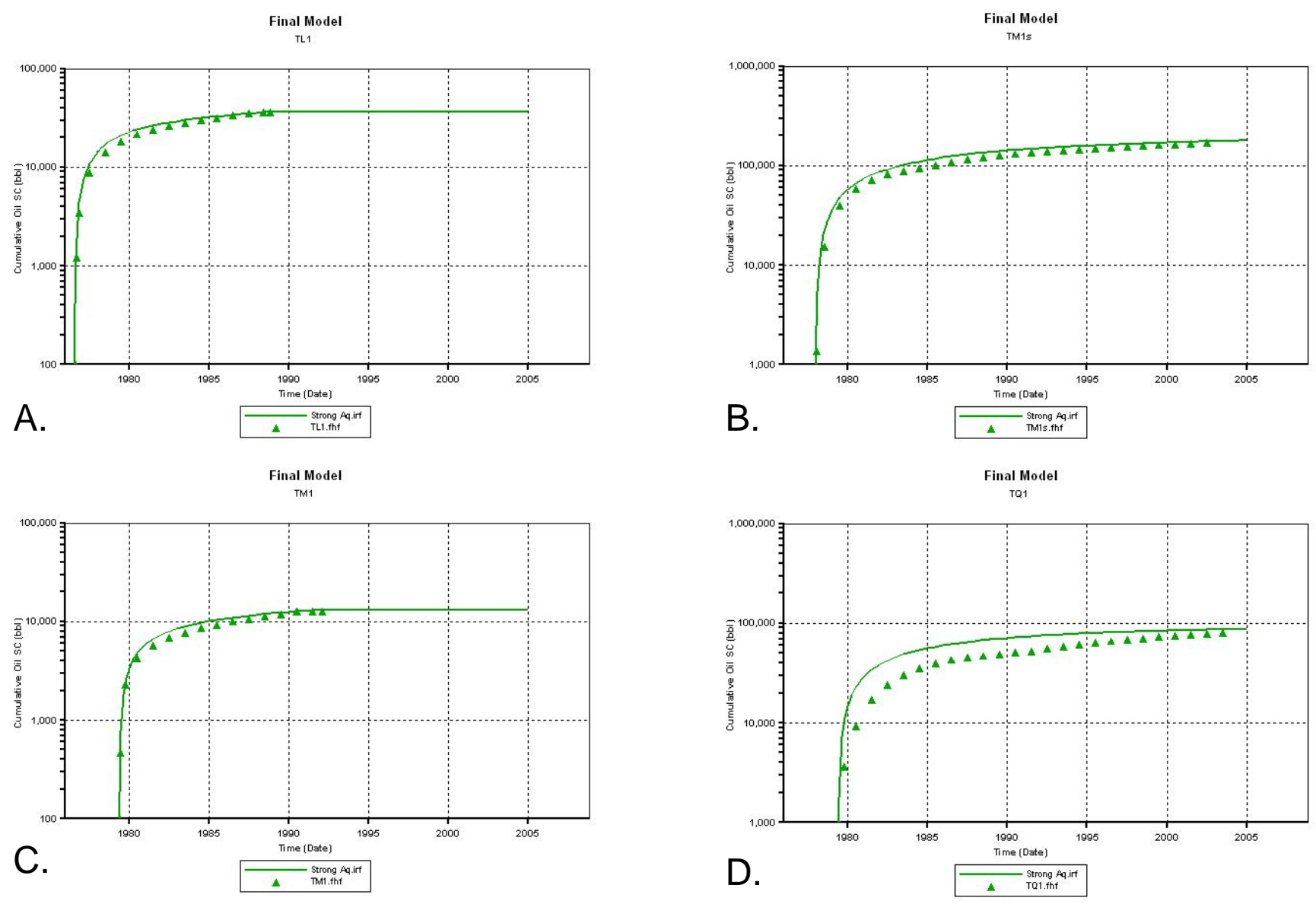

Figure 10.17: History matches of well-level oil production using a stronger analytical aquifer (referred to in Figure 10.16). 
Potential of Horizontal Infill - L5 \& L3 Stronger Aquifer

Well diam $=6$ "

Skin $=\mathbf{0 . 0}$

Lateral placed in L3 and L5 (1000 ft) Cum oil $=15.1 \mathrm{MBO}$ after 5 years.

Pwf $=60$ psi

Avg. res. Pr. $=361$ psi $($ Jan 2010)

Strong Aquifer Lateral in L3 \& L5

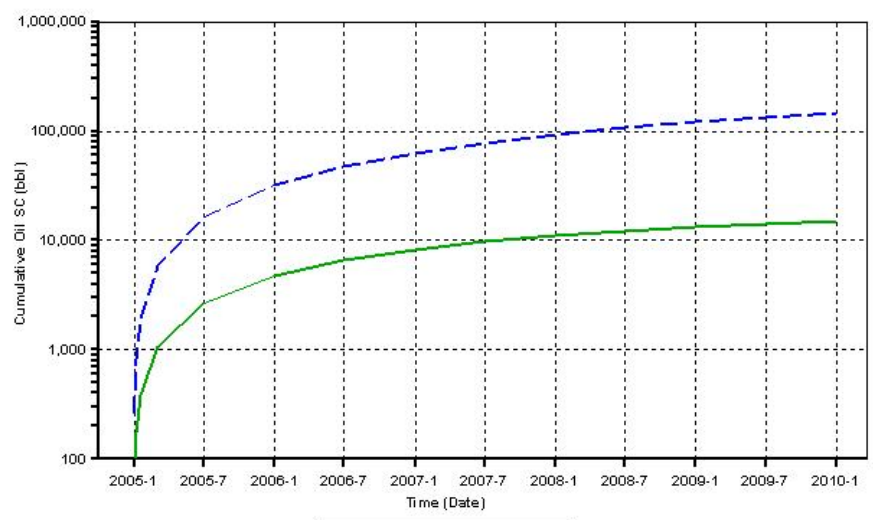

A.

Figure 10.18: Drainage (oil-feet, product of porosity, oil saturation, and pay) and estimated production from an infill horizontal well using a stronger analytical aquifer (referred to in Figure 10.16).

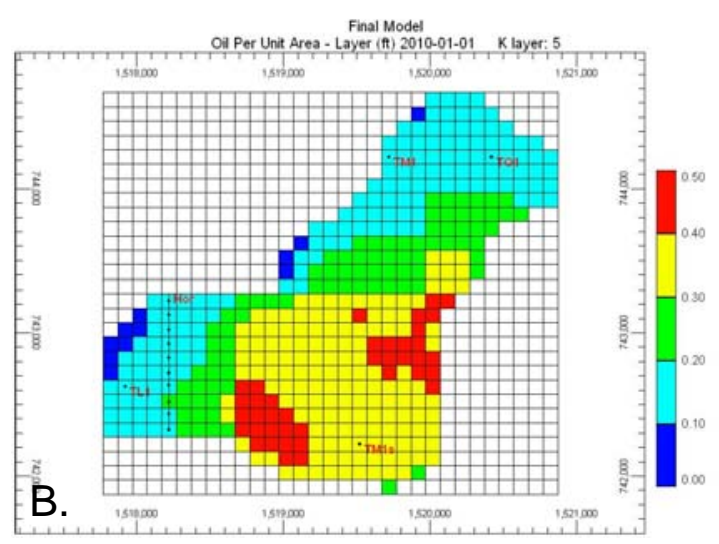


$\underline{\text { Potential of Horizontal Infill - L5 }}$

Stronger Aquifer

Extend into Neighboring Lease

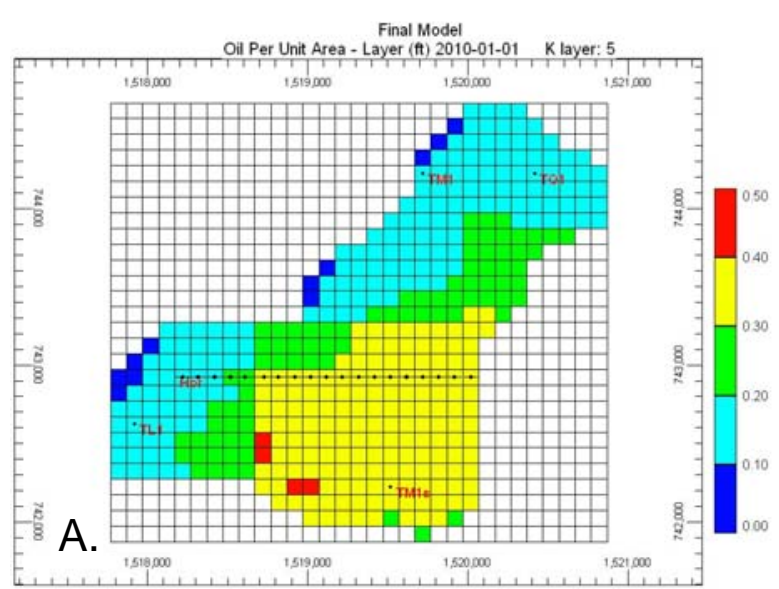

Cum oil = 28.6 MBO after 5 years.

Well diam $=6 ”$

Skin $=0.0$

Lateral placed in L5 (1900 ft).

Pwf $=60$ psi.

Strong Aquifer

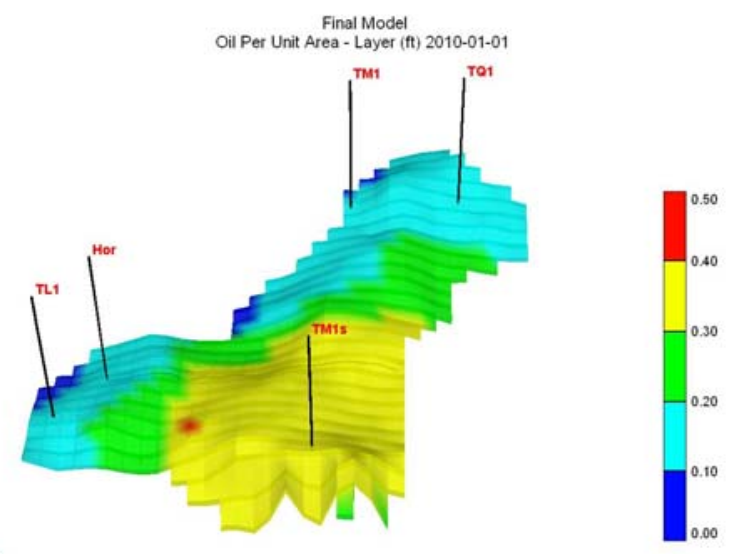

B.

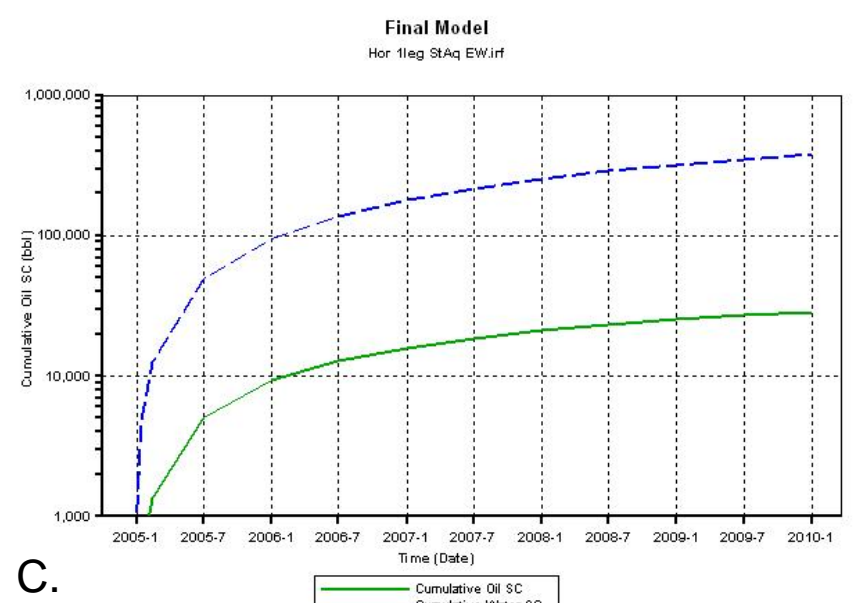

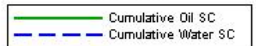

Figure 10.19: A) Location of a horizontal infill well extending into the neighboring lease. B) Drainage, in terms of oil-feet (product of porosity, oil saturation, and pay after 5 years (as of January 2010) by the horizontal infill. C) Simulator-estimated production potential from the horizontal infill well. 


\section{Approximate Drilling Costs in Kansas}

Vertical well dry - $\$ 105,000$
Vertical well completed - $\$ 260,000$
Horizontal well dry - $\$ 350,000$
Horizontal well completed - $\$ 500,000$

Table 10.1: Approximate MDCI drilling expenses. 


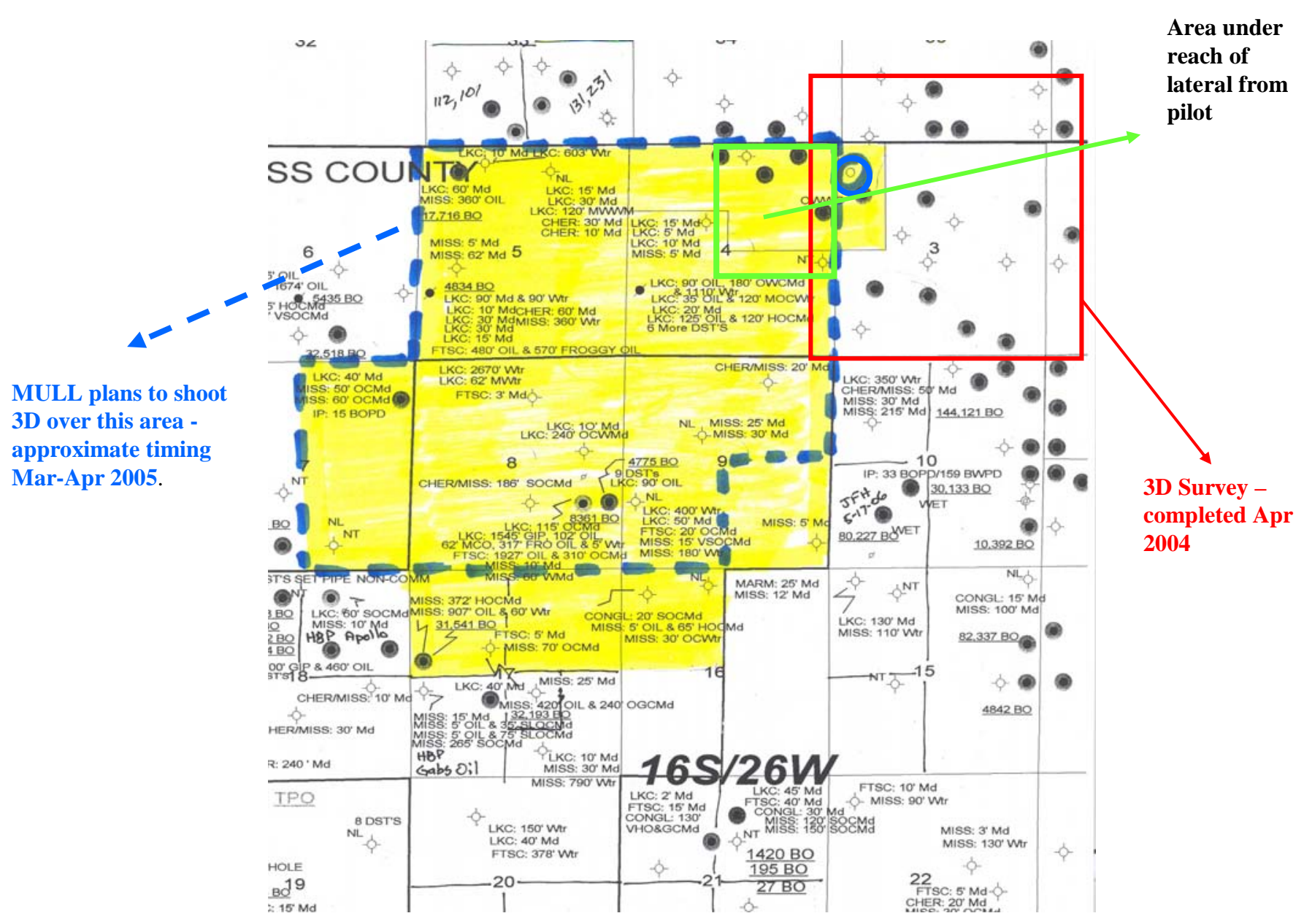

Map 10.1: Map showing location and extent of additional 3D data to be collected by MDCI in 2005. 


\section{Conclusions}

a) Mississippi (Spergen-Warsaw) reservoirs are layered by lithofacies (dolomitized carbonate mudstones, wackestones and packstones) that can be traced by electric log character from well-to-well and mapped. Layers are fairly continuous on a local scale and can be traceable within the boundaries of each of the 3 fields modeled.

b) Main pay layers are dolomitized wackestones and packstones with bioclast moldic porosity. Non-pay layers are dolomitized mudstones without bioclast molds.

c) Solution-enhanced features such as vertical shale intervals have been reported to extend down from the karst erosional surface that marks the top of the Mississippian reservoir in one of the studied fields - Ness City North Field. Drilling experiences in this field suggest that these vertical shale intervals are unstable in open-hole completions and also create reservoir compartments that limit drainage by vertical wells.

d) An initial screening of Mississippian (Spergen-Warsaw) fields from a target area located in central Kansas was carried out using publicly available data. Quick screening of fields in the target area was based on cumulative primary production and pressure support evident from available DST data.

e) Selected fields were qualitatively ranked to short-list fields for secondary screening using criteria such as estimated remaining reserves per acre-feet, pay thickness, reservoir pressure, and well spacing.

f) Secondary screening of short-listed fields involved a more detailed analyses using analytical estimation of horizontal well performance based on average reservoir properties from type well(s), and an audit of field-particular available data 
including wireline logs, cores, well-level production data, and well/field pressure histories.

g) Given the structure of ownership prevalent in mature Mississippian fields of the mid-continent, a company's ability to work out an operational agreement with coowners and/or fellow interest holders plays a critical role in selecting viable candidates for horizontal infill drilling.

h) Based on the initial and secondary screening studies carried out in this project, 2 major factors appear to control the candidature of a mature Mississippian field for horizontal infill drilling. They are: a) adequate reservoir pressure support, and b) an average well spacing greater than 40 -acres. A candidate field requires strong pressure support for technical success. However, for economic success, an average well spacing in excess of 40-acres determines the volume of reserves available for drainage by a targeted horizontal well.

i) Operator experiences dealing with horizontal well drilling in Kansas, prior to 2003, and available from publicly available sources were summarized to provide a quick update of the learning curve.

j) Advanced decline-curve analyses were used effectively to estimate missing production data and also to verify if a well produced under unchanging bottom hole conditions - two critical inputs to reservoir simulation and often unavailable in many mid-continental fields.

k) Key reservoir and non-reservoir lithofacies, their depositional environment, and events important to their lithologic and petrophysical properties development were identified in cores from fields across the Mississippian productive region on the Central Kansas Uplift. A repeating association of original depositional facies and early diagenesis for these rocks produced lithofacies ranging from mudstones to grainstones with abundant moldic porosity. The nature of the molds varied 
through time reflecting the change in primary carbonate grain constituents which for the Mississippian primarily involved carbonate/siliceous sponge spicule and echinoderm/brachipod molds. The best reservoir facies are packstones with development of either sponge-spicule or echinoderm moldic porosity. In any given field, diagenetic events enhance porosity in either the sponge-spicule-rich or echinoderm-rich facies and may occlude porosity in the other facies.

l) In all fields where cores were studied, porosity and permeability increase with transition through the following lithofacies: mudstone-wackestone-packstonegrainstone. Comparison indicates that Mississippian reservoirs tend to exhibit similar ranges in porosity and permeability for similar lithofacies within a variance that may provide sufficient accuracy for screening and purposes of modeling.

i. Permeability and porosity were enhanced by: 1) the creation of moldic porosity from dissolution of echinoderm, bryozoan, and sponge-spicule grains, and 2) dolomitization resulting in intercrystalline porosity.

ii. For the systems investigated, depositional facies are the dominant control on petrophysical properties even with: 1) extensive and various, early and late diagenesis; 2) biotic constituent differences; 3) warm-cool water environments; 3) karst overprinting; and 4) burial overprinting.

iii. Permeability and porosity decrease significantly and continuously with decreasing grain/mold size from packstone to mudstone.

iv. Reservoir properties for each system, including porosity and permeability, are strongly correlated with original depositional facies despite significant fabric transformation, and in some cases even complete reversal of solid and pore space, with reservoir quality increasing from mudstone through grainstone. 
v. The permeability-porosity trends for all lithofacies are approximately bounded within two orders of magnitude by trendlines defined by:

$\log \mathrm{k}_{\text {in situ }}=0.25 \phi_{\text {in situ }}-2.5$ and $\log \mathrm{k}_{\text {in situ }}=0.25 \phi_{\text {in situ }}-4.5$

Between these bounding trends, each lithofacies exhibits unique sub-parallel trends with permeability decreasing with decreasing grain/mold size for any given porosity. The relationship between permeability and porosity for each lithofacies can be represented by a power law function of the form: $\mathrm{k}=\mathrm{A} \phi^{3.45}$

where A varies with lithofacies.

m) Capillary pressure properties of Mississippian carbonates differ between lithofacies. Structural closure in many Mississippian Kansas fields is less than 60 feet limiting oil column heights. At these oil column heights, understanding the exact capillary pressure relationship becomes important. Also, it is important to note that these values represent the maximum oil column height and that much of the volume of a field may lie below these heights.

Equations to construct generalized capillary pressure curves were constructed based on capillary curve definition for entry pressure and curve shape. Entry pressure can be predicted using:

Pcow $_{\text {entry }}=2.3903$ ki -0.4039 .

The capillary pressure curve shape factor was modeled using:

Pcow $_{\text {shape }}=-0.0218 \ln (\mathrm{ki})-1.069$.

Using curves constructed from these equations the first standard deviation error is $\pm 12 \%$ (saturation percent).

No publicly available imbibition relative permeability data could be located for Mississippian fields. To pin down relative permeability, end-points measurements were performed on selected samples and a complete measurement was performed on a selected sample. To provide oil and water relative permeability curves 
representative of the range of lithofacies, porosity, and permeability present in the Mississippian, Corey-type relative permeability equations were developed where the exponents and coefficients are tied to permeability predicted using the developed permeability-porosity equations. These equations take the form:

$$
\text { kro }=a_{1}(1-S w D)^{m}, k r w=a_{2} S w D^{n}
$$

where SwD $=($ Sw-Swi $) /(1-S w i-S o r w)$ and where $\mathrm{a}_{1}, \mathrm{a}_{2}, \mathrm{~m}, \mathrm{n}, \mathrm{Swi}$, and Sorw are predicted from other equations developed for the Mississippian.

n) Traditional wireline log calculation of saturations use the Archie equation with cementation (m) and saturation exponent (n) values of 2. Formation resistivity factors $(\mathrm{Ro} / \mathrm{Rw})$ measured at $\mathrm{Rw}=0.045 \mathrm{ohm}-\mathrm{m}$ indicate that the Archie cementation exponent (assuming an Archie intercept of 1.0) averages $\mathrm{m}=1.97 \pm 0.09$ for all facies. Echinoderm-rich facies can exhibit cementation exponents between 2.0 and 2.1 .

o) To provide petrophysical data to operators all publicly compiled petrophysical data and data measured for the project have been compiled into a web-accessible rock catalog database through the public domain web application GEMINI (http://www.kgs.ku.edu/Gemini/index.html). GEMINI creates projects from online data either from the Kansas Geological Survey (including digital logs, core analysis and photos, DST, and production data) or uploaded from the user. The rock catalog information is presented in relational context and not limited to categorical data.

p) Karst-induced heterogeneities make Mississippian (Spergen-Warsaw) reservoirs complex, and reservoir models built by integrating log, core, DST, and production data from existing wells on 40 -acre spacings may be insufficient to delineate reservoir compartments in these mature fields.

q) Limited data appear to indicate that reservoir compartmentalization can result in limited remaining reserves at depleted reservoir pressures. However, for 
successful exploitation of compartmentalized reservoirs, horizontal infill wells need to be placed in compartments with little or minimal pressure depletion.

r) 3D-seismic data contributes significant additional information, especially related to mapping of reservoir compartments in Mississippian (Spergen-Warsaw) reservoirs. Time-structure interpretation and conversion to depth enable delineation of reservoir boundaries.

s) Porosity-ft of Judica zone correlated with the base Warsaw LS amplitude map helped discriminate between dry and productive wells in the Judica field area. Further application of this technique needs to be carried out in other mature Mississippian (Spergen-Warsaw) fields to confirm if it is effective in identifying compartments with hydrocarbon saturations.

t) Reservoir compartments in Mississippian (Spergen-Warsaw) fields require adequate pressure support, hydrocarbon saturation, and requisite reservoir volume for horizontal infill wells to produce at economic rates. Detailed reservoir characterization and simulation studies on geomodels developed by integrating wireline log, core, petrophysical, production and pressure, and 3D-seismic data enable effective evaluation of a candidate field for horizontal infill applications. 


\section{REFERENCES}

Berg, R. R., 1975, Capillary pressures in stratigraphic traps: AAPG Bulletin, v. 59, p. 939-956.

Bhattacharya, S., Gerlach, P.M., Carr, T.R., Guy, W.R., Beaty, S., and Franseen, E.K., 1999a, PC-based Reservoir Characterization and Simulation of Schaben Field, Ness County, Kansas; Oklahoma Geological Survey Circular 101, p 171-183.

Bhattacharya, S., Gerlach, Byrnes, A., and Franseen, E.K., 1999b, Reservoir characterization of Ness City North Field, Ness County, Kansas, for horizontal well applications, Kansas Geological Survey Open File Report 1999-58.

Bhattacharya, S., Gerlach, P.M., and Carr, T.R., 2003, Cost-effective techniques for the independent producer to identify candidate reservoirs for horizontal drilling in mature oil and gas fields; Memoirs of the Hedberg Conference - Horizontal Wells, Focus on the Reservoir, Houston, American Association of Petroleum Geologists, p 205-223.

Brooks, R.H., and Corey, A.T., 1966, Properties of porous media affecting fluid flow, J. Irrig. Drainage Div., v. 6 (June 1966), p. 61-88.

Burdine, N.T., 1953, Relative permeability calculations from pore-size distribution data, Petroleum Transactions Am. Inst. Mechanical Engineers, v. 198, p. 71-77.

Byrnes, A.P., Franseen, E.K., Watney, W.L., Dubois, M.K., 2003, “The role of moldic porosity in Paleozoic Kansas reservoirs and the association of original depositional facies and early diagenesis with reservoir properties”, Kansas Geological Survey Open-file Report \#2003-32.

Byrnes, A.P., E.K. Franseen, W. L. Watney, and M.K. Dubois, 2003, The role of moldic porosity in Paleozoic Kansas reservoirs and the association of original depositional facies and early digenesis with reservoir properties, (abs.), 2003 American Association of Petroleum Geologists Annual Convention, Salt Lake City, V. 12, p. A24, and KGS Openfile Report 2003-32. http://www.kgs.ku.edu/PRS/publication/2003/ofr2003-32/index.html

Carman, P. C., 1937, Fluid flow through a granular bed: Transactions of the Institution of Chemical Engineers, v. 15, London, p. 150-167.

Carr, T.R., Guy, W.R., Franseen, E.K., and Bhattacharya, S., 1996, Enhanced carbonate reservoir model for an old reservoir utilizing new techniques: The Schaben field (Mississippian), Ness County, Kansas; American Association of Petroleum Geologists, Annual Meeting Abstracts, p. A23-A24. 
Carr, T. R., D.W. Green, and G.P. Willhite, 2001, Improved oil recovery in Mississippian carbonate reservoirs of Kansas - Near Term - Class II, Final Report Sep 1994 - Apr 2001, NETL, U.S. DOE, p. 137

Coffin, P., 1993, Horizontal well evaluation after 12 years; $68^{\text {th }}$ Annual Technical Conference and Exhibition of Society of Petroleum Engineers, Houston, TX, SPE 26618.

Corey, A.T., 1954, The interrelations between gas and oil relative permeabilities, Producers Monthly, v. 19 (Nov 1954), p 38-41.

Dubois, M.K., A.P. Byrnes, and S. Bhattacharya, 2003, Understanding Mississippi dolomite reservoirs in central Kansas, KGS Open-file Report 2003-73, http://www.kgs.ku.edu/PRS/publication/2003/ofr2003-73/OFR-2003-73.pdf

Franseen, E.K., Carr, T.R., Guy, W.J., and Beaty, S.D., 1998, Significance of depositional and early diagenetic controls on architecture of a karstic-overprinted Mississippian (Osagian) reservoir, Schaben field, Ness county, Kansas; American Association of Petroleum Geologists, Salt Lake City, Utah, Annual Meeting Abstracts, $4 \mathrm{p}$.

Fritz, R., 1991, Analyses show potential of horizontal drilling; The American Oil and Gas Reporter, v. 34, no. 6, p. 18-27.

Gerlach, P.M., S. Bhattacharya, T.R. Carr, 1998, Cost Effective Techniques for the Independent Producer to Evaluate Horizontal Drilling Candidates in Mature Areas: AAPG Hedberg Conference, International Horizontal Well Symposium: Focus on the Reservoir.

Gerlach, P., 1998, Pre-Pennsylvanian subcrop map: Kansas Geological Survey, Digital Petroleum Atlas, http://www.kgs.ku.edu/DPA/Plays/ProdMaps/miss_sub_oil.html, posted November 1998.

Goebel, E.D., 1968, Mississippian rocks of western Kansas: American Association of Petroleum Geologists Bulletin, v. 52, p. 1732-1778.

Heid, J.G., McMahon, J.J., Nielsen, R.F., and Yuster, S.T., 1950, Study of the permeability of rocks to homogeneous fluids, Am Petroleum Institute Drilling and Production Practices, p. 230-246.

Hubbert, M. K., 1953, Entrapment of petroleum under hydrodynamic conditions: AAPG Bulletin, v. 37, p. 1954-2026.

James III, Alfred., 1985, Kansas oil and gas fields, Volume \#5, Kansas Geological Society, p. 69-75 
Joshi, S.D., and Ding, W.Z., 1996, Horizontal well application: Reservoir management; Society of Petroleum Engineers International Conference on Horizontal Well Technology, Calgary, Canada, SPE 37036.

Joshi, S.D., 1991, Horizontal well technology; Pennwell Publishing Company, Tulsa. Lacy, S.L., Ding, W.Z., and Joshi, S.D., 1992, Prespectives on horizontal wells in the Rocky mountain region; Geological Studies Relevant to horizontal drilling: Examples from Western North America, The Rocky Mountain Association of Geologists, Denver, p. 25-32.

Lane, H.R., and DeKeyser, T.L., 1980, 1980, Paleogeography of the Late Early Mississippian (Tournaisian 3) in the Central and Southwestern United States: in Fouch, T.D., and Magathan, E.R., eds., Paleozoic Paleogeography of West-Central United States, Rocky Mountain Section, SEPM, p. 149-159.

Lucia, F.J., 1995, Rock-fabric/petrophysical classification of carbonate pore space for reservoir characterization: American Association of Petroleum Geologists Bulletin, v. 79, no. 9, p. 1275-1300.

Magathan, E.R., eds., Paleozoic Paleogeography of West-Central United States, Rocky Mountain Section, SEPM, p. 149-159.

Merriam, D.F., 1963, The geologic history of Kansas: Kansas Geological Survey Bulletin, 162, 317 p.

Montgomery, S. L., Franseen, E.K., Bhattacharya, S., Gerlach, P., Guy, W., Byrnes, A.P., and Carr, T.R., 2000, Schaben Field Kansas: Improving Performance in a Mississippian shallow-shelf carbonate; AAPG Bulletin, V. 84, No. 8 (August), p 1069-1086.

Nissen, S.E. and T.R. Carr, 2005, Using 3-D seismic attributes to identify subtle fracture trends in mid-continent Mississippian carbonate reservoirs, (abs.), 2005 American Association of Petroleum Geologists Annual Convention, Calgary, V. 14, p. A100.

Parker, J.M., Reservoir Evaluation and Volumetric Study - Fralick West Field, Kiowa County, Kansas, Kansas Geological Survey Library

Purcell, W. R., 1949, Capillary pressure - their measurements using mercury and the calculation of permeability therefrom: American Institute of Mechanical Engineers Petroleum Transactions, v. 186, p. 39-48.

RESMOD ${ }^{\text {TM }}$ User's Manual, 1998, Maurer Engineering Inc., Houston, Texas

Rogers, J.P., Longman, M.W., and Lloyd, R.M., 1995, Spiculitic Chert reservoir in Glick Field, South-Central Kansas: The Mountain Geologist, v. 32, p. 1-22. 
Selks, E.L., and Ciriacks, K.W., 1968, Mississippian Stratigraphy in Southern Kansas and Northern Oklahoma, Based on Conodont Fauna: Kansas Geological Survey Open-File Report 68-3, 5 p.

Thomas, M.A., 1982, Petrology and diagenesis of the Lower Mississippian, Osagean Series, Western Sedgwick Basin, Kansas: Kansas Geological Survey Open-file Report 82-24, 87 p.

Walton, P.H. and Preston, F., 1986, Waterflood feasibility study for the Fralick West Field, Kiowa County, Kansas, Kansas Geological Survey Library.

Washburn, E. W., 1921, A method of determining the distribution of pore sizes in a porous material: Proceedings of the National Academy of Sciences, v. 7, p. 115-116.

Watney, W.L., Guy, W.J., and Byrnes, A.P., 2001, Characterization of the Mississippian Chat in South-Central Kansas: AAPG Bulletin, v. 85, p. 85-114. 